\title{
European species of Hypocrea part II: species with hyaline ascospores
}

\author{
Walter M. Jaklitsch
}

Received: 23 November 2010 / Accepted: 19 December 2010/Published online: 15 March 2011

(C) The Author(s) 2011. This article is published with open access at Springerlink.com

\begin{abstract}
To date 75 species of Hypocrea/Trichoderma forming teleomorphs are recognised in Europe. The 56 hyaline-spored species are here described in detail and illustrated in colour plates, including cultures and anamorphs. This number includes 16 new holomorphs, two new teleomorphs and nine anamorphs of species previously described as teleomorphs. Phylogenetic placement and relationships of the species are shown on the strict consensus tree, based on sequences of RNA polymerase II subunit $b$ $(r p b 2)$ and translation elongation factor 1 alpha (tefl) exon, comprising 135 species of the genus Hypocrea/Trichoderma. All available holotypes of species described from Europe including some from North America have been examined. A dichotomous key to the species is provided primarily utilising ecological and morphological traits of the teleomorphs and, where necessary, morphology of the anamorphs and cultures, and growth rates. Species descriptions are subdivided among five chapters, arranged primarily according to the larger phylogenetic clades, viz. section Trichoderma with 13 species, the pachybasium core group with 13 species including four species with stipitate stromata ('Podostroma'), species forming large effused stromata with 10 species including the section Hypocreanum, 9 species of the Brevicompactum, Lutea and Psychrophila clades, and 11 residual species of various smaller clades or of unknown phylogenetic placement. Finally, a list comprising dubious names and species excluded from Hypocrea that are relevant for Europe, or species claimed to occur in Europe by other authors is provided. Hypocrea minutispora is by
\end{abstract}

\footnotetext{
W. M. Jaklitsch ( $\bowtie)$

Department of Systematic and Evolutionary Botany,

Faculty Centre of Biodiversity, University of Vienna,

Rennweg 14,

1030 Vienna, Austria

e-mail: walter.jaklitsch@univie.ac.at
}

far the most common species in Europe. For H. moravica, $H$. subalpina and $H$. tremelloides the anamorphs are newly described. The anamorphs of the latter two species and $H$. sambuci produce hyaline conidia on unusual structures new to Trichoderma. These three species form a new subclade of the morphologically strikingly different section Longibrachiatum, which is currently only represented by $H$. schweinitzii in Europe as a holomorph. The subclade is not named yet formally due to low statistical support. $H$. fungicola $\mathrm{f}$. raduli is described as the new species $H$. austriaca, while $H$. hypomycella was found not to belong to Hypocrea. The typification of $H$. pilulifera, $H$. tremelloides and $H$. lutea has been clarified. Gliocladium deliquescens, the anamorph of $H$. lutea, is combined in Trichoderma. Species are epitypified where appropriate. Anamorph names are established prospectively to avoid numerous new combinations in future when they may be possibly used as holomorphic names if the ICBN is altered accordingly.

Keywords Arachnocrea . Ascomycetes - DNA barcode . Gliocladium · Hypocreales · ITS · Morphology · Protocrea . rpb2 · Phylogenetic analysis · Systematics · Taxonomy · tef1 1 Trichoderma

Taxonomic novelties: Hypocrea/Trichoderma albolutescens Jaklitsch, Trichoderma alutaceum Jaklitsch, Hypocrea atlantica Jaklitsch, Trichoderma atlanticum Jaklitsch, Hypocrea auranteffusa Jaklitsch, Trichoderma auranteffusum Jaklitsch, Hypocrea austriaca Jaklitsch \& Voglmayr, Trichoderma austriacum Jaklitsch, Hypocrea bavarica Jaklitsch, Trichoderma bavaricum Jaklitsch, H./T. calamagrostidis Jaklitsch, Trichoderma delicatulum Jaklitsch, H./T. junci Jaklitsch, Trichoderma leucopus Jaklitsch, Hypocrea luteffusa Jaklitsch, Trichoderma 
luteffusum Jaklitsch, Hypocrea luteocrystallina Jaklitsch, Siepe \& L.G. Krieglst., Trichoderma luteocrystallinum Jaklitsch, Hypocrea margaretensis Jaklitsch, T. margaretense Jaklitsch, Trichoderma moravicum Jaklitsch, H./T. neorufoides Jaklitsch, Hypocrea pachypallida Jaklitsch, Trichoderma pachypallidum Jaklitsch, H./T. phellinicola Jaklitsch, Trichoderma placentula Jaklitsch, Trichoderma psychrophilum Jaklitsch, Hypocrea rhododendri Jaklitsch \& Voglmayr, Hypocrea sambuci Jaklitsch \& Voglmayr, H./T. silvae-virgineae Jaklitsch, Trichoderma subalpinum Jaklitsch, Hypocrea subeffusa Jaklitsch, Trichoderma subeffusum Jaklitsch, Trichoderma tremelloides Jaklitsch, Hypocrea valdunensis Jaklitsch, T. valdunense Jaklitsch.

New combination: Trichoderma deliquescens (Sopp) Jaklitsch.

\section{Introduction}

Hypocrea/Trichoderma is a taxonomically difficult, hyperdiverse genus with an extraordinarily high number of species, similar to Fusarium sensu lato. While in Fusarium the high species number is in part due to a heterogeneous assemblage of species based on the morphologically easily recognisable shape of macroconidia (Booth 1971), and Fusarium sensu stricto is more or less highly specialised to host plants (O'Donnell et al. 2000; Kvas et al. 2009), the high diversity in Hypocreal Trichoderma is a result of its hyperparasitic life style on other fungi.

Jaklitsch (2009) treated several aspects of the genus Hypocrea/Trichoderma, including the taxonomic history of the teleomorph genus Hypocrea and the anamorph genus Trichoderma, the development of the species concept, and important economic and social aspects. He explained the strategy of species identification and recognition followed in the underlying project. The project was designed to study the diversity of Hypocrea/Trichoderma starting from teleomorphs in Europe, because no such monograph was available for any continent including Europe, executed with a modern approach including multigene phylogeny.

A survey of 6 years resulted in about 620 specimens representing 75 species of Hypocrea. For all species sequences of ITS, $r p b 2$ and tefl were obtained, except for the three species $H$. argillacea, $H$. splendens and $H$. strobilina, which could not be recollected despite intense searches. Jaklitsch (2009) reported also on difficulties and reliability in ascospore isolation, and sketched the overall ecology of Hypocrea in Europe. A phylogenetic strict consensus tree based on sequences of $r p b 2$ and the tefl exon of the genus comprising 135 species, showed all species detected in Europe including many from other continents or others that are only known as Trichoderma anamorphs. He explained and defined the morphological traits used in the species descriptions and provided generalised descriptions of phenotypes of the Hypocrea teleomorph and the Trichoderma anamorph. A diagram illustrated the variation of growth rates among the European species of Hypocrea/Trichoderma, excluding most of those known exclusively as anamorphs.

In the first part of this treatment Jaklitsch (2009) keyed out and described the 19 green-spored species of Hypocrea detected in Europe in detail. This second part serves to describe all 56 hyaline-spored species of Hypocrea currently recognised in Europe.

\section{Materials and methods}

All materials and methods are as described by Jaklitsch (2009). Table 1 lists cultures and GenBank accession numbers of those species numbered as Hypocrea sp. 1, 2, etc. in Jaklitsch (2009). The following methodological issues are emphasised: 1) Colour perception is strongly dependent on lighting conditions and the magnification level. A factor with strong impact on colour reproduction is the characteristics of digital cameras, particularly the mode of white balance. Some images in the colour plates therefore deviate from the natural situation, most notably under-representing yellow hues in images taken through the stereo-microscope. 2) The reaction to $3 \% \mathrm{KOH}$ has been examined after rehydration of dry stromata overnight by vapour in a wet chamber; it is usually weak or absent in immature stromata, therefore mature stromata have to be used for examinations. 3) The detailed descriptions and illustrations of cultures are based on conditions standardised for growth experiments as defined in Jaklitsch (2009). Deviating conditions including the use of older cultures may cause different results; this may apply in particular to colony development, times and organisation of conidiation; the latter is also affected by the placement and shape of the inoculation plug. Some additional explanations: 'holomorph' given in specimen data means that both stromata and closely associated anamorph colonies are present in the specimen; 'under strong magnification' used in connection with stromata (surface, ostiolar dots, etc.) means observations at highest magnification levels in the stereo-microscope; the abbreviation ' $t$.' means 'textura'. Types of teleomorphs and anamorphs were not examined of those recently described species unequivocally identified by gene sequences. 
Table 1 Isolates and accession numbers for $r p b 2$ and tef 1 sequences of the species that were numbered in Jaklitsch (2009; 'part I') in the overall phylogenetic tree (Fig. 1) of the genus Hypocrea/Trichoderma. For ITS sequences search GenBank under the respective taxon or strain numbers

\begin{tabular}{|c|c|c|c|c|}
\hline Taxon & Name in part I & Strain & Accession $\mathrm{rpb} 2$ & Accession tef1 \\
\hline Hypocrea albolutescens & H. sp. 1 & CBS 119286 & FJ860517 & FJ860609 \\
\hline H. atlantica & H. sp. 11 & C.P.K. 1896 & FJ860545 & \\
\hline H. atlantica & H. sp. 11 & CBS 120632 & & FJ860649 \\
\hline H. auranteffusa & H. sp. 2 & CBS 119284 & FJ860520 & FJ860613 \\
\hline H. austriaca & H. sp. 3 & CBS 122494 & FJ860525 & FJ860619 \\
\hline H. bavarica & H. sp. 4 & C.P.K. 2021 & FJ860526 & FJ860620 \\
\hline H. calamagrostidis & H. sp. 5 & CBS 121133 & FJ860528 & FJ860622 \\
\hline H. margaretensis & H. sp. 6 & C.P.K. 3127 & FJ860529 & FJ860625 \\
\hline H. junci & H. sp. 9 & CBS 120926 & FJ860540 & FJ860641 \\
\hline H. luteffusa & H. sp. 10 & CBS 120537 & FJ860543 & FJ860645 \\
\hline H. luteocrystallina & H. sp. 8 & CBS 123828 & FJ860544 & FJ860646 \\
\hline H. neorufoides & H. sp. 12 & C.P.K. 1900 & FJ860553 & \\
\hline H. neorufoides & H. sp. 12 & CBS 119506 & & FJ860657 \\
\hline H. pachypallida & H. sp. 13 & CBS 120533 & FJ860559 & \\
\hline H. pachypallida & H. sp. 13 & CBS 122126 & & FJ860662 \\
\hline H. phellinicola & H. sp. 14 & CBS 119283 & FJ860569 & FJ860672 \\
\hline H. rhododendri & H. sp. 15 & CBS 119288 & FJ860578 & FJ860685 \\
\hline H. sambuci & H. sp. 16 & WU 29467 & FJ860585 & FJ860693 \\
\hline H. silvae-virgineae & H. sp. 7 & CBS 120922 & FJ860587 & FJ860696 \\
\hline H. subeffusa & H. sp. 17 & CBS 120929 & FJ860597 & FJ860707 \\
\hline H. valdunensis & H. sp. 18 & CBS 120923 & FJ860605 & FJ860717 \\
\hline
\end{tabular}

\section{Results and discussion}

Overview and phylogeny of the European Hypocreas

Of the 75 species of Hypocrea/Trichoderma so far recognised as forming teleomorphs in Europe 56 species have hyaline ascospores. These species are here described in detail and illustrated by colour plates, including cultures and anamorphs. The number of species described in this volume includes 16 new holomorphs, two new teleomorphs and nine anamorphs of species previously described as teleomorphs. Phylogenetic placement and relationships of all species are shown on the strict consensus tree (Fig. 1) based on a combined analysis of sequences of RNA polymerase II subunit $\mathrm{b}$ ( $r p b 2)$ and translation elongation factor 1 alpha (tef1) exon of the genus comprising 135 species. The tree is the same as presented by Jaklitsch (2009), but names are inserted for the species cited there only with a number. See Jaklitsch (2009) for a discussion of the tree topology. Sectional and clade names are used in a phylogenetic sense. This means that they are not necessarily congruent with the Trichoderma sections defined by Bissett (1991a) and that they are used synonymously for both Hypocrea and Trichoderma.

In fact, all major phylogenetic clades or sections except section Hypocreanum are heterogeneous with respect to anamorph morphology, i.e. many morphological traits in Trichoderma have evolved several times. Of Bissett's sections only Longibrachiatum and Hypocreanum represent natural entities.

Key to the European species of Hypocrea, Arachnocrea and Protocrea

'Keys are written by those who don't need them for those who can't use them' (Packer 2008).

Nevertheless, the following dichotomous key attempts to provide a basis for the identification of Hypocrea species. It is only applicable for species occurring in Europe. For many species the anamorph in culture is indispensable, but generally gene sequences are more reliable in identification. It is important to note that Trichoderma associated with stromata in nature are frequently misleading in identification.

Some definitions White-conidial means conidia white in mass and individually hyaline, green-conidial means conidia green or yellow green in mass and individually green or subhyaline. Colony traits were generally determined under standard conditions of growth rate experiments under $12 / 12 \mathrm{~h}$ alternating light/darkness at $25^{\circ} \mathrm{C}$ except where noted. The letter in parentheses after 
each species name indicates the chapter where the description can be found (1T.. section Trichoderma; 2P.. pachybasium core group; 3E.. Species with effuse stromata including section Hypocreanum; 4B.. Brevicompactum, Lutea and Psychrophila clades; 5M.. miscellaneous species). For descriptions of Arachnocrea stipata see Moravec (1956), Dennis (1981) or Rossman et al. (1999), for Protocrea farinosa and P. pallida (formerly Hypocrea pallida) see Jaklitsch et al. (2008b). For a detailed explanation of morphological terminology the reader is referred to Jaklitsch (2009).

Not included in the key are species of the hypomyceslike genus Sporophagomyces, (Põldmaa et al. 1999), where bicellular fusoid ascospores frequently disarticulate into part-spores after discharge. Reports from Europe include $S$. chrysostomus on Ganoderma spp. (Põldmaa 1999), or S. lanceolatus on a Byssocorticium (Dämon 1996). See Rogerson and Samuels (1993) for descriptions.

1 Ascospores green

see Jaklitsch (2009)

1' Ascospores hyaline 2

2 On Juncus, gramineous or herbaceous hosts; stromata pulvinate

2' On wood and bark, fungi or forest litter; stromata of various shapes

3 Stromata yellow; anamorphs white-conidial

3' Stromata orange- or reddish brown; anamorphs white- or green-conidial

4 On Juncus and herbaceous plants; stromata attached to the host by hyphae, easily falling off, $\mathrm{KOH}+$ red; distal ascospore cell $2.8-4.2 \times 2.5-3.8 \mu \mathrm{m}$; conidia ellipsoidal

H. placentula $(2 \mathrm{P})$

4' Only exceptionally on Juncus; stromata firmly attached to the host, KOH-; distal ascospore cell 3.7-6.0 $\times 3.5-5.5 \mu \mathrm{m}$; conidia globose

H. pilulifera (2P)

5 Stromata glabrous, orange- to reddish brown; ostiolar dots distinct; conidia hyaline

H. calamagrostidis $(4 \mathrm{~B})$

5' Stromata hairy when young, red to dark reddish brown; ostiolar dots absent or indistinct; conidia green H. junci (1T)

6 Stromata upright, height usually exceeding the width, with a sterile stipe (formerly Podostroma, Podocrea)

6' Stromata different

7 On wood and bark, stromata clavate or irregular, fertile part yellow; slow-growing; anamorph on CMD trichoderma-like, green-conidial when fresh

H. alutacea (2P)

$7^{\prime}$ On the ground on forest litter; anamorphs on CMD verticillium-like or reduced, white-conidial; predominantly in North Europe

8 Stromata large, to more than $10 \mathrm{~cm}$ long; fertile part reddish brown to brownish orange, pigment inhomogeneously distributed; distal ascospore cell 3.0-5.5 $\times 3.0-4.2 \mu \mathrm{m}$; conidia large, 5-21 $\times 3-9 \mu \mathrm{m}$, typically produced on solitary phialides

H. nybergiana $(2 \mathrm{P})$

$8^{\prime}$ Stromata smaller, typically $<5 \mathrm{~cm}$ long, fertile part paler, yellowish; distal ascospore cell $2.7-4.0 \times 2.3-3.5 \mu \mathrm{m}$; anamorph verticillium-like

Colour not changing upon drying, fertile part sharply delimited from the stipe; conidia ellipsoidal, $2.8-6.2 \times 2.0-3.0 \mu \mathrm{m}$

H. leucopus $(2 \mathrm{P})$

9' Colour changing to ochre upon drying, perithecia decurrent on the stipe; conidia subglobose to ellipsoidal, $2.5-4.5 \times 2.0-$ $3.7 \mu \mathrm{m}$

H. seppoi $(2 \mathrm{P})$

10 Stromata hypomyces-like, perithecia seated on or in a subiculum; anamorphs white-conidial

$10^{\prime}$ Perithecia embedded in a fleshy, at least partially pseudoparenchymatous stroma

11 Ascospore cells conical, 4-6×2-3 $\mu \mathrm{m}$, with minute acute appendages; anamorph verticillium-like Arachnocrea stipata

$11^{\prime}$ Ascospores rounded

12 On aphyllophoralean fungi; anamorphs gliocladium-like

$12^{\prime}$ On wood and bark, overgrowing fungi or bryophytes; anamorphs verticillium-like

13 On Skeletocutis spp. and other polypores; perithecia yellowish, amber to olive; subiculum white, KOH-

Protocrea farinosa

13' On Oligoporus and Tyromyces spp., perithecia orange, subiculum white or orange, KOH+ purple Protocrea pallida

14 Perithecia ochre, orange or brown, subiculum white or brownish, KOH-; perithecia small, up to $200 \mu \mathrm{m}$ diam; distal ascospore cell $2.3-3.7 \times 2.0-3.2 \mu \mathrm{m}$

H. delicatula $(3 \mathrm{E})$

$14^{\prime}$ Subiculum with different colours, more compact, $\mathrm{KOH}+$; distal ascospore cell 3.0-5.5 $\times 2.5-4.0 \mu \mathrm{m}$

15 Subiculum red in fertile areas, purple in $\mathrm{KOH}$

H. parmastoi $(3 \mathrm{E})$

$15^{\prime}$ Subiculum olive-brown to yellow-brown, turning brown to grey in $\mathrm{KOH}$

H. alcalifuscescens $(3 \mathrm{E})$

16 Stromata effuse to subpulvinate at maturity, extending to $>1 \mathrm{~cm}$; margin often attached on the substrate at least when 
young; surface not conspicuously hairy or velutinous except in H. pulvinata; anamorphs white-conidial

16' Stromata effuse, pulvinate, turbinate, lenticular or discoid; margin usually becoming free during stromatal development; surface hairy or glabrous; when effuse, then anamorphs green-conidial 23

17 On fungi

$17^{\prime}$ Not predominantly on fungi, but occasionally overgrowing fungi

18 On heterobasidiomycetes; stromata bright yellow

$18^{\prime}$ On polypores; stromata paler

19 On basidiomes of Exidia spp., distal ascospore cell 5-10×4.3-7.0 $\mu \mathrm{m}$

H. sulphurea (3E)

19' On basidiomes of Eichleriella deglubens; distal ascospore cell 3.7-6.5 $\times 3.0-5.0 \mu \mathrm{m}$

H. austriaca (3E)

20 On effused basidiomes of Phellinus spp.

H. phellinicola (3E)

$20^{\prime}$ On other polypores

21 On Fomitopsis pinicola and Piptoporus betulinus; stromata subpulvinate or effuse, (greenish-, brownish-) yellow pigment concentrated around the ostioles; surface velutinous to farinose due to numerous verrucose hairs; ascospore cells monomorphic; apical ostiolar cells lanceolate

H. pulvinata $(3 \mathrm{E})$

21' On Fomitopsis pinicola; stromata effuse; brownish pigment homogeneously distributed; surface if farinose only due to spore powder; ascospore cells dimorphic; ostiolar cells not lanceolate

H. protopulvinata $(3 \mathrm{E})$

22 On forest litter and soil, spreading from stumps, less commonly on attached bark; stromata whitish, yellow or cream to pale ochre; cortical tissue pseudoparenchymatous; distal ascospore cell 3.7-5.8 $\times 3.5-4.8 \mu \mathrm{m}$

H. citrina $(3 \mathrm{E})$

$22^{\prime}$ On wood and bark, overgrowing various fungi; stromata light yellow to light brown, cortical tissue prosenchymatous, distal ascospore cell 3.0-3.7×3.0-3.5 $\mu \mathrm{m}$; in Europe only known from southern France

H. decipiens (3E)

23 Stromata effuse to subpulvinate, to several cm long; surface glabrous; yellow or orange; conidia green, at least in mass

23' Stromata of different shapes, smaller; when effuse then surface hairy; conidia green or hyaline

24 Stromata effuse, up to $5 \mathrm{~cm}$ long, yellow; cortex of minute thick-walled labyrinthine cells; distal ascospore cell $2.3-4.3 \times 2.3-$ $3.2 \mu \mathrm{m}$; conidiation effuse, verticillium-like; conidia green on SNA, at least in mass

H. luteffusa $(2 \mathrm{P})$

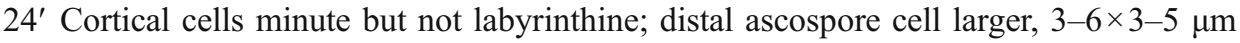

25 Stromata pale yellow when fresh, subeffuse, discoid to pulvinate; conidiation on PDA in well-defined green zones, colony radius $32-34 \mathrm{~mm}$ on $\mathrm{CMD}$ at $25^{\circ} \mathrm{C}$ after 3 days

H. rodmanii (4B)

$25^{\prime}$ Stromata with brighter colours, effuse to subpulvinate

26 Stromata bright yellow to bright orange, usually associated with brown rhizomorphs; growth slow, colony radius 4$6 \mathrm{~mm}$ on $\mathrm{CMD}$ at $25^{\circ} \mathrm{C}$ after 3 days; mycelium on CMD forming several concentric zones of equal width

H. auranteffusa $(4 \mathrm{~B})$

$26^{\prime}$ Stromata bright yellow, up to $2 \mathrm{~cm}$ diam, reminiscent of $H$. sulphurea; colony radius $22-28 \mathrm{~mm}$ on $\mathrm{CMD}$ at $25^{\circ} \mathrm{C}$ after 3 days; mycelium on CMD forming several concentric zones of unequal width; only known from Kärnten, Austria

27 Ascospore cells monomorphic

H. margaretensis (4B)

$27^{\prime}$ Ascospore cells dimorphic, proximal cell typically narrower than distal cell

28 Stromata green to grey, discoid, often undulate; ostioles green in lactic acid; on exposed wood; growing at and above $35^{\circ} \mathrm{C}$; anamorph green-conidial

H. schweinitzii $(5 \mathrm{M})$

$28^{\prime}$ Stromata white or yellow; ostioles not green in lactic acid; not growing at and above $35^{\circ} \mathrm{C}$; anamorph white-conidial 29

29 Stromata pulvinate, white, developing yellow spots, often shrinking to thin crusts upon drying; on well-decayed wood in ruderal habitats, riverine forests and parks; conidiation in pustules with straight or sinuous elongations

H. albolutescens $(5 \mathrm{M})$

29' Stromata discoid to flat pulvinate; yellow, turning ochre, rust to brown upon drying; on a white subiculum on bark of conifers in the upper montane zone of the Alps and in Northeast Europe; conidiation effuse, polypaecilum-like, i.e. with apically branched phialides

H. subalpina $(5 \mathrm{M})$

30 Stromata appearing waxy or gelatinous; growth slow, on CMD colony radius $<3 \mathrm{~mm}$ after 3 days at $25^{\circ} \mathrm{C}$; conidiophores odd verticillium-like, conidia hyaline

$30^{\prime}$ Stromata not appearing waxy or gelatinous (except for older stromata of $H$. silvae-virgineae; see [52]); growth faster, anamorphs different

31 Stromata incarnate or reddish, turning orange- to reddish brown, often yellowish when young; ostiolar dots absent, perithecial contours evident, minute; stromata often with violaceous-brown folds when dry and old; on wood and bark of various trees

H. tremelloides (5M) 
31' Stromata white, yellowish to honey-coloured, reddish brown when old; on Sambucus nigra $\quad$ H. sambuci (5M)

32 Stromatal surface hairy, at least when young (section Trichoderma, H. crystalligena; also stromata of H. pachybasioides and H. pachypallida (see [47] and [63]) are sometimes velutinous in young stages); ostiolar dots invisible or inconspicuous, at least when young and fresh 33

32 ' Stromatal surface glabrous under a lens; stromata pulvinate, turbinate or discoid 46

33 Stromata distinctly pulvinate when fresh, dark reddish brown to violaceous-brown when dry, often covered by powder of white crystals; ostiolar dots becoming distinct with age, particularly when dry; ascospores small, distal ascospore cell 2.5-4×2.5$3 \mu \mathrm{m}$; colony on CMD finely zonate, of radial fan-shaped segments, sometimes forming crystals in the agar; conidia hyaline

H. crystalligena (4B)

33' Stromatal shape and colour variable; crystalline covering absent or rare; ostiolar dots generally inconspicuous; ascospores larger; conidia green (sect. Trichoderma)

34 Stromata effuse, extending to $>3 \mathrm{~cm}$, white with unevenly distributed ochre to orange-brown fertile patches; margin fraying out as white mycelium attached to the substrate

H. ochroleuca (1T)

34 ' Stromata smaller, typically less than $1 \mathrm{~cm}$ long, often subeffuse when young 35

35 Stromata more or less reddish brown or variable within specimens; conidia smooth or ornamented 36

$35^{\prime}$ Stromata orange, orange-brown, or violaceous-brown to dark brown, more or less uniform within specimens; conidia smooth

36 Conidia smooth

$36^{\prime}$ Conidia verruculose or verrucose

37 Stromata reddish brown with a brick-red component; conidia subglobose; conidiophores with conspicuously widely spaced short branches; colony radius $45-48 \mathrm{~mm}$ on $\mathrm{CMD}$ at $25^{\circ} \mathrm{C}$ after 3 days; teleomorph rare $\mathbf{H}$. atroviridis (1T)

$37^{\prime}$ Stromata without brick-red component; conidia ellipsoidal; growth slow, colony radius to $23 \mathrm{~mm}$ on $\mathrm{CMD}$ at $25^{\circ} \mathrm{C}$ after 3 days; only known from the type locality in Austria

H. valdunensis $(1 \mathrm{~T})$

38 Stromata small, typically around $1 \mathrm{~mm}$ diam, very variable in colour, white, yellow, yellowish brown, light brown, rust, reddish brown, often varying within a specimen; conidia distinctly tubercular, (sub-)globose with $1 / \mathrm{w}=1.0$ 1.1, conidiophores and phialides on dense pustules on CMD conspicuously curved, not submoniliform; anamorph common, teleomorph uncommon

H. rufa $(1 \mathrm{~T})$

$38^{\prime}$ Stromata similar, mostly reddish brown; conidia verruculose, subglobose to ellipsoidal with $1 / \mathrm{w}=1.0-1.3$; conidiophores and phialides not conspicuously curved; on CMD terminal conidiophores often conspicuously submoniliform; pustules if formed not compact; common

H. viridescens (1T)

39 Dry mature stromata dark brown, violaceous-brown, to nearly black

$39^{\prime}$ Fresh and dry mature stromata primarily with orange, orange-brown to rust colours

40 Perithecial wall colourless; effuse and pustulate conidiation structurally similar

$40^{\prime}$ Perithecial wall yellow; stromata yellow when young and fresh; if pustules formed then effuse conidiation structurally different from pustulate conidiation

41 Stromata effuse to subpulvinate, typically dark violaceous-brown; in association with green algae on decorticated wood; large characteristic coilings produced on CMD; poor and limited growth at $30^{\circ} \mathrm{C}$

H. subeffusa (1T)

$41^{\prime}$ Stromata pulvinate, lacking violet tones; good growth at $30^{\circ} \mathrm{C}$

H. petersenii (1T)

42 On SNA pustules with phialides 4-11×3-3.7 $\mu$ m formed, mean $1 / \mathrm{w}$ of conidia 1.4 ; uncommon

H. neorufa (1T)

$42^{\prime}$ On SNA no pustules formed but characteristic broad and flat shrubs, in fresh isolates aggregating to flat hedges with phialides $7-20 \times 3-5 \mu \mathrm{m}$; mean $1 / \mathrm{w}$ of conidia 1.5 ; widespread and common

H. neorufoides (1T)

43 Stromata up to $15 \mathrm{~mm}$ long, effuse to flat pulvinate; usually associated with abundant, widely effused, bright blue-green anamorph; conidial pustules in culture with a yellow reverse, surrounded by surface hyphae with conspicuously thickened cells; conidiophores dimorphic, curved in a dense cluster and/or long regularly tree-like; uncommon $\mathbf{H}$. stilbohypoxyli (1T)

43' Stromata smaller; anamorph in nature less conspicuous

44 Stromata pulvinate, yellow- or orange-brown when young, becoming dark brown; mean 1/w of conidia 1.2

$44^{\prime}$ Stromata discoid or flat pulvinate when dry, remaining more or less orange-brown

H. petersenii (1T)

45 Mean $1 / \mathrm{w}$ of conidia 1.5 ; teleomorph rare

$45^{\prime}$ Mean 1/w of conidia 1.3-1.4; teleomorph locally common on Fagus

H. koningii (1T)

46 Stromata rosy, reddish, reddish-brown, at least when young

H. rogersonii (1T)

$46^{\prime}$ Stromata different in colour

47 Stromata remaining reddish during their development, ostiolar dots conspicuous, dark brown to black; on Alnus spp. 
above $1000 \mathrm{~m}$ in the Alps

H. voglmayrii $(5 \mathrm{M})$

$47^{\prime}$ Ostiolar dots not dark brown to black, except when old

48 Stromata rosy, off-white to pale yellowish; conidia hyaline, formed in white pustules with sterile helical elongations, best seen on SNA

H. pachybasioides $(2 \mathrm{P})$

$48^{\prime}$ Stromata changing from rosy or pink when young to yellow, yellowish brown to reddish brown during their development; conidia green, formed in shrubs or pustules lacking elongations

49 Distal ascospore cell 3.7-6.0 $\times 3.2-5.0 \mu \mathrm{m}$; colony radius on CMD $46-51 \mathrm{~mm}$ at $25^{\circ} \mathrm{C}$ after 3 days, conidiation on CMD effuse to subpustulate; the commonest species of Hypocrea in temperate zones

H. minutispora (2P)

$49^{\prime}$ Distal ascospore cell 3.0-5.3 $\times 2.5-4.0 \mu \mathrm{m}$; colony radius on CMD $22-25 \mathrm{~mm}$ at $25^{\circ} \mathrm{C}$ after 3 days; conidiation on CMD pustulate; known only from the type and one additional specimen

H. atlantica $(2 \mathrm{P})$

50 Stromata bright golden-yellow to bright orange; distinctly pulvinate with firm consistency

$50^{\prime}$ Stromatal colour different

51 On Rhododendron spp. in the subalpine zone; anamorph gliocladium-like, conidia hyaline

H. psychrophila (4B)

51' On Prunus laurocerasus in England; only known from the type specimen; anamorph unknown

H. splendens $(5 \mathrm{M})$

52 Stromata with conspicuously projecting perithecial contours; white when young, turning yellow-orange, apricot or orangebrown; sometimes appearing waxy to gelatinous; distal ascospore cell $4.3-9.0 \times 3.3-5.3 \mu \mathrm{m}$; growth poor at $30^{\circ} \mathrm{C}$; effuse conidiation gliocladium-like, pustulate conidiation on SNA pachybasium-like, with straight to sinuous fertile elongations; conidia oblong, green

H. silvae-virgineae $(5 \mathrm{M})$

$52^{\prime}$ Stromata without conspicuously projecting perithecial contours; stromatal colour in shades of whitish, yellow to brown; distal ascospore cell smaller

53 On cones of Pseudotsuga menziesii in England; stromata white to yellowish with orange-brown perithecial dots, $\mathrm{KOH}$-; distal ascospore cell 4.3-5.7×3.5-4.8 $\mu \mathrm{m}$; anamorph unknown; only known from the type specimen with certainty

H. strobilina $(5 \mathrm{M})$

53' On wood and bark; ascospores smaller

54 Stromata changing colour upon drying from pale or clear yellow to shades of dull orange, rust or brown

$54^{\prime}$ Stromata not or only slightly changing colour upon drying

55 Stromata pale yellowish when fresh, pale yellow-orange when dry, KOH-; on Rhododendron ferrugineum in the subalpine zone; no anamorph but white mycelial clumps formed on PDA, and sterile stromata on SNA

H. rhododendri (4B)

$55^{\prime}$ Stromata on other hosts; $\mathrm{KOH}+$ reddish orange or red

56 On Betula, less commonly on Alnus in riverine forests; ostiolar dots typically diffuse; distal ascospore cell (2.5-)2.8-3.2 $(-3.5) \times(2.3-) 2.5-3.0(-3.2) \mu \mathrm{m}$; cultures on CMD and PDA with characteristic, unpleasant odour; conidiation effuse, conidia hyaline

H. bavarica (2P)

$56^{\prime}$ Ascospores larger

57 Stromata argillaceous when fresh, greyish orange when dry; ostiolar dots typically diffuse; distal ascospore cell 4-6×3.5-5 $\mu \mathrm{m}$; anamorph unknown; on wood of Fraxinus excelsior in England; only known from the holotype

H. argillacea $(5 \mathrm{M})$

$57^{\prime}$ Stromata pale to bright yellow when fresh, turning brown; ostiolar dots well-defined when mature; ascospores smaller 58

58 Stromata typically on well-rotted wood in moist, often muddy places; surface glabrous; anamorph pachybasium-like, pustulate on CMD and SNA; conidia green

H. moravica $(5 \mathrm{M})$

58' Stromata on Fagus; surface with short hairs when mature; conidiation in white pustules with sterile helical elongations; conidia hyaline; rare, teleomorph in Europe known from a single location in the Czech Republic H. parapilulifera (2P)

59 On wood of Betula; stromata pale yellow, $\mathrm{KOH}-$; conidia hyaline, globose; teleomorph rare $\quad$ H. pilulifera (2P)

$59^{\prime}$ On other hosts; conidia not globose

60 Stromata pale to dull yellow, sometimes with a conspicuous whitish young stage; anamorph distinctly gliocladium-like with green conidia formed in large, dark green to black, deliquescent heads

$60^{\prime}$ Anamorph not gliocladium-like

61 Stromata small, with angular outline, typically in small numbers; fast growth at $35^{\circ} \mathrm{C}$; conidia ellipsoidal or oblong; widespread but uncommon

H. lutea (4B)

61' Teleomorph with a subeffuse, whitish young stage; mature stromatal surface covered with yellow crystals turning violet in $\mathrm{KOH}$; poor or no growth at $35^{\circ} \mathrm{C}$; conidia subglobose; on Abies and Picea; rare

H. luteocrystallina (4B)

62 Stromata when dry yellow-brown, brown-orange, brown, to reddish brown or dark brown, glabrous; conidiation effuse to subpustulate on CMD and SNA; conidia green

H. minutispora $(2 \mathrm{P})$ 
$62^{\prime}$ Stromata paler, often slightly downy when young; conidia hyaline

63 Stromata white, turning yellow, brown-orange to golden-yellow during their development; anamorph effuse, verticillium-like, lacking sterile helical elongations

H. pachypallida $(2 \mathrm{P})$

63' Stromatal colour variable, when fresh mostly white, pale yellowish, pale orange, yellow- brown or light brown; ostiolar dots often diffuse, large, often irregularly disposed; conidiation in white pustules with sterile helical elongations

H. pachybasioides (2P)

Note: To those who wished to see a key based exclusively on the Trichoderma anamorph and those who consider the lack of such a key a weak point of this work, I want to say the following: 1) This work is based on teleomorphs. No attempt has been made to identify Trichoderma anamorphs from natural sources based on morphology. We have no information on how many species occur in Europe above ground. To assess this information a project would be necessary that by far exceeds the scope of the current projects. 2) Gene sequences provide convincingly superior certainty in identification than morphology. 3) A key to anamorphs is not provided deliberately to avoid the deceptive impression that it may be possible to identify species of Trichoderma on natural substrates on few morphological traits like colour, size and shape of phialides and conidia. In addition, many Trichoderma species are currently only known as isolates from soil and we do not know whether they could be found on plant material or not. I am not familiar with the soil-inhabiting species and any key would thus have many gaps. 4) Finally, some species of Hypocrea do not form anamorphs or anamorphs are rare in nature, particularly in sect. Hypocreanum. To include such anamorphs in a key would not aid in identification.

\section{Description of the species}

As done in the first part of the monograph (Jaklitsch 2009), both combinations in Hypocrea and Trichoderma are given for all species, for the following reasons: For species described earlier I want to provide as complete taxonomic and nomenclatorial information as possible, and for new species I also establish names in Trichoderma for those who may need them and to avoid numerous new combinations in future when they may be possibly used as holomorphic names if the ICBN is altered accordingly. Article 59 and the recommendation 59A.3 of the ICBN demand the use of Hypocrea alone for the holomorphs, i.e. the anamorphs should not be named separately. There is, however, increased pressure to use the anamorphic generic name Trichoderma. Editors of certain journals are even trying to force authors to use Trichoderma instead of Hypocrea for naming new holomorphs, because Trichoderma is the older generic name. Such a concept has not reached a consensus among mycologists and is accordingly not implemented in Art. 59 . To the contrary, this concept, using the older name in disregard whether it denotes a teleo- or an anamorph genus, aims at the abolishment of Art. 59 of the Code. This is an alarming development, because forcing authors in such a direction is a top-down call to violate consensus-driven procedures and rules, i.e. a call towards non-compliance with the Code. Furthermore this constraint is unfair to authors, because it diminishes the availability of journals for systematic mycologists. In my opinion the disregard of a recommendation is much less severe than violating teleomorph priority that is clearly defined in Art. 59 of the Code.

\section{Subgeneric organisation of the species}

The 56 species of Hypocrea with hyaline ascospores occurring in Europe are described in five separate chapters, predominantly grouped according to their phylogenetic placements and subsidiarily to their stroma shape and size. The detailed descriptions are meant as small databases rather than concise descriptions for those who may study the morphology of these fungi in future. Species are epitypified where appropriate.

The chapters are as follows:

1) Hypocrea/Trichoderma section Trichoderma and its European species treats the thirteen species $H$. atroviridis, $H$. junci, $H$. koningii, $H$. neorufa, $H$. neorufoides, $H$. ochroleuca, $H$. petersenii, $H$. rogersonii, $H$. rufa, $H$. stilbohypoxyli, $H$. subeffusa, $H$. valdunensis, and $H$. viridescens.

2) The pachybasium core group comprises the four species $H$. alutacea, $H$. leucopus, $H$. nybergiana and $H$. seppoi forming upright, stipitate stromata, i.e. assignable to the former genus Podostroma, and the eight species $H$. atlantica, $H$. bavarica, $H$. minutispora, $H$. pachybasioides, H. pachypallida, $H$. parapilulifera, $H$. pilulifera, and $H$. placentula with pulvinate stromata, and $H$. luteffusa that forms effuse stromata.

3) European species of Hypocrea section Hypocreanum and other species forming large effused to subpulvinate stromata, comprises the ten species $H$. alcalifuscescens, $H$. austriaca, $H$. citrina, $H$. decipiens, $H$. delicatula, $H$. parmastoi, $H$. phellinicola, $H$. protopulvinata, $H$. pulvinata, $H$. sulphurea. 
4) The Brevicompactum, Lutea and Psychrophila clades. This chapter treats the three species $H$. auranteffusa, $H$. margaretensis and H. rodmanii of the Brevicompactum clade, the two species $H$. lutea and $H$. luteocrystallina of the Lutea clade, and the four species H. calamagrostidis, H. crystalligena, H. psychrophila and H. rhododendri of the Psychrophila clade.

5) Miscellaneous species: The eleven residual species $H$. albolutescens, $H$. argillacea, $H$. moravica, $H$. sambuci, $H$. schweinitzii, $H$. silvae-virgineae, $H$. splendens, $H$. strobilina, $H$. subalpina, $H$. tremelloides and $H$. voglmayrii are described in detail.

A list of dubious and excluded names concludes the work.

\section{Hypocrea/Trichoderma section Trichoderma and its European species}

\section{Introduction}

Hypocrea/Trichoderma section Trichoderma is the central phylogenetic clade of the genus, as it contains the type species $H$. rufa with its anamorph $T$. viride, the type species of Trichoderma. Originally (Bissett 1991a) the section was established to define a group of Trichoderma anamorphs with repeatedly rebranching, narrow and flexuous conidiophores with main axes up to $6 \mu \mathrm{m}$ wide, paired or verticillate branches, and lageniform to subulate phialides mostly in verticils of two or three. This group contained the 'T. viride aggregate' of Rifai (1969), T. atroviride, T. koningii, and T. aureoviride. Conidiophore morphology can be misleading, thus also $T$. harzianum belonged to the group for some time, but was later removed to 'section Pachybasium', and now is considered a clade of its own. Trichoderma aureoviride has conidiophores similar to those of the section, but its teleomorph is green-spored and phylogenetically it forms a sister group to the Chlorospora clade (see Fig. 1). No species of this section has green ascospores, while all have green or yellow conidia. Conidiophores of the section Trichoderma vary a great deal in morphology, making a definition of typical Trichoderma conidiophores difficult. Samuels et al. (2006a) presented the ' $T$. koningii aggregate species group' characterised by conidiophores, which can be subsumed as regularly tree-like. Jaklitsch et al. (2006b) in describing some species around $H$. rufa, recognised three types of conidiophores in this subgroup. In addition, even some species with typical pachybasium-like conidiophores, viz. T. hamatum, T. pubescens, T. strigosum and others (Chaverri et al. 2003; Samuels and Ismaiel 2009), are now placed in this section by phylogenetic analyses.
Inconveniently, the type of the former section Pachybasium, $T$. hamatum, belongs to this section, rendering the name 'section Pachybasium' obsolete. As in other clades of Trichoderma, phialides generally tend to be more plump with increasing complexity of the conidiation system, i.e. with a lower $1 / w$ ratio in pustules than in solitary, effuse conidiophores. However, this is not the case in many species of this section, particularly in $H$. rufa and $H$. viridescens.

The section conceived here is monophyletic; it is phylogenetically complex and a morphological species delimitation of anamorphs is difficult. Teleomorph morphology is essentially homogeneous. All species are characterised by more or less hairy or velutinous and often subeffuse stromata when young, of mostly small or moderate sizes with few exceptions, and generally inconspicuous ostiolar dots. More distinct or projecting dots may sometimes occur as a consequence of repeated drying and rehydration. It is generally easy with a good hand lens to determine whether stromata belong to the section or not but, due to a high degree of morphological conservation of the teleomorphs, the possibilities of morphological species delimitation are limited. Some teleomorphs, e.g. those of H. neorufa and $H$. neorufoides, are indistinguishable. In addition, not all traits that may be useful for identification are always present in a colony of stromata. Based on the colour of stromata, two series of species can be recognised: those with orange to orange-brown stromata, largely coinciding with the so-called ' $T$. koningii aggregate species group' (see Samuels et al. 2006a) and those with reddish brown to dark brown stromata mostly with the 'viride or viridescens clades' (see Jaklitsch et al. 2006b). However, several species form separate subsectional clades. Due to extensive and thorough investigations by Gary Samuels, many new species have been discovered and described in recent years, but the section Trichoderma has not yet been monographed as a whole. Even from the papers cited above it is obvious that species delimitation on a world-wide scale based on teleomorphs is impossible. Considering species like T. martiale (Hanada et al. 2008), which has essentially the $T$. viride morphology, anamorphs also will eventually not provide sufficient variation for species delimitation and identification. Ecological and biogeographic traits are therefore increasingly gaining importance in the species concept in addition to phylogeny.

\section{Species descriptions}

In Europe currently the following 13 species including four new ones of the section Trichoderma forming teleomorphs 
are recognised: $H$. atroviridis, $H$. junci, $H$. koningii, $H$. neorufa, $H$. neorufoides, $H$. ochroleuca, $H$. petersenii, $H$. rogersonii, $H$. rufa, $H$. stilbohypoxyli, $H$. subeffusa, $H$. valdunensis, and $H$. viridescens. They are described below. Species of Hypocrea/Trichoderma section Trichoderma known so far to occur in Europe exclusively as anamorphs, such as T. asperelloides, T. asperellum (Samuels et al. 2010), T. gamsii (Jaklitsch et al. 2006b), and T. koningiopsis (Samuels et al. 2006a) are beyond the scope of this work.

The notes after each species description help to distinguish some species. Most species of this section require culturing. Microscopic examination of conidia of anamorphs that are associated with stromata in nature may sometimes be useful for identification, e.g. globose and coarsely warted conidia in $T$. viride, subglobose to ellipsoidal and verruculose in $T$. viridescens, both often forming yellow mycelium, but most species have smooth conidia, i.e. resembling those of other sections. The safest way in species identification within Hypocrea/Trichoderma section Trichoderma is sequencing of ITS and tef1 introns.

Hypocrea atroviridis Dodd, Lieckf. \& Samuels, Mycologia 95: 36 (2003). Fig. 2

Anamorph: Trichoderma atroviride P. Karst., Finl. Mögelsv. p. 21 (1892). Fig. 3

Stromata when fresh $0.7-2.5 \mathrm{~mm}$ diam, $0.3-1 \mathrm{~mm}$ thick, solitary to aggregated in small groups, pulvinate, smooth; ostiolar dots invisible or indistinct; perithecia entirely immersed. Colour typically orange-red to brick-red, 6A67, 7A5-6, 8AB5-6. Spore deposits white.

Stromata when dry $(0.5-) 0.7-1.6(-2.3) \times(0.4-) 0.6-1.3$ $(-1.8) \mathrm{mm}, 0.3-0.6(-0.9) \mathrm{mm}$ thick $(n=30)$; pulvinate to semiglobose, broadly (on bark or wood) or narrowly (on ostioles of a fungal host) attached; margin free. Outline circular or oblong. Surface smooth or tubercular, with yellow, rust or light brown hyphae when young. Ostiolar dots (23-)30-46(-63) $\mu \mathrm{m}(n=30)$ diam, only visible after moistening the surface with water, hyaline, plane or convex. Stromata white to ochre when young, brick-red or dark (reddish-)brown, 7EF6-8, 7-8CD7-8 when mature or old, with short rust hairs and sometimes a purple tone. Stromata in $3 \% \mathrm{KOH}$ after rehydration tubercular and darkening, without a conspicuous colour change.

Stroma anatomy: Ostioles (67-)75-110(-117) $\mu \mathrm{m}$ long, plane or projecting to $15(-20) \mu \mathrm{m},(22-) 25-40(-45) \mu \mathrm{m}$ wide at the apex $(n=15)$, cylindrical or conical, periphysate, with apical palisade of inconspicuous, hyaline, narrowly clavate cells. Perithecia (135-)170-250(-265) $\times(130-) 160$ $250(-285) \mu \mathrm{m}(n=20)$, globose. Peridium (12-)15-21(-25) $\mu \mathrm{m}$ thick at the base and sides $(n=40)$. Cortical layer $(17-)$ $20-30(-35) \mu \mathrm{m}(n=30)$ thick, surrounding the entire stroma except the area of attachment, an orange-brown $t$. angularis of indistinct cells $(3-) 4-9(-12) \times(2.5-) 3-7(-11) \mu \mathrm{m}(n=60)$ in face view and in vertical section, with inhomogeneous pigment distribution; cells more distinct in vertical section. Hairs on mature stroma $(7-) 10-23(-26) \times(2.0-) 2.5-3.5$ $(-4.0) \mu \mathrm{m}(n=20)$, cylindrical, simple or sparsely branched, with narrowly rounded ends. Subcortical tissue a $t$. intricata reaching to the base of the perithecia, of thin-walled hyphae (2.2-)3.3-5.5(-5.7) $\mu \mathrm{m}(n=20)$ wide, partly appearing as $t$. globulosa due to variable orientation of hyphae. Subperithecial tissue a $t$. angularis of hyaline, partly brownish cells $(5-) 7-18(-23) \times(4-) 6-14(-20) \mu \mathrm{m}(n=30)$. Asci (74-) 78-89(-94) $\times(4.8-) 5.0-5.8(-6.2) \mu \mathrm{m}$, including a (5-)7-13 $(-16) \mu \mathrm{m}$ long stipe $(n=30)$. Ascospores hyaline, verrucose, cells dimorphic, but often of similar shape, distal cell $(3.4-) 3.8-4.5(-5.3) \times(3.3-) 3.7-4.4(-4.6) \mu \mathrm{m}, 1 / \mathrm{w} 1.0-1.1$ $(-1.2)$, (sub)globose, proximal cell $(3.3-) 4.0-5.4(-6.2) \times$ $(2.7-) 3.0-3.7(-4.2) \mu \mathrm{m}, 1 / \mathrm{w}(1.0-) 1.1-1.7(-2.3) \quad(n=30)$, oblong, plump wedge-shaped or subglobose.

Cultures and anamorph: optimal growth at $25^{\circ} \mathrm{C}$ on all media; hyphae dying after short and limited growth at $35^{\circ} \mathrm{C}$.

On CMD after $72 \mathrm{~h} 26-29 \mathrm{~mm}$ at $15^{\circ} \mathrm{C}, 45-48 \mathrm{~mm}$ at $25^{\circ} \mathrm{C}$, $38-42 \mathrm{~mm}$ at $30^{\circ} \mathrm{C},<1 \mathrm{~mm}$ at $35^{\circ} \mathrm{C}$; mycelium covering the plate after 5 days at $25^{\circ} \mathrm{C}$. Colony hyaline, thin; mycelium loose, reticulate, denser at the wavy, ill-defined margin; hyphae with little variability in width. Aerial hyphae inconspicuous, becoming fertile. No autolytic excretions, no coilings seen. No pigment noted, odour coconut-like. Chlamydospores noted after 1 days, after 11 days numerous, particularly close to conidiation tufts, $(7-) 8-10(-11) \times 7-9$ (10) $\mu \mathrm{m}, 1 / \mathrm{w}(0.9-) 1.0-1.1(-1.3)(n=30)$, globose or ellipsoidal, mostly terminal, smooth. Conidiation noted after 2 days, grey- to dark green, 26DE4-6, 26F5-8, after 3 days, in fluffy tufts or loose pustules $0.5-2(-4) \mathrm{mm}$ diam with irregular or circular outline, arranged in several indistinctly separated, concentric zones, irregularly confluent to $7 \mathrm{~mm}$. Tufts arising on thick-walled, verrucose 6-19 $\mu \mathrm{m}$ wide stipes, branching asymmetrically into primary branches of similar width, rebranching mostly at right angles. Conidiophores forming long main axes 2-4 $\mu \mathrm{m}$ wide, with long branches at lower levels and sparse, widely spaced, solitary or paired phialides, or short, 1-celled side branches bearing terminal whorls of 23 phialides in right angles or slightly inclined or curved upward. Phialides borne on 2-3 $\mu \mathrm{m}$ wide cells; phialides $(4-) 6-10(-12) \times(2.0-) 2.3-3.0(-3.3) \mu \mathrm{m}, 1 / \mathrm{w} \quad(1.5-) 2.1-3.9$

Fig. 1 Strict consensus tree of length 5952 resulting from a maximum parsimony (MP) analysis of 1529 characters of the combined rpb2 tef1 exon alignment of 135 species of Hypocrea/Trichoderma. Broad black lines represent nodes with MP bootstrap values $(\mathrm{BS})=70-100$ and Bayesian posterior probabilities $(\mathrm{PP})=95-100$, broad grey lines nodes with $\mathrm{BS}<70$ and $\mathrm{PP}=95-100$; asterisks $(*)$ mark nodes with $\mathrm{BS}>70$ and $\mathrm{PP}<95$. For strain and accession numbers of new species see Table 1, for others Jaklitsch (2009). Clade names are indicated to the right of the clades 


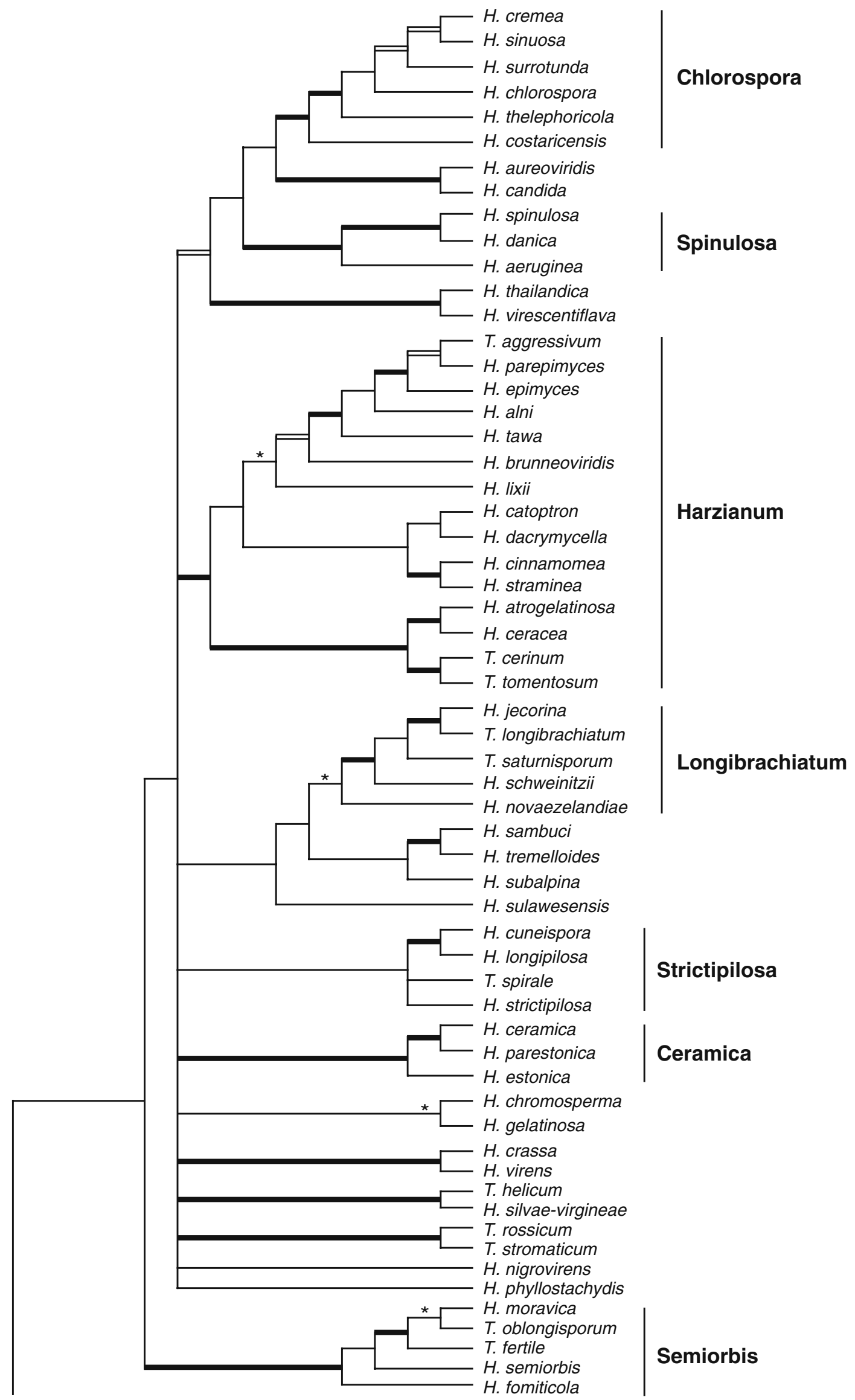




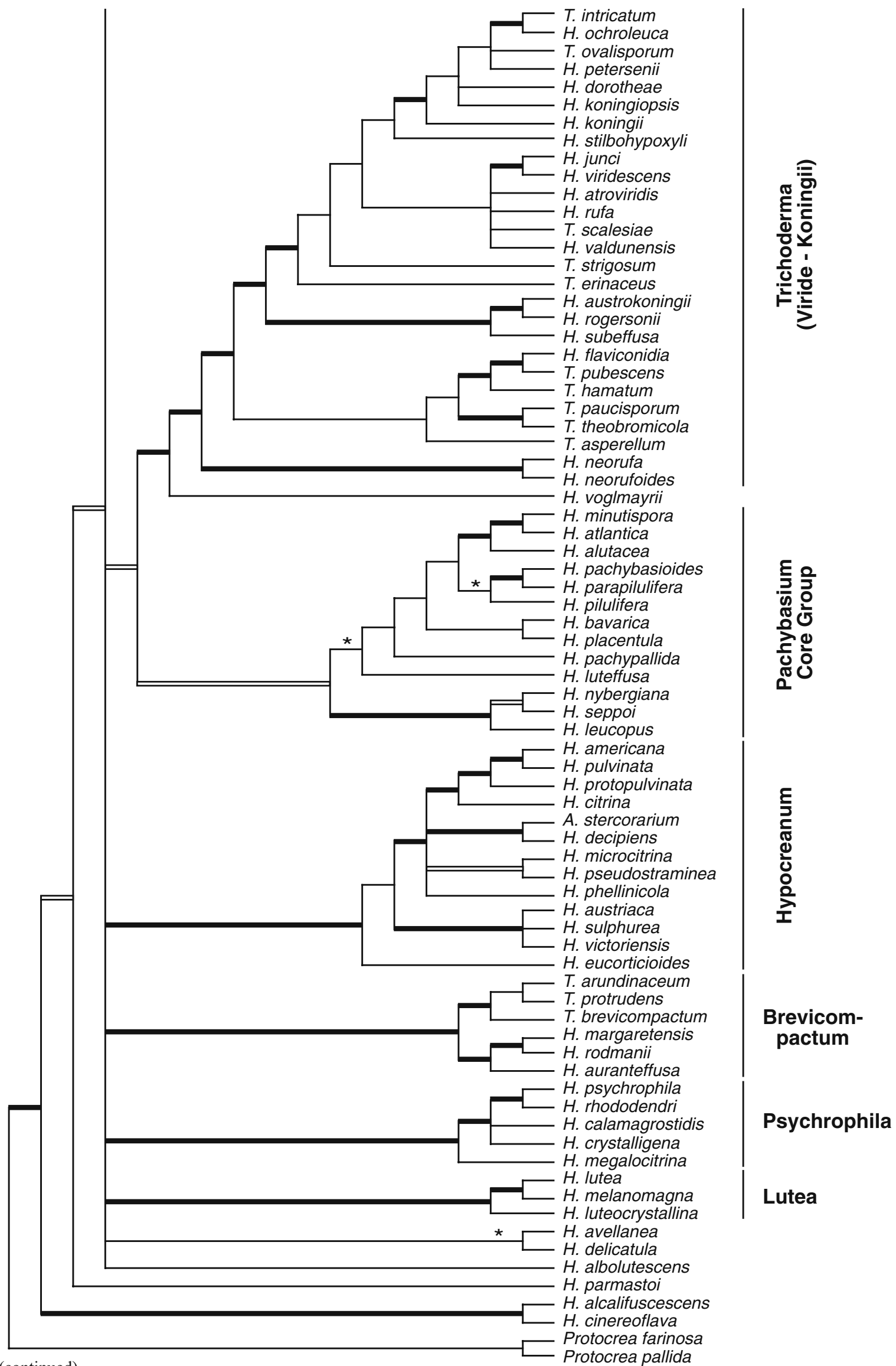

Fig. 1 (continued) 
(-5.4), (1.4-)1.6-2.2(-2.8) $\mu \mathrm{m}$ wide at the base $(n=30)$, lageniform, less commonly ampulliform, straight or slightly curved upward; widest part mostly median. Conidia formed in minute wet or dry heads $<20 \mu \mathrm{m}$ diam; conidia $(2.8-) 3.2-4.0(-$ $4.7) \times(2.8-) 3.0-3.5(-3.8) \mu \mathrm{m}, 1 / \mathrm{w} 1.0-1.2(-1.3)(n=30)$, dark green (also in microscopic mounts), (sub)globose or oval, smooth, finely multiguttulate when young; scar indistinct. At $15^{\circ} \mathrm{C}$ conidiation concentrated in large dark green tufts in distal areas of the colony; odour coconut-like; chlamydospores numerous. At $30^{\circ} \mathrm{C}$ concentric zones of green conidiation tufts well separated, agar turning yellow, 2A3-4, 4A4-5, 4B5-6. Odour pronounced coconut-like due to the formation of 6-pentyl- $\alpha$-pyrone; chlamydospores numerous.

On PDA after $72 \mathrm{~h} 26-28 \mathrm{~mm}$ at $15^{\circ} \mathrm{C}, 57-62 \mathrm{~mm}$ at $25^{\circ} \mathrm{C}, 40-43 \mathrm{~mm}$ at $30^{\circ} \mathrm{C}$, to $1.1 \mathrm{~mm}$ at $35^{\circ} \mathrm{C}$; mycelium covering the plate after 4 days at $25^{\circ} \mathrm{C}$. Colony thick; mycelium dense, of thick primary and narrow secondary hyphae, nearly reticulate; surface becoming hairy due to aerial hyphae. Aerial hyphae numerous, loosely disposed in the centre, thick and branched, mostly radially arranged, in a white to yellowish mat several $\mathrm{mm}$ high, forming strands and floccules with numerous large yellow to green drops. Autolytic excretions moderate to frequent, coilings inconspicuous. Reverse pale to dull yellow, 3-4AB3-4, centre grey-green, 29CD5-6, due to conidiation. Odour coconut-like. Conidiation noted after 1 day, loose on aerial hyphae and dense in compact white tufts in the centre, coalescing into an aggregate in a dense circular zone, turning yellow after 3-4 days and finally greygreen, 28E6-8, 27DE4-5. Eventually additional white, yellow to green, concentric conidiation zones formed. At $15^{\circ} \mathrm{C}$ white mat of aerial hyphae distinctly floccose, conidiation reduced, remaining white. Autolytic excretions numerous. At $30^{\circ} \mathrm{C}$ conidiation dense in several well-defined concentric zones, pale grey-green, 28-29CD5-6, 25CD3-4.

On SNA after $72 \mathrm{~h} 21-22 \mathrm{~mm}$ at $15^{\circ} \mathrm{C}, 34-37 \mathrm{~mm}$ at $25^{\circ} \mathrm{C}$, $25-29 \mathrm{~mm}$ at $30^{\circ} \mathrm{C}$, to $1.1 \mathrm{~mm}$ at $35^{\circ} \mathrm{C}$; mycelium covering the plate after 6 days at $25^{\circ} \mathrm{C}$. Colony hyaline, thin, resembling an ice crystal due to thick primary and numerous, densely arranged, short secondary hyphae at the margin; loose in the centre; margin wavy or lobed. Surface hyphae soon degenerating (appearing empty) from the centre. Aerial hyphae numerous, loosely disposed, long and high at the colony margin. Autolytic excretions and coilings inconspicuous. No diffusing pigment, no distinct odour noted. Chlamydospores noted after 1 day, numerous, particularly in areas of conidiation, terminal, globose. Conidiation noted after 2 days, green after 3 days, scant on aerial hyphae, dense in minute heads $<20 \mu \mathrm{m}$ diam in tufts/pustules to $1 \mathrm{~mm}$ diam, sometimes coalescing up to $13 \mathrm{~mm}$; arranged in several concentric zones spreading from the centre, first white, turning dark green, 2527F6-8, to nearly black. Zones denser and better separated and pustules more compact than on CMD. At $30^{\circ} \mathrm{C}$ conidiation reduced relative to 15 and $25^{\circ} \mathrm{C}$; coilings abundant.
Habitat: on wood and bark and fungi growing on them.

Distribution: Europe (Austria, France), Central and North America.

Holotype: France. Pyrénées Atlantiques, Isle de la Sauveterre de Bearn, elev. 100 m, on decorticated wood, 25 Oct. 1998, Samuels \& Candoussau (BPI 748312, cultures G.J.S. 98-134 = CBS 110086) (not examined).

Other material examined: Austria, Oberösterreich, Schärding, St. Willibald, Aichet, riverine forest, MTB 7648/ $1,48^{\circ} 21^{\prime} 17^{\prime \prime} \mathrm{N}, 13^{\circ} 41^{\prime} 01^{\prime \prime} \mathrm{E}$, elev. $400 \mathrm{~m}$, on corticated twigs of Prunus padus, $0.5-1.5 \mathrm{~cm}$ thick, on ostioles of Diaporthe padi, bark and wood, soc. rhizomorphs, holomorph, 30 July 2005, H. Voglmayr, W.J. 2824 (WU 29178, cultures CBS 119499, C.P.K. 2192).

Notes: The teleomorph of Hypocrea atroviridis seems to be rare, as it was only collected once in this study, while the anamorph is common in soil and also found as a contaminant of other Hypocrea species. Despite the characteristic brick-red stroma colour (see also Dodd et al. 2003), the teleomorph is difficult to distinguish from other species of the Viride clade, particularly from $H$. viridescens and $H$. valdunensis. However, the subglobose conidia, smooth in the light microscope, formed on minute heads on long conidiophores with conspicuously widely spaced short branches or phialides are diagnostic.

Hypocrea junci Jaklitsch, sp. nov. Fig. 4

MycoBank MB 516681

(?) = Hypocrea rufa f. sterilis Rifai \& J. Webster, Trans. Brit. Myc. Soc. 49: 294 (1966).

Anamorph: Trichoderma junci Jaklitsch, sp. nov. Fig. 5 MycoBank MB 516682

Stromata typice in culmis Junci effusi, pulvinata, fusco-rufa vel vinosa, $0.5-2 \mathrm{~mm}$ lata. Asci cylindrici, $(64-) 67-83(-98) \times(4.0-) 4.5-6.0(-6.5) \mu \mathrm{m}$. Ascosporae bicellulares, hyalinae, verruculosae, ad septum disarticulatae, pars distalis (sub)globosa, $(3.3-) 3.5-4.0(-4.6) \times$ 3.0-3.5(-4.0) $\mu \mathrm{m}$, pars proxima oblonga vel cuneata, $(4.0-) 4.5-5.2(-5.5) \times(2.3-) 2.5-3.0(-3.1) \mu \mathrm{m}$. Anamorphosis Trichoderma junci. Conidiophora similia Verticillii vel Trichodermati, in pustulis disposita in agaro CMD. Phialides divergentes, lageniformes, (6-)8-14($19) \times(2.0-) 2.5-3.3(-3.7) \mu \mathrm{m}$. Conidia ovalia vel ellipsoidea, viridia, glabra, $(3.5-) 3.7-4.6(-5.3) \times(2.4-) 2.5-$ $3.0 \mu \mathrm{m}$.

Etymology: junci refers to the occurrence on Juncus.

Stromata when fresh $0.5-2 \mathrm{~mm}$ diam, $0.5-1 \mathrm{~mm}$ thick, solitary or gregarious or aggregated in small numbers, lenticular to flat pulvinate, broadly attached, margin becoming free. Surface smooth. Ostioles indistinct, minute, hyaline. Colour dark reddish brown, $8 \mathrm{EF} 6-8$, when mature. Spore deposits white. 

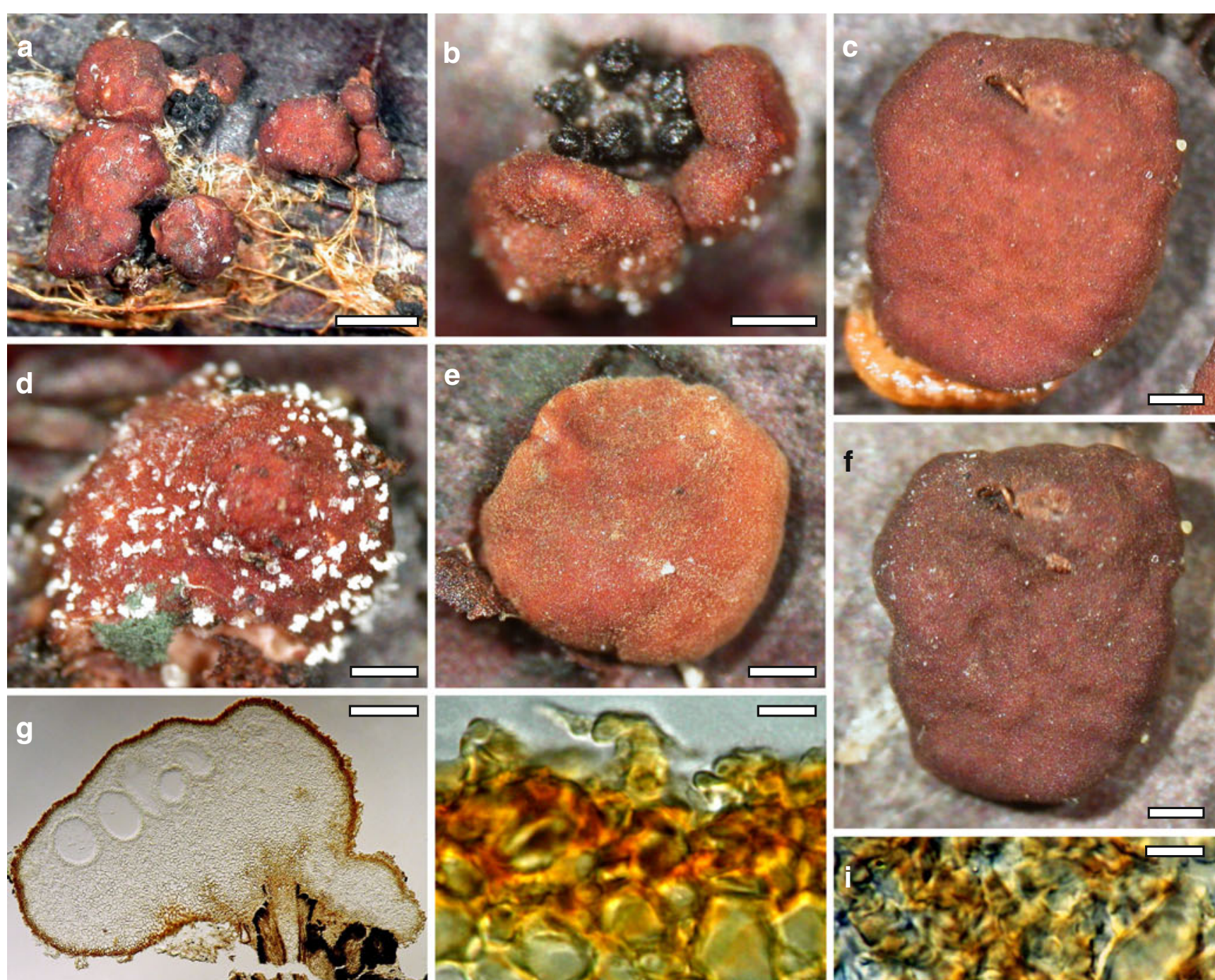
3) $10 x$
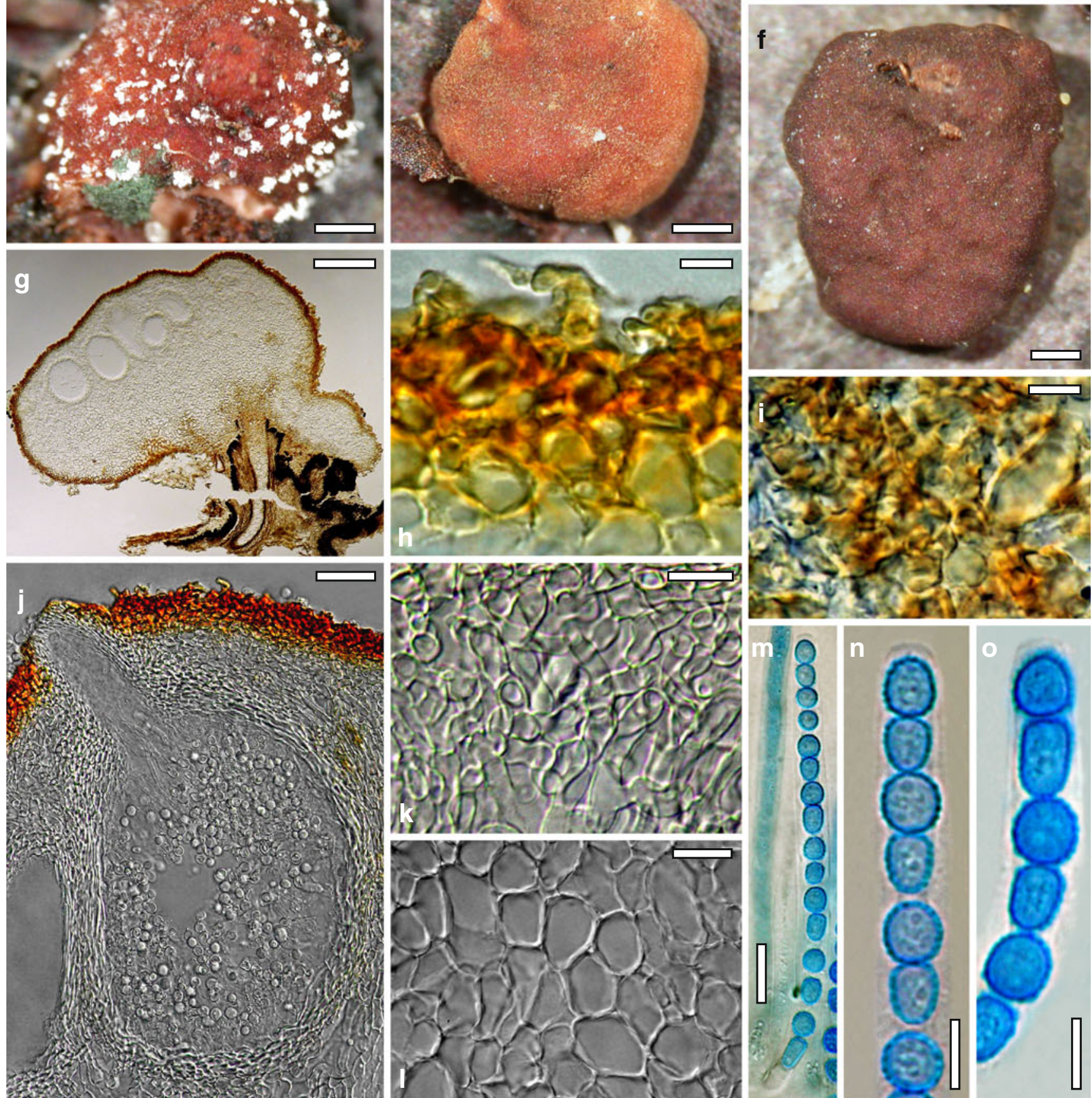
4 Fig. 2 Teleomorph of Hypocrea atroviridis (WU 29178). a-d. Fresh stromata (b. around ostioles of Diaporthe padi; $\mathbf{d}$. with spore deposits and anamorph on surface). e, f. Dry stromata (e. immature, hairy; $\mathbf{f}$. same as in c). g. Stroma on an ostiole of Diaporthe in section. $\mathbf{h}$. Cortex in section with a hair on the surface. $\mathbf{i}$. Cortex in face view. $\mathbf{j}$ Perithecium in section. k. Subcortical tissue in section. I. Subperithecial tissue in section. m. Ascus. n, o. Ascospores in ascus apex (m, $\mathbf{n}, \mathbf{o}$ in cotton blue/lactic acid). Scale bars: $\mathbf{a}=1 \mathrm{~mm}$. $\mathbf{b}-\mathbf{f}=0.3 \mathrm{~mm} . \mathbf{g}=$ $0.2 \mathrm{~mm}$. h, i, $\mathbf{n}, \mathbf{o}=5 \mu \mathrm{m} . \mathbf{j}=30 \mu \mathrm{m} . \mathbf{k}-\mathbf{m}=10 \mu \mathrm{m}$

Stromata when dry $(0.5-) 0.8-1.6(-2.2) \times(0.4-) 0.7-1.3(-$ $1.8) \mathrm{mm},(0.1-) 0.2-0.4(-0.6) \mathrm{mm}$ thick $(n=30)$; starting as white mycelium, turning reddish brown from the centre; finally pulvinate or discoid, broadly attached, margin free; outline circular or oblong. Surface smooth, rugose or slightly tubercular, velutinous when young. Ostiolar dots 16-28(-32) $\mu \mathrm{m}(n=30)$ diam, hardly visible, circular, light reddish or hyaline. Stroma colour dark reddish brown, vinose to nearly black, sometimes with fine rust floccules on the surface and sides. Rehydrated stromata larger than dry ones, shiny, dark reddish brown; pigment inhomogeneous; ostioles minute, subhyaline; in $3 \% \mathrm{KOH}$ darker reddish brown to black.

Stroma anatomy: Ostioles (42-)48-65(-73) $\mu \mathrm{m}(n=30)$ long, not projecting, (10-)12-23(-27) $\mu \mathrm{m}$ wide at the apex $(n=30)$, without specialized apical cells. Perithecia (110-) 140-180(-210)×(105-)120-170(-200) $\mu \mathrm{m}(n=30)$, globose or flask-shaped, peridium (13-)14-18(-22) $\mu \mathrm{m}(n=30)$ thick at the base, (7-)10-16(-19) $\mu \mathrm{m}(n=30)$ at the sides, hyaline to pale yellowish. Cortical layer (15-)18-30(-40) $\mu \mathrm{m}(n=33)$ thick, orange-brown, also present on steeply declining sides, composed of a thin amorphous, dull orange to reddish brown crust, concealing a narrow 2-4 celled layer of thin-walled, subhyaline or yellow, isodiametric to oblong, angular cells $(3-) 5-9(-12) \times(2-) 4-7(-9) \mu \mathrm{m}(n=50)$ in face view and in vertical section. Hairs on mature stromata $(6-) 9-20(-24) \times$ $(2-) 3-5(-6) \mu \mathrm{m}(n=20)$, infrequent, mostly at the sides, golden-yellow, 1-celled, smooth or verrucose, collapsing. Subcortical tissue a mixture of hyaline hyphae (2-)3-6(-9) $\mu \mathrm{m}(n=30)$ wide and (sub-)globose, thin-walled cells (4-)5-8 $(-11) \times(2-) 3-6(-9) \mu \mathrm{m}(n=30)$ in varying ratios. Subperithecial tissue a t. epidermoidea of hyaline, thin-walled, globose, angular, elongate or lobed cells $(7-) 11-28(-33) \times(5-) 7-13(-$ 17) $\mu \mathrm{m}(n=30)$; in the middle of the stroma merging into a basal layer to $250 \mu \mathrm{m}$ thick of loosely intertwined, thickwalled, yellow- to orange-brown hyphae $(2-) 3-6(-9) \mu \mathrm{m}$ $(n=30)$ wide. Asci $(64-) 67-83(-98) \times(4.0-) 4.5-6.0(-6.5)$ $\mu \mathrm{m}$, including a stipe $(1-) 4-9(-13) \mu \mathrm{m}$ long $(n=31)$. Ascospores hyaline, finely verruculose to nearly smooth, cells dimorphic; distal cell (3.3-)3.5-4.0(-4.6) ×3.0-3.5(-4.0) $\mu \mathrm{m}$, $1 / \mathrm{w}$ 1.0-1.2(-1.3) $(n=31)$, (sub)globose or wedge-shaped; proximal cell $(4.0-) 4.5-5.2(-5.5) \times(2.3-) 2.5-3.0(-3.1) \mu \mathrm{m}$, $1 / \mathrm{w}(1.4-) 1.6-1.9(-2.1)(n=31)$, oblong or wedge-shaped.

Cultures and anamorph: optimal growth at $25^{\circ} \mathrm{C}$ on all media; short, restricted growth, peg formation and autolysis at $30^{\circ} \mathrm{C}$; no growth at $35^{\circ} \mathrm{C}$.
On CMD after $72 \mathrm{~h} 17-21 \mathrm{~mm}$ at $15^{\circ} \mathrm{C}, 28-31 \mathrm{~mm}$ at $25^{\circ} \mathrm{C}, 2-4 \mathrm{~mm}$ at $30^{\circ} \mathrm{C}$; mycelium covering the plate after 7-9 days at $25^{\circ} \mathrm{C}$. Colony hyaline, thin, of coarse radial threads, wide and finely submoniliform marginal surface hyphae and characteristic minute secondary hyphae in the centre; margin ill-defined. Aerial hyphae numerous in distal areas, long and several $\mathrm{mm}$ high, forming strands, collapsing and eventually appearing as floccules. Autolytic activity none or inconspicuous, but numerous minute excretions seen at $30^{\circ} \mathrm{C}$. Coilings moderate, dissolving, causing yellowish discoloration of the agar, 1A3, 3-4AB3. No distinct odour noted. Conidiation at $25^{\circ} \mathrm{C}$ noted after 9 11 days in lateral and distal regions of the plate or in a broad distal zone, on white tufts or pustules to $2 \mathrm{~mm}$ diam, aggregating to $4-5 \mathrm{~mm}$ diam, turning pale to dull greygreen, 29CD4-6, 27DE4-6, or green with yellow margins, after 12-13 days. Pustules circular to oblong, of a loose reticulum of thin branches formed on a to $6 \mu \mathrm{m}$ wide stipe of variable length. Conidiophores on the periphery of the pustules numerous, narrow, radial, to $0.5 \mathrm{~mm}$ long, $2-4 \mu \mathrm{m}$ wide; with branches and phialides mostly in right angles or slightly inclined upwards, not or slightly increasing in length downwards; typically ending in 1-3(-4) phialides, often cruciform, followed by paired phialides and/or 1celled branches $30-40 \mu \mathrm{m}$ long, bearing 1-3 phialides, and/ or slightly longer, 2-3 celled branches to $c a 100 \mu \mathrm{m}$ long on lower levels. Sometimes longer branches occurring at higher levels, causing a broad conidiophore system. Phialides borne by $2-4(-5) \mu \mathrm{m}$ wide cells, (6-)8-14($19) \times(2.0-) 2.5-3.3(-3.7) \mu \mathrm{m}, 1 / \mathrm{w} \quad(2.2-) 2.4-5.2(-8.9)$, (1.6-)2.0-2.4(-2.7) $\mu \mathrm{m}$ wide at the base $(n=30)$, narrowly lageniform, widest in or above the middle; neck long, straight, becoming green with age. Conidia formed in minute wet heads $<20 \mu \mathrm{m}$ diam. Conidia (3.5-)3.7-4.6($5.3) \times(2.4-) 2.5-3.0 \mu \mathrm{m}, 1 / \mathrm{w} 1.3-1.8(-2.2)(n=30)$, yellowish green or lively green, oval, ellipsoidal with one end slightly attenuated, or oblong with walls often nearly parallel, thick-walled, smooth, with few minute guttules; scar minute, sometimes distinct. Chlamydospores noted after 12-14 days, $(6-) 7-12(-15) \times(5-) 6-11(-15) \mu \mathrm{m}, 1 /$ w $(0.8-) 1.0-1.3(-1.5) \quad(n=30)$, globose or ellipsoidal, infrequent, mainly in thin central hyphae, terminal and intercalary. At $15^{\circ} \mathrm{C}$ colony margin ill-defined; fine needlelike yellowish crystals formed along hyphae; surface becoming downy except for the centre; entire colony diffuse yellowish, 3-4A3; conidiation in pale green fluffy tufts and on long aerial hyphae.

On PDA after $72 \mathrm{~h} 18-20 \mathrm{~mm}$ at $15^{\circ} \mathrm{C}, 36-37 \mathrm{~mm}$ at $25^{\circ} \mathrm{C}, 3-4 \mathrm{~mm}$ at $30^{\circ} \mathrm{C}$; mycelium covering the plate after 6-7 days at $25^{\circ} \mathrm{C}$. Colony circular, dense; margin welldefined, marginal surface hyphae delicately submoniliform. Centre remaining flat and hyaline, larger outer part of the colony becoming covered by a thick whitish mat of aerial 

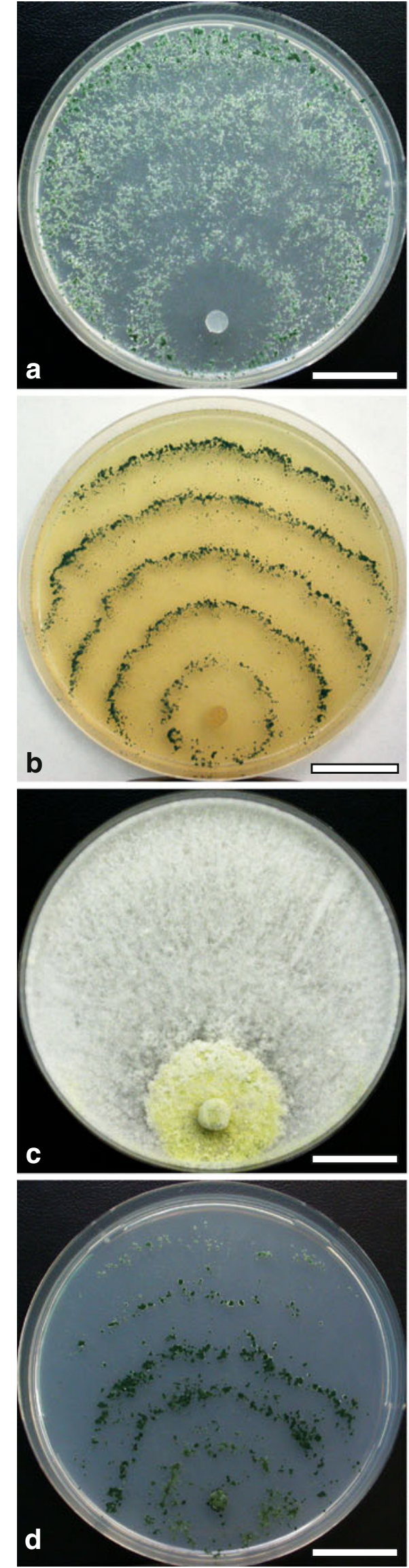
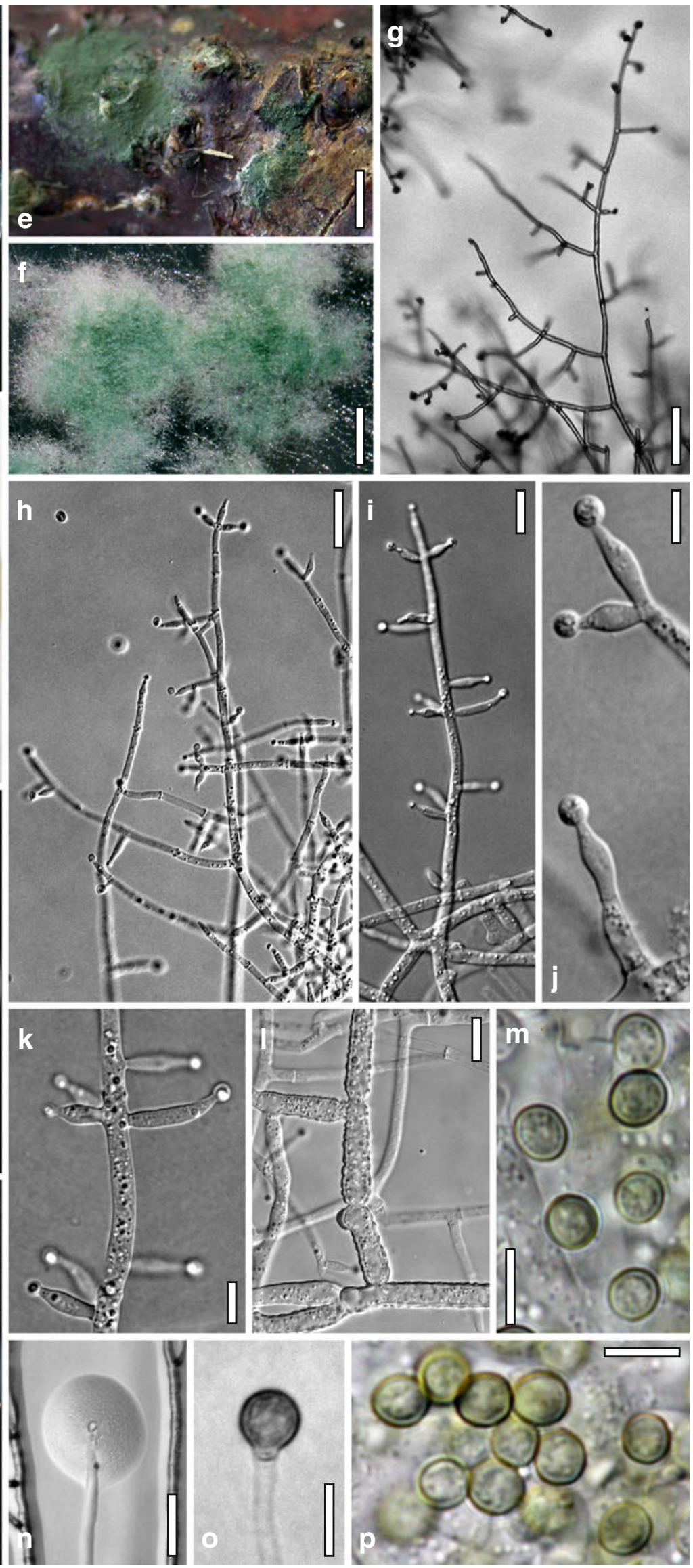
4Fig. 3 Cultures and anamorph of Hypocrea atroviridis (CBS 119499). a-d. Cultures after 7 days (a. on CMD, $25^{\circ} \mathrm{C}$ and b. $30^{\circ} \mathrm{C}$, c. on PDA and d. on SNA, $25^{\circ} \mathrm{C}$ ). e. Anamorph on natural substrate. f. Conidiation tufts (CMD, 4 days). g. Conidiophore on tuft margin on growth plate. h, i. Conidiophores. j, k. Phialides. l. Stipe and primary branches of conidiation tuft. $\mathbf{m}, \mathbf{p}$. Conidia. n. Autolytic excretion (PDA, $25^{\circ} \mathrm{C}, 1$ days). o. Chlamydospore (CMD, 11 days). e-o. All at $25^{\circ} \mathrm{C}$ except $\mathbf{b}$ and e. $\mathbf{g}-\mathbf{m}, \mathbf{p}$ On CMD, after 5 days. Scale bars: $\mathbf{a}-\mathbf{d}=$ $20 \mathrm{~mm} . \mathbf{e}=1.1 \mathrm{~mm} . \mathbf{f}=0.5 \mathrm{~mm} . \mathbf{g}, \mathbf{n}=40 \mu \mathrm{m} . \mathbf{h}=20 \mu \mathrm{m} . \mathbf{i}, \mathbf{l}, \mathbf{o}=10 \mu \mathrm{m}$. $\mathbf{j}, \mathbf{k}, \mathbf{m}, \mathbf{p}=5 \mu \mathrm{m}$

hyphae ascending to the lid of the Petri dish; orientation of aerial hyphae irregular, radial towards the margin, forming numerous drops, collapsing, becoming floccose and turning cream to yellowish. Autolytic activity none or inconspicuous, numerous minute excretions seen at $30^{\circ} \mathrm{C}$. No coilings, no distinct odour noted. Reverse (except centre) becoming dull greyish yellow, 3B3, 4BC4, 4B5, to golden-yellow, 4C5-7. Conidiation at $25^{\circ} \mathrm{C}$ noted after 7 days on long aerial hyphae, starting at the proximal margin and on low levels at the inner margin of the thick mat of aerial hyphae, on irregular short broad conidiophores bearing minute heads becoming dry; fluffy, spreading along the margin and ascending along the walls of the Petri dish; later also on small white tufts appearing along the flat centre and at the proximal margin; remaining colourless. At $15^{\circ} \mathrm{C}$ conidiation more abundant than at $25^{\circ} \mathrm{C}$, starting in the centre on long regular trees on aerial hyphae and on indistinct tufts at the margin of the flat centre and at the proximal margin, becoming tardily pale green, 30B4.

On SNA after $72 \mathrm{~h} 13-15 \mathrm{~mm}$ at $15^{\circ} \mathrm{C}, 24-25 \mathrm{~mm}$ at $25^{\circ} \mathrm{C}$, $1-3 \mathrm{~mm}$ at $30^{\circ} \mathrm{C}$; mycelium covering the plate after 7 days at $25^{\circ} \mathrm{C}$. Colonies hyaline, thin, resembling snow crystals; margin ill-defined. Surface becoming downy due to numerous long and high aerial hyphae. Marginal surface hyphae submoniliform, hyphae degenerating, becoming empty. Autolytic activity none or inconspicuous, excretions more frequent at 15 and $30^{\circ} \mathrm{C}$; coilings moderate, dissolving yellowish; colony faintly yellowish. No distinct odour noted. Chlamydospores noted after 9-11 days, infrequent, terminal and intercalary, (sub)globose. Conidiation noted after 10 11 days, in numerous minute wet heads $<20 \mu \mathrm{m}$ diam on long regular trees in tufts and on long aerial hyphae at the distal margin, becoming dry. Tufts to $2 \mathrm{~mm}$ diam, loosely and irregularly disposed, white, loose, with long narrow radial branches, turning pale greenish, 30CD5-6 after 12-14 days. No compact pustules formed within 3 week. At $15^{\circ} \mathrm{C}$ scant fine crystals formed along the hyphae; surface floccose due to long aerial hyphae aggregated in strands. Conidiation in thick, green, 27DE3-6, pustules to $6 \mathrm{~mm}$ diam, with long, mostly narrow radial conidiophores. Autolytic excretions and coilings frequent.

Habitat: on culms of Juncus effusus.

Distribution: Denmark, known only from the holotype specimen.
Holotype: Denmark, Nordjylland, Tranum Strand, behind the Himmerlandsfondens Kursus- og Feriecenter Tranum Strand, 5709'04" N, 09²6'12" E, elev. $6 \mathrm{~m}$, on dead standing stems of Juncus effusus, soc. effete immersed pyrenomycete, holomorph, 24 Aug. 2006, H. Voglmayr \& W. Jaklitsch, W.J. 2942 (WU 29229, ex-type culture CBS 120926=C.P.K. 2445). Holotype of Trichoderma junci isolated from WU 29229 and deposited as a dry culture with the holotype of $H$. junci as WU 29229a.

Notes: $H$. junci is currently the only species of sect. Trichoderma known on Juncus. Stromata resemble sclerotia of basidiomycetes like e.g. Typhula, with ostiolar openings virtually invisible. The conidiation on long radial conidiophores in green pustules is reminiscent of those in $T$. atroviride. However, T. atroviride and the closely related $T$. viridescens can be easily distinguished from $T$. junci by distinctly slower growth and development of conidiation in the latter. $T$. junci sporulated after more than 1 week on CMD, while conidiation in $T$. atroviride and the closely related $T$. viridescens can be noted from 2 days after inoculation. In addition, conidia of $T$. junci differ by a larger length/width ratio from those of the related species.

The holotype of Hypocrea rufa f. sterilis Rifai \& J. Webster, England, Norfolk, Holme-next-the-Sea, on culms of Agropyron pungens, 12 Sep. 1962, J. Webster (K(M) 154038), was examined and found to be morphologically indistinguishable from $H$. junci. Here it is briefly described: Stromata $0.5-1.6 \times 0.4-1.3 \mathrm{~mm}, 0.15-$ $0.6 \mathrm{~mm}$ thick $(n=20)$, pulvinate, solitary or aggregated in small numbers. Ostioles inconspicuous, minute, plane or convex, hyaline. Surface covered with brown hairs when young, later finely velutinous, some rugose. Colour dark red, vinose, dark reddish brown to nearly black, 8E5-8, some with mycelial margin. Asci (76-)80-90(-96) $\times$

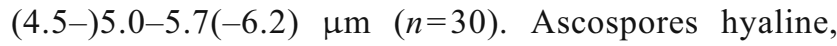
finely verruculose to nearly smooth, cells dimorphic; distal cell (3.5-)3.8-4.5(-5.0) ×(3.2-)3.3-3.8(-4.2) $\mu \mathrm{m}$, 1/W (1.0-)1.1-1.3 $(n=30)$, (sub)globose or wedge-shaped; proximal cell $(3.8-) 4.2-5.5(-6.6) \times(2.5-) 2.7-3.2(-3.4)$ $\mu \mathrm{m}, 1 / \mathrm{w}(1.2-) 1.4-1.9(-2.5)(n=30)$, oblong or wedgeshaped. A search at the original collection site was without success due to drought. The ascospore isolate (Rifai and Webster 1966) did not produce an anamorph on MEA, but abundant chlamydospores and a coconut odour. These findings are not in accordance with $H$. junci. The coconut odour rather suggest species such as $H$. atroviridis or $H$. viridescens.

Hypocrea koningii Lieckf., Samuels \& W. Gams, Can. J. Bot. 76: 1519 (1998). Fig. 6

Anamorph: Trichoderma koningii Oudem. in Oudemans \& Koning, Arch. Néerl. Sci. Exactes Nat., Sér. 2, 7: 291 (1902). Fig. 7 

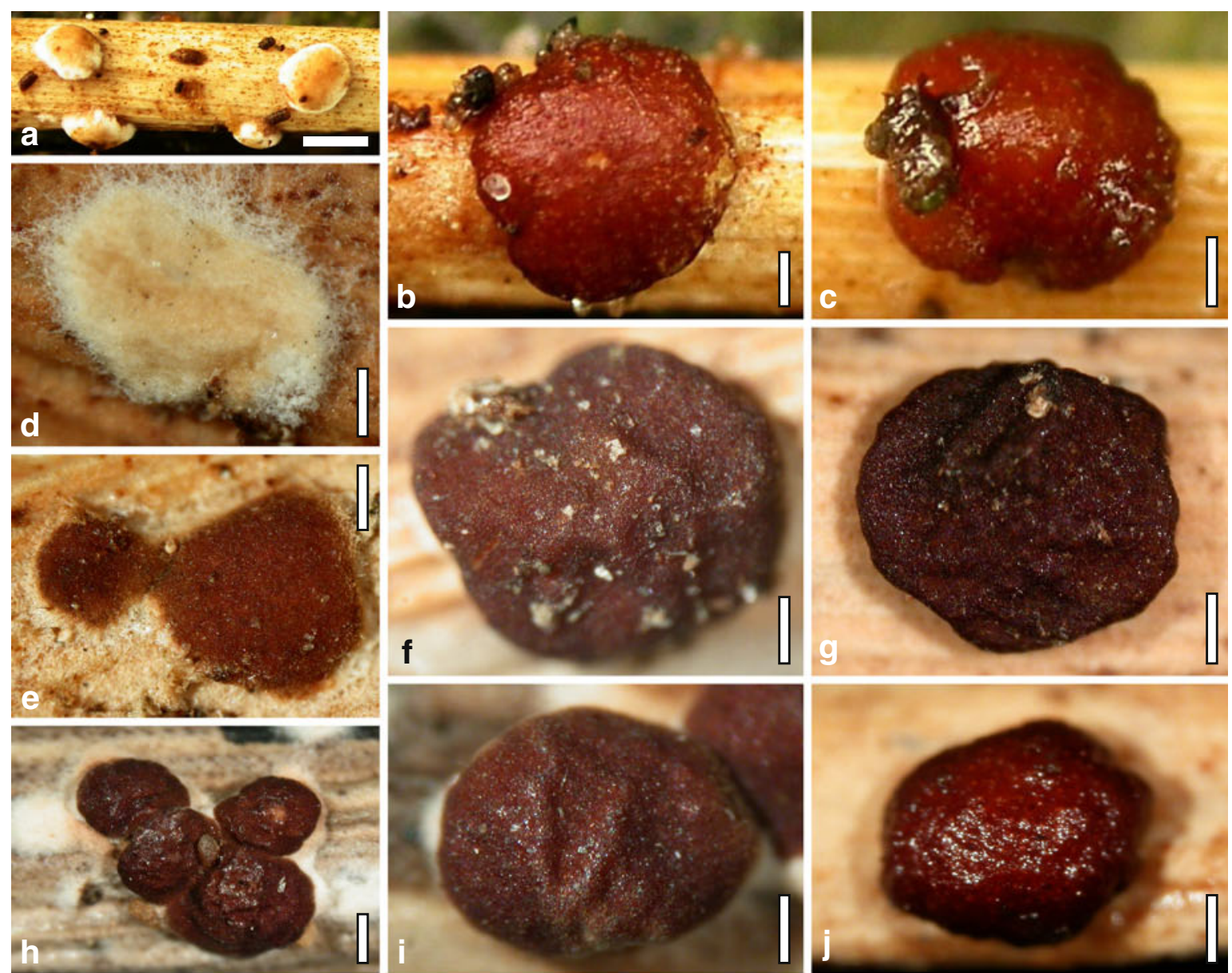
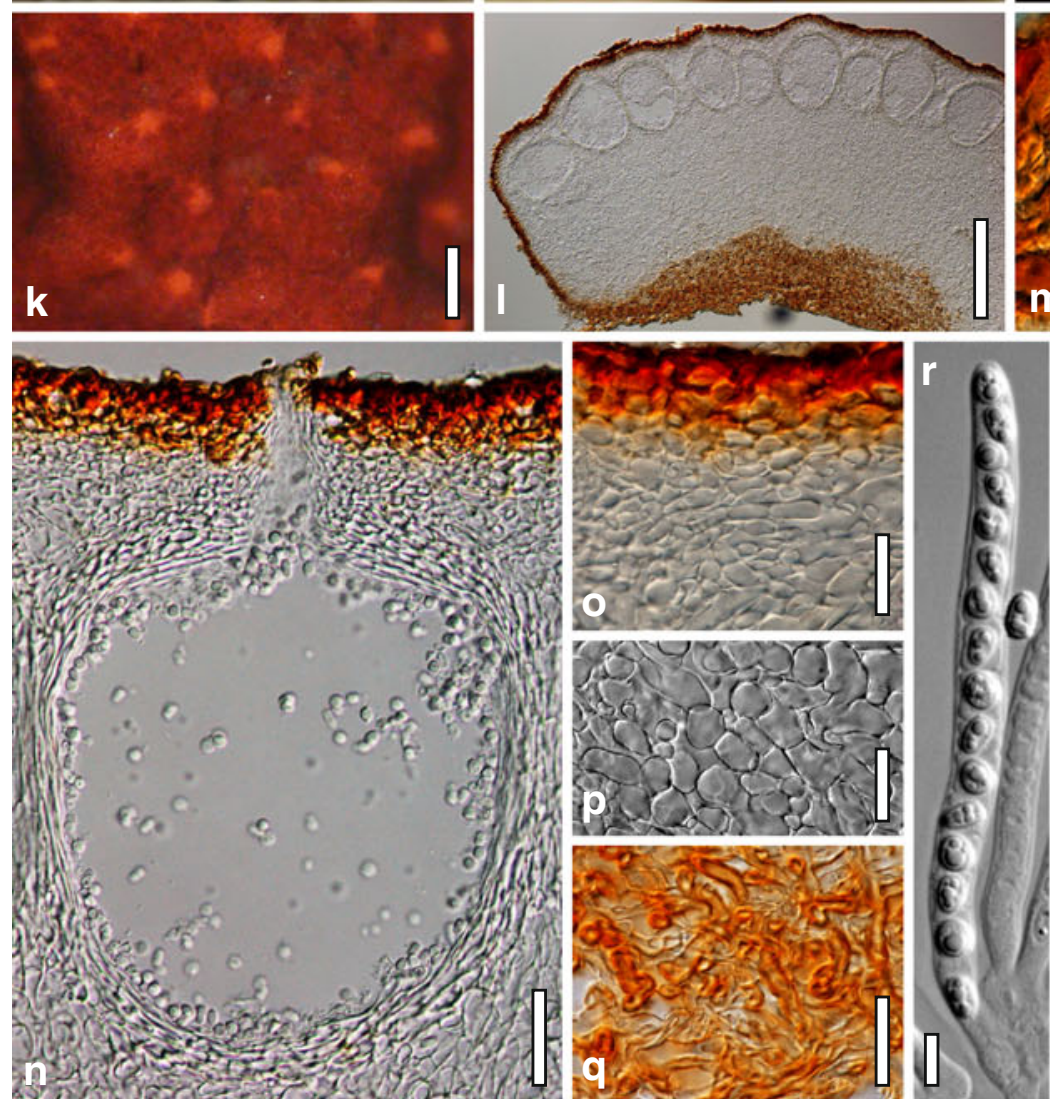
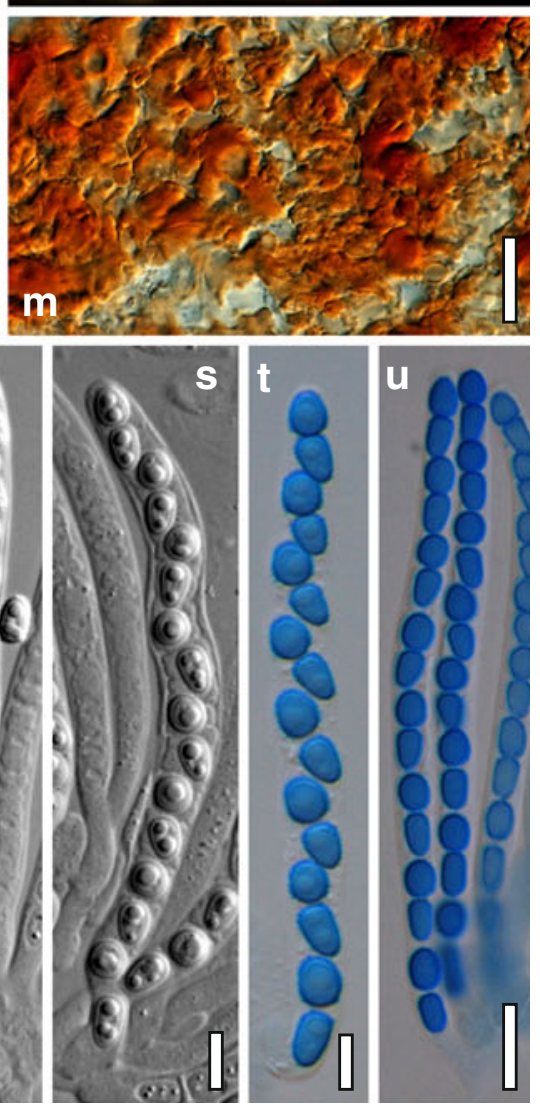
4Fig. 4 Teleomorph of Hypocrea junci (a-g, j-t; WU 29229) and $H$. rufa f. sterilis (h, i, u; K 154038). a-c. Fresh stromata (a. immature). d-i. Dry stromata (e. immature). j. Rehydrated stroma. k. Stroma surface showing ostiolar openings after rehydration. I. Stroma in vertical section. m. Stroma surface in horizontal section. $\mathbf{n}$. Perithecium in section. o. Cortical and subcortical tissue in section. p. Subperithecial tissue in section. q. Stroma base in section. $\mathbf{r}-\mathbf{u}$. Asci with ascospores ( $t, u$. in cotton blue/lactic acid). Scale bars: $\mathbf{a}=$ $1.3 \mathrm{~mm}$. b, e, e, $\mathbf{g}, \mathbf{i}=0.3 \mathrm{~mm}$. d, $\mathbf{f}, \mathbf{l}=0.2 \mathrm{~mm} . \mathbf{h}, \mathbf{j}=0.5 \mathrm{~mm} . \mathbf{k}=$ $50 \mu \mathrm{m}$. m, $\mathbf{r}, \mathbf{u}=10 \mu \mathrm{m}$. $\mathbf{n}, \mathbf{p}, \mathbf{q}=25 \mu \mathrm{m} . \mathbf{o}=15 \mu \mathrm{m} . \mathbf{r}-\mathbf{t}=5 \mu \mathrm{m}$

Stromata when fresh $0.5-3 \mathrm{~mm}$ diam, $0.5 \mathrm{~mm}$ thick, solitary or gregarious, pulvinate, smooth, lively orangebrown. Stromata when dry $(0.4-) 0.8-1.8(-2.4) \times(0.3-) 0.6-$ $1.3(-1.5) \mathrm{mm}(n=30), 0.15-0.45 \mathrm{~mm}(n=20)$ thick; flat pulvinate, discoid or lenticular; margin free. Outline circular or oblong. Ostiolar dots (17-)22-34(-38) $\mu \mathrm{m}(n=$ 30) diam, typically invisible, only rarely distinct, convex to semiglobose, hyaline, or with a dark ring. Stromata when young white, the centre turning pale yellow or orange, eventually dark orange-brown to reddish brown, 7-8CE78 , with or without white mycelial margin. Rehydrated stromata light orange-brown; ostiolar openings minute, hyaline; surface smooth, slightly velutinous. No change seen in $3 \% \mathrm{KOH}$.

Stroma anatomy: Ostioles (42-)49-70(-84) $\mu \mathrm{m}$ long, projecting to $15 \mu \mathrm{m},(12-) 17-37(-50) \mu \mathrm{m}$ wide at apex $(n=$ 20), conical, without conspicuous apical cells. Perithecia $(130-) 145-180(-195) \times(93-) 110-160(-175) \mu \mathrm{m}(n=20)$, globose or flask-shaped. Peridium (11-)13-17(-20) $\mu \mathrm{m}(n=20)$ thick at the base, $(6-) 9-14(-16) \mu \mathrm{m}(n=20)$ thick at the sides, hyaline. Cortical layer (13-)16-23(-27) $(n=30)$, an orangebrown $t$. angularis of minute thin-walled cells $(2-) 3-6(-7)$ $\mu \mathrm{m}$ long $(n=60)$ in face view and in vertical section. Hairs on mature stroma $(6-) 8-11(-12) \times 2-4(-6) \quad \mu \mathrm{m} \quad(n=20), 1-2$ celled, ends rounded, cylindrical or globose, smooth or warty, yellow-orange to pale brown, surface warty by projecting cells. Subcortical tissue a loose $t$. intricata of hyaline thinwalled hyphae 2.5-4.0(-4.5) $\mu \mathrm{m}(n=10)$ wide. Subperithecial tissue a dense $t$. epidermoidea of hyaline thin-walled cells $(5-) 6-14(-20) \times(3-) 4-9(-13) \mu \mathrm{m}(n=30)$. Stroma sides of a thin layer of narrow hyphae $(2.0-) 2.5-4.5(-5.0) \mu \mathrm{m}(n=10)$ wide. Asci $(62-) 68-75(-77) \times(4.5-) 4.8-5.5(-6.0) \mu \mathrm{m}$, stipe to $10 \mu \mathrm{m}$ long $(n=30)$. Ascospores hyaline, verruculose, cells dimorphic, but with little difference in shape, distal cell (2.7-) $3.0-3.8(-4.3) \times 3.0-3.5(-4.0) \mu \mathrm{m}, 1 / \mathrm{w}(0.9-) 1.0-1.1(-1.2)(n=$ 30 ), (sub)globose, proximal cell $(3.0-) 3.5-5.0(-6.3) \times(2.2-)$ 2.5-3.2(-3.8) $\mu \mathrm{m}, 1 / \mathrm{w}(0.9-) 1.2-1.7(-2.3) \quad(n=30)$, subglobose, oblong or wedge-shaped.

Cultures and anamorph: optimal growth at $25^{\circ} \mathrm{C}$ on all media; no or short growth at $35^{\circ} \mathrm{C}$.

On CMD after $72 \mathrm{~h} 22-23 \mathrm{~mm}$ at $15^{\circ} \mathrm{C}, 46-51 \mathrm{~mm}$ at $25^{\circ} \mathrm{C}, 38-43 \mathrm{~mm}$ at $30^{\circ} \mathrm{C}$; to $1 \mathrm{~mm}$ at $35^{\circ} \mathrm{C}$, hyphae autolysing within 1-2 days. Mycelium covering the plate after $4-5$ days at $25^{\circ} \mathrm{C}$. Colony circular, hyaline, thin; mycelium loose, little on the agar surface, hyphae with conspicuous differences in width, numerous characteristic minute secondary hyphae present. Margin becoming downy due to aerial hyphae. No autolytic activity seen; coilings not checked. No distinct odour noted. Chlamydospores noted after 5-7, measured after 11 days, $(6-) 7-10(-12) \times 5-8(-9)$ $\mu \mathrm{m}, 1 / \mathrm{w} 1.0-1.5(-1.9)(n=25)$, infrequent, intercalary and terminal, globose, pyriform or oblong. Conidiation noted after 2 days, becoming green, 26E3-4, 27F6-8 after 45 days; first effuse in small shrubs $0.1-0.5 \mathrm{~mm}$ diam forming aggregates to $1 \mathrm{~mm}$ diam and on side branches to $100 \mu \mathrm{m}$ long on aerial hyphae; spreading from the plug across the plate; later in fluffy tufts in distal and lateral areas, eventually compacting into granular pustules to $2.5 \mathrm{~mm}$ diam; aggregates to $6 \mathrm{~mm}$ long. Gradual transition from effuse to pustulate conidiation without distinct structural difference. Shrubs and pustules of a stipe with one or several long main axes with little branching and one or several regularly tree-like, terminal conidiophores 3-4(5) $\mu \mathrm{m}$ wide. Side branches mostly paired, in right angles or slightly inclined upward, increasing in length from the top, with simple further branching. Phialides formed on cells mostly $2.5-3.5 \mu \mathrm{m}$ wide, solitary or in whorls of $2-4(-5)$, rarely repetitive, i.e. terminal branches submoniliform. Conidiation starting within the shrubs. Conidia produced in small numbers in minute dry heads, aggregating in chains after 5-6 days. Phialides $(5-) 7-11(-15) \times(2.4-) 3.0$ $3.7(-4.3) \mu \mathrm{m}, 1 / \mathrm{w}(1.4-) 2.0-3.6(-5.3),(1.3-) 1.7-2.5(-2.9)$ $\mu \mathrm{m}$ wide at the base $(n=60)$; variable, lageniform or ampulliform, also cylindrical terminally on main axes, straight, mostly equilateral, widest in or below the middle, neck short. Conidia $(3.8-) 4.0-4.6(-5.0) \times 2.5-3.0(-3.5) \mu \mathrm{m}$, 1/w $(1.2-) 1.4-1.7(-1.8)(n=30)$, pale green, mostly oblong, also ellipsoidal or oval, smooth, multiguttulate, scar sometimes distinct. At $15^{\circ} \mathrm{C}$ development distinctly slower. At $30^{\circ} \mathrm{C}$ conidiation effuse and in green tufts or pustules to $5 \mathrm{~mm}$ diam, arranged in ill-defined concentric zones.

On PDA after $72 \mathrm{~h} 17-20 \mathrm{~mm}$ at $15^{\circ} \mathrm{C}, 47-50 \mathrm{~mm}$ at $25^{\circ} \mathrm{C}, 34-43 \mathrm{~mm}$ at $30^{\circ} \mathrm{C}$; mycelium covering the plate after $4-5$ days at $25^{\circ} \mathrm{C}$. Colony dense, thin, silky, not zonate. Surface becoming covered by a white cottony mat of aerial hyphae ascending to the lid of the Petri dish, forming strands, collapsing. Autolytic activity moderate. No diffusing pigment, no distinct odour noted. Conidiation noted after 1-2 days on low levels of aerial hyphae, becoming matt to dark grey-green, 25DE5-6, 26-27DE34 , after 3 days, spreading from the centre across the plate. At $15^{\circ} \mathrm{C}$ marginal surface hyphae conspicuously wide; distinct concentric zones formed; conidiation pale green, effuse and in fluffy tufts. At $30^{\circ} \mathrm{C}$ irregular concentric zones formed; conidiation effuse, pale green.

On SNA after $72 \mathrm{~h} 15-20 \mathrm{~mm}$ at $15^{\circ} \mathrm{C}, 37-39 \mathrm{~mm}$ at $25^{\circ} \mathrm{C}$, $22-30 \mathrm{~mm}$ at $30^{\circ} \mathrm{C}$ after $72 \mathrm{~h}$; mycelium covering the plate 

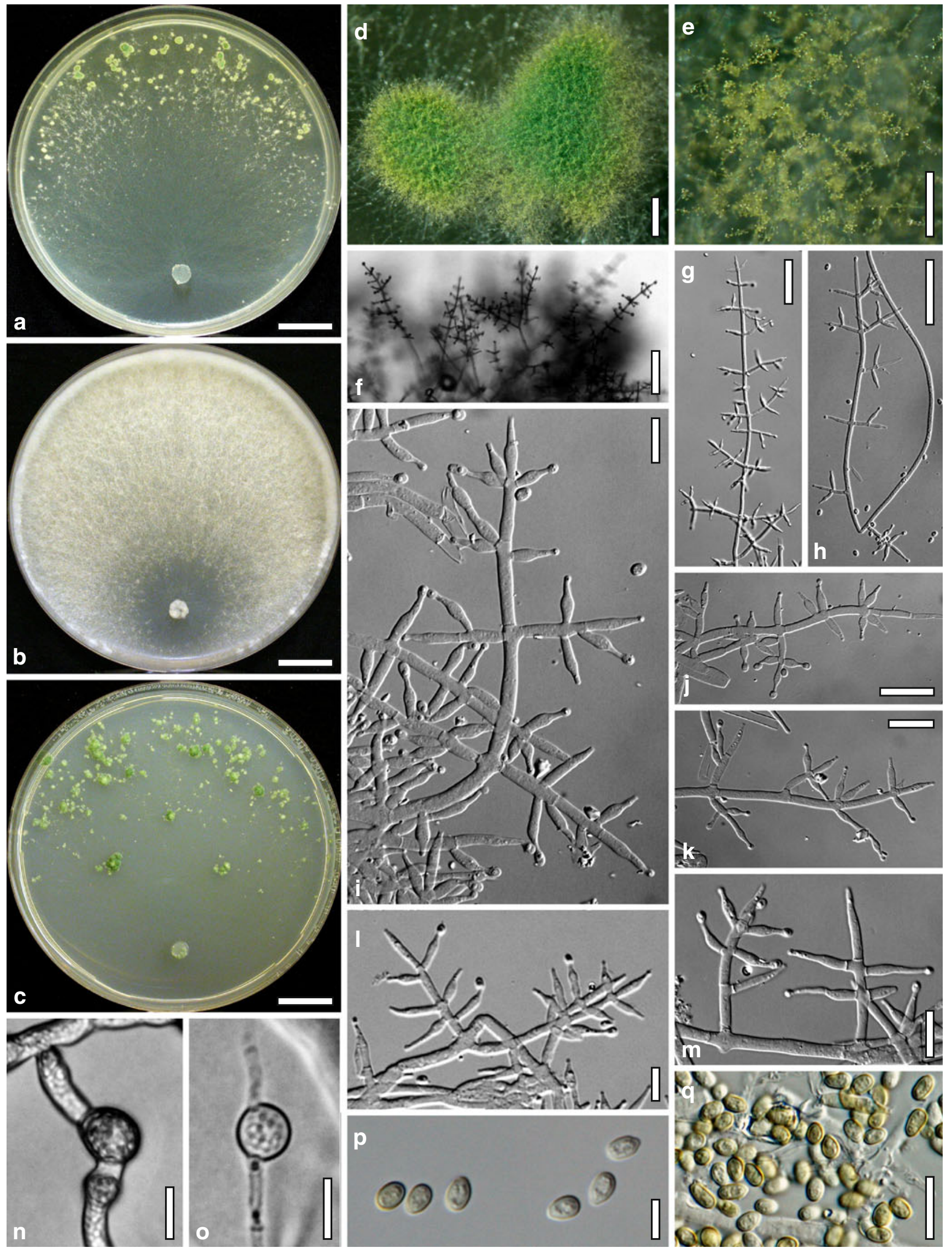
4 Fig. 5 Cultures and anamorph of Hypocrea junci (CBS 120926). a-c. Cultures (a. on $\mathrm{CMD}, 25^{\circ} \mathrm{C}, 14$ days; $\mathbf{b}$. on PDA, $25^{\circ} \mathrm{C}, 21$ days; $\mathbf{c}$. on SNA, $15^{\circ} \mathrm{C}, 21$ days). d, e. Conidiation in the stereo-microscope (d. pustules, e. on aerial hyphae). f. Conidiophores on pustule margin on growth plate $\left(15^{\circ} \mathrm{C}, 17\right.$ days). $\mathbf{g}-\mathbf{m}$. Conidiophores and phialides. $\mathbf{n}, \mathbf{o}$. Chlamydospores (after 22 days). p, q. Conidia. d-q. On CMD, at $25^{\circ} \mathrm{C}$ except $\mathbf{f}$. d, e, $\mathbf{g}-\mathbf{m}, \mathbf{p}$, q. After 12 days. Scale bars: $\mathbf{a}-\mathbf{c}=15 \mathrm{~mm}$. d, $\mathbf{e}=0.5 \mathrm{~mm} . \mathbf{f}=0.1 \mathrm{~mm} . \mathbf{g}=50 \mu \mathrm{m} . \mathbf{h}, \mathbf{j}, \mathbf{k}=20 \mu \mathrm{m} . \mathbf{i}, \mathbf{l}-\mathbf{0}, \mathbf{q}=10 \mu \mathrm{m}$. $\mathbf{p}=5 \mu \mathrm{m}$

after 5 days at $25^{\circ} \mathrm{C}$. Colony as on CMD. Autolytic activity and coilings moderate. No pigment, no distinct odour noted. Chlamydospores noted after 6-7 days. Conidiation noted after 2 days, effuse and in pustules to $2 \mathrm{~mm}$ diam, forming aggregates to $5 \mathrm{~mm}$ diam, arranged in several concentric zones, first white, becoming dark green, 26-27F5-8, from pustule centres after $3-4$ days. At $15^{\circ} \mathrm{C}$ conidiation effuse, green, short and on long aerial hyphae, also in pustules concentrated in lateral and distal areas of the colony. At $30^{\circ} \mathrm{C}$ conidiation mostly in central green pustules to $3 \mathrm{~mm}$ diam.

Habitat: teleomorph on wood and bark, rare; anamorph mostly isolated from soil.

Distribution: Europe, North America.

Holotype: USA, Maryland, Garrett County, approx. $10 \mathrm{mi}$ SSE of Grantsville, near Bittinger, High Bog, on decorticated wood, 23 Sep. 1989, G.J. Samuels et al. (BPI 745885, ex-type culture G.J.S. 89-122=IMI 378801=CBS 989.97). Neotype of T. koningii: Netherlands, Spanderswoud near Bussum, isolated from soil under pure stand of Pinus sylvestris, 1996, W. Gams (CBS 457.96=G.J.S. 96-117).

Specimen examined: Austria, Oberösterreich, Grieskirchen, Neukirchen am Walde, Leithen (Schluchtwald), MTB 7648/2, 48 $22^{\prime} 25^{\prime \prime} \mathrm{N}, 1^{\circ} 47^{\prime} 00^{\prime \prime} \mathrm{E}$, elev. $400 \mathrm{~m}$, on stump of Carpinus betulus, in a dry streambed, holomorph, 9 Sep. 2003, H. Voglmayr, W.J. 2392 (WU 29230, culture CBS 119500=C.P.K. 957).

Notes: The teleomorph of Hypocrea koningii is rare. It was collected only once in Europe in 6 years. Another teleomorph specimen from the Netherlands and two from Maryland and Pennsylvania were cited by Samuels et al. (2006a). Based on teleomorphs alone, H. koningii is virtually indistinguishable from the common $H$. rogersonii and several closely related non-European species. Also stromata of $H$. stilbohypoxyli can be similar. $H$. koningii has slightly smaller asci and ascospores than $H$. rogersonii and H. stilbohypoxyli. Trichoderma koningii was originally described from the Netherlands and neotypified by Lieckfeldt et al. (1998), who also described the teleomorph. See Lieckfeldt et al. (1998) and Samuels et al. (2006a) for further information on this species. T. koningii differs from $T$. rogersonii and $T$. stilbohypoxyli by faster growth on CMD and PDA at $25^{\circ} \mathrm{C}$ and a larger conidial $1 / \mathrm{w}$ ratio on average in T. koningii. In addition, T. rogersoni does not form distinct conidiation pustules on CMD, and T. stilbohypoxyli can be distinguished from $T$. koningii by a conspicuous blue-green anamorph in nature and conidia that become yellow on CMD before they turn green.

Hypocrea neorufa Samuels, Dodd \& Lieckf., Mycol. Prog. 1: 421 (2002). Fig. 8

Anamorph: Trichoderma sp. Fig. 9

Stromata when fresh 1-5 mm diam, 0.5-1.5 mm thick, often thinly effuse when young, becoming pulvinate to nearly semiglobose; broadly attached, with white basal mycelial margin when young. Margin attached or free. Outline circular, oblong or irregular. Surface smooth, no ostiolar dots present; ostiolar openings visible upon strong magnification as minute light dots. Stromata first whitish, yellow when young, soon losing the yellow colour (also upon incubation or drying), turning brown-orange, medium to dark brown, 6CD6-7, 6-7E7-8, 9F6-8, finally dark reddish brown, often with a violet tone, to blackish brown when old. Spore deposits white.

Stromata when dry $(0.5-) 1.0-3.2(-4.5) \times(0.4-) 0.8-2.1(-$ $2.8) \mathrm{mm},(0.15-) 0.2-0.5(-0.8) \mathrm{mm}$ thick $(n=40)$, solitary, gregarious or densely aggregated in variable numbers; flat pulvinate, discoid or subeffuse, sometimes effuse, breaking up into several individual stromata, broadly attached; outline roundish or irregular. Surface hairy when young, glabrous or slightly velutinous when mature, smooth, tubercular or rugose, particularly when immature. Ostiolar openings (8-) 18-34 $(-47) \mu \mathrm{m}(n=60)$ diam, only visible as minute reddish dots under strong magnification, hyaline and more distinct after re-wetting. Stromata when dry generally distinctly darker than fresh, typically dark brown, chocolate brown, 6E7-8, 6-7F3-8, dark reddish brown, sometimes with violet tones, 9F5-6, to nearly black when mature; when immature or young yellow, yellow-brown, light brown, grey-brown, 4A4, 4B5, 5CD5-7, with white to brownish mycelial margin; injured areas yellow due to the yellow perithecia. Spore deposits white. Rehydrated stromata dark brown with slightly lighter brown ostiolar openings. Surface smooth to very finely tubercular by slightly projecting perithecia. No change noted after addition of $3 \% \mathrm{KOH}$.

Stroma anatomy: Ostioles (50-)58-77(-85) $\mu \mathrm{m}$ long, not projecting, (20-)22-36(-47) $\mu \mathrm{m}$ wide at the apex internally $(n=20)$, mostly conical, without differentiated apical cells. Perithecia (130-)160-220(-240)×(80-)120$190(-240) \mu \mathrm{m}(n=20)$, flask-shaped or globose. Peridium $(10-) 13-20(-22) \mu \mathrm{m}(n=20)$ thick at the base, $(6-) 10$ $15 \mu \mathrm{m}(n=20)$ at the sides, distinctly yellow in lactic acid; yellow-brown with vinaceous tone in $3 \% \mathrm{KOH}$. Stroma surface of loose projecting cells, not compact. Hairs on mature stromata rare, $(7-) 8-18(-23) \times(2.0-) 2.5-4.0(-5.0)$ $\mu \mathrm{m}(n=20), 1-3$ celled, cylindrical with basal cell often inflated, brownish, smooth; sometimes undifferentiated reddish brown hyphae present. Cortical layer (15-)20-35 


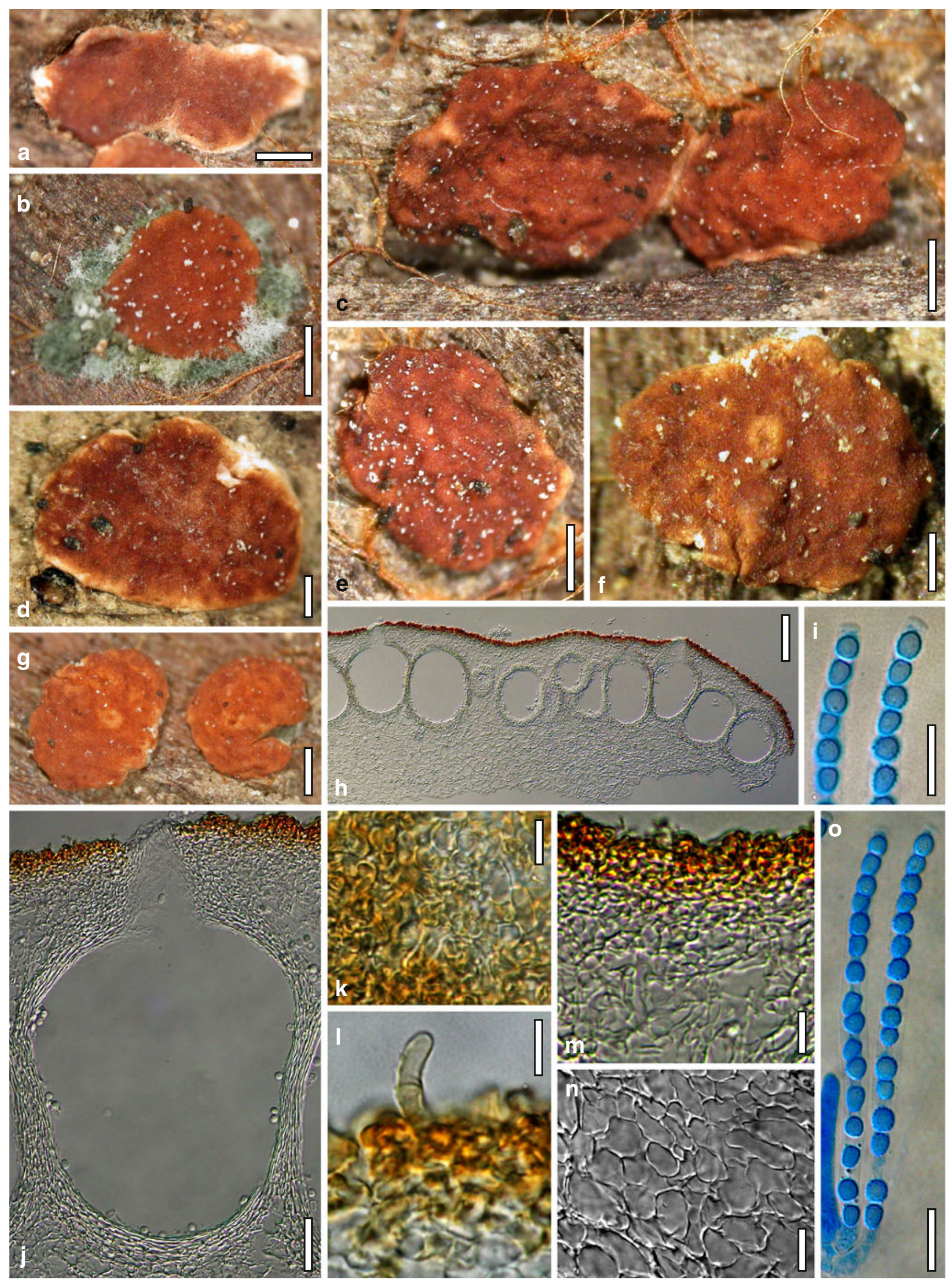


4Fig. 6 Teleomorph of Hypocrea koningii (WU 29230). a-f. Dry stromata (a. immature). g. Rehydrated stromata. h. Part of stroma in vertical section. i. Ascus apex in cotton blue/lactic acid. j. Perithecium in section. k. Stroma surface. I. Hair and cortical tissue in section. m. Cortical and subcortical tissue in section. n. Subperithecial tissue in section. o. Asci with ascospores in cotton blue/lactic acid. Scale bars: a, $\mathbf{c}, \mathbf{e}, \mathbf{g}=0.5 \mathrm{~mm} . \mathbf{b}, \mathbf{d}, \mathbf{f}=0.3 \mathrm{~mm} . \mathbf{h}=0.1 \mathrm{~mm}$. $\mathbf{i}, \mathbf{m}-\mathbf{o}=10 \mu \mathrm{m} . \mathbf{j}=25 \mu \mathrm{m}$. $\mathbf{k}, 1=5 \mu \mathrm{m}$

$(-45) \mu \mathrm{m}(n=30)$ thick, a $t$. angularis of thick-walled cells $(3-) 4-8(-12) \times(2-) 3-5(-8) \mu \mathrm{m}(n=60)$ in face view and in vertical section; intensely (reddish-) brown, gradually lighter downwards. Subcortical tissue where present a loose $t$. intricata of hyaline, thin-walled hyphae (2-)3-5 (-6) $\mu \mathrm{m}(n=20)$ wide. Subperithecial tissue a dense hyaline $t$. epidermoidea of variable cells $(7-) 9-25(-37) \times$ $(6-) 7-13(-16) \mu \mathrm{m}(n=30)$, partly with yellowish brown spots. Base a loose $t$. intricata of hyaline, thin-walled hyphae (2.0-)2.5-5.5(-6.5) $\mu \mathrm{m}(n=20)$ wide, sometimes partly intermingled with subperithecial cells. Asci (64-) $72-93(-102) \times(4.5-) 4.7-5.5(-6.0) \mu \mathrm{m}$, stipe $(3-) 5-17(-$ 24) $\mu \mathrm{m}$ long $(n=60)$. Ascospores hyaline, verruculose, cells dimorphic; distal cell (3.0-)3.3-4.0(-5.0) ×3.0-3.5(4.0) $\mu \mathrm{m}, 1 / \mathrm{w}(0.9-) 1.0-1.2(-1.6)(n=62)$, (sub)globose, oval or wedge-shaped; proximal cell $(3.8-) 4.2-5.5(-6.0) \times$ (2.4-)2.5-3.0(-3.5) $\mu \mathrm{m}, 1 / \mathrm{w}(1.3-) 1.5-2.0(-2.3)(n=62)$, oblong, wedge-shaped, less commonly globose.

Anamorph on the natural substrate hairy, light bluish-, medium- to dark green.

Cultures and anamorph: optimal growth at $30^{\circ} \mathrm{C}$ on all media; at $35^{\circ} \mathrm{C}$ solitary hyphae growing to less than $1 \mathrm{~mm}$.

On CMD after $72 \mathrm{~h} 10-11 \mathrm{~mm}$ at $15^{\circ} \mathrm{C}, 28-29 \mathrm{~mm}$ at $25^{\circ} \mathrm{C}$, 29-32 $\mathrm{mm}$ at $30^{\circ} \mathrm{C}$; mycelium covering the plate after $7-$ 8 days at $25^{\circ} \mathrm{C}$. Colony hyaline, thin, dense, not zonate; with indistinct or irregular margin; hyphae thin, with low variation in width; surface slightly downy. Aerial hyphae inconspicuous, but long and ascending several $\mathrm{mm}$ along the margin. No autolytic excretions, no coilings noted. Agar turning diffusely yellow, 1-3A3, 3-4B4. No distinct odour noted. Chlamydospores (after 15 days) abundant in lateral and distal pustule areas, terminal and intercalary, noted after 5-6 days, large, $(10-) 12-16(-19) \times(10-) 12-15(-18) \mu \mathrm{m}, 1 / \mathrm{w}(0.8-) 0.9-1.2$ $(-1.6)(n=32)$, globose, oval or fusoid. Conidiation noted after 1 days at $25^{\circ} \mathrm{C}$; first effuse, spreading quickly from the plug across the entire colony, forming several inconspicuous, macroscopically hardly visible, finely downy concentric zones. Conidia produced in numerous colourless to pale greenish wet heads $<30 \mu \mathrm{m}$ on short erect, irregularly verticillium-like conidiophores, also ascending on aerial hyphae. After 5-7 days white fluffy tufts appearing at the sides of the colony, spreading in a distal zone, turning to pustules $0.7-2.3(-3.7) \mathrm{mm}$ diam, grey-green to dark green, 28-29CD5-6, 27-28EF7-8, 26F7-8 after 7-10 days, with variable outline, loose texture and granular surface.
Conidiation symmetric, dense, dry; conidia finally adhering in chains. At $15^{\circ} \mathrm{C}$ conidiation effuse and in green granules concentrated in proximal and central areas of the colony. At $30^{\circ} \mathrm{C}$ mycelium dense, colony indistinctly zonate by aerial hyphae; zones turning greyish yellow, 1A3, 3-4AB4-5 by effuse conidiation; pustulate conidiation in granules and small pustules mainly along lateral and distal margins, pale to greyish green, 28CD5-7.

On PDA after $72 \mathrm{~h} 8-9 \mathrm{~mm}$ at $15^{\circ} \mathrm{C}, 23-25 \mathrm{~mm}$ at $25^{\circ} \mathrm{C}$, 26-27 $\mathrm{mm}$ at $30^{\circ} \mathrm{C}$; mycelium covering the plate after 8 9 days at $25^{\circ} \mathrm{C}$. Colony dense, margin hyaline, irregularly wavy; surface becoming downy to farinose, white from the centre due to conidiation. Aerial hyphae abundant, forming flat mats in several irregularly serrate concentric zones; each zone first white, turning yellowish to pale brownish. Autolytic excretions and coilings inconspicuous. Colony reverse yellow to brown-orange, 4A5, 4B5-6, 5C6-7; no distinct odour noted. Conidiation noted after 1 days at $25^{\circ} \mathrm{C}$, dense, effuse and in shrubs on surface and aerial hyphae, white to yellowish, degenerating after $c a 5$ days; not becoming green. At $15^{\circ} \mathrm{C}$ concentric zones more regular. At $30^{\circ} \mathrm{C}$ zones becoming obscured by a conspicuously dense flat mat of aerial hyphae; surface turning yellow, reverse more intensely coloured than at lower temperatures, orange to brown.

On SNA after $72 \mathrm{~h} 8-9 \mathrm{~mm}$ at $15^{\circ} \mathrm{C}, 25-26 \mathrm{~mm}$ at $25^{\circ} \mathrm{C}$, $27-28 \mathrm{~mm}$ at $30^{\circ} \mathrm{C}$; mycelium covering plate after 911 days at $25^{\circ} \mathrm{C}$. Colony as on CMD, but mycelium denser and margin more irregular. No autolytic excretions noted, coilings inconspicuous. No diffusing pigment, no distinct odour noted. Chlamydospores absent or rare, more frequent at $15^{\circ} \mathrm{C}$. Conidiation noted after 1 days at $25^{\circ} \mathrm{C}$, first effuse, macroscopically invisible or finely downy, spreading from the centre across the entire colony; developing over a long period, usually still fresh during pustulate conidiation. Conidiophores simple, short, erect, acremonium- to irregularly verticillium-like, of a single whorl of phialides on a short stipe, or branched basally, broad, with few phialides or short side branches, or of short side branches emerging from a single axis. Side branches typically unpaired, in right angles or inclined upwards, typically of 1-3(-6) long cells, re-branching into short, often paired, 1-2 celled terminal branches. Phialides formed on cells (2-)2.5-5 $\mu \mathrm{m}$ wide, solitary or in whorls of $(2-) 3(-4-5)$. Conidia produced in wet heads, green in the stereo-microscope. Phialides $(5-) 8-15(-19) \times 2.3-3.0(-3.3) \mu \mathrm{m}, 1 / \mathrm{w}(2.0-) 2.7-$ $5.8(-8),(1.4-) 1.7-2.4(-2.8) \mu \mathrm{m}$ wide at the base $(n=30)$, lageniform or nearly cylindrical, straight or slightly curved upwards, widest in or below the middle. Conidia (2.8-)3.3$4.3(-4.8) \times(2.0-) 2.3-2.7(-3.0) \mu \mathrm{m}, 1 / \mathrm{w}(1.1-) 1.4-1.7(-2.0)$ $(n=30)$, pale yellow-greenish, ellipsoidal or oval, smooth, scar indistinct or distinctly projecting. Pustulate conidiation starting slightly after effuse conidiation in a central zone, later in one or several additional distal zones. Pustules 

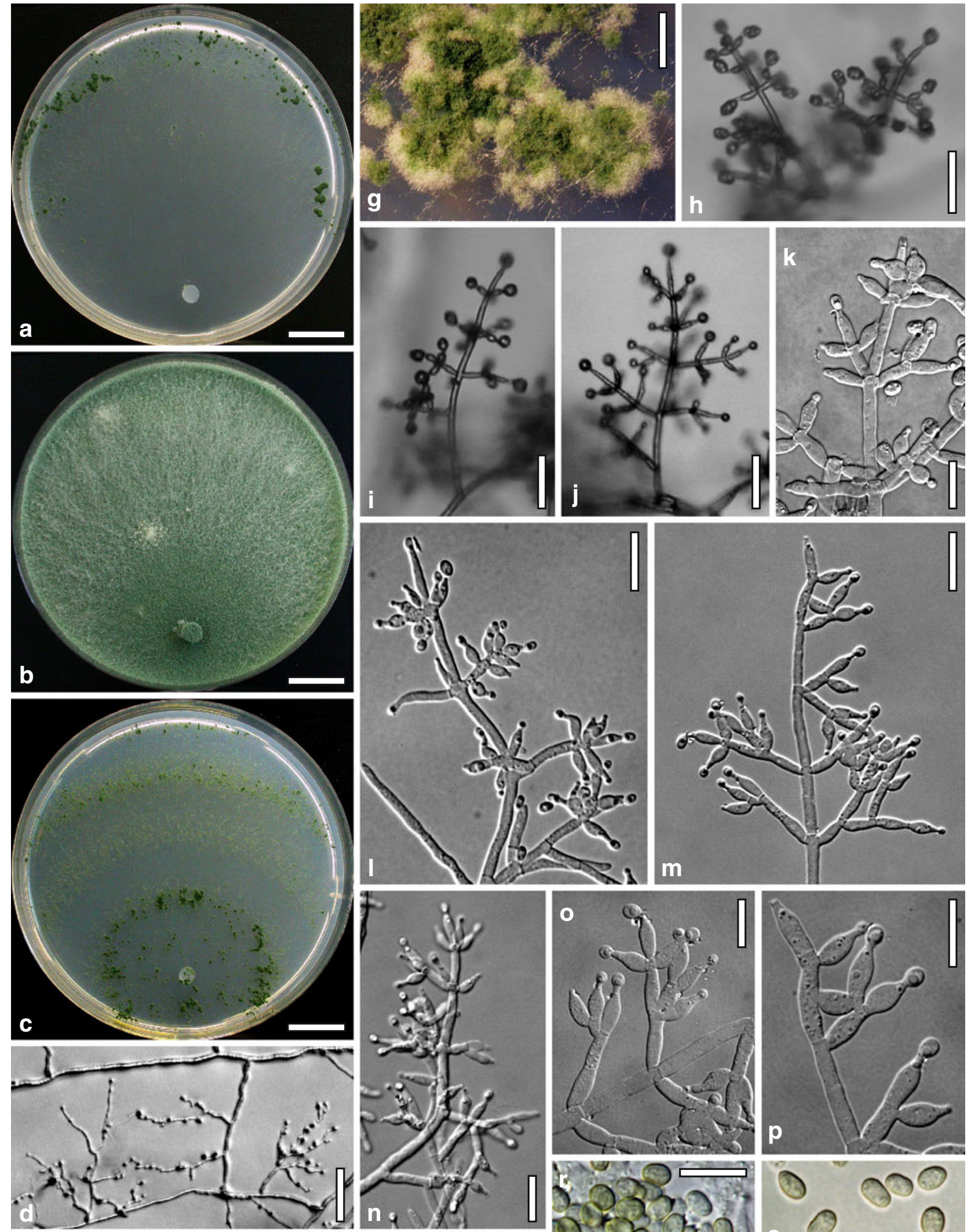

- क

\section{.}

1
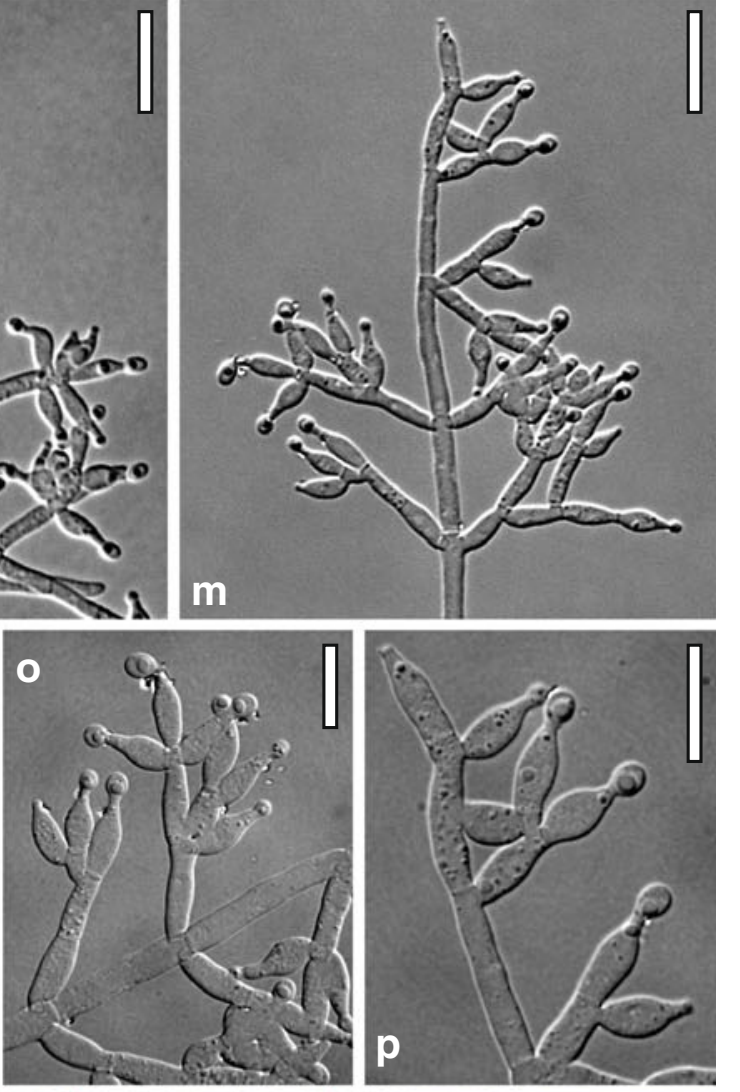

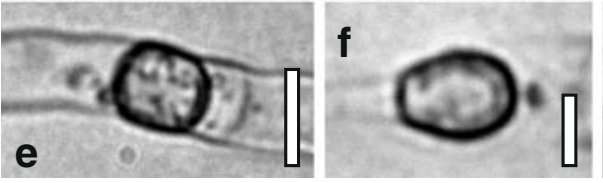

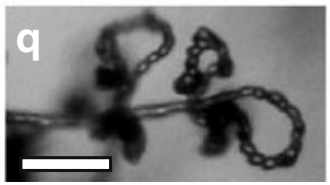

1. 03070 ,

(1) 00

की 
4Fig. 7 Cultures and anamorph of Hypocrea koningii (CBS 119500). a-c. Cultures at $25^{\circ} \mathrm{C}$ (a. on CMD, 14 days; b. on PDA, 13 days; c. on SNA, 14 days). d. Hyphae on agar surface (SNA, $15^{\circ} \mathrm{C}, 3$ days). e, $\mathbf{f}$. Chlamydospores (e. intercalary, f. terminal; 11 days). g-j. Conidiation on SNA, observed in the stereo-microscope (g. pustules, $25^{\circ} \mathrm{C}, 7$ days; $\mathbf{h}-\mathbf{j}$. on aerial hyphae; h, i. $25^{\circ} \mathrm{C}, 3$ days, j. $15^{\circ} \mathrm{C}, 8$ days). $\mathbf{k}-\mathbf{n}$. Conidiophores (k. showing lageniform and ampulliform phialides; 56 days). o, p. Phialides ( 5 days). q. Conidial chains ( 7 days). $\mathbf{r}-\mathbf{u}$. Conidia (6 days). e, f, $\mathbf{k}-\mathbf{u}$. On $\mathrm{CMD}$, at $25^{\circ} \mathrm{C}$. Scale bars: $\mathbf{a}-\mathbf{c}=$ $15 \mathrm{~mm} . \mathbf{d}=50 \mu \mathrm{m} . \mathbf{e}, \mathbf{k}, \mathbf{o}, \mathbf{p}, \mathbf{r}, \mathbf{t}=10 \mu \mathrm{m} . \mathbf{f}, \mathbf{s}, \mathbf{u}=5 \mu \mathrm{m} . \mathbf{g}=3 \mathrm{~mm} . \mathbf{h}-\mathbf{j}$, $\mathbf{q}=30 \mu \mathrm{m} . \mathbf{l}-\mathbf{n}=15 \mu \mathrm{m}$

large, $0.5-5(-7) \mathrm{mm}$ long, aggregating to $9 \times 5 \mathrm{~mm}$, variable in outline, flat, fluffy to loosely granular, grey-green, 27CE4-6, 28DE5-7, after 5-6 days. Pustules (after 8 days) apparently without a stipe. Complexity of branching within pustules depending on their size; with one or several long main axes emerging, often sterile on lower levels, bearing numerous, widely spaced, short side branches mostly paired, in right angles or slightly inclined upwards. Side branches wide, mostly 3-celled, shorter towards apices, rebranching 1-2 fold, forming short, 1-2 celled terminal branches. Resulting regular trees dense. Phialides formed on cells $2.5-4 \mu \mathrm{m}$ wide, solitary or predominantly in whorls of 3-5 on all kinds of branches within the pustule. Conidia dry, produced in dense pachybasium-like clusters. Phialides (4-) $5-8(-12) \times(2.8-) 3.0-3.5(-3.7) \mu \mathrm{m}, 1 / \mathrm{w}(1.3-) 1.5-2.7(-4.1)$, $(1.5-) 2.0-2.5(-3.0) \mu \mathrm{m}$ wide at the base $(n=30)$, ampulliform or lageniform, widest in various position, most commonly in the middle. Conidia 3.0-3.8(-5.0) $\times(2.0-) 2.2-2.6(-2.8) \mu \mathrm{m}$, $1 / \mathrm{w}(1.2-) 1.3-1.6(-2.2)(n=30)$, pale green, ellipsoidal, less commonly subglobose, smooth, thick-walled; scar indistinct. At $15^{\circ} \mathrm{C}$ conidiation effuse and mainly in dense green aggregates around the plug. At $30^{\circ} \mathrm{C}$ coilings more frequent, fertile aerial hyphae forming several narrow, downy, whitish to greenish concentric zones; pustulate conidiation mainly along the colony margin, fluffy, pale or grey-green.

Habitat: on dark, medium to well-decayed wood and bark of deciduous trees.

Distribution:Europe (Austria), North America; uncommon.

Holotype: USA, New Jersey, Cumberland County, Haleyville, at intersection of NJ routes $649 \& 718$, in mixed hardwood, elev. 0 m, on bark, G.J. Samuels, H.-J. Schroers \& G. Bills, 6 Jun. 1996, (BPI 744493, culture G.J. S. 96-135=CBS 111144; both not examined).

Specimens examined: Austria, Kärnten, Spittal/Drau, Mallnitz, Stappitz, at the brook parallel to the hiking trail 518, close to Gasthof Alpenrose, MTB 8945/3, 47 $01^{\prime} 05^{\prime \prime}$ $\mathrm{N}, 13^{\circ} 11^{\prime} 14^{\prime \prime}$ E, elev. $1340 \mathrm{~m}$, on a decorticated branch of Alnus incana $8-10 \mathrm{~cm}$ thick, on wood, soc. Hypoxylon fuscum, Neodasyscypha cerina, a myxomycete, white hyphomycete, 5 Sep. 2003, W. Jaklitsch, W.J. 2380 (WU 29290, culture CBS $119498=$ C.P.K. 949). Oberösterreich, Grieskirchen, Natternbach, at Gaisbuchen, MTB 7548/3, $48^{\circ}$ $24^{\prime} 36^{\prime \prime} \mathrm{N}, 13^{\circ} 41^{\prime} 22^{\prime \prime}$ E, elev. $560 \mathrm{~m}$, on a branch of Fagus sylvatica $4 \mathrm{~cm}$ thick, on wood, 10 Sep. 2003, H. Voglmayr, W.J. 2393 (WU 29291, culture C.P.K. 958). Same area, host and date, partly attacked by a grey mould, W.J. 2394 (part of WU 29291, culture C.P.K. 959). Natternbach, NE Oberantlang, MTB 7648/1, 48 $23^{\prime} 15^{\prime \prime} \mathrm{N}, 13^{\circ} 42^{\prime} 18^{\prime \prime}$ E, elev. $550 \mathrm{~m}$, on a branch of Fagus sylvatica, on wood, soc. hyphomycetes, 17 Jul. 2004, H. Voglmayr, W.J. 2529 (WU 29292, culture C.P.K. 1613). Schärding, Kopfing, Ahörndl, MTB $7547 / 2$, elev. $730 \mathrm{~m}$, on a branch of Betula pubescens lying in moss, 15 Aug. 2006, H. Voglmayr, W.J. 2929 (WU 29295, culture C.P.K. 2438). Vorarlberg, Bludenz, Nenzing, Rabenstein, at Beschling, MTB 8824/1, 47 $11^{\prime} 20^{\prime \prime} \mathrm{N}, 09^{\circ} 40^{\prime}$ 34" E, elev. $660 \mathrm{~m}$, on a decorticated branch of Fagus sylvatica 4-5 cm thick, on wood, soc. Nemania-anamorph, 29 Aug. 2004, H. Voglmayr \& W. Jaklitsch, W.J. 2631 (WU 29293 , culture C.P.K. 2016). Same area, $47^{\circ} 11^{\prime} 24^{\prime \prime}$ N, $09^{\circ} 40^{\prime}$ $16^{\prime \prime}$ E, elev. $680 \mathrm{~m}$, on partly decorticated branch of Corylus avellana $3 \mathrm{~cm}$ thick, on wood, also below bark, holomorph, 29 Aug. 2004, W. Jaklitsch \& H. Voglmayr, W.J. 2633 (WU 29294, culture C.P.K. 1969).

Notes: The stromata of Hypocrea neorufa are typical for teleomorphs of Trichoderma section Trichoderma, while the cortical cells are more distinct, also the dark colour is remarkable, as is the yellow perithecial wall. Conspicuous is also the colour change from bright yellow in fresh young stromata to brown upon drying or incubation in a moist chamber. The yellow peridium helps to distinguish this species and $H$. neorufoides from species like $H$. petersenii and $H$. subeffusa, which are also characterised by dark brown stromata, but have hyaline peridia. H. neorufoides is indistinguishable in teleomorph morphology from $H$. neorufa. Fresh mature stromata may sometimes resemble those of Hypoxylon fuscum in colour, but have a smooth even surface instead of large perithecial mounds in the latter fungus. Hypocrea neorufa was described by Dodd et al. (2002). See this paper for a more detailed description of the conidiophores of the pustulate conidiation. Although phylogenetically belonging to Trichoderma section Trichoderma, the anamorph of $H$. neorufa deviates in having both effuse and pustulate stages differing in structure from each other, and also in the pachybasium-like conidiophores in pustules.

Hypocrea neorufoides Jaklitsch, sp. nov. Fig. 10 MycoBank MB 516692

Anamorph: Trichoderma neorufoides Jaklitsch, sp. nov. Fig. 11

MycoBank MB 516693

Differt ab Hypocrea neorufa genetice, incremento optimo ad temperaturam inferiorem et anamorphosi. Anamorphosis Trichoderma neorufoides; conidiophora effuse 


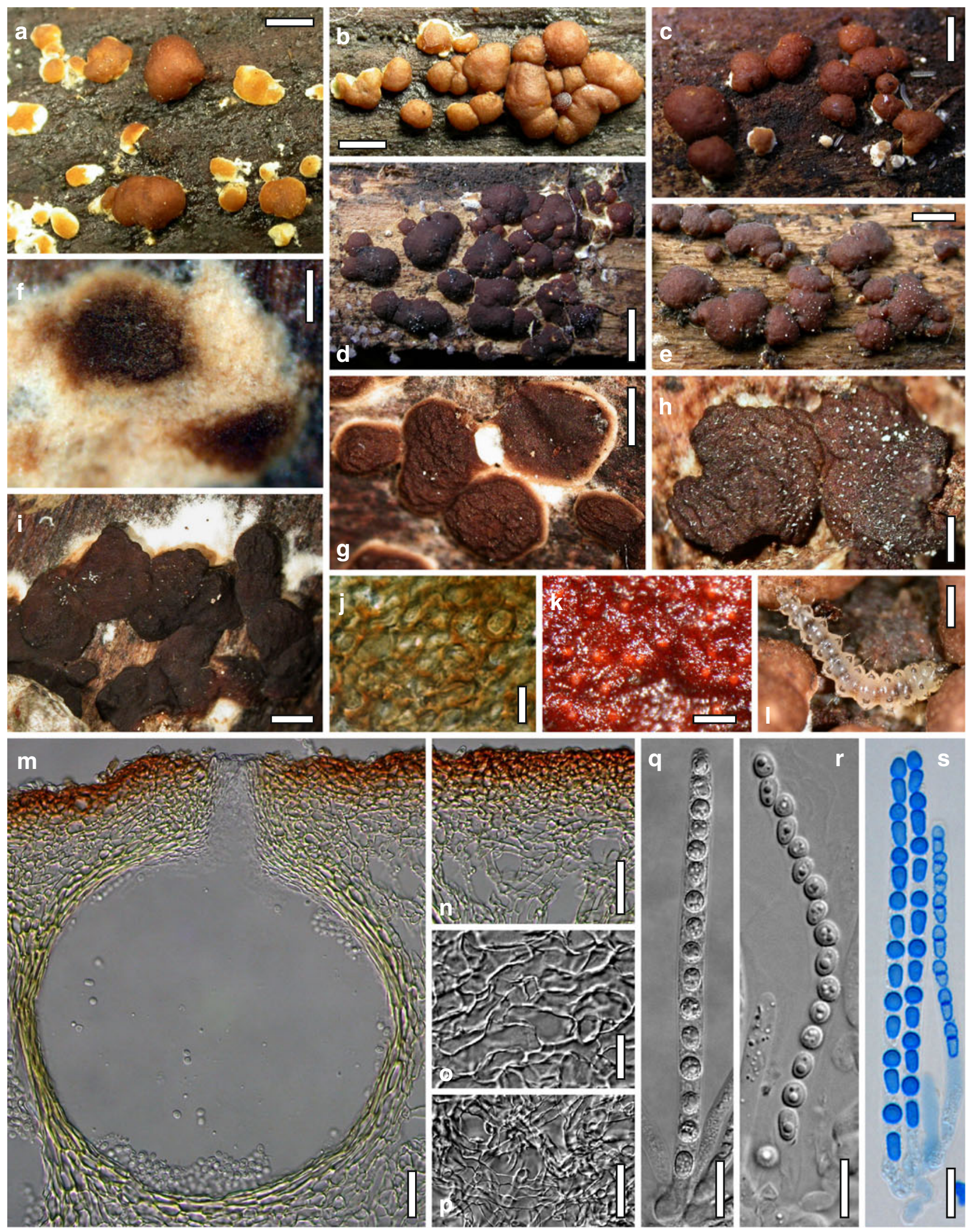


4 Fig. 8 Teleomorph of Hypocrea neorufa. a-e. Fresh stromata (a, b. immature). $\mathbf{f}-\mathbf{i}$. Dry stromata (f, g. immature). j. Stroma surface in face view. k. Rehydrated stroma surface showing ostiolar openings. I. Insect larva on fresh stromata. m. Perithecium in section. $\mathbf{n}$. Cortical and subcortical tissue in section. o. Subperithecial tissue in section. p. Stroma base in section. q-s. Asci with ascospores (s. in cotton blue/ lactic acid). a, b, f, i. WU 29294. c, d, j, m-q. WU 29290. e. WU 29293. k. WU 29291. g, h, l, r, s. WU 29295. Scale bars: a-c= $1.5 \mathrm{~mm} . \mathbf{d}=2.5 \mathrm{~mm}$. e, $\mathbf{g}, \mathbf{i}=1 \mathrm{~mm} . \mathbf{f}, \mathbf{l}=0.2 \mathrm{~mm} . \mathbf{h}=0.5 \mathrm{~mm}$. $\mathbf{j}=5 \mu \mathrm{m}$. $\mathbf{k}=100 \mu \mathrm{m} . \mathbf{m}, \mathbf{p}=25 \mu \mathrm{m} . \mathbf{n}, \mathbf{o}=20 \mu \mathrm{m} . \mathbf{q}-\mathbf{s}=10 \mu \mathrm{m}$

disposita et in pustulis parvis et planis, albis vel pallide luteis in agaris CMD et PDA, viridibus in agaro SNA. Conidiophora gradatim transeuntia de typo verticillii ad typum pachybasii, typice ad basim sterilia. Phialides in pustulis divergentes, variabiles, lageniformes, $(5.5-) 7-14(-20) \times(2.5-) 3.0-4.0(-$ 5.0) $\mu \mathrm{m}$. Conidia pallide viridia, ellipsoidea vel oblonga, glabra, (3.3-)3.8-5.2(-6.3)×(2.5-)2.7-3.2(-3.8) $\mu \mathrm{m}$.

Etymology: neorufoides denotes the resemblance and close relationship with Hypocrea neorufa.

Stromata when fresh 1-6(-8) $\mathrm{mm}$ diam, to $2 \mathrm{~mm}$ thick, at first often thinly effuse, with white mycelial margin, becoming pulvinate or discoid, compact. Outline roundish, angular or irregular. Margin free, sides often steep, smooth, white or yellowish. Surface downy when young, glabrous when mature, smooth or finely granular. Ostioles typically invisible, only rarely visible as darker dots, ostiolar openings appearing as minute, light reddish or hyaline convex dots under strong magnification. Stromata first yellow, yellow-orange, yellowbrown, 4B5-7, 5DE5-8, light brown, orange-, reddish brown, 6CD5-8, 7CE6-8, 8D7-8, with age darkening, mostly dark brown, 7E7-8, or dark reddish or purplish brown, 8-9F7-8. Injured areas yellow due to yellow perithecia. Spore deposits white, less commonly yellowish.

Stromata when dry $(0.6-) 1.0-3.6(-5.5) \times(0.4-) 0.7-2.7(-$ $5.5) \mathrm{mm},(0.2-) 0.3-0.7(-1.3) \mathrm{mm}$ thick $(n=50)$. solitary, gregarious or densely aggregated in variable numbers, thinly effuse to distinctly pulvinate, broadly attached, with often persistent, radiating, white to yellowish base mycelium. Outline variable. Margin attached or free, white or yellow when young. Surface hairy when young, slightly velutinous when mature, smooth, tubercular or rugose. Ostioles typically only seen under strong magnification as minute, slightly projecting, light dots $(15-) 19-40(-55) \mu \mathrm{m}(n=60)$ diam; distinct after re-wetting. Stromata when young yellow, 4A5, 4B5-7, yellow-brown, light brown, medium brown or orange-brown, 5-6CE7-8, 6CD4-5, 7-8E7-8; darkening with age to dark brown, dark chocolate brown, dark reddish or purplish brown, 6F4-7, 7-9F4-8, to nearly black. Rehydrated stromata not different from the fresh state, colour not changed in $3 \% \mathrm{KOH}$.

Stroma anatomy: Ostioles (47-)55-80(-94) $\mu \mathrm{m}$ long, plane or projecting to $22 \mu \mathrm{m},(12-) 22-38(-45)$ wide at the apex internally $(n=36)$; without differentiated apical cells. Perithecia (124-)160-205(-225)×(97-)125-175(-205) $\mu \mathrm{m}(n=47)$, globose or flask-shaped; peridium (6-)10-16(-22) $\mu \mathrm{m}(n=$ 80 ) thick at the base and sides, yellow in lactic acid; orange with vinaceous tone in 3\% KOH. Cortical layer (17-)20-30 $(-35) \mu \mathrm{m}(n=40)$ thick, a $t$. angularis of distinct, isodiametric, thick-walled, reddish- or yellowish brown cells (3-)5-11 $(-16) \times(2.5-) 4-9(-13) \mu \mathrm{m}(n=120)$ in face view and in vertical section, gradually paler downwards; absent at the attached base. Hairs on mature stromata $(6-) 8-25(-38) \times(2-)$ 3-4(-5) $\mu \mathrm{m}(n=31)$, rare, inconspicuous, 1-3 celled, cylindrical, straight or curved, smooth, rarely verruculose, brownish. Subcortical tissue a $t$. intricata of hyaline thinwalled hyphae $(2-) 3-6(-7) \mu \mathrm{m}(n=40)$ wide. Subperithecial tissue a $t$. epidermoidea of hyaline thin-walled cells (6-)9-35 $(-50) \times(5-) 7-12(-16) \mu \mathrm{m}(n=60)$, appearing as wide, mostly vertically oriented hyphae under lower magnification. Stroma base a $t$. intricata of hyaline hyphae $(2-) 3-5(-6) \mu \mathrm{m}(n=16)$ wide. Asci (76-)83-96(-108)×(4.7-)5.0-6.0(-6.5) $\mu \mathrm{m}$, stipe $(2-) 6-14(-24) \mu \mathrm{m}$ long $(n=50)$. Ascospores hyaline, verruculose; cells dimorphic, distal cell $(3.0-) 3.4-4.3(-5.7) \times(3.0-)$ $3.5-4.0(-4.5) \mu \mathrm{m}, 1 / \mathrm{w}(0.9-) 1.0-1.2(-1.6)(n=90)$, subglobose or oval, proximal cell $(3.0-) 4.0-5.5(-7.3) \times(2.2-) 2.8-$ $3.4(-4.0) \mu \mathrm{m}, 1 / \mathrm{w}(1.0-) 1.2-1.8(-2.6) \quad(n=90)$, oblong, wedge-shaped or subglobose.

Anamorph on the natural substrate typically light bluish green, effuse or pulvinate, powdery or hairy. Cultures and anamorph: optimal growth at $25^{\circ} \mathrm{C}$ on all media; no growth at $35^{\circ} \mathrm{C}$. On CMD after $72 \mathrm{~h} 8-9 \mathrm{~mm}$ at $15^{\circ} \mathrm{C}, 21-24 \mathrm{~mm}$ at $25^{\circ} \mathrm{C}, 17-23 \mathrm{~mm}$ at $30^{\circ} \mathrm{C}$; mycelium covering the plate after $8-10$ days at $25^{\circ} \mathrm{C}$. Colony hyaline, thin, dense, with wavy margin, not zonate; hyphae with radial arrangement, thin, with low variation in width. Aerial hyphae scant, becoming fertile. Autolytic activity nearly absent, no coilings seen. No chlamydospores seen. Agar becoming diffusely dull yellow, 3-4AB3-4, mostly in distal areas. Odour weakly coconut-like. After $c a 1$ month at $15^{\circ} \mathrm{C}$ sometimes yellow crystals appearing in the agar. Conidiation noted after 2 days, white to pale yellowish, green only in the stereo-microscope; effuse, macroscopically invisible, spreading from the plug. Conidiophores (after 4-12 days) simple, erect, verticillium-like, mostly short, 100-250 $\mu \mathrm{m}$ long, sometimes to $1 \mathrm{~mm}$ high; of one or few thick and thick-walled main axes 3-7 $\mu \mathrm{m}$ wide on a thick-walled stipe to $10 \mu \mathrm{m}$ wide at the base; typically sterile and unbranched on lower levels, on upper levels with few short branches in right angles or inclined upwards; more complex and longer in distal areas. Branches thick, 1-3 celled, sometimes re-branching, typically unpaired, but terminal branches or phialides often paired. Phialides emerging solitary or divergent in whorls of $2-3(-5)$ on cells 2 $5 \mu \mathrm{m}$ wide. Conidia produced in numerous minute wet heads $<40 \mu \mathrm{m}$ diam. Phialides $(7-) 10-18(-25) \times(2.0-) 2.7-$ $3.5(-4.7) \mu \mathrm{m}, 1 / \mathrm{w}(2.4-) 3.2-6.0(-8.9),(1.4-) 2.0-3.0(-3.6)$ $\mu \mathrm{m}$ wide at the base $(n=122)$, narrowly lageniform or 

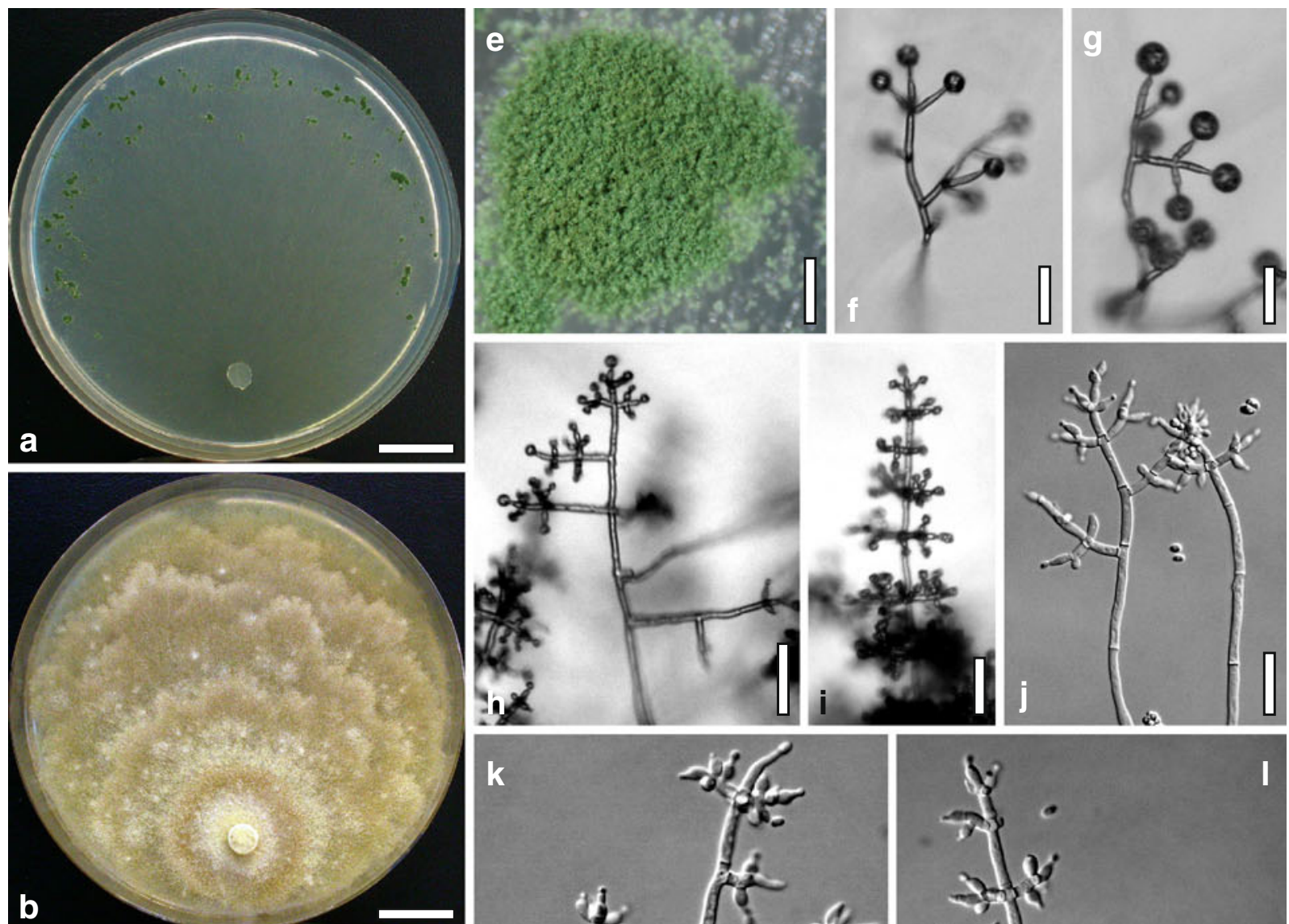

มิ

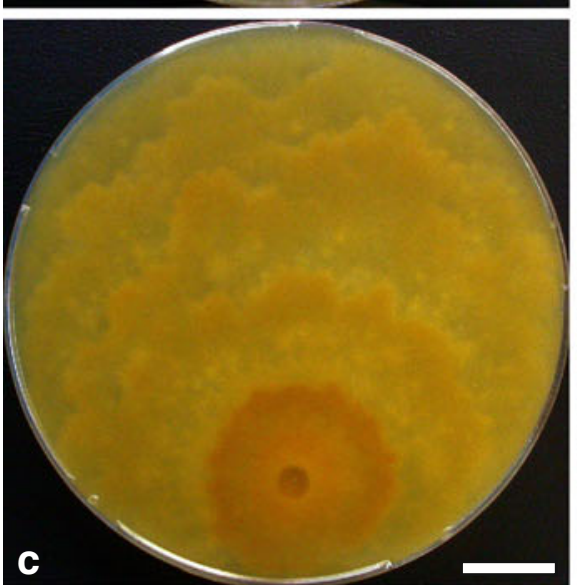

k
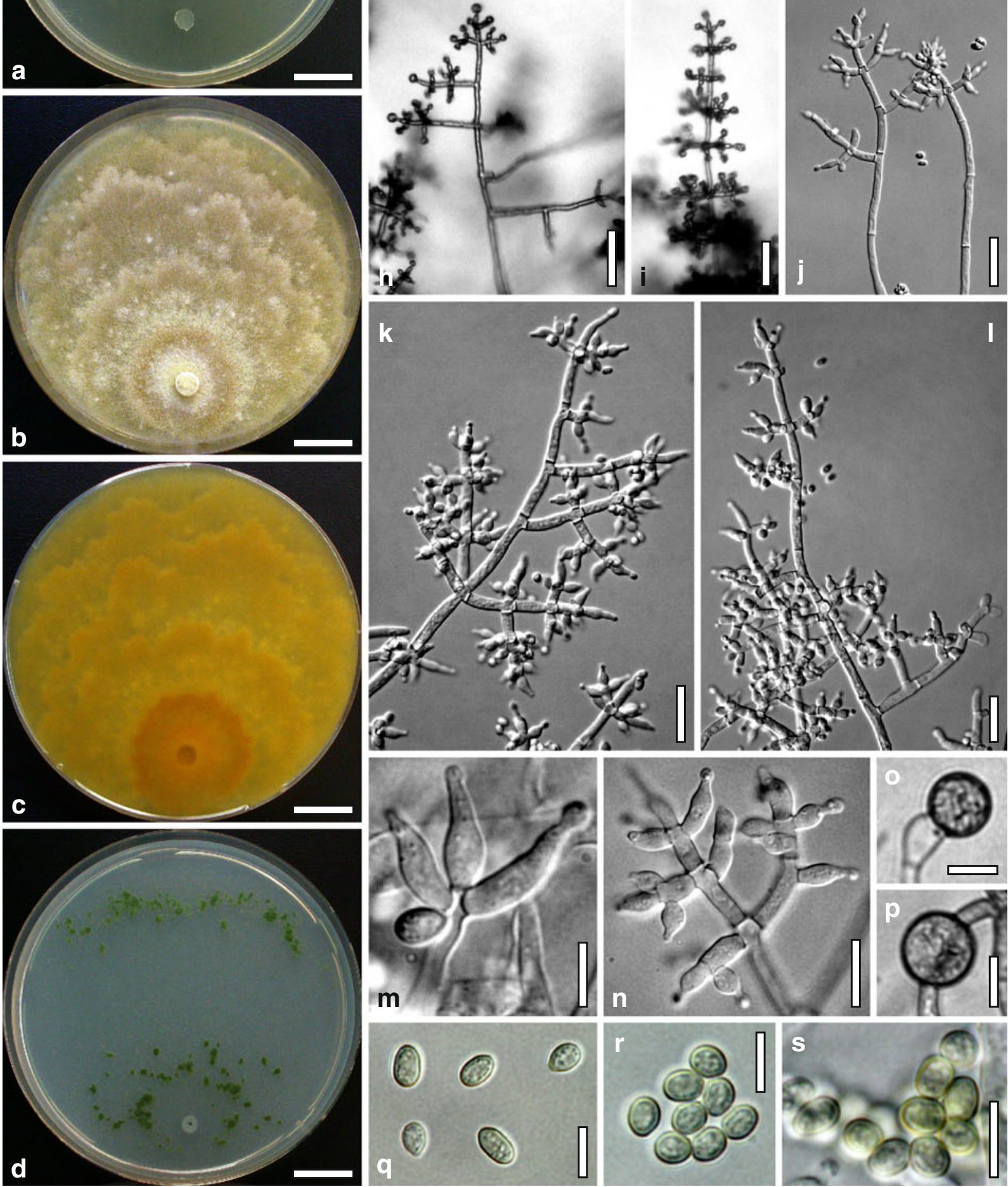

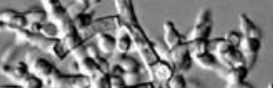

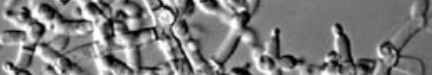
\% In 5 क bespis. $4 x^{3}$
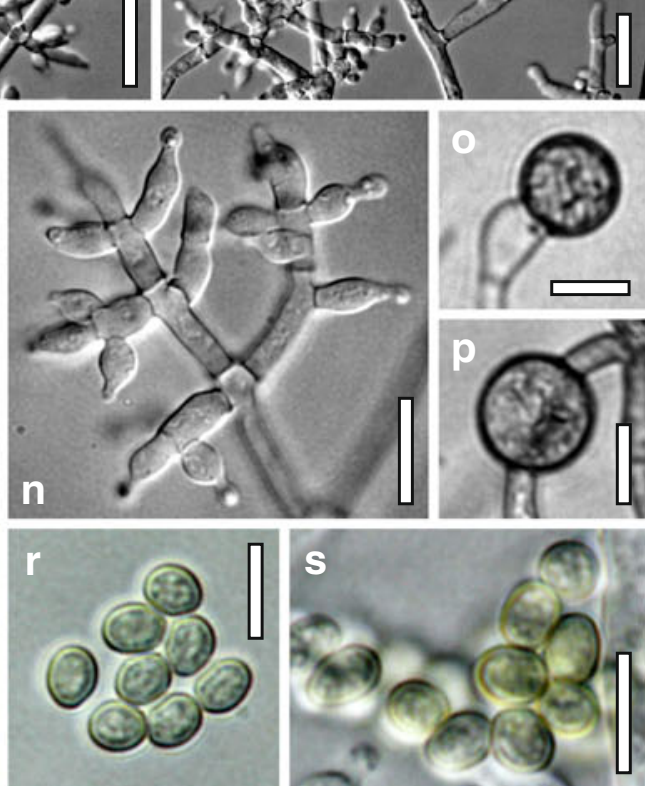
4 Fig. 9 Cultures and anamorph of Hypocrea neorufa (CBS 119498). a-d. Cultures after 14 days (a. on CMD; b. on PDA; c. on PDA, reverse; d. on SNA). e. Conidiation pustule (CMD, 14 days). $\mathbf{f}-\mathbf{i}$. Conidiophores on growth plates (f, g. effuse conidiation, CMD, 2 3 days; h, i. pustulate conidiation, SNA, 6 days). j-l. Conidiophores (SNA, 8 days). m, n. Phialides (SNA, $8-9$ days; m. effuse; $\mathbf{n}$. from pustules). o, p. Chlamydospores (CMD, 15 days; o. terminal, p. intercalary). q-s. Conidia (SNA, $8-9$ days, q. from effuse conidiation). a-s. All at $25^{\circ} \mathrm{C}$. Scale bars: $\mathbf{a}-\mathbf{d}=15 \mathrm{~mm}$. $\mathbf{e}=0.5 \mathrm{~mm}$. f, $\mathbf{g}, \mathbf{j}=$ $20 \mu \mathrm{m} . \mathbf{h}, \mathbf{i}=40 \mu \mathrm{m} . \mathbf{k}, \mathbf{l}=15 \mu \mathrm{m} . \mathbf{m}, \mathbf{q}-\mathbf{s}=5 \mu \mathrm{m} . \mathbf{n}-\mathbf{p}=10 \mu \mathrm{m}$

subulate, sometimes sinuous, straight or slightly curved upwards, scarcely swollen, widest mostly below the middle. Conidia (3.4-)4.0-5.6(-7.4) ×(2.3-)2.7-3.2(-3.8) $\mu \mathrm{m}$, $1 / \mathrm{w}(1.2-) 1.3-1.9(-2.6)(n=122)$, hyaline to pale green, ellipsoidal or oblong, sides often parallel, smooth, finely multiguttulate or with 1 to few large guttules, scar indistinct.

Effuse conidiation followed and accompanied by conidiation in broad, flat shrubs aggregating to 'hedges' several $\mathrm{mm}$ long, arranged in one or few distal wavy concentric zones, first becoming visible after $c a 6$ days at colony sides, white, downy or farinose, with age at most pale yellowish or with a greenish shimmer, pale greenish in the stereomicroscope (also at 15 and $30^{\circ} \mathrm{C}$ ). Shrubs (after 10-13 days) $0.4-0.8(-1) \mathrm{mm}$ diam, fluffy to granular, transparent, of a loose reticulum of thick primary branches $6-8 \mu \mathrm{m}$ wide in right angles with long fertile main axes; on a thick-walled $(1 \mu \mathrm{m})$ stipe 9-11(-16) $\mu \mathrm{m}$ wide including outer layer swelling in $\mathrm{KOH}$. Conidiophores (main axes) similar to effuse conidiation to pachybasium-like, 4-8 $\mu \mathrm{m}$ wide, 2.5$4 \mu \mathrm{m}$ terminally, typically with long stretches from the base sterile and only few, mostly short, 1-4 celled, side branches or phialides along their length; branches concentrated on the apex. Apex typically of few terminal branches and/or phialides or richly branched in dense fascicles forming narrow regular trees to $200 \mu \mathrm{m}$ long. Short 1-2 celled terminal branches and phialides often paired and slightly inclined upwards, sometimes appearing rough by minute guttules. Branching points sometimes globose, to 10$12 \mu \mathrm{m}$ wide. Phialides emerging solitary or divergent in whorls of $2-5$ on often slightly thickened cells $2.5-5 \mu \mathrm{m}$ wide. Conidia produced in numerous minute, first wet, soon dry heads $<20 \mu \mathrm{m}$ diam. Phialides $(5.5-) 7-14(-20) \times(2.5-)$ $3.0-4.0(-5.0) \mu \mathrm{m}, 1 / \mathrm{w}(1.6-) 2.1-4.1(-6.1),(1.5-) 2.2-3(-4)$ wide at the base $(n=90)$, lageniform or conical, rarely ampulliform, straight or curved upwards in dense whorls, widest mostly in or below the middle. Conidia (3.3-)3.8$5.2(-6.3) \times(2.5-) 2.7-3.2(-3.8) \mu \mathrm{m}, 1 / \mathrm{w}(1.2-) 1.3-1.7(-2.1)$ $(n=90)$, subhyaline to pale yellowish green, ellipsoidal, less commonly oblong or subglobose, smooth, finely multiguttulate; scar indistinct, less commonly prominent.

On PDA after $72 \mathrm{~h} 6-8 \mathrm{~mm}$ at $15^{\circ} \mathrm{C}, 24-26 \mathrm{~mm}$ at $25^{\circ} \mathrm{C}$, $11-20 \mathrm{~mm}$ at $30^{\circ} \mathrm{C}$; mycelium covering plate after $10-14$ days at $25^{\circ} \mathrm{C}$. Colony first hyaline, thin, dense, with coarsely wavy margin, not zonate; hyphae with radial arrangement, thin, with low variation in width. Aerial hyphae numerous, thick, several $\mathrm{mm}$ long and high, forming strands, uniting into a dense reticulum, radially arranged on the margin, forming a thick mat separated into 2-3 broad zones; with large drops and coilings, finally collapsing. Autolytic activity moderate, coilings frequent. Reverse yellow, golden yellow to brownish from the centre, 3A4-5, 4AB4-6, 5CD7-8. Odour indistinct or faintly coconut-like. Conidiation noted after 2 days, effuse in dense lawns of small shrubs, short and on long aerial hyphae, long steep phialides, colourless, only pale greenish in the centre (stereo-microscope !). At $15^{\circ} \mathrm{C}$ yellow zones with broad thick, white hairy marginal zone of a reticulum of numerous aerial hyphae forming strands; reverse yellowish, 4A3-4, 4B4-5; conidiation effuse, colourless. At $30^{\circ} \mathrm{C}$ colony zonate, downy; reverse yellow; conidiation effuse, poor, colourless.

On SNA after $72 \mathrm{~h} 7-9 \mathrm{~mm}$ at $15^{\circ} \mathrm{C}, 21-22 \mathrm{~mm}$ at $25^{\circ} \mathrm{C}, 4$ $16 \mathrm{~mm}$ at $30^{\circ} \mathrm{C}$; mycelium covering plate after $10-14$ days at $25^{\circ} \mathrm{C}$. Colony similar to CMD. Aerial hyphae inconspicuous, more frequent along the margin, becoming fertile. Autolytic activity inconspicuous, coilings nearly absent. No diffusing pigment, no distinct odour noted. No chlamydospores seen. Conidiation noted after 2 days, abundant, first effuse, denser than on CMD, more or less evenly distributed on the colony surface or concentrated with distance from the plug; later in shrubs $0.2-0.8 \mathrm{~mm}$ diam formed in several narrow, wavy, downy to finely powdery to granular, equidistant concentric zones appearing consecutively, starting in a distal area, densely aggregating to $3-8 \mathrm{~mm}$, becoming light green or grey-green, 1C4-5, 29-30CD5-6, after 6-7 days. Conidiation structures same as on CMD, described above, measurements united. At $30^{\circ} \mathrm{C}$ growth slow, hyphae becoming multiguttulate, forming pegs, dying soon. Conidiation scant, effuse, simple, colourless.

Habitat: on medium to well-decayed wood and bark of deciduous trees, predominantly Fagus sylvatica.

Distribution: Europe (Austria, Denmark, Germany, Netherlands, United Kingdom).

Holotype: Austria, Niederösterreich, Wien Umgebung, Pressbaum, Rekawinkel, forest path south from the train station, MTB 7862/1, 48 $10^{\prime} 40^{\prime \prime} \mathrm{N}, 16^{\circ} 01^{\prime} 55^{\prime \prime} \mathrm{E}$, elev. $390 \mathrm{~m}$, on corticated branch of Fagus sylvatica 5-6 cm thick, mainly on bark, soc. white mould, effete Hypoxylon fragiforme, partly overgrown by a white mould, 18 Oct. 2003, H. Voglmayr \& W. Jaklitsch, W.J. 2474 (WU 29296, culture CBS 119506=C.P.K. 993). Holotype of Trichoderma neorufoides isolated from WU 29296 and deposited as a dry culture with the holotype of $H$. neorufoides as WU 29296a.

Other specimens examined: Austria, Niederösterreich, Melk, Loosdorf, Dunkelsteiner Wald, $0.7 \mathrm{~km}$ south of Umbach, MTB 7758/4, 48 $14^{\prime} 04^{\prime \prime} \mathrm{N}, 15^{\circ} 25^{\prime} 48^{\prime \prime}$ E, elev. $370 \mathrm{~m}$, on decorticated branch of Fagus sylvatica 2-3 cm thick, on wood and bark, soc. Chaetosphaeria bramleyi; partly overgrown by a black hyphomycete, holomorph, 5 Oct. 2004, W. Jaklitsch, W.J. 2769 (WU 29303, culture C.P. 

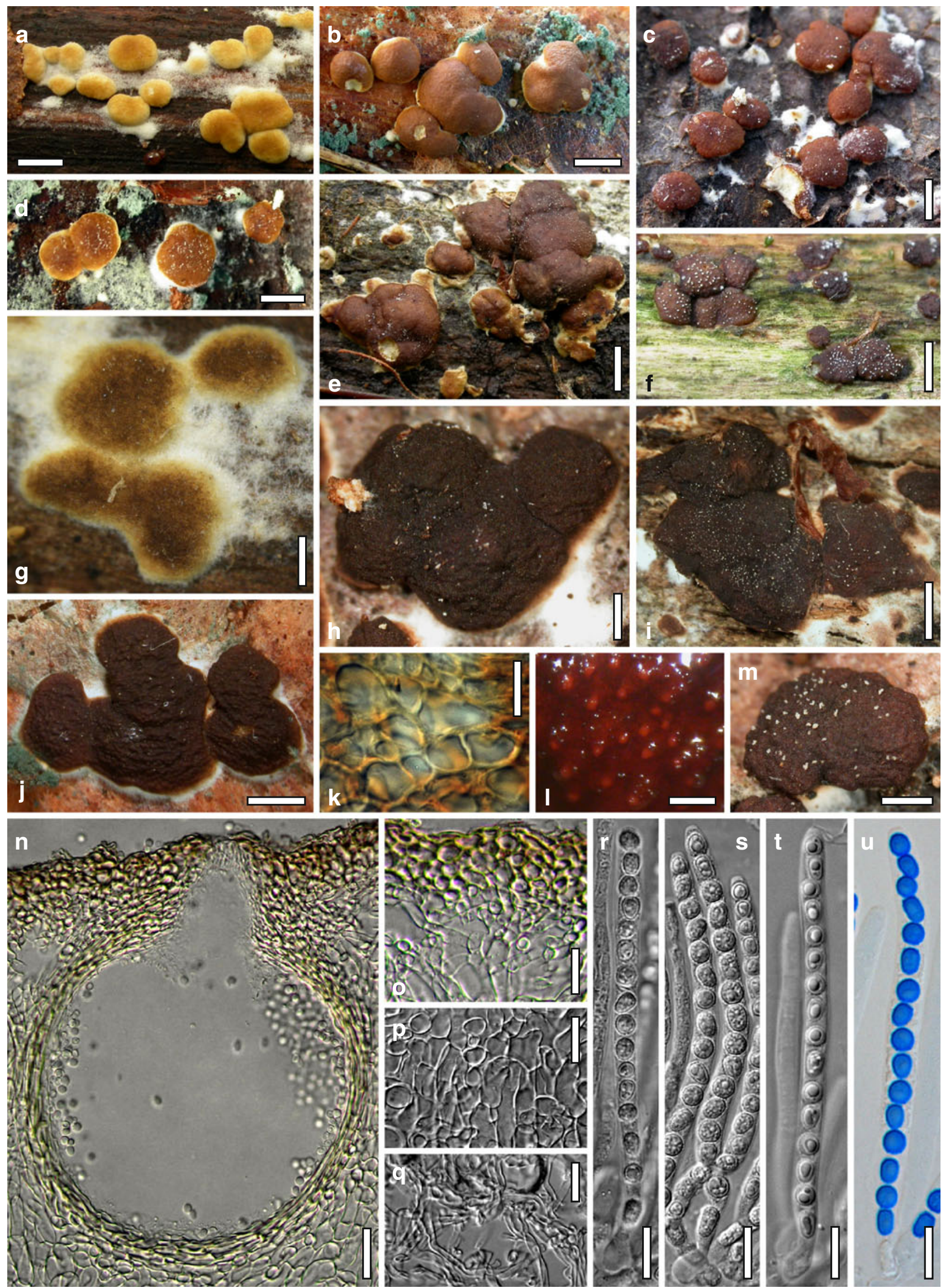
4 Fig. 10 Teleomorph of Hypocrea neorufoides. a-f. Fresh stromata (a, $\mathbf{b}, \mathbf{d}$. immature). $\mathbf{g}-\mathbf{j}$. Dry stromata (g, j. immature). k. Stroma surface in face view. l. Rehydrated stroma surface showing ostiolar openings. m. Rehydrated stroma. n. Perithecium in section. o. Cortical and subcortical tissue in section. p. Subperithecial tissue in section. q. Stroma base in section. $\mathbf{r}-\mathbf{u}$. Asci with ascospores (u. in cotton blue/ lactic acid). a, f, g. WU 29301. b, j, k, n-q, s. WU 29300. c, h, l, m, r. WU 29296. d, t, u. WU 29304. e, i. WU 29302. Scale bars: a, c, d, $\mathbf{f}, \mathbf{i}, \mathbf{j}=1.3 \mathrm{~mm} . \mathbf{b}, \mathbf{e}=2 \mathrm{~mm} . \mathbf{g}, \mathbf{h}=0.5 \mathrm{~mm} . \mathbf{k}, \mathbf{r}-\mathbf{u}=10 \mu \mathrm{m} . \mathbf{l}=100 \mu \mathrm{m}$. $\mathbf{m}=0.8 \mathrm{~mm} . \mathbf{n}, \mathbf{p}=25 \mu \mathrm{m} . \mathbf{o}, \mathbf{q}=15 \mu \mathrm{m}$

K. 1905). Oberösterreich, Vöcklabruck, Nußdorf am Attersee, close to Aichereben, MTB 8147/3, 47050'45" N, $13^{\circ} 30^{\prime} 13^{\prime \prime}$ E, elev. $710 \mathrm{~m}$, on decorticated branch of Fagus sylvatica $3 \mathrm{~cm}$ thick, on wood, holomorph, 8 Aug. 2004, W. Jaklitsch \& H. Voglmayr, W.J. 2590 (WU 29297, culture C. P.K. 1898). Denmark, Nordjylland, Tversted, Tversted Plantage, $57^{\circ} 35^{\prime} 18^{\prime \prime} \mathrm{N}, 10^{\circ} 15^{\prime} 19^{\prime \prime} \mathrm{E}$, elev. $10 \mathrm{~m}$, on partly decorticated branches of Fagus sylvatica 4-6 cm thick, on wood and bark, soc. white mould, Hypoxylon fragiforme with Polydesmia pruinosa, holomorph, 24 Aug. 2006, H. Voglmayr \& W. Jaklitsch, W.J. 2941 (WU 29304, culture C. P.K. 2444). Germany, Niedersachsen, Landkreis SoltauFallingbostel, Bispingen, Niederhaverbeck, riverine forest

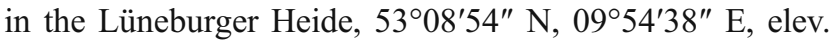
$90 \mathrm{~m}$, on partly decorticated branches of Alnus glutinosa 2$4 \mathrm{~cm}$ thick, on wood, holomorph, 26 Aug. 2006, H. Voglmayr \& W. Jaklitsch, W.J. 2950 (WU 29305, culture C. P.K. 2451). Netherlands, Gelderland, Otterlo, National Park De Hoge Veluwe, close to the hunting castle St. Hubertus, 52 $07^{\prime} 15^{\prime \prime} \mathrm{N}, 05^{\circ} 49^{\prime} 47^{\prime \prime} \mathrm{E}$, elev. $45 \mathrm{~m}$, on mostly decorticated branch of Fagus sylvatica $5 \mathrm{~cm}$ thick, on wood, 18 Sep. 2004, H. Voglmayr, W. Jaklitsch \& W. Gams, W.J. 2728 (WU 29302, culture C.P.K. 1904). United Kingdom, Buckinghamshire, Slough, Burnham Beeches, $51^{\circ} 33^{\prime} 08^{\prime \prime} \mathrm{N}, 00^{\circ} 37^{\prime} 56^{\prime \prime} \mathrm{W}$, elev. $30 \mathrm{~m}$, on partly decorticated branches of Fagus sylvatica 4-5 cm thick, on wood and bark, soc. Tubeufia cerea on an effete pyrenomycete, white mould, mostly old, holomorph, 15 Sep. 2004, W. Jaklitsch, W.J. 2718 (WU 29301, culture C.P.K. 1902). Same area, on partly decorticated branches of Fagus sylvatica $2-3 \mathrm{~cm}$ thick, on wood and bark, holomorph, 15 Sep. 2004, W. Jaklitsch, W.J. 2719 (combined with WU 29301, culture CBS $119505=$ C.P.K. 1903). Same area, $51^{\circ}$ $33^{\prime} 34^{\prime \prime} \mathrm{N}, 00^{\circ} 37^{\prime} 41^{\prime \prime} \mathrm{W}$, elev. $40 \mathrm{~m}$, on partly decorticated branches of Fagus sylvatica 5-6 cm thick, on well-decayed wood and bark, soc. Hypoxylon fragiforme, resupinate polypores, holomorph, 15 Sep. 2007, W. Jaklitsch \& H. Voglmayr, W.J. 3165 (WU 29306, culture C.P.K. 3153). Norfolk, Thetford, Thetford National Forest Park, north of the town, MTB 35-30/4, 52 $26^{\prime} 26^{\prime \prime} \mathrm{N}, 00^{\circ} 43^{\prime} 55^{\prime \prime} \mathrm{E}$, elev. $30 \mathrm{~m}$, on corticated branch of Fagus sylvatica $4 \mathrm{~cm}$ thick, on bark, soc. Lopadostoma turgidum, mostly old, holomorph, 13 Sep. 2004, H. Voglmayr \& W. Jaklitsch, W.J. 2707 (WU 29298, culture C.P.K. 1899). Same region, shortly before Lynford coming from Thetford, MTB 35-30/ $1,52^{\circ} 28^{\prime} 54^{\prime \prime} \mathrm{N}, 00^{\circ} 41^{\prime} 01^{\prime \prime} \mathrm{E}$, elev. $30 \mathrm{~m}$, on corticated branch of Fagus sylvatica 4-5 cm thick, on bark, few stromata on wood below loose bark, and on a Corticiaceae, soc. effete Diatrypella cf. verruciformis, holomorph, 13 Sep. 2004, H. Voglmayr \& W. Jaklitsch, W.J. 2709 (WU 29299, culture C.P.K. 1900). Thetford, Emilys Wood, near Brandon, MTB 35-31/2, 52 $28^{\prime} 08^{\prime \prime} \mathrm{N}, 00^{\circ} 38^{\prime} 20^{\prime \prime}$ E, elev. $20 \mathrm{~m}$, on partly decorticated branch of Fagus sylvatica $3 \mathrm{~cm}$ thick, mainly on wood, and a white Corticiaceae, soc. Hypocrea minutispora and Trichoderma stilbohypoxyli, holomorph, 13 Sep. 2004, H. Voglmayr \& W. Jaklitsch, W.J. 2713 (WU 29300, culture C.P.K. 2357). Same area, on partly decorticated branches of Fagus sylvatica 3-4 cm thick, on bark and wood, soc. Hypocrea minutispora, holomorph, 13 Sep. 2004, H. Voglmayr \& W. Jaklitsch, W.J. 2714 (combined with WU 29300, culture C.P.K. 1901).

Notes: Hypocrea neorufoides is closely related to $H$. neorufa. The teleomorphs of these species are indistinguishable. H. neorufoides is widespread in Europe and more common than H. neorufa, particularly in southern England and eastern Austria. Morphologically these species establish an intermediate position between Trichoderma sect. Trichoderma and the pachybasium core group, deviating from other species of the first section in more distinct surface cells and in a yellow perithecial wall, and in thick, i.e. pachybasium-like conidiophores. Contrary to $H$. neorufa the conidiation in T. neorufoides develops continuously from effuse and verticillium-like to a pachybasium-like shrub conidiation without statistically significant differences in the sizes of phialides and conidia. Nevertheless, both measurements are given in order to highlight the differences to $H$. neorufa. Additional differences from $H$. neorufa are a lower growth optimum, particularly on SNA and PDA, a different macroscopic growth pattern on PDA, larger and more variable conidia and slightly longer phialides. The pigmentation of the reverse on PDA is distinctly less pronounced than in H. neorufa. The shrub conidiation of H. neorufoides on CMD often disappears after several transfers and only simple effuse conidiation remains.

Hypocrea ochroleuca Berk. \& Ravenel, Grevillea 4: 14 (1875). Fig. 12

Anamorph: Trichoderma sp. Fig. 13

Stromata when fresh $2-33 \times(1-) 7-12 \mathrm{~mm}, 0.5-1 \mathrm{~mm}$ thick, widely effuse, entirely attached, of a white mat with indeterminate growth, containing greyish orange to brown orange, $6 \mathrm{~B} 5-6$ to $6 \mathrm{C} 7-8$, fertile patches in varying configurations; margin mycelial, fimbriate, white.

Stromata when dry (2-)5-23(-33) $\times(1-) 3-15(-21) \mathrm{mm}$ $(n=37), 0.15-0.4 \mathrm{~mm}$ thick $(n=20)$, widely and thinly effuse, following bark contours, with white margin; outline 

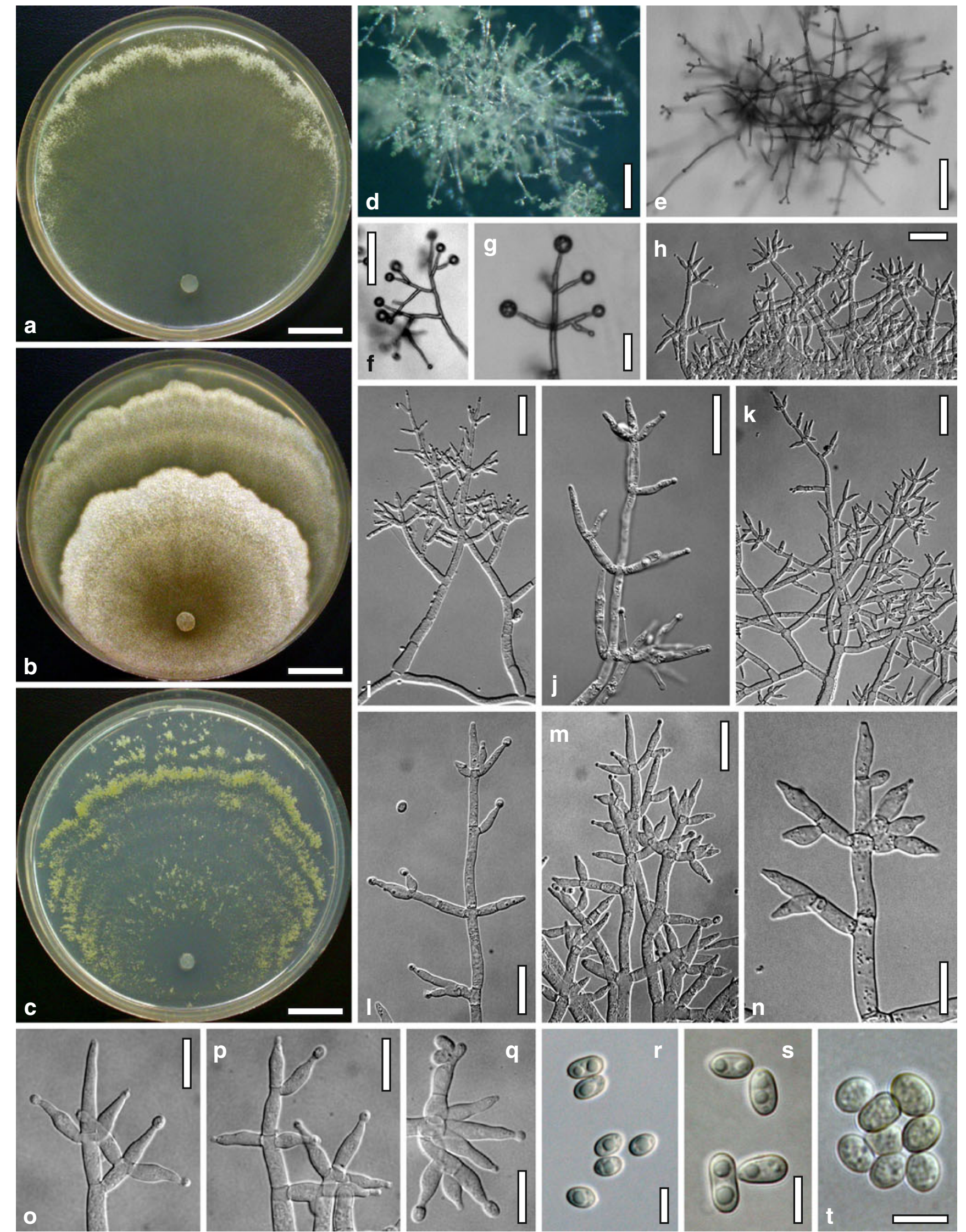
4 Fig. 11 Cultures and anamorph of Hypocrea neorufoides. a-c. Cultures (a. on CMD, 21 days; b. on PDA, 21 days; c. on SNA, 14 days). d, e. Conidiation shrubs (d. SNA, 11 days; e. CMD, 10 days). f, g. Conidiophores of effuse conidiation on growth plates (SNA, 4-9 days). $\mathbf{h}, \mathbf{k}-\mathbf{n}$. Conidiophores from shrubs; h. SNA, 9 days; k-n. CMD, 13 days). i, j. Conidiophores of effuse conidiation (CMD, 9 days). o-q. Phialides from shrubs (SNA, 9 days;). r-t. Conidia (CMD; r, s. from effuse conidiation, $6-12$ days; t. from shrubs, 11 days). a-t. All at $25^{\circ} \mathrm{C}$. $\mathbf{a}-\mathbf{h}, \mathbf{o}, \mathbf{q}, \mathbf{s}-\mathbf{t}$. CBS 119506. i, j. C.P.K. 2357. k, n. C.P.K. 1900. r. C.P. K. 2451. Scale bars: $\mathbf{a}-\mathbf{c}=15 \mathrm{~mm}$. d, $\mathbf{e}=100 \mu \mathrm{m} . \mathrm{f}=50 \mu \mathrm{m} . \mathrm{g}, \mathrm{j}, \mathrm{l}, \mathrm{m}=$

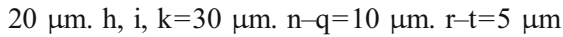

variable; perithecia immersed, irregularly scattered, aggregated in patches. Surface velvety when young, later smooth, with inconspicuous, minute, plane, rarely convex, light ostiolar dots $(20-) 25-40(-47) \mu \mathrm{m}(n=30)$ diam only seen under high magnification; surface around dots sometimes cracked in stellate configuration. Stromata white, fertile patches brown-orange, light brown, 6CD6-8. Spore deposits white. Rehydrated stromata with more distinct hyaline ostiolar openings, not changing colour in 3\% $\mathrm{KOH}$.

Stroma anatomy: Ostioles (65-)72-92(-102) $\mu \mathrm{m}$ long, plane or projecting to $17 \mu \mathrm{m},(22-) 27-41(-45) \mu \mathrm{m}$ wide at the apex $(n=20)$, periphysate, without differentiated apical cells. Perithecia $(130-) 150-185(-195) \times(125-) 140-180(-$ 195) $\mu \mathrm{m}(n=20)$, flask-shaped or subglobose, loosely disposed, sometimes crowded, often slightly projecting including covering cortex; peridium (11-)13-17(-20) $\mu \mathrm{m}$ $(n=40)$ thick at the base and sides, hyaline. Cortical layer $(15-) 17-27(-35) \mu \mathrm{m}(n=30)$ thick, mostly only present above the perithecia and their surroundings, a $t$. angularis of thin-walled, angular, globose or ellipsoidal cells (3-)4-7($9) \times(2-) 3-5 \mu \mathrm{m}(n=60)$ in face view and in vertical section, yellow to golden-brown, gradually lighter to subhyaline downwards. Hairs on mature stromata (7-)11-22(-29)× $(2.5-) 3-4(-4.5) \mu \mathrm{m}(n=20), 1-2$ celled, cylindrical, subhyaline to pale brown, smooth or verruculose, unevenly distributed on the stroma surface, sometimes mixed with undifferentiated hyphae. Subcortical tissue a dense $t$. intricata of hyaline thin-walled hyphae (2-)3-6(-7.5) $\mu \mathrm{m}$ $(n=30)$ wide. Subperithecial tissue a dense $t$. angularis of thick-walled refractive cells (3-)5-11(-15)×(3-)4-7(-9) $\mu \mathrm{m}$ $(n=30)$, stratified, i.e. interrupted by a denser, narrow, horizontal, hyaline hyphal layer; also at the base intermingled with thick-walled hyaline hyphae. Asci (80-)85103(-118) ×5.0-6.5(-8.0) $\mu \mathrm{m}$, stipe $(6-) 8-26(-40) \mu \mathrm{m}(n=$ $30)$; no croziers seen. Ascospores hyaline, verrucose or spinulose, warts to $0.5 \mu \mathrm{m}$ high and wide; cells dimorphic; distal cell (3.3-)3.5-4.5(-5.0)×(3.3-)3.5-4.3(-5.0) $\mu \mathrm{m}, 1 /$ w $0.9-1.1(-1.5)(n=30)$, globose to ellipsoidal; proximal cell $(3.5-) 4.0-5.5(-6.2) \times(2.5-) 3.0-3.8(-4.3) \mu \mathrm{m}, 1 / \mathrm{w}(1.1-) 1.2-$ $1.7(-2.3)(n=30)$, oblong or wedge-shaped, sometimes subglobose; at the septum often flattened.

Cultures and anamorph: optimal growth at $25^{\circ} \mathrm{C}$ on all media, poor growth at $30^{\circ} \mathrm{C}$; no growth at $35^{\circ} \mathrm{C}$.
On CMD after $72 \mathrm{~h} 11-13 \mathrm{~mm}$ at $15^{\circ} \mathrm{C}, 29-31 \mathrm{~mm}$ at $25^{\circ} \mathrm{C}, 2-5 \mathrm{~mm}$ at $30^{\circ} \mathrm{C}$; mycelium covering the plate after 1 week at $25^{\circ} \mathrm{C}$. Colony hyaline, thin, loose; margin irregularly wavy; mycelium cobweb-like, of thin hyphae with little variation in width and irregular orientation, not distinctly radial. Aerial hyphae inconspicuous, becoming fertile; more frequent on the distal margin, causing a long persistent white margin. Autolytic excretions and coilings absent or rare; autolytic excretions abundant at $30^{\circ} \mathrm{C}$. No diffusing pigment noted; odour indistinct. Chlamydospores rare, noted after 3-6 days. Conidiation noted after 1 days, abundant, effuse, on simple conidiophores spread in a lawn, on thick long aerial hyphae, and in short complex shrubs to $0.5 \mathrm{~mm}$ diam and height spreading from the centre across the entire colony, concentrated in finely powdery or granular, indistinct concentric or radial zones, after 3 days turning bluish green to grey-green from the proximal margin, 26-27DE4-6, finally dark green, 26F5-8, denser on lateral and distal margins, forming a continuous aggregate, and only few irregularly distributed individual shrubs growing to pustules $1-1.5 \mathrm{~mm}$ diam; soon dry, degenerating from the centre and proximal margin, with conidia adhering in chains, with new shrubs emerging at the same time. Conidiophores mostly symmetric, verticilliumto trichoderma-like, similarly in more simple solitary forms to $c a 180 \mu \mathrm{m}$ diam, often forked or branched close to the base, only scarcely re-branching into steep long branches, and in shrubs more richly, broader and more densely branched than solitary conidiophores. Shrubs consisting of a thick-walled $(1-2.5 \mu \mathrm{m})$ stipe $6-7 \mu \mathrm{m}$ wide, with several unpaired primary branches (=main axes) $5-6 \mu \mathrm{m}$ wide in right angles. Main axes typically forming long slender conidiophores with narrow side branches loosely disposed, paired or unpaired, long at lower levels, shorter with distance from the base, in right angles or more commonly slightly inclined upwards. Phialides solitary, often paired, or divergent in whorls of $2-5$, mostly 3 , on often widened cells $2-3 \mu \mathrm{m}$ wide. Conidia formed in minute dry heads. Phialides (5.5-)7-13(-18) $\times(2.3-) 2.5-3.2(-3.8) \mu \mathrm{m}, 1 /$ $\mathrm{w}(1.8-) 2.4-5(-7),(1.3-) 1.5-2.3(-2.8) \mu \mathrm{m}$ wide at the base $(n=65)$, lageniform, often subulate in the middle of the whorls, rarely ampulliform, straight or slightly curved, necks often narrow, long; widest point in variable positions. Conidia $(2.5-) 3.2-4.5(-5.5) \times(2.0-) 2.5-3.0(-3.2) \mu \mathrm{m}, 1 /$ $\mathrm{w}(1.0-) 1.2-1.7(-1.9)(n=30)$, yellowish green, ellipsoidal, oval or oblong, smooth, with several minute guttules; scar indistinct; often agglutinated in dense packets or chains. At $15^{\circ} \mathrm{C}$ conidiation similar to $25^{\circ} \mathrm{C}$ in shrubs arranged in several flat, powdery greenish concentric zones. At $30^{\circ} \mathrm{C}$ colony finely zonate, conidiation effuse, scant; autolytic excretions frequent, minute.

On PDA after $72 \mathrm{~h} 10-12 \mathrm{~mm}$ at $15^{\circ} \mathrm{C}, 27-30 \mathrm{~mm}$ at $25^{\circ} \mathrm{C}$, $2-3 \mathrm{~mm}$ at $30^{\circ} \mathrm{C}$; mycelium covering the plate after $7-8$ days 

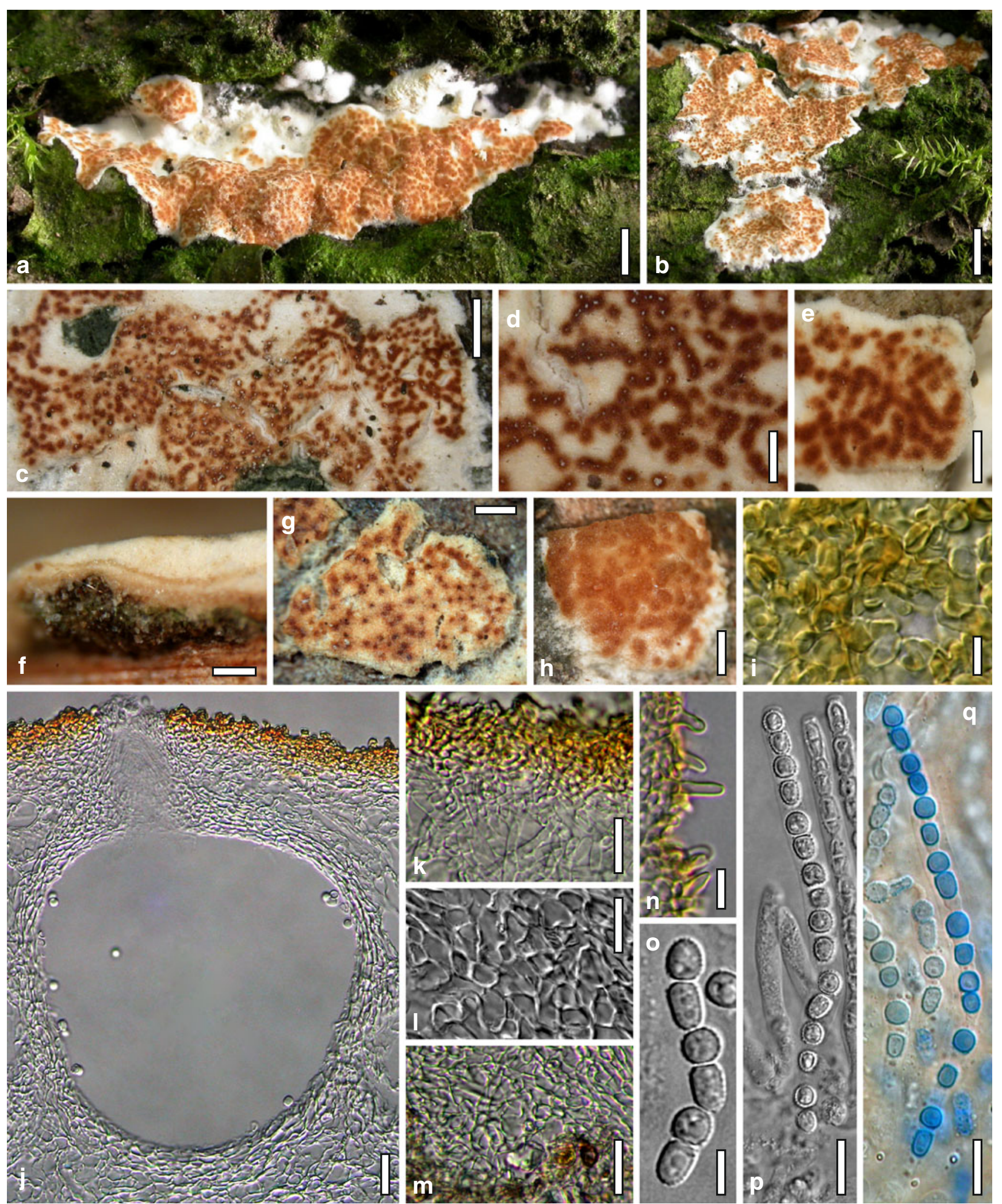

Fig. 12 Teleomorph of Hypocrea ochroleuca. a, b. Fresh stromata. c, d, f, g. Dry stromata (f. vertical section showing layered subperithecial tissue). e, h. Stromata in 3\% KOH after rehydration. i. Stroma surface in face view. j. Perithecium in section. k. Cortical and subcortical tissue in section. 1. Subperithecial tissue in section. $\mathbf{m}$. Stroma base in section. n. Hairs on the stroma surface. o. Ascospores. p, q. Asci with ascospores (q. in cotton blue/lactic acid). a-f, h-q. WU 29310. g. holotype K 56075 . Scale bars: $\mathbf{a}=1.5 \mathrm{~mm} . \mathbf{b}=2.5 \mathrm{~mm} . \mathbf{c}=1 \mathrm{~mm}$. d, e, $\mathbf{g}, \mathbf{h}=0.5 \mathrm{~mm} . \mathbf{f}=150 \mu \mathrm{m}$. $\mathbf{i}, \mathbf{o}=5 \mu \mathrm{m} . \mathbf{j}, \mathbf{k}, \mathbf{m}=20 \mu \mathrm{m}$. $\mathbf{l}, \mathbf{n}, \mathbf{p}, \mathbf{q}=$ $10 \mu \mathrm{m}$ 
at $25^{\circ} \mathrm{C}$. Colony circular, dense, hyphae thin except for wider marginal surface hyphae. Aerial hyphae frequent, mostly short and erect, becoming fertile; at the margin long, forming radial strands. Autolytic excretions frequent on surface hyphae within the colony, coilings moderate to frequent. No diffusing pigment noted; reverse pale yellowish, 3-4A3, to greenish due to translucent conidiation, dull yellowish brown, 4B4-5, 5C6-7, below mycelial aggregations. Odour indistinct or like fermenting fruits. Conidiation noted after 1 days, abundant, effuse, on short, mostly symmetric, verticillium- to trichoderma-like conidiophores as on CMD, also on aerial hyphae to $2 \mathrm{~mm}$ high, starting around the plug, spreading across the entire colony, eventually arranged in several broad, flat, indistinctly separated, concentric zones, with the distal margin long remaining white, cottony. Surface of the conidiation zones finely granular to floccose, after 2 days greyish green, 27DE4-7, 28D5-6, 27C4-5, after 10-14 conidiation also in some coarse mycelial spots or fluffy tufts; soon degenerating/collapsing from the centre. At $15^{\circ} \mathrm{C}$ conidiation similar, abundant. At $30^{\circ} \mathrm{C}$ growth poor, hyphae dying soon, autolytic excretions abundant, conidiation effuse, scant.

On SNA after $72 \mathrm{~h} 10-11 \mathrm{~mm}$ at $15^{\circ} \mathrm{C}, 25-27 \mathrm{~mm}$ at $25^{\circ} \mathrm{C}$, $2-3 \mathrm{~mm}$ at $30^{\circ} \mathrm{C}$; mycelium covering the plate after 1 week at $25^{\circ} \mathrm{C}$. Colony similar to $\mathrm{CMD}$ apart from thick marginal surface hyphae. Autolytic excretions and coilings common. No diffusing pigment noted; odour indistinct. Chlamydospores noted after 5-9 days, uncommon, irregularly distributed, after 22 days $(5-) 6-11(-16) \times(3-) 4-8(-11) \mu \mathrm{m}, 1 /$ $\mathrm{w}(1.0-) 1.1-1.7(-2.1)(n=20)$, terminal and intercalary, globose or angular, smooth. Conidiation noted after 1 days, effuse, starting around the plug, simple, verticillium-to trichoderma-like, short, to $2 \mathrm{~mm}$ high on aerial hyphae along the colony margin, and in loose shrubs to $0.5 \mathrm{~mm}$ diam with regularly symmetric trichoderma-like conidiophores, spreading across the entire colony, greyish green, 26-27E4-6, after 3-4 days, later to dark green to $26 \mathrm{~F} 5-8$, arranged in finely granular to powdery radial patches and eventually concentrated in distal areas of the colony, there also some small pustules to $1 \mathrm{~mm}$ diam formed. Conidia produced in minute dry heads, soon degenerating, adhering in chains or agglutinated in dense clumps, with a concomitant emergence of fresh shrubs. At $15^{\circ} \mathrm{C}$ conidiation in shrubs with looser branching than on $\mathrm{CMD}$, appearing as a green, 26-27E4-6, powder in fine concentric zones; autolytic excretions frequent. At $30^{\circ} \mathrm{C}$ growth poor, hyphae dying soon, autolytic excretions frequent, minute, conidiation effuse, scant.

Habitat: on bark, possibly associated with other fungi.

Distribution: Europe, North America.

Holotype: USA, South Carolina, unlocalised, on trunk of Myrica cerifera, partly soc. Hymenochaete sp. and a pyrenomycete in the bark, H.W. Ravenel 1382 (K 56075).

Other material examined: United Kingdom, North East London, Epping Forest, Strawberry Hill Ponds, MTB 43-34/ $1,51^{\circ} 39^{\prime} 01^{\prime \prime} \mathrm{N}, 00^{\circ} 02^{\prime} 34^{\prime \prime} \mathrm{E}$, elev. $30 \mathrm{~m}$, on corticated log of Betula pendula $17 \mathrm{~cm}$ thick, on bark, soc. Annulohypoxylon multiforme, holomorph, anamorph dark green, teleomorph largely immature; cultured from ascospores and conidia, 16 Sep. 2004, W. Jaklitsch \& H. Voglmayr, W.J. 2725 (WU 29310, culture CBS $119502=$ C.P.K. 1895).

Notes: Hypocrea ochroleuca was originally described from South Carolina, USA. The British collection agrees perfectly in teleomorph morphology with the holotype. However, due to the lack of any specimen collected recently in the USA, the British collection is only tentatively named $H$. ochroleuca. The material is therefore not used to epitypify the species, nor is the anamorph formally described as a new taxon. The situation is complicated by the Asian Hypocrea albofulva Berk. \& Broome (J. Linn. Soc., Bot. 14(2): 113 (1875)), which agrees morphologically with $H$. ochroleuca, apart from a slight difference in ascospore size (G.J. Samuels, pers. comm.). Several isolates of specimens collected in Thailand (G.J. Samuels, pers. comm.) differ in ITS sequences consistently in a single nucleotide from the British isolate, while tef1 and $r p b 2$ sequences deviate more distinctly. The strains G.J.S. 01-234 and G.J.S. 01-265, with gene sequences deposited in GenBank are assignable to $H$. albofulva rather than to H. ochroleuca. It is still possible that these species are conspecific, as Y. Doi annotated on the holotype of $H$. ochroleuca. Also the conidiophores, phialides and conidia illustrated by Doi (1972, p. 736) for a Japanese isolate of a fungus determined by him as $H$. albofulva agree well with the anamorph of the British isolate. However, proof of conspecificity requires fresh North American material.

Hypocrea ochroleuca is obviously rare in north temperate regions. It is a typical member of Trichoderma sect. Trichoderma except for the large effuse stromata. The conidiation in culture persists for a long time, because several new generations of shrubs develop after the collapse of older ones.

The holotype of Hypocrea ochroleuca consists of two pieces of bark with effuse stromata. Growth indeterminate, stromata widely effuse. Largest stroma $c a 46 \times 12 \mathrm{~mm}$, effluent, disintegrated into many smaller angular part stromata $(0.5-) 0.8-11.5(-25) \times 0.5-7(-12) \mathrm{mm}(n=17), 0.1-$ $0.2 \mathrm{~mm}$ thick, entirely attached when young, margin of white mycelium; in older stromata margin free or elevated, white mycelium between fertile patches and part stromata. Surface smooth to somewhat tubercular, velvety, with perithecia partly convex, solitary or in groups, gregarious in lawns. Ostiolar dots (30-)35-70(-95) $\mu \mathrm{m}(n=30)$ diam, plane or convex, reddish under strong magnification, shiny, distinct, with a circular perforation $10 \mu \mathrm{m}$ diam. Surface unevenly pigmented, whitish to yellowish and light to dull brown, 4A3(4), 5A3, 5B4, 5CD4-6 in fertile areas, lively orange-, reddish 

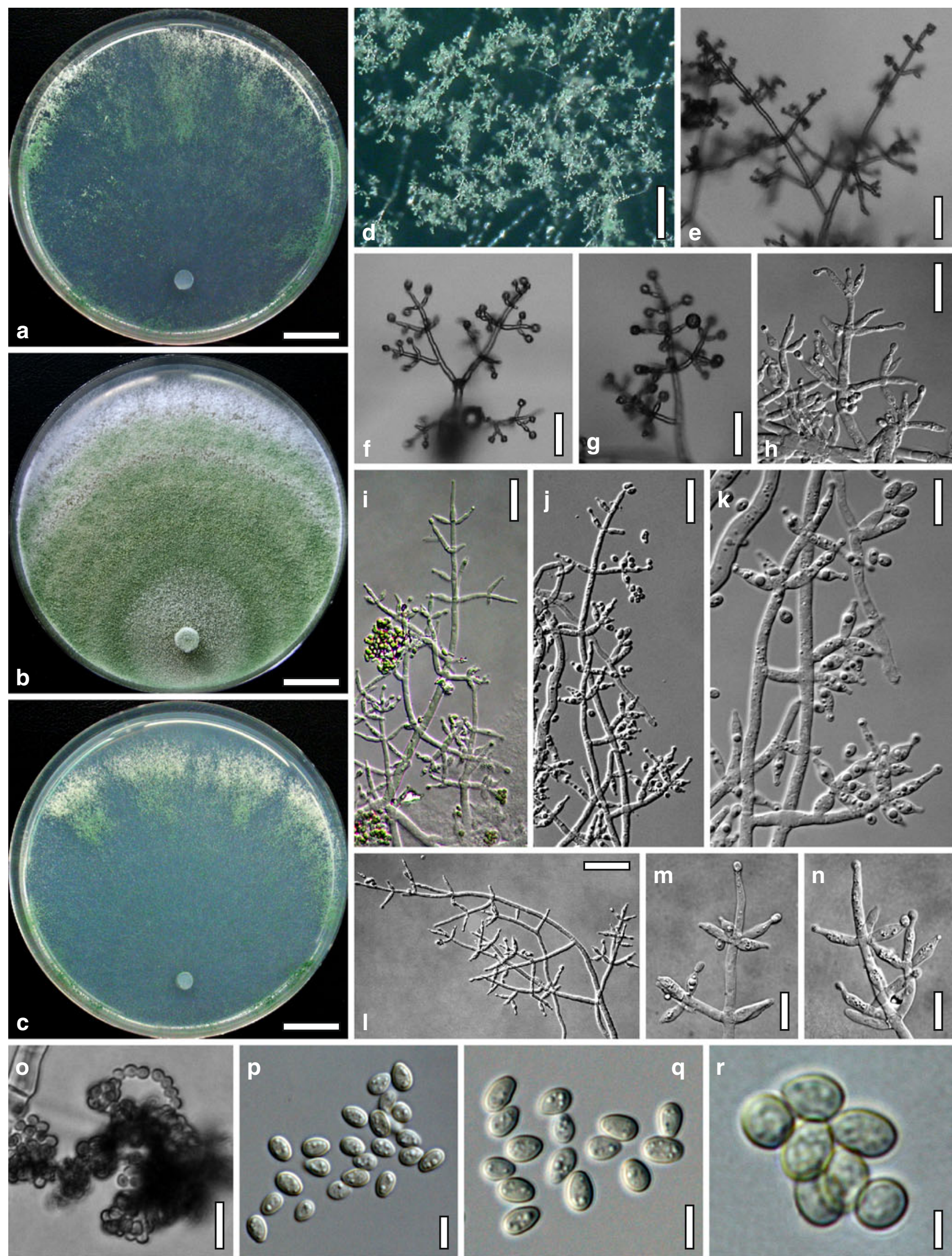
4 Fig. 13 Cultures and anamorph of Hypocrea ochroleuca (CBS 119502). a-c. Cultures after 7 days (a. on CMD; b. on PDA; c. on SNA). d. Conidiation shrubs (CMD, 4 days). e-g. Conidiophores on growth plates (4 days; e. CMD; f, g. SNA). h-l. Conidiophores (CMD, 4-7 days). $\mathbf{m}$, n. Phialides (CMD, 6 days). o. Conidia in chains and clumps (SNA, 22 days). p-r. Conidia (CMD, 4-5 days). a-r. All at $25^{\circ} \mathrm{C}$. Scale bars: $\mathbf{a}-\mathbf{c}=15 \mathrm{~mm} . \mathbf{d}=250 \mu \mathrm{m}$. e- $\mathbf{g}, \mathbf{l}=30 \mu \mathrm{m}$. $\mathbf{h}-\mathbf{j}=20 \mu \mathrm{m} . \mathbf{k}, \mathbf{m}-\mathbf{0}=10 \mu \mathrm{m} . \mathbf{p}, \mathbf{q}=5 \mu \mathrm{m} . \mathbf{r}=2 \mu \mathrm{m}$

brown. Stromata KOH-; with numerous short hyaline rounded hairs. No asci present. Ascospores verruculose with warts $0.5 \mu \mathrm{m}$ high or spinulose; presumed distal cell (sub)globose, $(3.5-) 4.0-4.7(-5.0) \times(3.2-) 3.5-4.3(-5) \mu \mathrm{m}, 1 / \mathrm{w} 1.0-1.2 \quad(n=$ $30)$; presumed proximal cell oblong, ellipsoidal or wedge-

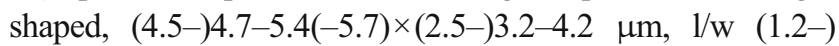
$1.3-1.6(-2)(n=30)$; many aberrant, to $7.5 \times 5-6.5 \mu \mathrm{m}$.

Hypocrea petersenii Samuels, Dodd \& Schroers, Stud. Mycol. 56: 122 (2006a). Fig. 14

Anamorph: Trichoderma petersenii Samuels, Dodd \& Schroers, Stud. Mycol. 56: 122 (2006a). Fig. 15

Stromata when fresh 1-3 mm diam, 0.5-1 mm thick, subeffuse or pulvinate, broadly attached; outline roundish; margin attached or free, often white; surface smooth; ostioles invisible. Colour first pale or yellow-, orange- to reddish brown, 7CD6-8, 6CD8, 6E6-8, soon distinctly dark brown, 7EF6-8, 8E6-8, 8F7, or darker.

Stromata when dry $(0.5-) 0.8-2(-3) \times(0.4-) 0.6-1.4(-2.0)$ $\mathrm{mm},(0.15-) 0.2-0.4(-0.5) \mathrm{mm}$ thick $(n=20)$; solitary, gregarious, rarely aggregated, subeffuse and effluent or discrete and pulvinate; surface slightly velutinous, smooth or coarsely tuberculate. Ostiolar dots typically absent, ostiolar openings (15-)20-30(-35) $\mu \mathrm{m}(n=15)$ when moistened, inconspicuous, slightly lighter than the stroma surface. Stroma initials light brown, with whitish margin, turning dark (reddish) brown, 7-8F4-8, to black when still immature; often with green anamorph floccules on and around immature stromata. Stromata after rehydration remaining dark brown, velutinous, not changing the colour in $3 \% \mathrm{KOH}$.

Stroma anatomy: Ostioles (60-)67-90(-102) $\mu \mathrm{m}$ long, plane or projecting to $15 \mu \mathrm{m},(17-) 20-35(-47) \mu \mathrm{m}$ wide at the apex $(n=20)$. Perithecia $(160-) 180-240(-260) \times(120-)$ 145-200(-230) $\mu \mathrm{m} \quad(n=20)$, globose or flask-shaped; peridium $(17-) 20-30(-34) \mu \mathrm{m}(n=20)$ thick at the base, $(11-) 15-22(-25) \mu \mathrm{m}(n=20)$ thick at the sides, hyaline, indistinctly separated from surrounding tissue, particularly at the base. Cortical layer (15-)17-28(-32) $\mu \mathrm{m} \quad(n=20)$ thick, a $t$. angularis of thick-walled, refractive cells (2-)3-6 $(-8) \times(2-) 3-5(-6) \mu \mathrm{m}(n=50)$ in face view and in vertical section, yellow-, orange- to reddish brown, lighter downwards, with inhomogeneously distributed pigment. Hairs on mature stromata $5-13(-18) \times 2-4 \mu \mathrm{m}(n=15)$, rare, cylindrical, straight or curved, 1-2 celled, brownish, smooth or verruculose; base sometimes thickened to $5 \mu \mathrm{m}$. Subcortical tissue a $t$. intricata of richly branched, short-celled, thinwalled, hyaline hyphae (2-)3-7(-9) $\mu \mathrm{m} \quad(n=50)$ wide, sometimes appearing pseudoparenchymatous depending on cutting angles. Subperithecial tissue a $t$. epidermoidea of variable, thin-walled, hyaline cells $(6-) 7-19(-30) \times(5-)$ 6-11(-13) $\mu \mathrm{m}(n=30)$, slightly smaller towards the base. Asci (76-)79-86(-90)×(4.8-)5.0-5.5(-6.0) $\mu \mathrm{m}$, stipe to $10 \mu \mathrm{m}$ long $(n=10)$. Ascospores hyaline, verruculose; cells dimorphic, distal cell (3.3-)3.7-4.5(-5.2) $\times(3.3-) 3.5-4.0(-$ 4.5) $\mu \mathrm{m}, 1 / \mathrm{w}(0.9-) 1.0-1.2(-1.3)(n=30)$, (sub-)globose or oval, proximal cell $(3.4-) 4.0-6.0(-6.7) \times(2.4-) 2.8-3.5(-$ 3.8) $\mu \mathrm{m}, 1 / \mathrm{w}(0.9-) 1.2-2.0(-2.8) \quad(n=30)$, oblong to cylindrical or subglobose.

Anamorph on the natural substrate typically bright green, floccose or effuse.

Cultures and anamorph: optimal growth at $25^{\circ} \mathrm{C}$ on all media, good growth at $30^{\circ} \mathrm{C}$; no growth at $35^{\circ} \mathrm{C}$.

On CMD after $72 \mathrm{~h} 17-19 \mathrm{~mm}$ at $15^{\circ} \mathrm{C}, 45-46 \mathrm{~mm}$ at $25^{\circ} \mathrm{C}$, $36-41 \mathrm{~mm}$ at $30^{\circ} \mathrm{C}$; mycelium covering the plate after 5 days at $25^{\circ} \mathrm{C}$. Colony hyaline, thin; margin often irregular to lobed; mycelium loose, with radial orientation. Aerial hyphae scant, short, more frequent and long along the colony margin. No autolytic activity noted, coilings not observed. No diffusing pigment, no distinct odour noted. Cultures of both isolates grown at $25^{\circ} \mathrm{C}$ developing a conspicuous and characteristic, deep yellow to orange-yellow colour, 1-2A3-4 to 4B5-8, upon subsequent storage for 3 week to 10 months at $15^{\circ} \mathrm{C}$. Chlamydospores noted after 4 -days at $25^{\circ} \mathrm{C}$, scant, nearly exclusively terminal in thin hyphae $2-4 \mu \mathrm{m}$ wide, $6-8 \times 5-$ $8 \mu \mathrm{m}, 1 / \mathrm{w} 1.0-1.2(-1.4)(n=15)$, globose, subglobose or pyriform, smooth. Conidiation noted after 2 days, green after 3-4 days, first at the proximal margin, in the centre and then in several, often incomplete, concentric rings, eventually dark green, 27E4-7; in dry shrubs growing to tufts or pustules to $1-1.5 \mathrm{~mm}$ diam with circular or irregular outline and fluffy or plumose surface; aggregates to $10 \mathrm{~mm}$ long. Pustules of a stipe to $c a 8 \mu \mathrm{m}$ wide, with thick outer wall swelling in $\mathrm{KOH}$, and with several wide, unpaired primary branches giving rise to a loose or dense reticulum. Conidiophores (main axes) radially emergent from the reticulum, tree-like, straight or slightly sinuous, with side branches arising along their length, mostly loosely disposed; rebranching or not; side and terminal branches longer from the tip down, in right angles on lower levels, inclined upwards, short and often paired at higher levels, often in whorls, often replaced by phialides on various levels. Phialides solitary or in whorls of $2-4$, arising on rarely thickened cells $2-3 \mu \mathrm{m}$ wide. Phialides $(6-) 7-11(-16) \times(2.3-) 2.5-3.3(-3.5) \mu \mathrm{m}, 1 / \mathrm{w}(1.8-) 2.0-4.2(-$ $6.7),(1.3-) 1.5-2.2(-2.5) \mu \mathrm{m}$ wide at the base $(n=30)$, lageniform or nearly cylindrical, less commonly ampulliform, straight, widest mostly above the middle. Conidia (2.8-)3.2$4.0(-4.3) \times(2.3-) 2.5-3.0(-3.8) \mu \mathrm{m}, 1 / \mathrm{w} \quad(1.0-) 1.1-1.3(-1.5)$ 

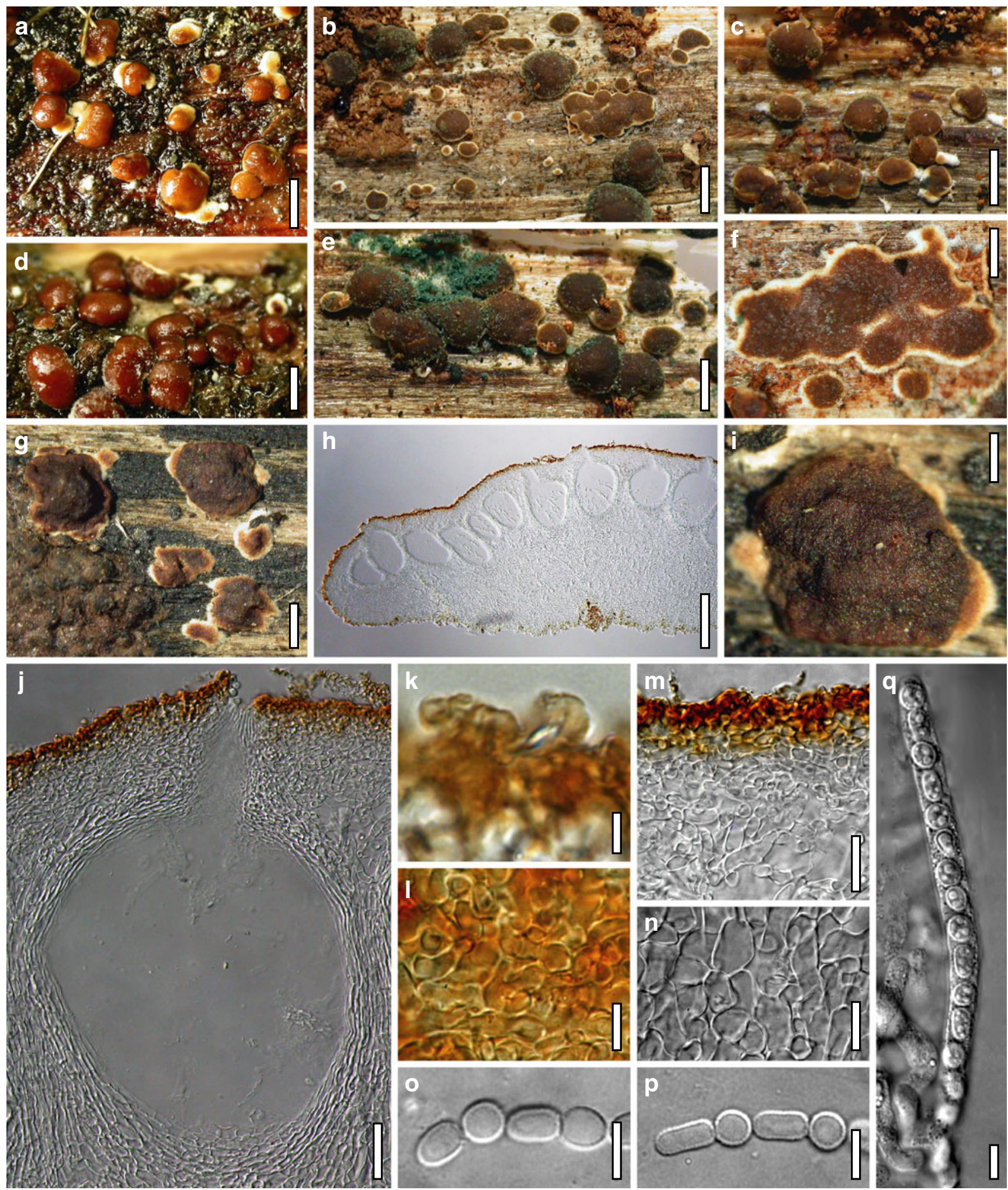

Fig. 14 Teleomorph of Hypocrea petersenii. a-e. Fresh stromata (most immature; a, d. wet; e. showing also the anamorph). f, g, i. Dry stromata (f. early subeffuse stage). h. Part of stroma in section. $\mathbf{j}$. Perithecium in section. k. Curved hairs. $\mathbf{l}$. Cortex in face view. $\mathbf{m}$. Cortical and subcortical tissue in section. $\mathbf{n}$. Subperithecial tissue in section. o, p. Ascospores. q. Ascus. a, d. WU 29398. b, c, e, f. WU 29397. g-q. WU 29396. Scale bars: a, $\mathbf{c}-\mathbf{e}=1.3 \mathrm{~mm}$. $\mathbf{b}=2 \mathrm{~mm} . \mathbf{f}, \mathbf{g}=$ $0.7 \mathrm{~mm} . \mathbf{h}=0.2 \mathrm{~mm}$. $\mathbf{i}=0.3 \mathrm{~mm} . \mathbf{j}=30 \mu \mathrm{m} . \mathbf{k}, \mathbf{l}, \mathbf{o}-\mathbf{q}=5 \mu \mathrm{m} . \mathbf{m}, \mathbf{n}=$ $15 \mu \mathrm{m}$ 

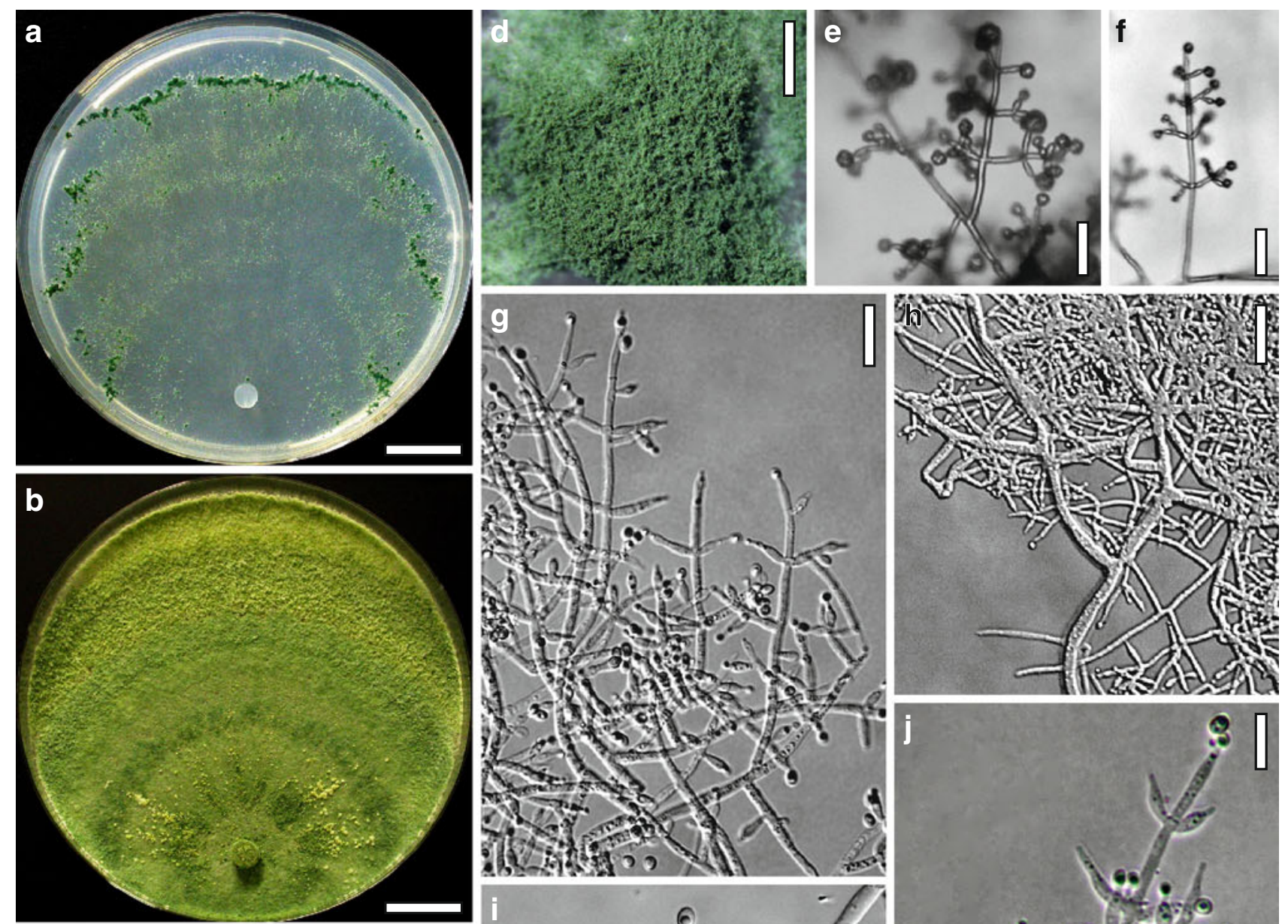

raskgurapors
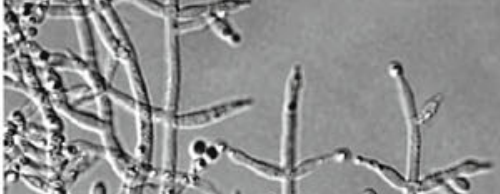

$x^{2}-2,4$

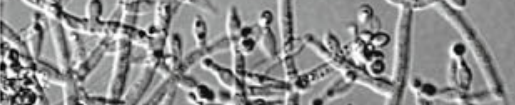

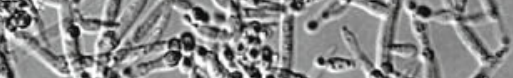
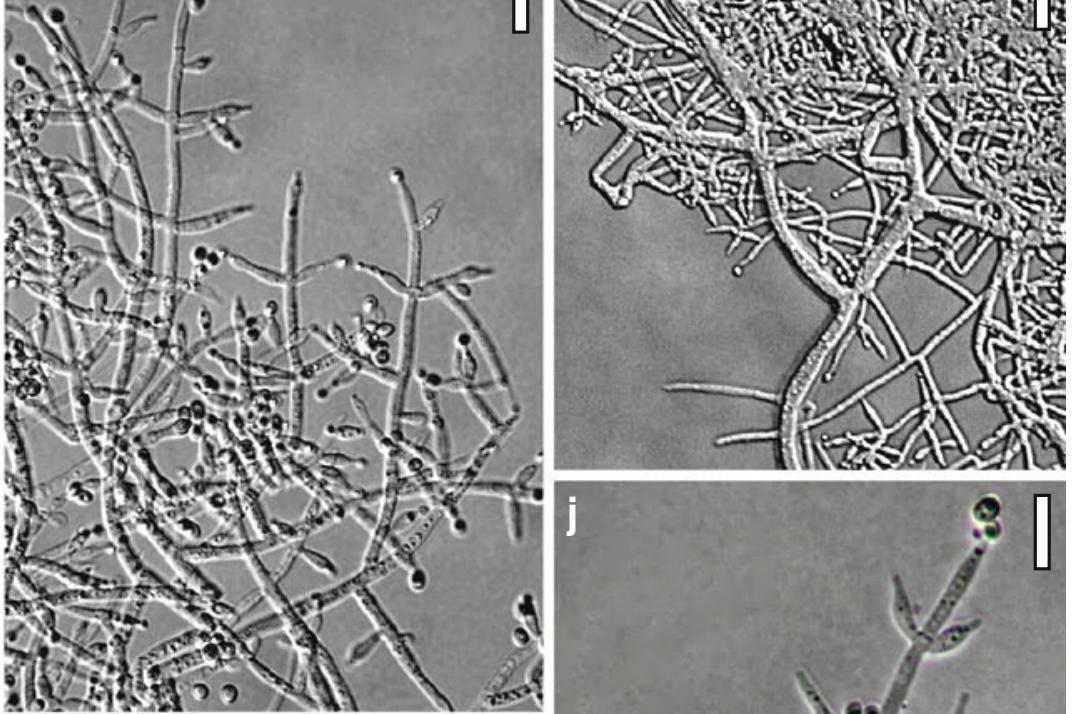

j
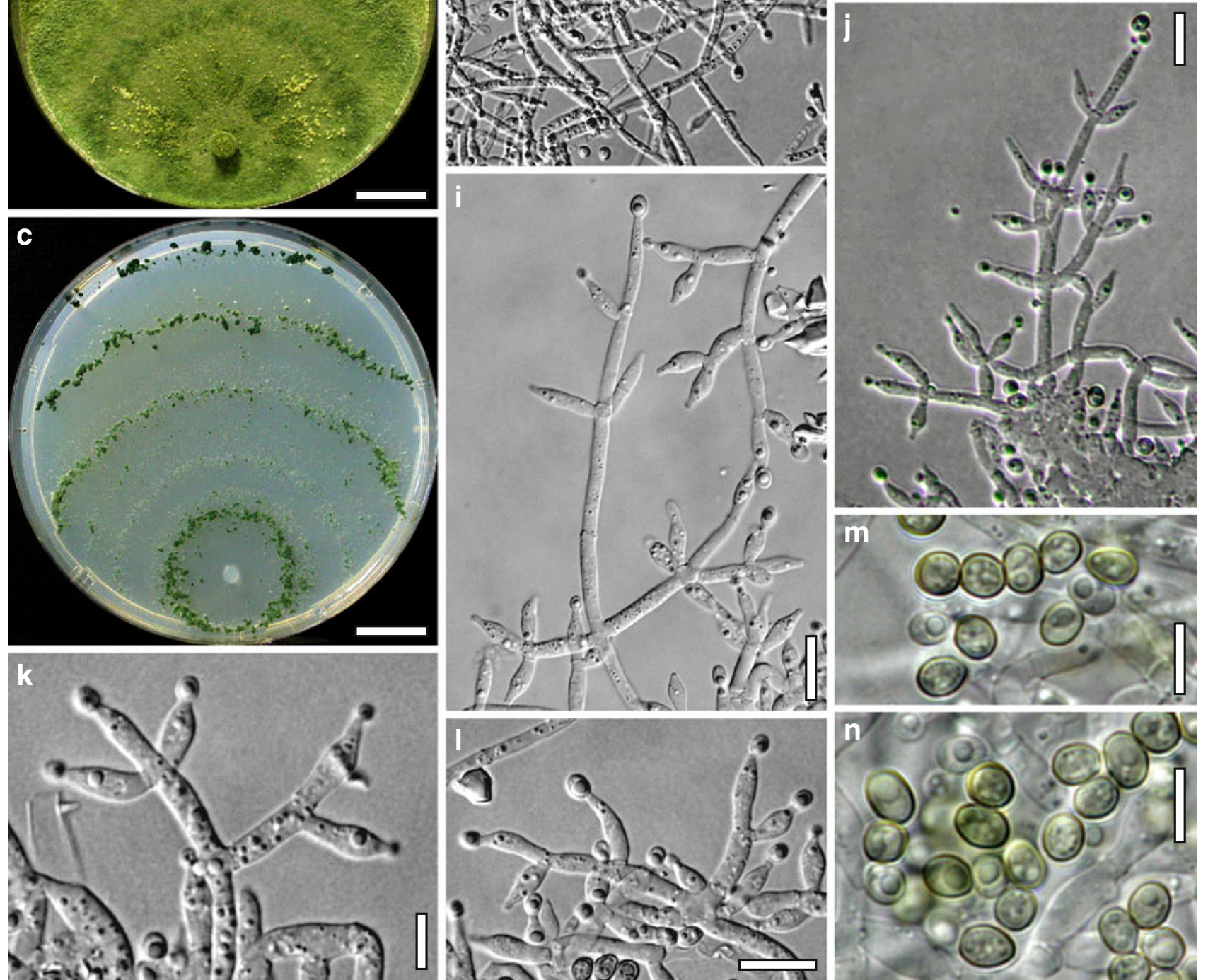
4Fig. 15 Cultures and anamorph of Hypocrea petersenii (CBS 119507). a-c. Cultures after 7 days (a. on CMD, b. on PDA, c. on SNA). d. Conidiation tuft (12 days). e, f. Conidiophores on growth plates (3 days; e. on SNA). g. Conidiophores on tuft margin. $\mathbf{h}$. Stipe and primary branches of conidiation tuft. $\mathbf{i}, \mathbf{j}$. Conidiophores. $\mathbf{k}, \mathbf{l}$. Phialides. $\mathbf{m}, \mathbf{n}$. Conidia. a-n. At $25^{\circ} \mathrm{C}$. d-n. On CMD except e. g-n. After 5-6 days. Scale bars: $\mathbf{a}-\mathbf{c}=15 \mathrm{~mm}$. $\mathbf{d}=0.3 \mathrm{~mm}$. e, $\mathbf{f}=30 \mu \mathrm{m}$. $\mathbf{g}, \mathbf{h}=20 \mu \mathrm{m} . \mathbf{i}, \mathbf{j}, \mathbf{l}=10 \mu \mathrm{m} . \mathbf{k}, \mathbf{m}, \mathbf{n}=5 \mu \mathrm{m}$

( $n=62$ ), broadly ellipsoidal or oval, green, smooth, finely multiguttulate; scar indistinct. At $15^{\circ} \mathrm{C}$ colony not or faintly zonate; conidiation in numerous tufts or pustules $0.7-2 \mathrm{~mm}$ diam mostly in a broad marginal zone, greenish after 78 days, green, 26DE5-6, 26F6, after 14 days. At $30^{\circ} \mathrm{C}$ little mycelium on the surface; conidiation on aerial hyphae and in irregular pustules to $2 \mathrm{~mm}$ long, arranged in several incomplete concentric zones, greenish after 4 days, turning dark green.

On PDA after $72 \mathrm{~h} 14-16 \mathrm{~mm}$ at $15^{\circ} \mathrm{C}, 39-42 \mathrm{~mm}$ at $25^{\circ} \mathrm{C}$, $35-38 \mathrm{~mm}$ at $30^{\circ} \mathrm{C}$; mycelium covering the plate after 5 days at $25^{\circ} \mathrm{C}$. Colony circular, compact, dense, aerial hyphae frequent, particularly at the distal margin. Autolytic activity low to moderate, coilings inconspicuous. No diffusing pigment produced; reverse greenish yellow, 1CD6-8, due to translucent conidiation. Odour indistinct. Conidiation noted after 1-2 days, in densely aggregated erect shrubs with regular trees, dense, thick, white, in 2-4 concentric zones, also in tufts 0.5-1 mm diam spreading from the centre; green, 29CD5-6, from the proximal margin and centre after 3 days, zones with varying tones of yellow-green or green. At $15^{\circ} \mathrm{C}$ colony centre yellow 2A2-3 after 6 days; conidiation seen after 3 days, distinctly decreased, in shrubs and on aerial hyphae, white, fluffy, thick, in several zones, greenish after 7-9 days, green, 27D4-6, in the centre after 14 days. At $30^{\circ} \mathrm{C}$ colony circular, shiny; hyphae thick; autolytic activity increased to conspicuous, surface white, downy. Conidiation after 2 days in the central zone, effuse, abundant, thick, dense, white, later forming several bright (yellow-)green zones, eventually dark green.

On SNA after $72 \mathrm{~h} 16-17 \mathrm{~mm}$ at $15^{\circ} \mathrm{C}, 39-41 \mathrm{~mm}$ at $25^{\circ} \mathrm{C}, 30-35 \mathrm{~mm}$ at $30^{\circ} \mathrm{C}$; mycelium covering the plate after 5-6 days at $25^{\circ} \mathrm{C}$. Colony similar to $\mathrm{CMD}$, but with more aerial hyphae, hyphae thick. Autolytic activity absent to moderate, coilings inconspicuous. No diffusing pigment, no distinct odour noted. Chlamydospores noted after $13-14$ days at $25^{\circ} \mathrm{C}$, uncommon. Conidiation noted after 2 days, green after 3 days, in steep erect shrubs and fluffy tufts, less on aerial hyphae; starting at the proximal margin, later in up to eight concentric zones of thick pustules $0.4-1.5 \mathrm{~mm}$ diam, aggregating to $7 \times 2.5 \mathrm{~mm}$, some pustules also between the zones, pustules turning green from inside. At $15^{\circ} \mathrm{C}$ pustules to $2 \mathrm{~mm}$ diam, aggregating to $7 \times 3.5 \mathrm{~mm}$, formed in several incomplete concentric zones, fluffy, green after 7 days from the proximal margin, dark green, 27E4-6, after 14 days. At $30^{\circ} \mathrm{C}$ colony with a broad white downy marginal zone; reverse yellow-green, 3BC5-6, after 7 days. Conidiation seen after 2 days, effuse on irregularly disposed aerial hyphae, and after 3 days in thick tufts or pustules to $3.5 \times$ $2.5 \mathrm{~mm}$ in several concentric zones, green after 3 days.

Habitat: on medium-decayed wood and bark of deciduous trees.

Distribution: North America (common in the East), Europe (uncommon).

Holotype: USA, Tennessee, Great Smoky Mts. National Park, vic. Cosby, Maddron Bald Track, $35^{\circ} 46^{\prime} \mathrm{N}, 83^{\circ} 16^{\prime} \mathrm{W}$, elev. 500 m, 12 July 2004, on decorticated wood (?Tsuga), G.J. Samuels (BPI 864092A; holotype of T. petersenii dry culture BPI 864092B; ex-type culture G.J.S. 04-355=CBS 119051; not examined).

Material examined: Austria, Kärnten, Klagenfurt Land, St. Margareten im Rosental, Drau-Auen, path south from the road to Dullach, MTB 9452/1, 46 32'51" N, 14²4'32" E, elev. $410 \mathrm{~m}$, on branch of Salix caprea $3 \mathrm{~cm}$ thick, on wood, on/soc. Hypoxylon perforatum/Immotthia atrograna, soc. Ionomidotis fulvotingens, holomorph, teleomorph largely immature, 6 Sep. 2003, W. Jaklitsch, W.J. 2386 (WU 29396, culture CBS 119507=C.P.K. 953). Germany, Bavaria, Landkreis Traunstein, Grabenstätt, south from Winkl and the A8, MTB 8141/3, 47 $48^{\prime} 50^{\prime \prime} \mathrm{N}, 12^{\circ} 31^{\prime} 05^{\prime \prime}$ E, elev. $530 \mathrm{~m}$, on partly decorticated log of Alnus glutinosa $9 \mathrm{~cm}$ thick, on wood, soc. Inonotus radiatus, holomorph, teleomorph immature, culture from conidia, 4 Sep. 2005, W. Jaklitsch, H. Voglmayr \& W. Klofac, W.J. 2841 (WU 29397, culture C.P.K. 2413). Hessen, Landkreis Fulda, Rhön, Rotes Moor, between Gersfeld and Wüstensachsen, from the parking place Moordorf at the B 278 heading to the peat bog, $50^{\circ} 27^{\prime} 35^{\prime \prime} \mathrm{N}, 09^{\circ} 58^{\prime} 59^{\prime \prime} \mathrm{E}$, elev. $810 \mathrm{~m}$, on branch of Salix sp. 1-3 cm thick, mostly on bark, attacked by a white hyphomycete, soc. Xylaria hypoxylon and moss, immature, 29 Aug. 2006, H. Voglmayr \& W. Jaklitsch, W.J. 2957 (WU 29398).

Notes: Hypocrea petersenii is uncommon if not rare in Europe and has been only found in wet habitats like riverine forests preferring species of Salix and Alnus, although it occurs commonly and sympatrically with $H$. rogersonii in diverse habitats on various trees in the Eastern USA (G.J. Samuels, pers. comm.). In Europe, H. rogersonii is found in beech forests. Hypocrea petersenii shares dark brown stromata with $H$. neorufa, $H$. neorufoides and $H$. subeffusa. The first two species can be distinguished from $H$. petersenii by yellow perithecial walls and pachybasium-like anamorphs, while $H$. subeffusa does not form distinctly pulvinate stromata, has more violet colour tones, and differs also in culture and anamorph characteristics like characteristic coilings, slower growth and lack of concentric zones of distinct conidiation tufts. Both Central European isolates of $H$. petersenii 
produced a characteristic, intense yellow colour on CMD not seen in any other species upon prolonged storage at $15^{\circ} \mathrm{C}$.

Hypocrea rogersonii Samuels, Stud. Mycol. 56: 125 (2006a). Fig. 16

Anamorph: Trichoderma rogersonii Samuels, Stud. Mycol. 56: 125 (2006a). Fig. 17

Stromata when fresh $1-8(-20) \mathrm{mm}$ long, to $c a 1 \mathrm{~mm}$ thick, solitary, gregarious or aggregated, generally in small numbers, thinly effuse, discoid or pulvinate; outline variable. Margin often white when young, first attached, cottony, later concolorous, free, sometimes irregularly crenate. Stroma surface velutinous, smooth or tubercular, typically without ostiolar dots; ostioles invisible or appearing as minute, inconspicuous light dots under high magnification. Perithecia entirely immersed, sometimes translucent as dark, indistinct, diffuse dots. Stromata first white, then yellow, ochre, orange to orange-brown with brown or rust hairs, 6B6-7, 6C7-8, 7CD6-8, 8CD5-6; white, sometimes yellowish inside. Spore deposits white.

Stromata when dry $0.5-4(-20) \times 0.4-2(-4) \mathrm{mm}, 0.15-0.3$ $(-0.4) \mathrm{mm}(n=30)$ thick, thinly effuse, discoid or flat pulvinate; outline variable, mostly oblong, angular or lobed; broadly attached. Margin first white or yellowish, cottony, attached, becoming free. Surface smooth, tubercular or wrinkled, velvety or hairy. Ostioles typically invisible, under high magnifications appearing as light or concolorous dots, sometimes slightly projecting to semiglobose; sometimes dark dots (23-)30-54(-63) $\mu \mathrm{m}(n=30)$ diam visible. Colour when young pale orange with white margin, turning yellow-brown, orange-brown to medium brown $5 \mathrm{CD} 6-8,6 \mathrm{CD} 7-8,6 \mathrm{E} 6-8$, finally dark orangebrown to reddish brown, dark brown 7-8CF6-8. Spore deposits white. Mature stromata slightly thicker upon rehydration; not changing or turning reversibly slightly darker reddish brown in $3 \% \mathrm{KOH}$.

Stroma anatomy: Ostioles (52-)63-93(-102) $\mu \mathrm{m}$ long, plane or projecting to $25(-32) \mu \mathrm{m},(30-) 40-60(-65) \mu \mathrm{m}$ wide at the apex $(n=20)$, with an apical palisade of hyaline, narrowly clavate cells. Perithecia (210-)225-265(-270) $\times$ $(150-) 170-230(-250) \mu \mathrm{m}(n=20)$, globose or ellipsoidal; peridium $(17-) 21-27 \mu \mathrm{m}(n=20)$ thick at the base, $(10-)$ 13-20 $(-23) \mu \mathrm{m}(n=20)$ thick at the sides, hyaline. Cortical layer (17-)20-32(-47) $\mu \mathrm{m}(n=30)$ thick, an orange $t$. angularis of small thick-walled angular, globose or oblong cells $(2.5-) 4.0-8.0(-9.5) \times(2.2-) 3.0-5.5(-6.5) \mu \mathrm{m}(n=30)$ in face view and in vertical section; surface uneven due to projecting groups of cells. Hairs on mature stromata frequent, $(7-) 12-26(-32) \times(2-) 3-5(-6) \mu \mathrm{m} \quad(n=20), 2-5$ celled, sometimes originating at the base of the cortical layer, then up to 10 -celled and to $40 \times 6 \mu \mathrm{m}$ including cells within the cortex, light brownish, cylindrical or with widened base, smooth or tubercular, with broadly rounded or truncate apex. Subcortical tissue a loose $t$. intricata of short-celled, thin-walled, hyaline hyphae $(2-) 3-5(-6) \mu \mathrm{m}$ $(n=20)$ wide. Subperithecial tissue a dense homogenous $t$. epidermoidea of variably shaped cells (4-)6-23(-44) $\times(3-)$ $5-12(-15) \mu \mathrm{m}(n=30)$, at the base sometimes intermingled with few narrow hyphae. Asci $(70-) 82-100(-117) \times(4.5-)$ 5.0-6.0(-6.5) $\mu \mathrm{m}$, stipe (3-)6-15(-28) $\mu \mathrm{m}$ long $(n=45)$, ascospores often oblique; no croziers apparent. Ascospores hyaline, verruculose, cells dimorphic, distal cell (3.5-)3.8$4.5(-5.5) \times(3.2-) 3.5-4.3(-5.5) \mu \mathrm{m}, 1 / \mathrm{w}(0.9-) 1.0-1.2(-1.4)$ $(n=70)$, subglobose to nearly wedge-shaped, proximal cell $(3.3-) 4.2-6.0(-7.2) \times(2.7-) 3.0-3.7(-4.7) \mu \mathrm{m}, 1 / \mathrm{w} \quad(1.1-)$ $1.3-1.8(-2.4)(n=70)$, oblong or subglobose; both cells showing light dots in cotton blue in contact areas.

Cultures and anamorph: optimal growth at $25-30^{\circ} \mathrm{C}$ on $\mathrm{CMD}$ and PDA, at $25^{\circ} \mathrm{C}$ on SNA; no growth at $35^{\circ} \mathrm{C}$.

On CMD after $72 \mathrm{~h} 16-19 \mathrm{~mm}$ at $15^{\circ} \mathrm{C}, 38-43 \mathrm{~mm}$ at $25^{\circ} \mathrm{C}, 36-42 \mathrm{~mm}$ at $30^{\circ} \mathrm{C}$; mycelium covering the plate after 5-7 days at $25^{\circ} \mathrm{C}$. Colony thin, hyaline, dense, homogeneous, not zonate; margin ill-defined, diffuse. Hyphae thin, finely reticulate, curly, i.e. without distinct radial arrangement. Aerial hyphae only frequent in a broad distal zone, causing a downy surface, becoming fertile. Minute green tufts appearing in 1-2(-4) indistinct concentric zones, typically concentrated at the distal margin. Autolytic activity and coilings absent or inconspicuous. Agar colourless to faintly yellowish, 3A3-3B4 after 1 or 2 week; no distinct odour noted. Chlamydospores noted after $4-6$ days at 15 and $30^{\circ} \mathrm{C}$. Conidiation noted after 12 days, effuse, verticillium-like, on simple erect conidiophores to $c a 100 \mu \mathrm{m}$ long arising from surface and aerial hyphae and in minute loose shrubs or tufts $0.1-0.6(-1) \mathrm{mm}$ diam of irregular outline, mostly at the distal and proximal margins; green after 4 days, with conidia packed in minute wet to mostly dry heads of $<20 \mu \mathrm{m}$ diam. Shrubs/tufts arising on thick, sometimes submoniliform stipes to $c a$ $15 \mu \mathrm{m}$ thick, with wide primary branches, attenuated upwards along a short distance, sparsely branched in right angles, bearing few short tree-like main axes with phialides at the top and branches progressively longer with distance from the top, once rebranching into mostly paired side branches, in right angles or slightly inclined upwards. Phialides arising solitary or in whorls of 2-4 on cells often slightly inflated and $c a 2-4(-5.5) \mu \mathrm{m}$ wide. Phialides (4.5-) $6.7-11.0(-14.0) \times(2.3-) 2.5-3.0(-3.5) \mu \mathrm{m}, 1 / \mathrm{w}(1.4-) 2.2-4$ $(-5),(1.5-) 2.0-2.5(-2.7) \mu \mathrm{m}$ wide at the base $(n=30)$, lageniform, conical, to nearly ampulliform, straight, inaequilateral or slightly curved upwards, widest in or below the middle, neck variable. Conidia (3.7-) 4.0-4.7(-5.3) $\times$ $(2.5-) 3.0-3.5(-3.7) \mu \mathrm{m}, 1 / \mathrm{w}(1.2-) 1.3-1.5(-1.6) \quad(n=30)$, ellipsoidal to oval, green, smooth, finely multiguttulate, scar rarely distinct. At $15^{\circ} \mathrm{C}$ up to 6 indistinct concentric 

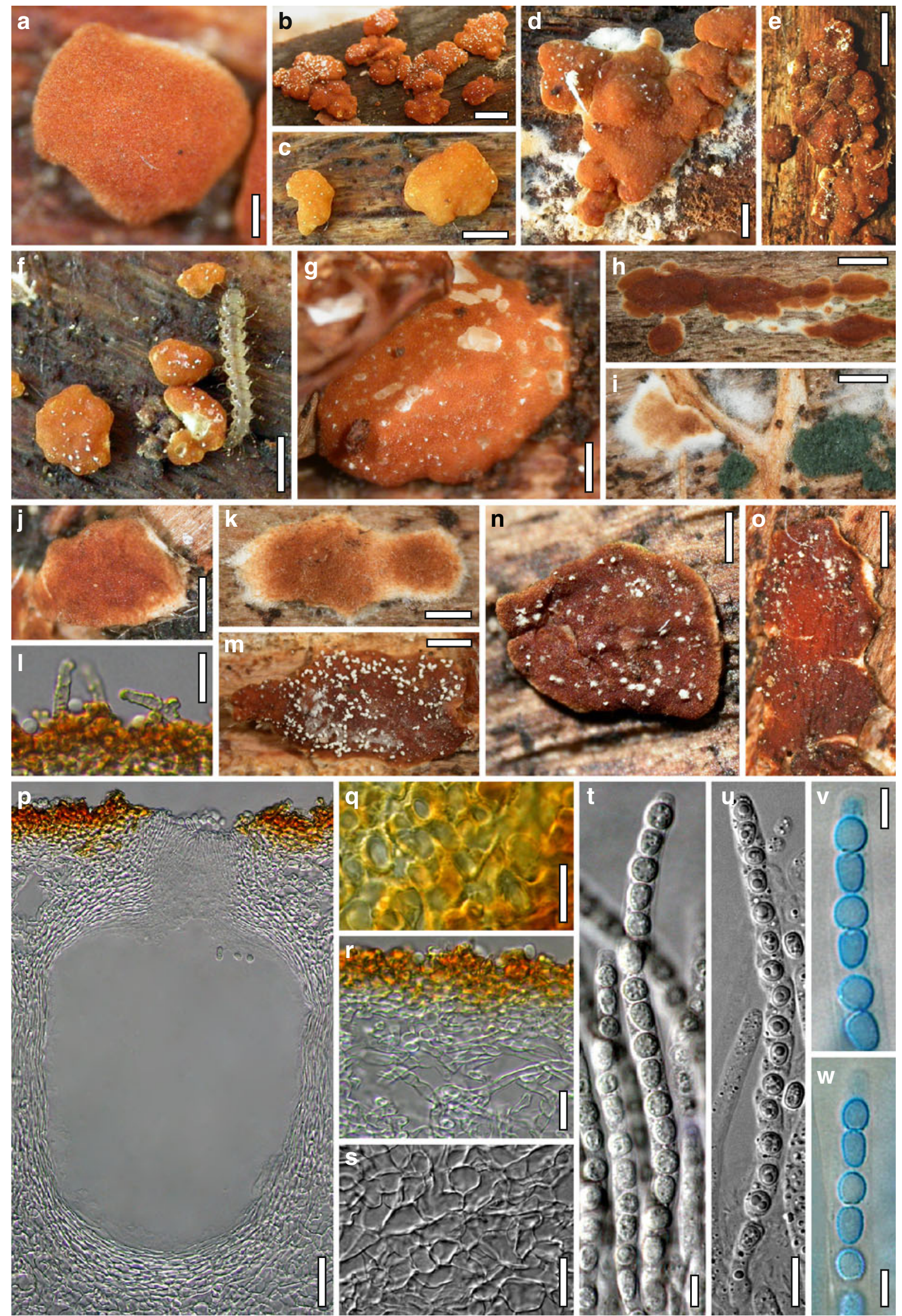
4Fig. 16 Teleomorph of Hypocrea rogersonii. a-g. Fresh stromata (a. immature; f, g. eaten by insect larvae). $\mathbf{h}-\mathbf{k}, \mathbf{m}-\mathbf{o}$. Dry stromata (h-k. immature; i. stroma initial with anamorph). 1. Hairs on stroma surface. p. Perithecium in section. q. Stroma surface in face view. r. Cortical and subcortical tissue in section. s. Subperithecial tissue in section. t, u. Asci with ascospores. v, w. Ascospores in cotton blue/lactic acid. a, g. WU 29451. b, e, h. WU 29450. c, f, k, l, p-t, v, w. WU 29448. d. WU 29447. i, j. WU 29449. m, o. WU 29446. n. WU 29453. u. WU 29456. Scale bars: $\mathbf{a}=0.2 \mathrm{~mm} . \mathbf{b}, \mathbf{e}=2 \mathrm{~mm}$. c, d, f, i, m, $\mathbf{o}=0.8 \mathrm{~mm} . \mathbf{g}$, $\mathbf{j}, \mathbf{k}, \mathbf{n}=0.4 \mathrm{~mm} . \mathbf{h}=1.5 \mathrm{~mm} . \mathbf{l}, \mathbf{r}, \mathbf{s}=15 \mu \mathrm{m} . \mathbf{p}=30 \mu \mathrm{m} . \mathbf{q}, \mathbf{u}=10 \mu \mathrm{m} . \mathbf{t}$, $\mathbf{v}, \mathbf{w}=5 \mu \mathrm{m}$

zones formed; conidiation in distinct, green 26E4-6 to 26F7-8 tufts at the distal and lateral margins after 10 days, more abundant than at $25^{\circ} \mathrm{C}$. At $30^{\circ} \mathrm{C}$ conidiation effuse, macroscopically invisible.

On PDA after $72 \mathrm{~h} 14-16 \mathrm{~mm}$ at $15^{\circ} \mathrm{C}, 39-43 \mathrm{~mm}$ at $25^{\circ} \mathrm{C}$, $37-38 \mathrm{~mm}$ at $30^{\circ} \mathrm{C}$; mycelium covering the plate after 5 7 days at $25^{\circ} \mathrm{C}$. On PDA hyphae without distinct radial arrangement; colony dense; margin ill-defined, diffuse; centre flat, with moniliform surface hyphae; residual part covered by a loose mat of long white aerial hyphae to $7 \mathrm{~mm}$ high, radially arranged towards the distal margin, particularly in up to four ill-defined concentric zones, becoming agglutinated in strands, bearing many coilings and guttules. Autolytic excretions frequent at all temperatures; coilings frequent at $25^{\circ} \mathrm{C}$. Reverse becoming diffusely yellow, 3A3, 3-4B 4, 3C45. Odour indistinct. Conidiation noted after 1 days, dry, on numerous short, verticillium-like conidiophores on long aerial hyphae ascending several $\mathrm{mm}$ high, and on compact short basal tree-like conidiophores, concentrated in the concentric zones, green $27 \mathrm{CD} 3-5$ after 7 days. At $15^{\circ} \mathrm{C}$ development slower; at $30^{\circ} \mathrm{C}$ colony conspicuously dense, thick, whitish, up to five downy to floccose zones of irregular outline; conidiation green only under the stereo-microscope.

On SNA after $72 \mathrm{~h} 14-18 \mathrm{~mm}$ at $15^{\circ} \mathrm{C}, 33-41 \mathrm{~mm}$ at $25^{\circ} \mathrm{C}$, $17-34 \mathrm{~mm}$ at $30^{\circ} \mathrm{C}$; mycelium covering the plate after 5 7 days at $25^{\circ} \mathrm{C}$. Colony thin, hyaline, homogeneous, of irregularly oriented secondary hyphae forming a delicate reticulum between thick curved primary hyphae. Margin illdefined, diffuse. Surface becoming downy, particularly in distal regions due to long aerial hyphae several $\mathrm{mm}$ high. Autolytic excretions frequent at all temperatures; coilings inconspicuous at $25^{\circ} \mathrm{C}$, frequent at 15 and $30^{\circ} \mathrm{C}$. No diffusing pigment formed, no odour noted. Surface mycelium degenerating and disappearing after 6-7 days. Chlamydospores scant at $25^{\circ} \mathrm{C}$, more frequent after $4-6$ days at $30^{\circ} \mathrm{C},(5-) 6-10$ $(-12) \times(4.5-) 5-8(-11) \mu \mathrm{m}, 1 / \mathrm{w} 1.0-1.4(-1.8)(n=30)$, loosely disposed across the entire plate, terminal and intercalary, globose, pyriform, or ellipsoidal. Conidiation noted after 12 days, green after 4-5 days, eventually 26-27F6-8, effuse, verticillium-like, on aerial hyphae in up to $4(-5)$ indistinctly separated, downy concentric zones, and dry and regularly tree-like in tufts eventually compacted to dense pustules of $0.5-3 \mathrm{~mm}$ diam, aggregating to $12 \mathrm{~mm}$ length, in concentric zones or irregularly distributed on the plate. Conidia formed in numerous wet heads growing to $60(-90) \mu \mathrm{m}$ diam. At $15^{\circ}$ $\mathrm{C}$ conidiation in irregular, loose green 26DE4-5 tufts to $6 \mathrm{~mm}$ long. At $30^{\circ} \mathrm{C}$ growth slower than on CMD and PDA; margin with irregular outgrowths; conidiation effuse, powdery or finely granular.

Habitat: on wood and bark of deciduous trees, in Central Europe chiefly on Fagus.

Distribution: Central Europe (Austria), Eastern North America.

Holotype: USA, Tennessee, Great Smoky Mts. National Park, vic. Cosby, Albright Trail, on decorticated wood, July 2005, B.E. Overton 04-04 (BPI 870964A; holotype of anamorph BPI 870964B; ex-type culture G.J.S. 04-158= CBS 119233; not examined).

Specimens examined: Austria, Kärnten, Klagenfurt Land, Obermieger, Sabuatach, MTB 9452/2, 46 $35^{\prime} 22^{\prime \prime}$ N, $14^{\circ} 27^{\prime} 03^{\prime \prime}$ E, elev. $650 \mathrm{~m}$, at forest edge, on twigs of Corylus avellana $2-4 \mathrm{~cm}$ thick, on inner bark, soc. Bisporella citrina, 14 Oct. 2006, W. Jaklitsch, W.J. 3020 (WU 29454, culture C.P.K. 2488). St. Margareten im Rosental, Sabosach, MTB 9452/3, 46 $32^{\prime} 23^{\prime \prime}$ N, 14 ${ }^{\circ} 24^{\prime}$ $40^{\prime \prime}$ E, elev. $550 \mathrm{~m}$, on decorticated branches of Fagus sylvatica 1-2.5 cm thick, on wood, soc. Exidia truncata, old Neodasyscypha cerina; pulvinate, light bluish green anamorph, 25 Oct. 2004, W. Jaklitsch, W.J. 2783 (WU 29448, culture CBS $119503=$ C.P.K. 1994). Same locality, on decorticated branch of Fagus sylvatica 5-6 cm thick, on wood, soc. Lophiotrema nucula, Resupinatus applicatus, rhizomorphs, Corticiaceae, a myxomycete; holomorph, 9 Jul. 2007, W. Jaklitsch, W.J. 3117 (WU 29455). St. Margareten im Rosental, Zabrde, MTB 9452/4, 46 $32^{\prime} 59^{\prime \prime}$ $\mathrm{N}, 14^{\circ} 25^{\prime} 12^{\prime \prime}$ E, elev. $565 \mathrm{~m}$, on partly decorticated branch of Fagus sylvatica 1-1.5 cm thick, on wood, 29 Oct. 2005, H. Voglmayr \& W. Jaklitsch, W.J. 2869 (WU 29453, culture C.P.K. 2424). Niederösterreich, Hollabrunn, Hardegg, Semmelfeld, between Niederfladnitz and Merkers-

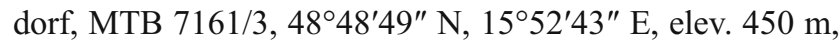
on partly corticated branch of Quercus petraea $4 \mathrm{~cm}$ thick, on wood and resupinate polypore, 21 Jul. 2004, H. Voglmayr \& W. Jaklitsch, W.J. 2531 (WU 29446, culture CBS 119504=C.P.K. 1614). Melk, Loosdorf, Dunkelsteiner Wald, $0.7 \mathrm{~km}$ south from Umbach, MTB 7758/4, 48 $14^{\prime} 04^{\prime \prime}$ N, $15^{\circ} 25^{\prime} 48^{\prime \prime}$ E, elev. 370 m, on branch of Fagus sylvatica on the ground in leaf litter, on wood, 5 Oct. 2004, W. Jaklitsch, W.J. 2768 (WU 29447, culture C.P.K. 1993). Wien-Umgebung, Mauerbach, east from the cemetery, MTB 7763/1, 48 $15^{\prime} 11^{\prime \prime} \mathrm{N}, 16^{\circ} 10^{\prime} 22^{\prime \prime}$ E, elev. $330 \mathrm{~m}$, on partly decorticated branch of Fagus sylvatica $4 \mathrm{~cm}$ thick, on wood, soc. young Hypoxylon rubiginosum, holomorph, 24 Sep. 2005, W. Jaklitsch, W.J. 2858 (WU 29451, culture C. P.K. 2420). Mauerbach, halfway heading to Allhang, MTB $7763 / 1,48^{\circ} 14^{\prime} 54^{\prime \prime} \mathrm{N}, 16^{\circ} 08^{\prime} 34^{\prime \prime} \mathrm{E}$, elev. $330 \mathrm{~m}$, on 

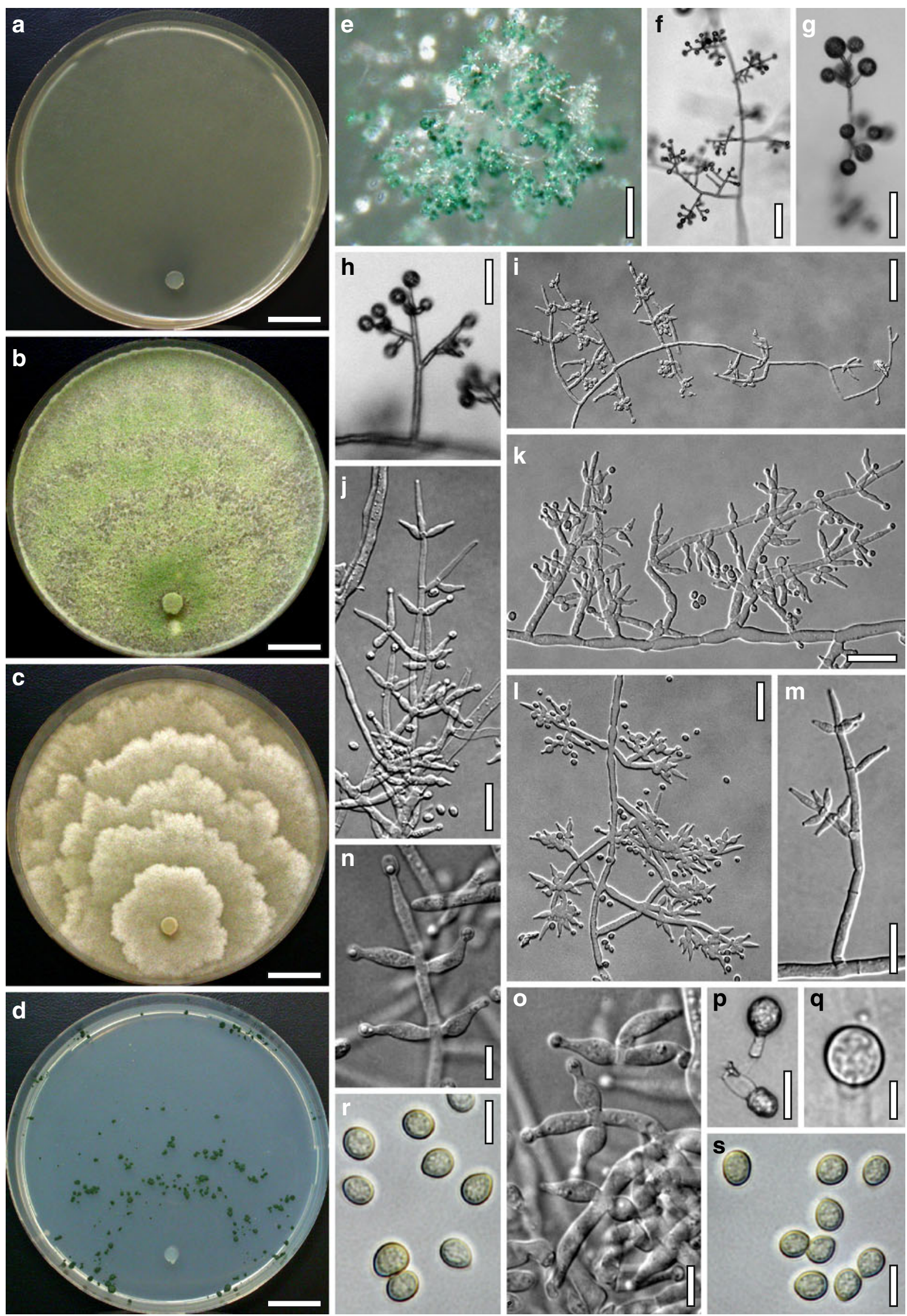
4Fig. 17 Cultures and anamorph of Hypocrea rogersonii. a-d. Cultures after 14 days (a. on $\mathrm{CMD}$; b. on PDA; c. on PDA, $30^{\circ} \mathrm{C}$; d. on SNA). e. Conidiation shrub (CMD, 7 days). $\mathbf{f}-\mathbf{h}$. Conidiophores on growth plates (f, h. CMD, 5 days; $\mathbf{g}$. conidial heads, SNA, 7 days). $\mathbf{i}-\mathbf{m}$. Conidiophores (CMD, 5 days). $\mathbf{n}, \mathbf{o}$. Phialides (CMD, 5 days). $\mathbf{p}$, q. Chlamydospores $\left(\mathrm{SNA}, 30^{\circ} \mathrm{C}, 21\right.$ days). r, s. Conidia (CMD, 7 days). a-s. All at $25^{\circ} \mathrm{C}$ except $\mathbf{c}, \mathbf{p}, \mathbf{q} . \mathbf{a}-\mathbf{e}, \mathbf{g}, \mathbf{i}-\mathbf{s}$. CBS 119503. f, h. C.P.K. 2422. Scale bars: $\mathbf{a}-\mathbf{d}=15 \mathrm{~mm}$. e, $\mathbf{f}=50 \mu \mathrm{m} . \mathbf{g}, \mathbf{i}=30 \mu \mathrm{m}$. h, $\mathbf{k}$, $\mathbf{I}=20 \mu \mathrm{m} . \mathbf{j}, \mathbf{m}=15 \mu \mathrm{m} . \mathbf{n}, \mathbf{o}, \mathbf{q}-\mathbf{s}=5 \mu \mathrm{m} . \mathbf{p}=10 \mu \mathrm{m}$

decorticated branch of Fagus sylvatica, on wood, soc. Cryptadelphia sp., black crust, Corticiaceae, 3 Aug. 2008, W. Jaklitsch (WU 29456). Pressbaum, Rekawinkel, forest path south from the train station, MTB 7862/1, 48 $10^{\prime} 29^{\prime \prime}$ $\mathrm{N}, 16^{\circ} 01^{\prime} 59^{\prime \prime} \mathrm{E}$, elev. $430 \mathrm{~m}$, on decorticated branch of Fagus sylvatica $5 \mathrm{~cm}$ thick, on wood, soc. Corticiaceae, Dacrymyces stillatus, light bluish green anamorph, 20 Aug. 2005, W. Jaklitsch, W.J. 2829 (WU 29449, culture C.P.K. 2410); same area, $48^{\circ} 10^{\prime} 27^{\prime \prime} \mathrm{N}, 16^{\circ} 01^{\prime} 53^{\prime \prime} \mathrm{E}$, elev. $430 \mathrm{~m}$, on partly corticated branches of Fagus sylvatica $6-8 \mathrm{~cm}$ thick, on wood, soc. Nemania serpens, Hypocrea minutispora, 15 Oct. 2005, W. Jaklitsch, W.J. 2864 (WU 29452, culture C.P.K. 2422). Oberösterreich, Vöcklabruck, Nußdorf am Attersee, forest on the left side of the road, shortly after the village heading to Limberg, MTB 8147/1, $47^{\circ} 51^{\prime} 58^{\prime \prime} \mathrm{N}, 13^{\circ} 30^{\prime} 54^{\prime \prime} \mathrm{E}$, elev. $560 \mathrm{~m}$, on mostly decorticated twigs of Fagus sylvatica 2-6 cm thick, on wood, overgrowing leaves, soc. Corticiaceae, Melanomma sanguinarium, holomorph, 4 Sep. 2005, W. Jaklitsch, H. Voglmayr \& W. Klofac, W.J. 2844 (WU 29450, culture C.P. K. 2193).

Notes: Teleomorphs of $H$. rogersonii and the rare $H$. koningii are morphologically indistinguishable, although asci and ascospores are slightly larger in $H$. rogersonii. Fresh stromata of these two species can be distinguished from other species of the clade because of their orange colour, while dry stromata are generally darker and more reddish brown than fresh ones, making a distinction from several other species of the clade difficult or impossible. Fresh stromata of $H$. rogersonii are frequently eaten by characteristic insect larvae, probably belonging to the Mycetophagidae, possibly a species of Triphyllus Latr.

The pustulate conidiation of $T$. rogersonii on SNA is similar to the more effuse conidiation on CMD, except for somewhat denser and longer conidiophores, and more variable, broadly ampulliform or narrowly lageniform phialides, often originating on an inflated cell. Trichoderma koningii has slightly larger and more oblong conidia, i.e. often with parallel sides. The conidiation of T. koningii on CMD is more distinctly pustulate than in $T$. rogersonii, colonies on PDA are hairy, with darker, uniformly grey-green, hardly zonate conidiation, becoming green also at $30^{\circ} \mathrm{C}$. Certain isolates of T. rogersonii ( $c f$. Samuels et al. 2006a) may form distinctly zonate colonies. The latter difference may also be due to different lighting conditions. See Samuels et al. (2006a) and Jaklitsch et al. (2006b) for distinction from other species of Trichoderma sect. Trichoderma.

Hypocrea rufa (Pers. : Fr.) Fr., Summa Veg. Scand., Sectio Post. 383 (1849). Fig. 18

ESphaeria rufa Pers., Obs. Mycol. 1: 20 (1796) : Fr., Syst. Mycol. 2: 335 (1823).

Anamorph: Trichoderma viride Pers., Neues Mag. Bot. [Roemer's] 1: 92 (1794): Fries, Syst. Mycol. 3: 215 (1832).

Fig. 19

= Trichoderma lignorum (Tode) Harz, Bull. Soc. Imp. Natur. Moscou 44: 116 (1871).

= Trichoderma glaucum E.V. Abbott, Iowa State Coll. J. Sci. 1: 27 (1927).

Stromata when fresh 1-4(-6) $\mathrm{mm}$ long, 0.5-1.5 $\mathrm{mm}$ high, solitary to gregarious, or aggregated in small numbers or crowded in lines along wood fibres, at first semi-effused, flat, velutinous, with white mycelial margin; becoming pulvinate, more rarely turbinate or discoid, circular to irregular in outline, broadly attached; margin often becoming free and concolorous with the stroma surface. Surface velutinous, at least when young, smooth, slightly uneven or granular. Ostioles invisible or appearing as watery, hyaline, or indistinct darker dots, less commonly projecting, convex, often irregularly distributed. Stromata at first white, remaining white with yellowish ostiolar dots ("albino" form), or more commonly becoming variably coloured from the centre: first yellowish, then pale ochre, light brownish or yellow-, orange-, rustbrown, 5A4-7, 5B4, 5C6-7, 6CD5-8, later light to dark reddish brown, 7-8CD6-8, 8E7-8, sometimes with whitish to rust-coloured scurf.

Stromata when dry $(0.5-) 0.6-3(-5.7) \times(0.4-) 0.6-2(-3.4)$ $\mathrm{mm},(0.2-) 0.3-0.6(-0.9) \mathrm{mm}$ thick $(n=31), \mathrm{KOH}-$, darker and surface more uneven than in fresh stromata, surface granular to finely tuberculate, sometimes extremely uneven with perithecial contours visible; ostioles not visible or partly convex or semiglobose, appearing as hyaline or brown dots (30-) 40-85(-126) $\mu \mathrm{m}(n=33)$ diam, generally hyaline after addition of water. Young stromata velvety to conspicuously hairy, with diffuse yellowish orange, yellowish brown or brown colours, 4B4-5, 5AB5-6, 5CD7-8, 6B5, 6CD5-8, later light-, 7CD5-8, 7E7-8, to deep reddish brown, 8EF5-8 to 7F6-8, 8CD5-6, to dark brown, 7EF56; albino form white or becoming pale yellowish, 4A3-4, with numerous, conspicuous light brownish dots.

Stroma anatomy: Ostioles (70-)80-110(-120) $\mu \mathrm{m}(n=21)$ long, plane with the surface or projecting to $45(-70) \mu \mathrm{m}$, (30-)33-55(-70) $\mu \mathrm{m}(n=15)$ wide at the apex; ostiolar opening surrounded by a palisade of hyaline, narrowly cylindrical, apically slightly expanded cells. Perithecia $(160-) 180-250(-310) \times(105-) 135-210(-250) \mu \mathrm{m} \quad(n=31)$, flask-shaped, ellipsoidal or globose. Peridium colourless, 

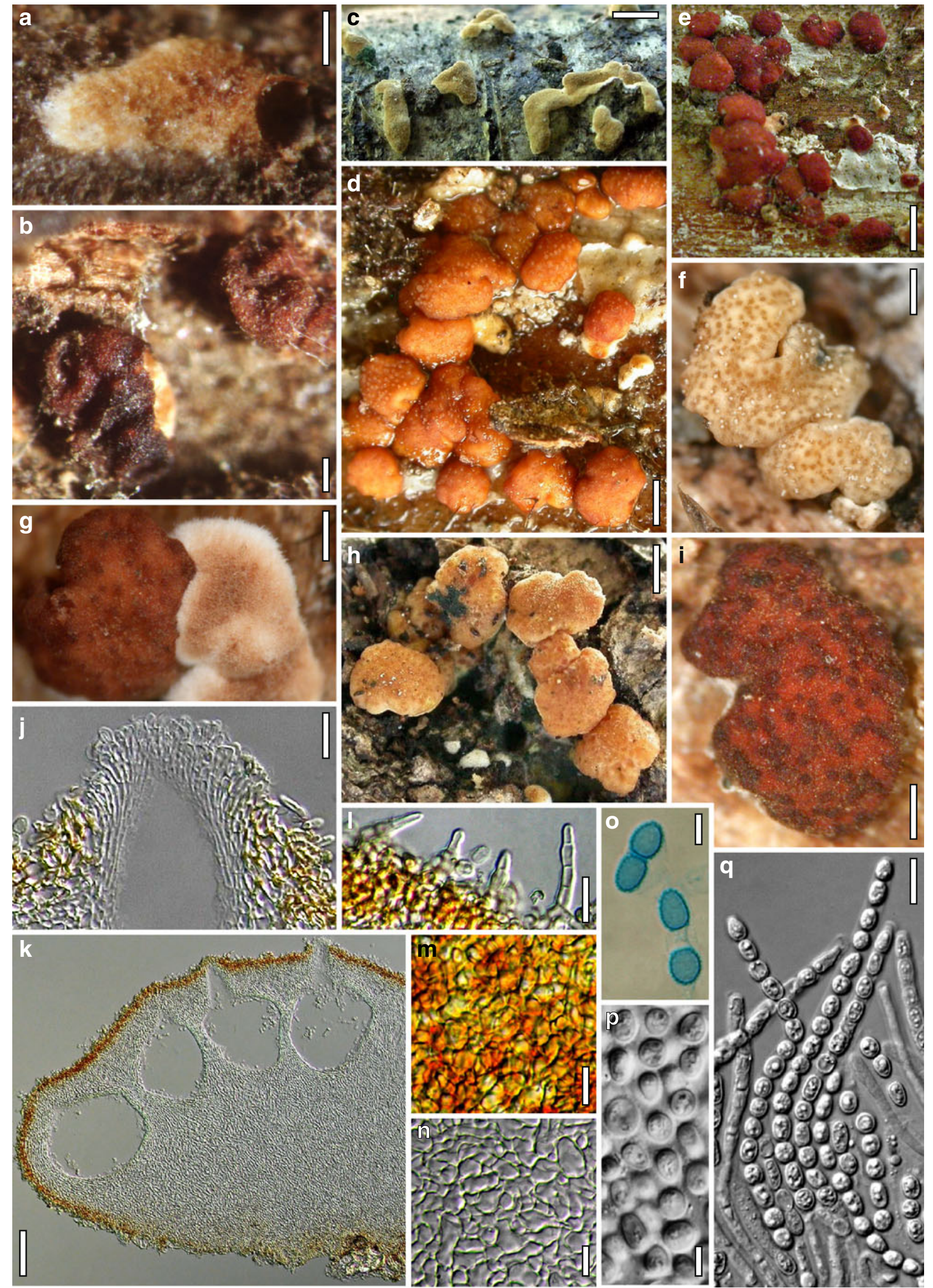
4Fig. 18 Teleomorph of Hypocrea rufa. a, b, f, g. Dry stromata (a. immature, downy; f. "albino" stroma; g. immature and mature). $\mathbf{c}-\mathbf{e}$, h. Fresh stromata (c. immature, nearly dry). i. Rehydrated stroma. j. Ostiole in section. k. Section of stroma with perithecia. l. Hairs on the surface of mature stroma. m. Stroma surface in face view. n. Subperithecial tissue in section. o, p. Ascospores (o. in cotton blue/ lactic acid). q. Asci with ascospores. a, b, p. neotype Scleromyceti Sueciae 303; c, h. WU 24011; d, e, i-o, q. epitype WU 24013, f, g. WU 24015. Scale bars: a, b, $\mathbf{g}, \mathbf{i}=0.3 \mathrm{~mm}$. $\mathbf{c}, \mathbf{d}, \mathbf{f}=0.5 \mathrm{~mm}$. e, $\mathbf{h}=$ $0.8 \mathrm{~mm} . \mathbf{j}, \mathbf{l}-\mathbf{n}, \mathbf{q}=10 \mu \mathrm{m}, \mathbf{k}=100 \mu \mathrm{m}, \mathbf{o}, \mathbf{p}=5 \mu \mathrm{m}$

10-22 $\mu \mathrm{m}$ thick. Cortical layer (12-)17-30(-35) $\mu \mathrm{m}(n=20)$ thick, a $t$. angularis of cells (3.5-)4.5-10(-14.5) $\mu \mathrm{m}(n=60)$ diam in face view and in section, with walls to $1 \mu \mathrm{m}$ thick, reddish brown in water, orange-brown in lactic acid, pigment unevenly deposited in cell walls, giving a mottled appearance to the stroma surface. Hairs arising from the stroma surface, yellowish to pale brown, comprising $2-5$ cells, apically rounded, rarely branched, sometimes consisting of only one inflated cell, (7-)10-30(-62)×(2.0-)3.5-5.0(-6.5) $\mu \mathrm{m}(n=49)$, walls $0.5-1 \mu \mathrm{m}$ thick. Subcortical tissue comprising a hyaline mixture of intertwined hyphae, (2.5-) 3.0-6.0(-6.5) $\mu \mathrm{m}(n=10)$ wide, vertical and parallel between perithecia, and few subglobose to angular cells similar to those of the cortex. Subperithecial tissue a homogeneous, dense $t$. epidermoidea of globose to elongate, thin-walled, hyaline cells, $(4-) 5-19(-26) \times(3-) 4-10(-13) \mu \mathrm{m} \quad(n=30)$, gradually smaller and interspersed with some narrow hyphae (2.0-)2.5-5.5(-6.5) $\mu \mathrm{m}(n=10)$ wide towards the base of the stroma. Asci $(70-) 87-112(-132) \times(4.0-) 5.5-7.0(-8.5) \mu \mathrm{m}$ $(n=72)$, stipe $(5-) 9-17(-22) \mu \mathrm{m}(n=30)$ long. Ascospores hyaline, verrucose, verrucae $c a 0.5 \mu \mathrm{m}$ diam; cells dimorphic, distal cell (3.7-)4.5-5.7(-7.7) ×(3.2-)4.0-4.7(-6.5) $\mu \mathrm{m}, 1 / \mathrm{w}(0.9-) 1.0-1.4(-1.8)(n=120)$, subglobose or oval, sometimes wedge-shaped, proximal cell (3.7-)4.7-6.5($8.0) \times(3.0-) 3.5-4.2(-5.2) \mu \mathrm{m}, 1 / \mathrm{w}(1.2-) 1.3-1.9(-2.3) \quad(n=$ 120 ), oblong to wedge-shaped, the lower end broadly rounded.

Cultures and anamorph: optimal growth at $25^{\circ} \mathrm{C}$ on all media; no growth at $35^{\circ} \mathrm{C}$.

On CMD after $72 \mathrm{~h} 25-27 \mathrm{~mm}$ at $15^{\circ} \mathrm{C}, 39-40 \mathrm{~mm}$ at $25^{\circ} \mathrm{C}, 8-14 \mathrm{~mm}$ at $30^{\circ} \mathrm{C}$; mycelium covering the plate after 5-6 days at $25^{\circ} \mathrm{C}$. Colony thin, hyaline, dense, homogeneous, not zonate; margin ill-defined, diffuse. Hyphae loosely arranged, thin, finely reticulate. Autolytic activity absent, coilings and aerial hyphae inconspicuous. No diffusing pigment formed. A weak coconut-like odour formed in some but not all strains. Chlamydospores rare, typically subglobose, terminal, less frequently intercalary, hyaline to pale yellowish. Conidiation noted after 2 days, in pustules more or less regularly distributed on the plate or forming in a broad band around the margin, less frequently in concentric rings, usually starting close to the point of inoculation, formed exclusively or preceded or accompanied by various amounts of simple conspicuously curved conidiophores or minute transparent tufts or shrubs. Pustules at first white, becoming green after 4 days or later, depending on the isolate, $28 \mathrm{D} 3-5$ or $26 \mathrm{E} 4-6$ to 27E4-6, finally $26 \mathrm{~F} 5-8$ to $27 \mathrm{~F} 6-8$ after 1 week, compact to cottony, pulvinate to hemispherical, $0.5-2.5(-5.0) \mathrm{mm}$ diam, $0.5-1.6 \mathrm{~mm}$ high. Structure of typical conidiophores, determined after 5-7(-11) d: pustules and minute tufts arising on $8-12 \mu \mathrm{m}$ thick stipes, often with constricted septa, bearing several thick primary branches arising at various angles, both partly verrucose, further branching dense and complex, final long branches thin, bearing short terminal branches at various angles, with 1 or $2(-3)$ terminal phialides. Conidiophores ill-defined, no main axes discernible or at best weakly developed, conspicuously and extremely variably curved to sinuous, often seen as short elongations on the periphery of pustules; branches and phialides generally unpaired. Simple conidiophores and shrubs sometimes tending to be more regularly paired, with tree-like branching. Branches sometimes originating on thickened nodes, 7-11 $\mu \mathrm{m}$ wide with up to 5 branches, often tending to be less curved. Phialides (4.0-)6.5-11.5($18.5) \times(1.0-) 2.5-3.3(-4.0) \mu \mathrm{m}, 1 / \mathrm{w}(1.2-) 2.0-4.5(-13.2)$, $(1.0-) 1.7-2.5(-3.0) \mu \mathrm{m}$ wide at the base $(n=600)$, originating singly or in groups of $2-3$, on rarely inflated, 2 $3 \mu \mathrm{m}$ thick cells, usually not paired, variable among isolates, lageniform to long cylindrical, typically strongly curved to sinuous, less commonly straight, usually with long necks up to $10 \mu \mathrm{m}$, not or slightly thickened in various positions, tending to be longer and narrower in minute tufts and shorter and more swollen when crowded. Conidia $(3.0-) 3.5-4.5(-5.5) \times(2.8-) 3.5-4.0(-5.0) \quad \mu \mathrm{m}, \quad 1 / \mathrm{w}=(0.8-)$ $1.0-1.2(-1.5)(n=720)$, globose to subglobose, infrequently nearly oval, (olive-)green, basal scar sometimes visible, coarsely tuberculate, containing few guttules, in aged cultures often in chains.

On PDA after $72 \mathrm{~h} 21-23 \mathrm{~mm}$ at $15^{\circ} \mathrm{C}, 29-31 \mathrm{~mm}$ at $25^{\circ} \mathrm{C}$, 4-10 $\mathrm{mm}$ at $30^{\circ} \mathrm{C}$; mycelium covering the plate after 1 week at $25^{\circ} \mathrm{C}$. Colony dense, whitish, downy. Aerial hyphae well developed at the margin, soon degenerating, colonies therefore flat. Autolytic activity absent. No diffusing pigment formed, odour indistinct or rarely slightly coconut-like. Conidiation effuse, starting in the centre, white, condensed, farinose to finely granular, green from the centre after 3 days, subsequently forming alternating green, 28DE5-7, 27DE3-6 to 27F7-8 and dull yellow, 3A3-4, concentric zones.

On SNA after $72 \mathrm{~h} 21-22 \mathrm{~mm}$ at $15^{\circ} \mathrm{C}, 27-31 \mathrm{~mm}$ at $25^{\circ} \mathrm{C}$, $1-8 \mathrm{~mm}$ at $30^{\circ} \mathrm{C}$; mycelium covering the plate after $7-8$ days at $25^{\circ} \mathrm{C}$. Colony similar to $\mathrm{CMD}$, not zonate. Aerial hyphae inconspicuous, autolytic activity absent, coilings somewhat more pronounced than on CMD.

No pigment, no distinct odour noted. Chlamydospores noted after 1 week, inconspicuous, more frequent than on 

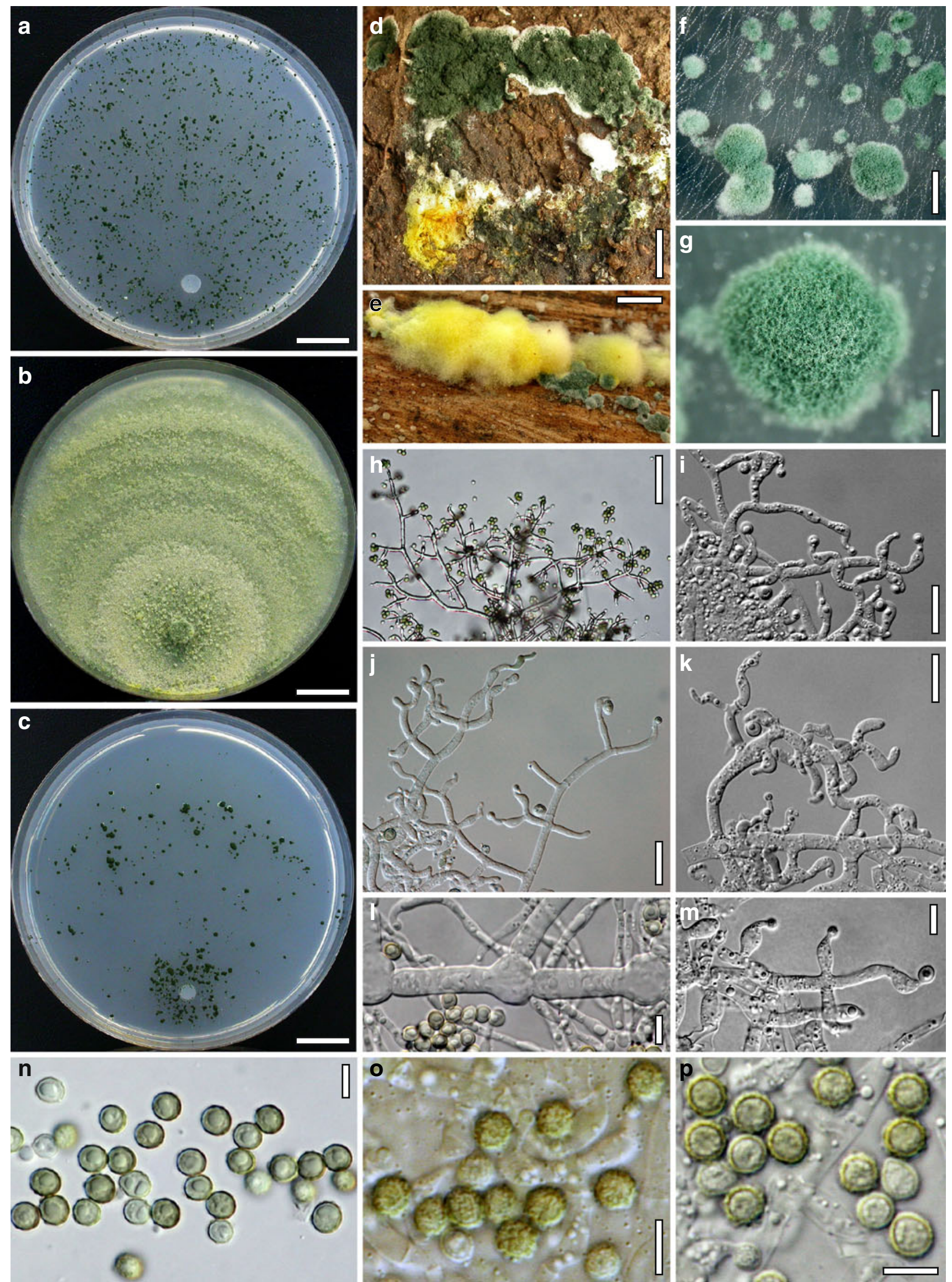
Fig. 19 Cultures and anamorph of Hypocrea rufa. a-c. Cultures after 12 days at $25^{\circ} \mathrm{C}$ (a. on CMD; b. on PDA; c. on SNA). d, e. Anamorph on natural substrate showing yellow mycelium. f, g. Conidiation pustules (6 days). h. Conidiophores from shrub (7 days). $\mathbf{i}-\mathbf{k}$. Conidiophores from pustule periphery (7-8 days). I. Conidiophore thickenings (10 days). m. Phialides ( 8 days). n-p. Conidia (7-8 days). f-p. From $\mathrm{CMD}, 25^{\circ} \mathrm{C}$. a-c, f-h, n. CBS 119326. d, e, l. CBS 119325. i-k. C.P.K. 2867. m, o, p. CBS 119327. Scale bars: $\mathbf{a}-\mathbf{c}=$ $14 \mathrm{~mm} . \mathbf{d}, \mathbf{e}=3 \mathrm{~mm} . \mathbf{f}=1.5 \mathrm{~mm} . \mathbf{g}=0.5 \mathrm{~mm} . \mathbf{h}=50 \mu \mathrm{m} . \mathbf{i}, \mathbf{k}=10 \mu \mathrm{m}$. $\mathbf{j}=15 \mu \mathrm{m} . \mathbf{l}-\mathbf{p}=5 \mu \mathrm{m}$

CMD, terminal and intercalary, (5.0-)6.5-10.5(-12.5) $\mu \mathrm{m}$ $(n=21)$ diam, mostly globose, smooth, hyaline to pale yellowish. Conidiation similar to CMD, asymmetrical, starting in the centre in loosely arranged compact pustules of ca 1-2 $\mathrm{mm}$ diam, aggregating to $4 \mathrm{~mm}$ diam, and on smaller shrubs and solitary conidiophores, green 26EF5-7 to $27 \mathrm{~F} 6-8$ after $3-4$ days; conidia formed in minute dry heads.

Habitat: Anamorph common, isolated from soil, peat, wood, and leaf litter. Teleomorph uncommon, inconspicuous, found on wood, less commonly on bark of cut branches, tree tops or logs. In Europe found in open coniferous or mixed deciduous forests, grassland with single trees or at shady roadsides, often in piles of logs stored or lying on bare moist soil, in leaf litter or in grass, to $3 \mathrm{~m}$ above the ground at the edge of forests, on often hard wood in little to medium degree of decomposition. In Central and Northern Europe mainly on coniferous trees (Pinus sylvestris, Picea abies), in Western Europe more frequent on deciduous trees (e.g. found on Quercus robur, Acer pseudoplatanus).

Distribution: Teleomorph collected in Europe (Austria, Czech Republic, France, Germany, Netherlands, Sweden, UK) and USA (North Carolina, Virginia). Anamorph north and south-temperate, including Canada, Europe, Japan, New Zealand, and USA.

Neotype: Scleromyceti Sueciae No. 303 (UPS). Epitype, designated by Jaklitsch et al. (2006b): Czech Republic, South Bohemia, Frymburk, $3.4 \mathrm{~km}$ north from Lipno, MTB $7351 / 3,48^{\circ} 38^{\prime} 04^{\prime \prime} \mathrm{N}, 14^{\circ} 11^{\prime} 19^{\prime \prime} \mathrm{E}$, elev. $745 \mathrm{~m}$, on partly decorticated logs of Pinus sylvestris $12-30 \mathrm{~cm}$ thick, on the ground or elevated in a pile of logs stored at the roadside and edge of a coniferous (Picea/Pinus) forest, soc. Ophiostoma sp., Neonectria fuckeliana, Pezicula eucrita, Schizophyllum commune, Valsa pini, unidentified Corticiaceae, 3 Oct. 2004, W. Jaklitsch, W.J. 2753 (WU 24013; culture CBS 119325 = C.P.K. 1997 = G.J.S. 04-372). Lectotype of Trichoderma viride (designated by Bisby 1939): 'Prope Parisiis, Hb. Pers.', Herb. Lugd. Bat. 910 263-877 (L 0018559 = 'Rijksherbarium No 148-1'). Epitype of Trichoderma viride isolated from WU 24013 and deposited as a dry culture with the holotype of $H$. rufa as WU 24013a.
Other specimens examined: Austria, Niederösterreich, Zwettl, Traunstein, roadside, $1 \mathrm{~km}$ after the western end of the village, MTB 7556/4, 48 $26^{\prime} 10^{\prime \prime} \mathrm{N}, 15^{\circ} 05^{\prime} 57^{\prime \prime} \mathrm{E}$, elev. $830 \mathrm{~m}$, on partly decorticated cut logs of Picea abies, up to $45 \mathrm{~cm}$ thick, in a pile stored at the edge of a Picea/Fagus forest, soc. Ophiostoma sp., 5 Oct. 2004, W. Jaklitsch, W.J. 2766 (WU 24015; culture CBS 119327=C.P.K. 1999). Steiermark, Liezen, Kleinsölk, close to the NE corner of the

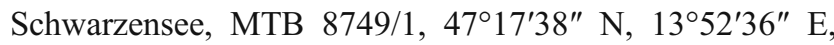
elev. $1170 \mathrm{~m}$, on partly decorticated cut logs of Pinus sylvestris, $20-25 \mathrm{~cm}$ thick, stored in a pile at roadside and edge of a spruce forest, soc. Ophiostoma sp., 7 Oct. 2004, W. Jaklitsch, W.J. 2773 (WU 24016; culture C.P.K. 2000). Liezen, Weng im Gesäuse, Ennstal, Gstatterboden, 0.9 km after the village heading east, MTB $8453 / 2,47^{\circ} 35^{\prime} 34^{\prime \prime} \mathrm{N}$, $14^{\circ} 39^{\prime} 09^{\prime \prime}$ E, elev. $570 \mathrm{~m}$, on cut $\log$ of Picea abies $120 \mathrm{~cm}$ thick, $2.5 \mathrm{~m}$ above ground, in a pile stored at roadside, soc. Trichaptum abietinum, 8 Oct. 2004, W. Jaklitsch, W.J. 2774 (WU 24017; isolate C.P.K. 2001). Czech Republic, South Bohemia, at roadside $5.7 \mathrm{~km}$ north from Frymburk, MTB 7250/4, 48 $42^{\prime} 36^{\prime \prime} \mathrm{N}, 1^{\circ} 08^{\prime} 06^{\prime \prime} \mathrm{E}$, elev. $750 \mathrm{~m}$, on partly decorticated cut log of Picea abies $22 \mathrm{~cm}$ thick, on the ground, protected by grass, herbs, soc. Neonectria fuckeliana, Stereum sanguinolentum, Sarea resinae, immature, culture from conidia, 22 Sep. 2003, W. Jaklitsch, W.J. 2408 (WU 24010; culture C.P.K. 965); $2.7 \mathrm{~km}$ before Frymburk approaching from Lipno, MTB $7351 / 3,48^{\circ} 38^{\prime} 22^{\prime \prime} \mathrm{N}, 14^{\circ} 10^{\prime} 52^{\prime \prime} \mathrm{E}$, elev. $740 \mathrm{~m}$, on partly decorticated logs of Pinus sylvestris $10-43 \mathrm{~cm}$ thick, stored in a pile at the roadside, mostly immature, 3 Oct. 2004, W. Jaklitsch, W.J. 2758 (WU 24014; culture C.P.K. 1998). France, La Moselle, Parc Lorraine, Héming, between Étang du Stock and Maizières de Vic, $48^{\circ} 43^{\prime} 35^{\prime \prime} \mathrm{N}, 06^{\circ}$ $54^{\prime} 07^{\prime \prime}$ E, elev. $180 \mathrm{~m}$, on cut and mostly corticated branches and logs of Quercus robur 2-40 cm thick, on bare ground or squeezed into moist soil, soc. Amphiporthe leiphaemia, Diatrypella sp., Bulgaria inquinans, part attacked by white mould, 5 Sep. 2004, W. Jaklitsch \& H. Voglmayr, W.J. 2677 (WU 24011; culture C.P.K. 1995). Germany, Bavaria, Unterfranken, Landkreis Haßberge, Haßfurt, close to Mariaburghausen, left roadside heading from Knetzgau to Haßfurt, MTB 5929/3, 5000'31" N, $10^{\circ}$ $31^{\prime} 17^{\prime \prime}$ E, elev. $270 \mathrm{~m}$, on cut branches of Quercus robur 4 $5 \mathrm{~cm}$ thick, on bark, holomorph, teleomorph immature, 29 Aug. 2006, W. Jaklitsch \& H. Voglmayr, W.J. 2962 (WU 29457, culture C.P.K. 2457). Nordrhein-Westfalen, Märkischer Kreis, Plettenberg-Böddinghausen, Naturschutzgebiet Bommecketal, $1 \mathrm{~km}$ south from the entrance to the nature reserve, MTB 4713/3, elev. $300 \mathrm{~m}$, on corticated log of Fraxinus excelsior $15 \mathrm{~cm}$ thick, on bark, soc. Neonectria coccinea, 8 Oct. 2006, K. Siepe \& F. Kasparek, W.J. 3061 (WU 29459, culture C.P.K. 2867). Netherlands, Putten, in Armen Bos of the arboretum Landgoed Schovenhorst, elev. 
$0 \mathrm{~m}$, on corticated branch of Quercus robur 4-10 cm thick, on bark, holomorph, teleomorph immature, 19 Nov. 2006, H. Voglmayr, W.J. 3048 (WU 29458, culture C.P.K. 2856). Sweden, Uppsala Län, Fredrikslund, pine forest near nature reserve Kungshamn-Morga, $1.5 \mathrm{~km}$ NE of Fredrikslund, $59^{\circ} 47^{\prime} 00^{\prime \prime} \mathrm{N}, 17^{\circ} 39^{\prime} 00^{\prime \prime} \mathrm{E}$, elev. $50 \mathrm{~m}$, on cut and mostly corticated tree tops and branches of Pinus sylvestris $5-9 \mathrm{~cm}$ thick, on the ground, 8 Oct. 2003, W. Jaklitsch \& S. Ryman, W.J. 2450 (BPI 872089; cultures CBS 119326=C. P.K. 984, G.J.S. 04-21 from white stroma). United Kingdom, Derbyshire, Baslow, Longshaw Country Park,

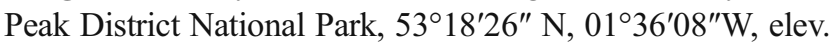
$350 \mathrm{~m}$, on corticated branches and logs of Acer pseudoplatanus $2-10 \mathrm{~cm}$ thick, on the ground in open grassland, holomorph, teleomorph immature, culture from conidia, 10 Sep. 2004, W. Jaklitsch \& H. Voglmayr, W.J. 2695 (WU 24012; culture C.P.K. 1996). Hampshire, Lyndhurst, New Forest, Whitley Wood, 50 $50^{\prime} 50^{\prime \prime} \mathrm{N}, 01^{\circ} 34^{\prime} 50^{\prime \prime} \mathrm{W}$, elev. $30 \mathrm{~m}$, on basidiome of Phellinus ferruginosus and wood of Fagus sylvatica, holomorph, scant, 14 Sep. 2007, W. Jaklitsch \& H. Voglmayr, W.J. 3161 (WU 29461). Hertfordshire, Hertford, Waterford, Waterford Heath, 51 ${ }^{\circ} 48^{\prime} 51^{\prime \prime} \mathrm{N}$, $00^{\circ} 05^{\prime} 25^{\prime \prime} \mathrm{W}$, elev. $70 \mathrm{~m}$, on cut branch of Betula pendula 15-20 cm thick, holomorph, teleomorph immature, soc. Annulohypoxylon multiforme, Oligoporus sp., Corticiaceae, 12 Sep. 2007, W. Jaklitsch, H. Voglmayr \& K. Robinson, W. J. 3154 (WU 29460).

Notes: Hypocrea rufa is the type species of the genus Hypocrea. Despite frequent citations in the literature and the numerous, often wrongly identified specimens in herbaria the teleomorph of this species is uncommon or even rare in many regions. It occurs typically on stored wood of conifers such as Picea or Pinus in Central Europe. In Western Europe it has been primarily collected on wood and bark of Quercus and other deciduous trees. It is difficult to find good teleomorph material. Stromata apparently develop slowly and in a narrow range of ecological conditions, particularly regarding moisture, temperature, and age and degree of decay of the substrates. Moreover, they often develop in open habitats, well susceptible to desiccation. The frequency of long dry periods has increased in recent years. This may contribute to the fact that teleomorphs are rather rarely collected. On the other hand, if a habitat is too moist, stromata are soon attacked by hyphomycetes, often seen in specimens as white mould on stromata. These are obviously reasons why specimens mostly contain immature stromata. Anthropogenic influence, particularly cutting of logs and branches, strongly enhances growth of this species.

The most common species of Hypocrea in temperate regions, $H$. minutispora, or sometimes $H$. pachybasioides, are frequently wrongly identified as $H$. rufa. Stromata of $H$. rufa may approach those of $H$. pachybasioides or $H$. minutispora in shape and colour, particularly when their ostiolar openings are clearly visible, but $H$. rufa forms typically inconspicuous, small stromata, mostly $1-2 \mathrm{~mm}$ diam, and the stroma surface is velutinous or hairy, especially in young stromata.

Hypocrea rufa cannot be confidently differentiated from its closest relative, $H$. viridescens, by the morphology of the teleomorph, and also barely from other similar species. Stromata of $H$. rufa are usually accompanied by the Trichoderma viride anamorph. Conidia found in nature are dark green, $26 \mathrm{~F} 5-8$ to $27 \mathrm{~F} 4-8$, and often citrine- to sulphuryellow, 4A4-6, hairy patches of mycelium are found. Intensely yellow cottony patches are found also with $H$. viridescens. However, the coarsely warted, globose or subglobose conidia of $T$. viride are diagnostic of the species, except for the recently described Brazilian Theobroma endophyte T. martiale (Hanada et al. 2008), while T. viridescens has finely verruculose, ellipsoidal conidia. Conidia of most other Trichoderma species have smooth conidia.

Measurements of perithecia, asci, ascospores, phialides and conidia given above include those obtained on North American material studied by G.J. Samuels. For more information see Jaklitsch et al. (2006b).

Hypocrea stilbohypoxyli B.S. Lu \& Samuels, Sydowia 55: 265 (2003). Fig. 20

Anamorph: Trichoderma stilbohypoxyli Samuels \& Schroers, Stud. Mycol. 56: 128 (2006a). Fig. 21

Stromata when fresh $1-15 \mathrm{~mm}$ diam, to $1 \mathrm{~mm}$ thick, solitary, gregarious or densely aggregated in small numbers, thinly effuse to subpulvinate. Margin first white, later concolorous, attached or free and rounded. Surface hairy when young, becoming glabrous, smooth to tubercular. Perithecia entirely immersed; ostiolar dots invisible or indistinct brownish dots or spots. Stroma colour orange to reddish brown, 7-8C6-8.

Stromata when dry $(0.7-) 1.1-6.2(-12) \times 0.6-4.3(-8.0)$ $\mathrm{mm}, 0.2-0.4(-0.7) \mathrm{mm}$ thick $(n=30)$; effuse or subpulvinate; outline variable, circular, oblong or irregularly lobed. Surface velutinous, covered by whitish to rust hairs when immature, smooth or irregularly tubercular, sometimes with white or green conidiophores when immature; glabrous when mature. Ostiolar dots $(31-) 50-78(-94) \mu \mathrm{m} \quad(n=20)$, appearing

Fig. 20 Teleomorph of Hypocrea stilbohypoxyli. a-d. Fresh stromata (a, b. immature; b. holomorph). e-j. Dry stromata (f, $\mathbf{g}, \mathbf{i}, \mathbf{j}$. immature; f. on stroma of Rosellinia corticium). k. Rehydrated mature stromata. I. Stroma surface in face view. $\mathbf{m}$. Perithecium in section. $\mathbf{n}$. Cortical and subcortical tissue in section. o. Subperithecial tissue in section. p. Stroma base in section. q, r. Asci with ascospores (q. in cotton blue/ lactic acid). s, t. Ascospores in cotton blue/lactic acid (t. immature, before disarticulation). a, c, f, g, j, r. WU 29479. b, i. WU 29477. d, e, $\mathbf{h}, \mathbf{k}-\mathbf{q}, \mathbf{s}, \mathbf{t}$. WU 29478. Scale bars: $\mathbf{a}, \mathbf{b}=2 \mathrm{~mm}$. c, $\mathbf{d}, \mathbf{i}=1.3 \mathrm{~mm}$. e, $\mathbf{f}=$ $0.3 \mathrm{~mm} . \mathbf{g}=0.8 \mathrm{~mm}$. h, j, $\mathbf{k}=0.5 \mathrm{~mm}$. $\mathbf{l}, \mathbf{o}, \mathbf{q}, \mathbf{r}=10 \mu \mathrm{m} . \mathbf{m}, \mathbf{p}=30 \mu \mathrm{m}$. $\mathbf{n}=20 \mu \mathrm{m} . \mathbf{s}, \mathbf{t}=5 \mu \mathrm{m}$ 

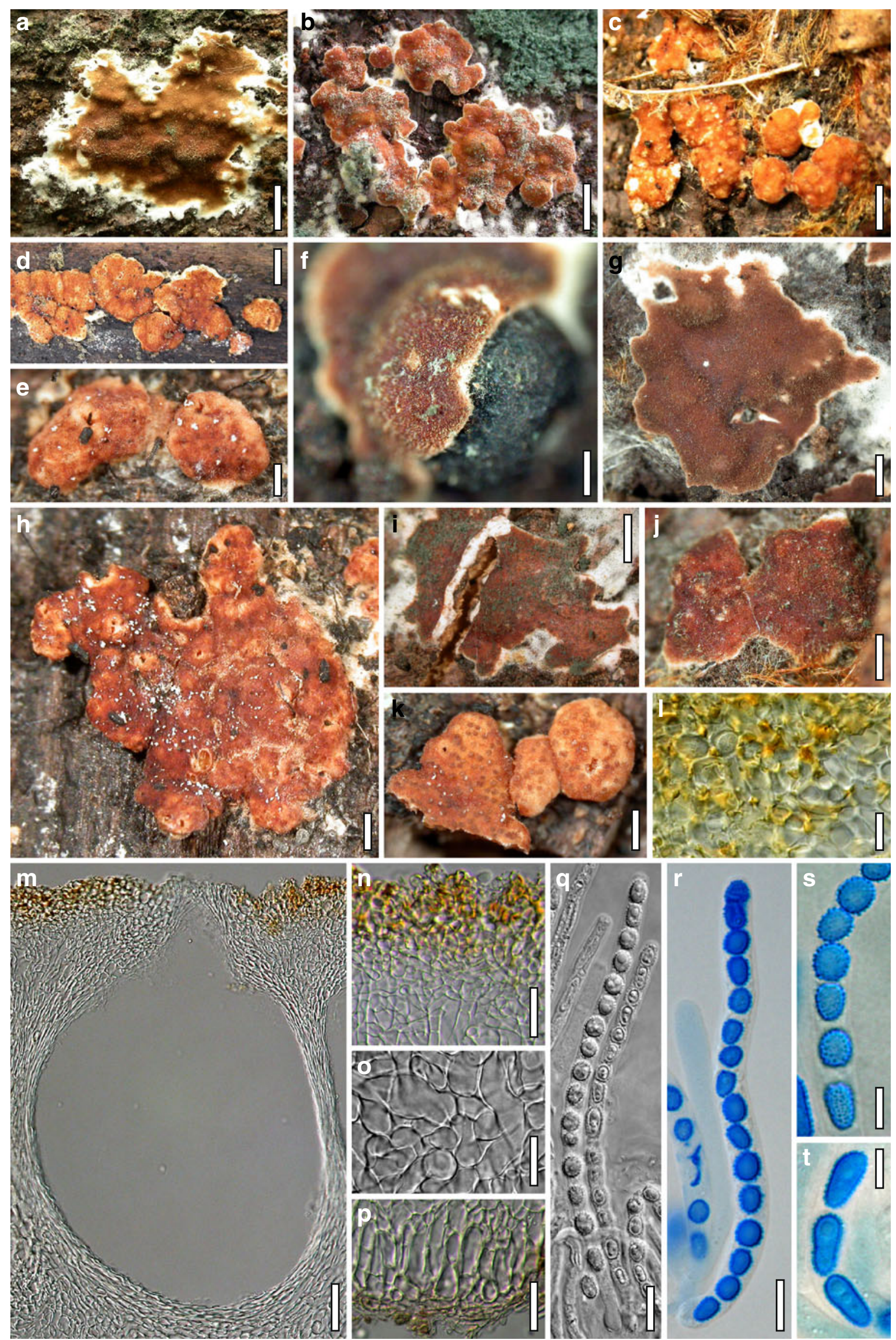

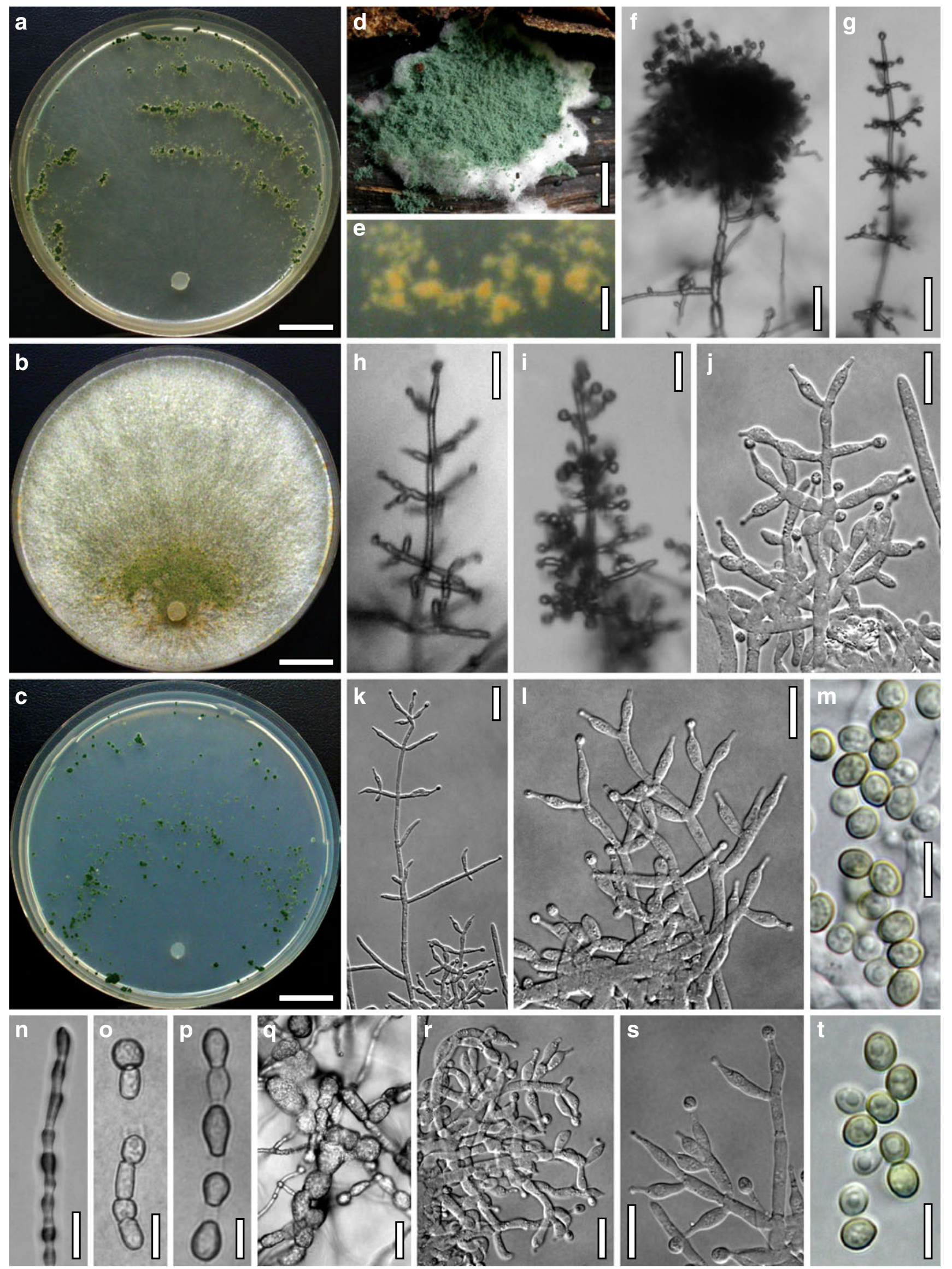
4Fig. 21 Cultures and anamorph of Hypocrea stilbohypoxyli. a-c. Cultures after 14 days (a. on CMD; b. on PDA; c. on SNA). d. Fresh anamorph on the natural substrate. e. Reverse of conidiation pustules (CMD, 14 days). f. Dense core of conidiation pustule on stipe (CMD, 7 days). $\mathbf{g}-\mathbf{i}$. Regularly tree-like conidiophores on growth plates (7 days; g, i. SNA; h. CMD). $\mathbf{j}-\mathbf{l}$, r. Conidiophores (CMD, 7 days; $\mathbf{r}$. from dense pustule core). m, t. Conidia (CMD, 6 days). n. Submoniliform surface hypha (PDA, $30^{\circ} \mathrm{C}, 1$ days). o, p. Chlamydospores (SNA, $30^{\circ} \mathrm{C}$, 8 days). q. Thickenings in surface hyphae around conidiation pustules (CMD, 16 days). s. Phialides (CMD, 7 days). a-c, e-m, q-t. At $25^{\circ} \mathrm{C}$. $\mathbf{a}-\mathbf{c}, \mathbf{e}-\mathbf{g}, \mathbf{i}, \mathbf{n}-\mathbf{q}$. C.P.K. 1978. d, h, j-m, r-t. CBS 119501 (WU 29478). Scale bars: a-c $=15 \mathrm{~mm}$. d. $2 \mathrm{~mm}$. e. $4 \mathrm{~mm} . \mathbf{f}=50 \mu \mathrm{m}$. g, $\mathbf{n}, \mathbf{q}=$ $30 \mu \mathrm{m} . \mathbf{h}, \mathbf{i}, \mathbf{k}, \mathbf{o}=15 \mu \mathrm{m} . \mathbf{j}, \mathbf{l}, \mathbf{p}, \mathbf{r}, \mathbf{s}=10 \mu \mathrm{m} . \mathbf{m}, \mathbf{t}=5 \mu \mathrm{m}$

slightly darker than the stroma surface, of hyaline ostioles with darker margin, plane or slightly projecting, mostly illdefined, more distinct after rehydration. Stromata dark orange-brown to reddish brown, with lighter or white margin, 5-6EF6-8, 6-7CD7-8, 7-8E5-8. Stromata unchanged or orange-red in $3 \% \mathrm{KOH}$, with mottled pigment and minute hyaline ostiolar openings.

Stroma anatomy: Ostioles (55-)65-86(-99) $\mu \mathrm{m}$ long, umbilicate or projecting to $20(-37) \mu \mathrm{m},(30-) 37-61(-80)$ $\mu \mathrm{m}$ wide at the apex $(n=20)$; apical palisade of hyaline, narrowly clavate cells. Perithecia (175-)210-275(-300) $\times$ (105-)150-225(-270) $\mu \mathrm{m}(n=20)$, globose or flask-shaped; peridium hyaline, $(7-) 11-18(-20) \mu \mathrm{m}(n=40)$ thick at the base and sides. Cortical layer $(20-) 21-38(-47) \mu \mathrm{m}(n=20)$ thick, yellow-brown, mottled, i.e. with inhomogeneously distributed pigment, a $t$. angularis of thin-walled cells (3.5-) $5-10(-13) \times(3-) 4-7(-9) \mu \mathrm{m}(n=60)$ in face view and in vertical section; present around the entire stroma except for the attachment area. Hairs (12-) $13-28(-35) \times(2.5-) 3-5(-6)$ $\mu \mathrm{m}(n=15)$, scant, short, 2-4 celled, verrucose, narrowly rounded apically. Subcortical tissue a loose $t$. intricata of hyaline, thin-walled hyphae (2.5-)3.5-6.0(-7.5) $\mu \mathrm{m}(n=20)$ wide. Subperithecial tissue a narrow, dense, hyaline $t$. epidermoidea of thin-walled cells $(5-) 7-18(-26) \times(3-) 5-11$ $(-14) \mu \mathrm{m}(n=30)$, followed by a palisade of coarse, elongate, thick-walled, refractive cells $(15-) 16-29(-36) \times(8-) 10-15(-$ 18) $\mu \mathrm{m}(n=20)$, and a basal layer of hyphae $(2.0-) 2.8-5.2(-$ 6.0) $\mu \mathrm{m}$ wide $(n=10)$, intermingled with small-celled textura angularis, hyaline, partly brownish. Asci (74-)84-105(116) $\times(4.7-) 5.3-6.3(-7.0) \mu \mathrm{m}$, stipe $2-13(-16) \mu \mathrm{m}$ long $(n$ $=50$ ), without croziers. Ascospores hyaline, distinctly verrucose or spinulose with tubercles to $c a 0.7 \mu \mathrm{m}$ long and wide; cells dimorphic, distal cell (2.8-)4.0-5.5(-6.6) $\times(2.7-) 3.3-$ 4.3(-5.2) $\mu \mathrm{m}, 1 / \mathrm{w} 1.0-1.4(-2.2)(n=70)$, globose, subglobose or wedge-shaped, particularly in the ascus apex, proximal cell $(3.7-) 4.5-6.3(-7.5) \times(2.8-) 3.0-3.7(-4.7) \mu \mathrm{m}$, $(1.1-) 1.3-1.9(-2.4)(n=70)$, oblong, wedge-shaped or subglobose, contact area distinctly flattened before maturation.

Anamorph on the natural substrate typically conspicuous, spreading over large areas or entire branches, thickly effuse, bright blue-green when fresh, when dry dull or grey- green $25 \mathrm{E} 4-6,26 \mathrm{E} 3-4$ to $26 \mathrm{~F} 5$, with white margin when young.

Cultures and anamorph: optimal growth at $25^{\circ} \mathrm{C}$ on all media, no growth at $35^{\circ} \mathrm{C}$.

On CMD after $72 \mathrm{~h} 12-16 \mathrm{~mm}$ at $15^{\circ} \mathrm{C}, 35-37 \mathrm{~mm}$ at $25^{\circ} \mathrm{C}, 28-34 \mathrm{~mm}$ at $30^{\circ} \mathrm{C}$; mycelium covering the plate after 6-7 days at $25^{\circ} \mathrm{C}$. Colony hyaline, thin, dense, not zonate. Autolytic excretions inconspicuous, frequent at $30^{\circ} \mathrm{C}$, coilings and aerial hyphae inconspicuous. Reverse diffuse greenish yellow 1-3B3-4 after 1 week; after 2 weeks a weak coconut-like odour noticeable. Chlamydospores noted after 3-6 days, frequent in distal and lateral areas, intercalary and terminal, (sub-)globose, ellipsoidal to oblong. See under SNA for measurements. Conidiation starting after 3 days, in cottony tufts at the distal margin or in several often incomplete concentric rings. Tufts growing to $1.5(-2) \mathrm{mm}$ diam, confluent to $c a 5 \mathrm{~mm}$, compacting to pustules and turning dark green, 28F7-8, 27EF6-8, after 5 days; pustule reverse yellow, 2C4-5, darkening to dull orange, greyish yellow or golden, 4A6-7 to 4BC5-6. Surface hyphae surrounding pustules often with conspicuously and irregularly thickened to moniliform cells. Tufts/pustules originating on a more or less erect stipe up to $12 \mu \mathrm{m}$ thick, often with strongly constricted septa. Larger pustules consisting of a conspicuously dense, more or less globose conidiation unit (pustule core) to $c a 0.5 \mathrm{~mm}$ diam, surrounded by loosely radially emerging, long regular tree-like conidiophores. Both types of conidiophores also independently formed in shrubs, small tufts, directly on surface or aerial hyphae. Dense conidiation units consisting of ill-defined, broadly tree-like or irregular conidiophores with conspicuous curvatures and curved phialides. Regularly tree-like conidiophores $0.1-1 \mathrm{~mm}$ long, of a narrow, straight main axis bearing mostly paired side branches in right angles or slightly inclined upwards, the latter short or replaced by phialides on upper levels, tree-like and longer, 50-100 $\mu \mathrm{m}$, on lower levels. Phialides formed solitary or mostly in whorls of 2-3(-4), divergent, sometimes cruciform, often on 1-2 celled, sometimes thickened terminal branches mostly 2-3 $\mu \mathrm{m}$ wide. Phialides (4.5-)6-11(-14) $\times$ $2.3-3.0(-3.5) \mu \mathrm{m}, 1 / \mathrm{w}=(1.7-) 2.4-4.6(-5.6),(1.2-) 1.5-2.0(-$ $2.5) \mu \mathrm{m}$ wide at the base $(n=30)$, narrowly lageniform, often with long neck, mostly inaequilateral, straight in tree-like conidiophores, curved in dense pustule cores. Conidia (2.8-) $3.2-4.0(-4.5) \times(2.3-) 2.5-3.0 \mu \mathrm{m}, 1 / \mathrm{w}=(1.1-) 1.2-1.5(-1.7)$ $(n=30)$, yellowish green, ellipsoidal, smooth, with 1-2 guttules or eguttulate, scar indistinct. At $30^{\circ} \mathrm{C}$ surface hyphae with numerous submoniliform thickenings and constricted septa; autolytic activity and coilings conspicuous; coconut-like odour appearing after 3-4 days; chlamydospores more abundant; conidiation scant and ill-organised.

On PDA after $72 \mathrm{~h} 9-12 \mathrm{~mm}$ at $15^{\circ} \mathrm{C}, 38-40 \mathrm{~mm}$ at $25^{\circ} \mathrm{C}$, $27-33 \mathrm{~mm}$ at $30^{\circ} \mathrm{C}$; mycelium covering the plate after 56 days at $25^{\circ} \mathrm{C}$. Colony with distinct circular outline and well- 
defined margin, conspicuously dense with thick surface hyphae radially agglutinated in densely arranged strands, not zonate. Centre flat, mottled, with moniliform surface hyphae, surface of the residual colony covered by a thick whitish tomentum of long and high aerial hyphae, the latter radially arranged towards the margin, often agglutinated into strands, soon collapsing, producing yellow drops. Autolytic excretions abundant, coilings frequent. Reverse turning yellow from the centre, 3A3-5, dull yellow, 4AB4-5, after 2 weeks; odour indistinct. Conidiation starting after 2 days in the flat centre mostly on short aerial hyphae, effuse, spreading slowly towards the distal margin, ascending on long aerial hyphae, mostly as long narrow regularly tree-like conidiophores, turning green only in the centre. At $15^{\circ} \mathrm{C}$ development slower, at $30^{\circ} \mathrm{C}$ marginal hyphae submoniliform, chlamydospores abundant in aerial hyphae, conidiation scant.

On SNA after $72 \mathrm{~h} 8-12 \mathrm{~mm}$ at $15^{\circ} \mathrm{C}, 24-35 \mathrm{~mm}$ at $25^{\circ} \mathrm{C}$, $19-22 \mathrm{~mm}$ at $30^{\circ} \mathrm{C}$; mycelium covering the plate after 1 week at $25^{\circ} \mathrm{C}$. Colony hyaline, thin, loose; indistinctly broadly, irregularly zonate with margins of individual zones ill-defined with irregular outgrowths; hyphae with conspicuous differences in thickness; distal region slightly downy due to aerial hyphae arising several $\mathrm{mm}$ high; surface and aerial hyphae degenerating within a week. Autolytic excretions inconspicuous, frequent at $30^{\circ} \mathrm{C}$, coilings common, abundant at $30^{\circ} \mathrm{C}$. No pigment, no distinct odour noted. Chlamydospores seen after 3-4 days, abundant, terminal and intercalary, globose to pyriform, often in chains. Conidiation tufts or pustules appearing after 3-4 days in indistinctly separated concentric rings and close to the distal margin, up to $4 \mathrm{~mm}$ diam, aggregations to $9 \mathrm{~mm}$ long, turning green, 26-27F6-8, after 4-5 days. Structure of tufts or pustules similar to CMD. At $15^{\circ} \mathrm{C}$ slow development, with tufts confluent to large irregular masses; chlamydospores rare. At $30^{\circ} \mathrm{C}$ growth more regular, denser, surface hyphae with submoniliform thickenings and often in irregular strands, conidiation macroscopically invisible, scant, on short conidiophores with moniliform terminal branches. Autolytic activity conspicuous, coilings abundant. Chlamydospores conspicuously abundant, intercalary and terminal, (6-)7-13(-21) × (3-)5-10(-14) $\mu \mathrm{m}, 1 / \mathrm{w}=0.8-2.1$ $(-4.4)(n=91)$, variable, subglobose, fusoid, ellipsoidal, oblong to rectangular, often in chains and sometimes resembling dimorphic ascospores.

Habitat: on wood, bark and lignicolous fungi such as species of Stilbohypoxylon or Rosellinia, also endophytic in wood of Theobroma spp.

Distribution: uncommon but widespread, Africa (Ghana), Central and South America (Brazil, Costa Rica, Ecuador, Puerto Rico), Europe (Germany, UK).

Holotype: Puerto Rico, Caribbean National Forest, El Yunque Recreation Area, trail from Palo Colorado, elev. 700$800 \mathrm{~m}$, on palm leaf midribs with Stilbohypoxylon moelleri, 22 Feb. 1996, G.J.S. 8076 (BPI 744463; holotype of T. stilbohypoxyli BPI 744463B; ex-type culture G.J.S. 96-30= ATCC MYA 2970=CBS 992.97=DAOM 231834; not seen).

Specimens examined: Germany, Rheinland-Pfalz, Eifel, Landkreis Daun, Gerolstein, Eifel, forest path shortly after Mürlenbach, left off the road heading north, $50^{\circ} 09^{\prime} 32^{\prime \prime} \mathrm{N}$, $06^{\circ} 36^{\prime} 36^{\prime \prime} \mathrm{E}$, elev. $380 \mathrm{~m}$, on partly decorticated branch of Carpinus betulus $8 \mathrm{~cm}$ thick on moist bare ground, on wood, soc. Hypoxylon howeianum, Mollisia sp., holomorph, 20 Sep. 2004, H. Voglmayr \& W. Jaklitsch, W.J. 2736 (WU 29478, culture CBS 119501=C.P.K. 1979). United Kingdom, Essex, Loughton, Epping Forest, Strawberry Hill Ponds, MTB 43-34/1, 51 $38^{\prime} 58^{\prime \prime}$ N, $00^{\circ} 02^{\prime} 22^{\prime \prime}$ E, elev. $30 \mathrm{~m}$, on a branch of Fagus sylvatica $15 \mathrm{~cm}$ thick, on bark, stromata and subiculum of Rosellinia corticium and ozonium, holomorph, 12 Sep. 2007, H. Voglmayr \& W. Jaklitsch, W.J. 3158 (WU 29479, culture C.P.K. 3150). Norfolk, Thetford, Emilys Wood, near Brandon, MTB 35$31 / 2,52^{\circ} 28^{\prime} 08^{\prime \prime} \mathrm{N}, 00^{\circ} 38^{\prime} 20^{\prime \prime} \mathrm{E}$, elev. $20 \mathrm{~m}$, on partly decorticated branch of Fagus sylvatica $3.5 \mathrm{~cm}$ thick on the ground, present as anamorph, soc. Hypocrea neorufoides, 13 Sep. 2004, H. Voglmayr \& W. Jaklitsch (deposited as $H$. neorufoides WU 29300; culture C.P.K. 1978). Thetford, close to the town on the right side of the road from Elveden, at a parking place, $52^{\circ} 24^{\prime} 00^{\prime \prime} \mathrm{N}, 00^{\circ} 42^{\prime} 43^{\prime \prime} \mathrm{E}$, elev. $30 \mathrm{~m}$, on branches of Fagus sylvatica $10 \mathrm{~cm}$ thick in a small pile on the ground, holomorph, teleomorph immature, culture from conidia, 12 Sep. 2004, H. Voglmayr \& W. Jaklitsch, W.J. 2704 (WU 29477, culture C.P.K. 1977).

Notes: Hypocrea stilbohypoxyli is a typical species of the section Trichoderma with low tendency to form pulvinate stromata, i.e. often maturing when effused. It produces the largest stromata of the section in Europe apart from $H$. ochroleuca and $H$. subeffusa. The anamorph of $H$. stilbohypoxyli may attract attention in nature due to its abundance under favourable conditions and its bright bluegreen colour. In culture, T. stilbohypoxyli is conspicuous particularly on CMD at $25^{\circ} \mathrm{C}$, due to pustules with a yellow reverse that consist of a dense core of curved conidiophores and phialides reminiscent of $H$. rufa/T. viride, surrounded by regularly tree-like conidiophores. Characteristic are also the irregularly thickened cells in surface hyphae around pustules, and notable the abundant chlamydospores on SNA at $30^{\circ} \mathrm{C}$ that are sometimes reminiscent of ascospores. These cultural traits have not been ascertained in nonEuropean strains. According to Samuels et al. (2006a) $H$. stilbohypoxyli has a remarkably wide geographic distribution. Whether or not all these specimens and cultures represent a single species is not clear. In fact, although clustering together, the European isolates differ from others consistently in gene sequences, one nucleotide in ITS, five in $\mathrm{rpb} 2$ and 21 nucleotides in tef1 introns four and five. Other differences deduced from the description in Samuels et al. (2006a) are smaller stroma size, slightly smaller 
ascospores, faster growth, distinctly zonate, green colonies on PDA, and infrequent chlamydospores in non-European strains.

Hypocrea subeffusa Jaklitsch, sp. nov. Fig. 22 MycoBank MB 516705

Anamorph: Trichoderma subeffusum Jaklitsch, sp. nov. Fig. 23

MycoBank MB 516706

Stromata subeffusa vel subpulvinata, fusce rubro- ad ianthinobrunnea, tomentosa, $1-8 \mathrm{~mm}$ lata. Asci cylindrici, $(63-) 70-90(-114) \times(4-) 5-6(-7) \mu \mathrm{m}$. Ascosporae bicellulares, hyalinae, verruculosae vel spinulosae, ad septum disarticulatae, pars distalis (sub)globosa, (3.3-)3.5-4.2($4.7) \times(3.0-) 3.5-4.0(-4.7) \mu \mathrm{m}$, pars proxima oblonga vel cuneata, $(3.3-) 4.0-5.0(-6.3) \times(2.3-) 2.8-3.5(-4.0) \mu \mathrm{m}$. Anamorphosis Trichoderma subeffusum. Conidiophora disposita in pustulis laxis in agaro CMD. Phialides divergentes, anguste lageniformes, $(9-) 10-14(-18) \times(2.0-) 2.2-2.5(-3.0)$ $\mu \mathrm{m}$. Conidia ellipsoidea, dilute viridia, glabra, (2.8-)3.3-4.0 $(-4.7) \times(2.3-) 2.5-3.0(-3.5) \mu \mathrm{m}$.

Etymology: subeffusa addresses the subeffuse stroma shape.

Stromata when collected were not quite fresh; $1-8 \mathrm{~mm}$ diam, to $0.5 \mathrm{~mm}$ thick, gregarious or aggregated in small numbers, mostly thinly (sub-)effuse, broadly attached, margin partly detached; outline variable. Surface hairy at least when young; ostiolar dots typically invisible. Colour brown to dark reddish- to violaceous-brown, with white margin when young. Associated anamorph dark green.

Stromata when dry $(0.3-) 1.4-8(-28) \times 0.3-3(-8) \mathrm{mm}$, $0.1-0.25(-0.4) \mathrm{mm}(n=58)$ thick; thinly (sub-)effuse, membranaceous, larger stromata breaking up into smaller, discoid or flat pulvinate pieces; broadly attached, margin rounded, often becoming detached and sometimes involute. Outline roundish, oblong or irregularly lobed. Surface velutinous to smooth, with rust hairs or finely floccose when young. Ostiolar dots $(15-) 20-38(-80) \mu \mathrm{m}(n=50)$ diam, indistinct, only visible after high magnification, pale or concolorous with the surface, roundish or oblong, plane, rarely papillate. Stromata first white with the centre turning rust to reddish brown, later turning entirely dark brown, reddish brown, or often violaceous-brown, 9-12F(5-)6-8, to black. Spore deposits white. Entostroma narrow, white or of a white basal and a yellowish upper layer. Dark subeffuse stroma after rehydration distinctly red to reddish brown, slightly thicker than dry, with distinct, minute, hyaline, convex ostiolar openings; colour mottled, dark red to black in $3 \% \mathrm{KOH}$.

Stroma anatomy: Ostioles (42-)50-63(-75) $\mu \mathrm{m}$ long, plane or projecting to $10 \mu \mathrm{m},(8-) 11-23(-28) \mu \mathrm{m}(n=30)$ wide at the apex inside, with inconspicuous apical cells sometimes clavate and to $4 \mu \mathrm{m}$ wide. Perithecia (105-) $130-190(-215) \times(87-) 110-160(-180) \mu \mathrm{m}(n=30)$, globose to flask-shaped, crowded, often lacking in marginal areas of the stroma; peridium (11-)13-19(-24) $\mu \mathrm{m}(n=30)$ thick at the base, $(6-) 10-15(-19) \mu \mathrm{m}(n=30)$ at the sides. Cortical layer (13-)17-28(-34) $\mu \mathrm{m}(n=30)$ thick, a narrow reddish brown $t$. angularis of indistinct, thick-walled, angular cells $(2.5-) 4.0-7.0(-8.5) \times(2.0-) 3.0-5.0(-6.5) \mu \mathrm{m} \quad(n=67)$ in face view and in vertical section; surface smooth or with protuberances, mottled, i.e. pigment inhomogeneously distributed, appearing as resinous drops. Hairs on mature stromata $(6-) 8-22(-33) \times(2.5-) 3-5(-7) \mu \mathrm{m} \quad(n=32)$, frequent, sometimes fasciculate, erect, cylindrical or attenuated terminally, 1-6 celled, pale brown, smooth or with minute globose warts. Subcortical tissue a (sub-)hyaline $t$. angularis of thin-walled cells $(4-) 5-11(-15) \times(2.5-) 4-7(-$ 8) $\mu \mathrm{m}(n=30)$ intermingled with some hyphae $(1.5-) 3.0$ $6.0(-7.5) \mu \mathrm{m}(n=30)$ wide. Subperithecial tissue a typically narrow $t$. angularis-epidermoidea of variable thin-walled cells $(4.5-) 5-14(-22) \times(2.5-) 4-7(-9) \mu \mathrm{m}(n=30)$, hyaline or with yellowish brown patches. Basal and marginal tissue a $t$. intricata of hyaline to pale yellowish brown, thinwalled hyphae $(1.5-) 2-6(-10) \mu \mathrm{m}(n=30)$ wide, often incorporating algal cells. Thickness of subperithecial and basal tissues smaller than or equal to perithecial height. Asci (63-)70-90(-114)×(4-)5-6(-7) $\mu \mathrm{m}$, stipe (1-)6-17(30) $\mu \mathrm{m}(n=45)$ long; croziers apparently absent. Ascospores hyaline, verruculose or finely spinulose, often smooth inside asci, cells dimorphic, distal cell (3.3-)3.5-4.2(-4.7) $\times$ (3.0-)3.5-4.0(-4.7) $\mu \mathrm{m}, 1 / \mathrm{w} 1.0-1.1(-1.2) \quad(n=60)$, (sub-) globose, sometimes wedge-shaped, proximal cell (3.3-)4.0 $5.0(-6.3) \times(2.3-) 2.8-3.5(-4.0) \mu \mathrm{m}, 1 / \mathrm{w}(1.2-) 1.3-1.6(-1.8)$ $(n=60)$, oblong, wedge-shaped, or subglobose.

Cultures and anamorph: optimal growth at $25^{\circ} \mathrm{C}$ on all media, poor and limited growth at $30^{\circ} \mathrm{C}$, no growth at $35^{\circ} \mathrm{C}$.

On CMD after $72 \mathrm{~h} 15-18 \mathrm{~mm}$ at $15^{\circ} \mathrm{C}, 26-28 \mathrm{~mm}$ at $25^{\circ} \mathrm{C}, 4-6 \mathrm{~mm}$ at $30^{\circ} \mathrm{C}$; mycelium covering the plate after 1 week at $25^{\circ} \mathrm{C}$. Colony hyaline, thin, circular; hyphae with irregular orientation. Margin well-defined, appearing curly due to numerous large coilings and numerous minute secondary hyphae. Aerial hyphae infrequent, becoming fertile; more abundant and longer in distal areas and there often visible as white radial patches. No autolytic activity noted, but minute excretions frequent at $30^{\circ} \mathrm{C}$. Coilings characteristic, conspicuous, particularly in marginal areas of the colony, large, $150-500 \mu \mathrm{m}$ diam. No pigment, no distinct odour noticeable. Chlamydospores rare, noted after $1-2$ weeks, abundant at $30^{\circ} \mathrm{C}$. Conidiation at $25^{\circ} \mathrm{C}$ starting after 2 days; first effuse, on short, erect, narrow, simple conidiophores with few asymmetrical branches, long phialides and mostly 2-3 conidial heads; spreading loosely across the entire colony, becoming dry and pale greenish in the stereo-microscope; later in 

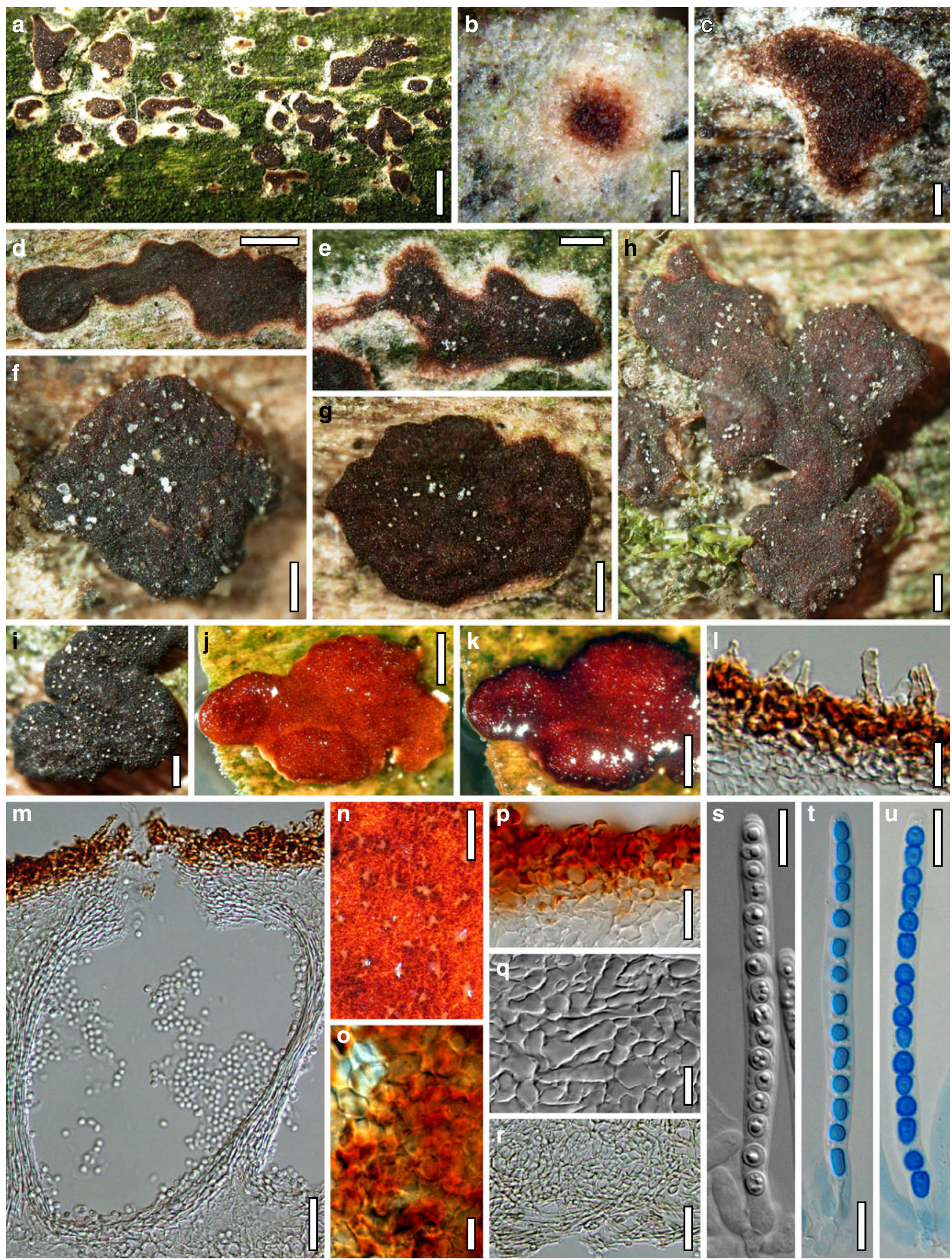
4Fig. 22 Teleomorph of Hypocrea subeffusa. a-i. Dry stromata (a. habit, nearly fresh; b. stroma initial; c-e. immature). j. Rehydrated mature stroma. k. Stroma of j in $3 \% \mathrm{KOH}$. I. Hairs on stroma surface. m. Perithecium in section. n. Rehydrated stroma surface. o. Stroma surface in face view. p. Cortical and subcortical tissue in section. q. Subperithecial tissue in section. r. Stroma base in section. s-u. Asci with ascospores (t, $\mathbf{u}$. in cotton blue/lactic acid). a, $\mathbf{c}, \mathbf{e}, \mathbf{j}-\mathbf{t}$. holotype WU 29487. b, d, g-i. WU 29488. f, u. WU 29490. Scale bars: $\mathbf{a}=$ $1.5 \mathrm{~mm} . \mathbf{b}, \mathbf{c}=0.12 \mathrm{~mm} . \mathbf{d}=1 \mathrm{~mm} . \mathbf{e}-\mathbf{i}=0.3 \mathrm{~mm} . \mathbf{j}, \mathbf{k}=0.8 \mathrm{~mm} . \mathbf{l}, \mathbf{p}=$ $15 \mu \mathrm{m}$. m, $\mathbf{r}=25 \mu \mathrm{m} . \mathbf{n}=70 \mu \mathrm{m} . \mathbf{o}=5 \mu \mathrm{m} . \mathbf{q}, \mathbf{s}-\mathbf{u}=10 \mu \mathrm{m}$

numerous asymmetrical shrubs on distal and lateral margins, growing to amorphous fluffy tufts or loose transparent pustules $0.8-1.5 \mathrm{~mm}$ diam, confluent to $3-5 \mathrm{~mm}$, becoming pale yellowish green, 28-29CD5-8 to 28E5-8, after 910 days; spreading back across the plate, finally collapsing; pustules more regularly circular and compact at $15^{\circ} \mathrm{C}$. No major structural differences apparent between effuse and tuft conidiation. Shrubs or tufts arising on thick-walled stipes to $0.3 \mathrm{~mm}$ long, with few mostly unpaired, primary branches in right angles. Stipes and primary branches 5-7.5 $\mu \mathrm{m}$ wide, thickenings to $10 \mu \mathrm{m}$. Primary branches either forming treelike conidiophores directly or rebranching into a loose net of delicate branches mostly $3-4(-5) \mu \mathrm{m}$ wide, giving rise to regular terminal tree-like conidiophores with branches attenuated to (1.5-)2.0-2.5(-3.0) $\mu \mathrm{m}$ in terminal regions. Branches slightly or distinctly inclined upwards, bearing phialides solitary or divergent, rarely parallel, in simple whorls of 2-3 (-4) on cells 1.5-3 $\mu \mathrm{m}$ wide. Phialides (9-) $10-14(-18) \times$ (2.0-)2.2-2.5(-3.0) $\mu \mathrm{m}, 1 / \mathrm{w}(3.3-) 4.0-5.7(-7.0),(1.3-) 1.7-$ $2.2(-2.7) \mu \mathrm{m}(n=60)$ wide at the base, narrowly lageniform, straight, slightly curved or sinuous, not or only slightly thickened in various positions. Conidia produced in small numbers in minute wet to dry heads. Conidia (2.8-)3.3-4.0 $(-4.7) \times(2.3-) 2.5-3.0(-3.5) \mu \mathrm{m}, 1 / \mathrm{w}(1.2-) 1.3-1.4(-1.6)(n=$ $63)$, pale green, ellipsoidal, less commonly oval or pyriform, smooth, with 1 or several guttules, scar indistinct or broadly truncate. At $15^{\circ} \mathrm{C}$ conidiation in compact pustules to $2 \mathrm{~mm}$ diam along distal and lateral margins, green, 30CD4-6, 30E5-8, 28E4-8. At $30^{\circ} \mathrm{C}$ poor growth, hyphae forming numerous pegs, conidiation finely effuse, simple, dry; chlamydospores abundant, globose, mainly terminal.

On PDA after $72 \mathrm{~h} 14-16 \mathrm{~mm}$ at $15^{\circ} \mathrm{C}, 25-28 \mathrm{~mm}$ at $25^{\circ} \mathrm{C}$, 2-3 $\mathrm{mm}$ at $30^{\circ} \mathrm{C}$; mycelium covering the plate after 1 week at $25^{\circ} \mathrm{C}$. Colony circular, compact, dense, zonate; margin welldefined; hyphae narrow. Surface becoming whitish, downy to floccose, centre denser and farinose. Aerial hyphae numerous, thin, complexly branched, becoming fertile; simpler, longer and more radially arranged on the distal margin, forming strands arranged in a stellate manner. Autolytic activity inconspicuous, but numerous minute excretions noted at $30^{\circ} \mathrm{C}$; coilings absent or inconspicuous. Reverse turning dull yellow to yellow-brown, 4BD4-5; no distinct odour noted. Conidiation at $25^{\circ} \mathrm{C}$ noted after 2 days, effuse and farinose, short, spreading from the plug or proximal margin across the colony, in numerous densely set fine asymmetrical shrubs appearing as floccules or diffuse tufts with delicate tree-like conidiophores; also loose on long thin aerial hyphae; eventually condensing into a flat continuum in the centre and at the proximal margin, becoming pale yellowish green, 28BC4-6, 29B2-5, 29CD5-6, 30B2-3, $30 \mathrm{AB} 4-5$ to $27 \mathrm{CD} 4-5$ after $4-6$ days, diffusely spreading from the centre along the margin. At $15^{\circ} \mathrm{C}$ conidiation dry, in confluent shrubs to $0.8 \mathrm{~mm}$ diam with regular radial trees, becoming yellowish green, 29AB4, 30AB3-4, 29-30CD4-6, from the proximal margin. At $30^{\circ} \mathrm{C}$ growth poor, hyphae autolysing quickly.

On SNA after $72 \mathrm{~h} 12-13 \mathrm{~mm}$ at $15^{\circ} \mathrm{C}, 16-19 \mathrm{~mm}$ at $25^{\circ} \mathrm{C}$, 4-5 $\mathrm{mm}$ at $30^{\circ} \mathrm{C}$; mycelium covering the plate after 2 weeks at $25^{\circ} \mathrm{C}$. Colony irregular, with ill-defined to lobed margins; hyphae narrow, finely tubercular, loosely branched; usually only irregular lobes growing and few hyphae reaching the distal margin. Aerial hyphae scant, short, becoming fertile. Autolytic excretions frequent, minute, more numerous at $30^{\circ} \mathrm{C}$, coilings absent or inconspicuous; no pigment, no distinct odour noted. Chlamydospores noted after ca 1 week, infrequent, abundant at $30^{\circ} \mathrm{C}$. Conidiation at $25^{\circ} \mathrm{C}$ noted after 1 day, not becoming green within 3 weeks; effuse, on loosely disposed, simple, short conidiophores and in loose delicate shrubs with asymmetrical branching; at most visible as whitish down or few whitish fluffy tufts resulting from aggregation of small shrubs; wet conidial heads to $40 \mu \mathrm{m}$ diam, green in the stereomicroscope. Chlamydospores at $30^{\circ} \mathrm{C}(6-) 8-14(-17) \times(6-) 7-$ $13(-18) \mu \mathrm{m}, 1 / \mathrm{w}(0.8-) 0.9-1.2(-1.3)(n=33)$, globose, oval or ellipsoidal, terminal and intercalary. At $15^{\circ} \mathrm{C}$ marginal surface hyphae sinuous; conidiation scant, effuse. At $30^{\circ} \mathrm{C}$ growth poor, hyphae narrow, forming numerous pegs, autolysing with numerous minute excretions; chlamydospores frequent; conidiation effuse.

Habitat: on decorticated, medium to well-decomposed wood, apparently associated with green algae.

Distribution: Europe (Austria, Ukraine).

Holotype: Austria, Niederösterreich, Wien-Umgebung, Mauerbach, Friedhofstrasse, MTB 7763/1, 48 15'25" N $16^{\circ}$ $10^{\prime} 18^{\prime \prime}$ E, elev. $320 \mathrm{~m}$, on decorticated branch of Sambucus nigra $1.5-3 \mathrm{~cm}$ thick partly attached to the shrub, on/soc. green algae, soc. Hyphoderma sambuci and an effete pyrenomycete, holomorph, 30 Sep. 2006, W. Jaklitsch, W. J. 2998 (WU 29487; ex-type culture CBS 120929=C.P.K. 2479). Holotype of Trichoderma subeffusum isolated from WU 29487 and deposited as a dry culture with the holotype of $H$. subeffusa as WU 29487a.

Other specimens examined: Austria, Niederösterreich, Hagenbrunn, east side of the Bisamberg, entering from Wolfsbergen-Siedlung, MTB 7664/3, 48 ${ }^{\circ} 19^{\prime} 25^{\prime \prime} \mathrm{N} \mathrm{16} 23^{\prime}$ $18^{\prime \prime} \mathrm{E}$, elev. $300 \mathrm{~m}$, on branch of Carpinus betulus $5-6 \mathrm{~cm}$ thick, on wood, 1 Nov. 2007, W. Jaklitsch, W.J. 3185 (WU 29490, culture C.P.K. 3171). Ukraine, Kharkivska Oblast, 

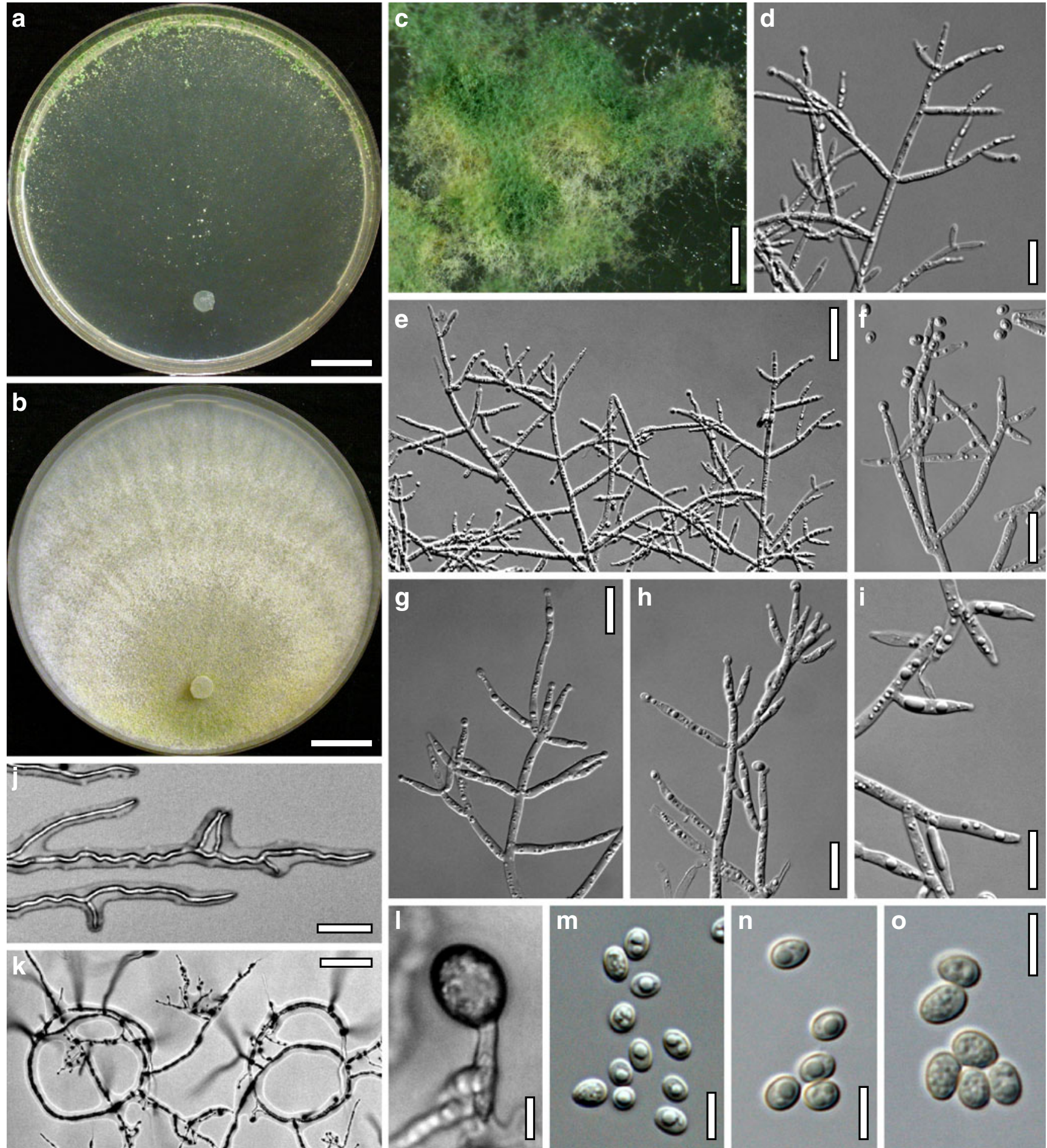

Fig. 23 Cultures and anamorph of Hypocrea subeffusa. a, b. Cultures (a. on CMD, 14 days; b. on PDA, 7 days). c. Conidiation tufts (CMD, 20 days). $\mathbf{d}-\mathbf{h}$. Conidiophores (6-7 days). i. Phialides (6 days). j. Sinuous surface hyphae (SNA, $15^{\circ} \mathrm{C}, 4$ days). k. Coilings in surface hyphae

Kharkov, National nature park Gomolshanskie lesa, Zmiev area, on decorticated branch of Quercus robur, soc. green algae and immature thyriothecia, 25 Nov. 2006, O. Prilutsky, comm. A. Akulov AS 2136 (WU 29488, culture

(5 days). I. Terminal chlamydospore (SNA, $30^{\circ} \mathrm{C}, 7$ days). $\mathbf{m}-\mathbf{0}$. Conidia (5-7 days). a-o. All at $25^{\circ} \mathrm{C}$ except j, I. d-i, $\mathbf{k}, \mathbf{m}-\mathbf{0}$. From CMD. a-f, $\mathbf{i}-\mathbf{m}$. CBS 120929. g, h, n, o. C.P.K. 2864. Scale bars: $\mathbf{a}, \mathbf{b}=15 \mathrm{~mm}$. c. $0.5 \mathrm{~mm}$. $\mathbf{d}, \mathbf{f}-\mathbf{h}=15 \mu \mathrm{m} . \mathbf{e}=30 \mu \mathrm{m} . \mathbf{i}=10 \mu \mathrm{m} . \mathbf{j}=50 \mu \mathrm{m} . \mathbf{k}=100 \mu \mathrm{m} . \mathbf{l}-\mathbf{o}=5 \mu \mathrm{m}$

C.P.K. 2864). Same area, on hardwood, 6 July 2007, A. Akulov AS 2441 (WU 29489, culture C.P.K. 3134).

Notes: Hypocrea subeffusa is characterised by more or less effuse, violaceous-brown stromata growing in associ- 
ation with green algae on decorticated wood. Stromata were nearly dry at collection times and may be more reddish brown when fresh, as suggested by the red colour after rehydration. Dry stromata may be confounded with those of $H$. neorufa and $H$. neorufoides, which differ in a yellow colour when young, in darker and more compact dry stromata, in yellow perithecial walls, and in many culture and anamorph characteristics. The dark brown dry stromata of $H$. petersenii lack violet tones. T. petersenii sporulates well on all media, grows well at $30^{\circ} \mathrm{C}$ and grows substantially faster on all media than T. subeffusum. The large coilings on the surface of larger colonies of $T$. subeffusum on CMD close to the distal margin have been detected in all isolates. They have not been seen in any other Hypocrea anamorphs in Europe so far, i.e. they are characteristic for this species. In addition, T. subeffusum is one of the few species that sporulate well on CMD, but poorly on SNA.

Hypocrea valdunensis Jaklitsch, sp. nov. Fig. 24

MycoBank MB 516708

Anamorph: Trichoderma valdunense Jaklitsch, sp. nov. Fig. 25

\section{MycoBank MB 516709}

Differt a Hypocrea viridescente ascosporis minoribus, incremento tardiore et conidiis glabris. Ascosporae bicellulares, hyalinae, verruculosae vel spinulosae, ad septum disarticulatae, pars distalis (sub)globosa, (3.0-)3.3-3.7 $(-4.0) \times(2.8-) 3.0-3.5 \mu \mathrm{m}$, pars proxima oblonga, $(3.5-)$ $3.8-4.5(-5.0) \times(2.3-) 2.5-3.0 \mu \mathrm{m}$. Phialides divergentes, lageniformes, $(4.5-) 6-11(-14) \times(1.8-) 2.2-2.8(-3.2) \mu \mathrm{m}$. Conidia ellipsoidea vel ovalia, luteo-viridia in agaro CMD, glabra, (2.7-)3.2-3.8(-4.0)×(2.3-)2.5-2.8(-3.0) $\mu \mathrm{m}$.

Etymology: referring to its occurrence in Valduna, Vorarlberg, Austria.

Stromata when fresh 1-6 mm diam, $0.5-1.5 \mathrm{~mm}$ thick, gregarious, first effuse, effluent, becoming pulvinate, compact; outline circular to oblong; margin attached or free. Surface smooth, without ostiolar dots, yellowish brown to light brown with white margin in early stages, later caramel to bright reddish brown, eventually dark red when mature.

Stromata when dry $(0.7-) 1.2-5(-7) \times(0.5-) 1-3(-4.3) \mathrm{mm}$, $0.2-0.7(-1.1) \mathrm{mm}$ thick $(n=30)$; first thin, membranaceous, becoming flat pulvinate when mature, broadly attached; margin mostly concolorous, partly free, rounded. Outline circular, oblong or irregularly lobed. Surface smooth, tubercular or rugose, when young finely velvety or covered by rust hairs. Ostiolar dots absent, ostiolar openings sometimes visible, (16-)20-30(-32) $\mu \mathrm{m}(n=30)$ wide, inconspicuous, pale, more distinct and shiny after rehydration. Stromata starting as an effuse white mycelium, becoming light, yellowish-, orange-brown from the centre, $5 \mathrm{~B} 4,5-6 \mathrm{CD}(\mathrm{E}) 5-8$, eventually entirely medium to dark brown, 6-7E6-8, 6F7-8, 7F4-8. Rehydrated pulvinate stromata thicker than dry; hyaline ostiolar openings and radial cracks surrounding them becoming visible; turning dark red $8 \mathrm{~F} 6-8$ to black in $3 \% \mathrm{KOH}$.

Stroma anatomy: Ostioles (50-)56-73(-86) $\mu \mathrm{m}$ long, plane with the surface, (10-)14-24(-28) $\mu \mathrm{m}$ wide at the apex $(n=30)$; with convergent periphyses $1-2 \mu \mathrm{m}$ wide, lined by a palisade of hyaline, cylindrical to subclavate cells to $3 \mu \mathrm{m}$ wide at the apex. Perithecia $(128-) 145-210(-255) \times(75-)$ 115-175(-190) $\mu \mathrm{m}(n=30)$, numerous, 7-8 per mm stroma length, subglobose or flask-shaped; peridium (9-)14-21 $(-25) \mu \mathrm{m}(n=60)$ thick at the base and sides; hyaline to pale yellowish. Cortical layer (20-)26-43(-57) $\mu \mathrm{m}(n=30)$ thick, a thin irregular, amorphous, pigmented crust above a dense unevenly pigmented $t$. angularis of indistinct, thick-walled cells $(3-) 4-9(-12) \times(2.2-) 3.5-6.0(-9.0) \mu \mathrm{m}(n=65)$ in face view and in vertical section; orange-brown in lactic acid, reddish brown in water. Hairs on mature stromata (7-)9-24 $(-40) \times(2-) 3-5(-6) \mu \mathrm{m}(n=35)$, short cylindrical, smooth, rarely verrucose, of 1 to few cells, pale brown, infrequent at the upper surface, more frequent at stroma sides. Subcortical tissue a loose hyaline $t$. intricata of thin-walled hyphae (2-) $3-5(-5.5) \mu \mathrm{m}(n=30)$ wide. Subperithecial tissue a hyaline t. epidermoidea of thin-walled cells $(5-) 8-20(-29) \times(4-)$ $6-11(-12) \mu \mathrm{m}(n=32)$, partly orange-brown due to basal tissue reaching upwards into the subperithecial tissue in the centre. Basal and lateral tissue towards the base a dense $t$. intricata of hyaline to yellowish-, or orange-brown hyphae (2.0-)2.5-5.5 $(-7.0) \mu \mathrm{m}(n=33)$ wide. Asci $(69-) 70-80(-84) \times(3.8-) 4.2-5$ $(-5.7) \mu \mathrm{m}$, stipe (4-)6-12(-16) $\mu \mathrm{m}(n=30)$ long. Ascospores hyaline, verruculose, cells dimorphic, distal cell (3.0-)3.3-3.7 $(-4.0) \times(2.8-) 3.0-3.5 \mu \mathrm{m}, 1 / \mathrm{w} 1.0-1.1(-1.2) \quad(n=34)$, (sub-) globose, proximal cell $(3.5-) 3.8-4.5(-5.0) \times(2.3-) 2.5-3.0 \mu \mathrm{m}$, 1/w $(1.2-) 1.3-1.7(-1.9) \quad(n=34)$, oblong or slightly tapered downwards.

Cultures and anamorph: optimum but often limited growth at $25^{\circ} \mathrm{C}$ on all media except MEA; no growth at $35^{\circ} \mathrm{C}$. Good growth on MEA, therefore precultures were prepared using this medium.

On MEA plate nearly entirely covered by mycelium after 10 days. Conidiation effuse or in floccose (yellow-)green shrubs; right angles common; phialides in whorls to 4 on cells $2-4 \mu \mathrm{m}$ wide, becoming green with age, often curved to sinuous; thickly lageniform, often inaequilateral, with variable thickenings, mostly in or above the middle. Conidia pale, hyaline to yellowish green, distinctly yellow-green only in mass, smooth, subglobose or ellipsoidal, rarely oblong, with few minute guttules, scar indistinct.

On CMD after $72 \mathrm{~h} 1-10 \mathrm{~mm}$ at $15^{\circ} \mathrm{C}, 1-23 \mathrm{~mm}$ at $25^{\circ} \mathrm{C}$, $1-13 \mathrm{~mm}$ at $30^{\circ} \mathrm{C}$; mycelium covering the plate after 19 25 days at $25^{\circ} \mathrm{C}$. Colony of narrow hyphae, hyaline, thin, 

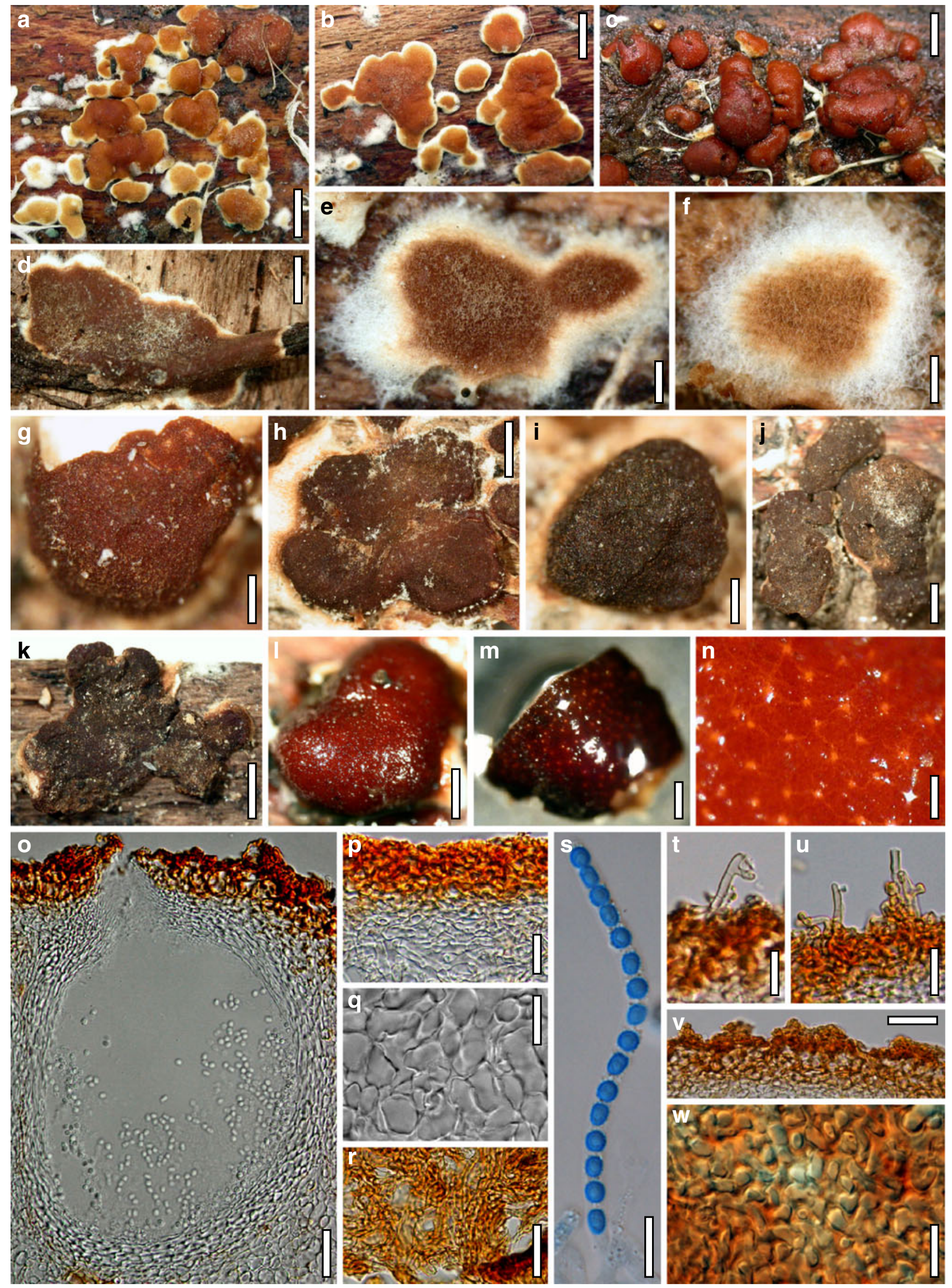
4Fig. 24 Teleomorph of Hypocrea valdunensis (WU 29516). a-c. Fresh stromata. d-k. Dry stromata (d-f. immature). 1. Rehydrated mature stroma. m. Stroma in $3 \% \mathrm{KOH}$ after rehydration. n. Rehydrated stroma surface showing ostiolar openings and inhomogeneous pigment. o. Perithecium in section. p. Cortical and subcortical tissue in section. q. Subperithecial tissue in section. r. Stroma base in section. s. Ascus with ascospores in cotton blue/lactic acid. t, u. Hairs on stroma surface. $\mathbf{v}$. Tubercular stroma surface in section. w. Stroma surface in face view. Scale bars: $\mathbf{a}-\mathbf{c}=2 \mathrm{~mm} . \mathbf{d}, \mathbf{h}, \mathbf{j}, \mathbf{k}=1 \mathrm{~mm}$. e, $\mathbf{f}, \mathbf{i}$, $\mathbf{m}=0.3 \mathrm{~mm} . \mathbf{g}=0.2 \mathrm{~mm} . \mathbf{I}=0.7 \mathrm{~mm} . \mathbf{n}=70 \mu \mathrm{m} . \mathbf{o}, \mathbf{r}, \mathbf{v}=25 \mu \mathrm{m} . \mathbf{p}, \mathbf{q}, \mathbf{t}$, $\mathbf{u}=15 \mu \mathrm{m} . \mathbf{s}, \mathbf{w}=10 \mu \mathrm{m}$

dense, homogeneous, with ill-defined, often irregularly lobed margin. Surface becoming finely downy to granular due to conidiation, granules growing to pustules $1(-2) \mathrm{mm}$ diam with granulose surface. Aerial hyphae scant, autolytic activity and coilings inconspicuous. No diffusing pigment, no distinct odour noted. Chlamydospores noted after 1 week at $30^{\circ} \mathrm{C}$, infrequent, terminal and intercalary, 5-11(-18) $\times(5-) 6-9(-11)$ $\mu \mathrm{m}, 1 / \mathrm{w}$ 0.8-1.4(-2.1) $(n=30)$, (sub-)globose, often only thickenings without septa formed. Conidiation noted after 2 days, (yellow-)green after 6-8 days; first effuse, on scant, short, simple conidiophores 30-100 $\mu \mathrm{m}$ long, sessile on surface hyphae, little and loosely branched, asymmetrical, with regularly tree-like terminal conidiophores; the latter also on some long aerial hyphae, 100-170 $\mu \mathrm{m}$ long. Phialides loosely disposed, solitary or in whorls of 2-3. Branches and phialides slightly or strongly inclined upwards. Effuse conidiation shortly followed by the formation of whitish shrubs $0.2-0.7 \mathrm{~mm}$ diam, growing to pustules, more or less radially disposed and along the margin, bearing minute wet conidial heads to $20(-40) \mu \mathrm{m}$ diam, drying. Pustules formed on a thick stipe asymmetrically branched into primary branches; stipe and primary branches 7-9 $\mu \mathrm{m}$ wide, thickwalled, verrucose, wall with wavy outline, swelling in $\mathrm{KOH}$; primary branches gradually tapering to $2 \mu \mathrm{m}$ terminally or forming a loosely branched right-angled reticulum. Peripheral terminal conidiophores steep, variable, broad, narrow with parallel sides, or regularly tree-like, i.e. with phialides on top, followed by 1-celled branches, and branches longer downwards, straight, in right angles or slightly inclined upwards. Phialides arising from sometimes slightly thickened cells $2-3.5 \mu \mathrm{m}$ wide, divergent in whorls of $2-4(-6)$, commonly 4 , often with 2 paired phialides emerging directly below the whorl. Phialides $(4.5-) 6-11(-14) \times(1.8-) 2.2-2.8$ $(-3.2) \mu \mathrm{m}, 1 / \mathrm{w}(1.8-) 2.3-4.6(-5.5),(1.0-) 1.5-2.0(-2.5) \mu \mathrm{m}$ wide at the base $(n=32)$, lageniform, not thickened or thickened at various positions, straight, mostly inaequilateral. Conidia $(2.7-) 3.2-3.8(-4.0) \times(2.3-) 2.5-2.8(-3.0) \mu \mathrm{m}$, $1 / \mathrm{w}(1.1-) 1.2-1.5(-1.7) \quad(n=30)$, subhyaline to yellowish green, ellipsoidal or oval, smooth, with minute guttules; scar indistinct or distinct and truncate. No structural difference except for increased complexity in pustules apparent between effuse and pustulate conidiation. At $15^{\circ} \mathrm{C}$ conidiation effuse, farinose. At $30^{\circ} \mathrm{C}$ colony outline irregular with wavy to lobed margin, dense; conidiation effuse, mostly central, with wet heads to $40 \mu \mathrm{m}$ diam, and in green, 28 $30 \mathrm{~F} 5-8$, pustules to $1 \mathrm{~mm}$ diam with minute wet heads on regular trees with narrow branches and fertile straight elongations to $0.3 \mathrm{~mm}$ long.

On PDA after $72 \mathrm{~h} 1-5 \mathrm{~mm}$ at $15^{\circ} \mathrm{C}, 0-15 \mathrm{~mm}$ at $25^{\circ} \mathrm{C}, 0$ $5 \mathrm{~mm}$ at $30^{\circ} \mathrm{C}$; mycelium covering the plate after $2-3$ weeks at $25^{\circ} \mathrm{C}$. Colony circular, dense to opaque, margin wavy to lobed, surface flat, whitish, downy to granular or floccose; often irregular outgrowths formed after temporary termination of growth; often a dense continuous, chalky to yellow zone of irregular outline or broad yellow, $4 \mathrm{AB} 4$, areas formed. Aerial hyphae numerous, forming a flat layer of radiating shrubs and short thick, irregularly oriented strands resulting in broom-like floccules or granules, becoming fertile. Autolytic activity inconspicuous, excretions minute, coilings moderate to frequent. Reverse becoming yellow, $4 \mathrm{AB} 3-5$, spreading from the plug; odour indistinct or slightly mushroomy. Conidiation noted after 2-4 days, effuse, on aerial hyphae mostly on lower levels, spreading from the plug, also on sessile, densely disposed, shrubs, remaining colourless. Conidial yield poor, more abundant in yellow areas.

On SNA after $72 \mathrm{~h} 1-4 \mathrm{~mm}$ at $15^{\circ} \mathrm{C}, 1-8 \mathrm{~mm}$ at $25^{\circ} \mathrm{C}, 0$ $7 \mathrm{~mm}$ at $30^{\circ} \mathrm{C}$; mycelium covering the plate after $3-4$ weeks at $25^{\circ} \mathrm{C}$. Colony of thin hyphae, circular and compact, or irregular with lobed margin and varying density, thin, indistinctly zonate. Aerial hyphae inconspicuous; no autolytic activity noted, coilings moderate. No pigment, no distinct odour noted. Conidiation noted after 1-2 days, more distinct than on CMD; first effuse and loosely disposed on aerial hyphae, with wet conidial heads to $70 \mu \mathrm{m}$, spreading from the plug. After degeneration of the effuse conidiation pustules to $1.5 \mathrm{~mm}$ diam with straight fertile elongations formed around the plug spreading across the colony or concentrated in a broad, concentric, diffuse distal zone, turning green, 2728E4-5 to $28 \mathrm{~F} 5-8$, after 11-13 days. Conidia produced in numerous minute wet heads on regular small trees. Chlamydospores rare, noted after 3 weeks at $25^{\circ} \mathrm{C}$.

Habitat: on wood of Fagus sylvatica.

Distribution: Austria, known only from the type specimen.

Holotype: Austria, Vorarlberg, Feldkirch, Rankweil, behind the hospital LKH Valduna, MTB 8723/2, 47 $15^{\prime}$ $40^{\prime \prime} \mathrm{N}, 09^{\circ} 39^{\prime} 00^{\prime \prime}$ E, elev. $510 \mathrm{~m}$, on decorticated branches of Fagus sylvatica 4-6 cm thick, on wood, soc. effete Bertia moriformis/Neobarya parasitica, Nemania serpens, Phlebiella vaga; holomorph, teleomorph largely immature, 31 Aug. 2004, H. Voglmayr \& W. Jaklitsch, W.J. 2646 (WU 29516, culture CBS $120923=$ C.P.K. 2050). Holotype of Trichoderma valdunense isolated from WU 29516 and deposited as a dry culture with the holotype of $H$. valdunensis as WU 29516a.

Notes: Mature stromata of $H$. valdunensis appear to be intermediate between $H$. viridescens due to bright reddish 


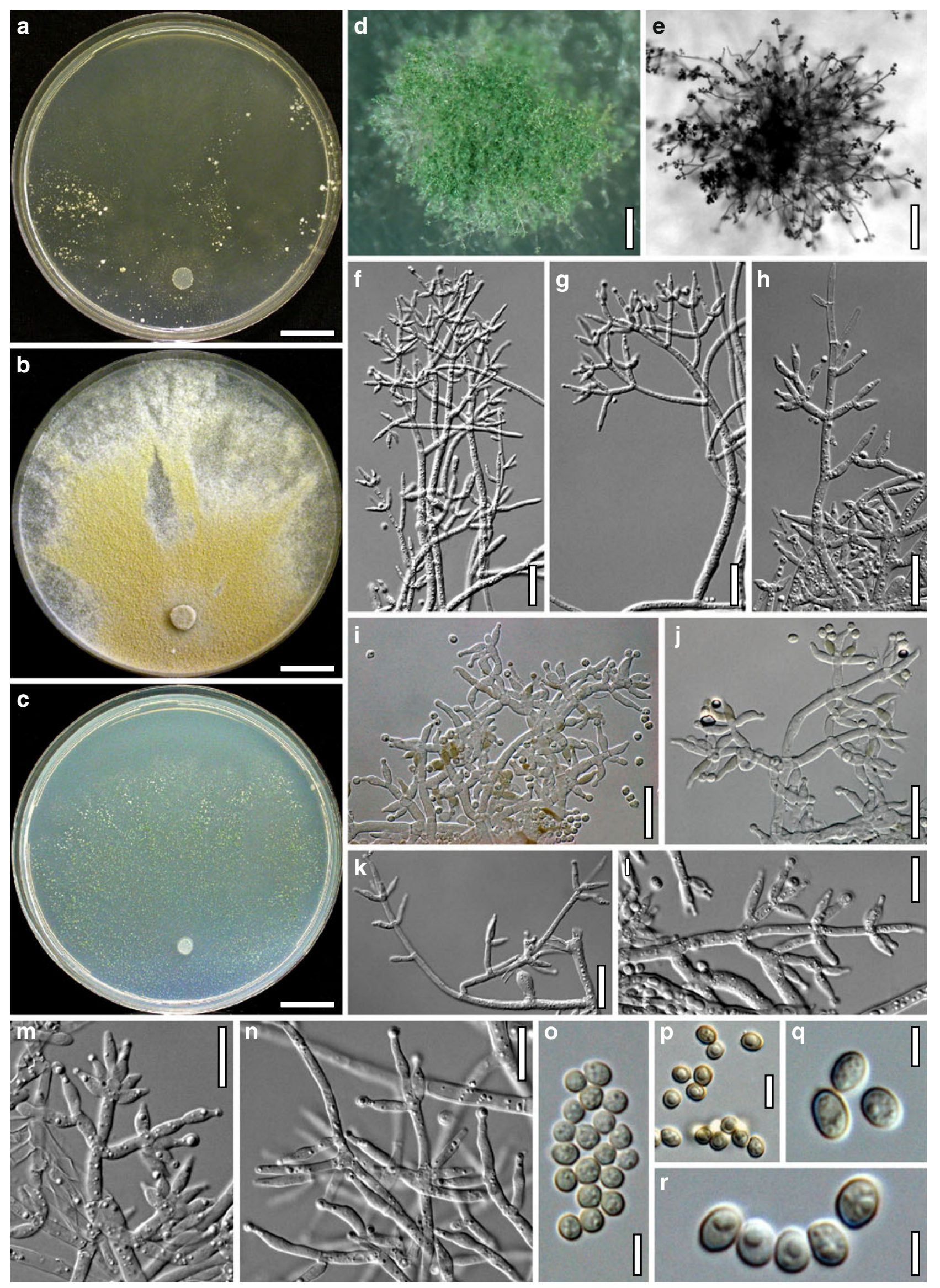


4Fig. 25 Cultures and anamorph of Hypocrea valdunensis (CBS 120923). a-c. Cultures (a. on CMD, 19 days; b. on PDA, 19 days; c. on SNA, 21 days). d, e. Conidiation tufts (CMD; d. 27 days, stereomicroscope. e. 11 days, compound microscope, $10 \times$ objective). $\mathbf{f}-\mathbf{m}$. Conidiophores (f-h, k-m. CMD, 6-8 days; $\mathbf{i}, \mathbf{j}$. MEA, 10 days). $\mathbf{n}$. Phialides (CMD, 8 days). o-r. Conidia (o. MEA, 10 days; p. from tuft, CMD, 27 days; q, r. CMD, 6 days). a-r. All at $25^{\circ} \mathrm{C}$. Scale bars: $\mathbf{a}-\mathbf{c}=$ $15 \mathrm{~mm}$. d, e. $=80 \mu \mathrm{m}$. f, $\mathbf{g}=20 \mu \mathrm{m}$. $\mathbf{h}-\mathbf{k}=15 \mu \mathrm{m}$. $\mathbf{l}-\mathbf{n}=10 \mu \mathrm{m} . \mathbf{o}, \mathbf{p}=$ $5 \mu \mathrm{m} . \mathbf{q}, \mathbf{r}=3 \mu \mathrm{m}$

brown colours when fresh and $H$. neorufa, $H$. neorufoides, $H$. petersenii and $H$. subeffusa due to the dark brown colour when dry. The phylogenetically closest related species, $H$. viridescens, has in addition smaller stromata, slightly larger perithecia, larger ascospores and wider, verruculose conidia. Limited and conspicuously slow growth, i.e. less than half of the growth rate of $H$. neorufoides, necessitating the use of MEA as a preculture medium for growth rate experiments, but also the farinose yellow conidiation on PDA, set it apart from all other species of the section Trichoderma currently known in Europe to form teleomorphs. However, one isolate may not be sufficient to estimate its entire variation.

Hypocrea viridescens Jaklitsch \& Samuels, Stud. Mycol. 56: 156 (2006b). Fig. 26

Anamorph: Trichoderma viridescens (A.S. Horne \& H.S. Williamson) Jaklitsch \& Samuels, Stud. Mycol. 56: 156 (2006b). Fig. 27

$\equiv$ Eidamia viridescens A.S. Horne \& H.S. Williamson, Ann. Bot. 37: 396 (1923).

Stromata when fresh 0.5-4 mm diam, 0.5-1.5 mm thick, solitary, loosely gregarious or densely aggregated in lines, first subeffuse, becoming pulvinate, broadly or centrally attached; margins free, concolorous, sometimes white when young. Outline circular, angular or irregular. Surface downy when young, covered with yellowish to rust hairs; later glabrous, smooth or finely granular by perithecial contours. Ostiolar dots invisible or appearing as inconspicuous, light to dark dots. Stroma colour when young brown-orange, light brown, yellow-brown to bright reddish brown, 5B5-6, 6CD5-8, 8BC7-8; when mature mostly dark reddish brown to dark red, 7DE7-8, 8-9EF6-8, 10CD7-8; rarely rosy-brownish or greyish red, 8CD5-6, or orange to orange-red, 6A6-7, 7A5-6.

Stromata when dry $(0.2-) 0.6-1.6(-3.6) \mathrm{mm} \quad(n=277)$ diam, $0.2-0.5(-0.8) \mathrm{mm}(n=33)$ thick; thin, semi-effuse to effuse, hairy, with white to rust margin young; later effluent, discrete and pulvinate with circular, angular to irregular outline. Surface uneven, tubercular to wrinkled; ostioles invisible or appearing as dots (24-)34-64(-79) $\mu \mathrm{m}$ $(n=33)$ diam, light with darker marginal rings, plane or convex. Stromata when young first white, turning yellowish, yellow-, orange-, rust-brown, 4A4, 5BD4-7, 6-7CD(E) $5-8$, later in the great majority of stromata deep and dark reddish brown, 7-9EF5-8, unchanged or slightly darkened in $3 \% \mathrm{KOH}$.

Stroma anatomy: Ostiolar canal (53-)70-98(-130) $\mu \mathrm{m}$ $(n=138)$ long, plane or projecting up to $15 \mu \mathrm{m},(30-) 33-49$ $(-57) \mu \mathrm{m}(n=15)$ wide at the opening, the opening formed by a palisade of hyaline, apically elongate narrowly clavate cells. Perithecia flask-shaped, ellipsoidal or globose, (135-) $220-290(-340) \times(72-) 150-225(-280) \mu \mathrm{m}(n=149)$; peridium (17-)19-26(-30) $\mu \mathrm{m}$ thick at the base, (11-)13-20 $(-22) \mu \mathrm{m}$ thick laterally $(n=15)$, hyaline. Cortical tissue $(15-) 18-36(-60) \mu \mathrm{m}(n=63)$ thick, present around the entire stroma except for the point of attachment, a $t$. angularis of isodiametric to slightly elongated, thin- to thick-walled cells $(2-) 3-9(-19) \times(1.5-) 2.5-6(-10) \mu \mathrm{m}(n=360)$ in face view and in vertical section, with reddish brown to yellow-brown pigment inhomogeneously deposited. Hairs arising from cells of the stroma surface, usually abundant when young, scant on mature stromata, 1-5 celled, thin- or thick-walled, (5-)10-24(-47) $\mu \mathrm{m}(n=240)$ long, (2.0-)3.2-5.0(-7.0) $\mu \mathrm{m}$ $(n=83)$ wide, apically rounded, pale brownish, smooth to slightly verruculose. Subcortical tissue comprising a mixture of intertwined hyphae (3-)4-6(-7) $\mu \mathrm{m}(n=15)$ wide, vertical and parallel between perithecia, and hyaline, subglobose to angular cells $(3-) 5-10(-13) \mu \mathrm{m} \quad(n=30)$ diam, flanking the ostioles. Subperithecial tissue a homogeneous, dense $t$. angularis-epidermoidea of thin-walled cells $(3.5-) 4.5-15(-39) \times(2.0-) 4.5-10(-17) \mu \mathrm{m} \quad(n=337,240)$ wide, hyaline to pale brownish, gradually smaller and interspersed with few narrow hyphae 3-4 $\mu \mathrm{m}$ wide towards the base; above the point of attachment stratified by a palisade of oblong refractive glassy cells 14-31×4-9 $\mu \mathrm{m}$; sometimes irregular brownish pigment in patches incorporated through the whole tissue; basally delimited by the reddish brown cortex. Asci (56-)82-101(-118) $\times(3-) 5-7$ (-9) $\mu \mathrm{m} \quad(n=314)$, stipe (4-)6-22(-33) $\mu \mathrm{m} \quad(n=31)$ long. Ascospores hyaline, verruculose to verrucose with verrucae ca $0.5 \mu \mathrm{m}$ long and diam, cells dimorphic; distal cell (3.3-)

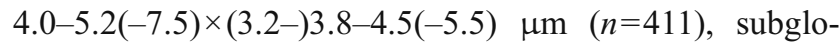
bose, oval to wedge-shaped; proximal cell (3.4-)4.5-5.8 $(-8.0) \times(2.7-) 3.3-4.0(-5.3) \mu \mathrm{m}(n=411)$, oblong to wedgeshaped, lower end broadly rounded.

Cultures and anamorph: optimal growth at $25^{\circ} \mathrm{C}$ on all media, no growth at $35^{\circ} \mathrm{C}$.

On CMD after $72 \mathrm{~h} 14-17 \mathrm{~mm}$ at $15^{\circ} \mathrm{C}, 39-41 \mathrm{~mm}$ at $25^{\circ} \mathrm{C}$, $14-24 \mathrm{~mm}$ at $30^{\circ} \mathrm{C}$; mycelium covering the plate after 56 days at $25^{\circ} \mathrm{C}$. Colony hyaline, thin, circular, not zonate; hyphae loosely arranged. Autolytic activity inconspicuous, coilings abundant in some isolates. Aerial hyphae scarce during fast growth, becoming abundant, particularly towards the margin, broad zone at the margin becoming downy. A diffuse greenish yellow pigment, 1B2-6, 2A3, 3B4, 29A2-3, often diffusing through the entire culture after 1-2 weeks. Typically a distinct coconut-like odour formed. Chlamydo- 


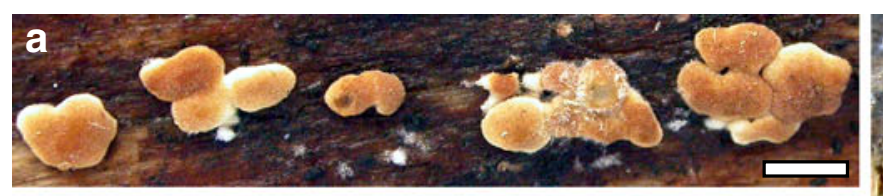

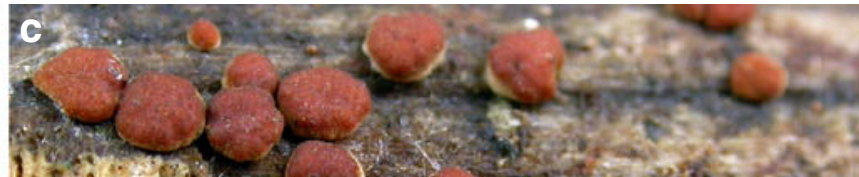

b
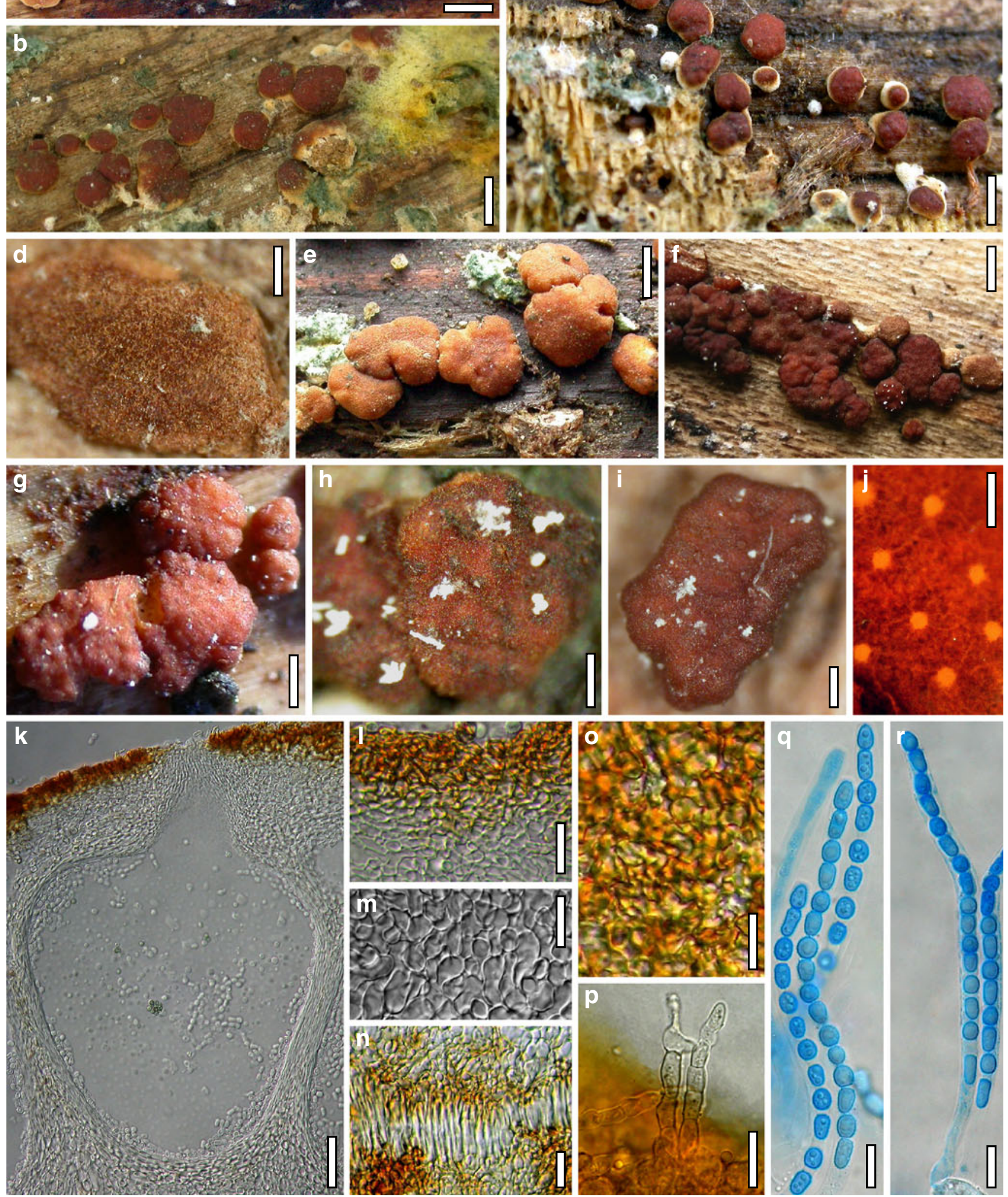
4Fig. 26 Teleomorph of Hypocrea viridescens. a-g. Fresh stromata (a, d, e: immature). h, i. Dry mature stromata. j. Surface of rehydrated stroma showing ostioles and unevenly distributed pigment. $\mathbf{k}$. Perithecium in section. I. Cortical and subcortical tissue in section. $\mathbf{m}$. Subperithecial tissue in section. $\mathbf{n}$. Basal palisade of cells above the attachment point in section. o. Stroma surface in face view. p. Hairs on lateral stroma surface. q, r. Asci with ascospores in cotton blue/lactic acid. a, l, o, p, q. WU 24025. b, c. WU 24027. d, f. holotype WU 24029. e. WU 24024. g, j, k, m, n, r. WU 24019. h. WU 24018. i. WU 24028. Scale bars: $\mathbf{a}=1.3 \mathrm{~mm}$. b, c, e, f=1 mm. $\mathbf{d}, \mathbf{g}=0.5 \mathrm{~mm}$. h, $\mathbf{i}=0.2 \mathrm{~mm} . \mathbf{j}=90 \mu \mathrm{m} . \mathbf{k}=35 \mu \mathrm{m} . \mathbf{l}-\mathbf{n}=15 \mu \mathrm{m} . \mathbf{o}-\mathbf{r}=10 \mu \mathrm{m}$

spores noted after 5-6 days, uncommon, terminal or intercalary, (7-)8-12(-16)×(6-)7-11(-13) $\mu \mathrm{m}, 1 / \mathrm{w}(0.9-) 1.0-1.3(-$ 1.5) $(n=28)$, globose or subglobose; size dependent on hyphal width. Conidiation starting after 2 days, developing slowly, turning pale to dark green, 28A4-5 to 27F5-8, after 5 days; typically effuse, spreading from the centre and particularly concentrated at the distal and lateral margins, often followed by the formation of polymorphic, loose shrubs or tufts of $0.2-1.5 \mathrm{~mm}$ diam, confluent up to $3 \times 2 \mathrm{~mm}$, sometimes in up to three concentric rings or evenly or irregularly disposed. Sometimes small pustules formed early in proximal areas of the plate. Inoculation in the middle of the plate often resulting in more regular distribution of tufts or pustules. Conidiophores typically visible at the surface of the pustules. Shrubs, tufts or pustules arising on a thick-walled and verrucose stipe to ca $11 \mu \mathrm{m}$ wide, of varying length, asymmetrically branched into thick and long primary branches 2-3 times further branched, spanning a loose reticulum of long and thin, paired or unpaired conidiophores. Conidiophores not conspicuously curved or sinuous, comprising a) a well-discernible main axis with a tree-like terminus and short, more or less straight, regularly tree-like side branches, often paired and mostly inclined upwards along the axis or b) particularly in effuse, more simple conidiophores, a distinct or indistinct main axis with or without paired or unpaired, long, straight or curved, side branches in right angles or inclined upwards, terminating in one or two phialides; phialides appearing to proliferate percurrently, often resulting in a submoniliform chain of 26 cells swollen in the middle and more or less conspicuously constricted above and below the middle. Phialides produced on cells $2-3(-5) \mu \mathrm{m}$ wide, singly or divergent in often cruciform whorls of $2-3$. Phialides $(4.8-) 6-11(-16) \times(2.0-)$ 2.5-3.3(-4.0) $\mu \mathrm{m}, 1 / \mathrm{w}(1.4-) 2.2-3.9(-5.6),(1.2-) 1.5-2.2(-$ 2.5) $\mu \mathrm{m}$ wide at the base $(n=60)$, lageniform to nearly ampulliform, mostly straight, sometimes slightly curved to sinuous, widest in various positions, mostly median, neck and often base narrow. Conidia (2.8-)3.5-4.3(-5.2) $\times(2.8-) 3.0$ $3.7(-4.0) \mu \mathrm{m}, 1 / \mathrm{w} 1.0-1.3(-1.7)(n=123)$, subglobose, oval or ellipsoidal, green, verruculose, with minute guttules, rarely with a distinct apiculus. At 15 and $30^{\circ} \mathrm{C}$ slower development with less conidiation and less strong coconut-like odour formed, coilings more frequent at $30^{\circ} \mathrm{C}$.
On PDA after $72 \mathrm{~h} 10-13 \mathrm{~mm}$ at $15^{\circ} \mathrm{C}, 32-37 \mathrm{~mm}$ at $25^{\circ} \mathrm{C}$, $10-19 \mathrm{~mm}$ at $30^{\circ} \mathrm{C}$; mycelium covering the plate after 5-6 days at $25^{\circ} \mathrm{C}$. Colony homogeneous, typically not zoned, covered by a dense mat of aerial hyphae several mm thick. Autolytic activity low or conspicuous, more pronounced at $15^{\circ} \mathrm{C}$, coilings more frequent at $30^{\circ} \mathrm{C}$. No diffusing pigment formed, reverse only slightly yellowish, 3A3-4, 3B4; odour indistinct or weakly coconut-like. Conidiation starting after 2 days, effuse in lower regions of long aerial hyphae in proximal and central parts of the colony, ill-defined, dry, usually not becoming green and soon degenerating. In some isolates conidia developing in 3 or 4 distinct concentric green rings. Slower development at 15 and $30^{\circ} \mathrm{C}$, conidiation becoming green, 28DE5-6.

On SNA after $72 \mathrm{~h} 11-12 \mathrm{~mm}$ at $15^{\circ} \mathrm{C}, 34-37 \mathrm{~mm}$ at $25^{\circ} \mathrm{C}$, $5-13 \mathrm{~mm}$ at $30^{\circ} \mathrm{C}$; mycelium covering the plate after 6 days at $25^{\circ} \mathrm{C}$; hyphae loosely arranged radially. Colony similar to $\mathrm{CMD}$, not zoned; aerial hyphae and coilings often more pronounced. Chlamydospores noted after 6-9 days, mostly intercalary and angular to ellipsoidal, more frequent than on CMD. No distinct odour and no pigment formed. Conidiation starting after 2 days, first effuse on long aerial hyphae, spreading across the entire plate, followed by a formation of loose tufts or pustules to $c a 1 \mathrm{~mm}$ diam, more conspicuous than on CMD, confluent to $6 \times 4 \mathrm{~mm}$, becoming green after 5 days, eventually after $c a 2$ weeks dark green, 27F4-8. Conidiophores more or less regularly tree-like, submoniliform terminal branches rare. At $30^{\circ} \mathrm{C}$ autolytic activity conspicuous and percurrently proliferating phialides more frequent.

Habitat: Anamorph isolated from various materials. Holomorph or teleomorph occurring on wood and bark of deciduous and coniferous trees, often on cut and usually at least partly decorticated branches and logs; overgrowing various fungi.

Distribution: Common, especially as anamorph, in north- and south-temperate regions: Europe (Austria, Czech Republic, England, France, Germany, Northern Ireland, Russia, Sweden) and North America (USA: Georgia, North Carolina, Oregon; Mexico); also Australia, Japan, New Zealand and Taiwan.

Holotype of the teleomorph: Austria, Kärnten, Völkermarkt, Eisenkappel-Vellach, Vellacher Kotschna, MTB 9653/1, 462 $4^{\prime} 02^{\prime \prime} \mathrm{N}, 14^{\circ} 34^{\prime} 06^{\prime \prime}$ E, elev. 970 m, on split and partly decorticated branch of Fagus sylvatica 7-8 cm thick, on the ground, soc. Corticium roseum, 31 Oct. 2005, H. Voglmayr \& W. Jaklitsch, W.J. 2881 (WU 24029, culture CBS 119321=C.P.K. 2140). Neotype of Eidamia viridescens, dried culture of the original strain CBS 433.34 (herb. CBS 7868), isolated from rotten apples, UK. Epitype of $T$. viridescens, designated by Jaklitsch et al. (2006b): C.P.K. 2140 deposited as a dry culture together with the holotype of H. viridescens as WU 24029a.

Other specimens examined: Austria, Kärnten, Klagenfurt Land, St. Margareten im Rosental, Trieblach, above 


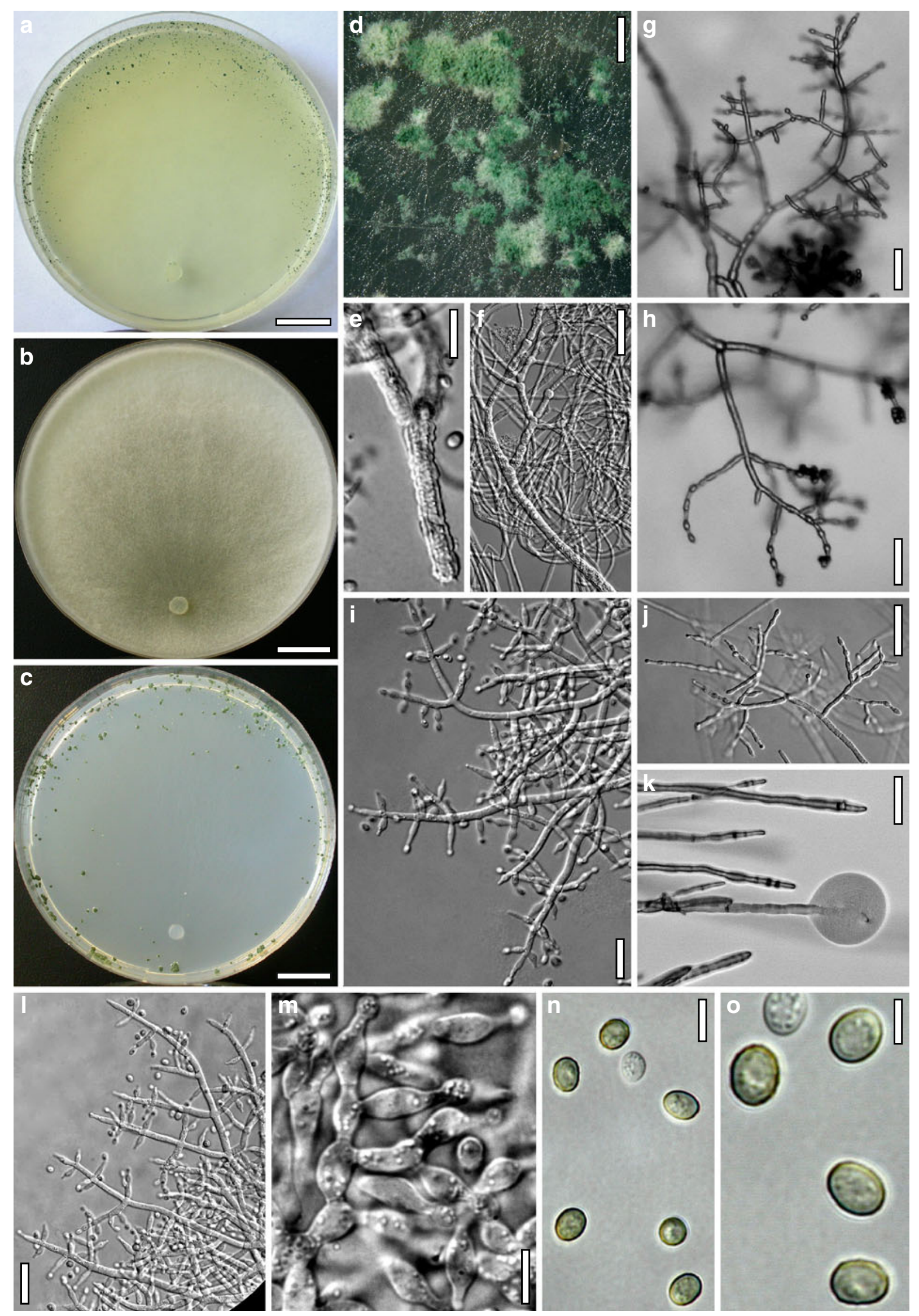


4Fig. 27 Cultures and anamorph of Hypocrea viridescens. a-c. Cultures (a. on CMD, 11 days; b. on PDA, 14 days; c. on SNA, 11 days). d. Conidiation tufts (6 days). e, f. Stipe and primary branches (5-8 days). g, h. Conidiophores on growth plates (h. showing submoniliform branches; 7 days). i, j, l. Conidiophores (i, l. . regularly tree-like conidiophores; $\mathbf{j}$. with submoniliform branches; $6-$ 8 days). k. Autolytic excretion (Difco-PDA, $25^{\circ} \mathrm{C}, 3$ days). $\mathbf{m}$. Proliferating phialides (5 days). n, o. Conidia (6 days). d-o. All on $\mathrm{CMD}$ at $25^{\circ} \mathrm{C}$ except $\mathbf{k}$. a-c, f, g, h, j. CBS 119324 . d, e, i, l-o. CBS 119322. k. holotype CBS 119321. Scale bars: $\mathbf{a}-\mathbf{c}=15 \mathrm{~mm}$. $\mathbf{d}=$ $0.4 \mathrm{~mm} . \mathbf{e}, \mathbf{i}=15 \mu \mathrm{m} . \mathbf{f}, \mathbf{j}=30 \mu \mathrm{m} . \mathbf{g}, \mathbf{h}, \mathbf{l}=20 \mu \mathrm{m} . \mathbf{k}=50 \mu \mathrm{m} . \mathbf{m}, \mathbf{n}=$ $5 \mu \mathrm{m} . \mathbf{0}=3 \mu \mathrm{m}$

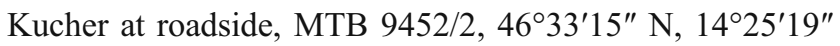
E, elev. $440 \mathrm{~m}$, on logs of Picea abies $>20 \mathrm{~cm}$ thick in a pile, holomorph, 14 Oct. 2006, W. Jaklitsch, W.J. 3022 (WU 29520, culture C.P.K. 3122). Oberösterreich, Grieskirchen, Natternbach, forest close to Gaisbuchen, MTB $7548 / 3,48^{\circ} 24^{\prime} 39^{\prime \prime} \mathrm{N}, 13^{\circ} 41^{\prime} 40^{\prime \prime}$ E, elev. $580 \mathrm{~m}$, on branch of Fagus sylvatica on leaf litter in spruce forest, 1 Aug. 2004, H. Voglmayr, W.J. 2553 (WU 24022; culture C.P.K. 2043). Schärding, St. Willibald, Großer Salletwald at the

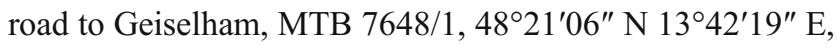
elev. $450 \mathrm{~m}$, on branch of Salix caprea 3-4 cm thick, 2 Sep. 2006, H. Voglmayr, W.J. 2970 (WU 29519, culture C.P.K. 2462). Steiermark, Liezen, Kleinsölk, walking path between Schwarzensee $1170 \mathrm{~m}$, on log segment of Picea abies $100 \mathrm{~cm}$ thick in grass, soc. Neonectria fuckeliana, 6 . Aug. 2003, H. Voglmayr \& W. Jaklitsch, W.J. 2306 (WU 24018; culture CBS 119324=C.P.K. 942); (Ost-)Tirol, Lienz, Defereggental, Hopfgarten in Defereggen, Dölsach, at roadside between the current transformer and the beverage depot, MTB 9041/3, 46 55'23" N, 12³2'41" E, elev. $990 \mathrm{~m}$, on stored log of Picea abies $16 \mathrm{~cm}$ thick, in grass, 4. Sep. 2003, W. Jaklitsch, W.J. 2374 (WU 24019; culture C.P.K. 947). Vienna, 22nd district, Lobau, at Panozzalacke, MTB 7865/1, 48 $11^{\prime} 11^{\prime \prime} \mathrm{N}, 16^{\circ} 29^{\prime} 23^{\prime \prime}$ E, elev. $150 \mathrm{~m}$, on branch of Ulmus campestris $5 \mathrm{~cm}$ thick, holomorph, 18 Nov. 2006, W. Jaklitsch, W.J. 3037 (WU 29521, culture C.P.K. 2851). Vienna, 23rd district, Maurer Wald, MTB 7863/1, 4808'57" N 16 14'50" E, elev. 360 m, on decorticated branch of Carpinus betulus on the ground, soc. Tubeufia cerea, 3 Oct. 1998, W. Jaklitsch, W.J. 1223 (WU 24009, BPI 747557; culture G.J.S. 98-182=CBS 120067). Denmark, Soenderjylland, Roedekro, Rise Skov,

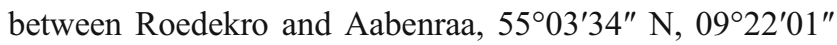
E, elev. $70 \mathrm{~m}$, on decorticated branch of Quercus robur $9 \mathrm{~cm}$ thick, on wood, soc. Mycena sanguinolenta, holomorph, anamorph with yellow spots, 23 Aug. 2006, H. Voglmayr \& W. Jaklitsch, W.J. 2935 (WU 29517, culture C. P.K. 2442). Germany, Baden-Württemberg, Freiburg, Landkreis Schwarzwald-Baar-Kreis, Furtwangen, shortly before Kaltenherberg coming from Gasthof Thurner, MTB 8015/1, 47 59'36" N, 08 $10^{\prime} 50^{\prime \prime}$ E, elev. $1000 \mathrm{~m}$, on cut logs of Picea abies $20-40 \mathrm{~cm}$ thick, in a pile at roadside, part with white mould, 2 Sep. 2004, W. Jaklitsch \& H. Voglmayr, W.J. 2664 (WU 24023; culture C.P.K. 2138); Landkreis Breisgau-Hochschwarzwald, St. Märgen, shortly after Glashütte, coming from Hexenloch, on the right side of the road close to a bridge, MTB 8014/2, 47 $59^{\prime} 37^{\prime \prime} \mathrm{N}$, $08^{\circ} 07^{\prime} 32^{\prime \prime}$ E, elev. $750 \mathrm{~m}$, on cut branch of Picea abies $4 \mathrm{~cm}$ thick on moist ground, 2 Sep. 2004, H. Voglmayr \& W. Jaklitsch, W.J. 2665 (WU 24024; culture C.P.K. 2044); Landkreis Lörrach, Todtnau, at the crossing to St. Blasien,

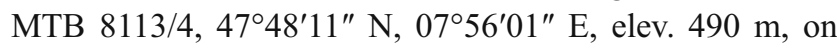
mostly decorticated cut logs of Picea abies up to $35 \mathrm{~cm}$ thick, in pile, soc. effete Ophiostoma sp., white mould, 3 Sep. 2004, W. Jaklitsch \& H. Voglmayr, W.J. 2670 (WU 24025; culture CBS $119323=$ C.P.K. 2045); Bavaria, Starnberg, Tutzing, Erling, at the Hartschimmel terrain, $47^{\circ} 56^{\prime}$ $41^{\prime \prime} \mathrm{N}, 11^{\circ} 10^{\prime} 37^{\prime \prime} \mathrm{E}$, elev. $700 \mathrm{~m}$, on partly decorticated branch of Fagus sylvatica $13-15 \mathrm{~cm}$ thick, on the ground in leaf litter, 3 Sep. 2005, W. Jaklitsch, W.J. 2838 (WU 24028; culture C.P.K. 2139). Hessen, Rhön, SW Gersfeld, "Gichenbachtal", MTB 5525/3, elev. $550 \mathrm{~m}$, on wood of Picea abies, 20 July 2008, L. Krieglsteiner. Niedersachsen, Landkreis Soltau-Fallingbostel, Bispingen, Behringen, east of Hengstberg and the road leading to the NSG Lüneburger

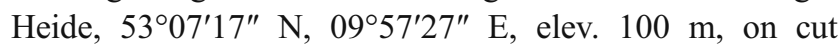
branch segments of Betula pendula, Pinus sylvestris and Quercus robur 6-10 cm thick, on wood, mostly cutting areas, soc. H. schweinitzii, H. minutispora on Betula, holomorph, anamorph with yellow spots, 26 Aug. 2006, H. Voglmayr \& W. Jaklitsch, W.J. 2948 (WU 29518, culture C.P.K. 2449). Sweden, Stockholms Län, Nothamn, mixed forest at the coast, MTB 4179/3, 60 $01^{\prime} 42^{\prime \prime} \mathrm{N}, 18^{\circ}$ $50^{\prime} 46^{\prime \prime}$ E, elev. $10 \mathrm{~m}$, on corticated branch of Corylus avellana $2-3 \mathrm{~cm}$ thick, in moss, soc. Diatrype stigma s.l., 7 Oct. 2003, W. Jaklitsch, W.J. 2447 (WU 24020; culture C.P. K. 983); Uppsala Län, Sunnersta, forest opposite the virgin forest Vardsätra Naturpark across the main road, MTB $3871 / 2$, 59 $47^{\prime} 24^{\prime \prime} \mathrm{N}, 17^{\circ} 37^{\prime} 51^{\prime \prime} \mathrm{E}$, elev. $15 \mathrm{~m}$, on cut branch of Salix caprea $7 \mathrm{~cm}$ thick, soc. Capronia $\mathrm{cf}$. pilosella, 8 Oct. 2003, W. Jaklitsch, W.J. 2453 (WU 24021; culture C.P.K. 985). Ukraine, Kharkivska Oblast, Kharkov, National nature park Gomolshanskie lesa, Zmiev area, on branch of Quercus robur, 27 July 2007, A. Akulov (AS 2440, culture C.P.K. 3133). United Kingdom, Devon, Exeter, Stoke Woods, close to the parking place Forest

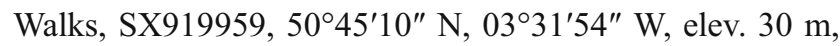
on branch of Fagus sylvatica $4 \mathrm{~cm}$ thick, on the ground in leaf litter, 8 Sep. 2004, H. Voglmayr, W. Jaklitsch \& J. Webster, W.J. 2686 (WU 24026; culture C.P.K. 2046); Hertfordshire, Stevenage, Box Wood, on decorticated branch of Quercus robur, 4 Dec. 2007, Kerry Robinson (WU 29523). Waterford, Waterford Heath, Mole Wood, elev. $70 \mathrm{~m}, 51^{\circ} 48^{\prime} 42^{\prime \prime} \mathrm{N}, 0^{\circ} 05^{\prime} 22^{\prime \prime} \mathrm{W}$, on basidiomata of Hymenochaete corrugata on cut branches, $10-12 \mathrm{~cm}$ thick, 
of Corylus avellana 12 Sep 2007, W. Jaklitsch, K. Robinson, H. Voglmayr, W.J. 3186 (WU 29522, culture C.P.K. 3172). Westland Green, Caley Wood, on decorticated branch of Carpinus betulus, cm thick, on, 23 Dec. 2007, Kerry Robinson (WU 29524). North East London, Epping Forest, between Robin Hood Roundabout and Hill Wood, 43-34/1, 51 $39^{\prime} 15^{\prime \prime} \mathrm{N}, 00^{\circ} 02^{\prime} 13^{\prime \prime}$ E, elev. $40 \mathrm{~m}$, on branch of Fagus sylvatica on the ground in leaf litter, soc. and partly on a resupinate polypore, soc. Hypocrea lixii, Ascocoryne sarcoides, Diatrype decorticata, 16 Sep. 2004, H. Voglmayr \& W. Jaklitsch, W.J. 2723 (WU 24027; culture CBS $119322=$ C.P.K. 2047).

Notes: Measurements of teleomorph characters include those determined by G.J. Samuels on non-European material (see Jaklitsch et al. 2006b). Culture characteristics are here described for European isolates only. Conidiophores with regularly tree-like side branches correspond to Type 2 conidiophores, and those with percurrently proliferating phialides, i.e. submoniliform side branches, to Type 3 conidiophores of Jaklitsch et al. (2006b). Sometimes both may occur in the same isolate. In nature the teleomorph of $H$. viridescens is usually associated with its anamorph, sometimes showing citrine to sulphur-yellow hairy patches as in H. rufa. The conidia, globose to subglobose and coarsely tubercular in $H$. rufa/T. viride versus subglobose to ellipsoidal and verruculose in H./T. viridescens, from natural substrates as well as from agar media help to distinguish these two species, although their teleomorphs are indistinguishable. Phialides of H. rufa are often solitary, hooked to sinuous, and conidiophores lack a discernable main axis, and are also usually distinctly curved to sinuous on pustule margins, whereas conidiophores of T. viridescens observed on SNA, and often also CMD, tend to be more typical of Trichoderma, i.e. regularly tree-like, with paired branches that increase in length with distance from the tip. Phialides in pustules of $T$. viride do not proliferate percurrently, a common and distinctive feature of T. viridescens. A coconut odour is typical of $T$. viridescens but unusual in T. viride. Another species forming submoniliform conidiophore branches is $T$. gamsii, which can be distinguished from $T$. viridescens by narrower, smooth conidia. See Jaklitsch et al. (2006b) for further details on this and similar species.

\section{The pachybasium core group, including species formerly classified in Podostroma}

\section{Introduction}

The genus Pachybasium Sacc. (Saccardo 1885) was originally established for P. hamatum and similar species. Bissett (1991a) reduced the genus to a section of Trichoderma, with Trichoderma hamatum as its type, including also $T$. harzianum, T. piluliferum, T. polysporum and the anamorph of Hypocrea gelatinosa. Later (Bissett 1991b) he enlarged the section to 20 species. Species of this section are characterised by repeatedly branched, stout conidiophores with dense clusters of plump, ampulliform phialides. These conidiophores are formed in pustules and have frequently conspicuous sterile or terminally fertile, straight, sinuous or helical elongations. Conidia are green or hyaline. However, molecular phylogeny (Kindermann et al. 1998; KullnigGradinger et al. 2002) has shown that Trichoderma section Pachybasium as defined by Bissett (1991b) was paraphyletic. Trichoderma hamatum and some other species cluster with section Trichoderma, and all species that have green-spored Hypocrea teleomorphs turned out to belong to several unrelated clades (Chaverri et al. 2003; Chaverri and Samuels 2003; Jaklitsch 2009). The phylogenetic clade representing the remaining species around $T$. polysporum was later termed the Pachybasioides clade (Jaklitsch et al. 2005, 2006a; Samuels et al. 2006a). Doi (1972) discovered and described $H$. pachybasioides, the teleomorph of $T$. polysporum, having earlier (Doi 1966) interpreted it as $H$. citrina. Lu et al. (2004) reviewed some species of the clade and added several new species, among them H. minutispora, the common teleomorph of T. minutisporum. Jaklitsch et al. (2008b) discovered that species with upright stromata, assignable to the former genera Podostroma or Podocrea, also belonged in this clade. Accordingly, this phylogenetic clade, now termed the pachybasium core group, is morphologically heterogeneous, comprising teleomorphs with upright, stipitate stromata and small pulvinate stromata. Hypocrea luteffusa is an exception, because the teleomorph superficially resembles those of section Hypocreanum and the Brevicompactum clade, being closer to the latter. Also anamorphs in this group vary greatly. The pachybasium-like conidiation as defined by Bissett (1991b) is present in pustules, but several species produce only effuse, verticillium-like conidiophores.

Species forming rosy or yellow pulvinate stromata are difficult to distinguish. Hypocrea parapilulifera can hardly be distinguished morphologically from $H$. pachybasioides, even in the anamorph. Hypocrea minutispora is by far the commonest species of the genus in Europe. The teleomorphs of $H$. atlantica, $H$. minutispora and $H$. pachybasioides are similar. The typification of $H$. pilulifera was debated by Lu et al. (2004). This issue has been settled and it appears that the species forms its stromata on wood of Betula rather than on Juncus, where the holotype was collected, apparently as an exception.

Species like $H$. argillacea and H. strobilina not collected recently, may also belong in this clade. Hypocrea moravica of the Semiorbis clade and H. silvae-virgineae, which clusters with Trichoderma helicum (see Fig. 1), are morphologically similar to species of the pachybasium core group. 


\section{Species descriptions}

The following 13 species including four new ones are grouped in alphabetical order within two morphologically defined groups, treating the species assignable to the former genus Podostroma first: Hypocrea alutacea, H. leucopus, $H$. nybergiana, and $H$. seppoi; followed by $H$. atlantica, $H$. bavarica, $H$. luteffusa, $H$. minutispora, $H$. pachybasioides, H. pachypallida, H. parapilulifera, $H$. pilulifera, and $H$. placentula.

Hypocrea alutacea (Pers. : Fr.) Tul. \& C. Tul., Sel. Fung. Carpol. I: 62. (1861). Fig. 28

$\equiv$ Sphaeria alutacea Pers., Comm. fung. clav. (Lipsiae): 12 (1797) : Fries, Syst. Mycol. 2: 325 (1823).

$\equiv$ Hypocrea alutacea (Pers. : Fr.) Ces. \& De Not., Schem. Classif. Sferiacei. Comm. Soc. Critt. Ital. 1: 193. (1863).

$\equiv$ Cordyceps alutacea (Pers.) Quél., Mém. Soc. Émul. Montbéliard, Sér. 2, 5: 487 (1875).

$\equiv$ Podocrea alutacea (Pers.) Lindau, in Engler \& Prantl, Nat. Pflanzenfam. (Leipzig) 1(1): 364 (1897).

$\equiv$ Podostroma alutaceum (Pers.) G.F. Atk., Bot. Gaz. 40: 401 (1905).

$=$ Sphaeria clavata Sowerby, Col. Fig. Engl. Fung. Mushr. 2: 67 (1799).

Anamorph: Trichoderma alutaceum Jaklitsch, sp. nov. Fig. 29

MycoBank MB 516665

Incrementum tardum in agaro CMD. Conidiophora irregularia in micropustulis. Phialides lageniformes, (5-)8$13(-19) \times(2.5-) 3.0-3.8(-4.8) \mu \mathrm{m}$. Conidia (3.0-)3.5-5.5($8.5) \times(2.0-) 2.5-3.0(-3.8) \mu \mathrm{m}$, viridia, oblonga, cylindracea vel ellipsoidea.

Fresh stromata similar to dry stromata, with smoother surface and lighter colour, typically pale yellowish, 4A3. Stromata when dry (7-)11-38(-50) $(n=12) \mathrm{mm}$ long, upright; solitary, more frequently gregarious or densely aggregated and often laterally fused in fascicles of 3-5 with demarcating lines in both fertile part and stipe; sometimes basally branched, i.e. fertile parts fasciculate on a common stipe. Fertile (upper) part (5-)7-22(-30) mm long, corresponding to $(50-) 60-70(-80) \%$ of total length $(n=$ 11); $(2.5-) 3-9(-11) \times(1.5-) 2-5(-6.5) \mathrm{mm}(n=19)$ thick, clavate, cylindrical, spathulate or of irregular shape, with apex slightly attenuated; often laterally compressed, transverse sections therefore more frequently oblong or ellipsoidal than circular; sometimes patches or one entire side sterile. Surface often with wrinkles or folds, otherwise smooth and with white covering mycelial layer when young, or finely roughened by numerous, densely disposed ostiolar dots $(25-) 40-100(-160) \mu \mathrm{m}(n=150)$ diam. Dots light and diffuse when young, later distinct, circular, plane or convex, pale brown or ochre with hyaline centre. Stroma colour determined by the ostiolar dots on whitish to pale yellowish background, light orange, grey-orange, brownorange to pale greyish brown, 5AB3-4(-5), 5CD3-5, 6CD3-4; white to yellowish inside; variable parts often hollow. Spore deposits fine, white, first appearing at the lower end of the fertile part. Sterile stipe (2-)3-14(-20) $\mathrm{mm}$ $(n=11)$ long, $(2-) 4-9(-10) \times(1-) 2-3.5(-4) \mathrm{mm} \quad(n=20)$ thick; cylindrical or laterally compressed, typically not distinctly separated from the fertile part, with fertile patches often decurrent on the stipe. Stipe white or light creamcoloured, frequently curved, smooth or longitudinally rugose; base sometimes thickened, sometimes with white arachnoid base mycelium. Rehydrated stromata smoother, white with lively ochre or yellow ostiolar dots (50-)60$140 \mu \mathrm{m}$ diam; no colour change noted after addition of $3 \%$ $\mathrm{KOH}$, except for a better rehydration, with the whole surface becoming uniformly orange-ochre.

Stroma anatomy: Ostioles (50-)56-75(-85) $\mu \mathrm{m}$ long, plane with the surface or projecting to 10 , rarely $50 \mu \mathrm{m}$, (27-)30-50(-60) $\mu \mathrm{m}$ wide at the apex $(n=30)$, conical, periphysate, with some subclavate or globose cells to $6 \mu \mathrm{m}$ diam flanking their margins. Perithecia (160-)220-270($290) \times(100-) 120-190(-220) \mu \mathrm{m}(n=30)$, flask-shaped or subglobose, crowded, (6-)8-9/mm stroma length. Peridium (11-)18-29(-34) $\mu \mathrm{m}$ thick at the base, $(10-) 13-19(-22)$ $\mu \mathrm{m}$ at the sides $(n=30)$, hyaline to yellowish. Entostromatic tissues prosenchymatous, but in part appearing cellular (mostly globose) due to sectioning through variably oriented hyphae. Cortical layer (19-)23-40(-46) $\mu \mathrm{m}(n=$ 30) thick, pale yellowish, a dense $t$. intricata of hyphae $(2.2-) 3.0-4.5(-7.0) \mu \mathrm{m}(n=30)$ wide in face view, with numerous hyphae appearing as thick-walled globose or oblong cells $(3-) 4-9(-16) \times(2.5-) 3.5-6.0(-8.5) \quad(n=60)$ in face view and (2.5-)3.5-6.5(-8.0) $\times(2.5-) 3.0-4.5(-5.0) \mu \mathrm{m}$ $(n=30)$ in vertical section. Subcortical tissue a loose $t$. intricata of hyaline hyphae (2.0-)2.5-5.0(-6.0) $\mu \mathrm{m}(n=30)$ wide, with slightly narrower walls than the cortical hyphae. Subperithecial tissue a dense small-celled $t$. angularisglobulosa of hyaline, thick-walled cells $(3-) 4-9(-11) \times$ (2.5-)3.5-5.0(-6.0) $\mu \mathrm{m}(n=30)$, interspersed with thickwalled hyphae (2.5-)3.0-6.0(-7.5) $\mu \mathrm{m}(n=40)$ wide. Asci $(67-) 77-100(-115) \times(4.2-) 4.5-5.2(-6.0) \mu \mathrm{m}$, stipe (5-)9$25(-40) \mu \mathrm{m}$ long $(n=100)$, with minute pore or ring, croziers present. Ascospores hyaline, verruculose, smooth within asci, cells dimorphic; distal cell (sub)globose, sometimes wedge-shaped, $(3.0-) 3.3-4.0(-4.8) \times(2.8-) 3.0$ 3.6(-4.0) $\mu \mathrm{m}, 1 / \mathrm{w}(0.9-) 1-1.2(-1.3)$; proximal cell oblong or wedge-shaped, $(3.2-) 4.0-5.0(-6.0) \times(2.3-) 2.7-3.1(-3.5)$ $\mu \mathrm{m}, 1 / \mathrm{w}(1.1-) 1.3-1.8(-2.2)(n=120)$.

Cultures and anamorph: ascospore germination and growth slow, optimal growth at $25^{\circ} \mathrm{C}$ on all media; no growth at 30 and $35^{\circ} \mathrm{C}$. 

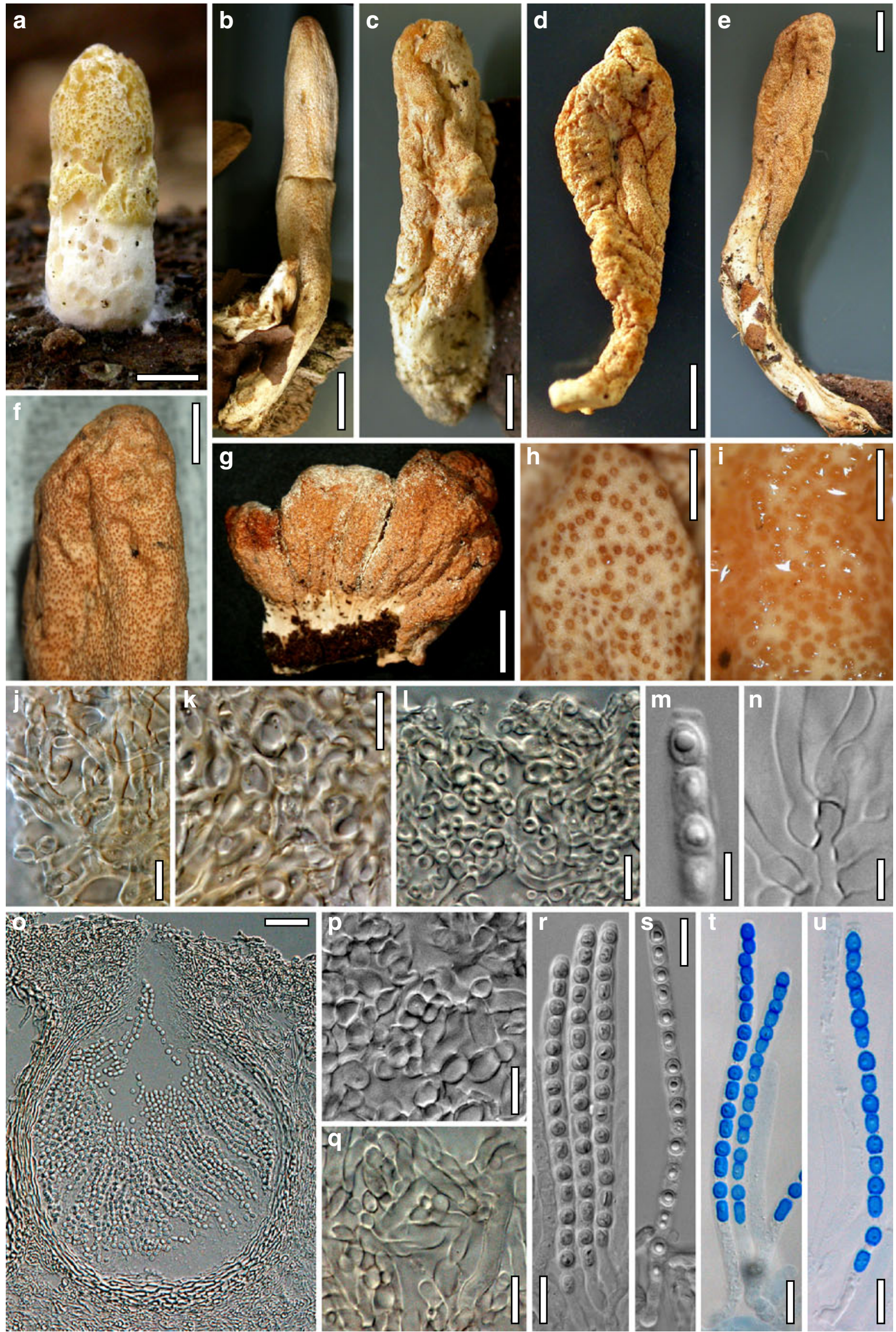
4Fig. 28 Teleomorph of Hypocrea alutacea. a. Fresh young stroma. bg. Dry stromata (b. immature, f. upper part of fertile region, g. laterally fused stromata). h, i. Stroma surface showing ostiolar dots (h. dry, i. in $3 \% \mathrm{KOH}$ after rehydration). j. Surface hyphae in face view. k. Surface cells close to ostiole in face view. I. Cortical and subcortical tissue in section. m. Ascus ring. n. Crozier. o. Perithecium in section. p, q. Subperithecial tissue (p. featuring angular cells, q. featuring hyphae). $\mathbf{r}-\mathbf{u}$. Asci with ascospores (t, $\mathbf{u}$. in cotton blue/lactic acid). $\mathbf{a}, \mathbf{m}, \mathbf{n}, \mathbf{s}$, u. WU 29177. b. K 142759. c, d, h, i, l, o-q, t. WU 8690. e, f, j, k. K 155403. g, r. IMI 47042. Scale bars: $\mathbf{a}=2 \mathrm{~mm}$. b, d, $\mathbf{e}=5 \mathrm{~mm}$. $\mathbf{c}, \mathbf{f}, \mathbf{g}=$ $3 \mathrm{~mm}$. h, $\mathbf{i}=0.5 \mathrm{~mm} . \mathbf{j}-\mathbf{l}, \mathbf{p}-\mathbf{u}=10 \mu \mathrm{m} . \mathbf{m}, \mathbf{n}=5 \mu \mathrm{m} . \mathbf{o}=25 \mu \mathrm{m}$

On CMD after $72 \mathrm{~h} 1-2 \mathrm{~mm}$ at $15^{\circ} \mathrm{C}$ and $5-7 \mathrm{~mm}$ at $25^{\circ} \mathrm{C}$; mycelium covering the plate after $3-4$ weeks at $25^{\circ} \mathrm{C}$. Colony hyaline, thin, radial, shiny, indistinctly zonate; little mycelium on the agar surface, dense mycelium within the agar. Aerial hyphae inconspicuous, becoming fertile. No autolytic excretions nor coilings seen. Colour none to pale yellowish in aged cultures; odour indistinct or mushroomy, aromatic, reminiscent of Sarcodon imbricatus, vanishing with age. Chlamydospores (examined after 46 days) noted after 3-7 weeks in surface and aerial hyphae, (10-)11-18(-22)×(9-)10-16(-19) $\mu \mathrm{m}, 1 /$ w (0.9-)1.0-1.3(-1.6) $(n=21)$, globose or oblong, smooth, intercalary, less commonly terminal. Conidiation noted after 4-5 days, green after (7-)14-25 days, effuse, on simple, erect conidiophores around the plug and on aerial hyphae $(0.1-$ $1 \mathrm{~mm}$ long), and in loosely disposed loose shrubs and denser granules to $0.5 \mathrm{~mm}$ diam, aggregations to $2 \mathrm{~mm}$, mainly concentrated along the colony margin; white, turning green, 28D5-6 to 27E4-6, finally degenerating and conidia often adhering in chains. Conidiophores (CBS 332.69, CBS 120535 ) short, simple, of a stipe with thick wavy (verrucose when old) outer wall to 6-11 $\mu \mathrm{m}$ wide, with asymmetric branches, or broad shrubs or small pustules with sparse asymmetric branches, without clearly discernable main axes. Branches mostly 4-6 $\mu \mathrm{m}$ wide, attenuated terminally to 2.5$3.5 \mu \mathrm{m}$. Branches and phialides typically divergent but steeply inclined upward. Phialides and conidial heads concentrated in the upper, terminal levels of the conidiophores, in verticillium-like or irregular arrangements on short, 1-3 celled, broad (e.g. fan-shaped, $200 \mu \mathrm{m}$ diam, 80-100 $\mu \mathrm{m}$ long) terminal branches. Terminal branches and phialides often paired, straight, sometimes sinuous. Phialides arising solitarily or in whorls of $2-4(-5)$ on cells $2.5-4.5 \mu \mathrm{m}$ wide. Conidia formed in mostly dry minute heads $<30 \mu \mathrm{m}$ diam. Phialides (5-)8-13(-19) ×(2.5-)3.0-3.8(-4.8) $\mu \mathrm{m}, 1 / \mathrm{w}(1.7-)$ $2.3-3.8(-5.4),(1.5-) 2.0-2.8(-4.0) \mu \mathrm{m}$ wide at the base $(n=$ 91 ), lageniform or subulate, straight, curved or sinuous, mostly inaequilateral, not or slightly widened in or above the middle. Conidia (3.0-)3.5-5.5(-8.5) $\times(2.0-) 2.5-3.0(-3.8)$ $\mu \mathrm{m}, 1 / \mathrm{w}(1.1-) 1.3-1.9(-3.0)(n=97)$, light (yellowish) green, oblong or cylindrical, more ellipsoidal in lower size range, smooth, finely multiguttulate or with 1-2 larger guttules, scar indistinct. On MEA structure of conidiophores and sizes identical to those on CMD (measurements here united).
On PDA after $72 \mathrm{~h}<1 \mathrm{~mm}$ at $15^{\circ} \mathrm{C}$ and $1-3 \mathrm{~mm}$ at $25^{\circ} \mathrm{C}$; mycelium covering the plate after $3-4$ weeks at $25^{\circ} \mathrm{C}$. Colony zonate, with radial streaks and thick, wavy or crenate margin; mycelium conspicuously dense, hyphae agglutinated. Surface downy to floccose, whitish-cream, reverse pale yellow to greyish yellow, 3A3-4, 4A3-4B4. Aerial hyphae numerous, appearing rigid, thick, long and high, forming radial strands, becoming fertile; white mycelial patches appearing in aged cultures. Autolytic excretions rare; no coilings seen. Odour mushroomy, aromatic, reminiscent of Sarcodon imbricatus, vanishing with age. Conidiation noted after 4-5 days, effuse, in minute dry heads on small side branches formed on thick aerial hyphae ascending several $\mathrm{mm}$, spreading from the plug, colourless, greenish only in the stereo-microscope.

On SNA after $72 \mathrm{~h} 1.5-2 \mathrm{~mm}$ at $15^{\circ} \mathrm{C}$ and $2-4 \mathrm{~mm}$ at $25^{\circ} \mathrm{C}$; mycelium covering the plate after $\mathrm{ca} 2$ months at $25^{\circ} \mathrm{C}$. Colony irregular, dense, indistinctly zonate, with little mycelium on the surface; hyphae appearing rigid, reminiscent of $H$. aureoviridis, but branching not distinctly in right angles. Aerial hyphae frequent, long, high, becoming fertile. Autolytic excretions and coilings absent or inconspicuous. No distinct odour, no pigment noted. Chlamydospores noted after 3-4 weeks, infrequent. Conidiation noted after 4 days, turning green after 12-14 days; effuse, in dry heads on aerial hyphae; upon stronger branching and aggregation appearing powdery, concentrated in minute white granules at the proximal margin and in ill-defined concentric zones and radial patches, becoming yellow- or grey-green, 29CD4-6, 28CD5-6; sometimes aggregated to nearly $2 \mathrm{~mm}$ diam. At $15^{\circ} \mathrm{C}$ conidiation concentrated in a ring of dense shrubs around the plug.

Habitat: on well-decayed wood of angiosperms.

Distribution: Europe (Austria, Germany, UK), Japan, North America.

Neotype designated by Chamberlain et al. (2004): Illustration in Persoon (1800), Obs. Mycol. 2: 66, Tab I, Fig. 2 a-c, evidenced in a copy at BPI.

Holotype of T. alutaceum isolated from WU 29177 and deposited with the teleomorph specimen as the dry culture WU 29177a.

Other specimens examined: Austria, Niederösterreich, Ziersdorf, Kleinwetzdorf, Heldenberg, MTB 7561/2, on partly corticated, deciduous wood, soc. ?Helicosporium sp., A. Hausknecht, 30 June 1990 (WU 8690). Germany; Teutoburger Wald, Beller Holz, on decaying wood, Jan. 1973, W. Gams (CBS 199.73; only culture used for sequencing). Japan, Matsumoto (CBS 332.69, only culture available). United Kingdom, England, Herefordshire, Downton Gorge, on wood of Quercus sp., 17 Sep. 1951, J. Webster (IMI 47042). Nottinghamshire, East Midlands, Worksop, Clumber Park, near Visitors Centre, SK 627739 , $53^{\circ} 16^{\prime} 16^{\prime \prime} \mathrm{N}, 01^{\circ} 04^{\prime} 19^{\prime \prime} \mathrm{W}$, elev. $100 \mathrm{~m}$, on branch of Quercus robur $15 \mathrm{~cm}$ thick, on crumbly wood, (below bark), soc. rhizomorphs and an effete ?Ophiostoma sp., 11 Sep. 

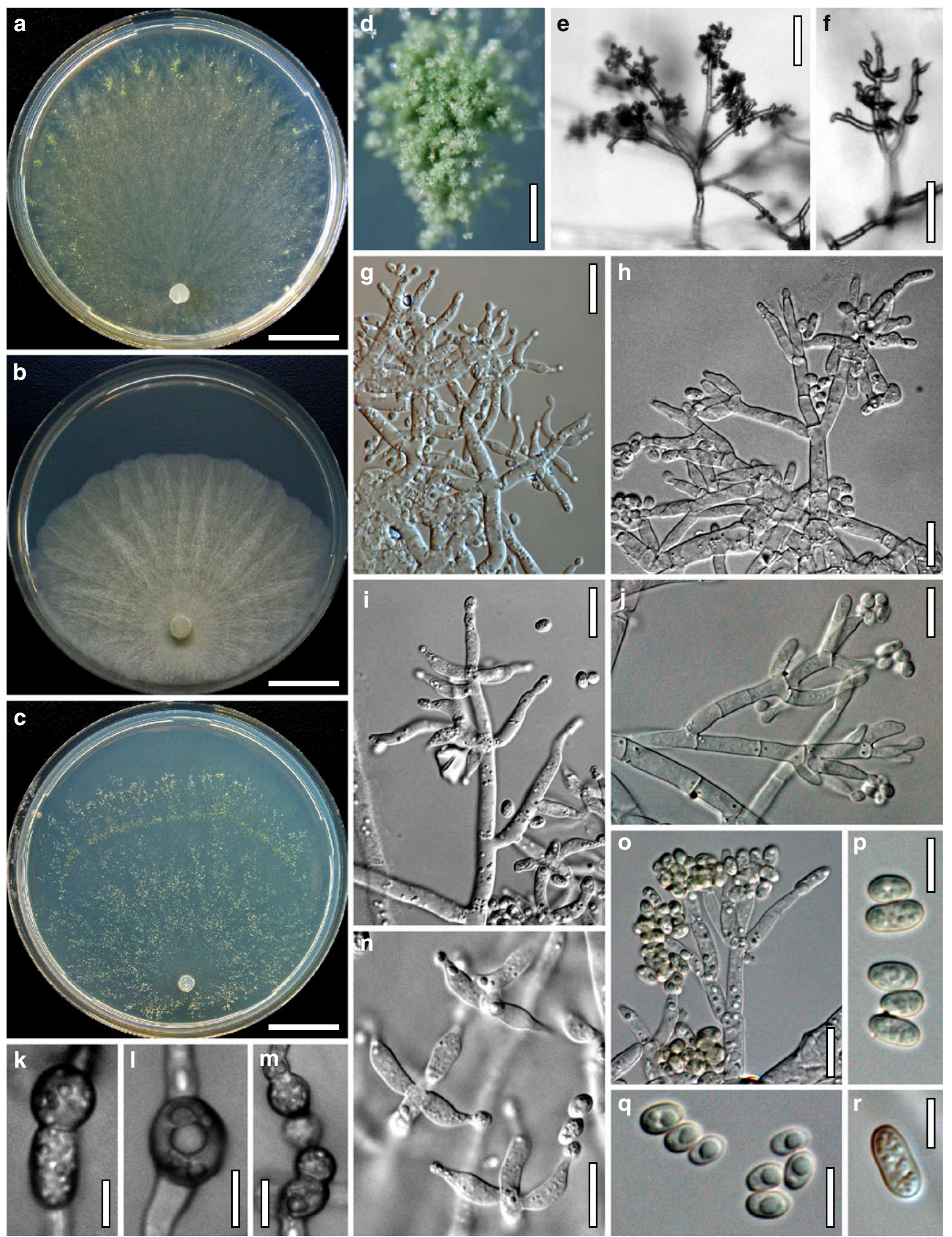
4 Fig. 29 Cultures and anamorph of Hypocrea alutacea. a-c. Cultures (a. on CMD, 35 days. b. on PDA, 14 days. c. on SNA, 35 days). d. Conidiation granule (28 days). e, f. Conidiophores on growth plate (e. 21 days; f. SNA, $15^{\circ} \mathrm{C}, 21$ days). $\mathbf{g}-\mathbf{j}$. Conidiophores (g, i.7 days; $\mathbf{h}, \mathbf{j}$. MEA, 11 days). k-m. Chlamydospores (46 days). n. Phialides ( 7 days). o. Phialides and conidia (20 days). p-r. Conidia (p-q. 20 days, r. 7 days). All at $25^{\circ} \mathrm{C}$ except f. d-r. On CMD except f, h, j. $\mathbf{a}-\mathbf{f}, \mathbf{h}, \mathbf{j}, \mathbf{k}-\mathbf{m}, \mathbf{o}-\mathbf{q}$. CBS 120535. g, i, n, r. CBS 332.69. Scale bars: $\mathbf{a}-\mathbf{c}=19 \mu \mathrm{mm} . \mathbf{d}=100 \mu \mathrm{m} . \mathbf{e}, \mathbf{f}=40 \mu \mathrm{m} . \mathbf{g}, \mathbf{m}=15 \mu \mathrm{m} . \mathbf{h}-\mathbf{l}, \mathbf{n}$, $\mathbf{o}=10 \mu \mathrm{m} . \mathbf{p}-\mathbf{r}=5 \mu \mathrm{m}$

2004, H. Voglmayr \& W. Jaklitsch, W.J. 2699, (WU 29177, culture CBS $120535=$ C.P.K. 1906). Surrey, Sheepleas, on decayed $\log$ of Fagus sylvatica, R. Alder, 4 Nov. 2006, confirmed by B. Spooner (K 142759). Same area, 7 Oct. 1982, I. Frazer (K 155403).

Notes: Hypocrea alutacea is currently the only species of Hypocrea in Europe that forms upright, stipitate stromata on logs lying on the ground. It has been mixed up with $H$. leucopus since Saccardo (1883a), and Atkinson (1905) synonymized the two species. Chamberlain et al. (2004) and Jaklitsch et al. (2008b) showed that H. leucopus and other species found on the ground on leaf litter in coniferous forests are different species, both morphologically and phylogenetically. No evidence supports the earlier view (see Winter 1885 [1887], p. 142) that the upright shape of $H$. alutacea (obviously meaning H. leucopus), would result from parasitism of basidiomes of a Clavaria or ascomata of a Spathularia by an effused Hypocrea stroma. Doi (1975) interpreted the specimen IMI 47042 with laterally fused stromata as Hypocrea brevipes Mont. Although lateral fusion of stromata was also described for H. brevipes by Samuels and Lodge (1996), probably only based on IMI 47042, there is no convincing evidence for this identification, because this morphological trait is not uncommon in $H$. alutacea. The tropical $H$. brevipes typically forms capitate stromata; it has not been found in Europe. Lateral 'fusion' of stromata or fasciculate stromata on a common stipe may alternatively mean, that first a complex, large compound stroma is formed, which breaks up into several individual stromata during its development, as seen in many Hypocrea species forming pulvinate stromata. After several transfers the conidiation in $H$. alutacea remains colourless or white on all media including CMD.

Hypocrea leucopus (P. Karst.) H.L. Chamb., Karstenia 44: 16 (2004). Fig. 30

三Podostroma leucopus P. Karst., Hedwigia 31: 294 (1892).

Anamorph: Trichoderma leucopus Jaklitsch, sp. nov. Fig. 31

MycoBank MB 516683

Conidiophora in agaro CMD effuse disposita, simplicia, ramis sparsis brevibus praedita, similia Verticillii. Phialides divergentes, lageniformes vel subulatae, (7-)10-17(-26)×
(2.0-)2.4-3.0(-3.7) $\mu \mathrm{m}$. Conidia ellipsoidea vel oblonga, hyalina, glabra, $(2.9-) 3.2-5.5(-8.3) \times(1.9-) 2.2-3.4(-5.4)$ $\mu \mathrm{m}$. Pustulae in agaro SNA tarde provenientes, conidiophoris similibus Pachybasii. Phialides lageniformes, (5.0-)6.0 $8.5(-9.2) \times(2.3-) 2.5-3.2(-3.4) \mu \mathrm{m}$. Conidia ellipsoidea, hyalina, glabra, $(2.5-) 2.8-3.3(-3.7) \times(2.2-) 2.3-2.5(-2.7) \mu \mathrm{m}$.

Etymology: a white foot, taken from the teleomorph epithet.

Stromata not seen in fresh condition. Stromata when dry (20-)28-40(-41) mm long, clavate, straight or more commonly curved. Fertile part (7-)8-14(-16) mm long, comprising $30-40 \%$ of the total length; typically welldelimited and distinctly broadened above the cylindrical stipe, typically laterally compressed and $(2-) 3-6(-7) \times(1-)$ $1.5-4(-5) \mathrm{mm}$ thick $(n=20)$. Apex often broadly rounded. Often hollow inside. Surface smooth, slightly tubercular or somewhat rugose, often more tubercular towards the stipe. Ostiolar dots (23-)40-75(-118) $\mu \mathrm{m}(n=120)$ diam, numerous, well-defined, plane or convex, with circular outline. Colour of fertile part pale yellow or greyish orange, $4 \mathrm{~A} 3-4$, $5 \mathrm{AB} 4$, due to a white to pale yellow stroma surface and yellow to nearly orange ostiolar dots. Stipe (14-)20-27(-28) $\mathrm{mm}(n=11)$ long, (1.3-)1.7-3.3(-4.5) $\times(0.8-) 1.0-2.5(-3.0)$ mm thick $(n=22)$; base often thickened and $2-6 \mathrm{~mm}(n=11)$ thick. Stipe cylindrical, sterile, sometimes with inconspicuous, short, longish vertical fertile patches or few solitary perithecia in the uppermost part; straight or curved, smooth or slightly longitudinally furrowed, white or yellowish, similar to or paler than fertile part. Stroma white inside. Spore deposits white or yellowish. Rehydrated stromata slightly larger than dry, pale ochre, ostiolar dots 90-200 $\mu \mathrm{m}$ diam, indistinct, diffuse, with little white stroma in between, stroma inside appearing watery or gelatinous; no distinct colour change noted after the addition of $3 \% \mathrm{KOH}$.

Stroma anatomy: Ostioles (45-)63-85(-94) $\mu \mathrm{m}$ long, projecting to $30 \mu \mathrm{m},(40-) 48-74(-86) \mu \mathrm{m}$ wide at the apex $(n=30)$; with a thick wall and narrow opening 13-20 $\mu \mathrm{m}$ wide; rarely with clavate to fusoid cells to $6 \mu \mathrm{m}$ diam at the apex. Perithecia (200-)225-285(-310)×(115-)160-220(270) $\mu \mathrm{m}$, flask-shaped, ellipsoidal or subglobose. Peridium $(17-) 18-25(-30) \mu \mathrm{m}(n=30)$ thick at the base, $(13-) 16-22$ $(-25) \mu \mathrm{m}(n=30)$ thick at the sides, subhyaline or pale yellowish; of coarse cells merging at the perithecial apex abruptly into the palisade of narrow periphyses. Cortical layer $(18-) 22-43(-60) \mu \mathrm{m}(n=30)$ thick, a hyaline to pale yellowish $t$. angularis of thin-walled cells $(2-) 5-10(-12) \times$ $(2-) 3-6(-8) \mu \mathrm{m}$ in face view and in vertical section $(n=65)$. Subcortical tissue when present a hyaline $t$. intricata of thin-walled hyphae $(2-) 3-5(-7) \mu \mathrm{m}(n=30)$ wide. Subperithecial tissue an ill-defined $t$. intricata of thin-walled hyaline hyphae (2-)3-8(-12) $\mu \mathrm{m}(n=31)$ wide. Asci (57-) 62-80(-93) $\times(3.3-) 4.0-5.0(-5.3) \mu \mathrm{m}$; stipe $(3-) 4-16(-25)$ $\mu \mathrm{m}$ long $(n=70)$, with two basal septa. Ascospores hyaline, 

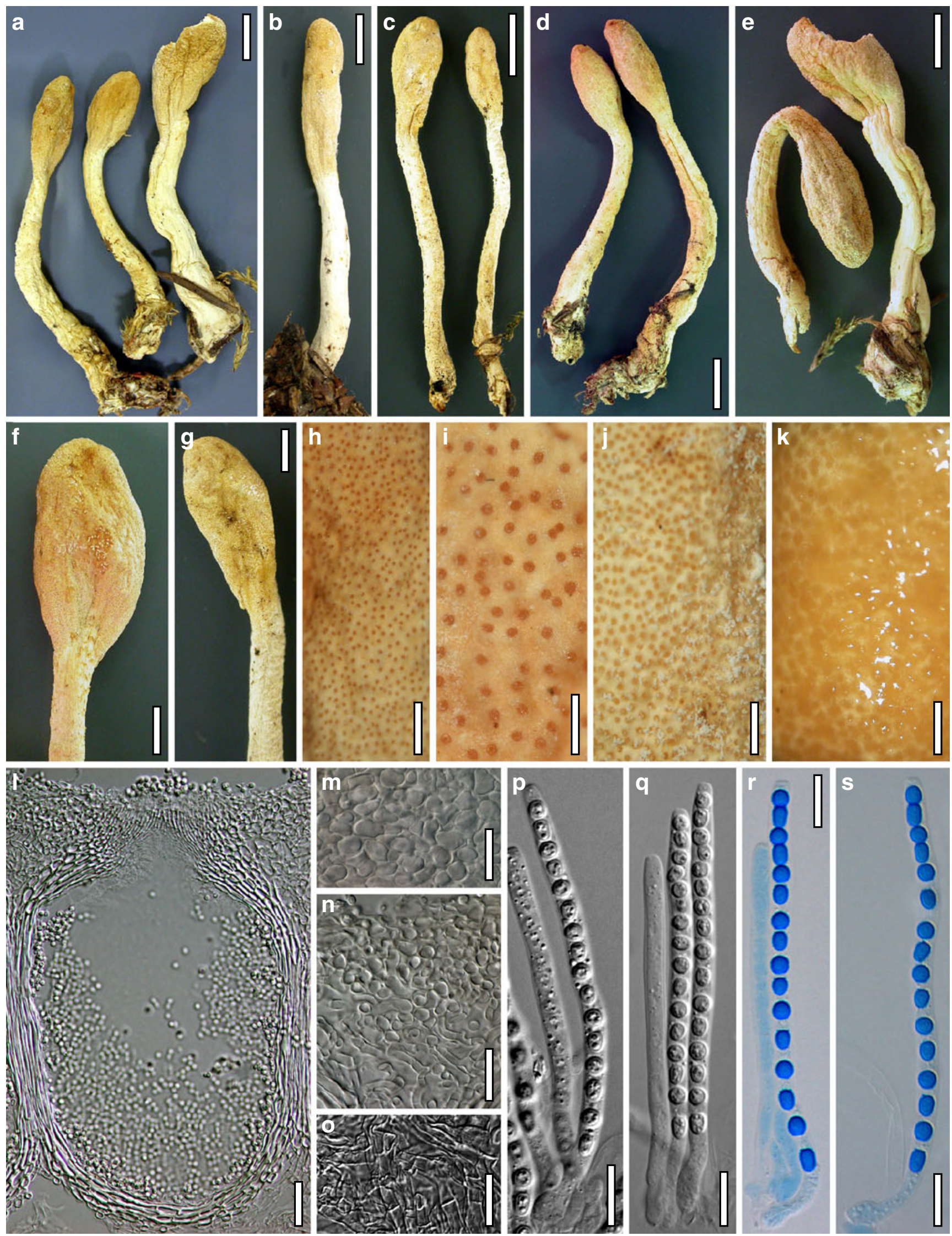
4Fig. 30 Teleomorph of Hypocrea leucopus. a-g. Dry stromata. $\mathbf{h}-\mathbf{k}$. Stroma surface in the stereo-microscope $(\mathbf{h}-\mathbf{j}$. dry, $\mathbf{j}$. showing spore deposits, $\mathbf{k}$. in $3 \% \mathrm{KOH}$ after rehydration). $\mathbf{l}$. Perithecium in section. m. Surface cells in face view. n. Cortical and subcortical tissue in section. o. Subperithecial tissue. $\mathbf{p}-\mathbf{s}$. Asci with ascospores (r, s. in cotton blue/lactic acid). a, d-f, h, i, k-o, r. WU 29231. b, j. Huhtinen 07/108. c, g, p, q, s. T. Rämä 21 Sep.07. Scale bars: $\mathbf{a}-\mathbf{e}=5 \mathrm{~mm}$. f, $\mathbf{g}=$ $2 \mathrm{~mm} . \mathbf{h}=1 \mathrm{~mm} . \mathbf{i}=0.3 \mathrm{~mm} . \mathbf{j}, \mathbf{k}=0.7 \mathrm{~mm} . \mathbf{l}, \mathbf{o}=30 \mu \mathrm{m} . \mathbf{m}=15 \mu \mathrm{m}$. $\mathbf{n}=20 \mu \mathrm{m} . \mathbf{p}-\mathbf{s}=10 \mu \mathrm{m}$

finely verruculose or spinulose; cells dimorphic, distal cell $(2.7-) 3.0-3.5(-4.0) \times(2.3-) 2.8-3.2(-3.5) \mu \mathrm{m}, 1 / \mathrm{w}(0.9-)$ $1.0-1.2(-1.5)(n=120),($ sub $)$ globose, proximal cell $(3.0-)$ $3.4-4.2(-5.0) \times(2.0-) 2.4-2.8(-3.0) \mu \mathrm{m}, 1 / \mathrm{w}(1.1-) 1.3-1.6(-$ 1.9) $(n=120)$, oblong, wedge-shaped or subglobose; contact area usually distinctly flattened.

Cultures and anamorph: optimal growth at $25^{\circ} \mathrm{C}$ on all media; at $30^{\circ} \mathrm{C}$ death of hyphae observed after short growth; no growth at $35^{\circ} \mathrm{C}$. The values given below are from a single experiment.

On CMD 6-7 $\mathrm{mm}$ at $15^{\circ} \mathrm{C}, 12 \mathrm{~mm}$ at $25^{\circ} \mathrm{C}, 3 \mathrm{~mm}$ at $30^{\circ} \mathrm{C}$ after $72 \mathrm{~h}$; mycelium covering the plate after 16 days at $25^{\circ} \mathrm{C}$. Colony circular, hyaline, thin, dense, finely zonate; margin well defined or slightly wavy, hyphae distinctly sinuous. Margin becoming downy and whitish due to conidiation. Aerial hyphae inconspicuous. No autolytic excretions noted, coilings infrequent. No chlamydospores seen. No diffusing pigment noted. Odour indistinct or slightly unpleasant, 'chemical'. Conidiation noted after 3 days, colourless to white, effuse, farinose, floccose or cottony, on short, mostly 50-150(-250) $\mu \mathrm{m}$ long, simple, verticillium-like conidiophores erect on surface hyphae; similar conidiophores also 30-120 $\mu \mathrm{m}$ long formed widely spaced on aerial hyphae to $1 \mathrm{~mm}$ long; conidiophores with more complex branching in loose shrubs along the margin. After several months at $15^{\circ} \mathrm{C}$ sometimes white, pachybasium-like pustules to $c a 1 \mathrm{~mm}$ diam appearing along margin. Pustules not examined. Structure of conidiophores determined after 5-7 days; consisting of a straight stipe or axis with a single terminal whorl of phialides or with solitary phialides or 1-2 whorls of 3-5(-6) phialides along its length; sometimes with few paired or unpaired branches in right angles or slightly inclined upwards, each with 1-3 whorls of phialides. Branches straight, less commonly sinuous. Conidiophores 3-6 $\mu \mathrm{m}$ wide at the base, 2-3 $\mu \mathrm{m}$ at the apex. Phialides solitary or more commonly divergent in whorls of 2-5 on cells $2-3.5 \mu \mathrm{m}$ wide. Conidia formed in minute wet heads to $10(-15) \mu \mathrm{m}$ diam. Phialides (7-)10-17(-26) $\times(2.0-) 2.4-3.0$ $(-3.7) \mu \mathrm{m}, 1 / \mathrm{w}(2.2-) 3.6-6.4(-8.8),(1.5-) 1.7-2.4(-3.3)(n=$ $65)$ wide at the base, lageniform or subulate, straight or slightly curved, narrow, mostly symmetric, widest in or below the middle. Conidia (2.9-)3.2-5.5(-8.3) $\times(1.9-) 2.2-$ $3.4(-5.4) \mu \mathrm{m}, 1 / \mathrm{w}(0.8-) 1.2-2(-2.8)(n=84)$, hyaline, variable, ellipsoidal or oblong, smooth, with few guttules, scar indistinct, sometimes pointed or truncate.
On PDA $8 \mathrm{~mm}$ at $15^{\circ} \mathrm{C}, 18 \mathrm{~mm}$ at $25^{\circ} \mathrm{C}, 1-2 \mathrm{~mm}$ at $30^{\circ} \mathrm{C}$ after $72 \mathrm{~h}$; mycelium covering the plate after 4 weeks at $25^{\circ} \mathrm{C}$. Colony dense, indistinctly coarsely zonate, first circular, margin becoming dentate or lobed. Surface flat, white, centre finely floccose. Aerial hyphae numerous, dense and short in the centre, loose, long and high in distal areas, becoming fertile, collapsing. Autolytic excretions infrequent, no coilings noted. Reverse yellow- to orange-brown, 5-6CD5-7, pigment diffusing into the agar. Odour unpleasant, reminiscent of cultures of $H$. bavarica. No chlamydospores seen. Conidiation noted after 3 days, effuse, white, verticillium-like, first short on surface hyphae in the centre, later ascending onto high levels on aerial hyphae along margin. At $15^{\circ} \mathrm{C}$ hyphae conspicuously sinuous, brown crystals appearing in the agar; conidiation on aerial hyphae.

On SNA $3-4 \mathrm{~mm}$ at $15^{\circ} \mathrm{C}, 8 \mathrm{~mm}$ at $25^{\circ} \mathrm{C}, 1-2 \mathrm{~mm}$ at $30^{\circ} \mathrm{C}$ after $72 \mathrm{~h}$; mycelium covering the plate after 2 weeks at $25^{\circ} \mathrm{C}$. Colony hyaline, thin, circular, finely zonate, dense, with a well-defined or wavy margin; hyphae conspicuously sinuous. Long aerial hyphae frequent, becoming fertile, collapsing, forming floccules. No autolytic excretions noted, coilings infrequent. No chlamydospores seen. No diffusing pigment, no distinct odour noted. Conidiation noted after 3 days, similar to CMD, effuse, spreading across entire plate, also noted within agar to the bottom of the plate. Conidiophores short, on surface and aerial hyphae, also in small white pustules; little branched, with a single terminal whorl of phialides or with 1-2 additional whorls below, mostly to $100 \mu \mathrm{m}$ long, to $220 \mu \mathrm{m}$ long towards margin. Phialides mostly in whorls of $2-5(-6)$, formed on cells $2-4(-5.5) \mu \mathrm{m}$ wide, corresponding to condiophore width. Conidia formed in minute wet heads $<30(-50) \mu \mathrm{m}$ diam. Phialides $(8-) 11-17(-23) \times(2.0-) 2.3-2.8(-3.0) \mu \mathrm{m}, \mathrm{l} /$ $\mathrm{w}(3.5-) 4-7(-9.5),(1.5-) 1.7-2.5(-3.0) \mu \mathrm{m}$ wide at the base $(n=30)$, lageniform or subulate, mostly symmetric, sometimes shorter and with median thickening. Conidia (2.8-) $3.0-4.7(-6.2) \times(2.0-) 2.3-2.5(-3.0) \mu \mathrm{m}, 1 / \mathrm{w}(1.1-) 1.2-1.9(-$ 2.7) $(n=45)$, hyaline, mostly ellipsoidal, also oblong or subglobose, with few minute guttules and indistinct scar. Pustules formed after 20 days, starting in marginal areas, small, thick, dense, with wide pachybasium-like branches in right angles and phialides mostly in whorls of $2-3(-4)$. Phialides (5.0-)6.0-8.5(-9.2) ×(2.3-)2.5-3.2(-3.4) $\mu \mathrm{m}, \mathrm{l} /$ w (1.6-)2.0-3.0(-3.7), (1.5-)2.0-2.5(-2.8) $(n=30)$ wide at the base, lageniform. Conidia $(2.5-) 2.8-3.3(-3.7) \times(2.2-)$ $2.3-2.5(-2.7) \mu \mathrm{m}, 1 / \mathrm{w}(1.1-) 1.2-1.3(-1.4)(n=30)$, hyaline, ellipsoidal, smooth, with few minute guttules, no scar, smaller than in effuse conidiation due to the absence of oblong conidia.

On OA erect stromata were produced by the strain CBS 122499 (CBS, pers. comm.).

Habitat: on forest litter in mixed forests dominated by conifers such as Picea abies. 

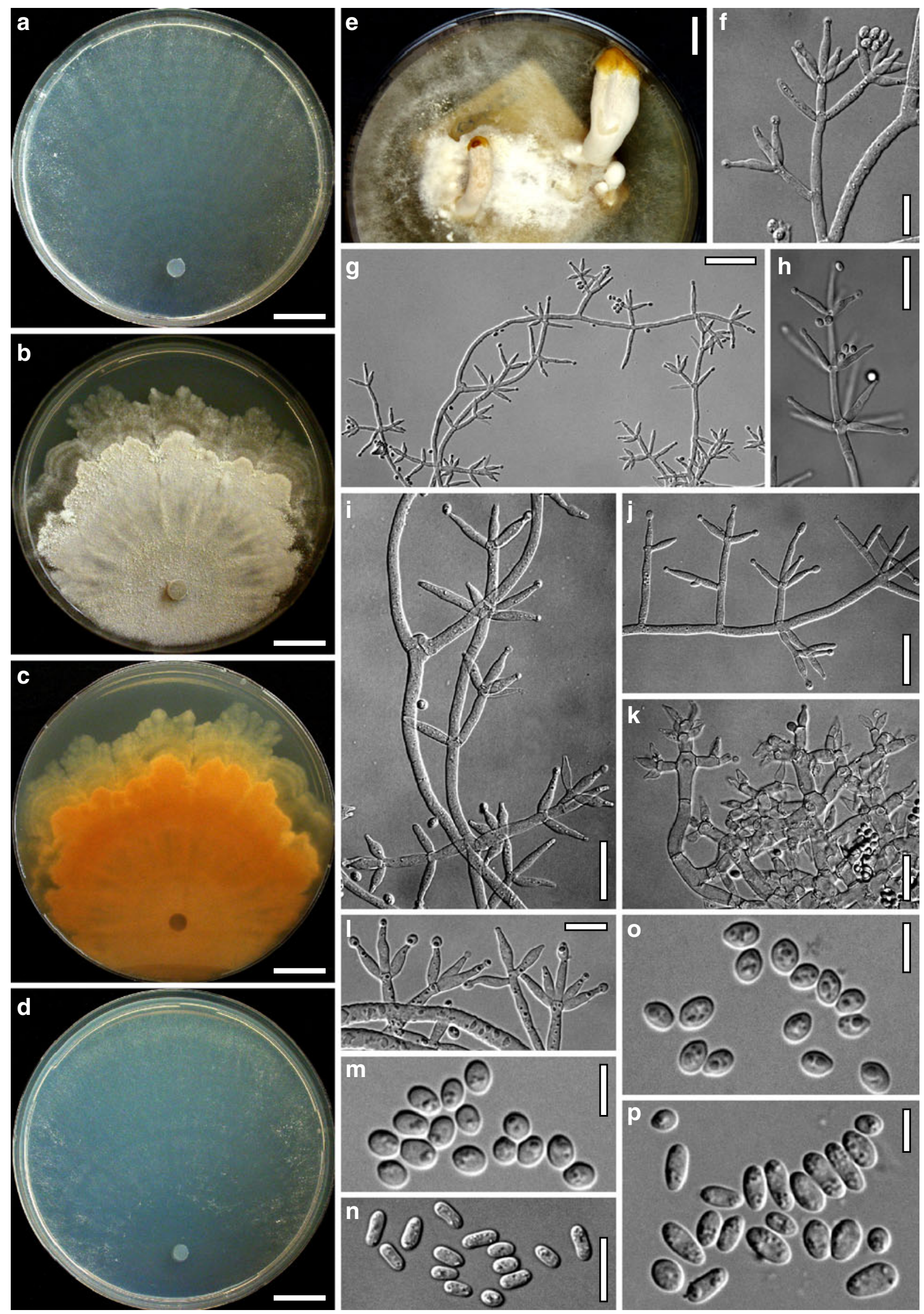
4Fig. 31 Cultures and anamorph of Hypocrea leucopus. a-d. Cultures after 21 days (a. on CMD. b. on PDA. c. on PDA, reverse. d. on SNA). e. Stromata on oatmeal agar $\left(20^{\circ} \mathrm{C}, 3\right.$ weeks; photograph: $\mathrm{G}$. Verkley, CBS). $\mathbf{f}-\mathbf{j}$. Conidiophores of effuse conidiation (f, $\mathbf{g}, \mathbf{i}, \mathbf{j}$. CMD, 18 days; h. SNA, 9 days). k. Pachybasium-like conidiophores from overmature pustule (SNA, 21 days). I. Phialides of effuse conidiation (CMD, 18 days). $\mathbf{m}-\mathbf{p}$. Conidia (m, n. SNA, 21/9 days, $\mathbf{m}$. from pustule; o, p. CMD, $18 / 5$ days). a-p. All at $25^{\circ} \mathrm{C}$ except e. a-e, k, m, p. CBS 122499. f, g, i, j, l, o. CBS 122495. h, n. C.P.K. 3527. Scale bars: $\mathbf{a}-\mathbf{d}=15 \mathrm{~mm} . \mathbf{e}=10 \mathrm{~mm} . \mathbf{f}, \mathbf{l}, \mathbf{n}=10 \mu \mathrm{m} . \mathbf{g}=45 \mu \mathrm{m} . \mathbf{h}, \mathbf{i}, \mathbf{k}=$ $15 \mu \mathrm{m} . \mathbf{j}=20 \mu \mathrm{m} . \mathbf{m}, \mathbf{o}, \mathbf{p}=5 \mu \mathrm{m}$

Distribution: Europe (Austria, Finland, Germany), North America.

Holotype: Finland, Etelä-Häme. Tammela, Syrjä, 30 Sep. 1892, P.A. Karsten 3247 (H; not examined). Holotype of Trichoderma leucopus isolated from WU 29231 and deposited as a dry culture with the holotype of H. leucopus as WU 29231a.

Specimens examined: Austria, Kärnten, Klagenfurt Land, St. Margareten im Rosental, Oberdörfl, at Nagu, MTB 9452/ 4, 46 $31^{\prime} 55^{\prime \prime} \mathrm{N}, 14^{\circ} 27^{\prime} 01^{\prime \prime} \mathrm{E}$, elev. $710 \mathrm{~m}$, on the ground under Picea abies, 8 Sep. 1998, H. Voglmayr (WU 18557). Finland, Etelä-Häme, Luopioinen; grid 68100:2544, on needle litter in spruce forest, 14 Aug. 2007, E. Smolander (WU 29231, culture CBS 122499=C.P.K. 3160). PohjoisKarjala, Kitee, Komolinmäki Nature Reserve, grid 6888:664, mixed forest with spruce and birch, on the ground under Picea abies, soc. Oxalis sp., attached to litter of spruce needles and birch leaves, 21 Sep. 2007, S. Huhtinen 07/108 (TUR, culture CBS 122495, C.P.K. 3164). Pohjois-Karjala, Kitee, Komolinmäki Nature Reserve, grid 6888:664, mixed forest with spruce and birch, on the ground, 21 Sep. 2007, T. Rämä (TUR), culture C.P.K. 3527. Germany, Bavaria, Oberfranken, $10 \mathrm{~km} \mathrm{~W}$ of Bayreuth, grid 6034/2, in leaf litter on the ground between Pseudotsuga menziesii, Fagus, Betula and Larix, soc. Spathularia flavida, 27 Aug. 2010, A. Bröckel, comm. C. Gubitz (WU 30205).

Notes: Hypocrea leucopus, the type species of Podostroma P. Karst. (1892), has long been considered as a synonym of H. alutacea, the type species of Podocrea (Sacc.) Lindau (1897). The latter forms clavate to irregular, often laterally fused stromata on branches and logs of deciduous trees usually well above the ground, and forms a Trichoderma-like anamorph with conidia being green on CMD, at least in fresh cultures. Hypocrea leucopus occurs on the ground in forests typically containing coniferous trees. Forest debris such as leaves, needles, minute twigs, moss and fungal rhizomorphs are typically firmly appressed to the base of the stromata. The fungus may therefore probably feed on cellulose-containing materials and/or fungi. Associated bryophytes are often vital and possibly provide for a favourable moist microclimate. Stromata of a specimen from South Carolina, U.S.A. (WU 30284), identified using gene sequences from DNA extracted from them, were growing on Carya nutshells.
Other species forming upright stromata in leaf litter of North European forests are Hypocrea nybergiana and $H$. seppoi. The former differs from $H$. leucopus by larger and more intensely pigmented stromata, slightly larger ascospores and larger conidia on large solitary phialides, while the latter forms smaller, delicate stromata with horizontal perithecial groups in the transition area between the fertile part and the stipe, a more irregular verticillium-like anamorph, and it grows considerably more slowly at $25^{\circ} \mathrm{C}$ on CMD, PDA and SNA than $H$. leucopus. Pustulate pachybasium-like conidiation in addition to effuse verticillium-like conidiation on SNA or CMD has not been seen in any of the other Hypocrea species with upright stromata. Due to difficulties to reproduce pustules, only a short description of an overmature pustule of T. leucopus is given.

Hypocrea nybergiana T. Ulvinen \& H.L. Chamb., Karstenia 44: 21 (2004). Fig. 32

Anamorph: Trichoderma sp. Fig. 33

Stromata not seen in fresh condition. Stromata when dry (37-)46-93(-106) mm $(n=11)$ long, cylindrical, clavate, sometimes nearly spathulate, straight or curved; sometimes hollow inside. Fertile part (13-)22-60(-76) $\mathrm{mm}(n=16)$ long, comprising $40-60(-80) \%$ of total length; typically gradually merging into the stipe, not sharply delimited, with fertile patches longitudinally decurrent on the stipe; typically laterally compressed and $5-15 \times 2-8 \mathrm{~mm}(n=12 ; 19)$ thick. Apex rounded, sometimes strongly laterally compressed, $1-$ $4.5 \mathrm{~mm}$ thick. Surface often with coarse, mostly vertical wrinkles or folds, otherwise smooth to finely tubercular by slightly projecting perithecia. Ostiolar dots (47-)57-148(236) $\mu \mathrm{m}(n=130)$ diam, numerous, densely disposed, welldefined, diffuse when young, plane or convex, with roundish or oblong outline, and light centres, bright ochre to brown; large and diffuse close to the stipe. Colour of the fertile part resulting from white to yellow surface and ochre to brown ostiolar dots, always darker at the top, from yellowish, 4A3, close to the stipe, over greyish orange, 5-6B4-5, brownorange, light brown, 6-7CD4-7(-8) to brown 7E5-8, at the apex. Pigment inhomogeneously distributed, under strong magnification sometimes appearing as minute stripes or appressed scales. Stipe (14-)19-44(-64) mm long, 1-9($21) \times 1-10(-20) \mathrm{mm}$ thick $(n=18)$; base $(2-) 3-12(-20) \mathrm{mm}$ $(n=14)$ thick, sometimes with white to yellowish basal mycelium. Stipe cylindrical, straight or curved, smooth or longitudinally furrowed, white or pale yellow, 4A2-3, typically paler than the fertile part, sometimes with pigment scales as on the fertile part; becoming brittle, papyraceous with age. Stroma white inside. Spore deposits white to pale yellowish. Rehydrated stromata smooth, yellowish to pale ochre, ostiolar dots convex, intensely ochre to light brown, $100-160(-210) \mu \mathrm{m}$ diam. After addition of $3 \% \mathrm{KOH}$ 


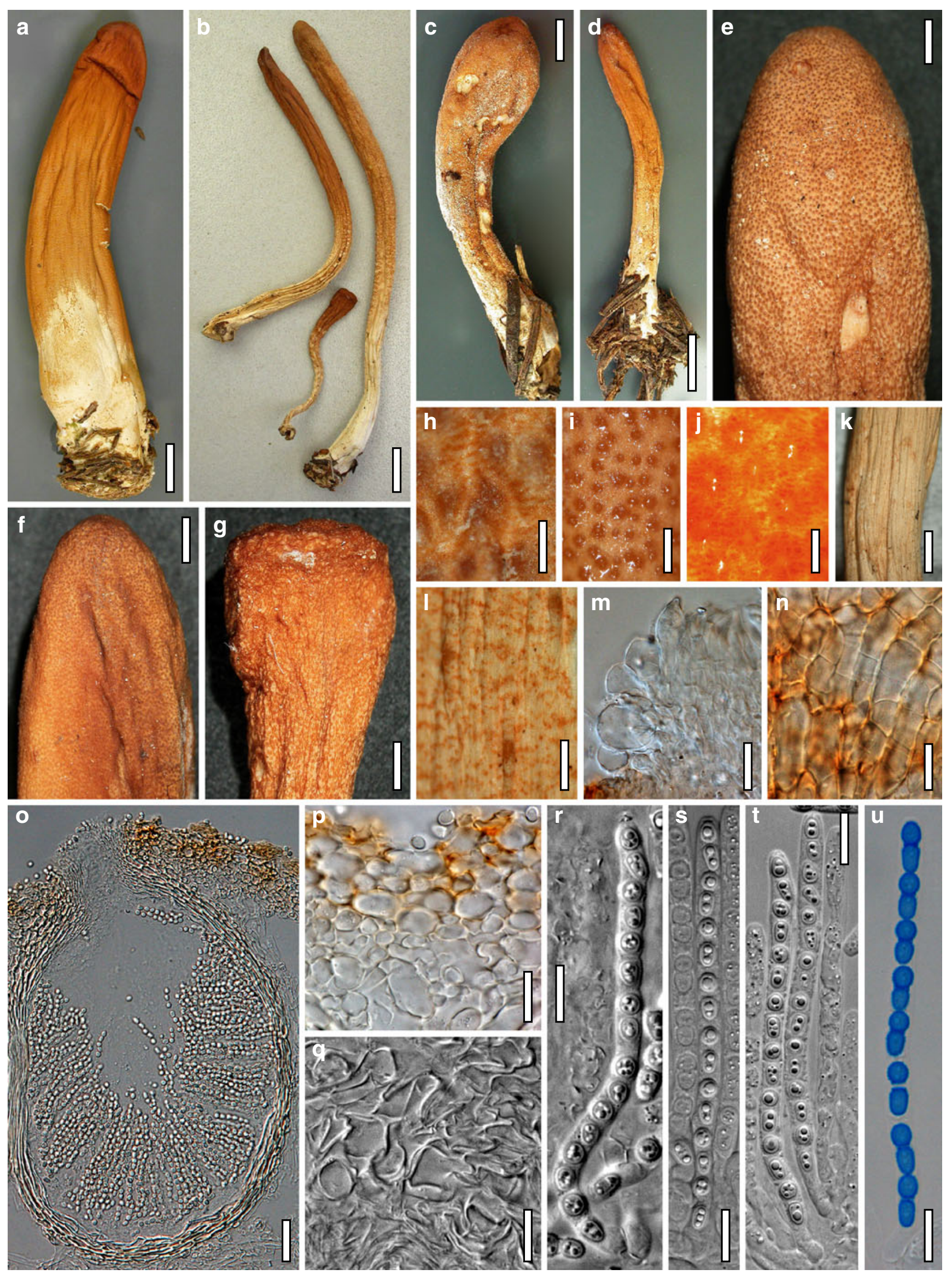


4Fig. 32 Teleomorph of Hypocrea nybergiana. a-d. Dry stromata. e-g. Apical fertile part of dry stromata. $\mathbf{h}-\mathbf{j}$. Stroma surface in the stereomicroscope (h. dry, showing inhomogeneous pigment distribution; i. rehydrated; $\mathbf{j}$. in $3 \% \mathrm{KOH}$ after rehydration). $\mathbf{k}$, l. Stipe surface in the stereo-microscope (l. showing pigment flakes). $\mathbf{m}$. Part of an ostiole in vertical section showing inflated marginal apex cells. $\mathbf{n}$. Surface cells in face view. o. Perithecium in section. p. Cortical and subcortical tissue in section. q. Subperithecial tissue. $\mathbf{r}-\mathbf{u}$. Asci with ascospores (u. in cotton blue/lactic acid). a. L. Koukku Aug. 2007 (JOE). b, e, g, s. WU 29308. c, d, f, n, r. S. Huhtinen 07/98 (TUR). h-m, o-q, u. WU 29307. t. WU 29309. Scale bars: $\mathbf{a}, \mathbf{b}, \mathbf{d}=10 \mathrm{~mm}$. $\mathbf{c}=5 \mathrm{~mm}$. e- $\mathbf{g}=1.5 \mathrm{~mm}$. $\mathbf{h}=250 \mu \mathrm{m}$. $\mathbf{i}, \mathbf{l}=0.5 \mathrm{~mm} . \mathbf{j}=150 \mu \mathrm{m} . \mathbf{k}=2.5 \mathrm{~mm} . \mathbf{m}, \mathbf{n}, \mathbf{p}-\mathbf{u}=10 \mu \mathrm{m} . \mathbf{o}=30 \mu \mathrm{m}$

macroscopically light brown, without a colour change, under the stereo-microscope more orange and fine pigment stripes more distinct, often concentric around the ostioles.

Stroma anatomy: Ostioles (50-)57-75(-90) $\mu \mathrm{m}$ long, projecting to $25 \mu \mathrm{m},(40-) 47-68(-76) \mu \mathrm{m}$ wide at the apex $(n=30)$, short-cylindrical, periphysate, sometimes lined at the apex by subglobose or apically pointed, hyaline cells $5-$ 9(-14) $\mu \mathrm{m}$ wide. Perithecia $(190-) 260-320(-340) \times(120-)$ 160-240(-285) $\mu \mathrm{m}(n=30)$, crowded, flask-shaped, ellipsoidal or globose; peridium (15-)18-25(-28) $\mu \mathrm{m}(n=30)$ thick at the base, $(10-) 13-19(-22) \mu \mathrm{m}(n=30)$ at the sides, yellow. Cortical layer (18-)24-38(-44) $\mu \mathrm{m}(n=30)$ thick, a $t$. angularis of distinct, thin- or thick-walled cells (3.5-)6$14(-23) \times(3-) 5-9(-10) \mu \mathrm{m}(n=60)$ in face view and in vertical section, subhyaline, yellow to orange, with inhomogeneously distributed pigment, around the ostioles typically smaller and in parallel rows. Subcortical tissue variable, mostly a $t$. intricata of hyaline, thin-walled hyphae $(2-) 4-6(-7) \mu \mathrm{m}(n=30)$ wide, or a $t$. angularis of hyaline, thin-walled cells $(3-) 5-9(-15) \times(3-) 4-7(-8) \mu \mathrm{m}(n=30)$. Subperithecial tissue an ill-defined $t$. intricata of hyaline, thin-walled hyphae $(2.5-) 4-9(-12) \mu \mathrm{m}(n=40)$ wide. Asci (63-)80-98(-112)×(4.5-)4.7-5.5(-6.0) $\mu \mathrm{m}$, stipe 5-18(34) $\mu \mathrm{m}$ long $(n=90)$, apex with a minute flat ring, base with crozier. Ascospores hyaline, verruculose or spinulose with spines to $0.5 \mu \mathrm{m}$ long; cells dimorphic; distal cell (3.0-) $3.5-4.0(-5.5) \times 3.0-3.5(-4.2) \mu \mathrm{m}, 1 / \mathrm{w}(0.9-) 1.0-1.3(-1.7)$ $(n=120)$, (sub)globose, sometimes wedge-shaped at the apex; proximal cell $(3.2-) 4.0-4.8(-5.5) \times(2.2-) 2.7-3.0(-$ 4.0) $\mu \mathrm{m}, 1 / \mathrm{w}(1.2-) 1.4-1.7(-2.1) \quad(n=120)$, oblong, ellipsoidal or plump wedge-shaped, sometimes subglobose.

Cultures and anamorph: growth rate only studied in a single experiment using a single isolate; optimal growth at $25^{\circ} \mathrm{C}$ on all media; at $30^{\circ} \mathrm{C}$ hyphae dying after a short initial growth of max. $0.5 \mathrm{~mm}$; no growth at $35^{\circ} \mathrm{C}$.

On CMD after $72 \mathrm{~h} 8 \mathrm{~mm}$ at $15^{\circ} \mathrm{C}, 11 \mathrm{~mm}$ at $25^{\circ} \mathrm{C}$; mycelium covering the plate after 17 days at $25^{\circ} \mathrm{C}$. Colony hyaline, thin, circular, indistinctly broadly zonate, margin diffuse; hyphae with little variation in width. Aerial hyphae inconspicuous, loose, several $\mathrm{mm}$ long and high. Autolytic activity absent, coilings rare. No chlamydospores seen. No diffusing pigment, no distinct odour noted. Conidiation noted after 10 days as scant conidia on aerial hyphae.

On PDA after $72 \mathrm{~h} 5 \mathrm{~mm}$ at $15^{\circ} \mathrm{C}, 12 \mathrm{~mm}$ at $25^{\circ} \mathrm{C}$; mycelium covering the plate after 10 days at $25^{\circ} \mathrm{C}$. Colony circular, dense, compact with well-defined margin, numerous yellow crystals formed in the agar. Aerial hyphae abundant, often with subglobose thickenings to $6-11 \mu \mathrm{m}$ terminally or along their length; forming a thick white to yellowish cottony mat, ascending to the lid of the Petri dish. Autolytic activity and coilings absent. Reverse yellow, orange, 4-5AB4-5, to orange-brown or yellow-brown, 5CD7-8. No distinct odour noted. Conidiation noted after 3 days; conidia produced in small numbers in wet to dry heads on scant solitary, cylindrical or subulate phialides on aerial hyphae. Conidia (5-)6-15(-21) $\times(3.0-) 4.0-6.7(-9.3)$ $\mu \mathrm{m}, 1 / \mathrm{w}(1.1-) 1.3-2.7(-3.9) \quad(n=30)$, variable in shape, ellipsoidal, oval, subglobose, oblong, broadly fusoid, or clavate, hyaline, smooth, eguttulate or rarely with few small guttules; scar indistinct or truncate; often adhering in small clusters. At $15^{\circ} \mathrm{C}$ colony coarsely zonate, with crystals and white cottony mat; no conidiation seen.

On SNA after $72 \mathrm{~h} 4 \mathrm{~mm}$ at $15^{\circ} \mathrm{C}, 10 \mathrm{~mm}$ at $25^{\circ} \mathrm{C}$; mycelium covering the plate after 13 days at $25^{\circ} \mathrm{C}$. Colony circular, dense, with well-defined or irregular margin, becoming hairy by numerous, loosely disposed, long, dichotomously branched aerial hyphae ascending to the lid of the Petri dish along the colony margin, with some thickenings 6-9(-15) $\mu \mathrm{m}$. Autolytic excretions locally frequent, coilings absent. No diffusing pigment, no distinct odour noted. No chlamydospores seen. Conidiation noted after 10 days. Conidia (examined after 14-28 days) produced in small numbers in minute wet to dry heads on solitary phialides or simple conidiophores on long aerial hyphae in mostly marginal, whitish, arachnoid to cottony areas. Conidiophores $2-5(-6.5) \mu \mathrm{m}$ wide, of a main axis to $150 \mu \mathrm{m}$ long, with few unpaired, often right-angled branches or phialides, apically with one, more rarely $2-3(-4)$ divergent phialides. Phialides $(11-) 22-43(-55) \times(2.3-) 3.0-4.0(-5.0)$ $\mu \mathrm{m}, 1 / \mathrm{w}(2.7-) 6.5-13(-17),(1.7-) 2.2-3.0(-3.5) \mu \mathrm{m}$ wide at the base $(n=40)$, cylindrical or subulate, sometimes lanceolate or fusoid, mostly straight, equilateral, sometimes with a clamp-like widening on their base. Conidia (5-)6-16(-29) $\times$ (3.0-)4.0-6.5(-8.0) $\mu \mathrm{m}, 1 / \mathrm{w} \quad(1.2-) 1.3-3.0(-5.0) \quad(n=70)$, hyaline, extremely variable in shape, mostly oblong to cylindrical, also ellipsoidal, subglobose, oval, pyriform, sometimes curved, smooth, eguttulate, scar indistinct or truncate; often adhering in clusters.

Habitat: on forest litter in mixed forests dominated by conifers such as Picea abies.

Distribution: North Europe, northern areas of Finland and Sweden.

Holotype: Finland, Oulun Pohjanmaa. Haukipudas, Kello, Kalimeenkylä, Kalimeenoja, $1.5 \mathrm{~km}$ upstream of Saarela, in a spruce forest at the Suo-oja brook, 24 Aug. 

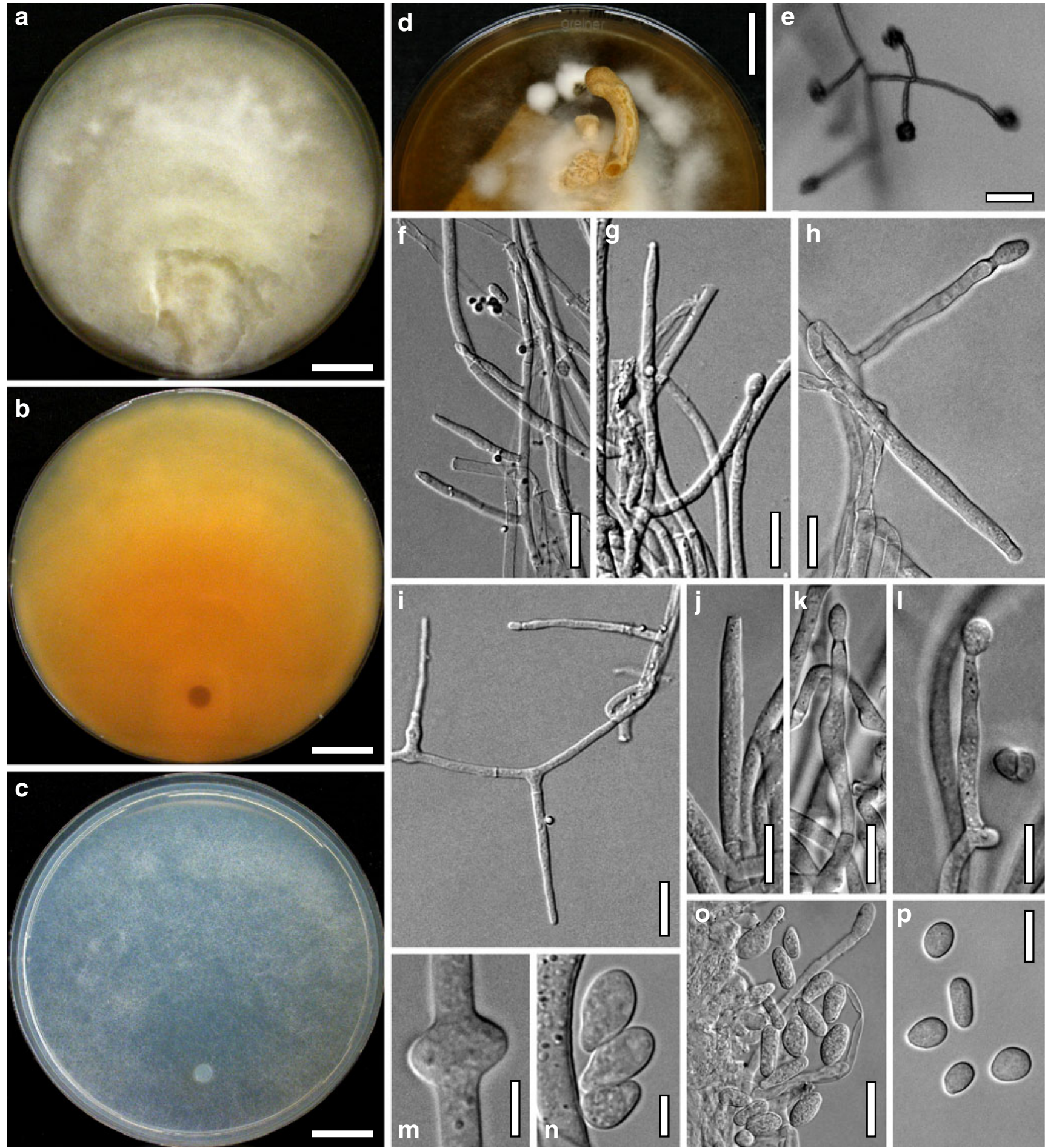

Fig. 33 Cultures and anamorph of Hypocrea nybergiana. a-c. Cultures after 14 days (a. on PDA. b. on PDA, reverse. c. on SNA). d. Stroma on OA $\left(20^{\circ} \mathrm{C}, 3\right.$ weeks; photograph: G. Verkley, CBS). e. Conidiophore on aerial hypha on the growth plate (14 days). $\mathbf{f}-\mathbf{i}$. Conidiophores (14 days). j-l. Phialides (j. PDA, 10 days; k, l.

1967, T. Ulvinen (OULU F 49597, isotype OULU F 49596; not examined).

Material examined: Finland, Oulun Pohjanmaa, Kiiminki. Pikkuhalmeenmaa, Jolosmäki. In calcareous spruce

14 days). $\mathbf{m}$. Thickened cell in aerial hypha (14 days). $\mathbf{n}-\mathbf{p}$. Conidia (n. PDA, 7 days; o, p. 28 days). a-p. All at $25^{\circ}$ C. e-p. All on SNA except j, n. a-c, j, n. CBS 122500. d-i, k-m, o, p. CBS 122496. Scale bars: $\mathbf{a}-\mathbf{d}=15 \mathrm{~mm} . \mathbf{e}=30 \mathrm{~mm} . \mathbf{f}, \mathbf{i}=20 \mu \mathrm{m} . \mathbf{g}, \mathbf{o}=15 \mu \mathrm{m} . \mathbf{h}, \mathbf{j}-\mathbf{l}$, $\mathbf{p}=10 \mu \mathrm{m} . \mathbf{m}, \mathbf{n}=5 \mu \mathrm{m}$

forest. Grid $27^{\circ} \mathrm{E} 7228: 445$, elev. $45 \mathrm{~m}$, on soil/leaf litter, 15 Aug. 2007, T. Rahko, det. I. Kytovuori (WU 29307). Pohjois-Karjala, Tohmajärvi, Kaurila, Okkula, 700-800 m east of the statue of Siiri Rantanen, grid $27^{\circ}$ E 6902:683, on 
the ground in a spruce-dominated mixed forest in leaf litter, immature, 9 Aug. 2007, L. Koukku, det. M. Kirsi 07-045 as P. alutaceum (JOE). Pohjois-Pohjanmaa, Koillismaa, Kuusamo, Oulanka National Park, E of Nurmisaarenniemi; grid $27^{\circ} \mathrm{E} 73638: 6104$; in a moist mossy eutrophic depression in a forest with Picea abies and Betula, on leaf litter in moss, 27 Aug. 2007, J. Vauras 25047 (WU 29308, part in TUR-A; culture CBS 122500=C.P.K. 3159). Kuusamo, Iivaara, Tienoro, N slope, grid $27^{\circ}$ E 7304:622; forest with Picea abies, Pinus sylvestris and Betula, on soil/leaf litter, 4 Sep. 2007, K. Kokkonen \& J. Vauras 25276 (WU 29309, part in TUR-A). Pohjois-Savo, Heinävesi, Heinolanmäki Nature Reserve, grid 6923:582, on thick needle litter with a moss cover under a large spruce, 19 Sep. 2007, S. Huhtinen 07/98 as H. alutacea (TUR; culture CBS $122496=$ C.P.K. 3163).

Notes: Among the species with upright stromata in Europe Hypocrea nybergiana forms the largest and darkest stromata. This species is characterized by an unusual combination of traits found in different clades of Hypocrea/Trichoderma. Although $H$. nybergiana phylogenetically belongs to the pachybasium core group, the inhomogeneous distribution of the cortical pigment is mainly found in teleomorphs of Trichoderma sect. Trichoderma. However, in contrast to that section the cortical cells are distinct, and inflated cells line the ostiolar apex. The anamorph is primitive, unusual for Trichoderma, and at most somehow similar to anamorphs of sect. Hypocreanum. The conidia are variable in shape, reminiscent of those of $H$. protopulvinata.

Hypocrea seppoi Jaklitsch, Karstenia 48: 5 (2008b). Fig. 34 Anamorph: Trichoderma seppoi Jaklitsch, Karstenia 48: 5 (2008b).

Stromata when dry 8-24 mm long; fertile part 3-12 mm long, $1.5-4.5 \times 0.5-3 \mathrm{~mm}$ thick; stipe $5-13 \mathrm{~mm}$ long, $1-3 \times$ $0.3-2 \mathrm{~mm}$ thick, base $1.2-3 \mathrm{~mm}$ thick $(n=4)$. Fertile part clavate to spathulate, distinctly laterally compressed or longitudinally furrowed or folded, gradually tapered downwards. Stroma surface white, smooth, largely concealed by numerous, densely disposed, convex to papillate, ochre ostiolar dots (30-)50-110(-165) $\mu \mathrm{m}$ diam $(n=60)$, giving the surface a finely roughened appearance. Colour yellowochre or greyish orange, 5AB4, 5B5, 6B4. Stipe thin, cylindrical, fibrous to delicately longitudinally striate, slightly compressed, off-white to cream-ochre, straight or strongly curved, also twisted around its axis. Stipe surface dotted by scattered or aggregated perithecia decurrent nearly its whole length. Base not or slightly thickened, typically carrying needles of Picea colonized by brown rhizomorphs. Spore deposits on stroma surface delicate, white. After rehydration stromata somewhat larger than in dry condition, lighter, light yellow-ochre, stroma white, perithecia yellow. Reaction to $3 \% \mathrm{KOH}$ indistinct. Entostroma white.
Stroma anatomy: Ostioles $(43-) 53-70(-75) \mu \mathrm{m}$ long, plane or projecting to $30(-47) \mu \mathrm{m},(30-) 45-65(-85) \mu \mathrm{m}$ wide at the apex $(n=30)$, cylindrical, periphysate, apex widened; apical cells in a palisade, cylindrical to clavate, to $5 \mu \mathrm{m}$ wide. Perithecia $(125-) 180-250(-280) \times(70-) 100-$ $175(-220) \mu \mathrm{m}(n=30)$, crowded, mostly laterally compressed, flask-shaped, ellipsoidal or subglobose. Peridium $(11-) 15-19(-20) \mu \mathrm{m}$ thick at the base, $(9-) 12-16(-18) \mu \mathrm{m}$ $(n=30)$ at the sides, hyaline to pale yellowish. Cortical layer $(16-) 20-30(-36) \mu \mathrm{m}$ thick $(n=30)$, a subhyaline to pale yellow $t$. angularis of isodiametric to oblong cells (4-)6-14 $(-18) \times(4-) 5-9(-12) \mu \mathrm{m}$ in face view and $(2.5-) 4-10(-$ $16) \times(2-) 3-6(-8) \mu \mathrm{m}(n=30)$ in vertical section. Subcortical tissue absent or a loose hyaline $t$. intricata of thinwalled hyphae $(2-) 3-5(-6) \mu \mathrm{m}(n=35)$ wide. Subperithecial tissue a loose hyaline $t$. intricata of thin-walled hyphae $(2-) 3-5(-7) \mu \mathrm{m}(n=30)$ wide, often collapsed, with variable orientation, therefore in part appearing as irregular t. epidermoidea upon strong magnification. Asci (62-)68$84(-87) \times 4.0-4.5(-5.0) \mu \mathrm{m}$, stipe $(6-) 10-25(-30) \mu \mathrm{m}(n=$ $20)$ long. Ascospores hyaline, finely verruculose, cells dimorphic; distal cell $(2.7-) 3.0-3.5(-4.0) \times(2.5-) 2.7-3.2(-$ 3.5) $\mu \mathrm{m}, 1 / \mathrm{w}(0.9-) 1.0-1.2(-1.5)(n=70)$, (sub)globose to nearly wedge-shaped; proximal cell $(3.0-) 3.5-4.5(-5.5) \times$ $(2.0-) 2.3-2.7(-3.0) \mu \mathrm{m}, 1 / \mathrm{w}(1.2-) 1.4-2.0(-2.4) \quad(n=70)$ oblong to wedge-shaped; sometimes inverted inside the asci.

Cultures and anamorph (growth rate determined in a single experiment): optimal growth at $25^{\circ} \mathrm{C}$ on PDA and SNA, on CMD at $30^{\circ} \mathrm{C}$; no growth at $35^{\circ} \mathrm{C}$.

On CMD $3 \mathrm{~mm}$ at $15^{\circ} \mathrm{C}, 6-7 \mathrm{~mm}$ at $25^{\circ} \mathrm{C}, 8-9 \mathrm{~mm}$ at $30^{\circ} \mathrm{C}$ after $72 \mathrm{~h}$; mycelium covering the plate after $c a$ 3 weeks at $25^{\circ} \mathrm{C}$. Colony hyaline, thin, of 2 zones, a dense central zone with irregularly lobed margin, and a broad marginal zone distinctly separated from and growing faster than the central zone. Surface becoming slightly farinose by white conidiation; mycelium dense, hyphae narrow. Aerial hyphae none to inconspicuous. Autolytic excretions, coilings, pigment, distinct odour, and chlamydospores absent. Conidiation noted after 3 days at $25^{\circ} \mathrm{C}$, effuse, irregularly verticillium-like, starting around the plug, spreading across the plate. Conidiophores short, $\mathrm{ca} 30-60 \mu \mathrm{m}$ long, with 1-2 branching levels; phialides solitary or in whorls of 2-6, straight or curved to sinuous, strongly inclined upwards. Conidia formed in small numbers in variable wet heads, hyaline, ellipsoidal(-subglobose-oblong), smooth, with some fine guttules, scar indistinct; for measurements see on SNA.

On PDA $1 \mathrm{~mm}$ at $15^{\circ} \mathrm{C}, 7-8 \mathrm{~mm}$ at $25^{\circ} \mathrm{C}, 1-1.5 \mathrm{~mm}$ at $30^{\circ} \mathrm{C}$ after $72 \mathrm{~h}$; mycelium covering the plate after $c a$ 4 weeks at $25^{\circ} \mathrm{C}$. Colony dense, of several irregularly lobed concentric zones. Surface flat, farinose, mottled, white to cream, reverse becoming yellowish to light brown, 5CD56 , in central areas. Aerial hyphae inconspicuous, short, becoming fertile. No autolytic excretions, no coilings noted. 

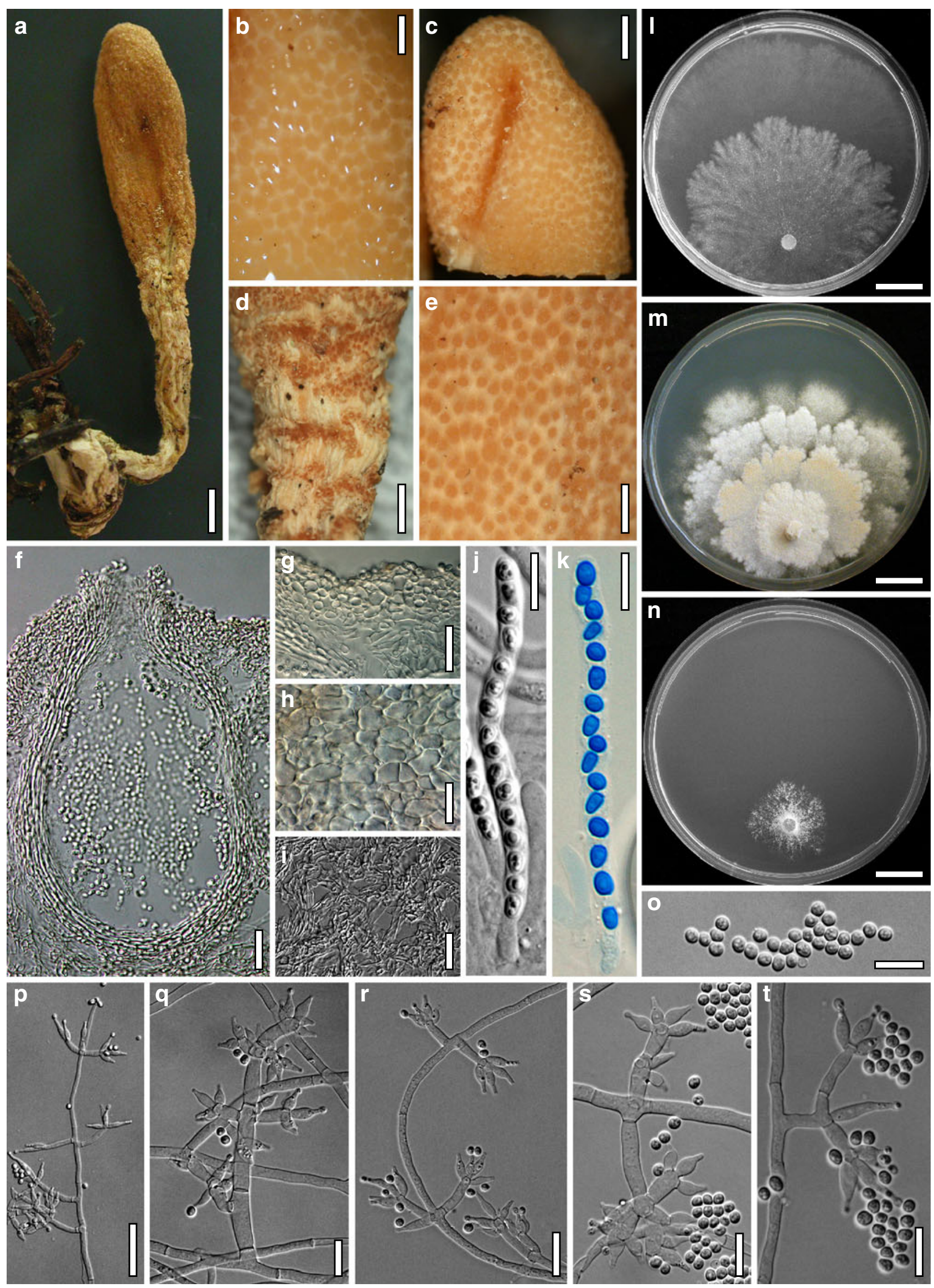
Fig. 34 Hypocrea seppoi. a-k. Teleomorph. a. Dry stroma. b. Stroma surface in $3 \% \mathrm{KOH}$. c. Rehydrated fertile stroma fraction. d. Part of stipe with groups of perithecia. e. Rehydrated stroma surface. f. Perithecium in section. g. Cortical and subcortical tissue in section. $\mathbf{h}$. Stroma surface in face view. i. Subperithecial tissue in section. j, k. Asci with ascospores (k. in cotton blue/lactic acid). l-t. Cultures and anamorph. I-n. Cultures after 21 days at $25^{\circ} \mathrm{C}(1$. on $\mathrm{CMD}, \mathbf{m}$. on PDA, n. on SNA). o. Conidia (SNA, 18 days, 15 C). p-t. Conidiophores with phialides on SNA $\left(18\right.$ days, $\left.15^{\circ} \mathrm{C}\right)$. a, d, e, h. WU 28698. b, c, f, g, i-k. WU 28699. I-n. CBS 122498. o-t. CBS 122497. Scale bars: $\mathbf{a}=2 \mathrm{~mm}$. b, e= $=0.25 \mathrm{~mm} . \mathbf{c}=0.5 \mathrm{~mm} . \mathbf{d}=0.8 \mathrm{~mm}$. $\mathbf{f}, \mathbf{g}, \mathbf{i}, \mathbf{p}=25 \mu \mathrm{m} . \mathbf{h}, \mathbf{l}-\mathbf{n}, \mathbf{r}=15 \mu \mathrm{m} . \mathbf{j}, \mathbf{k}, \mathbf{o}, \mathbf{q}, \mathbf{s}, \mathbf{t}=10 \mu \mathrm{m}$

Odour none to slightly mushroomy. Conidiation noted after 3 days at $25^{\circ} \mathrm{C}$, effuse, spreading from the plug, dense, short, white, irregularly verticillium-like. At $30^{\circ} \mathrm{C}$ little growth, no conidiation seen.

On SNA $1 \mathrm{~mm}$ at $15^{\circ} \mathrm{C}, 2 \mathrm{~mm}$ at 25 and $30^{\circ} \mathrm{C}$ after $72 \mathrm{~h}$. Colony irregularly lobed, radial, developing white farinose streaks; hyphae narrow, forming pegs. Autolytic excretions, coilings, pigment, distinct odour, and chlamydospores absent. Conidiation noted after 9 days at $25^{\circ} \mathrm{C}$, effuse, on short, irregularly verticillium-like conidiophores, particularly in streaks. At $30^{\circ} \mathrm{C}$ colony dense, white; conidiation effuse. At $15^{\circ} \mathrm{C}$ colony circular, hyaline, dense, narrow, white, farinose ring formed around the plug. Conidiation effuse, better developed than at $25^{\circ} \mathrm{C}$, noted after 9 days, examined after 18 days: Conidiophores in dense lawns, erect on surface hyphae and paired or unpaired, in right angles on aerial hyphae; simple, short, 20-60(-150) $\mu \mathrm{m}$ long, 2-5(-7) $\mu \mathrm{m}$ wide, with some thickenings to $9.5 \mu \mathrm{m}$ wide, 1-3 celled, unbranched or branched at up to 4 levels. Branches 1(-2) celled, right-angled or slightly inclined upwards, mostly paired, often thickened in the middle. Phialides formed on cells 3-5 $\mu \mathrm{m}$ wide, solitary or in whorls of 2-6, often inclined upwards in steep angles, sometimes nearly cruciform. Conidia mostly formed in minute dry heads $<10 \mu \mathrm{m}$ diam and in some wet heads $<40 \mu \mathrm{m}$ diam. Phialides $(5-) 6-11(-19) \times(2.5-) 2.8-$ $3.6(-4.0) \mu \mathrm{m}, 1 / \mathrm{w}(1.4-) 1.8-3.5(-7.3),(1.3-) 1.7-2.5(-3.0)$ $\mu \mathrm{m}(n=63)$ wide at the base, lageniform, mostly symmetric and with long, abruptly attenuated narrow tip, also base often thin; straight, less commonly strongly curved, generally distinctly thickened in or below the middle; often longer $(>11 \mu \mathrm{m})$ and nearly subulate when solitary. Conidia (2.5-) $3.0-3.8(-4.5) \times(2.0-) 2.5-3.0(-3.7) \mu \mathrm{m}, 1 / \mathrm{w}(1.1-) 1.2-1.4(-$ 1.5) $(n=93)$, hyaline, subglobose to ellipsoidal, smooth, with 1 to few guttules, scar indistinct.

Habitat: on the ground in Picea-dominated forests.

Distribution: Finland, only known from the type locality.

Holotype: Finland, Pohjois-Savo, Heinävesi, close to Hernelampi, grid 6925:586, on soil in a grass-rich spruce forest slope, 19 Sep. 2007, Stefan Jakobsson 4741 (WU 28698; culture CBS $122498=$ C.P.K. 3161).

Other specimen examined: ca $100 \mathrm{~m}$ from the type location, grid 6925:587, on soil in mossy and old spruce- dominated forest, 19 Sep. 2007, H. \& M. Lahti (WU 28699; culture CBS $122497=$ C.P.K. 3162).

Notes: This species forms the smallest stromata, with a maximum length of $2.5 \mathrm{~cm}$, of the stipitate species of Hypocrea found in Europe. The colour of the fertile part of dry stromata is between the lighter yellow H. leucopus and the darker orange-brown $H$. nybergiana, being closer to the latter. Also the decurrent perithecia on the stipe of stromata are shared with $H$. nybergiana. However, the latter species has slightly larger ascospores, while $H$. leucopus cannot be differentiated from $H$. seppoi by ascospore characters. The conidiophores of $T$. seppoi are not as regularly verticillate as in the anamorph of H. leucopus; the phialides are wider and shorter, and the conidia tend to be subglobose, smallersized than in both $H$. leucopus and H. nybergiana.

Hypocrea atlantica Jaklitsch, sp. nov. Fig. 35

MycoBank MB 516666

Anamorph: Trichoderma atlanticum Jaklitsch, sp. nov. Fig. 36

MycoBank MB 516669

Stromata typice in cortice et ligno Fagi sylvaticae, 2-8 mm diam, pulvinata, rosea, rufa, luteo-brunnea vel brunnea. Asci cylindrici, (73-)80-96(-107) $\times(4.0-) 4.3-5.5(-6.0) \mu \mathrm{m}$. Ascosporae hyalinae, verruculosae, ad septum disarticulatae, pars distalis (sub)globosa vel ellipsoidea, (3.0-)3.3-4.0($5.3) \times(2.5-) 3.0-3.5(-4.0) \mu \mathrm{m}$, pars proxima oblonga, ellipsoidea vel cuneata, $(3.3-) 3.7-4.8(-6.3) \times(2.3-) 2.5-3.1 \mu \mathrm{m}$. Anamorphosis Trichoderma atlanticum. Conidiophora in agaro CMD in pustulis disposita, similia Pachybasii. Phialides divergentes, lageniformes, $(6-) 8-13(-17) \times(2.5-)$ 2.7-3.4(-4.3) $\mu \mathrm{m}$. Conidia pallide viridia, ellipsoidea, partim oblonga, glabra, 3.2-4.5(-5.8) ×2.5-3.0(-3.2) $\mu \mathrm{m}$.

Etymology: atlantica denotes its occurrence in the atlantic climate zone.

Stromata when fresh $2-8 \mathrm{~mm}$ diam, to $3 \mathrm{~mm}$ thick, pulvinate; surface smooth, with numerous brown ostiolar dots; colour rosy when immature, yellow-brown to reddish brown when mature or old.

Stromata when dry $(0.6-) 1.7-4.2(-5.4) \times(0.5-) 1.4-3.4(-$ 5.1) $\mathrm{mm},(0.4-) 0.5-1.3(-1.8) \mathrm{mm}$ thick $(n=35)$, solitary, gregarious or aggregated in small numbers, pulvinate or placentiform, broadly attached, edge rounded, free; sometimes with a white mycelial margin when young; sometimes consisting of a white or yellowish base and a laterally projecting fertile part above; perithecia sometimes free. Outline circular, angular oblong or irregularly lobed. Surface smooth or rugose, iridescent, sometimes covered by a white scurf when young, or downy before the appearance of ostiolar dots. Ostiolar dots (40-)48-82(102) $\mu \mathrm{m}(n=60)$ diam, numerous, densely disposed, welldefined, minute but distinct, plane or convex, with circular 

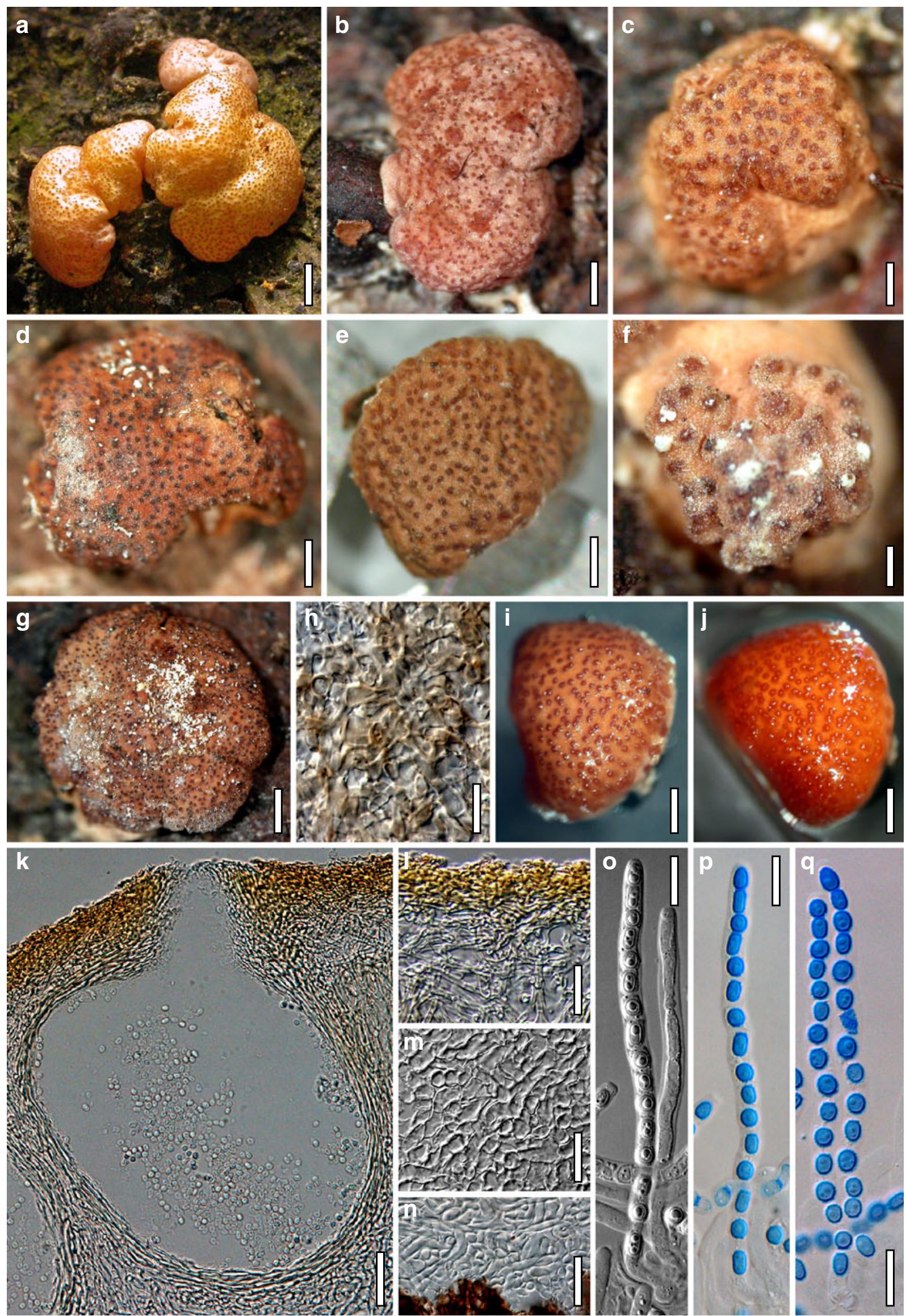
4Fig. 35 Teleomorph of Hypocrea atlantica. a. Fresh stromata (half mature). b-g. Dry stromata (b, c. immature, $\mathbf{b}$. with whitish scurf). $\mathbf{h}$. Stroma surface in face view. i. Stroma of e rehydrated. $\mathbf{j}$. Stroma of $i$ in $3 \% \mathrm{KOH}$. k. Perithecium in section. I. Cortical and subcortical tissue in section. $\mathbf{m}$. Subperithecial tissue in section. $\mathbf{n}$. Stroma base in section. $\mathbf{0}-\mathbf{q}$. Asci with ascospores (p, q. in cotton blue/lactic acid). ac, e-n, q. WU 29280. d, o, p. WU 29279. Scale bars: $\mathbf{a}=1 \mathrm{~mm}$. b, d, $\mathbf{e}=0.5 \mathrm{~mm} . \mathbf{c}=0.3 \mathrm{~mm} . \mathbf{f}=0.2 \mathrm{~mm} . \mathbf{g}, \mathbf{i}, \mathbf{j}=0.7 \mathrm{~mm} . \mathbf{h}, \mathbf{o}-\mathbf{q}=10 \mu \mathrm{m} . \mathbf{k}$, $\mathrm{m}=30 \mu \mathrm{m} . \mathbf{l}, \mathbf{n}=20 \mu \mathrm{m}$

outline, brown with light centres on rosy to yellow background, dark brown to black and shiny when old. Stroma colour first white, turning yellowish, rosy or greyish red 9C4, darkening to (yellow-) brown, brown-orange, reddish brown, 7-8CE4-6. Spore deposits white or yellow. Rehydrated stromata slightly larger than dry, semiglobose, surface smooth, yellow; ostiolar dots red, well-defined. After addition of 3\% $\mathrm{KOH}$ stroma surface orange-red in the stereo-microscope, macroscopically dark reddish brown; compact, hard.

Stroma anatomy: Ostioles (63-)67-98(-120) $\mu \mathrm{m}$ long, projecting to $20 \mu \mathrm{m},(32-) 38-54(-63) \mu \mathrm{m}$ wide at the apex $(n=30)$, with broad yellow wall, without specialized apical cells. Perithecia (170-)200-250(-260) $\times(120-) 140-220(-$ 240) $\mu \mathrm{m}(n=30)$, 6-7 per $\mathrm{mm}$ stroma length, flaskshaped; peridium (15-)18-25(-28) $\mu \mathrm{m}(n=30)$ thick at the base, $(7-) 11-19(-23) \mu \mathrm{m}(n=30)$ thick at the sides, distinctly thickened in upper part, yellow, distinctly paler than the cortex; turning orange in $\mathrm{KOH}$. Cortical layer (15-)18-30(-41) $\mu \mathrm{m}(n=30)$ thick, a $t$. epidermoideaangularis of indistinct, compressed, thick-walled (1$2.5 \mu \mathrm{m})$ cells $(3-) 5-11(-16) \times(2-) 3-5(-7) \mu \mathrm{m}(n=70)$ in face view and in vertical section, dense, yellow, turning deeply orange in $\mathrm{KOH}$, more hyphal at stroma sides. Subcortical tissue where present a loose hyaline $t$. intricata of thick-walled $(1 \mu \mathrm{m})$ hyphae $(2-) 3-5(-6) \mu \mathrm{m}(n=30)$ wide; if absent, cortex $>30 \mu \mathrm{m}$ thick. Subperithecial tissue a dense, hyaline $t$. epidermoidea of thick-walled $(2 \mu \mathrm{m})$, elongate to globose or angular cells (8-)11-38(-52) $\times$ (7-)9-14(-18) $\mu \mathrm{m}(n=30)$; towards the stroma base smaller, (3-)4-10(-14)×(3-)4-7(-8) $\mu \mathrm{m} \quad(n=30)$, merging into a dense hyaline $t$. intricata of thick-walled hyphae (3-) 4-6(-8) $\mu \mathrm{m}(n=35)$ wide at the base, often appearing as globose cells when cut across. Asci (73-)80-96(-107) $\times$ (4.0-)4.3-5.5(-6.0) $\mu \mathrm{m}$, stipe (5-)10-21(-32) $\mu \mathrm{m}$ long $(n=$ 45). Ascospores hyaline, verruculose, cells dimorphic, distal cell $(3.0-) 3.3-4.0(-5.3) \times(2.5-) 3.0-3.5(-4.0) \mu \mathrm{m}, 1 / \mathrm{w} 1.0-$ 1.3(-1.6) $(n=60)$, (sub)globose or ellipsoidal, proximal cell

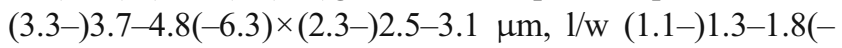
2.6) $(n=60)$, oblong, ellipsoidal or subglobose.

Cultures and anamorph: optimal growth at $25^{\circ} \mathrm{C}$ on all media, slow growth at $30^{\circ} \mathrm{C}$; no growth at $35^{\circ} \mathrm{C}$.

On CMD $13-16 \mathrm{~mm}$ at $15^{\circ} \mathrm{C}, 22-25 \mathrm{~mm}$ at $25^{\circ} \mathrm{C}, 7-$ $11 \mathrm{~mm}$ at $30^{\circ} \mathrm{C}$ after $72 \mathrm{~h}$; mycelium covering the plate after 8-9 days at $25^{\circ} \mathrm{C}$. Colony circular, mycelium loose, radially arranged, primary surface hyphae to $c a 10 \mu \mathrm{m}$ wide; several narrow concentric zones formed by conidiation; zones downy, later granular by small tufts or pustules. Pustules $0.5-1.5 \mathrm{~mm}$ diam concentrated and larger at the proximal margin and at lateral zone ends, first white, turning greyish yellow, light or grey-green, 2B3-4 to 2830B4-5, 29-30CD5-6, 29D4. Aerial hyphae inconspicuous, more frequent in distal areas, thick, long, richly branched. Autolytic activity and coilings inconspicuous, autolytic excretions frequent at $30^{\circ} \mathrm{C}$. No diffusing pigment noted, agar at most diffusely greyish yellow, 1B3, odour indistinct or slightly acidic. After prolonged storage at $15^{\circ} \mathrm{C}$ agar dull orange, with crystals in the agar. Chlamydospores noted after 7-9 days, uncommon, mostly around conidiation pustules, terminal and intercalary, globose. Conidiation at $25^{\circ} \mathrm{C}$ noted after 3 days, green after 6-7 days, nearly entirely confined to shrubs, tufts or small pustules without sterile elongations at the proximal margin and in concentric conidiation zones, particularly at their lateral ends. Pustulate conidiation preceded only by scant effuse conidiation on aerial hyphae and by few simple short erect conidiophores around the plug with conidial heads to $40 \mu \mathrm{m}$ diam. Pustules 1-2 mm diam, discrete, circular or confluent in oblong groups to $3 \mathrm{~mm}$ long; generally pale (yellow-)green, loose or compact, dry, with velutinous or fluffy surface due to short, straight conidiophores projecting to $200 \mu \mathrm{m}$ beyond the pustule surface, fertile to their tips. Pustules (examined after 12 days) of a thick-walled stipe to 7-10 $\mu \mathrm{m}$ wide, with asymmetric, thick-walled (to $2 \mu \mathrm{m}$ ) primary branches, forming a reticulum with right-angled branching points, sometimes thickened to $9 \mu \mathrm{m}$. Main axes to 300 (400) $\mu \mathrm{m}$ long, emerging from the reticulum in radial arrangement. Conidiophores (mostly unpaired side branches of main axes) (3-)4-6(-7) $\mu \mathrm{m}$ wide, attenuated to 2-4 $\mu \mathrm{m}$ terminally, variable, slender or often broader from the top down, with 1-3 phialides at the apex, followed by solitary phialides, typically paired branches in right angles or slightly inclined upwards, 20-40 $\mu \mathrm{m}$ long on upper levels, unpaired, rebranching and $<170 \mu \mathrm{m}$ long on lower levels. Phialides solitary or in whorls of $2-4(-5)$, most commonly 3-4, divergent, sometimes nearly parallel in terminal whorls, emerging from cells $2.0-3.5 \mu \mathrm{m}$ wide. Conidia condensed in wet heads $<30 \mu \mathrm{m}$ in older pustules. Phialides $(6-) 8-13(-17) \times(2.5-) 2.7-3.5(-4.3) \mu \mathrm{m}, 1 /$ w (1.9-)2.5-4.3(-5.5), (1.3-)1.8-2.6(-3.0) $\mu \mathrm{m}$ wide at the base $(n=62)$, slender, lageniform, less commonly plump, nearly ampulliform, straight or curved and inaequilateral, widening at variable position, mainly median or above the middle. Conidia 3.2-4.5(-5.8) $\times 2.5-3.0(-3.2)$, 1/W (1.1-) $1.2-1.6(-2.0)(n=62)$, pale green, ellipsoidal, less commonly subglobose or oblong, smooth, finely multiguttulate; scar indistinct, sometimes narrowly projecting. At $15^{\circ} \mathrm{C}$ similar to $25^{\circ} \mathrm{C}$, increased effuse conidiation noted. At $30^{\circ} \mathrm{C}$ 

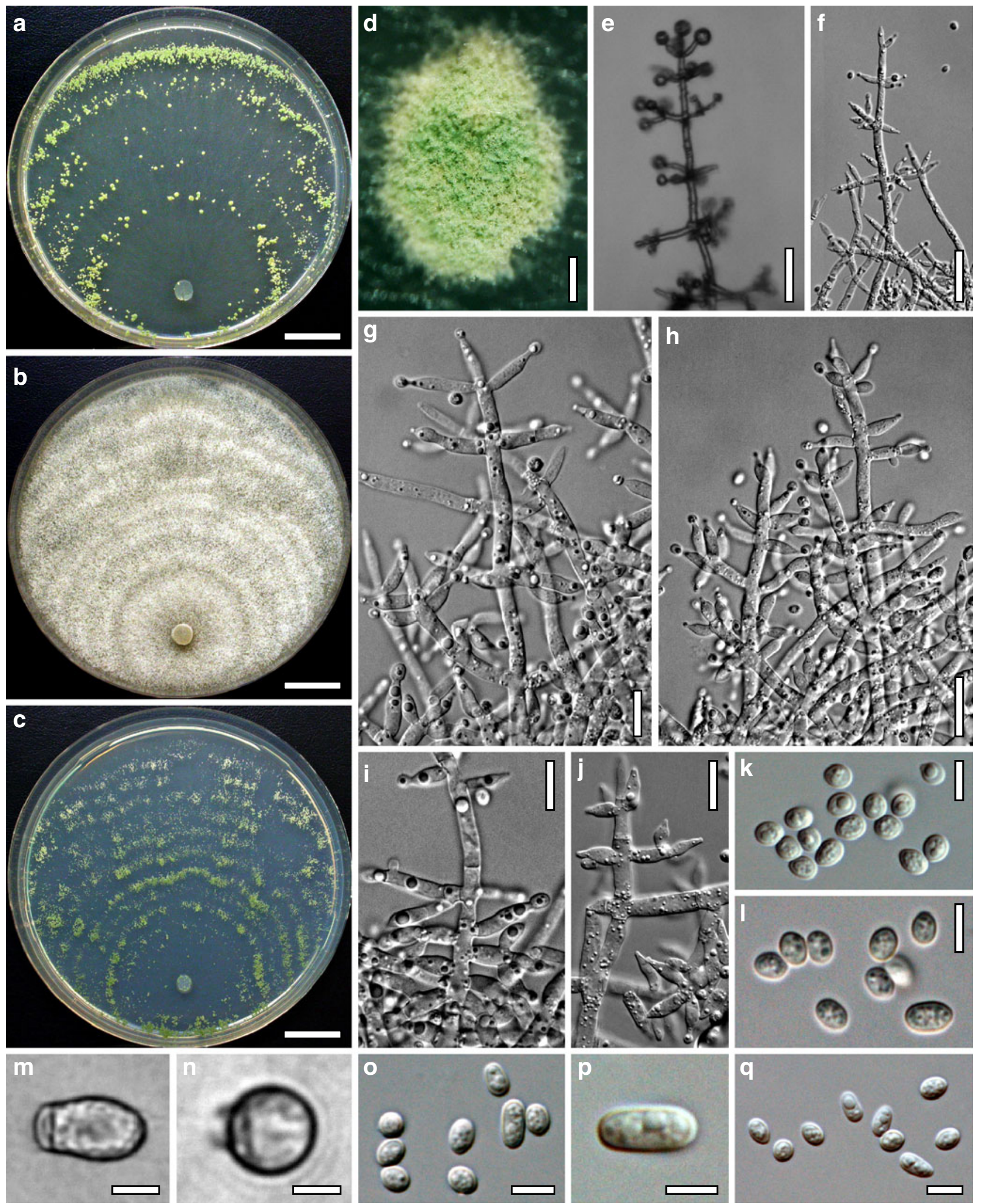

Fig. 36 Cultures and anamorph of Hypocrea atlantica. a-c. Cultures at $25^{\circ} \mathrm{C}$ after 14 days (a. on CMD; b. on PDA; c. on SNA). d. Conidiation pustule (16 days). e. Conidiophore on pustule margin on growth plate (SNA, 14 days). f-h. Conidiophores (12-13 days). i, j. Phialides (12-

13 days). k, l, o-q. Conidia (12 days). m, n. Chlamydospores (SNA, 17 days). d-q. All at $25^{\circ} \mathrm{C}$; all from CMD except e, m, n. a-c, e, $\mathbf{l}-\mathbf{n}$. C.P.K. 1896; d, f-k, o-q. CBS 120632. Scale bars: $\mathbf{a}-\mathbf{c}=15 \mathrm{~mm}$. $\mathbf{d}=$ $0.3 \mathrm{~mm}$. e, $\mathbf{f}=30 \mu \mathrm{m} . \mathbf{g}, \mathbf{i}, \mathbf{j}=10 \mu \mathrm{m} . \mathbf{h}=15 \mu \mathrm{m}$. $\mathbf{k}-\mathbf{0}, \mathbf{q}=5 \mu \mathrm{m} . \mathbf{p}=3 \mu \mathrm{m}$ 
poor growth, hyphae autolysing; conidiation in small shrubs, remaining colourless.

On PDA $11-13 \mathrm{~mm}$ at $15^{\circ} \mathrm{C}, 20-22 \mathrm{~mm}$ at $25^{\circ} \mathrm{C}, 4$ $5 \mathrm{~mm}$ at $30^{\circ} \mathrm{C}$ after $72 \mathrm{~h}$; mycelium covering the plate after 9-10 days at $25^{\circ} \mathrm{C}$. Colony dense, with thin, diffuse margin, surface hyphae forming radial strands; marginal surface hyphae thick. Surface downy, farinose to floccose, macroscopically homogeneous, later indistinctly and irregularly zonate by aerial hyphae, whitish to pale yellowish. Aerial hyphae numerous, richly branched, ascending several $\mathrm{mm}$, radial towards margin, forming a loose mat and strands collapsing into floccules; coalescing in the centre to a continuum. Autolytic activity inconspicuous, no coilings seen, autolytic excretions frequent at $30^{\circ} \mathrm{C}$. No diffusing pigment noted, reverse yellowish, 4AB4-5. Odour rancid. Conidiation at $25^{\circ} \mathrm{C}$ noted after 2 days, mostly in small shrubs in the central continuum and aerial hyphae; more or less verticillium-like, with short numerous phialides, but small numbers of conidia; remaining colourless or white. At $15^{\circ} \mathrm{C}$ colony well-defined, finely zonate; zones crenate or angular; conidiation colourless. At $30^{\circ} \mathrm{C}$ poor growth, no conidiation seen.

On SNA $11-12 \mathrm{~mm}$ at $15^{\circ} \mathrm{C}, 15-16 \mathrm{~mm}$ at $25^{\circ} \mathrm{C}, 3-$ $5 \mathrm{~mm}$ at $30^{\circ} \mathrm{C}$ after $72 \mathrm{~h}$; mycelium covering the plate after 9-15 days at $25^{\circ} \mathrm{C}$. Colony similar to CMD; except for up to 12 narrow, indistinctly separated, concentric zones of numerous irregular, powdery granules or small white pustules becoming light green, 29CD4, from the proximal margin. Aerial hyphae scant. Autolytic excretions inconspicuous, abundant and yellow at $30^{\circ} \mathrm{C}$; no coilings seen. No diffusing pigment noted. Odour indistinct to slightly rancid. Chlamydospores noted after 6-9 days, loosely disposed, terminal and intercalary, (4-)6-10(-13) $\times(4-) 6-9$ $(-10) \mu \mathrm{m}, 1 / \mathrm{w}(0.9-) 1.0-1.3(-1.5) \quad(n=32)$, globose to ellipsoidal, sometimes oblong and 2-celled. Conidiation at $25^{\circ} \mathrm{C}$ noted after 4 days, green after $6-7$ days, only in shrubs, tufts or pustules to $1 \mathrm{~mm}$ diam with granular surface, with short phialides in whorls of 2-3, often strongly inclined upwards; conidia dry or in wet heads to $50 \mu \mathrm{m}$. At $15^{\circ} \mathrm{C}$ conidiation in small pustules, at most pale greenish. At $30^{\circ} \mathrm{C}$ short growth, hyphae autolysing.

Habitat: on wood and bark of Fagus sylvatica and fungi growing on it.

Distribution: Europe (Austria, France).

Holotype: France, Lorraine, Vosges, Col de la Schlucht, shortly after the village heading to Le Hohneck, $48^{\circ} 03^{\prime} 18^{\prime \prime}$ $\mathrm{N}, 07^{\circ} 00^{\prime} 46^{\prime \prime}$ E, elev. $1050 \mathrm{~m}$, on mostly corticated branches of Fagus sylvatica 6-9 $\mathrm{cm}$ thick, on wood and bark, on/soc. stromata of Hypoxylon fragiforme, soc. Annulohypoxylon cohaerens with Polydesmia farinosa, effete Quaternaria quaternata; holomorph, anamorph pustulate, light green, 4 Sep. 2004, W. Jaklitsch \& H. Voglmayr, W.J. 2676 (WU 29280, culture CBS 120632=
C.P.K. 1897). Holotype of Trichoderma atlanticum isolated from WU 29280 and deposited as a dry culture with the holotype of $H$. atlantica as WU 29280a.

Other specimen examined: Austria, Vorarlberg, Bludenz, Nenzing, Rabenstein, at Beschling, MTB 8824/1, 47 $11^{\prime}$ $28^{\prime \prime} \mathrm{N}, 09^{\circ} 40^{\prime} 04^{\prime \prime} \mathrm{E}$, elev. $670 \mathrm{~m}$, on decorticated branch of Fagus sylvatica $4 \mathrm{~cm}$ thick, on hard wood, below bark, soc. Bertia moriformis, black hyphomycetes, etc.; 29 Aug. 2004, H. Voglmayr \& W. Jaklitsch, W.J. 2630 (WU 29279, culture C.P.K. 1896).

Notes: Hypocrea atlantica was first collected as $H$. minutispora, because it is morphologically barely distinguishable from the latter, except for the slightly smaller ascospores. Two specimens may possibly not be sufficient to ascertain differences in the teleomorph such as the stronger orange $\mathrm{KOH}$ reaction of the stromata of $H$. atlantica. Trichoderma atlanticum differs from T. minutisporum by growth only half as fast on all media, more distinctly pustulate conidiation on CMD and the presence of oblong conidia in addition to ellipsoidal ones.

\section{Hypocrea bavarica Jaklitsch, sp. nov. Fig. 37}

MycoBank MB 516673

Anamorph: Trichoderma bavaricum Jaklitsch, sp. nov. Fig. 38

MycoBank MB 516674

Stromata typice in cortice Betulae, 1-8 $\mathrm{mm}$ diam, pulvinata vel semiglobosa, humida lutea, sicca brunnea. Asci cylindrici, (50-)60-75(-85)×(3.3-)3.8-4.7(-5.5) $\mu \mathrm{m}$. Ascosporae hyalinae, verruculosae, ad septum disarticulatae, pars distalis (sub)globosa vel oblonga, $(2.5-) 2.8-3.2(-3.5) \times(2.3-) 2.5-3.0$ $(-3.2) \mu \mathrm{m}$, pars proxima oblonga vel cuneata $(2.8-) 3.3-4.2(-$ $5.0) \times(1.8-) 2.2-2.5(-2.8) \mu \mathrm{m}$. Anamorphosis Trichoderma bavaricum. Conidiophora in agaros CMD, PDA et SNA effuse disposita, simplicia, similia Acremonii vel Verticillii. Phialides divergentes, lageniformes vel subulatae, (7-)11-22 $(-33) \times(2.0-) 2.5-3.3(-4.3) \mu \mathrm{m}$. Conidia hyalina, subglobosa, ovalia vel pyriformia, partim oblonga vel ellipsoidea, glabra, $(2.5-) 3.0-4.8(-6.7) \times(2.0-) 2.3-3.0(-3.5) \mu \mathrm{m}$.

Stromata when fresh 1-8 $\mathrm{mm}$ diam, to $1-2 \mathrm{~mm}$ thick, erumpent from or superficial on bark, less commonly on wood, solitary, gregarious, or aggregated in small fascicles, pulvinate, broadly attached. Surface smooth, with brown ostiolar dots. Colour first white to pale citrine, pale ochre or yellow, darkening within few hours after collecting except when immature (without dots, pale yellow 3A3), to yellow, greyish orange or light brown, 4A3-4, 5B4-5, 6D6-8; also with a rosy or reddish tone.

Stromata when dry $(0.5-) 1-3(-5) \times(0.5-) 1.0-2.2(-3)$ $\mathrm{mm},(0.2-) 0.4-1.0(-1.4) \mathrm{mm}$ thick $(n=70)$; solitary, gregarious to aggregated in small groups, pulvinate to semiglobose, less commonly subeffuse to effluent; flat, 

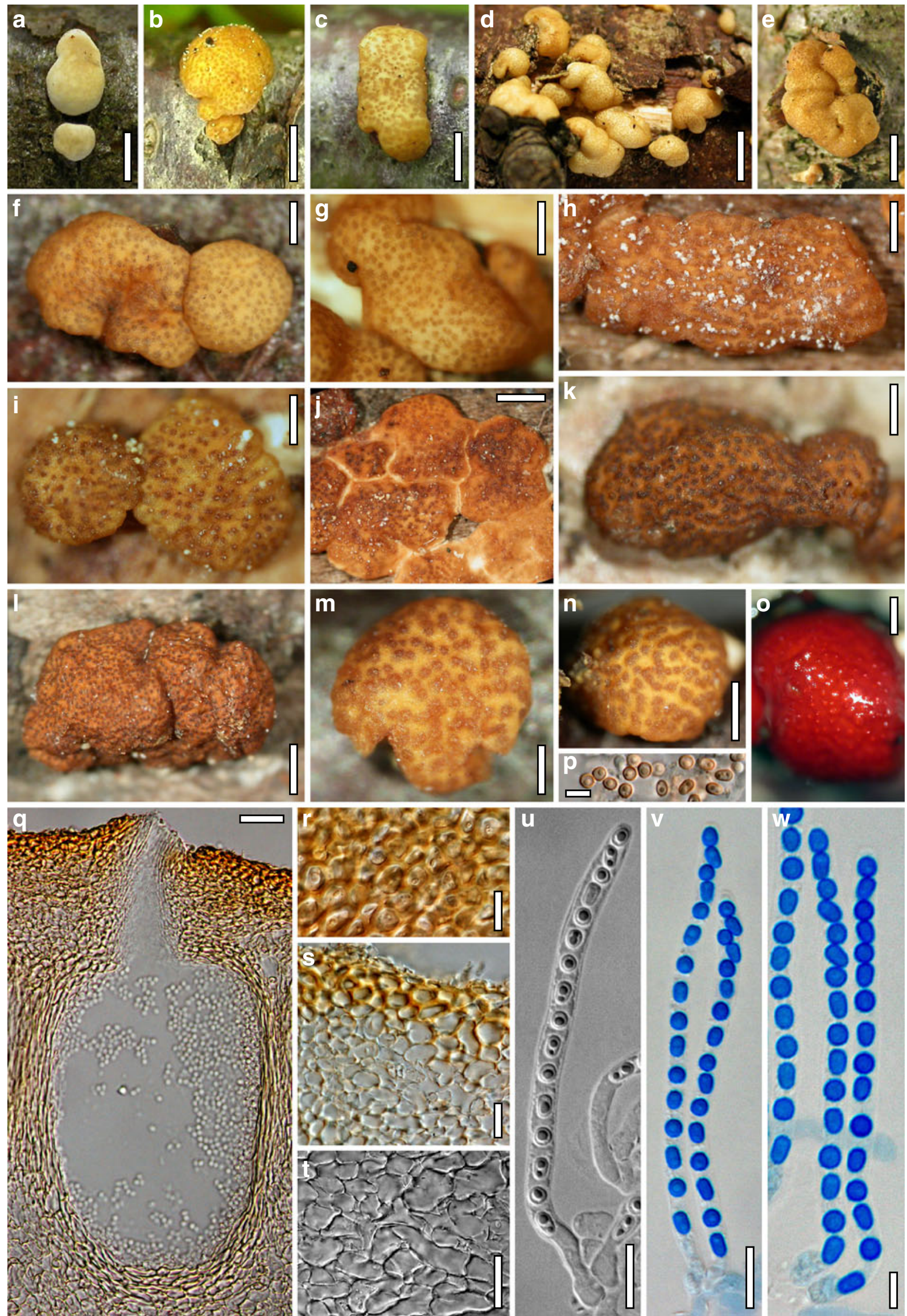
4Fig. 37 Teleomorph of Hypocrea bavarica. a-e. Fresh stromata (a. immature). f-m. Dry stromata (f. 'halfdry'; j. 'effluent', breaking up into several single stromata). n. Rehydrated stroma. o. Stroma in 3\% $\mathrm{KOH}$ after rehydration. p. Ejected orange ascospores. q. Perithecium in section. r. Stroma surface in face view. s. Cortical and subcortical tissue in section. t. Subperithecial tissue in section. $\mathbf{u}-\mathbf{w}$. Asci with ascospores (v, w. in cotton blue/lactic acid). $\mathbf{a}-\mathbf{g}, \mathbf{k}, \mathbf{m}-\mathbf{t}, \mathbf{v}$. WU 29196. h-j, l, w. WU 29197. u. WU 29195. Scale bars: $\mathbf{a}-\mathbf{c}=1 \mathrm{~mm}$. d, $\mathbf{e}=1.5 \mathrm{~mm} . \mathbf{f}-\mathbf{i}, \mathbf{k}, \mathbf{m}-\mathbf{o}=0.4 \mathrm{~mm} . \mathbf{j}, \mathbf{l}=0.7 \mathrm{~mm} . \mathbf{p}, \mathbf{w}=5 \mu \mathrm{m} . \mathbf{q}$, $\mathbf{t}=20 \mu \mathrm{m} . \mathbf{r}, \mathbf{s}, \mathbf{u}, \mathbf{v}=10 \mu \mathrm{m}$

placentiform, discoid and irregularly tubercular or rugose when old. Outline circular, oblong or irregularly lobed. Margin free, thick, rounded, sometimes strongly projecting beyond a short wide base, or with smooth, vertical, sterile sides. Sides when young sometimes whitish and with white basal mycelium. Surface smooth to finely granular due to ostiolar dots, sometimes with white anamorph flakes or downy when young, strongly tubercular to rugose when old. Perithecia sometimes slightly prominent. Ostiolar dots (31-)40-96(-197) $\mu \mathrm{m}(n=110)$ diam, numerous, typically inconspicuous or ill-defined, diffuse, flat or convex, pale brown; more conspicuous, distinct and dark brown in overmature stromata. Development and colour: starting as white mycelium, becoming compact, yellow or greyish orange, 4-5AB4-5, from the centre; mature stromata mostly yellow-brown, brown-orange, golden-brown or light brown (5-)7CD5-6, 5CD6-8 (yellow stroma surface plus ochre or brown ostiolar dots), dark reddish-brown to dull brown, 8CD6-8, (6-)7-8E5-8, 8-9F5-8, when old. Spore deposits minute, white or yellow. Rehydrated stromata thickly pulvinate to semiglobose, slightly larger than dry. Margin free, projecting. Stromata orange, with ochre ostiolar dots and yellow surface between them. After addition of $3 \%$ $\mathrm{KOH}$ turning macroscopically dark (orange-)red to nearly black, bright red in the stereo microscope.

Stroma anatomy: Ostioles (60-)65-77(-84) $\mu \mathrm{m}$ long, plane or projecting to $20 \mu \mathrm{m},(19-) 24-35(-40) \mu \mathrm{m}(n=30)$ wide at the apex, conical or cylindrical, periphysate; no specialised apical cells seen. Perithecia (150-)180-235($260) \times(97-) 110-170(-225) \mu \mathrm{m}(n=30)$, flask-shaped to subglobose, crowded, ca 8 per $\mathrm{mm}$ of stromal length; peridium (14-)17-25(-31) $\mu \mathrm{m}$ thick at the base and (7-) $11-17(-20) \mu \mathrm{m}(n=30)$ at the sides, turning orange-red in $\mathrm{KOH}$, yellow in lactic acid, paler than cortex. Surface smooth, with rare remnants of short, collapsed, brownish hyphae. Cortical layer (14-)16-26(-33) $\mu \mathrm{m}(n=30)$ wide, a distinct, yellow $t$. angularis of isodiametric to oblong, thick-walled, angular cells (4-)6-11(-13) $\times(3-) 4-8(-10)$ $\mu \mathrm{m}(n=60)$ in face view and in vertical section. Cortex turning bright orange in $\mathrm{KOH}$. Subcortical tissue a pale yellowish $t$. angularis of thin-walled cells $(4-) 5-11(-16) \times$ (3-)3.5-6(-7) $\mu \mathrm{m}(n=30)$, mixed with scant, subhyaline to yellowish hyphae $(2.5-) 3-5(-6) \mu \mathrm{m}(n=30)$ wide. Subperithecial tissue a hyaline to yellowish $t$. epidermoidea of thin-walled cells $(6-) 10-28(-42) \times(4-) 7-15(-19) \mu \mathrm{m}$ $(n=30)$, extending into the substrate. Asci (50-)60-75 $(-85) \times(3.3-) 3.8-4.7(-5.5) \mu \mathrm{m}$, stipe $(1-) 5-15(-25) \mu \mathrm{m}$ long $(n=80)$; fasciculate on long ascogenous hyphae. Ascospores hyaline, often yellow or orange after ejection, nearly smooth to minutely verruculose, cells dimorphic; distal cell $(2.5-) 2.8-3.2(-3.5) \times(2.3-) 2.5-3.0(-3.2) \mu \mathrm{m}, 1 / \mathrm{w}(0.9-)$ 1.0-1.2(-1.4), (sub-)globose or oblong; proximal cell (2.8-) $3.3-4.2(-5.0) \times(1.8-) 2.2-2.5(-2.8) \mu \mathrm{m}$, oblong or wedgeshaped (or subglobose), 1/w (1.2-)1.4-1.8(-2.3) $(n=100)$.

Anamorph on natural substrate observed as a white, thin, loose, crumbly layer in association with stromata; dense conidial heads on small regular conidiophores with $1-3(-4)$ terminal phialides. Phialides $(6-) 8-15(-17) \times(2.5-) 3-4(-4.1)$ $\mu \mathrm{m}, 1 / \mathrm{w}(2-) 2.5-4.3(-5.4),(1.9-) 2.2-2.8(-3.1) \mu \mathrm{m}(n=20)$ wide at the base, lageniform, pointed, straight to sinuous, often collapsed. Conidia (2.8-)3.0-4.5(-5.6) $\times(2.3-) 2.4-3.0$ $(-3.6) \mu \mathrm{m}, 1 / \mathrm{w} 1.2-1.6(-2.4) \quad(n=30)$, hyaline, mostly subglobose to pyriform, less commonly broadly ellipsoidal or oblong, smooth, scar sometimes distinct.

Cultures and anamorph: optimal growth at $25^{\circ} \mathrm{C}$ on all media, at $30^{\circ} \mathrm{C}$ hyphae soon dying after onset of growth; no growth at $35^{\circ} \mathrm{C}$.

On CMD after $72 \mathrm{~h} 5-8 \mathrm{~mm}$ at $15^{\circ} \mathrm{C}, 7-10 \mathrm{~mm}$ at $25^{\circ} \mathrm{C}$, 0-3 $\mathrm{mm}$ at $30^{\circ} \mathrm{C}$; mycelium covering the plate after $\mathrm{ca}$ 2 weeks at $25^{\circ} \mathrm{C}$. Colony hyaline, thin, smooth, homogeneous, not zonate. Mycelium loose, little on the surface; hyphae generally narrow, curly, without specific orientation. Margin ill-defined, diffuse, of solitary strands. Aerial hyphae infrequent, loose, thick, becoming fertile. Surface becoming indistinctly downy by conidiation mainly on the distal and lateral margins. Autolytic activity moderate to strong, coilings abundant. Sometimes fine whitish granules $0.5-0.7 \mathrm{~mm}$ diam of aggregated conidiophores with dry conidiation appearing in distal and lateral areas of the plates. No chlamydospores seen, but globose or irregularly thickened cells appearing in surface hyphae in aged cultures. Conidia swelling on the agar surface forming clumps, probably wrapped in an excreted substance. Agar hyaline, sometimes becoming faintly yellowish, 2AB3. Odour after 14 days week unpleasant, chemical (reminiscent of organic solvents like pyridin). Colony after 34 months condensed, opaque, with a rubber-like consistency and a peculiar unpleasant odour. Conidiation noted after 3-4 days at $25^{\circ} \mathrm{C}$, macroscopically invisible or arranged in inconspicuous, downy, concentric zones; colourless, effuse, starting around the plug, spreading across plate and often pronounced at distal and lateral margin of growth plates; simple, acremonium- to verticillium-like. Phialides arising directly from surface hyphae or from conidiophores. Conidiophores (after 7-10 days) loosely disposed, short, typically to $250(-450) \mu \mathrm{m}$ tall, longer (to ca $1 \mathrm{~mm}$ ) with distance from the plug; erect, simple, forked or sparsely, 


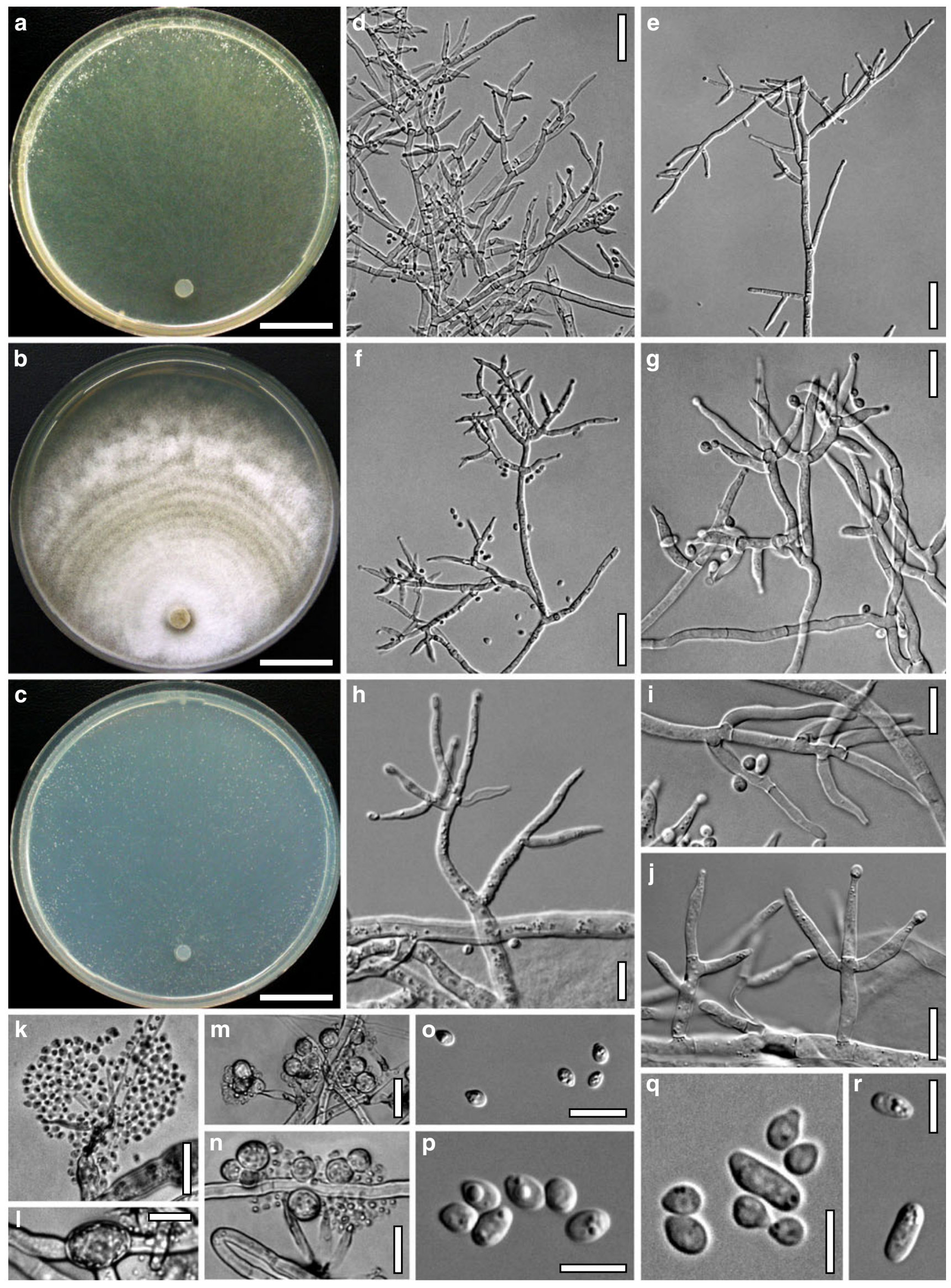

包 Springer 
4Fig. 38 Cultures and anamorph of Hypocrea bavarica. a-c. Cultures (a. CMD, 21 days. b. PDA, 14 days. c. SNA, 21 days). d-h. Conidiophores. i, j. Phialides. k. Conidia on agar surface (CMD, 24 days). I. Chlamydospore (CMD, 29 days). m, n. Swollen conidia on agar surface (CMD, 29 days). o-r. Conidia. a-r. All at $25^{\circ} \mathrm{C}$. d, f, g, i, q. On Sigma PDA, after 9 days. e, h, j, o, p, r. On CMD, 79 days. a-c, h, k-p, r. C.P.K. 2021. d, f, g, i, q. CBS 120538. e, j. C.P. K. 2847. Scale bars: $\mathbf{a}-\mathbf{c}=20 \mathrm{~mm} . \mathbf{d}-\mathbf{f}=30 \mu \mathrm{m} . \mathbf{g}-\mathbf{j}, \mathbf{l}-\mathbf{0}=10 \mu \mathrm{m} . \mathbf{k}=$ $15 \mu \mathrm{m} . \mathbf{p}-\mathbf{r}=5 \mu \mathrm{m}$

asymmetrically branched. Side branches 1-7 celled, to $c a$ $120 \mu \mathrm{m}$ long, typically strongly inclined upwards. Main axis to $7(-9) \mu \mathrm{m}$ wide and thick-walled at the base, $2-3 \mu \mathrm{m}$ wide terminally. Phialides borne on cells $2-4.5 \mu \mathrm{m}$ wide, solitary or divergent in whorls of $2-3(-4)$; phialides (7-) $11-22(-33) \times(2.0-) 2.5-3.3(-4.3) \mu \mathrm{m}, 1 / \mathrm{w}(2.0-) 4.0-7.5(-$ $13.5),(1.2-) 2.0-2.8(-3.8) \mu \mathrm{m}(n=120)$ wide at the base, lageniform or subulate, narrow and pointed, only slightly widened at a variable level, often inaequilateral and slightly curved. Conidia formed in wet heads to $30(-50) \mu \mathrm{m}$ diam, $(2.5-) 3.0-4.8(-6.7) \times(2.0-) 2.3-3.0(-3.5) \mu \mathrm{m}, 1 / \mathrm{w}(1.1-)$ $1.2-1.8(-2.8)(n=130)$, subglobose, oval or pyriform, partly ellipsoidal or oblong, hyaline, smooth, finely multiguttulate, abscission scar inconspicuous or projecting and narrowly truncate. Chlamydospores rare, $12-22 \times 10-20 \mu \mathrm{m}, 1 / \mathrm{w} 1.1-$ $1.4(n=4)$, globose or ellipsoidal; hyphal thickenings more frequent. Swollen conidia to $6 \mu \mathrm{m}$ diam commonly noted after 3 weeks on the agar surface, globose, smooth, often surrounded by an amorphous, resinous substance.

On PDA after $72 \mathrm{~h} 2-5 \mathrm{~mm}$ at $15^{\circ} \mathrm{C}, 7-8 \mathrm{~mm}$ at $25^{\circ} \mathrm{C}$, $<1 \mathrm{~mm}$ at $30^{\circ} \mathrm{C}$; mycelium covering plate after 9-14 days at $25^{\circ} \mathrm{C}$. Colony flat, of thin, densely interwoven hyphae, more loosely arranged with distance from the plug. Surface hyaline, finely zonate, becoming white and farinose or finely floccose from the centre; slightly yellowish in age. Margin diffuse and thin. Aerial hyphae short, thick, loosely disposed; longer and forming a flat mat of nearly reticulate, irregular strands towards the margin. Autolytic excretions inconspicuous, coilings abundant and conspicuous. Surface white, reverse becoming yellow from the centre, 2A2-3, 3A3-4, 4AB3-5, occasionally with brownish zones 5CD68. Odour strong after ca 2 weeks, unpleasant, pungent, pyridine-like. Chlamydospores abundant in marginal hyphae, subglobose to angular. Conidiation noted after 3 days at $25^{\circ} \mathrm{C}$, white, effuse, spreading from the plug, in continuous, dense lawns of fine, ill-defined, spiny, sessile shrubs, and on long aerial hyphae, particularly in the centre and in white, mealy to floccose areas of the colony. Shrubs finally collapsing and becoming condensed into roundish aggregates. Conidiophores (from Sigma-PDA after 9 days) variable, irregularly branched, mostly 100-150 $\mu \mathrm{m}$ long, broad, asymmetric, mostly $2-5(-7) \mu \mathrm{m}$ wide, $7-9 \mu \mathrm{m}$ wide at the base, $2.0-2.5 \mu \mathrm{m}$ at the ends; often with paired branches towards the ends. Phialides borne on cells 2.0-
$3.5 \mu \mathrm{m}$ wide, solitary or in whorls of $2-3(-5)$, divergent, lageniform to beak-like, long, often curved or sinuous, often longer when solitary. Conidia formed in minute wet heads, minute, pyriform, oval or subglobose, less commonly oblong and larger; hyaline, smooth, with few finest guttules; abscission scar often distinct, projecting, short and flat. Measurements united with those determined on $\mathrm{CMD}$.

On SNA after $72 \mathrm{~h} 4-6 \mathrm{~mm}$ at $15^{\circ} \mathrm{C}, 4-8 \mathrm{~mm}$ at $25^{\circ} \mathrm{C}$, $<1 \mathrm{~mm}$ at $30^{\circ} \mathrm{C}$; mycelium covering plate after $2-3$ weeks at $25^{\circ} \mathrm{C}$. Colony similar as on $\mathrm{CMD}$, slightly more irregular and mycelium looser; hyaline, margin diffuse, growth faster inside the agar. Surface becoming floccose, with fine white granules or floccules $(0.2-0.6 \mathrm{~mm})$ of larger or aggregated conidiophores. Autolytic activity moderate to strong, coilings abundant. No distinct odour, no pigment, no chlamydospores noted. Conidiation effuse, starting after 3-4 days at $25^{\circ} \mathrm{C}$ around the plug, spreading across the entire colony, denser in downy areas; similar to but more abundant than on CMD. Phialides often sinuous, spiny, on thick stipes, conidia formed in minute wet heads to $20-30(-60) \mu \mathrm{m}$ diam, colourless. At $15^{\circ} \mathrm{C}$ poor growth observed.

Habitat: on corticated branches of Betula pendula, rarely other hosts

Distribution: Europe, collected in Germany (Bavaria) and Austria

Holotype: Germany, Bavaria, Landkreis Traunstein, Grabenstätt, south from Winkl and the A8, MTB 8141/3, $47^{\circ} 48^{\prime} 50^{\prime \prime} \mathrm{N}, 12^{\circ} 31^{\prime} 05^{\prime \prime} \mathrm{E}$, elev. $530 \mathrm{~m}$, on corticated branches and twigs cut from a tree of Betula pendula 0.3$2 \mathrm{~cm}$ thick, emergent through and on bark and on/soc. Diatrypella favacea, also overgrowing long-necked effete pyrenomycete in the bark, soc. Tubeufia cerea, 4 Sep. 2005, H. Voglmayr \& W. Jaklitsch, W.J. 2842 (WU 29196, culture CBS $120538=$ C.P.K. 2414). Holotype of Trichoderma bavaricum isolated from WU 29196 and deposited as a dry culture with the holotype of H. bavarica as WU 29196a.

Other specimens examined: Austria, Niederösterreich, Mödling, Wienerwald, Kaltenleutgeben, along brook Dürre Liesing between Am Brand and Stangau, MTB 7862/4, $48^{\circ}$ $06^{\prime} 45^{\prime \prime} \mathrm{N}, 16^{\circ} 08^{\prime} 43^{\prime \prime} \mathrm{E}$, elev. $450 \mathrm{~m}$, on branches of Alnus glutinosa, soc. Hypocrea moravica and effete Bertia moriformis, 22 Oct. 2006, W. Jaklitsch \& H. Voglmayr, W.J. 3032 (WU 29197, culture C.P.K. 2847). Germany, Bavaria, Unterfranken, Kitzingen, Mainfränkische Platten, monastery forest, north of the town, MTB 6227/1, 49 $45^{\prime} 00^{\prime \prime} \mathrm{N}, 10^{\circ} 12^{\prime}$ $00^{\prime \prime} \mathrm{E}$, elev. $200 \mathrm{~m}$, on corticated branch of Betula pendula, emerging through and superficial on bark, soc. Diatrypella favacea, Steccherinum ochraceum, 31 Oct. 2004, L. Krieglsteiner, W.J. 2794 (WU 29195, culture C.P.K. 2021).

Notes: Hypocrea bavarica is an uncommon species. The most striking feature is the colour change during drying, from pale or light yellow to (yellow-)brown within a few 
hours. Similar colour changes are seen in H. moravica and $H$. subalpina. Superficially the teleomorph of $H$. bavarica is similar to $H$. argillacea, albeit with a more intense stroma colour when dry. H. argillacea, as far as known, differs primarily by distinctly larger ascospores. Also $H$. moravica can be easily confounded with $H$. bavarica, but differs generally in more conspicuous ostiolar dots, larger ascospores, and in a green-conidial pustulate anamorph. Overmature, rugose stromata sometimes also resemble those of $H$. tremelloides. H. bavarica is an unusual species of the pachybasium core group, in forming an effuse, irregularly verticillium-like anamorph, and no pustules on the media examined. In this respect, this species resembles stipitate species like e.g. H. seppoi. Another interesting trait of $H$. bavarica is the peculiar, unpleasant odour detected in cultures on CMD and PDA, apparently caused by an excreted resinous substance, that also provokes hardening of the agar in aged cultures.

Hypocrea luteffusa Jaklitsch, sp. nov. Fig. 39

MycoBank MB 516685

Anamorph: Trichoderma luteffusum Jaklitsch, sp. nov. Fig. 40

MycoBank MB 516686

Stromata effusa, lutea, prosenchymatosa, 2-50 $\times 1-22 \mathrm{~mm}$. Asci cylindrici, (70-)78-93(-104) $\times 3.5-4.5 \mu \mathrm{m}$. Ascosporae bicellulares, hyalinae, verruculosae, ad septum disarticulatae, pars distalis (sub)globosa vel ovoidea, (2.3-)2.7-3.5(-4.3)× (2.3-)2.5-3.0(-3.2) $\mu \mathrm{m}$, pars proxima oblonga, (2.8-)3.2-4.4 $(-5.0) \times 2.0-2.5(-2.8) \mu \mathrm{m}$. Anamorphosis Trichoderma luteffusum. Conidiophora in agaro SNA effuse disposita, simplicia, ramis sparsis brevibus, similia Verticillii. Phialides divergentes, lageniformes vel subulatae, $(6-) 7-14(-20) \times$ (2.0-)2.3-3.0(-3.3) $\mu \mathrm{m}$. Conidia subglobosa, ellipsoidea, oblonga vel cylindracea, viridia in acervulis, glabra, (2.7-) $3.0-5.3(-8.2) \times(2.0-) 2.2-2.8(-3.3) \mu \mathrm{m}$.

Etymology: referring to the yellow effuse stromata.

Stromata when fresh 2-50×1-22 mm; 0.5-2 mm thick, aggregated in small numbers, (semi-) effuse. Surface smooth or slightly tubercular, with numerous brown dots; pale yellowish, 3-4A3-4.

Stromata when dry $0.2-0.6(-0.8) \mathrm{mm}(n=17)$ thick, effuse, entirely attached, following the host surface; white inside; consistency tough, nearly leathery. Margin white, mycelial, partly rounded, compact, sterile. Surface smooth. Ostiolar dots (32-)46-97(-126) $\mu \mathrm{m}(n=30)$ diam, numerous, first appearing as indistinct spots with circular perforation, becoming distinct, plane or convex, yellowish, ochre or brownish, responsible for the stroma colour; stroma surface between ostiolar dots white to cream. Stroma colour pale yellow or yellow-orange, 4A3-4(-6); in 3\% $\mathrm{KOH}$ unchanged or slightly darker brown and appearing gelatinous. Spore powder white.
Stroma anatomy: Ostioles (67-)73-94(-112) $\mu \mathrm{m}$ long, $(20-) 32-50(-62) \mu \mathrm{m}$ wide internally directly below the dense apex $(n=20)$; umbilicate or plane, broad, in section visible as densely packed sheets of hyaline, parallel, narrow cylindrical hyphae obliquely oriented to the ostiolar axis. Perithecia $(180-) 230-310(-320) \times(130-) 170-260(-300)$ $\mu \mathrm{m}(n=20)$, subglobose, ellipsoidal or flask-shaped, crowded, usually with the height exceeding diam; peridium $(15-) 16-25(-30) \mu \mathrm{m}(n=20)$ thick at the base, $(9-) 13-22$ $(-24) \mu \mathrm{m}(n=20)$ thick at the sides, pale yellowish. Cortical layer $(17-) 23-34(-40) \mu \mathrm{m}(n=30)$ thick, pale yellowish or subhyaline, labyrinthine, of extremely densely compacted, refractive hyphae and minute globose or ellipsoidal cells $(2.5-) 3.5-6.0(-8.0) \times(2.0-) 3.0-4.5(-5.5) \mu \mathrm{m}$ in face view and in vertical section $(n=60)$, with walls $0.5-1.5(-2) \mu \mathrm{m}$ thick; hairs absent. Residual entostroma a hyaline t. intricata, with hyphae becoming thicker and more loosely arranged downwards, some appearing globose or compressed due to various sectioning angles; subcortical hyphae (2.5-)3.0-5.5(-7.5) $\mu \mathrm{m}(n=30)$ wide, hyaline, thin-walled; subperithecial hyphae (3-)5-11(-15) $\mu \mathrm{m}$ $(n=30)$ wide, thin- to thick-walled; basal hyphae thickwalled (to $c a 1.5 \mu \mathrm{m}),(3-) 4-8(-10) \mu \mathrm{m}(n=30)$ wide, deeply penetrating into the wood. Asci (70-)78-93(-104) $\times$ 3.5-4.5 $\mu \mathrm{m}$; stipe (10-)14-25(-33) $\mu \mathrm{m}$ long $(n=30)$; apex with a minute pore; no croziers seen. Ascospores hyaline, nearly smooth to verruculose or spinulose; cells dimorphic, distal cell $(2.3-) 2.7-3.5(-4.3) \times(2.3-) 2.5-3.0(-3.2) \mu \mathrm{m}$, $1 / \mathrm{w}(0.9-) 1.0-1.3(-1.5) \quad(n=30)$, (sub-)globose or oval, proximal cell $(2.8-) 3.2-4.4(-5.0) \times 2.0-2.5(-2.8) \mu \mathrm{m}$, $1 / \mathrm{w}(1.1-) 1.4-1.9(-2.4)(n=30)$, oblong, slightly attenuated downwards, sometimes subglobose.

Cultures and anamorph: optimal growth at $25^{\circ} \mathrm{C}$ on all media; virtually no growth and no conidiation at $30^{\circ} \mathrm{C}$, no growth at $35^{\circ} \mathrm{C}$.

On CMD after $72 \mathrm{~h} 8-9 \mathrm{~mm}$ at $15^{\circ} \mathrm{C}, 12-13 \mathrm{~mm}$ at $25^{\circ} \mathrm{C}$, to $0.8 \mathrm{~mm}$ at $30^{\circ} \mathrm{C}$; mycelium covering the plate after $15-$ 18 days at $25^{\circ} \mathrm{C}$. Colony hyaline, thin, circular, compact, with hyphae distinctly sinuous along their length, forming radial threads; finely zonate with up to 17 lighter and 16 darker concentric zones; surface becoming finely granular to downy at the sides or proximal margin due to conidiation, there turning macroscopically green after $c a 2$ weeks or remaining hyaline; green powder spreading mainly along margin of the plate. Aerial hyphae scant and short. Autolytic activity and coilings absent. Agar colourless to pale yellowish. Odour indistinct. No chlamydospores seen. Conidiation starting after 3-4 days at the proximal margin and around the plug; effuse, verticillium-like, short, macroscopically invisible; spreading, becoming concentrated at margins, (yellowish-) green in the stereo-microscope after 6 days at the proximal margin. Conidiophores of an erect stipe with 1 terminal whorl of 3-6 phialides, or with few unpaired branches and 

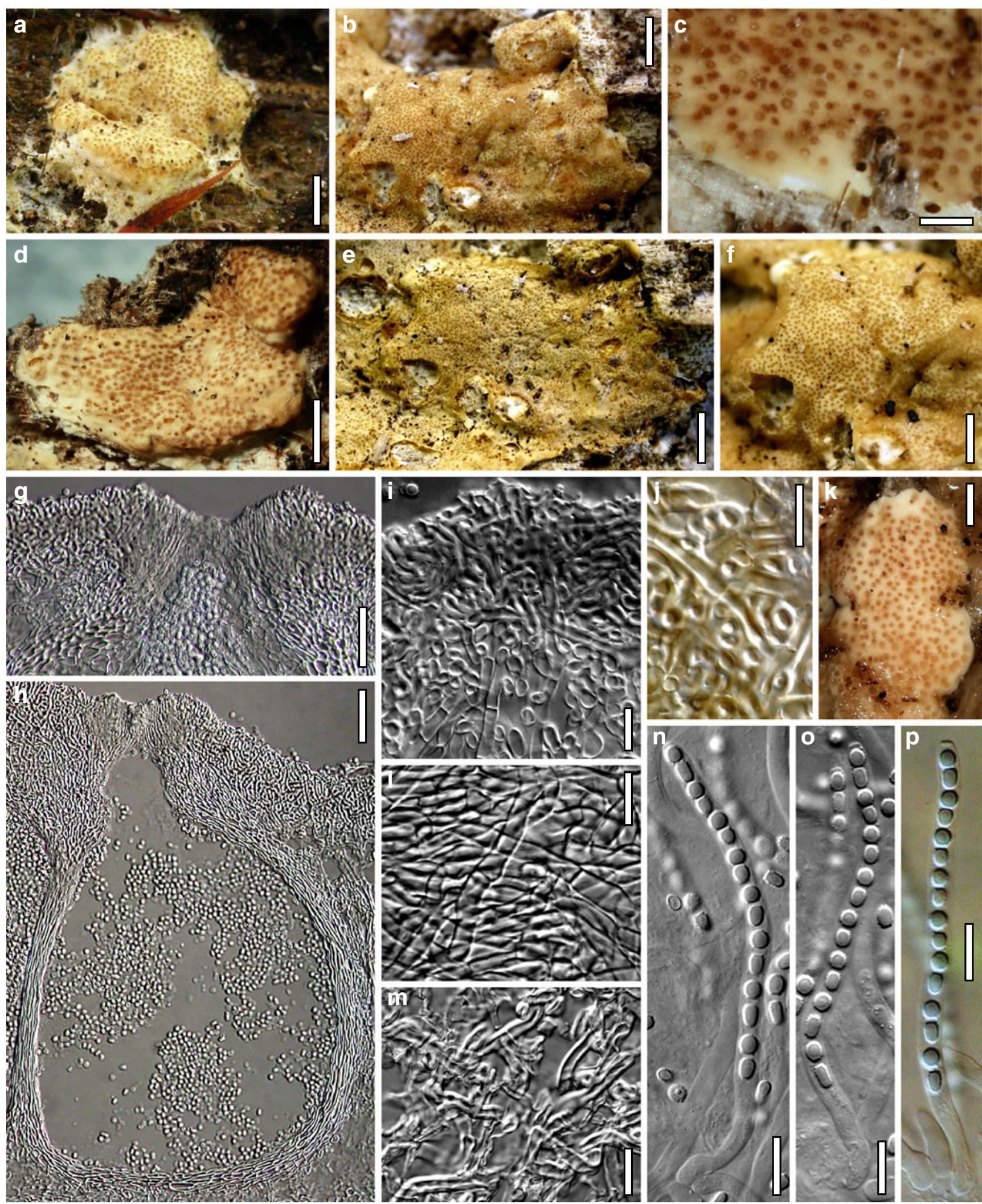

Fig. 39 Teleomorph of Hypocrea luteffusa (holotype WU 29236). a, b. Fresh stromata. $\mathbf{c}-\mathbf{e}$. Dry stromata (c, $\mathbf{d}$. in the stereo-microscope). f. Rehydrated stroma. g. Ostiole in section. h. Perithecium in section. i. Cortical and subcortical tissue in section. j. Stroma surface in face view. k. Stroma in 3\% KOH after rehydration. I. Subperithecial tissue in section. m. Basal tissue in section. n-p. Asci with ascospores (in varying concentrations of cotton blue/lactic acid). Scale bars: $\mathbf{a}, \mathbf{d}, \mathbf{f}=$ $1.5 \mathrm{~mm}$. b, e=2 mm. $\mathbf{c}=0.3 \mathrm{~mm} . \mathbf{g}, \mathbf{h}=30 \mu \mathrm{m} . \mathbf{i}, \mathbf{j}, \mathbf{n}-\mathbf{p}=10 \mu \mathrm{m} . \mathbf{k}=$ $0.6 \mathrm{~mm} . \mathbf{l}, \mathbf{m}=20 \mu \mathrm{m}$ 

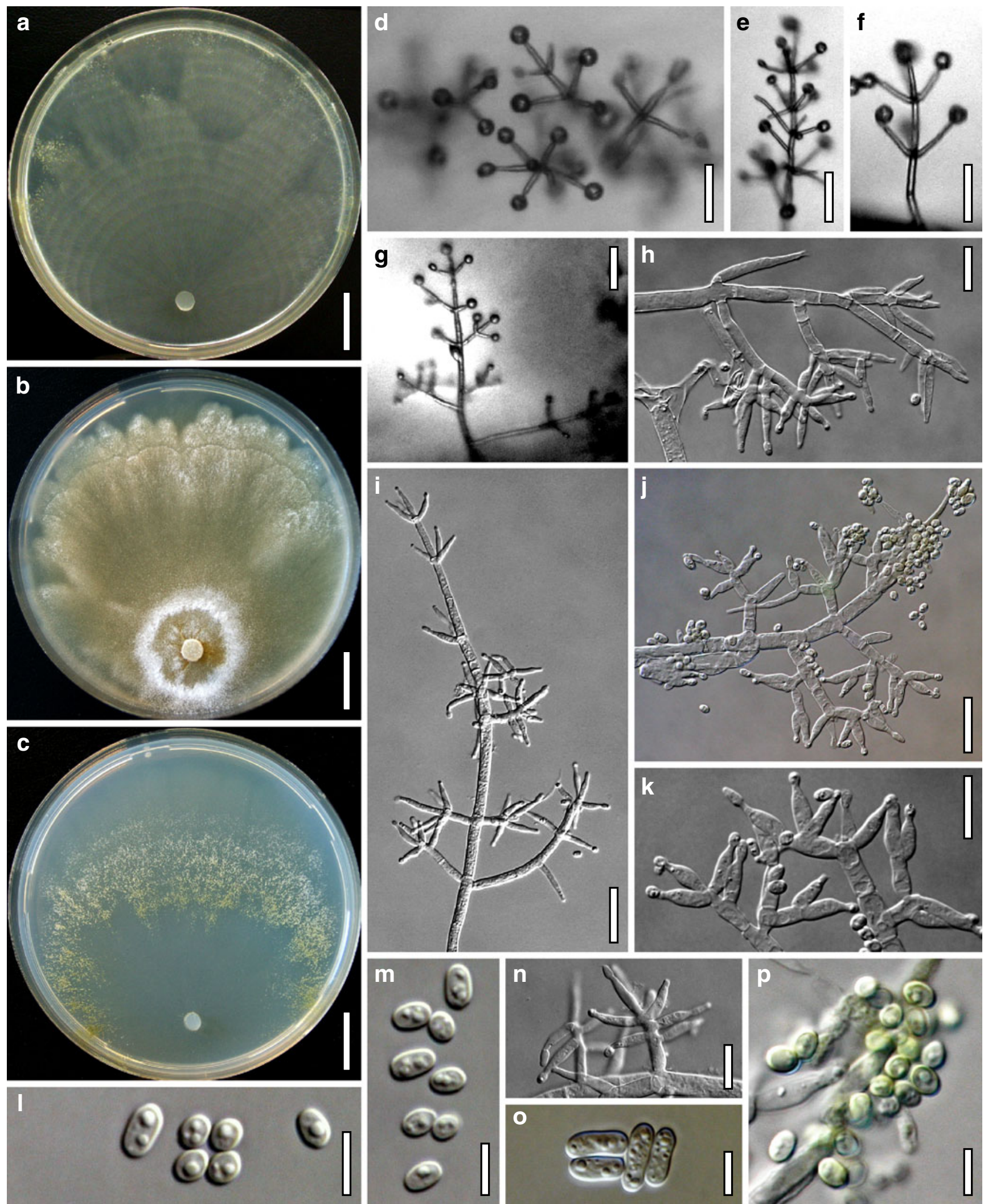

Fig. 40 Cultures and anamorph of Hypocrea luteffusa (CBS 120537). a-c. Cultures (a. on CMD, 21 days; b. on PDA, 21 days; c. on SNA, 14 days). d. Conidiophores on growth plate in face view (CMD, 3 days). e- $\mathbf{g}$. Conidiophores on inoculation plug (3 days; e, f. CMD,

g. SNA). $\mathbf{h}-\mathbf{j}$. Conidiophores. $\mathbf{k}, \mathbf{n}$. Phialides. $\mathbf{l}, \mathbf{m}, \mathbf{o}, \mathbf{p}$. Conidia. a-p. All at $25^{\circ}$ C. $\mathbf{h}-\mathbf{p}$. On SNA after 9-14 days. Scale bars: $\mathbf{a}-\mathbf{c}=15 \mathrm{~mm}$. $\mathbf{d}, \mathbf{f}, \mathbf{i}=20 \mu \mathrm{m}$. e, $\mathbf{g}=30 \mu \mathrm{m}$. h, $\mathbf{k}, \mathbf{n}=10 \mu \mathrm{m}$. j=15 $\mu \mathrm{m}$. l, m, o, $\mathbf{p}=$ $5 \mu \mathrm{m}$ 
paired or unpaired phialides bearing numerous wet, minute conidial heads $<20 \mu \mathrm{m}$ diam. Phialides long, thin, acute.

On PDA after $72 \mathrm{~h} 4-8 \mathrm{~mm}$ at $15^{\circ} \mathrm{C}, 7-9 \mathrm{~mm}$ at $25^{\circ} \mathrm{C}$, to $0.3 \mathrm{~mm}$ at $30^{\circ} \mathrm{C}$; mycelium covering the plate after $c a 3$ weeks at $25^{\circ} \mathrm{C}$. Hyphae finely sinuous, becoming multiguttulate. Colony compact, dense, indistinctly zonate; appearing as a small yellowish centre with a granular surface, followed by a densely farinose or loosely floccose white zone, and a broad, downy or slightly floccose major part; margin broadly wavy to lobed. Sometimes irregular patches of condensed mycelium appearing, forming broad white spots with dense short conidiation. Aerial hyphae loosely disposed, short in the centre, long and dense close to the colony margin; erect, arising several $\mathrm{mm}$, richly branched, becoming fertile, soon collapsing, aggregating into strands appearing as floccules or irregular white spots after 3 weeks. Autolytic activity moderate; coilings moderate or frequent. Colony reverse, particularly in the centre, turning pale yellow, greyish yellow or yellow-brown 4A3-4, 3-4B4, 5C7. Odour indistinct. Chlamydospores abundant. Conidiation starting after 24 days around the plug, effuse, short and dense in a central lawn and loosely disposed on long aerial hyphae spreading across the colony, longer and ascending higher in more distal areas; also short and dense in white spots. Conidia formed in minute heads on thin and needle-like phialides; colourless, white in mass. Dense white conidiation and increased autolytic activity noted at $15^{\circ} \mathrm{C}$.

On SNA after $72 \mathrm{~h} 6-8 \mathrm{~mm}$ at $15^{\circ} \mathrm{C}, 11-13 \mathrm{~mm}$ at $25^{\circ} \mathrm{C}$, to $0.3 \mathrm{~mm}$ at $30^{\circ} \mathrm{C}$; mycelium covering the plate after $15-$ 16 days at $25^{\circ} \mathrm{C}$. Colony hyaline, thin, circular, smooth, indistinctly zonate; margin becoming wavy; hyphae forming radial threads; primary hyphae wide, distinctly sinuous along their length; surface hyphae degenerating from the centre; greatest part of the mycelium disappearing within 3-4 weeks. Aerial hyphae scant, short, becoming fertile. Autolytic activity and coilings inconspicuous. No pigment, no distinct odour noted. No chlamydospores seen. Conidiation noted after 2-3 days around the plug and at the proximal margin; effuse, verticillium-like; more abundant than on CMD; first macroscopically invisible; spreading across the colony, loosely disposed across entire plate; greenish in the stereomicroscope after 5-6 days, first at the proximal margin. After (7-)9-10 days conidiation becoming visible as a fine, green 29D4-6, 29E6-7, 28DE5-7 powder, consisting of granules or aggregated conidiophores to $0.5 \mathrm{~mm}$ diam, arranged in indistinct concentric zones, particularly in distal areas of the colony. Conidiophores after 3-15 days short, first simple, of an unbranched stipe 5-6(-8) $\mu \mathrm{m}$ wide with a terminal whorl of up to 5 phialides bearing minute wet conidial heads 5$15 \mu \mathrm{m}$ diam; becoming forked or branched close to the base, mostly asymmetrical, forming 3-5 main axes to $300 \mu \mathrm{m}$ long, bearing 1-2 celled, paired or unpaired side branches. Side branches inclined upwards at upper levels; at lower levels longer, often in right angles and sometimes re-branching, bearing phialides mostly in terminal whorls of 3-5, or singly, on cells (2.0-)2.5-4.5(-5.5) $\mu \mathrm{m}$ wide; whorls often appearing complex due to several paired or unpaired phialides situated directly below the terminal whorl. Main axes and side branches (3-)4-5 $\mu \mathrm{m}$ wide at the base, attenuated upwards to $2-3 \mu \mathrm{m}$. Phialides $(6-) 7-14(-20) \times(2.0-) 2.3-3.0(-3.3)$ $\mu \mathrm{m}, 1 / \mathrm{w}(2.5-) 3.0-5.4(-7.4),(1.5-) 1.8-2.4(-2.8) \mu \mathrm{m}$ wide at the base $(n=60)$; lageniform or subulate, often inaequilateral, widest mostly in or below the middle, longer ones more frequent on lower branches. Conidia (2.7-)3.0-5.3 $(-8.2) \times(2.0-) 2.2-2.8(-3.3) \mu \mathrm{m}, 1 / \mathrm{w} \quad(1.1-) 1.2-2.0(-3.1)$ $(n=63)$, subglobose, ellipsoidal, oblong or cylindrical, green in mass, individually subhyaline, smooth, with few small guttules; scar indistinct, sometimes distinct and projecting. At $15^{\circ} \mathrm{C}$ growth more irregular; conidiation dense, white, partly in fluffy tufts.

Habitat: on strongly decomposed crumbly wood and bark of deciduous trees.

Distribution: Germany; known only from the type locality.

Holotype: Germany, Rheinland-Pfalz, Eifel, Landkreis Daun, Gerolstein, between Büscheich and Salm, 50'10'33" N, $06^{\circ} 41^{\prime} 50^{\prime \prime} \mathrm{E}$, elev. $560 \mathrm{~m}$, on decorticated, cut branch of Fagus sylvatica $15 \mathrm{~cm}$ thick, on moist, strongly decomposed wood, soc. Armillaria rhizomorphs, Ascocoryne cylichnium, effete Coniochaeta cf. velutina, Trametes versicolor, Xylaria hypoxylon anamorph, etc., 20 Sep. 2004, W. Jaklitsch \& H. Voglmayr, W.J. 2732 (WU 29236, culture CBS $120537=$ C.P.K. 2018). Holotype of Trichoderma luteffusum isolated from WU 29236 and deposited as a dry culture with the holotype of H. luteffusa as WU 29236a.

Notes: The description of Hypocrea luteffusa is based on a single, for the greatest part, overmature specimen. Morphologically, both in teleomorph and anamorph, this species is similar to the species of the Brevicompactum clade, $H$. auranteffusa, $H$. margaretensis, and $H$. rodmanii, while the teleomorph has some similarity to $H$. citrina. The peculiar ostioles, the labyrinthine cortex of thick-walled surface cells and the hyphal subperithecial tissue in $H$. luteffusa has not been seen in any of these species. $H$. luteffusa differs from $H$. citrina also by smaller ascospores, warmer yellow colour, growth on wood, smaller phialides and smaller and green conidia. H. auranteffusa, $H$. margaretensis and $H$. rodmanii differ from $H$. luteffusa also in brighter stroma colour, larger ascospores, and smaller conidia. The conidiation is morphologically similar to $H$. pachypallida, but the conidia of the latter species do not turn green on SNA or CMD.

Hypocrea minutispora B.S. Lu, Fallah \& Samuels, Mycologia 96: 335 (2004) Fig. 41 


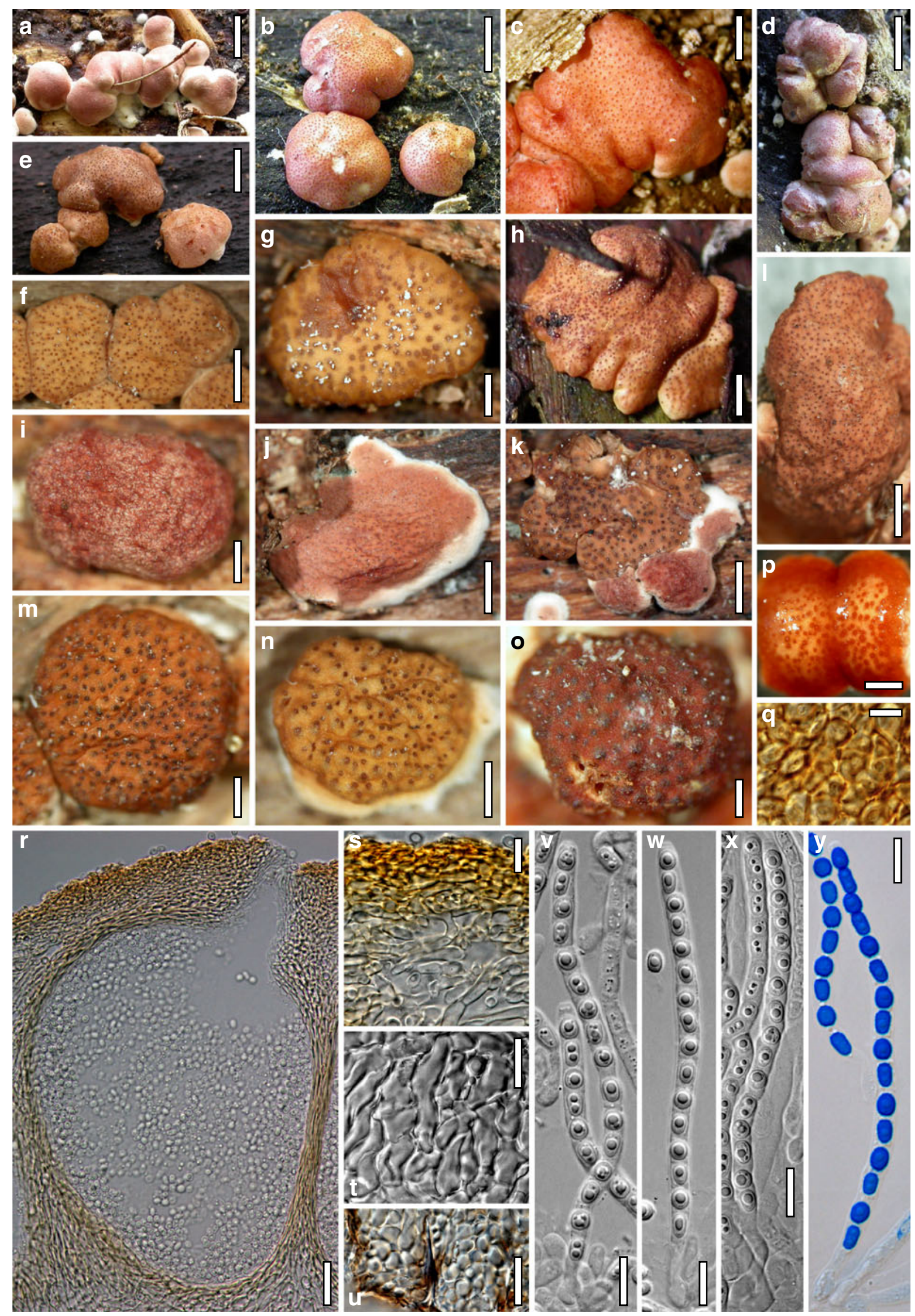


4Fig. 41 Teleomorph of Hypocrea minutispora. a-h. Fresh stromata (a-e. immature. d. with whitish scurf. $\mathbf{f}-\mathbf{h}$. mature, with white spore deposits). i-o. Dry stromata (i, j, l. immature. i. with white scurf. j. with white margin. k. mature and immature (rosy) stromata. $\mathbf{m}-\mathbf{0}$. mature). p. Stroma in $3 \% \mathrm{KOH}$ after rehydration. q. Stroma surface in face view. r. Perithecium in section. s. Cortical and subcortical tissue in section. t. Subperithecial tissue in section. u. Stroma base, with brown inclusions. $\mathbf{v}-\mathbf{y}$. Asci with ascospores (y. in cotton blue/lactic acid). a. WU 29258. b, d. WU 29246. c. WU 29248. e. WU 29267. f, m, n, y. WU 29277. g. WU 29273. h. WU 29241. i. WU 29242. j, k. WU 29244. l. WU 29253. o, w. WU 29250. p-u. WU 29270. v. WU 29238. x. WU 29264. Scale bars: a, $\mathbf{d}=2 \mathrm{~mm}$. b, e=1.5 mm. c, f, h, j$\mathbf{I}=1 \mathrm{~mm} . \mathbf{g}, \mathbf{i}, \mathbf{m}, \mathbf{n}, \mathbf{p}=0.5 \mathrm{~mm} . \mathbf{o}=0.3 \mathrm{~mm} . \mathbf{q}=5 \mu \mathrm{m} . \mathbf{r}, \mathbf{t}=25 \mu \mathrm{m} . \mathbf{s}$, $\mathbf{v}-\mathbf{y}=10 \mu \mathrm{m} . \mathbf{u}=20 \mu \mathrm{m}$

Anamorph: Trichoderma minutisporum Bissett, Can. J. Bot. 69: 2396 (1991b). Fig. 42

Stromata when fresh 1-7(-11) mm diam, 0.5-2.5(-3) mm thick, pulvinate or semiglobose, sometimes turbinate or discoid, broadly attached, sometimes with white base mycelium. Margin or edges adnate or free, often lobed or undulate, smooth, sterile, lighter than stroma surface or white when young, typically rounded and concealing sides, less commonly sharp with visible sides. Sides sterile, white, smooth. Outline circular, oblong, ellipsoidal or irregular. Surface smooth or slightly wrinkled, finely tubercular due to convex ostioles, sometimes with white or silvery covering layer; rarely perithecia slightly protuberant when old. Ostiolar dots numerous, minute but well-defined, plane or convex, slightly darker than the stroma surface, to reddish-, oliveor dark brown. Stromata starting as a white mycelium, becoming compacted, turning rosy from the centre, 7$8 \mathrm{~A} 2$, or rosy-brown, brown-orange, light brown, pale red, greyish red to reddish brown, with or without white margin, 7-8A3-5, 7-8B4-6, 7-8CD5-7, 10C3, 9A5, or reddish yellow, 4A6-7, later rosy colour disappearing and margin concolorous, yellow ground colour becoming apparent, resulting colour greyish orange, brown-orange, yellow-brown, brown, 5AC5-7, 5D8, 6B4-5, 6AD6-7, to reddish brown, 7-8CE6-8, 9CD5-7 when old; alternatively yellow to (greyish-) orange, 3A5-6, 4-5A2-5, 5B4, to yellow-brown without previous formation of rosy tones.

Stromata when dry $(0.8-) 1.8-4.5(-7.5) \times(0.5-) 1.5-3.5$ $(-5.4) \mathrm{mm},(0.2-) 0.5-1.4(-2.5) \mathrm{mm}$ thick $(n=140)$, solitary, gregarious or aggregated in variable numbers, often in lines, sometimes in compound stromata disintegrating into several parts; pulvinate, discoid or undulate, broadly attached; sometimes with white base mycelium. Outline circular, angular or oblong. Margin often lobed, edges or margin adnate or free, rounded or sharp, white when young; fertile part sometimes projecting beyond the sterile sides. Sides smooth, white or concolorous with the surface. Stroma surface first finely velutinous while still lacking ostiolar dots; soon glabrous and smooth or rugose or finely tubercular by papillate ostioles; sometimes with white, finely floccose scurf when young. Ostiolar dots (20-)30-70 $(-173) \mu \mathrm{m}(n=250)$ diam, numerous, plane or convex, well-defined, distinct, also appearing annular with light centre, slightly or distinctly darker than the stroma surface, red or brown, nearly black when mature or old. Stroma colour variable, first white, then typically rosy with white to yellowish margin, with or without a white covering layer, or entirely rosy, greyish orange, pale red, greyish red when immature, 5-8A2-3, 7-9BD4-7, 9A4, to reddish brown, 9CE5-8, 10DE4. Reddish pigment persistent or disappearing and yellow to brown colours emerging, stromata becoming yellow-brown, brown-orange, brown, mostly (5-)6-7CD5-8 when mature, to reddish brown or dark brown, 7-8CE4-8, 8F5-8; less commonly yellow to greyish orange 4-6B4, 5A4; sometimes yellow-brown from the start without rosy colours. Spore deposits white.

Mature stromata after rehydration brown with yellow surface and reddish brown dots 47-80(-95) $\mu \mathrm{m}$ diam; white inside; perithecia brown; lower margin white, smooth. After addition of 3\% $\mathrm{KOH}$ brown, no distinct discoloration but brown to reddish perithecial colour more prominent; ostiolar openings hyaline.

Stroma anatomy: Ostioles (50-)56-80(-105) $\mu \mathrm{m}$ long, plane or projecting to $15 \mu \mathrm{m},(20-) 26-40(-47) \mu \mathrm{m}$ wide at the apex $(n=30)$, conical or cylindrical, periphysate; no specialized cells apparent. Perithecia (190-)210-270 $(-320) \times(115-) 130-200(-240) \mu \mathrm{m} \quad(n=30)$, numerous, crowded, 6-9 per $\mathrm{mm}$ stroma length, ellipsoidal, flaskshaped or globose; peridium (11-)14-17(-19) $\mu \mathrm{m}(n=30)$ thick at the base, $(5-) 10-15(-17) \mu \mathrm{m}(n=30)$ thick at the sides, yellow, orange in $3 \% \mathrm{KOH}$. Surface smooth, welldefined. Cortical layer (10-)15-25(-30) $\mu \mathrm{m}(n=30)$ thick, yellow, orange in $3 \% \mathrm{KOH}$, of a thin amorphous layer and below a dense $t$. angularis of thick-walled cells (3-)4-9 $(-12) \times(2-) 3-6(-7) \mu \mathrm{m}(n=30)$ in face view and in vertical section. Subcortical tissue a hyaline $t$. intricata of hyphae $(2.0-) 2.5-4.5(-6.0) \mu \mathrm{m}(n=30)$ wide. Subperithecial tissue a dense hyaline $t$. epidermoidea of mostly elongate, vertically oriented, thick-walled cells (5-)7-34(-63) $\times(4-)$ 7-13(-16) $\mu \mathrm{m}(n=35)$, appearing as a $t$. oblita under low magnification; cells tending to be smaller and more isodiametric towards the stroma base. Asci (77-)90-110 $(-120) \times(5.0-) 5.5-6.5(-7.0) \mu \mathrm{m}$, stipe $(3-) 9-20(-27) \mu \mathrm{m}$ long $(n=100)$; croziers present. Ascospores hyaline, verruculose; cells dimorphic; distal cell (3.7-)4.0-4.8(-6.0) $\times$ (3.2-)3.5-4.0(-5.0) $\mu \mathrm{m}, 1 / \mathrm{w} 1.0-1.3(-1.8)(n=170)$, subglobose, ellipsoidal or wedge-shaped; proximal cell (4.2-) $4.8-6.0(-7.2) \times(2.7-) 3.0-3.5(-4.0) \quad \mu \mathrm{m}, 1 / \mathrm{w}(1.2-) 1.4-1.9$ $(-2.4)(n=170)$, wedge-shaped or oblong.

Anamorph on the natural substrate effuse, extending to several $\mathrm{mm}$, bluish- to medium green; conidia ellipsoidal, smooth, light bluish green in mass. 

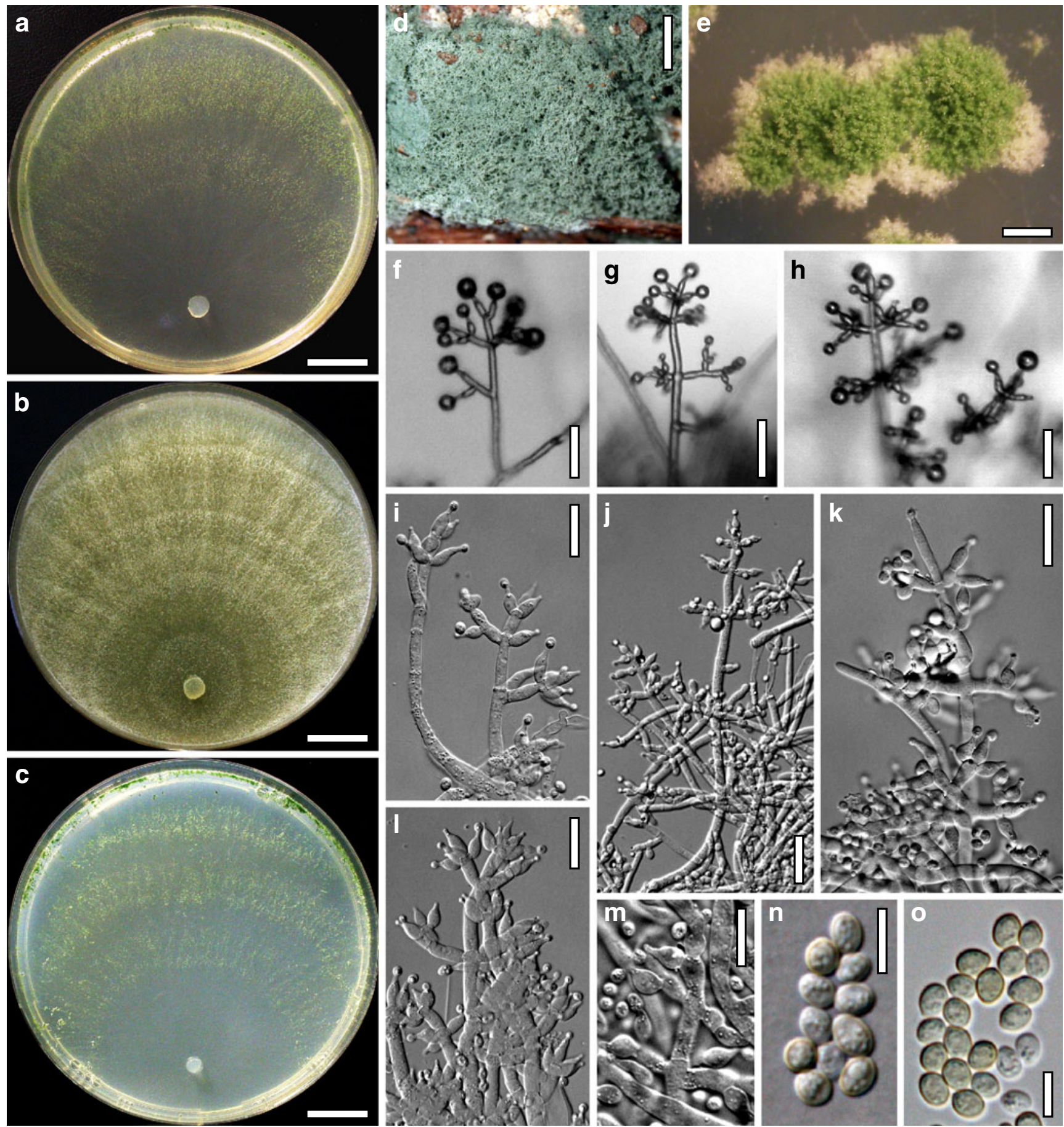

Fig. 42 Cultures and anamorph of Hypocrea minutispora. a-c. Cultures at $25^{\circ} \mathrm{C}$ after 7 days (a. on CMD; b. on PDA; c. on SNA). d. Conidiation mat on the natural substrate. e. Conidiation pustules on growth plate (SNA, 11 days). $\mathbf{f}-\mathbf{h}$. Conidiophores on growth plate (f. effuse; $\mathbf{g}, \mathbf{h}$. from shrub or tuft margin; CMD, 4-9 days). i-l. Conidiophores (i. effuse; $\mathbf{j}-\mathbf{l}$. pustulate; $\mathbf{k}$. with variable phialides; $\mathbf{i}, \mathbf{l}$.

Cultures and anamorph: optimal growth at $25^{\circ} \mathrm{C}$ on all media; no growth at $35^{\circ} \mathrm{C}$.

On CMD $22-24 \mathrm{~mm}$ at $15^{\circ} \mathrm{C}, 46-51 \mathrm{~mm}$ at $25^{\circ} \mathrm{C}, 24$ $36 \mathrm{~mm}$ at $30^{\circ} \mathrm{C}$ after $72 \mathrm{~h}$; mycelium covering the entire
CMD; j, k. SNA; 5 days). m. Ampulliform phialides (SNA, 5 days). n, o. Conidia (5 days; n. CMD, o. SNA). e-o. All at $25^{\circ} \mathrm{C}$. a-c, e, f, h, i, l, n. CBS 121276 , d. C.P.K. 979, g. C.P.K. 986, j, k, m, o. C.P.K. 2869. Scale bars: $\mathbf{a}-\mathbf{c}=15 \mathrm{~mm} . \mathbf{d}=1 \mathrm{~mm}$. $\mathbf{e}=0.3 \mathrm{~mm}$. f, $\mathbf{h}, \mathbf{j}=20 \mu \mathrm{m}$. $\mathbf{g}=\mathbf{3 0} \mu \mathrm{m} . \mathbf{i}, \mathbf{k}, \mathbf{l}=\mathbf{1 5} \mu \mathrm{m} . \mathbf{m}=\mathbf{1 0} \mu \mathrm{m} . \mathbf{n}, \mathbf{0}=\mathbf{5} \mu \mathrm{m}$

plate after $4-5$ days at $25^{\circ} \mathrm{C}$. Colony hyaline, thin, circular; mycelium loose, not zonate; broad marginal zone becoming downy by long aerial hyphae. Autolytic activity and coilings lacking or inconspicuous. No diffusing pigment, 
no distinct odour noted. Chlamydospores noted after 4 5 days, uncommon, sometimes becoming abundant around the inoculation plug. Conidiation noted after 2-3 days, green after 4-5 days; starting at the distal margin; effuse, short, on surface hyphae and aerial hyphae, forming broad, diffuse concentric zones of shrubs or granules. Conidia produced in minute wet heads. Typically no distinct pustules formed; occasionally ( 4 of 60 isolates) green tufts or pustules to $2 \mathrm{~mm}$ diam seen on CMD directly after ascospore isolation. At $15^{\circ} \mathrm{C}$ hyphae wider; effuse conidiation remaining colourless (after 14 days). At $30^{\circ} \mathrm{C}$ colony zonate, chlamydospores increased in number; conidiation green after 1 week.

On PDA $18-20 \mathrm{~mm}$ at $15^{\circ} \mathrm{C}, 39-42 \mathrm{~mm}$ at $25^{\circ} \mathrm{C}, 11-$ $22 \mathrm{~mm}$ at $30^{\circ} \mathrm{C}$ after $72 \mathrm{~h}$; mycelium covering the plate after 5-6 days at $25^{\circ} \mathrm{C}$. Colony dense, zonate, becoming hairy to floccose by abundant aerial hyphae forming a white to yellowish mat and radial strands. Autolytic excretions and coilings inconspicuous. No diffusing pigment produced, reverse yellowish, 2-4A3. Odour inconspicuous or unpleasant, rancid. Conidiation noted after 2 days, effuse, poor, e.g. on solitary phialides on aerial hyphae, colourless to white, not becoming green. At $15^{\circ} \mathrm{C}$ hyphae conspicuously wide, sometimes moniliform, conidiation effuse. At $30^{\circ} \mathrm{C}$ colony irregular, flat, velutinous. Hyphae soon degenerating. Autolytic excretions frequent. Reverse yellow to greyish orange, 3A3, 4A4-5, 5B4-5. Rancid odour conspicuous. Conidiation reduced or absent.

On SNA $18-21 \mathrm{~mm}$ at $15^{\circ} \mathrm{C}, 36-42 \mathrm{~mm}$ at $25^{\circ} \mathrm{C}, 8-$ $22 \mathrm{~mm}$ at $30^{\circ} \mathrm{C}$ after $72 \mathrm{~h}$; mycelium covering the plate after 5-6 days at $25^{\circ} \mathrm{C}$. Colony hyaline, thin, circular; mycelium loose, not zonate; hyphae wide, radially arranged. Aerial hyphae scant, more frequent and long at the distal margin. Autolytic activity inconspicuous, coilings moderate. No diffusing pigment, no distinct odour noted. Chlamydospores noted after 5 days, uncommon; terminal and intercalary, (5-)6-9(-11)×(4-)5-8(-10) $\mu \mathrm{m}, 1 / \mathrm{w}(0.9-)$ $1.0-1.5(-2.1) \quad(n=27)$, sometimes to $20 \mu \mathrm{m}$ long when intercalary, globose, ovoid or pyriform, also fusoid or rectangular when intercalary. Conidiation noted after 2 days, pale green after 5-6 days; effuse, on simple, minute, short, erect conidiophores in lawns, in numerous small shrubs to $0.3 \mathrm{~mm}$ diam and $0.2 \mathrm{~mm}$ high, with up to 5 main axes, irregularly distributed or in broad, diffuse concentric zones, more abundant with distance from the plug; more rarely on aerial hyphae. Branches of simple conidiophores mostly unpaired, in shrubs tending to be paired in terminal side branches; generally short, 1-3 celled. Stipes of shrubs 8$11 \mu \mathrm{m}$ wide, simple conidiophores and main axes 6-7 $\mu \mathrm{m}$ wide at their bases, 2-4 $\mu \mathrm{m}$ terminally. Phialides formed solitary or in whorls of $2-3(-5)$ on cells $3-4.5 \mu \mathrm{m}$ wide. Conidia formed in minute wet green heads to $30 \mu \mathrm{m}$ diam. Shrubs growing to circular or oblong tufts to $1.5 \mathrm{~mm}$ diam mostly along the distal margin after $c a 10$ days, aggregating to $4 \mathrm{~mm}$. Tufts or pustules small, circular, loose, of a stipe to $11 \mu \mathrm{m}$ wide, with unpaired primary branches $6-9 \mu \mathrm{m}$ wide, and several straight, radial main axes $200-400 \mu \mathrm{m}$ long, typically with short paired side branches emerging in right angles; main axes and side branches fertile to the tips, attenuated upwards to $2-4(-5) \mu \mathrm{m}$. Side branches often pyramidal or slender with short side branches $20-80 \mu \mathrm{m}$ long, sometimes 1- or 2- fold re-branching, forming dense structures. Phialides divergent in whorls of $2-5(-6)$ on cells (1.5-)2.0-3.5 $\mu \mathrm{m}$ wide and often thickened their apices. Conidia formed in minute wet heads to $20 \mu \mathrm{m}$ diam. Phialides $(4-) 6-10(-17) \times(2.7-) 3.2-4.0(-4.8) \mu \mathrm{m}$, $1 / \mathrm{w}(1.2-) 1.5-2.8(-4.3),(1.3-) 1.7-2.5(-3.3) \mu \mathrm{m}$ wide at the base $(n=63)$, lageniform, long and in effuse conidiation, ampulliform and short in tufts or pustules, widest mostly below the middle, often inaequilateral and curved, with abruptly narrowed, thin, cylindrical neck. Terminal phialides in extension of the conidiophore axis often long, slender, nearly subulate. Conidia $(2.8-) 3.3-4.0(-5.0) \times$ $(2.5-) 2.7-3.2(-3.8) \mu \mathrm{m}, 1 / \mathrm{w}(1.1-) 1.2-1.4(-1.7) \quad(n=63)$, green, ellipsoidal, less commonly subglobose, smooth, with minute guttules in varying numbers; scar indistinct. At $30^{\circ}$ $\mathrm{C}$ colony irregular, conidiation effuse, greenish.

Habitat: on hard, little degraded or medium-decayed wood and bark of deciduous trees, mostly Fagus sylvatica, and fungi growing on it, less commonly on wood and bark of coniferous trees.

Distribution: the commonest hyaline-spored Hypocrea species in the temperate zones of Europe and North America.

Holotype: USA, North Carolina, Macon County, Ammons Branch Campground, off Bull Pen road, elev. $3000 \mathrm{ft} .35^{\circ} 1^{\prime} \mathrm{N} 83^{\circ} 8^{\prime} \mathrm{W}$, on bark, 14 Oct. 1990, Y. Doi, A. Y Rossman \& G.J. Samuels (BPI 1109373, ex-type culture G.J.S. 90-81=ATCC MYA-2951; not examined).

Specimens examined: Austria, Burgenland, Matters-

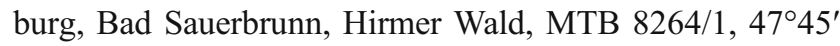
$31^{\prime \prime} \mathrm{N}, 16^{\circ} 21^{\prime} 31^{\prime \prime}$ E, elev. $270 \mathrm{~m}$, on branch of Quercus petraea $3 \mathrm{~cm}$ thick, on wood, soc. effete pyrenomycetes, immature, 13 Jul. 2004, H. Voglmayr \& W. Jaklitsch, W.J. 2525. Kärnten, Klagenfurt Land, St. Margareten im Rosental, Schwarzgupf, above Umwiese, MTB 9452/4, 46 $31^{\prime}$ $40^{\prime \prime} \mathrm{N}, 14^{\circ} 25^{\prime} 26^{\prime \prime}$ E, elev. $870 \mathrm{~m}$, on partly decorticated branches of Fagus sylvatica, 2-8 cm thick, on wood, below bark, soc. Melanomma sanguinarium, Peniophora cinerea, holomorph, 21 Oct. 2003, W. Jaklitsch, W.J. 2480 (WU 29250, culture CBS 121276=C.P.K. 1607); same village, Stariwald and close to Bauhof Jaklitsch, MTB 9452/4, $46^{\circ}$ $32^{\prime} 56^{\prime \prime} \mathrm{N}, 14^{\circ} 25^{\prime} 25^{\prime \prime} \mathrm{E}$ and $46^{\circ} 32^{\prime} 29^{\prime \prime} \mathrm{N}, 14^{\circ} 25^{\prime} 40^{\prime \prime} \mathrm{E}$, elev. $570 \mathrm{~m}$, on decorticated branches of Fagus sylvatica $2-3 \mathrm{~cm}$ thick, on wood, on/soc. Armillaria rhizomorphs, soc. Corticiaceae, holomorph, 19 Aug. 2004, W. Jaklitsch, W. 
J. 2606, 2609 (WU 29259, cultures C.P.K. 1951, 1952); same village, Wograda, near Fechterkreuz, MTB 9452/3, $46^{\circ} 32^{\prime} 41^{\prime \prime} \mathrm{N}, 14^{\circ} 24^{\prime} 59^{\prime \prime}$ E, elev. $560 \mathrm{~m}$, on branch of Fagus sylvatica 4-5 cm thick, on wood, soc. Laxitextum bicolor with Capronia porothelia, holomorph, 22 Oct. 2003, W. Jaklitsch, W.J. 2484 (WU 29251, culture C.P.K. 995); same area, MTB 9452/3, 46 $32^{\prime} 36^{\prime \prime} \mathrm{N}, 1^{\circ} 24^{\prime} 50^{\prime \prime}$ E, elev. $540 \mathrm{~m}$, on partly decorticated branches of Fagus sylvatica 7-10 cm thick, on wood, soc. hyphomycetes, holomorph, 25 Oct. 2004, W. Jaklitsch, W.J. 2781 (WU 29272, culture C.P.K. 1968). Spittal/Drau, Mallnitz, Stappitz, along hiking trail 518 close to Gasthof Alpenrose, MTB 8945/3, 47 $01^{\prime} 06^{\prime \prime}$ $\mathrm{N}, 13^{\circ} 11^{\prime} 14^{\prime \prime} \mathrm{E}$, elev. $1340 \mathrm{~m}$, on decorticated branch of Alnus incana $9 \mathrm{~cm}$ thick, on wood, soc. Corticiaceae, holomorph, 5 Sep. 2003, W. Jaklitsch, W.J. 2381 (WU 29241, culture C.P.K. 950). Völkermarkt, Globasnitz, Altendorf, on roadside heading to Sagerberg, MTB 9453/ $4,46^{\circ} 32^{\prime} 52^{\prime \prime} \mathrm{N}, 14^{\circ} 38^{\prime} 45^{\prime \prime}$ E, elev. $570 \mathrm{~m}$, on decorticated branch of Fagus sylvatica $8 \mathrm{~cm}$ thick, on wood, soc. Hypocrea lixii, Nemania sp., Corticiaceae; holomorph, teleomorph mostly immature, 17 Aug. 2004, W. Jaklitsch, W.J. 2599 (WU 29258, culture C.P.K. 1950). Niederösterreich, Hollabrunn, Hardegg, Semmelfeld, between Niederfladnitz and Merkersdorf, MTB 7161/3, 48 48'49" N, $15^{\circ}$ $52^{\prime} 43^{\prime \prime}$ E, elev. $450 \mathrm{~m}$, on branch of Fagus sylvatica $3 \mathrm{~cm}$ thick, on/soc. effete Hypoxylon fragiforme, immature, 21 Jul. 2004, H. Voglmayr \& W. Jaklitsch, W.J. 2530. Krems Land, Krumau, virgin forest at the dam of the Dobra

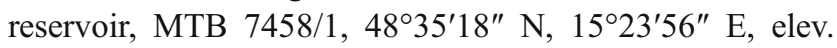
$490 \mathrm{~m}$, on decorticated branch of Fagus sylvatica $2.5 \mathrm{~cm}$ thick, on wood, soc. Corticiaceae, holomorph, 28 Sep. 2003, W. Jaklitsch, W.J. 2432 (WU 29245, culture C.P.K. 979). Rastenfeld, Mottingeramt, MTB 7458/1, 48 $33^{\prime} 55^{\prime \prime}$ N, 15 $24^{\prime} 36^{\prime \prime}$ E, elev. 600 m, on branch of Fagus sylvatica, on wood, 31 Aug. 2008, W. Jaklitsch \& O. Sükösd, W.J. 3204 (WU 29278). Lilienfeld, Sankt Aegyd am Neuwalde, Lahnsattel, virgin forest Neuwald, MTB 8259/1, 47 46'24" $\mathrm{N}, 15^{\circ} 31^{\prime} 20^{\prime \prime} \mathrm{E}$ and $47^{\circ} 46^{\prime} 21^{\prime \prime} \mathrm{N}, 1^{\circ} 31^{\prime} 16^{\prime \prime} \mathrm{E}$, elev. $950 \mathrm{~m}$, on partly decorticated branches of Fagus sylvatica $4-10 \mathrm{~cm}$ thick, on wood, emergent through bark, soc. Bisporella citrina, white corticiaceous fungus, 16 Oct. 2003, H. Voglmayr \& W. Jaklitsch, W.J. 2464+2467 (WU 29248, cultures C.P.K. 2400, 2402); same area, elev. $1000 \mathrm{~m}$, on branch of Fagus sylvatica, on hard wood, 25 Sep. 2007, H. Voglmayr, W.J. 3171 (WU 29277, culture C.P.K. 3156). Melk, Sankt Leonhard am Forst, $400 \mathrm{~m}$ after Großweichselbach heading to Melk, MTB 7857/2, 48 $10^{\prime}$ $39^{\prime \prime} \mathrm{N}, 15^{\circ} 17^{\prime} 48^{\prime \prime}$ E, elev. $380 \mathrm{~m}$, on decorticated branch of Fagus sylvatica $3 \mathrm{~cm}$ thick, on wood, holomorph, 30 Sep. 2004, W. Jaklitsch, W.J. 2750 (WU 29269, culture C.P.K.

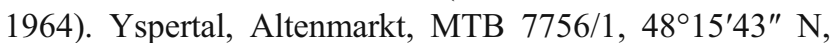
$15^{\circ} 03^{\prime} 21^{\prime \prime} \mathrm{E}$, elev. $460 \mathrm{~m}$, on decorticated branches of Fagus sylvatica $2-8 \mathrm{~cm}$ thick, on wood, soc. Corticiaceae, effete pyrenomycetes, myxomycete, holomorph, 25 Jul. 2004, H. Voglmayr \& W. Jaklitsch, W.J. 2541 (WU 29252, culture C.P.K. 1944). Scheibbs, Lunz am See, forest path from Schloß Seehof in the direction Mittersee, MTB 8156/ $3,47^{\circ} 50^{\prime} 44^{\prime \prime} \mathrm{N}, 15^{\circ} 04^{\prime} 30^{\prime \prime} \mathrm{E}$ and $47^{\circ} 50^{\prime} 39^{\prime \prime} \mathrm{N}, 15^{\circ} 04^{\prime} 24^{\prime \prime}$ E, elev. $620 \mathrm{~m}$, on branches of Fagus sylvatica 2-3 cm thick, on wood, soc. effuse Hypoxylon sp., Diatrypella verruciformis, Quaternaria quaternata, 16 Oct. 2003, W. Jaklitsch \& H. Voglmayr, W.J. 2457+2462 (WU 29247, culture C.P.K. 2399). Wien-Umgebung, Mauerbach, Friedhofstraße, MTB 7763/1, 48 $15^{\prime} 14^{\prime \prime} \mathrm{N}, 16^{\circ} 10^{\prime} 15^{\prime \prime}$ E, elev. $320 \mathrm{~m}$, on branch of Carpinus betulus 7-8 cm thick, on wood and bark, soc. Armillaria rhizomorphs, holomorph, 9 Jul. 2003, W. Jaklitsch, W.J. 2278 (WU 29238, culture C.P.K. 940). Tulbinger Kogel, NE Passauerhof, on the hiking trail to Mödihütte, MTB 7762/2, $48^{\circ} 16^{\prime} 08^{\prime \prime} \mathrm{N}$, $16^{\circ} 08^{\prime} 31^{\prime \prime}$ E, elev. $400 \mathrm{~m}$, on branch of Fraxinus excelsior $5 \mathrm{~cm}$ thick, on wood and bark, soc. Corticiaceae, light rhizomorphs, effete Hypoxylon sp. on bark, Cryptosphaeria eunomia in bark, holomorph, 11 Oct. 2003, H. Voglmayr, W.J. 2456 (WU 29246, culture C.P.K. 988). Pressbaum, Rekawinkel, forest path south from the train station, MTB $7862 / 1,48^{\circ} 10^{\prime} 40^{\prime \prime} \mathrm{N}, 16^{\circ} 01^{\prime} 55^{\prime \prime} \mathrm{E}$ to $48^{\circ} 10^{\prime} 46^{\prime \prime} \mathrm{N}, 16^{\circ} 02^{\prime}$ 03" E, elev. 360-390 m, on decorticated branches of Fagus sylvatica 2-8 $\mathrm{cm}$ thick, on wood and bark, soc. effete Annulohypoxylon cohaerens, Armillaria rhizomorphs, Phlebiella vaga, holomorph, 18 Oct. 2003 and 26 Sep. 2004, W. Jaklitsch \& H. Voglmayr, W.J. 2468, 2471, 2472, 2741 (combined as WU 29249, cultures C.P.K. 1963, 2403, 2405, 2406). Zwettl, Altmelon, Kleinpertenschlag, at the wayside shrine Zum Eisernen Bild, MTB 7555/4, 48 ${ }^{\circ} 24^{\prime}$ $49^{\prime \prime} \mathrm{N}, 14^{\circ} 57^{\prime} 00^{\prime \prime}$ E, elev. $850 \mathrm{~m}$, on partly decorticated branches of Fagus sylvatica and Picea abies, 3-9 cm thick, on wood and bark, soc. Laxitextum bicolor/Capronia porothelia, Annulohypoxylon cohaerens, Hypoxylon fragiforme, Pycnoporus cinnabarinus, Neobulgaria pura, Quaternaria quaternata, Trametes versicolor, Polyporus brumalis, holomorph, 5 Oct. 2004, W. Jaklitsch (W.J. 2765, WU 29271, culture C.P.K. 1967). Oberösterreich, Grieskirchen, Natternbach, at Gaisbuchen, MTB 7548/3, $48^{\circ} 24^{\prime} 39^{\prime \prime} \mathrm{N}, 13^{\circ} 41^{\prime} 40^{\prime \prime}$ E, elev. $580 \mathrm{~m}$, on partly decorticated branch of Fagus sylvatica, on wood, on/soc. Bertia moriformis, 1 Aug. 2004, H. Voglmayr \& W. Jaklitsch, W.J. 2552 (WU 29253, culture C.P.K. 1945). Vöcklabruck, Nußdorf am Attersee, small wood at Aichereben, MTB 8147/3, 47 $50^{\prime} 45^{\prime \prime} \mathrm{N}, 13^{\circ} 30^{\prime} 13^{\prime \prime} \mathrm{E}$, elev. $710 \mathrm{~m}$, on corticated branch of Fagus sylvatica 6-7 cm thick, on bark and in bark fissures, soc. Hypoxylon fragiforme, Quaternaria quaternata, holomorph, teleomorph mostly immature, 8 Aug. 2004, H. Voglmayr \& W. Jaklitsch, W.J. 2589 (WU 29257, culture C.P.K. 1949). Steiermark, Leoben, Gesäuse, Hieflau, Hartelsgraben, MTB 8454/1, $47^{\circ} 35^{\prime} 29^{\prime \prime} \mathrm{N}, 14^{\circ} 42^{\prime} 24^{\prime \prime}$ E, elev. $520 \mathrm{~m}$, on branches of 
Fagus sylvatica $10 \mathrm{~cm}$ thick, on wood and a phlebioid corticiaceous fungus, soc. Hypocrea sinuosa, effete pyrenomycete; holomorph, 7 Aug. 2003, H. Voglmayr \& W. Jaklitsch, W.J. 2315 (WU 29239, culture C.P.K. 2386). Weiz, Laßnitzthal, opposite to the Arboretum Gundl, MTB $8959 / 2,4^{\circ} 04^{\prime} 17^{\prime \prime} \mathrm{N}, 15^{\circ} 38^{\prime} 38^{\prime \prime}$ E, elev. $420 \mathrm{~m}$, on branch of Fagus sylvatica $5 \mathrm{~cm}$ thick, on hard wood, holomorph, 8 Aug. 2003, W. Jaklitsch \& H. Voglmayr, W.J. 2323 (WU 29240, culture C.P.K. 2387).Vorarlberg, Bludenz, Nenzing, Rabenstein, at Beschling, MTB 8824/1, 47 $11^{\prime} 20^{\prime \prime} \mathrm{N}, 09^{\circ}$ $40^{\prime} 34^{\prime \prime}$ E, elev. $660 \mathrm{~m}$, on corticated branch of Fagus sylvatica $8 \mathrm{~cm}$ thick, on bark, soc. Corticiaceae, effete pyrenomycete, 29 Aug. 2004, H. Voglmayr \& W. Jaklitsch, W.J. 2632 (WU 29260, culture C.P.K. 1953). Feldkirch, Rankweil, behind the hospital LKH Valduna, MTB 8723/2, $47^{\circ} 15^{\prime} 40^{\prime \prime} \mathrm{N}, 09^{\circ} 39^{\prime} 00^{\prime \prime}$ E, elev. $510 \mathrm{~m}$, on mostly decorticated branches of Fagus sylvatica 4-6 cm thick, on wood, 31 Aug. 2004, H. Voglmayr \& W. Jaklitsch, W.J. 2641 (WU 29261, culture C.P.K. 1954). Czech Republic, Bohemian Switzerland, Mezní Louka, Kozí Hrbet/Ponova Louka, MTB 5151/2, 50 $53^{\prime} 05^{\prime \prime} \mathrm{N}, 14^{\circ} 19^{\prime} 27^{\prime \prime} \mathrm{E}$ and 50 53' $06^{\prime \prime} \mathrm{N}, 14^{\circ} 19^{\prime} 37^{\prime \prime}$ E, elev. $350 \mathrm{~m}$, on decorticated branches of Fagus sylvatica, 4-7 cm thick, on wood, soc. Corticiaceae with rhizoids, holomorph, 19 Sep. 2003, W. Jaklitsch, W.J. 2400, 2401 (WU 29242, cultures C.P.K. 963, 964). Southern Bohemia, Záhvozdí, Černý les, MTB 7149/4, $48^{\circ}$ $50^{\prime} 43^{\prime \prime} \mathrm{N}, 13^{\circ} 58^{\prime} 34^{\prime \prime} \mathrm{E}$ to $48^{\circ} 50^{\prime} 38^{\prime \prime} \mathrm{N}, 13^{\circ} 58^{\prime} 41^{\prime \prime} \mathrm{E}$, elev. $850 \mathrm{~m}, 6$ specimens on corticated and decorticated branches of Fagus sylvatica 2-6 cm thick, on wood and bark, on and soc. Inonotus hastifer, soc. Annulohypoxylon cohaerens, Chaetosphaeria pygmaea/myriocarpa, Diatrype disciformis, Nemania serpens, Orbilia delicatula, Phanerochaete sp. with Helminthosphaeria cf. odontiae, Quaternaria quaternata, holomorph, 24 Sep. 2003, W. Jaklitsch, W.J. 2414-2420 (combined as WU 29243, cultures C.P.K. 969973). Záton, Boubínský prales (NSG), MTB 7048/2, 4858' $03^{\prime \prime} \mathrm{N}, 13^{\circ} 49^{\prime} 24^{\prime \prime} \mathrm{E}$ and $48^{\circ} 58^{\prime} 30^{\prime \prime} \mathrm{N}, 13^{\circ} 49^{\prime} 15^{\prime \prime} \mathrm{E}$, elev. 900-1000 m, on mostly decorticated branches of Fagus sylvatica $2-11 \mathrm{~cm}$ thick, on wood and bark, soc. pyrenomycetes, Corticiaceae, Bisporella citrina, Oligoporus subcaesius, holomorph, 4 Oct. 2004, W. Jaklitsch, W.J. 2759+ 2760 (WU 29270, culture C.P.K. 1965, 1966). Žofín, Žofínský prales (NSG), MTB 7354/1, 48 40 $40^{\prime} 13^{\prime \prime} \mathrm{N}, 14^{\circ}$ $42^{\prime} 28^{\prime \prime} \mathrm{E}$ to $48^{\circ} 40^{\prime} 07^{\prime \prime} \mathrm{N}, 14^{\circ} 42^{\prime} 22^{\prime \prime} \mathrm{E}$, elev. $820 \mathrm{~m}$, on branches of Fagus sylvatica 2-7 cm thick, on wood, in bark fissures, soc. white mould, holomorph, 26 Sep. 2003, W. Jaklitsch, W.J. 2429-2431 (WU 29244, cultures C.P.K. 978, 2392, 2393). Denmark, Soenderjylland, Roedekro,

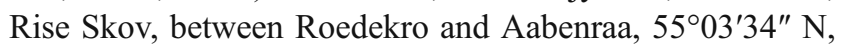
$09^{\circ} 22^{\prime} 01^{\prime \prime}$ E, elev. $70 \mathrm{~m}$, on partly decorticated branch of Fagus sylvatica $15-20 \mathrm{~cm}$ thick, on wood and bark and stromata of Hypoxylon fragiforme, soc. Calocera cornea, 23 Aug. 2006, H. Voglmayr \& W. Jaklitsch, W.J. 2937
(WU 29274, culture C.P.K. 2443). Estonia, Harjumaa Co., Põhja-Kõrvemaa landscape reserve, on wood, 28 Oct. 2007, K. Põldmaa K.P. 375. France, Lorraine, Vosges, Col de la Schlucht, Route des Crêtes, Gazon du Faing, Forêt des Hospices de Nancy, 48 $07^{\prime} 24^{\prime \prime} \mathrm{N}, 07^{\circ} 04^{\prime} 11^{\prime \prime}$ E, elev. $1000 \mathrm{~m}$, on decorticated branch of Fagus sylvatica $8 \mathrm{~cm}$ thick, on black wood, soc. Phlebia sp., effete pyrenomycetes, 4 Sep. 2004, W. Jaklitsch \& H. Voglmayr, W.J. 2675 (WU 29263, culture C.P.K. 1956). Moselle, Lorraine, Pont a Mousson, close to the motorway Nancy/Metz, 48 $55^{\prime} 26^{\prime \prime}$ N, $06^{\circ} 05^{\prime} 55^{\prime \prime}$ E, elev. $200 \mathrm{~m}$, on decorticated branch of Fagus sylvatica 5-7 cm thick, along the whole branch, soc. Hypocrea lixii, holomorph, 5 Sep. 2004, W. Jaklitsch \& H. Voglmayr, W.J. 2682 (WU 29264, culture C.P.K. 1957). Germany, Baden Württemberg, Freiburg, Landkreis Breisgau-Hochschwarzwald, St. Märgen, parking area

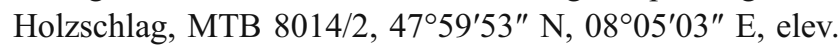
$620 \mathrm{~m}$, on partly decorticated cut log of Abies alba 18$22 \mathrm{~cm}$ thick, on wood and bark, soc. Armillaria rhizomorphs, Trichaptum abietinum, Exidiopsis sp., 2 Sep. 2004, H. Voglmayr \& W. Jaklitsch, W.J. 2667 (WU 29262, culture C.P.K. 1955). Tübingen-Pfrondorf, Tiefenbach, Einsiedlerweg, on branch of Fagus sylvatica, on wood, 20 Oct. 2002, W. Jaklitsch \& H.O. Baral, W.J. 2006. Bavaria, Oberbayern, Altmühltal, Eichstätt, 2-3 km after Pfahldorf heading to Eichstätt, MTB 7033/4, 48 $57^{\prime} 00^{\prime \prime} \mathrm{N}, 11^{\circ} 18^{\prime} 20^{\prime \prime}$ E, elev. $540 \mathrm{~m}$, on decorticated branch of Fagus sylvatica $4 \mathrm{~cm}$ thick, on wood, soc. Corticiaceae, holomorph, 5 Aug. 2004, W. Jaklitsch \& H. Voglmayr, W.J. 2574 (WU 29255, culture C.P.K. 1947). Habach, Thomamühle, south of the road B472, elev. $640 \mathrm{~m}$, MTB 8233/4/23, on branch of Picea abies, on bark, 23 Dec. 2008, P. Karasch, WU 29528. Starnberg, Tutzing, Pähl, Pähler Schlucht, MTB 8033/3, $47^{\circ} 54^{\prime} 38^{\prime \prime} \mathrm{N}, 11^{\circ} 11^{\prime} 50^{\prime \prime} \mathrm{E}$, elev. $650 \mathrm{~m}$, on decorticated branch of Fagus sylvatica $10 \mathrm{~cm}$ thick, soc. effete Eutypa lata, 7 Aug. 2004, H. Voglmayr, W. Jaklitsch \& P. Karasch, W.J. 2586 (WU 29256, culture C.P.K. 1948). Unterfranken, Landkreis Haßberge, Haßfurt, close to Mariaburghausen, left roadside heading from Knetzgau to Haßfurt, MTB $5929 / 3,50^{\circ} 00^{\prime} 33^{\prime \prime} \mathrm{N}, 10^{\circ} 31^{\prime} 10^{\prime \prime}$ E, elev. $270 \mathrm{~m}$, on mostly corticated branches of Tilia cordata 5-6 cm thick, on wood and bark, soc. Hypocrea strictipilosa, Corticiaceae, 04 Aug. 2004, W. Jaklitsch \& H. Voglmayr, W.J. 2561+2562 (WU 29254, culture C.P.K. 1946). Nordrhein-Westfalen, Herne, Böwinghauser Bachtal, MTB 4409/4, elev. $80 \mathrm{~m}$, on decorticated branch of Fraxinus excelsior $15 \mathrm{~cm}$ thick, on wood, holomorph, teleomorph immature, 3 Jun. 2007, K. Siepe \& F. Kasparek (WU 29276, culture from conidia, C.P. K. 3125). Rheinland-Pfalz, Eifel, Daun, Weinfelder Maar, $50^{\circ} 10^{\prime} 44^{\prime \prime} \mathrm{N}, 06^{\circ} 51^{\prime} 07^{\prime \prime}$ E, elev. $480 \mathrm{~m}$, on partly decorticated branch of Alnus glutinosa $6 \mathrm{~cm}$ thick, on wood, soc. Hypoxylon rubiginosum, Peniophora cinerea, Corticiaceae, holomorph, 21 Sep. 2004, H. Voglmayr \& W. 
Jaklitsch, W.J. 2737 (WU 29268, culture C.P.K. 1962). Gerolstein, between Büscheich and Salm, 50 $10^{\prime} 33^{\prime \prime}$ N, $06^{\circ}$ $41^{\prime} 50^{\prime \prime} \mathrm{E}$, elev. $560 \mathrm{~m}$, on partly decorticated branches of Fagus sylvatica 7-8 cm thick, on dark wood, soc. ? Cylindrobasidium evolvens, 20 Sep. 2004, W. Jaklitsch \& H. Voglmayr, W.J. 2733 (WU 29267, culture C.P.K. 1961). Spain, Canarias, La Palma, San Isidro, elev. $700 \mathrm{~m}$, on decorticated branch of Chamaecytisus proliferus, on wood, holomorph, 13 Jan. 2005, P. Karasch, W.J. 2795 (WU 29273, culture C.P.K. 2022). Sweden, Uppsala Län, Sunnersta, forest opposite the virgin forest Vardsätra Naturpark across the road, MTB 3871/2, 59 $47^{\prime} 24^{\prime \prime} \mathrm{N}$, $17^{\circ} 37^{\prime} 51^{\prime \prime}$ E, elev. $15 \mathrm{~m}$, on branch of Salix caprea $8 \mathrm{~cm}$ thick, on wood, 8 Oct. 2003, W. Jaklitsch, W.J. 2454, culture C.P.K. 986. United Kingdom, Buckinghamshire, Chorleywood, Carpenters' Wood, on branch of Fagus sylvatica, on wood, soc. hyphomycetes, pyrenomycetes, algae, 4 Mar. 2007, K. Robinson, comm. P. Wilberforce, W. J. 3084 (WU 29275, culture C.P.K. 2869). Slough, Burnham Beeches, 51 $33^{\prime} 07^{\prime \prime} \mathrm{N}, 00^{\circ} 37^{\prime} 50^{\prime \prime} \mathrm{W}$, elev. $30 \mathrm{~m}$, on decorticated branches of Fagus sylvatica 5-11 cm thick, on wood, 15 Sep. 2004, W. Jaklitsch, W.J. 2717 (WU 29266, culture C.P.K. 1960). Derbyshire, Baslow, Stand Wood Walks behind Chatsworths House, $53^{\circ} 13^{\prime} 47^{\prime \prime} \mathrm{N}, 01^{\circ}$ $36^{\prime} 20^{\prime \prime} \mathrm{W}$, elev. $200 \mathrm{~m}$, on thick cut corticated log segment of Fagus sylvatica $35 \mathrm{~cm}$ thick, on wood, 10 Sep. 2004, W. Jaklitsch \& H. Voglmayr, W.J. 2698, culture C.P.K. 1958. Norfolk, Thetford, Emilys Wood, near Brandon, MTB 35-31/2, 52 $28^{\prime} 08^{\prime \prime} \mathrm{N}, 00^{\circ} 38^{\prime} 20^{\prime \prime}$ E, elev. $20 \mathrm{~m}$, on partly decorticated branch of Fagus sylvatica $4 \mathrm{~cm}$ thick, on wood, soc. Hypocrea neorufoides, cf. Letendraea helminthicola, attacked by white mould, 13 Sep. 2004, H. Voglmayr \& W. Jaklitsch, W.J. 2712 (WU 29265, culture C.P.K. 1959).

Notes: This common species is usually identified as the uncommon Hypocrea rufa by amateur mycologists, but it is unrelated to that species, which differs in a hairy stroma surface, inconspicuous ostiolar dots, smaller stromata, larger ascospores, globose verrucose conidia, slender trichodermalike conidiophores on well-defined pustules, etc. Hypocrea rufa is often found on wood of coniferous trees, while $H$. minutispora is rarely encountered on such hosts. Hypocrea minutispora does not have particularly small ascospores; the species epithet is taken from the anamorph T. minutisporum (see Lu et al. 2004), originally described by Bissett (1991b). The conidiation in Trichoderma minutisporum shows a gradual transition from effuse to pustulate, with pustules typically distinctly less developed on CMD than on SNA. Generally, phialides tend to be more lageniform on simple conidiophores, wider and more ampulliform with increasing complexity and density of conidiation structures. Branching of conidiophores is asymmetric in simple conidiophores and symmetric in tufts or pustules.
Hypocrea pachybasioides Yoshim. Doi, Bull. Natn. Sci. Mus. Tokyo 12: 685 (1972). Fig. 43

Anamorph: Trichoderma polysporum (Link : Fr.) Rifai, Mycol. Pap. 116: 18 (1969). Fig. 44

$=$ [Sporotrichum polysporum Link, Mag. Ges. Naturf. Freunde Berl. 7: 34 (1815): Fries, Syst. Mycol. 3: 424 (1832)]. (See Rifai [1969] for further synonyms).

Stromata when fresh $(0.5-) 1-6 \mathrm{~mm}$ diam, $0.5-1.5(-2)$ $\mathrm{mm}$ thick, solitary, scattered, gregarious or aggregated, typically in small numbers, sometimes in lines or large convolutes; pulvinate to semiglobose, broadly attached, sometimes on a sterile base; margin rounded or sharp; edge free. Outline circular, sometimes angular or with undulate margin. Surface smooth, perithecial contours rarely slightly projecting. Ostiolar dots typically large and diffuse when young, when mature well-defined, plane or convex, brownish, often irregularly disposed. Stromata first white, remaining nearly white or yellowish, turning either rosy, pale yellow, 3A2-3, 3AB4-6, 4A5, pale orange 5AB4-5(6), 6A3-4, to brown-orange or yellow- brown, 5-6CD5-6, rosy-brown or light brown, 7CD6-7(8), eventually dark reddish brown. Spore deposits white to yellowish,

Stromata when dry $(0.5-) 1-3(-5) \times(0.3-) 0.8-2.3(-3.8)$ $\mathrm{mm},(0.2-) 0.3-1.0(-1.6) \mathrm{mm}$ thick $(n=97)$; solitary, scattered, gregarious or aggregated in small numbers, less commonly formed by disintegration of a flat subeffuse compound stroma to $3 \mathrm{~cm}$ long; pulvinate to discoid, flatter than fresh, broadly attached, with white base mycelium and/or white margin when young. Margin attached or free, rounded, sometimes lobed. Outline circular, angular, oblong or irregular. Sides when visible, vertical or slightly constricted downwards, concolorous, smooth and glabrous, floccose when young. Surface finely floccose or downy in initial stages, later typically glabrous, smooth, tubercular or rugose. Ostiolar dots (24-)35-76(-134) $\mu \mathrm{m}(n=175)$, in small or large numbers, well-defined, plane or convex, circular to oblong in outline, brown, red or reddish brown, large and diffuse due to translucent perithecia when young. Stromata first white, turning either yellow or rosy or more rarely directly brownish. Yellow stromata 2-3A23 , 4A3, 4B4, turning pale or greyish orange, 5A3,

Fig. 43 Teleomorph of Hypocrea pachybasioides. a-f. Fresh stromata (a-d. immature). g-j. Dry stromata (g. downy stroma initial). k. Ostiole apex in section. I. Stroma surface in face view. $\mathbf{m}$. Rehydrated stroma (black dots are Cheirospora conidia). n. Stroma in $3 \% \mathrm{KOH}$ after rehydration. o. Perithecium in section. p. Cortical and subcortical tissue in section. q. Subperithecial tissue in section. $\mathbf{r}$. Stroma base in section. s-v. Asci with ascospores (u, v. in cotton blue/lactic acid). a. WU 29324. b, e. WU 29322. c, k-r. WU 29325. d. WU 29311. f. WU 29321. g. WU 29312. h. WU 29319. i. WU 29314. j. WU 29315. s. WU 29318. t-v. WU 29323. Scale bars $\mathbf{a}=1 \mathrm{~mm}$. b, c, f, $\mathbf{g}, \mathbf{m}=$ $0.4 \mathrm{~mm}$. d, $\mathbf{h}-\mathbf{j}, \mathbf{n}=0.3 \mathrm{~mm}$. $\mathbf{e}=0.7 \mathrm{~mm} . \mathbf{k}, \mathbf{l}, \mathbf{r}-\mathbf{v}=10 \mu \mathrm{m} . \mathbf{o}=25 \mu \mathrm{m}$. $\mathbf{p}, \mathbf{q}=15 \mu \mathrm{m}$ 

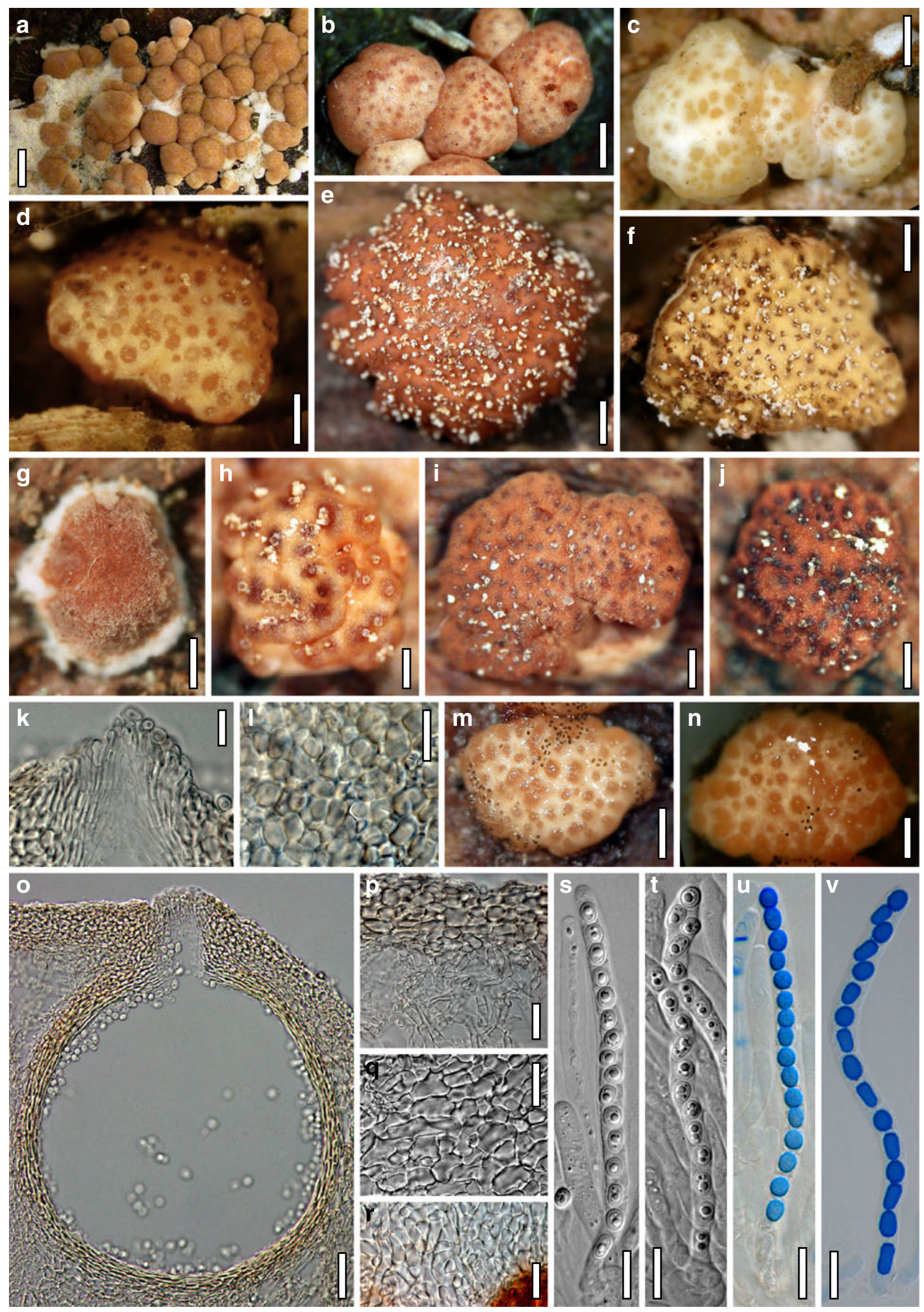

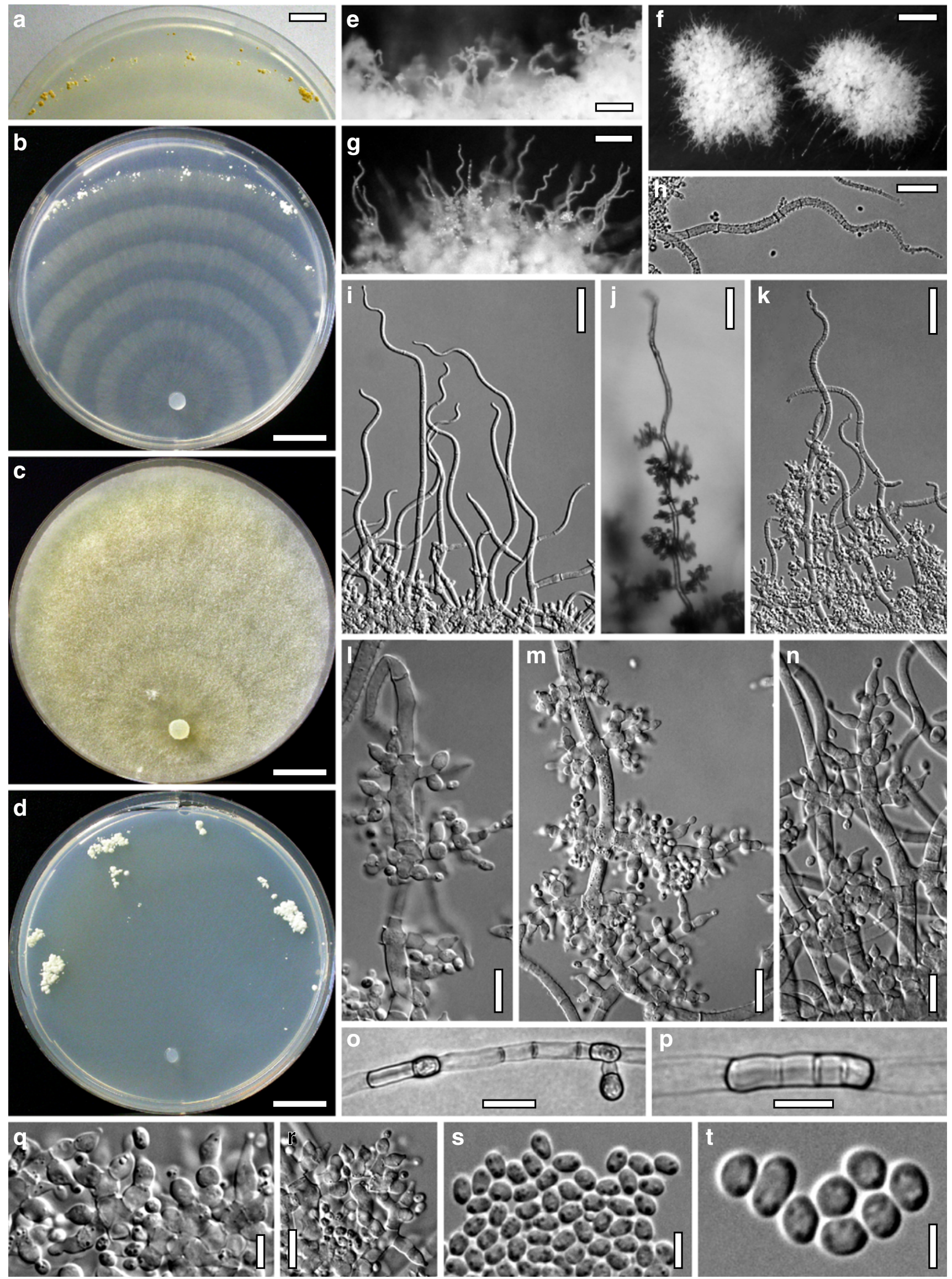
4Fig. 44 Cultures and anamorph of Hypocrea pachybasioides (= Trichoderma polysporum). a. Yellow conidiation pustules on CMD (28 days). b-d. Cultures after 14 days (b. on CMD; c. on PDA; d. on SNA). e. Periphery of a conidiation tuft on the natural substrate. $\mathbf{f}, \mathbf{g}$. Conidiation pustules on SNA (g. showing elongations on pustule margin; 13 days). h, i. Elongations (SNA, h. verrucose, 8 days at $25^{\circ} \mathrm{C}$ plus 25 days at $15^{\circ} \mathrm{C} ;$ i. 9 days). j. Conidiophore on growth plate (SNA, 7 days). $\mathbf{k}-\mathbf{n}$. Conidiophores (SNA, 9 days; $\mathbf{n}$. lacking elongation). o, p. Chlamydospores (SNA, $30^{\circ} \mathrm{C}, 11$ days). q, r. Phialides (SNA, 9 days). s, t. Conidia (SNA, 8 days at $25^{\circ} \mathrm{C}$ plus 25 days at $15^{\circ} \mathrm{C}$ ). a-r. All at $25^{\circ} \mathrm{C}$ except h, o, p. a-d, h, j, o, p, s, t. CBS 121277 . e. WU 29321. i, k-n, q, r. C.P.K. 2461. f, g. C.P.K. 989. Scale bars $\mathbf{a}=10 \mathrm{~mm}$. b-d= $15 \mathrm{~mm} . \mathbf{e}, \mathbf{g}=100 \mu \mathrm{m} . \mathbf{f}=0.3 \mathrm{~mm} . \mathbf{h}, \mathbf{k}=30 \mu \mathrm{m} . \mathbf{i}, \mathbf{j}=40 \mu \mathrm{m} . \mathbf{l}, \mathbf{n}, \mathbf{p}, \mathbf{r}=$ $10 \mu \mathrm{m} . \mathbf{m}, \mathbf{o}=15 \mu \mathrm{m} . \mathbf{q}, \mathbf{s}=5 \mu \mathrm{m} . \mathbf{t}=3 \mu \mathrm{m}$

6AB4-6, brown-orange, ochre, light brown or yellow-brown, 6-7CD5-8, 6E7-8; eventually dark brown, 7-8EF6-8. Rosy or greyish red stromata 7A4, 6-7B4-5, sometimes first with a white covering, turning brown-red to greyish brown, 8CD4-6, eventually dark (reddish-)brown, 8EF5-8, with nearly black ostiolar dots. Spore deposits white or pale yellow. Mature yellow stromata after rehydration thicker, more pulvinate, surface smooth, light yellow to nearly white between large, yellow-brown ostiolar dots (50-)90-170 $\mu \mathrm{m}$ diam; after addition of $3 \% \mathrm{KOH}$ colour change absent or inconspicuous, perithecial dots slightly more ochre to nearly orange.

Stroma anatomy (yellow mature stroma sectioned): Ostioles (47-)59-74(-90) $\mu \mathrm{m}$ long, plane or projecting to $30 \mu \mathrm{m},(22-) 26-34(-41) \mu \mathrm{m}$ wide at the apex $(n=30)$ inside, periphysate, apical marginal cells cylindrical, sometimes clavate, to $5 \mu \mathrm{m}$ wide. Perithecia (130-)160-205($235) \times(85-) 120-180(-220) \mu \mathrm{m}(n=30)$, globose or flaskshaped, crowded, 6-7 per $\mathrm{mm}$ stroma length; peridium $(11-) 14-18(-20) \mu \mathrm{m}(n=30)$ thick at the base, $(5-) 10-15(-$ 17) $\mu \mathrm{m}(n=30)$ thick at the sides, pale yellow, in $3 \% \mathrm{KOH}$ pale orange. Stroma surface smooth, without hairs. Cortical layer (17-)20-30(-37) $\mu \mathrm{m} \quad(n=30)$ thick, a dense $t$. angularis of isodiametric, thin-walled cells $(3-) 4-9(-12) \times$ $(2.5-) 3-6(-7) \mu \mathrm{m}(n=65)$ in face view and in vertical section, pale yellow. Subcortical tissue where present a loose $t$. intricata of thin-walled hyaline hyphae (2.0-)2.5$4.0(-5.5) \mu \mathrm{m}(n=35)$ wide. Subperithecial tissue a $t$. angularis-epidermoidea of thin-walled hyaline cells (5-) $6-18(-31) \times(3.5-) 5-9(-12) \mu \mathrm{m}(n=30)$, smaller towards the base and intermingled with hyaline hyphae $(2-) 3-5(-7)$ $\mu \mathrm{m} \quad(n=30)$ wide in attachment areas, otherwise base consisting of cortical tissue. Asci $(65-) 82-100(-115) \times$ (4-)5-6(-7.5) $\mu \mathrm{m}$, stipe to $20(-35) \mu \mathrm{m}$ long $(n=70)$; croziers present. Ascospores hyaline, verruculose; cells dimorphic; distal cell (3.0-)3.7-4.8(-5.7) $\times(2.5-) 3.5-4.0(-$ $4.5), 1 / \mathrm{w} 1.0-1.3(-1.6)(n=160)$, (sub)globose or ellipsoidal; proximal cell $(3.0-) 4.3-5.8(-7.0) \times(2.3-) 2.8-3.5(-4.0)$ $\mu \mathrm{m}, 1 / \mathrm{w}(1.2-) 1.3-1.9(-2.6)(n=160)$, oblong, ellipsoidal, wedge-shaped, or subglobose, to $10 \mu \mathrm{m}$ long in aberrant ascospores; contact area often flattened.
Anamorph on natural substrates in accordance with the anamorph in culture, typically appearing as discrete white tufts $0.5-5 \mathrm{~mm}$ long in close association with stromata, less commonly as effuse mats; with sterile, helical elongations projecting.

Cultures and anamorph: optimal growth at $25^{\circ} \mathrm{C}$ on all media; no growth at $35^{\circ} \mathrm{C}$.

On CMD after $72 \mathrm{~h} 19-21 \mathrm{~mm}$ at $15^{\circ} \mathrm{C}, 32-34 \mathrm{~mm}$ at $25^{\circ} \mathrm{C}, 9-21 \mathrm{~mm}$ at $30^{\circ} \mathrm{C}$; mycelium covering the plate after 6-7 days at $25^{\circ} \mathrm{C}$. Colony hyaline, thin, distinctly zonate, zones of similar width, alternating light and dark; primary hyphae conspicuously wide, tertiary/terminal hyphae thin and short. Aerial hyphae inconspicuous, more frequent along the margin. Autolytic activity and coilings lacking or inconspicuous. No diffusing pigment, no distinct odour noted. Rarely (CBS 119319) yellow crystals appearing in the agar. Chlamydospores noted after 2-3 weeks. Conidiation visible after 4-5 days, first effuse, scant, simple, only in distal areas and at the ends of lighter zones, as early stages of pustulate conidiation. After 7 days conidiation in the most distal zones in white pustules $0.5-1.7 \mathrm{~mm}$ diam, confluent to $5 \mathrm{~mm}$ (after 10 days), with sterile, smooth to rough helical elongations from the beginning. Pustules sometimes turning yellow 4A4-5 after 20-28 days, to saffron or dark orange 5A6-8 after 6 months at $15^{\circ} \mathrm{C}$ without light. At $15^{\circ} \mathrm{C}$ development slower, colony circular, zonation absent or inconspicuous, hyphae $>10 \mu \mathrm{m}$ wide, conidiation late, after 9-10 days, scant. Conidiation often absent after several transfers. At $30^{\circ} \mathrm{C}$ colony circular, zonate, darker zones narrower, autolytic activity increased, no conidiation noted.

On PDA after $72 \mathrm{~h} 15-17 \mathrm{~mm}$ at $15^{\circ} \mathrm{C}, 31-34 \mathrm{~mm}$ at $25^{\circ} \mathrm{C}$, 9-16 $\mathrm{mm}$ at $30^{\circ} \mathrm{C}$; mycelium covering the plate after 6 days at $25^{\circ} \mathrm{C}$. Colony denser than on $\mathrm{CMD}$, indistinctly zonate, hyphae becoming moniliform, mycelium conspicuously dense, surface hyphae forming radial strands. Aerial hyphae numerous, long, dense, forming strands or irregular aggregates in a white to yellowish, downy, farinose to granular mat. Autolytic activity variable, coilings lacking or inconspicuous. No diffusing pigment, no distinct odour noted. Conidiation noted after (6-)10-14 days, white, effuse and in fluffy tufts. At $15^{\circ} \mathrm{C}$ hyphae conspicuously wide; conidiation more abundant and earlier (after 6-8 days) than at $25^{\circ} \mathrm{C}$, on small shrubs and long aerial hyphae, chalky, dense, granular. At $30^{\circ} \mathrm{C}$ reverse yellow 3A4-5 after 7 days, surface thickly downy, white to yellowish; odour mushroomy; conidiation lacking or scant at the proximal margin.

On SNA after $72 \mathrm{~h} 17-19 \mathrm{~mm}$ at $15^{\circ} \mathrm{C}, 37-30 \mathrm{~mm}$ at $25^{\circ} \mathrm{C}$, $3-10 \mathrm{~mm}$ at $30^{\circ} \mathrm{C}$; mycelium covering the plate after 1 week at $25^{\circ} \mathrm{C}$. Colony hyaline, thin, loose, with little mycelium on the agar surface, not or indistinctly zonate, becoming zonate by conidiation in white tufts after 5-6 days; margin downy by long aerial hyphae; hyphae degenerating/dissolving soon. 
Autolytic activity and coilings lacking or inconspicuous. No diffusing pigment, no distinct odour noted. Chlamydospores noted after 6 days, (4-)5-7(-8)×(3-)4-6(-7) $\mu \mathrm{m}, 1 / \mathrm{w} 1.0-1.4$ $(-1.8)(n=21)$, globose to oval when terminal, when intercalary 5-32×(4-)5-7(-8) $\mu \mathrm{m}, 1 / \mathrm{w} \quad 1.0-6.5 \quad(n=32)$, globose, fusoid, oblong, cylindrical, $1-4$ celled, smooth. Conidiation noted after 4-5 days, in white tufts or pustules visible after 5-6 days in distal and lateral areas of the colony or irregularly disposed, dry. Tufts or pustules $1-2.5 \mathrm{~mm}$ diam, aggregating and confluent to convolutes $4-12 \times 3-$ $6 \mathrm{~mm}$, convex, thickly pulvinate, chalky, dense. Pustules of a reticulum with branching points often thickened to 8-9 $\mu \mathrm{m}$ and numerous main axes (= conidiophores) apically tapering off into helical elongations or less commonly fertile to the tip, in the latter case $4-5 \mu \mathrm{m}$ wide, tapered to $2.5 \mu \mathrm{m}$ apically, with phialides in whorls to 5 . Side branches on several levels at the base of the elongations mostly paired and in right angles, short, 10-40(-50) $\mu \mathrm{m}$ long, (3-)5$7.5 \mu \mathrm{m}$ wide, of $1-3$ cells $1-5 \mu \mathrm{m}$ long, often rebranching into short 1-2 celled branches, with phialides solitary or in dense whorls to $c a 6$. Side branches on lower levels longer and often unpaired, in right angles or slightly inclined upwards. Elongations formed from the beginning, conspicuous, 50-200(-330) $\mu \mathrm{m}$ long from last branching, gradually attenuated upwards to 1.5-3 $\mu \mathrm{m}$ terminally, unbranched, helical, often distinctly warted, sterile, rarely fertile with 1-2 phialides terminally. Phialides $(3.5-) 4.5-6.7(-10) \times(2.7-)$ $3.2-3.8(-4.2) \mu \mathrm{m}, 1 / \mathrm{w}(1.0-) 1.3-1.9(-2.7,(1.5-) 2.0-3.0(-$ 3.8) $\mu \mathrm{m}$ wide at the base $(n=60)$, ampulliform, tending to be lageniform on elongations and conidiophores lacking elongations, straight or inaequilateral, short or often long and thin. Conidia (2.5-)3.0-3.7(-5.0) $\times(2.0-) 2.3-2.6(-3.0) \mu \mathrm{m}$, 1/w (1.1-)1.2-1.5(-1.9) $(n=63)$, hyaline, ellipsoidal, less commonly oblong, smooth, scarcely with minute guttules, scar indistinct. At $15^{\circ} \mathrm{C}$ similar to $\mathrm{CMD}$, not zonate; conidiation in thick white pustules to $2 \mathrm{~mm}$ diam, growing or confluent to $7 \mathrm{~mm}$ after 2 weeks. At $30^{\circ} \mathrm{C}$ colony not zonate, chlamydospores more abundant.

Habitat: on wood and bark of deciduous and coniferous trees, overgrowing fungi.

Distribution: Australia, Europe, Japan, Korea, New Zealand, North America, according to Lu et al. (2004).

Holotype: Japan, Otsuno, Kochi City, on bark, 3 May 1966, Y. Doi TNS.D-77 (TNS-F-190528, not examined).

Specimens examined: Austria, Kärnten, Völkermarkt, Gallizien, shortly after Vellach heading to Sittersdorf, MTB

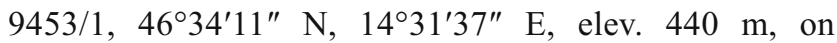
corticated branch of Corylus avellana $2 \mathrm{~cm}$ thick, on bark, soc. young stromata of Hypoxylon howeianum, green Trichoderma, holomorph, 11 Jul. 2007, W. Jaklitsch, W.J. 3122 (WU 29323, culture C.P.K. 3131). Niederösterreich, Lilienfeld, Sankt Aegyd am Neuwalde, Lahnsattel, virgin

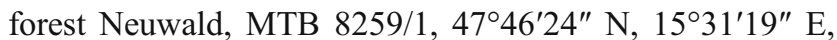

elev. $950 \mathrm{~m}$, on mostly decorticated branch of Fagus sylvatica $6 \mathrm{~cm}$ thick, on wood, on/soc. Corticiaceae, 16 Oct. 2003, W. Jaklitsch \& H. Voglmayr, W.J. 2466 (WU 29312, culture CBS $121277=$ C.P.K. 991); same area, elev. 1000 m, on hymenophore of Fomes fomentarius, 25 Sep. 2007, H. Voglmayr, W.J. 3173 (WU 29324, culture from conidia C.P.K. 3157). Scheibbs, Lunz am See, forest path from Schloß Seehof in the direction Mittersee, MTB 8156/ $3,47^{\circ} 50^{\prime} 39^{\prime \prime} \mathrm{N}, 15^{\circ} 04^{\prime} 24^{\prime \prime} \mathrm{E}$, elev. $630 \mathrm{~m}$, on a decorticated branch of Fagus sylvatica $6 \mathrm{~cm}$ thick, on wood, on/soc. stromata of Hypoxylon rubiginosum, holomorph, 16 Oct. 2003, W. Jaklitsch \& H. Voglmayr, W.J. 2461 (WU 29311, culture C.P.K. 989). St. Pölten Land, Michelbach, Mayer-

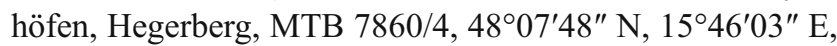
elev. $450 \mathrm{~m}$, on corticated branch of Tilia cordata $3 \mathrm{~cm}$ thick, on bark, soc. Nematogonum ferrugineum, Trichoderma cerinum, ?Exosporium sp., effete Hypoxylon sp., holomorph, 24 Nov. 2004, W. Klofac, W.J. 2791 (WU 29319, culture C.P.K. 1989). Wiener Neustadt Land, NW Pernitz, Muggendorf, brook margin shortly above the Myra falls, MTB 8061/4, elev. $560 \mathrm{~m}$, on branch of ?Alnus glutinosa, on Phellinus punctatus, moss and welldecomposed dark wood, holomorph, 9 Jun. 2007, H. Voglmayr, W.J. 3100 (WU 29322, culture C.P.K. 3123). Oberösterreich, Schärding, St. Willibald, between Loitzmayr and Obererleinsbach at the Erleinsbach, MTB 7648/3, $48^{\circ}$ $20^{\prime} 43^{\prime \prime} \mathrm{N} 13^{\circ} 43^{\prime} 03^{\prime \prime}$ E, elev. $420 \mathrm{~m}$, on branch of Fraxinus excelsior, on bark, soc. Hypoxylon cercidicola, Corticiaceae, ?Hymenochaete sp., green Trichoderma, holomorph, 2 Sep. 2006, H. Voglmayr, W.J. 2969 (WU 29321, culture C.P.K. 2461). Steiermark, Graz-Umgebung, Peggau, at the castle ruin Peggau, MTB 8758/3, elev. $460 \mathrm{~m}$, on branch of Corylus avellana, on inner bark, soc. Melogramma campylosporum, Tubeufia cerea, Cheirospora botryospora, white hyphomycete, green Trichoderma, holomorph, 26 Oct. 2007, H. Voglmayr, W.J. 3184 (WU 29325, culture C.P.K. 3170). Vorarlberg, Feldkirch, Rankweil, behind the hospital LKH Valduna, MTB 8723/2, 47 $15^{\prime} 40^{\prime \prime} \mathrm{N}, 09^{\circ} 39^{\prime} 00^{\prime \prime} \mathrm{E}$, elev. $510 \mathrm{~m}$, on a stump of Abies alba $33 \mathrm{~cm}$ thick, on wood (cut area), soc. moss, lichens, 31 Aug. 2004, H. Voglmayr \& W. Jaklitsch, W.J. 2643 (WU 29316, culture C. P.K. 1986). Czech Republic, Southern Bohemia, Záton, Boubínský prales (NSG), at the parking area Idina Pila, MTB 7048/2, 48 $57^{\prime} 35^{\prime \prime} \mathrm{N}, 13^{\circ} 49^{\prime} 39^{\prime \prime}$ E, elev. $850 \mathrm{~m}$, on a decorticated cut log of Alnus glutinosa $18 \mathrm{~cm}$ thick lying in water, on wet wood, attacked by a white mould, soc. effete Hypoxylon sp., Trichocladium sp., holomorph, 4 Oct. 2004, W. Jaklitsch, W.J. 2763 (WU 29318, culture C.P.K. 1988). Germany, Bavaria, Starnberg, Tutzing, Erling, Goaßlweide, Hartschimmelhof, Feld 2, MTB 8033/3, 47 $56^{\prime} 33^{\prime \prime} \mathrm{N}, 11^{\circ} 11^{\prime} 00^{\prime \prime} \mathrm{E}$, elev. $730 \mathrm{~m}$, on decorticated branch of Quercus robur 3-4 cm thick, on inner bark, 7 Aug. 2004, W. Jaklitsch, H. Voglmayr, P. Karasch \& E. Garnweidner, 
W.J. 2579 (WU 29313, culture C.P.K. 1983); same region,

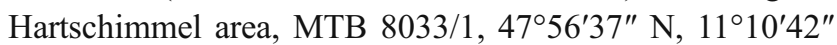
E, elev. $700 \mathrm{~m}$, on decorticated branch of Fagus sylvatica, on wood, soc. Trichoderma harzianum, a resupinate polypore, Corticiaceae, holomorph, 3 Sep. 2005, W. Jaklitsch, W.J. 2836 (WU 29320, culture from conidia CBS 119319); same area, at the crossing to Hartschimmelhof (halfway between Erling and Fischen), MTB 8033/3, 47 $56^{\prime}$ $46^{\prime \prime} \mathrm{N}, 11^{\circ} 10^{\prime} 15^{\prime \prime}$ E, elev. $650 \mathrm{~m}$, on decorticated branch of Fagus sylvatica $4 \mathrm{~cm}$ thick, on wood, soc. hyphomycetes, effete pyrenomycetes, Phlebiella vaga, 7 Aug. 2004, H. Voglmayr, W. Jaklitsch, P. Karasch \& E. Garnweidner, W.J. 2583 (WU 29314, culture C.P.K. 1984); same region, Leutstetten, Würmtal, parking area at a bridge over the

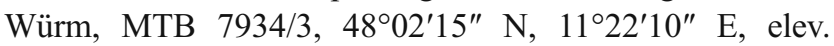
$600 \mathrm{~m}$, on two mostly decorticated branches of Fagus sylvatica 4-8 cm thick, on dark wood and bark, on/soc. Phellinus ferruginosus, soc. Annulohypoxylon cohaerens, green Trichoderma, 7 Aug. 2004, W. Jaklitsch \& H. Voglmayr, W.J. 2587 (WU 29315, culture C.P.K. 1985). United Kingdom, Norfolk, Lynford, Lynford Lakes and Arboretum, close to Lynford Hall, MTB 34-30/3, 52 $30^{\prime} 43^{\prime \prime}$ $\mathrm{N}, 00^{\circ} 40^{\prime} 41^{\prime \prime}$ E, elev. $30 \mathrm{~m}$, on decorticated branch of Acer pseudoplatanus $4 \mathrm{~cm}$ thick, on a brown crust on wood, mostly overgrown by white mould, 13 Sep. 2004, W. Jaklitsch \& H. Voglmayr, W.J. 2710 (WU 29317, culture C. P.K. 1987).

Notes: Hypocrea pachybasioides is difficult to recognize in the field. Its stromata are often indistinguishable from those of H. minutispora, although they are usually paler and less rosy than in the latter species and have large watery spots when young. The stroma colour is remarkably variable, making also a distinction from other species of the pachybasium core group difficult or even impossible. Trichoderma polysporum, the white pustulate anamorph with helical elongations, typical for section Pachybasium sensu Bissett (1991a, b), provides a good basis for the distinction from other species except for the rare $H$. parapilulifera, which produces a similar anamorph. See $\mathrm{Lu}$ et al. 2004 for more information on the taxa discussed here. $T$. polysporum is a low-temperature representative of the genus (Domsch et al. 2007) that has been used for biological control of pathogenic fungi in low-temperature situations.

Hypocrea pachypallida Jaklitsch, sp. nov. Fig. 45

MycoBank MB 516694

Anamorph: Trichoderma pachypallidum Jaklitsch, sp. nov. Fig. 46

MycoBank MB 516695

Stromata 1-8 $\mathrm{mm}$ diam, pulvinata vel subeffusa, pallide lutea. Asci cylindrici, $(65-) 70-90(-110) \times(3.5-) 4.0-4.7(-$ 5.0) $\mu \mathrm{m}$. Ascosporae hyalinae, verruculosae, ad septum disarticulatae, pars distalis (sub)globosa vel cuneata, (3.0-) $3.5-4.0(-4.7) \times(2.7-) 3.0-3.5(-4.0) \mu \mathrm{m}$, pars proxima oblonga vel subglobosa, $(3.3-) 3.8-5.0(-6.3) \times(2.2-) 2.5-$ $3.0(-3.3) \mu \mathrm{m}$. Anamorphosis Trichoderma pachypallidum. Conidiophora in agaris CMD, PDA et SNA effuse disposita, simplicia, similia Acremonii vel Verticillii. Phialides divergentes, lageniformes, (8-)10-17(-26) $\times\left(1.8^{-}\right)$ 2.3-3.0(-4.0) $\mu \mathrm{m}$. Conidia hyalina, oblonga vel ellipsoidea, glabra, (3.0-)3.5-5.0(-7.0)×(2.0-)2.2-2.7(-3.0) $\mu \mathrm{m}$.

Etymology: pachy indicates the pertinence of the species to the pachybasium core group, pallida stands for the pallid stromata.

Stromata when fresh $1-8 \mathrm{~mm}$ diam, $0.5-1.5 \mathrm{~mm}$ thick, pulvinate, or flat, sometimes discoid, elongate or irregular effluent bands; broadly attached, often with fertile part elevated on a short stipe-like, white base. Outline circular to irregular. Margin or edges free, sharp or rounded, often white when young. Surface smooth, rugose when old. Ostiolar dots minute, olive or brown. Stroma colour first white, turning yellow, 4A3-4, brown-orange, 5CD5, greyish- to golden-yellow, 3B5-6, 4BC5-7, eventually (reddish) brown, 7E7-8, 6D7-8; mostly distinctly yellow when wet.

Stromata when dry $(0.6-) 1.3-3.8(-8.0) \times(0.4-) 1.1-2.7(-$ 4.7) $\mathrm{mm},(0.3-) 0.4-0.8(-1.1) \mathrm{mm}$ thick $(n=75)$; solitary, gregarious or aggregated in small numbers (to 3) and pulvinate, or formed in large, subeffuse, flat and effluent, longish masses, becoming separated into individual stromata by cracks. Fertile part often flat, elevated on a short, stout, white stipe-like base, with margins laterally projecting beyond the base. Outline circular, angular, oblong or irregular. Margin margin sharply delimited, rounded, free, often white when young. Sides vertical or slightly retracted downwards, white or yellowish, initially with radiating base mycelium. Surface initially typically with a white, later disintegrating, covering layer, smooth, finely granular to rugose, often slightly downy. Ostiolar dots minute, (20-) $32-58(-80) \mu \mathrm{m}(n=75)$ diam, numerous, first often concealed by the covering white layer, becoming distinct, plane, less commonly convex, with circular or oblong outline, brown. Stromata first of small white mycelial tufts, becoming compacted, turning argillaceous, pale to greyish yellow-orange, 4A3-4, 5A2-4, 4-6B4-5, 6A4, $6 \mathrm{C} 4$, mostly yellow with brown dots, i.e. yellow-brown, 5CD4-7, eventually pale brown to reddish brown, 6E68, 7CD5-6, 8E5-8, when old. Spore deposits white or yellow. Rehydrated mature stromata pulvinate, with plane, finely floccose, yellow surface and numerous distinct, plane, (orange-)brown ostiolar dots. Ostiolar openings hyaline in water. After addition of $3 \% \mathrm{KOH}$ stroma surface turning bright red to dark red; ostiolar openings hyaline; drying reddish brown. Immature stroma after rehydration semiglobose, smooth, white, 

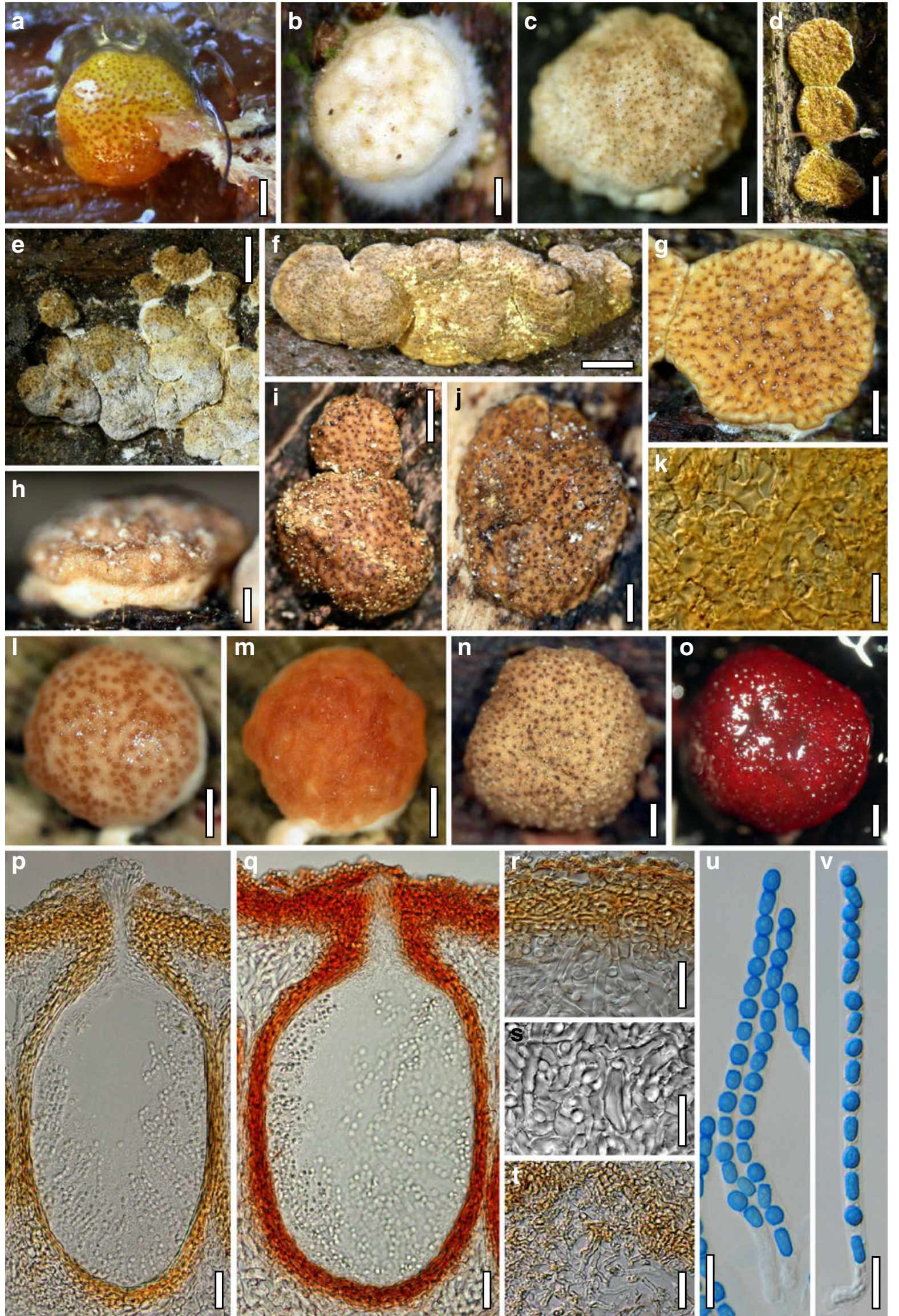
4 Fig. 45 Teleomorph of Hypocrea pachypallida. a. Wet fresh stroma with unusual bright colour. b-j. Dry stromata (b, c. immature. e, f. effluent). k. Stroma surface with undifferentiated hyphae in face view. l, n. Rehydrated stromata (l. immature; n. mature). m, o. Stromata in $3 \%$ $\mathrm{KOH}$ after rehydration (m. immature; o. mature). p, q. Perithecium in section (p. in lactic acid; q. in 3\% $\mathrm{KOH}$ ). r. Cortical and subcortical tissue in section. s. Subperithecial tissue in section. t. Stroma base in section. u, v. Asci with ascospores in cotton blue/lactic acid. a, j. WU 29328. b, c, h, i, l-t. WU 29326. d, g. WU 29329. e, v. WU 29330. f, k, u. WU 29327. Scale bars: a, c, $\mathbf{g}, \mathbf{j}, \mathbf{l}-\mathbf{0}=0.5 \mathrm{~mm}$. $\mathbf{b}, \mathbf{h}=0.2 \mathrm{~mm}$. d, $\mathbf{e}=$ $1.3 \mathrm{~mm} . \mathbf{f}, \mathbf{i}=1 \mathrm{~mm} . \mathbf{k}, \mathbf{u}, \mathbf{v}=10 \mu \mathrm{m} . \mathbf{p}-\mathbf{s}=20 \mu \mathrm{m} . \mathbf{t}=30 \mu \mathrm{m}$

with numerous irregular, plane or convex, light ochre dots; after addition of $3 \% \mathrm{KOH}$ ostiolar dots first slightly orange, later surface turning homogeneously pale orange; eventually stroma macroscopically dark brown to nearly black.

Stroma anatomy: Ostioles (58-)66-85(-92) $\mu \mathrm{m}$ long, plane or projecting to $20(-30) \mu \mathrm{m},(20-) 25-40(-57) \mu \mathrm{m}$ wide at the apex $(n=30)$, periphysate, sometimes with clavate marginal cells to $6 \mu \mathrm{m}$ wide at the apex. Perithecia (148-)180-220($230) \times(90-) 110-170(-205) \mu \mathrm{m}(n=30), 7-8$ per mm stroma length, flask-shaped or globose, often crowded and laterally compressed; peridium (11-)14-17(-18) $\mu \mathrm{m}(n=30)$ thick at the base, $(3-) 8-15(-18) \mu \mathrm{m}(n=30)$ thick at the sides, golden yellow; bright orange-red in $3 \% \mathrm{KOH}$. Cortical layer (18-) 20-35(-42) $\mu \mathrm{m}(n=30)$ thick; surface of a thin adhesive layer of undifferentiated, often collapsed, thick-walled, subhyaline or yellow hyphae $(2-) 3-5(-7) \mu \mathrm{m}(n=30)$ wide, usually with numerous ascospores, followed downwards by a dense, small-celled $t$. angularis-epidermoidea of indistinct, isodiametric or oblong, thin- to thick-walled, refractive cells (3-)5$10(-13) \times(3-) 4-7(-10) \mu \mathrm{m}(n=30)$ in face view, $(3-) 4-9(-$ $13) \times(2-) 3-5(-6) \mu \mathrm{m}(n=30)$ in vertical section; cells distinctly (golden-)yellow, orange-red in $3 \% \mathrm{KOH}$; downwards at stroma sides paler, of hyphae partly projecting as cylindrical, thick-walled, smooth 'hairs' (9-)12-26(-35) $\times$ $(2.5-) 3.0-5.0(-6.5) \mu \mathrm{m}(n=30), 1-5$ celled, with rounded end cells. Subcortical tissue a well-defined $t$. intricata of thinwalled, hyaline hyphae (2-)3-5(-7) $\mu \mathrm{m}(n=30)$ wide. Subperithecial tissue a dense $t$. epidermoidea of mostly oblong, thin-walled, hyaline cells $4-16(-26) \times(2.5-) 4.5-8.5(-$ 12) $\mu \mathrm{m}(n=33)$, containing some hyphae. Stroma base of subperithecial cells mixed with thick-walled hyaline to brownish hyphae $(2-) 3-6(-8) \mu \mathrm{m}(n=33)$ wide. Asci (65-) $70-90(-110) \times(3.5-) 4.0-4.7(-5.0) \mu \mathrm{m}$, stipe $(1-) 6-18(-31)$ $\mu \mathrm{m}$ long $(n=80)$; in fascicles on ascogenous hyphae. Ascospores hyaline, often yellow or orange after ejection, verruculose, cells dimorphic; distal cell $(3.0-) 3.5-4.0(-4.7) \times$ (2.7-)3.0-3.5(-4.0) $\mu \mathrm{m}, 1 / \mathrm{w} 1.0-1.2(-1.6) \quad(n=120)$, (sub-) globose or wedge-shaped; proximal cell (3.3-)3.8-5.0($6.3) \times(2.2-) 2.5-3.0(-3.3) \mu \mathrm{m}, 1 / \mathrm{w}(1.1-) 1.4-1.9(-2.5) \quad(n=$ $120)$, oblong or subglobose; septal areas often flattened.

Cultures and anamorph: optimal growth at $25^{\circ} \mathrm{C}$ on all media; no growth at $35^{\circ} \mathrm{C}$.
On CMD after $72 \mathrm{~h} 10-16 \mathrm{~mm}$ at $15^{\circ} \mathrm{C}, 30-34 \mathrm{~mm}$ at $25^{\circ} \mathrm{C}, 7-16 \mathrm{~mm}$ at $30^{\circ} \mathrm{C}$; mycelium covering the plate after 6-7 days at $25^{\circ} \mathrm{C}$. Colony hyaline, thin, circular, with welldefined margin, little mycelium on the surface, conspicuously (to ca $15 \mu \mathrm{m}$ ) wide, distinctly radially oriented primary hyphae; loose, not zonate; 2-4 finely downy or floccose concentric zones produced by effuse conidiation. Margins downy, floccose to powdery by aerial hyphae to $3 \mathrm{~mm}$ long and high; aerial hyphae scant in other areas, becoming fertile. Floccules caused by thick and short strands. Autolytic activity lacking or inconspicuous, coilings nearly lacking. No diffusing pigment, no distinct odour produced. Chlamydospores lacking or rare. After extended storage (e.g. 4 months) at $15^{\circ} \mathrm{C}$ agar turning pale yellowish and hard, rubber-like. Conidiation noted after 2 days at $25^{\circ} \mathrm{C}$, effuse, colourless, macroscopically invisible apart from indistinct down or floccules; abundant; spreading from the centre across the entire colony, sessile, short, from solitary phialides or whorls of 2-6 phialides on short stipes originating on surface hyphae, acremonium- like, to verticillium-like conidiophores, concentrated in concentric zones and arising typically unpaired, in right angles or inclined upwards on long aerial hyphae along the colony margin. Conidiophores 25 $150(-200) \mu \mathrm{m}$ long, 4-6(-8) $\mu \mathrm{m}$ wide at the base, attenuated upwards to 2-3 $\mu \mathrm{m}$ terminally, simple, unbranched with verticils of phialides or with few, loosely spaced, short, 1celled branches slightly inclined upwards, each with a whorl of phialides. Phialides arising solitary, paired or in whorls of $3-4(-6)$ on often thickened cells $2-5 \mu \mathrm{m}$ wide. Conidia produced in colourless wet heads mostly $<40 \mu \mathrm{m}$, sometimes to $70(-100) \mu \mathrm{m}$ diam, eventually conidia lying on the agar surface. Phialides $(8-) 10-17(-26) \times(1.8-) 2.3-3.0(-4.0) \mu \mathrm{m}$, $1 / \mathrm{w}(2.8-) 3.5-6.5(-10.3),(1.2-) 1.7-2.3(-3.0) \mu \mathrm{m}$ wide at the base $(n=94)$, lageniform, long, slender, often thickened below the middle, less commonly in the middle, typically constricted below a long neck, straight or slightly curved upwards. Conidia (3.0-)3.5-5.0(-7.0) $\times(2.0-) 2.2-2.7(-3.0)$ $\mu \mathrm{m}, 1 / \mathrm{w}(1.2-) 1.5-2.1(-2.5)(n=90)$, hyaline, oblong, less commonly ellipsoidal, often slightly constricted in the middle, smooth, finely multiguttulate or with 1-2 larger guttules; scar indistinct. Conidiation also occurring within the agar, particularly in proximal and central areas, conidia formed in heads $<15 \mu \mathrm{m}$ with maximal 15 conidia per head. At $15^{\circ} \mathrm{C}$ minute sinuous secondary hyphae dominant, particularly at the colony margin. Conidiation colourless, effuse, spreading across the entire colony. At $30^{\circ} \mathrm{C}$ colony denser in the centre; hyphae thin; conidiation effuse, less abundant than at lower temperatures.

On PDA after $72 \mathrm{~h} 6-10 \mathrm{~mm}$ at $15^{\circ} \mathrm{C}, 20-24 \mathrm{~mm}$ at $25^{\circ}$ C, $7-15 \mathrm{~mm}$ at $30^{\circ} \mathrm{C}$; mycelium covering the plate after 910 days at $25^{\circ} \mathrm{C}$. Colony dense, of few flat, broad, concentric zones with irregular outline and a whitish to pale yellowish, downy, hairy, finely floccose or farinose 

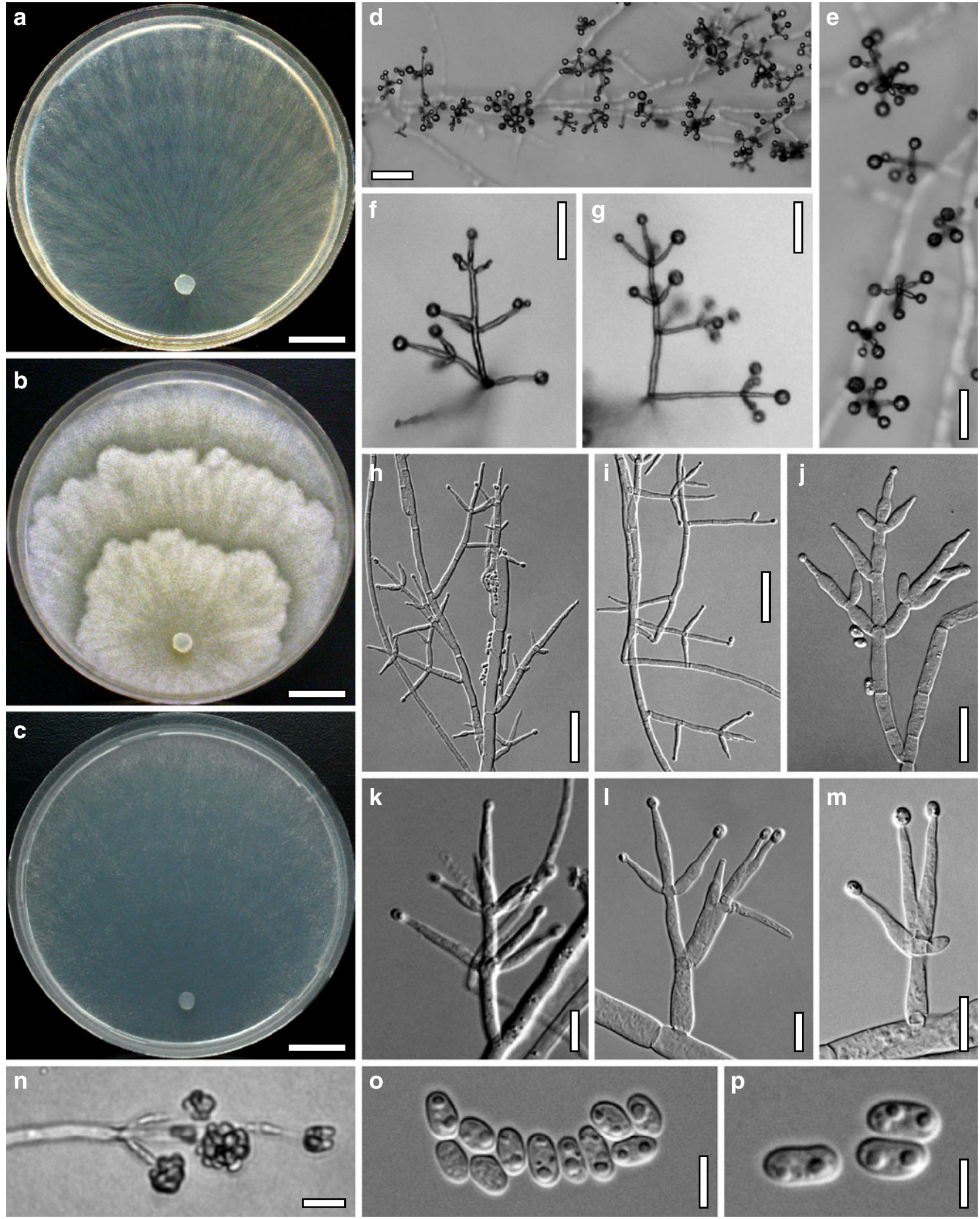
4Fig. 46 Cultures and anamorph of Hypocrea pachypallida. a-c. Cultures after 14 days at $25^{\circ} \mathrm{C}$ (a. on CMD; b. on PDA; c. on SNA). d, e. Short conidiophores on surface hyphae in face view on growth plate (7 days). f, g. Conidiophores on growth plates (f. SNA, $15^{\circ} \mathrm{C}$, 8 days; $\mathbf{g} .4$ days). $\mathbf{h}-\mathbf{m}$. Conidiophores and phialides (4-14 days). $\mathbf{n}$. Conidiation submerged in agar ( 9 days). o, p. Conidia (14 days). d-p. All from CMD at $25^{\circ} \mathrm{C}$ except f. a, b, f, j, n-p. CBS 120533. c. C.P.K. 1975. k. C.P.K. 2458. $\mathbf{g - i}$, l, m. C.P.K. 967. Scale bars $\mathbf{a}-\mathbf{c}=15 \mathrm{~mm}$. $\mathbf{d}=50 \mu \mathrm{m} . \mathbf{e}-\mathbf{i}=30 \mu \mathrm{m} . \mathbf{j}=15 \mu \mathrm{m} . \mathbf{k}-\mathbf{n}=10 \mu \mathrm{m} . \mathbf{o}=5 \mu \mathrm{m} . \mathbf{p}=3 \mu \mathrm{m}$

surface. Aerial hyphae numerous, loose, only few mm high, without a distinct orientation, becoming fertile. Autolytic activity inconspicuous or moderate, no coilings seen. Reverse yellowish, cream, 3A3, 4AB3-4. Odour indistinct or slightly sour. Conidiation noted after 2 days at $25^{\circ} \mathrm{C}$, effuse, spreading from the centre across the entire colony, abundant, dense in downy areas, short and ascending on aerial hyphae. Conidiophores loose, verticillium-like; phialides in whorls of 3-5; conidia hyaline, formed in wet heads to $50(-70) \mu \mathrm{m}$ diam. At $15^{\circ} \mathrm{C}$ colony dense, hyphae thin, yellowish $3 \mathrm{~A} 3$, surface downy to farinose, not zonate or 2 irregular zones; conidiation effuse. At $30^{\circ} \mathrm{C}$ colony compact, circular, dense, finely zonate, glabrous or centre hairy to fluffy. Autolytic excretions lacking at the colony margin, frequent inside the colony, yellow-brown. Reverse yellowish, 4AB3-4. Odour yeast-like to sour. Conidiation effuse, scant or in dense lawns.

On SNA after $72 \mathrm{~h} 9-12 \mathrm{~mm}$ at $15^{\circ} \mathrm{C}, 27-32 \mathrm{~mm}$ at $25^{\circ} \mathrm{C}$, $3-11 \mathrm{~mm}$ at $30^{\circ} \mathrm{C}$; mycelium covering the plate after 6-7 days at $25^{\circ} \mathrm{C}$. Colony similar to $\mathrm{CMD}$, but denser and surface hyphae degenerating, appearing empty. Mycelium not zonate, colony becoming zonate by conidiation. Autolytic activity moderate to conspicuous, coilings nearly lacking. No diffusing pigment, no distinct odour produced. Chlamydospores noted after 2-3 weeks, scant, mainly in the centre; appearing after 10 days and more frequent at $30^{\circ} \mathrm{C},(4-) 5-8(-12) \times$ (4.0-)4.5-6.0(-7.0) $\mu \mathrm{m}, 1 / \mathrm{w} 1.0-1.5(-2.2)(n=30)$, globose, pyriform or oval, mostly terminal, more ellipsoidal, rectangular or fusoid when intercalary. Conidiation noted after 2 days at $25^{\circ} \mathrm{C}$, effuse, similar to $\mathrm{CMD}$, but less abundant, concentrated in finely floccose, concentric zones and on the downy margin; conidial heads to $40(-70) \mu \mathrm{m}$ diam. At $15^{\circ} \mathrm{C}$ similar to $\mathrm{CMD}$, conidiation also on long aerial hyphae, reminiscent of $\mathrm{T}$. sect. Hypocreanum; solitary phialides common. At $30^{\circ} \mathrm{C}$ growth variable, often poor, faster within the agar; colony irregular. Conidiation effuse, more abundant than on CMD, conidial heads to $40 \mu \mathrm{m}$ diam.

Habitat: on medium- to well-decayed wood and bark of deciduous trees.

Distribution: Europe (Austria, Czech Republic, Germany, Sweden), uncommon.

Holotype: Czech Republic, Southern Bohemia, Záton, Boubínský prales (NSG), MTB 7048/2, 48 58'34" N, $13^{\circ}$ 49'03" E, elev. $1010 \mathrm{~m}$, on branch of Fagus sylvatica $4 \mathrm{~cm}$ thick, on dry bark, partly on wood in bark fissures, also on ?Diatrypella sp., soc. effete pyrenomycetes, a hyphomycete, rhizomorphs, 23 Sep. 2003, W. Jaklitsch, W.J. 2412 (WU 29327, ex-type culture CBS 122126=C.P.K. 968). Holotype of Trichoderma pachypallidum isolated from WU 29327 and deposited as a dry culture with the holotype of H. pachypallida as WU 29327a.

Other material examined: Austria, Burgenland, Oberpullendorf, Raiding, Ragerwald, MTB 8465/1, 47³3'49" N, $16^{\circ} 34^{\prime} 08^{\prime \prime}$ E, elev. $260 \mathrm{~m}$, on decorticated branch of Carpinus betulus $4 \mathrm{~cm}$ thick, on well-decayed wood, soc. Hypoxylon fuscum, $H$. howeianum, dematiaceous hyphomycete, effete pyrenomycete, rhizomorphs, resupinate polypore, green Trichoderma, 3 Sep. 2006, W. Jaklitsch \& O. Sükösd, W.J. 2965 (WU 29330, culture C.P.K. 2458). Czech Republic, Southern Bohemia, Záton, Boubínský prales (NSG), MTB 7048/2, 48 $58^{\prime} 34^{\prime \prime} \mathrm{N}, 13^{\circ} 49^{\prime} 03^{\prime \prime} \mathrm{E}$, elev. $1010 \mathrm{~m}$, on partly decorticated branches of Fagus sylvatica $2-5 \mathrm{~cm}$ thick, on well-decayed, crumbly wood, partly attacked by a white hyphomycete, soc. effete Eutypa sp., ?Lasiosphaeria sp., rhizomorphs, Quaternaria quaternata in bark, 23 Sep. 2003, W. Jaklitsch; two specimens from different branches, W.J. 2410, 2411 (united as WU 29326, cultures C.P.K. 967, CBS 120533=C.P.K. 966). Germany, Baden-Württemberg, Stuttgart, Landkreis Schwäbisch Hall, Sulzbach-Laufen, Krempelbachtal near Wengen (between Gaildorf and Abtsgmünd in a side valley of Kochertal, N from Ulm, NE from Stuttgart), MTB 7025/3, 48 $55^{\prime} 50^{\prime \prime} \mathrm{N}$, $09^{\circ} 52^{\prime} 20^{\prime \prime}$ E, elev. $370 \mathrm{~m}$, on a branch of Fagus sylvatica, on wood, soc. effete pyrenomycete, rhizomorphs, 21 Oct. 2004, L. Krieglsteiner, K. Siepe, Hena, SI 28/2004, W.J. 2790 (WU 29329, culture C.P.K. 1975). Sweden, Uppsala Län, Vänge, Fiby urskog, MTB 3970/1, 5952'57" N, $17^{\circ} 21^{\prime} 04^{\prime \prime}$ E, elev. $50 \mathrm{~m}$, on decorticated branches Corylus avellana 3-4 cm thick, on wood, soc. Bertia moriformis, Corticiaceae, Orbilia delicatula, Hymenochaete tabacina, green Trichoderma; 6 Oct. 2003, W. Jaklitsch, W.J. 2443 (WU 29328, culture C.P.K. 982).

Notes: Hypocrea pachypallida is a species of the pachybasium core group forming pale pulvinate stromata, which may be similar to those of several other species including $H$. bavarica, H. moravica, H. pachybasioides and $H$. parapilulifera. These species form either green or white pustulate Trichoderma anamorphs, while H. bavarica and $H$. pachypallida produce their hyaline conidia in verticillium-like effuse conidiation. Hypocrea bavarica differs from $H$. pachypallida in a different ecology, i.e. a distinct affinity to Betula, typically appearing on bark early after the death of branches, a conspicuous and fast colour change upon drying, a pseudoparenchymatous subcortical tissue, slightly smaller ascospores, predominantly subglobose to oval conidia, an unpleasant odour on PDA, and a substantially slower growth. $H$. moravica differs from $H$. 
pachypallida also in considerably larger ostiolar dots, $H$. argillacea differs in larger ascospores. The Swedish specimen of $H$. pachypallida is somewhat untypical due to more intense yellow colours and larger ostiolar dots. ITS and $r p b 2$ sequences of the six isolates are identical, while there is considerable variation in tefl sequences, which may eventually lead to a recognition of two species. However, differences may possibly be caused by technical issues rather than a true genetic difference.

Hypocrea parapilulifera B.S. Lu, Druzhin. \& Samuels, Mycologia 96: 331 (2004). Fig. 47

Anamorph: Trichoderma sp. Fig. 48

Stromata when fresh $2-4 \mathrm{~mm}$ diam, $0.5-1.5 \mathrm{~mm}$ thick, solitary or gregarious, pulvinate; surface smooth, ostiolar dots large, irregularly disposed; colour first white, then pale to bright yellow $3 \mathrm{~A} 2-6$, turning reddish yellow, orangebrown, brown, 4A5-6 to 6CD6-7.

Stromata when dry $(0.5-) 1.0-2.3(-3.0) \times(0.5-) 0.8-1.8$ $(-2.2) \mathrm{mm},(0.3-) 0.4-1.0(-1.4) \mathrm{mm}$ thick $(n=30)$; solitary, gregarious or aggregated in small numbers, pulvinate or semiglobose, broadly attached, margin rounded, angular or undulate, often free, with a white mycelial base margin when young or sometimes fertile yellow part laterally projecting over a whitish, stipe-like base or stromata arising from and lifted above a thick whitish mat containing the anamorph. Outline circular, oblong or irregular. Surface smooth to finely tubercular or wrinkled, often slightly downy or floccose. Ostiolar dots (39-)50-100(-140) $\mu \mathrm{m}(n=33)$ diam, plane, circular, brown with lighter centres, first diffuse, becoming distinct. Stroma colour from yellow, 4AB4-6, over yellow-brown, 5CD5-8, to brown-orange or brown, 67CD7-8, 7E6-8. Spore deposits white or yellowish. Rehydrated stromata larger by $30-40 \%$, reddish brown to the unaided eye, yellow to orange in the stereo-microscope, with papillate, orange-brown dots; after addition of $3 \% \mathrm{KOH}$ instantly orange-red, macroscopically dark red.

Stroma anatomy: Ostioles (67-)74-100(-128) $\mu \mathrm{m}$ long, plane or projecting to $20 \mu \mathrm{m},(15-) 20-35(-50) \mu \mathrm{m}$ wide at the apex inside $(n=30)$, cylindrical, with or without clavate marginal cells $3-5 \mu \mathrm{m}$ wide at the apex. Perithecia (180-) $225-300(-325) \times(100-) 130-230(-290) \mu \mathrm{m}(n=30)$, globose or flask-shaped; peridium (15-)18-27(-33) $\mu \mathrm{m}(n=$ $30)$ thick at the base, $(6-) 12-22(-24) \mu \mathrm{m}(n=30)$ thick at the sides, pale yellowish, in $\mathrm{KOH}$ pale orange. Cortical layer (20-)25-37(-46) $\mu \mathrm{m}(n=30)$ thick, a dense $t$. angularis of distinct, thin- to thick-walled cells (3-)5-10 $(-12) \times(2.5-) 4-7(-11) \mu \mathrm{m}(n=63)$ in face view and in vertical section, yellow, gradually paler downwards, in $\mathrm{KOH}$ orange, on stroma sides paler to hyaline and intermingled with hyaline hyphae $(2-) 3-6(-7) \mu \mathrm{m}(n=30)$ wide in lower parts. Hair-like projections on mature stromata $(4-) 5-12(-17) \times(2-) 3-5(-6.5) \mu \mathrm{m}(n=30), 1-3$ celled, hyaline or yellowish, mostly cylindrical, often with thickened base, smooth or verruculose. Subcortical tissue a loose $t$. intricata of hyaline thin-walled hyphae (2-)3-5(-6) $\mu \mathrm{m}(n=30)$ wide. Subperithecial tissue a $t$. angularisepidermoidea-prismatica of hyaline, mostly oblong, thinwalled cells $(7-) 10-30(-58) \times(4.5-) 6-11(-14) \mu \mathrm{m}(n=30)$. Asci $(98-) 110-130(-140) \times(4.8-) 5.3-6.5(-7.0) \mu \mathrm{m}$, stipe $(13-) 23-40(-50) \mu \mathrm{m}(n=30)$. Ascospores hyaline, sometimes yellow, even inside asci, verruculose; cells dimorphic, distal cell $(3.5-) 4.0-5.3(-5.7) \times(3.2-) 3.5-4.0(-4.5) \mu \mathrm{m}, 1 /$ w (0.9-)1.1-1.4(-1.7) $(n=32)$, (sub)globose or wedgeshaped, proximal cell $(3.8-) 5.0-6.5(-7.5) \times(2.8-) 3.2-3.8(-$ $4.0) \mu \mathrm{m}, 1 / \mathrm{w}(1.1-) 1.4-1.9(-2.2)(n=32)$, oblong or wedgeshaped; contact area often flattened.

Anamorph on the natural substrate forming white cottony tufts, e.g. $1.5 \times 1 \mathrm{~mm}$, associated with stromata, with short, straight to helical elongations. Right-angled branching common. Conidiophores often fertile to the tip, 4-6(-8.5) $\mu \mathrm{m}$ wide, $3 \mu \mathrm{m}$ terminally. Phialides (4-)5-7(-9)×(2.5-)3.0-3.8 $(-4.0) \mu \mathrm{m}, 1 / \mathrm{w}(1.2-) 1.3-2.1(-2.9),(1.5-) 2.0-3.0(-3.5) \mu \mathrm{m}$ wide at the base $(n=30)$, lageniform or ampulliform, neck short cylindrical. Conidia (3.0-)3.2-3.7(-4.2) $\times(2.0-) 2.2-2.5$ $(-2.8) \mu \mathrm{m}, 1 / \mathrm{w}(1.2-) 1.4-1.6(-1.9)(n=32)$, hyaline, oblong or ellipsoidal, smooth, with minute guttules; scar indistinct.

Cultures and anamorph: optimal growth at $25^{\circ} \mathrm{C}$ on all media; at $30^{\circ} \mathrm{C}$ hyphae autolysing after short growth; excretions abundant, brown; no growth at $35^{\circ} \mathrm{C}$.

On CMD after $72 \mathrm{~h} 17-22 \mathrm{~mm}$ at $15^{\circ} \mathrm{C}, 32-34 \mathrm{~mm}$ at $25^{\circ} \mathrm{C}, 0.6-1.2 \mathrm{~mm}$ at $30^{\circ} \mathrm{C}$; mycelium covering the plate after $6-7$ days at $25^{\circ} \mathrm{C}$. Colony hyaline, thin, first loose, becoming dense in distal regions, zonate, margin wavy; hyphae radially arranged, thick surface hyphae irregularly curved around the plug, surface mycelium scant. Aerial hyphae scant. After 6 days numerous long acicular, radial, yellow to reddish crystals appearing in the agar from the centre, on the agar surface disintegrating into minute part crystals; also hyphae becoming yellow to red; colony turning light to golden yellow, 3A3-5, 3-4B4-5, 4C6-7, in broad concentric zones. Autolytic activity inconspicuous, conspicuous at $30^{\circ} \mathrm{C}$, no coilings seen. No distinct odour noted. No conidiation seen within 4 weeks. Chlamydospores noted after 6-7 days, uncommon, eventually more common than on SNA, terminal and intercalary, globose or

Fig. 47 Teleomorph of Hypocrea parapilulifera (WU 29395). a, b, e. Fresh stromata. c, d, f-i. Dry stromata (c. immature). j. Rehydrated stroma. k. Ostiole, upper part in section. I. Lateral cortex, lower region. m. Lateral cortex, upper region. n. Stroma surface in face view. o. Stroma in $3 \% \mathrm{KOH}$ after rehydration. p, q. Perithecia in section (p. in lactic acid; q. in $3 \% \mathrm{KOH}$ ). r. Cortical and subcortical tissue in section showing hair-like outgrowths on the stroma surface. s. Subperithecial tissue in section. t, u. Asci with ascospores (u. in cotton blue/lactic acid). Scale bars $\mathbf{a}, \mathrm{e}=1.5 \mathrm{~mm} . \mathbf{b}, \mathrm{d}=1 \mathrm{~mm}$. $\mathbf{c}, \mathbf{h}-\mathbf{j}, \mathbf{o}=0.5 \mathrm{~mm}$. f, $\mathbf{g}=$ $0.3 \mathrm{~mm} . \mathbf{k}, \mathbf{n}=10 \mu \mathrm{m} . \mathbf{l}, \mathbf{m}, \mathbf{r}-\mathbf{u}=15 \mu \mathrm{m} . \mathbf{p}=40 \mu \mathrm{m} . \mathbf{q}=30 \mu \mathrm{m}$ 

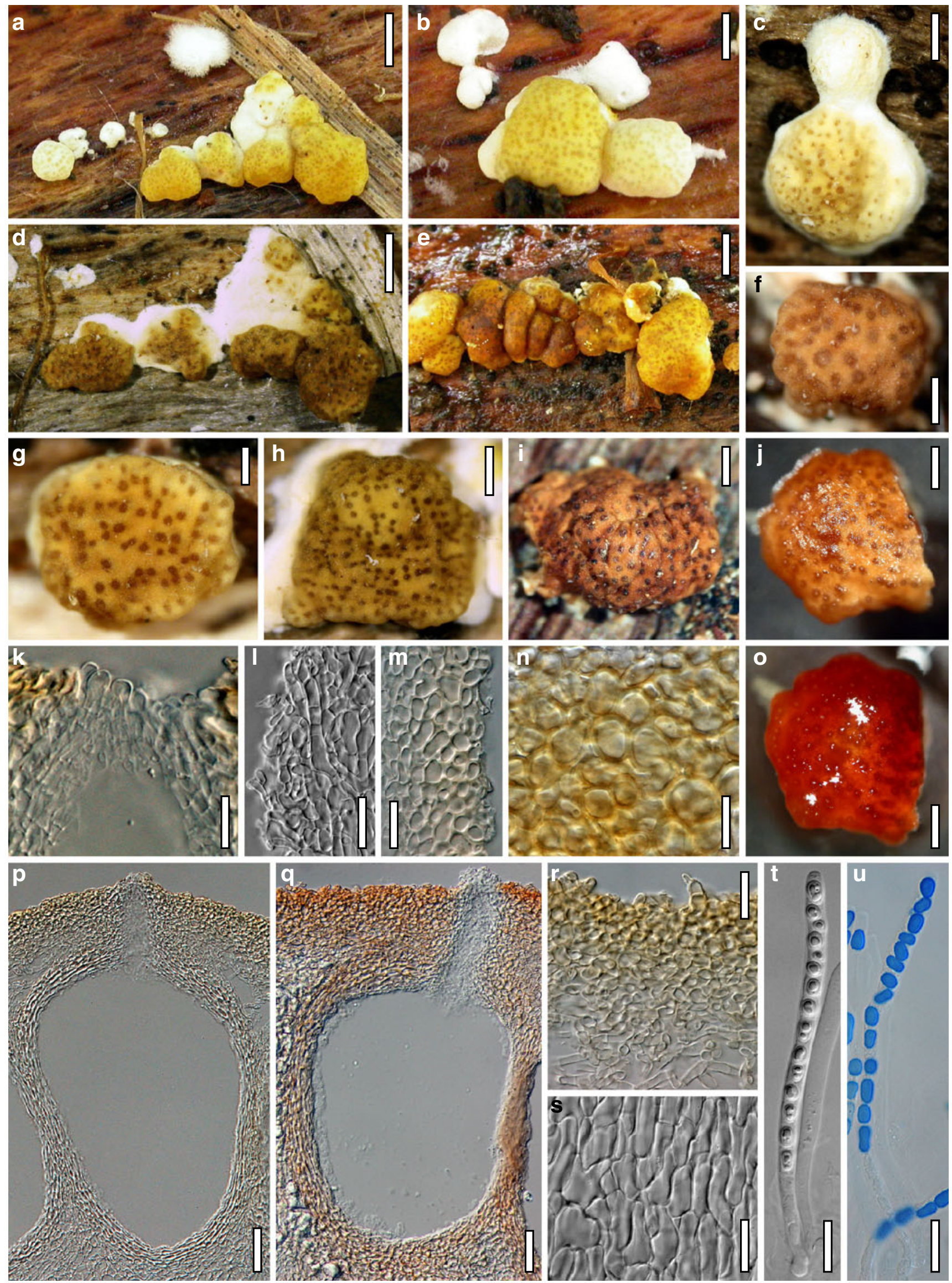

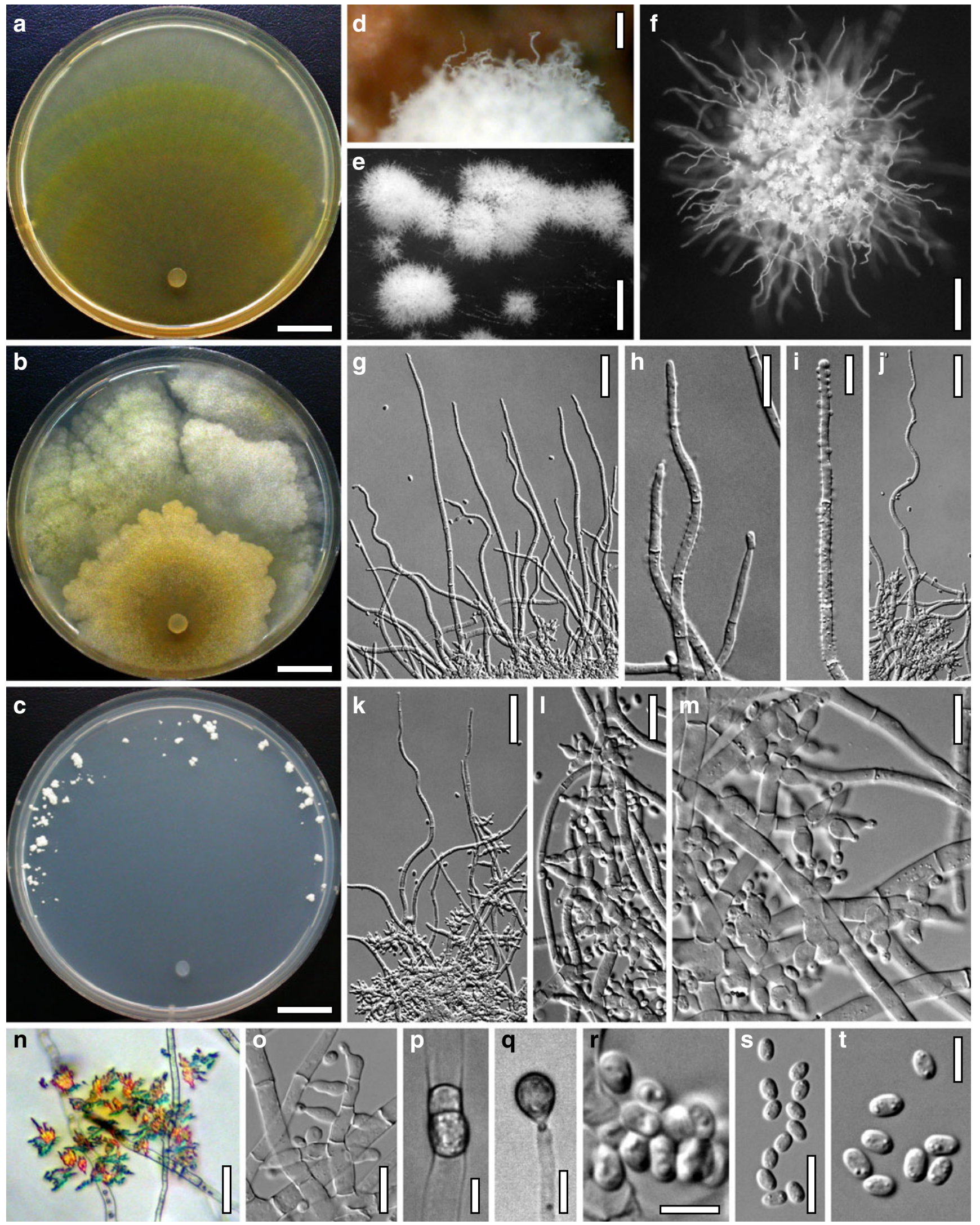
4 Fig. 48 Cultures and anamorph of Hypocrea parapilulifera (CBS 120921). a-c. Cultures (a. on CMD, 10 days; b. on PDA, 14 days; $\mathbf{c}$. on SNA, 28 days). d. Periphery of a conidiation tuft on the natural substrate (WU 29395). e, f. Conidiation pustules on SNA (14-20 days; f. showing elongations on pustule margin). g-i. Elongations (h, i. showing semiglobose warts). $\mathbf{j}-\mathbf{m}$. Conidiophores. $\mathbf{n}$. Crystals on CMD (9 days). o. Phialides. p, q. Chlamydospores (SNA, $25^{\circ} \mathrm{C}, 23$ days). r-t. Conidia (r. on the natural substrate). g-m, o, s, t. On SNA at $25^{\circ} \mathrm{C}$ after 20 days. Scale bars $\mathbf{a}-\mathbf{c}=15 \mathrm{~mm} . \mathbf{d}=100 \mu \mathrm{m}$. $\mathbf{e}=0.8 \mathrm{~mm} . \mathbf{f}=0.2 \mathrm{~mm}$. g, $\mathbf{j}, \mathbf{k}=40 \mu \mathrm{m}$. h, $\mathbf{i}, \mathbf{m}, \mathbf{o}, \mathbf{s}=10 \mu \mathrm{m} . \mathbf{l}=15 \mu \mathrm{m} . \mathbf{p}-\mathbf{r}, \mathbf{t}=5 \mu \mathrm{m}$

ellipsoidal. Dark olive colours developing after extended storage at $15^{\circ} \mathrm{C}$ in $\mathrm{CMD}$ cultures. At $15^{\circ} \mathrm{C}$ colony zonate, crystalline pigment turning the agar yellow, 1A3, 2A3-4, 3A5, 3B3-4; no conidiation seen.

On PDA after $72 \mathrm{~h} 14-17 \mathrm{~mm}$ at $15^{\circ} \mathrm{C}, 23-26 \mathrm{~mm}$ at $25^{\circ} \mathrm{C}$, $<1 \mathrm{~mm}$ at $30^{\circ} \mathrm{C}$; mycelium covering the plate after $10-14$ days at $25^{\circ} \mathrm{C}$. Colony conspicuously dense to opaque; surface hyphae forming irregularly oriented strands at the colony margin; growth discontinuous, resulting in a large, flat, golden yellow central zone with irregular margin, and irregular outgrowths forming zonate patches and yellow spots. Aerial hyphae loose in the central zone, otherwise numerous, forming a dense, downy to floccose flat reticulum of irregular strands with large connectives and drops, and yellow acicular crystals, eventually orange, collapsing. Autolytic activity and coilings conspicuous at all temperatures. Numerous minute, yellow crystals appearing in the agar turning it yellow, 23A3-6, from the centre on the surface and the reverse, centre eventually 4B4-6. No distinct odour noted. No conidiation seen within 4 weeks. At $15^{\circ} \mathrm{C}$ colony indistinctly zonate, margin angular to lobed, surface downy; yellow pigment and crystals produced turning the agar yellow, 2A4-5, 3AB4-6, 4AB5-6; no conidiation seen.

On SNA after $72 \mathrm{~h} 17-20 \mathrm{~mm}$ at $15^{\circ} \mathrm{C}, 22-25 \mathrm{~mm}$ at $25^{\circ} \mathrm{C}$, $<1 \mathrm{~mm}$ at $30^{\circ} \mathrm{C}$; mycelium covering the plate after $9-10$ days at $25^{\circ} \mathrm{C}$. Colony similar to CMD, zonate, with little mycelium on the agar surface, surface hyphae soon degenerating, appearing empty. Aerial hyphae nearly lacking. Autolytic activity and coilings moderate. No diffusing pigment, no distinct odour produced. Chlamydospores noted after 3-5 days, uncommon, mostly intercalary, $(5-) 6-10(-13) \times 5-8(-10) \mu \mathrm{m}$, 1/W 1.0-1.5(-1.8) $(n=30)$, globose, ellipsoidal, fusoid or angular, smooth, rarely 2-celled. Conidiation noted after $12-$ 14 days in white shrubs slowly developing into tufts or pustules $0.5-1.5 \mathrm{~mm}$ diam in lateral and distal areas of the colony, aggregating in groups to $11 \mathrm{~mm}$ or confluent to $\mathrm{ca}$ $5 \mathrm{~mm}$ long. Conidiation dense, dry, mainly inside tufts. Tufts/ pustules loose to compact, but not opaque, i.e. with small spaces between dense conidial clusters, consisting of a rightangled reticulum of branches 4-7 $\mu \mathrm{m}$ wide, with connectives thickened to $8 \mu \mathrm{m}$ and long, little branched, radially divergent main axes fertile to the tip, mostly 4-5 $\mu \mathrm{m}$ wide and to $150(-220) \mu \mathrm{m}$ long, or with straight, sinuous or helical elongations to $300 \mu \mathrm{m}$ long to the first branching, 1.5-2 $\mu \mathrm{m}$ wide terminally, with semiglobose warts $1-2 \mu \mathrm{m}$ diam, sterile, rarely with $1(-2)$ lageniform to subulate phialides (7-) $11-17(-19) \times(1.7-) 2.0-2.5(-3.0) \mu \mathrm{m}, 1 / \mathrm{w} \quad(2.6-) 4.4-8.0(-$ $8.9), 1.5-2.0(-2.2) \mu \mathrm{m}$ wide at the base $(n=20)$. Side branches on elongation bases in right angles or slightly inclined upwards, paired or unpaired, short, 1-celled, longer, 2-3 celled, downwards, unbranched or rebranching into short, 1-celled branches 2.5-5.5 $\mu \mathrm{m}$ wide with phialides solitary or in whorls of 2-3. Phialides $(4.3-) 5.0-7.5(-9.5) \times$ $(2.8-) 3.0-4.0(-4.3) \mu \mathrm{m}, 1 / \mathrm{w}(1.1-) 1.3-2.3(-3.0),(1.8-) 2.0$ $2.8(-3.0) \mu \mathrm{m}$ wide at the base $(n=30)$, lageniform or ampulliform. Conidia (3.2-)3.5-4.0(-4.7) $\times(2.2-) 2.3-2.5(-$ 2.7) $\mu \mathrm{m}, 1 / \mathrm{w}(1.3-) 1.4-1.7(-2.0)(n=30)$, hyaline, oblong or ellipsoidal, smooth, with two groups of terminal guttules or minute guttules irregularly disposed, scar indistinct. At $15^{\circ} \mathrm{C}$ colony zonate; conidiation after $c a 3$ weeks in white tufts with mostly straight elongations, scant.

Habitat: on decorticated wood.

Distribution: Europe (Czech Republic), USA; also Australia fide Lu et al. (2004); rare.

Holotype: USA, Virginia: Giles County, Mountain Lake Biological Station, Little Spruce Bog, 378229 N, 808319 W, elev. 1170 m, on decorticated wood, 17 Sep. 1991, G.J. Samuels et al. (BPI 112832, culture G.J.S. 91-60; not examined).

Material examined: Czech Republic, Southern Bohemia, Záton, Boubínský prales (NSG), MTB 7048/2, 4858'34" N, $13^{\circ} 49^{\prime} 07^{\prime \prime}$ E, elev. 1000 m, on decorticated branch of Fagus sylvatica $5 \mathrm{~cm}$ thick, on wood, soc. greenish Trichoderma, Melanopsammella inaequalis, rhizomorphs, holomorph, 4 Oct. 2004, W. Jaklitsch, W.J. 2762 (WU 29395, culture CBS $120921=$ C.P.K. 1908).

Notes: Hypocrea parapilulifera is a rare species, with certainty known from only two teleomorphic specimens, one from North America, one from Europe. It was also identified in drinking water by Hageskal et al. (2008). The most closely related species is $H$. pachybasioides. $H$. parapilulifera differs from the latter in hairs on the stroma surface, a more distinct colour change during development and drying, a positive $\mathrm{KOH}$ reaction of the stromata, later appearance and slower development of conidiation, virtually no growth at $30^{\circ} \mathrm{C}$, pustules with a looser structure and the formation of a yellow to dark olive pigment on CMD. The latter two traits and formation of crystals on CMD do not seem consistent, because the $H$. pachybasioides strain CBS 119319 behaves similarly. The semiglobose warts on elongations of $H$. parapilulifera may be diagnostic for the species if consistent among the strains. The isolate from the Czech specimen sporulated only on SNA, while Lu et al. (2004) reported also conidiation on CMD for their North American isolate.

Hypocrea pilulifera J. Webster \& Rifai, Trans. Brit. Mycol. Soc. 51: 511 (1968). Fig. 49 

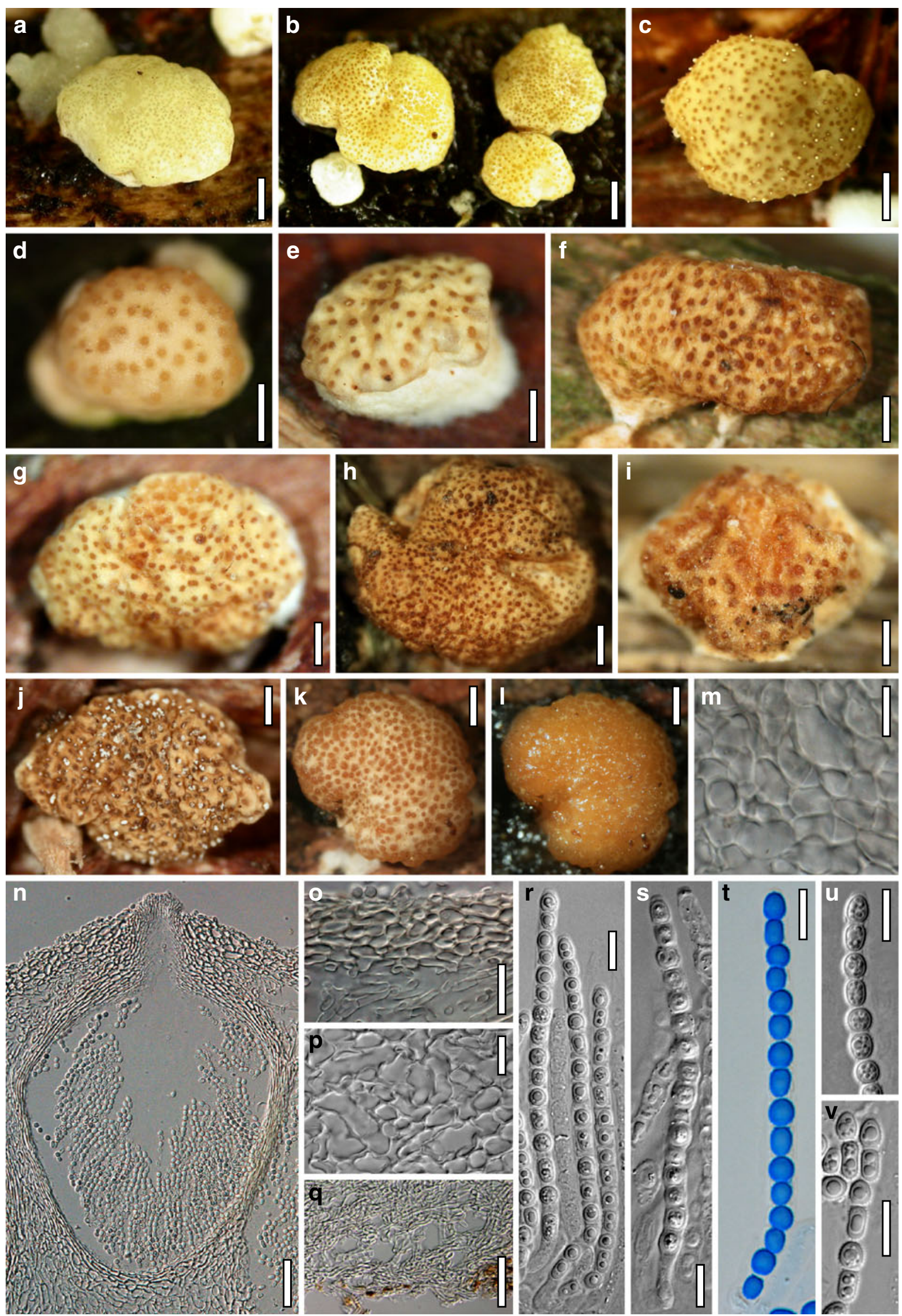
4 Fig. 49 Teleomorph of Hypocrea pilulifera. a-d. Fresh stromata (a, d. immature, b. partly immature). e-j. Dry stromata (e. immature, with stipe-like base). k. Rehydrated stroma. I. Stroma in 3\% $\mathrm{KOH}$ after rehydration. $\mathbf{m}$. Stroma surface in face view. $\mathbf{n}$. Perithecium in section. o. Cortical and subcortical tissue in section. p. Subperithecial tissue in section. q. Stroma base in section. r-t. Asci with ascospores (t. in cotton blue/lactic acid). u, v. Ascospores (u. vital, multiguttulate; v. cells distinctly dimorphic; viable and dead). $\mathbf{a}, \mathbf{b}, \mathbf{d}, \mathbf{f}, \mathbf{h}, \mathbf{k}-\mathbf{q}, \mathbf{v}$. WU 29408. c, e, g, j, r, t, u. WU 29409. i, s. Holotype K 64379. Scale bars $\mathbf{a}, \mathbf{b}, \mathbf{k}, \mathbf{l}=1 \mathrm{~mm}$. c, $\mathbf{h}=0.6 \mathrm{~mm}$. d, $\mathbf{i}=0.3 \mathrm{~mm}$. e-g, $\mathbf{j}=0.4 \mathrm{~mm}$. $\mathbf{m}$, $\mathbf{r}-\mathbf{v}=10 \mu \mathrm{m} . \mathbf{n}, \mathbf{q}=40 \mu \mathrm{m} . \mathbf{o}, \mathbf{p}=20 \mu \mathrm{m}$

Anamorph: Trichoderma piluliferum J. Webster \& Rifai, Mycol. Pap. 116: 16 (1969). Fig. 50

Stromata when fresh 1-5 mm diam, 1-1.5 mm thick, pulvinate, broadly attached, margin free, surface smooth, ostiolar dots distinct, first watery, yellowish to olivegreenish, later ochre to brown. Stroma colour first white, turning light yellow, nearly citrine, $2-3 \mathrm{~A} 2-4$, cream or argillaceous when mature, mostly $4 \mathrm{AB} 4$.

Stromata when dry $(0.7-) 1.5-3.4(-4.0) \times(0.6-) 1.2-2.6(-$ $3.5) \mathrm{mm},(0.3-) 0.5-1.1(-1.5) \mathrm{mm}$ thick $(n=44)$, solitary, scattered or aggregated in small numbers (2-3), pulvinate or discoid, broadly attached; outline circular or oblong; rarely with radiating white basal mycelium. Edges free, sides rounded or straight vertical, smooth, sometimes present as a white broad stipe-like base with the apical fertile part laterally projecting over it. Surface smooth, finely granular due to ostiolar dots or rugose. Ostiolar dots distinct, (39-)48-97(-165) $\mu \mathrm{m}(n=85)$ diam, plane or convex, with circular or oblong outline; bright ochre or brown. Development from white cottony pulvinate mycelium, compacting, turning yellow from the centre before the appearance of ostiolar dots. Stroma colour pale yellow to nearly citrine, 2-3A3, 3A4, 4A3-5, more greyish yellow, cream, greyish orange or pale brown when mature, 4-5B46, 5CD5-6; sometimes reddish brown when older and with densely disposed dots. Spore deposits white or yellowish. Rehydrated stromata thickly pulvinate, smooth, with distinct, convex, bright ochre ostiolar dots, white in between. No distinct colour change noted after addition of $3 \% \mathrm{KOH}$, only dots more papillate and rehydration more efficient, colour more evenly pale brownish, paler again after drying.

Stroma anatomy: Ostioles (65-)82-104(-110) $\mu \mathrm{m}$ long, plane or projecting to $20(-30) \mu \mathrm{m},(38-) 42-66(-75) \mu \mathrm{m}$ wide at the apex $(n=30)$; hyaline marginal apical cells cylindrical or clavate, $2-5 \mu \mathrm{m}$ wide. Perithecia (180-)240-305(-330) $\times$ (130-)180-260(-330) $\mu \mathrm{m}(n=30)$, globose or flask-shaped, crowded or not; peridium (14-)17-25(-32) $\mu \mathrm{m}(n=30)$ thick at the base, $(10-) 15-21(-26) \mu \mathrm{m}(n=30)$ thick at the sides, hyaline to pale yellowish. Cortical layer (22-)24-35(-41) $\mu \mathrm{m}$ $(n=30)$ thick, a $t$. angularis of distinct thick-walled, hyaline to pale yellowish cells $(5-) 6-12(-17) \times(3-) 5-8(-10) \mu \mathrm{m}(n=$ $30)$ in face view, (4-)6-19(-30)×(3-)4-8(-10) $\mu \mathrm{m}(n=31)$ in vertical section; surface smooth, no hairs present. Subcortical tissue where present a loose $t$. intricata of thin-walled hyaline hyphae $(2-) 3-5(-7) \mu \mathrm{m}(n=30)$ wide. Subperithecial tissue a dense $t$. epidermoidea of thick-walled hyaline cells (4-)8-28 $(-53) \times(4-) 7-14(-17) \mu \mathrm{m}(n=30)$. Stroma base a $t$. intricata of thick-walled hyaline hyphae $(2-) 3-6(-9) \mu \mathrm{m} \quad(n=32)$ wide. Asci $(78-) 88-110(-136) \times(5.0-) 5.5-6.5(-7.5) \mu \mathrm{m}$, stipe (3-)8-20(-42) $\mu \mathrm{m}$ long $(n=80)$. Ascospores hyaline, spinulose or verruculose, cells dimorphic, but often with little difference in shape and size; distal cell (3.7-)4.3-5.3(-6.0) $\times$ (3.5-)4.0-4.8(-5.5) $\mu \mathrm{m}, 1 / \mathrm{w}(0.9-) 1.0-1.2(-1.5) \quad(n=110)$, (sub)globose or wedge-shaped; proximal cell (4.0-)4.8-6.0($7.0) \times(3.0-) 3.2-4.3(-5.4) \mu \mathrm{m}, 1 / \mathrm{w}(1.0-) 1.2-1.7(-2.2) \quad(n=$ $110)$, oblong, ellipsoidal, wedge-shaped or subglobose.

Cultures and anamorph: optimal growth at $15-20^{\circ} \mathrm{C}$ on all media; no growth at 30 and $35^{\circ} \mathrm{C}$.

On CMD after $72 \mathrm{~h} 14-18 \mathrm{~mm}$ at $15^{\circ} \mathrm{C}, 13-14 \mathrm{~mm}$ at $25^{\circ} \mathrm{C}$; mycelium covering the plate after $10-11$ days at $15^{\circ} \mathrm{C}$, after 19-20 days at $25^{\circ} \mathrm{C}$. Colony hyaline, thin, with discontinuous/ multiphasic growth resulting in irregular zones of varying density ('imbricate') and an ill-defined, often lobed margin; numerous characteristic, narrow, short and irregularly sinuous ('curly') secondary peg-like hyphae present. Aerial hyphae virtually absent. Autolytic activity and coilings absent. No pigment, no distinct odour noted. Chlamydospores noted after $10-20$ days in variable numbers. No conidiation seen at $25^{\circ} \mathrm{C}$. At $15^{\circ} \mathrm{C}$ colony circular, with similar hyphae but denser and margin better defined than at $25^{\circ} \mathrm{C}$. Conidiation noted after 12-20 days, scant, developing slowly, pachybasium-like, in thick white fluffy tufts $2-9 \mathrm{~mm}$ diam, mostly on the distal and lateral margins, with many right angles and straight or slightly sinuous sterile elongations to $0.5 \mathrm{~mm}$ long.

On PDA after $72 \mathrm{~h} 12-14 \mathrm{~mm}$ at $15^{\circ} \mathrm{C}, 11-13 \mathrm{~mm}$ at $25^{\circ} \mathrm{C}$; mycelium not covering the plate within a month at 15 and $25^{\circ} \mathrm{C}$. Hyphae narrow, secondary hyphae minute, wavy, peg-like. Colony with wavy or lobed margin, not zonate, dense to opaque, with lighter radial patches or homogeneous, whitish downy surface. Aerial hyphae numerous, without distinct orientation, forming a loose whitish mat with irregular strands and large connectives, eventually collapsing to floccules. Autolytic activity absent, coilings common. No diffusing pigment produced, reverse cream-yellowish, 34A3, 4B4; odour indistinct. Conidiation absent at $25^{\circ} \mathrm{C}$. At $15^{\circ} \mathrm{C}$ similar, colony more regular, dense, shiny, with lighter radial rays. Conidiation noted after 25-32 days in white tufts to $3 \mathrm{~mm}$ diam in the centre, scant, pachybasium-like; sometimes confluent to larger masses.

On SNA after $72 \mathrm{~h} 10-13 \mathrm{~mm}$ at $15^{\circ} \mathrm{C}, 4-5 \mathrm{~mm}$ at $25^{\circ} \mathrm{C}$; mycelium covering the plate after 2 weeks at $15^{\circ} \mathrm{C}$, not covering the plate within a month at $25^{\circ} \mathrm{C}$. Colony circular, dense, with numerous minute, peg-like secondary hyphae; indistinctly zonate, hyphae degenerating from the centre, becoming empty. Aerial hyphae inconspicuous, minute. 

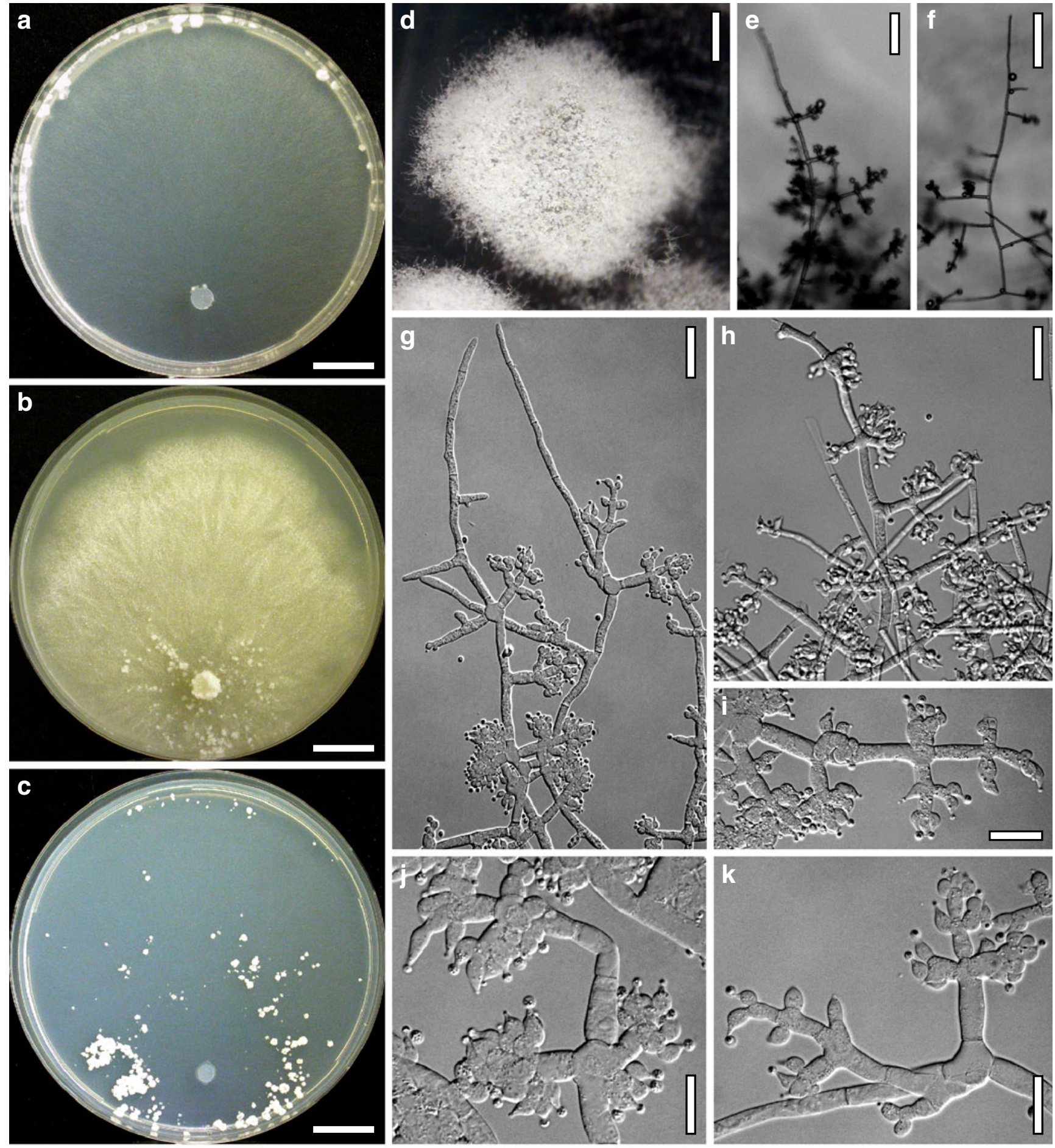

3.

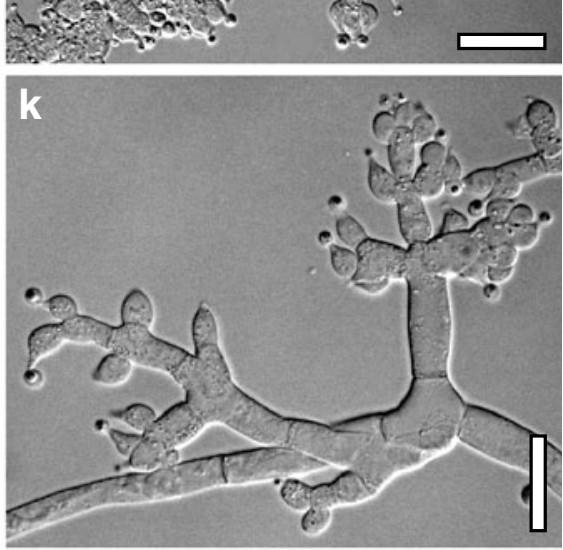
? 8
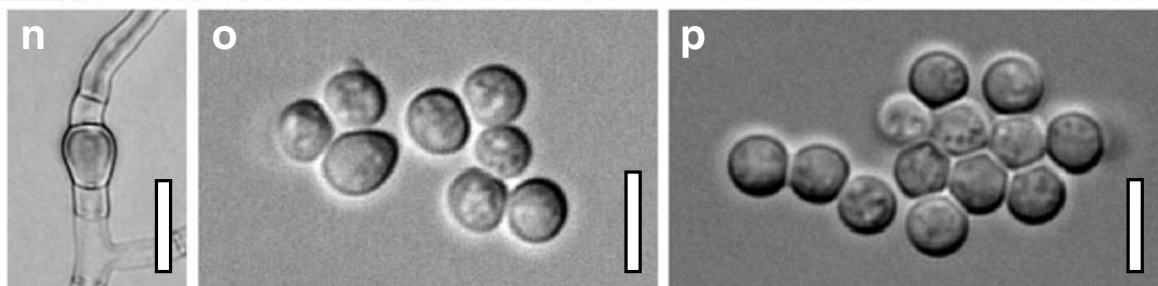
4 Fig. 50 Cultures and anamorph of Hypocrea pilulifera (CBS 120927). a-c. Cultures (a. CMD, 25 days. b. PDA, 28 days. c. SNA, 25 days). d. Conidiation pustule on SNA (18 days). e, f. Conidiophores with elongations on pustule margins on growth plate (f. young, showing right-angled branching; 18 days). g-k. Conidiophores (18 days; g. showing sterile elongations). I. Phialides (18 days). m, n. Chlamydospores ( 21 days). o, p. Conidia $\left(25^{\circ} \mathrm{C}, 45\right.$ days). a-p. All at $15^{\circ} \mathrm{C}$ except $\mathbf{0 , p .} \mathbf{d}-\mathbf{p}$. All on SNA. Scale bars $\mathbf{a}-\mathbf{c}=15 \mathrm{~mm}$. $\mathbf{d}=0.5 \mathrm{~mm}$. e, $\mathbf{g}, \mathbf{h}=$ $30 \mu \mathrm{m} . \mathbf{f}=70 \mu \mathrm{m} . \mathbf{i}, \mathbf{k}, \mathbf{n}=15 \mu \mathrm{m} . \mathbf{j}, \mathbf{l}, \mathbf{m}=10 \mu \mathrm{m} . \mathbf{o}, \mathbf{p}=5 \mu \mathrm{m}$

Autolytic activity and coilings absent. Chlamydospores noted after $10-14$ days at $15^{\circ} \mathrm{C}$, common, irregularly distributed, terminal and intercalary, $(6-) 7-11(-15) \times(4-)$ 6-10(-11) $\mu \mathrm{m}, 1 / \mathrm{w} 0.9-1.4(-2.1)(n=30)$, globose, oblong or clavate, sometimes $2-3$ celled. No diffusing pigment noted; odour indistinct. Conidiation absent at $25^{\circ} \mathrm{C}$ or in white pustules after $c a 1.5$ months. At $15^{\circ} \mathrm{C}$ colony circular, margin becoming wavy to lobed. Conidiation noted after 9 11 days, dry, pachybasium-like, developing from within white tufts or pustules $1-3(-5) \mathrm{mm}$ diam, confluent up to $9 \mathrm{~mm}$ long, irregularly disposed or in a concentric zone including the proximal margin and centre, or/and in a broad zone including the margin. Pustules dense but not opaque, a reticulum of mostly unpaired branches in right angles with erect conidiophores (main axes) to $c a 0.5 \mathrm{~mm}$ long emerging from it. Main axes to $7.5 \mu \mathrm{m}$ wide and thickwalled at the base, attenuated upwards to $2.5-4 \mu \mathrm{m}$ terminally, fertile to the tip or terminating in a straight or sinuous sterile elongation $50-150(-300) \mu \mathrm{m}$ long to the first branching, smooth or appearing rough in the stereomicroscope. Conidiophores (main axes without elongations and side branches) with a whorl of phialides at the top, followed by short paired or unpaired 1-2 celled branches in right angles, each with a terminal whorl of phialides. Branches not or once rebranching into thick, short paired, right-angled branches with 1-3 whorls of phialides resulting in dense structures. Generally branches more commonly unpaired, but tending to be paired in short terminal branches to $150 \mu \mathrm{m}$ long or side branches directly below elongations. Branching points sometimes thickened to 10 $12 \mu \mathrm{m}$. Phialides mostly in whorls of $2-4$, less commonly solitary. Conidia densely packed in minute globose dry heads. Phialides $(4.5-) 5.0-8.0(-11.5) \times(3.0-) 3.4-4.2(-5.0)$ $\mu \mathrm{m}, 1 / \mathrm{w}(1.2-) 1.3-2.0(-3.0),(1.2-) 2.0-3.0(-4.0) \mu \mathrm{m}$ wide at the base $(n=34)$, ampulliform or subglobose with a curved neck and narrow base, less commonly lageniform, often inaequilateral or curved, widest mostly in or below the middle. Conidia $(2.5-) 2.8-3.5(-4.0) \times(2.5-) 2.7-3.2(-$ 3.7) $\mu \mathrm{m}, 1 / \mathrm{w} 1.0-1.2(-1.3) \quad(n=80)$, hyaline, globose, subglobose, sometimes oval, smooth, eguttulate, scar indistinct.

Habitat: on wood of Betula spp., less commonly on other hosts, e.g. Juncus effusus.
Distribution: Europe (Germany, United Kingdom), uncommon.

Typification: Webster and Rifai (1968) collected a specimen containing stromata on Juncus effusus in Derbyshire and designated it as the holotype of their new species H. pilulifera. Several other specimens were found by them only in the conidial state on wood of Betula and basidiomata of Heterobasidion annosum. One of them, on wood of Betula from Lancashire is available as the living culture CBS 814.68 providing a reference, e.g. for gene sequences. Holotype: United Kingdom, England, Derbyshire, Glossop, Chunal Moore, on dead culms of Juncus effusus, 11 Jul. 1965, J. Webster (K(M) 64379). The stroma of the holotype matches recently collected specimens. It is firmly attached to a culm of Juncus, pulvinate, $\mathrm{KOH}-$ and has ascospores distinctly larger than in $H$. placentula, which is found on the same host. However, only one incomplete stroma remains, therefore an epitype is designated here: Germany, Hessen, Landkreis Fulda, Gersfeld, Rhön, Rotes Moor (between Gersfeld and Wüstensachsen), from the parking place Moordorf at B278 to the peat bog, $50^{\circ} 27^{\prime} 42^{\prime \prime} \mathrm{N}, 09^{\circ} 58^{\prime} 58^{\prime \prime} \mathrm{E}$, elev. $810 \mathrm{~m}$, on a branch of Betula pubescens subsp. carpatica $6-8 \mathrm{~cm}$ thick, on medium- to well-decayed wood, soc. Chaetosphaeria ovoidea, ?Mollisia sp., dark hyphomycete, algae and moss, 29 Aug. 2006, H. Voglmayr \& W. Jaklitsch, W.J. 2959 (WU 29408, ex-epitype culture CBS $120927=$ C.P.K. 2455).

Additional material examined: United Kingdom, Staffordshire, Cannock Chase, Rugeley, Beaudesert Old Park, right from the car park (heading to Lichfield), $52^{\circ} 43^{\prime} 14^{\prime \prime \prime} \mathrm{N}$, $1^{\circ} 56^{\prime} 48^{\prime \prime} \mathrm{W}$, elev. $150 \mathrm{~m}$, on a decorticated twig of Betula pendula $2-3 \mathrm{~cm}$ thick embedded in moss, on well-decayed wood, soc. effete pyrenomycete, 7 Sep. 2007, W. Jaklitsch \& H. Voglmayr, W.J. 3142 (WU 29409, culture C.P.K. 3143). Culture only: Lancashire, Clitheroe, Dunsop Bridge, on dead wood of Betula, 23 Sep. 1962, J. Webster, culture CBS 814.68.

Notes: Hypocrea pilulifera seems to be specifically associated with Betula wood. A conspecificity of the material collected on Heterobasidion annosum (see $\mathrm{Lu}$ et al. 2004) has not been proven by gene sequences. The occurrence of the holotype specimen on Juncus may be a result of infection by this fungus from a Betula branch lying in a Juncus habitat. Several searches in such habitats including original collection sites in recent years failed to detect $H$. pilulifera, while $H$. placentula was found several times on Juncus. H. placentula differs from $H$. pilulifera by paler $\mathrm{KOH}+$ stromata with smaller perithecia and smaller ascospores, faster growth with a higher temperature optimum, and by ellipsoidal conidia produced in pustules lacking sterile elongations. In addition, conidiation in $H$. placentula starts terminal in the tuft, but within the pustule in H. pilulifera. Stromata of $H$. pilulifera are firmly attached 
to the host, whereas those of $H$. placentula are only attached by hyphae and fall off easily. All other species of Hypocrea forming yellow stromata in Europe, have differently shaped conidia, including H. bavarica, which also occurs on Betula, and differs also by smaller ascospores, $\mathrm{KOH}+$ stromata and an effuse, verticillium-like conidiation.

The growth rates given above were determined with CBS 120927 after several transfers. Freshly prepared cultures of $H$. pilulifera grow considerably faster, e.g. C.P. K. 3143 covered a $90 \mathrm{~mm}$ diam Petri dish in $c a 10$ days on SNA at $15^{\circ} \mathrm{C}$. This may indicate that richer media like MEA or OA should be used for precultures of growth rate experiments. However, the characteristic minute peg-like secondary hyphae were seen in all three isolates examined.

Hypocrea placentula Grove, J. Bot. (Lond.) 23: 133 (1885). Fig. 51

Anamorph: Trichoderma placentula Jaklitsch, sp. nov. Fig. 52

MycoBank MB 516698

Anamorphosis Trichoderma placentula: Conidiophora in agaro SNA emergentia ex pustulis laxis albis, stipitata, similia Pachybasii. Phialides vulgo in fasciculis brevibus, lageniformes, $(4.5-) 5.5-9.0(-12.5) \times(2.3-) 2.5-3.2(-3.5)$ $\mu \mathrm{m}$. Conidia hyalina, ellipsoidea, glabra, $(2.5-) 2.8-3.5(-$ $4.2) \times 2.0-2.5(-3.0) \mu \mathrm{m}$.

Stromata when fresh $0.5-3.5 \mathrm{~mm}$ diam, to $1 \mathrm{~mm}$ thick, pulvinate, placentiform or discoid with circular to irregular outline; surrounded by white cottony mycelium when young; attached by hyphae, easily detached. Surface smooth, ostiolar dots distinct, first yellowish, turning brown; perithecia rarely slightly projecting. Stromata first appearing as white hyphal tufts, compacting, turning pale yellow, developing ostiolar dots, maturing from culm bases upwards. Stromata white, yellow, 3A3, mature 4A2-4, when older pale brown, similar to the host surface. Spore deposits white. Sometimes accompanied by its anamorph as white tufts with right angles and compact conidial heads.

Stromata when dry $(0.4-) 0.8-2.0(-3.3) \times(0.4-) 0.6-1.4(-$ 2.4) $\mathrm{mm}, 0.15-0.4(-0.8) \mathrm{mm}$ thick $(n=83)$, solitary, scattered or aggregated in small numbers, flat pulvinate, placentiform or discoid, sometimes flat effuse, sometimes curved around the entire stem; often only attached by hyphae along stroma margin, readily falling off, exposing a smooth, white to pale yellowish, flat or concave lower side, typically leaving a ring of white mycelium on the host. Outline oblong, circular or irregular; upper side flat or convex; margin white or concolorous, first indistinct and surrounded by or embedded in white cottony mycelium, becoming well-defined, rounded, attached or free. Surface smooth or finely tubercular due to slightly projecting perithecia. Ostiolar dots (24-)34-73(-125) $\mu \mathrm{m}(n=120)$ diam, distinct when mature, convex, with circular or oblong outline, brown with lighter centres, sometimes nearly black. Stroma colour resulting from whitish to mostly deeply yellow surface and brown ostiolar dots, pale or deep yellow, 3A3, 4A2-4, 4BC4-5, to brown-orange, light or yellow-brown, 5CD4-6. Spore deposits white or pale yellowish. Stromata after rehydration thicker pulvinate, yellow, with smooth surface and distinct, papillate ostiolar dots; after addition of $3 \% \mathrm{KOH}$ stroma surface remaining yellow, ostiolar dots and perithecial wall in contrast turning distinctly orange-red, slowly changing to dark red. Colour change in $\mathrm{KOH}$ also noted after treatment of dry stromata; microscopic colour change less conspicuous.

Stroma anatomy: Ostioles (44-)54-70(-78) $\mu \mathrm{m}$ long, plane or projecting to $15(-20) \mu \mathrm{m},(26-) 30-42(-50) \mu \mathrm{m}$ wide at the apex inside $(n=30)$, sometimes with some broadly rounded or clavate marginal cells $2-5 \mu \mathrm{m}$ wide at the apex. Perithecia $(130-) 140-210(-240) \times(65-) 115-190$ $(-215) \mu \mathrm{m}(n=30)$, globose or flask-shaped, crowded or not; peridium $(6-) 9-16(-22) \mu \mathrm{m}(n=60)$ thick at the base and at the sides, distinctly yellow like the cortex. Cortical layer (14-)16-24(-30) $\mu \mathrm{m}(n=30)$ thick, a $t$. angularis of thin-walled cells $(3-) 5-10(-14) \times(2-) 4-7(-9) \mu \mathrm{m}(n=60)$ in face view and in vertical section; distinctly yellow. Stroma surface with short hair-like outgrowths (7-)9-15($20) \times(2.5-) 3-5(-6) \mu \mathrm{m}(n=30), 1-3$ celled, inconspicuous, erect or appressed to the surface, simple, rarely branched, hyaline or yellowish, cylindrical or attenuated upwards, with smooth or slightly verruculose, broadly rounded end cells; basal cell often thickened. Subcortical tissue where present a loose $t$. intricata of hyaline or pale yellowish thinwalled hyphae $(2-) 3-5(-8) \mu \mathrm{m}(n=33)$ wide. Subperithecial tissue a dense $t$. epidermoidea of thin- to thick-walled hyaline cells $(6-) 7-34(-52) \times(5-) 7-14(-17) \mu \mathrm{m}(n=30)$. Stroma base a narrow $t$. intricata of thin-walled hyaline hyphae $(2.5-) 3-6(-8.5) \mu \mathrm{m}(n=30)$ wide, often parallel along the host surface. Asci $(60-) 70-85(-94) \times(3.5-) 4.0$ 4.5(-5.0) $\mu \mathrm{m}$, stipe (4-)8-18(-26) $\mu \mathrm{m}$ long $(n=110)$, with 2 septa at the base. Ascospores hyaline, smooth within asci, outside finely verruculose or with larger scattered warts; cells typically distinctly dimorphic, distal cell (2.8-)3.0-3.8 $(-4.2) \times(2.5-) 2.8-3.3(-3.8) \mu \mathrm{m}, 1 / \mathrm{w}(0.9-) 1.0-1.2(-1.6)(n=$ $120)$, (sub)globose, proximal cell $(3.0-) 3.7-4.8(-5.7) \times$

Fig. 51 Teleomorph of Hypocrea placentula. a-f. Fresh stromata (a. initial; b. immature). g-k. Dry stromata (g. immature). l. Rehydrated stroma. $\mathbf{m}$. Stroma in 3\% KOH after rehydration. n. Stroma surface in face view. o. Hairs on stroma surface. p. Perithecium in section. q. Cortical and subcortical tissue in section. $\mathbf{r}$. Subperithecial tissue in section. s. Stroma base in section. $\mathbf{t}-\mathbf{v}$. Asci with ascospores $(\mathbf{u}, \mathbf{v}$. in cotton blue/lactic acid). a, c, f, i. WU 29410. b, e, j, v. WU 29411. d, g, h, l-u. WU 29412. k. Holotype K 154041. Scale bars $\mathbf{a}-\mathbf{c}, \mathbf{j}, \mathrm{k}=$ $0.3 \mathrm{~mm}$. d-f, $\mathbf{l}, \mathbf{m}=0.5 \mathrm{~mm}$. g, $\mathbf{i}=0.4 \mathrm{~mm} . \mathbf{h}=0.2 \mathrm{~mm} . \mathbf{n}, \mathbf{o}, \mathbf{t}-\mathbf{v}=$ $10 \mu \mathrm{m} . \mathbf{p}, \mathbf{s}=20 \mu \mathrm{m} . \mathbf{q}, \mathbf{r}=15 \mu \mathrm{m}$ 

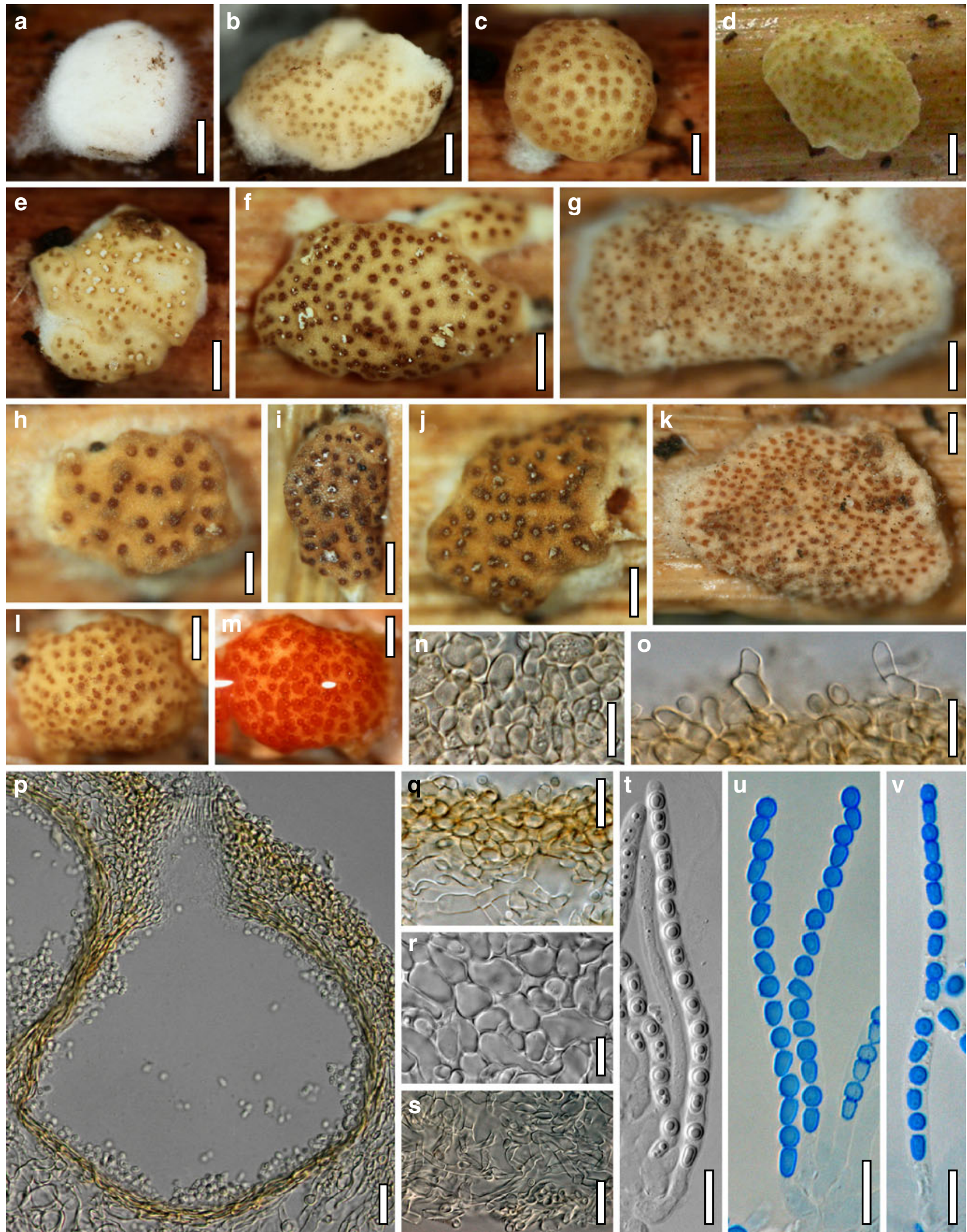

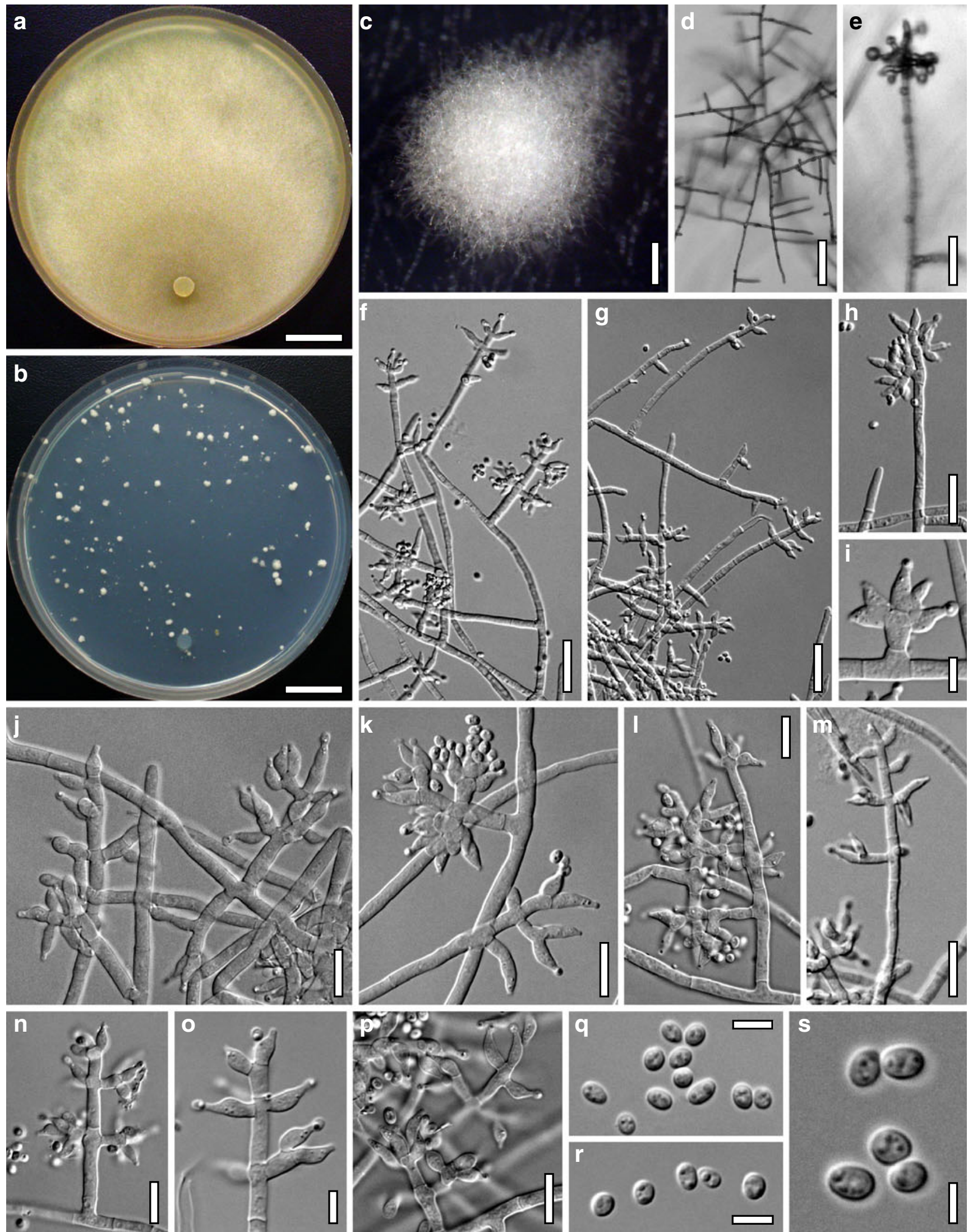

s

00
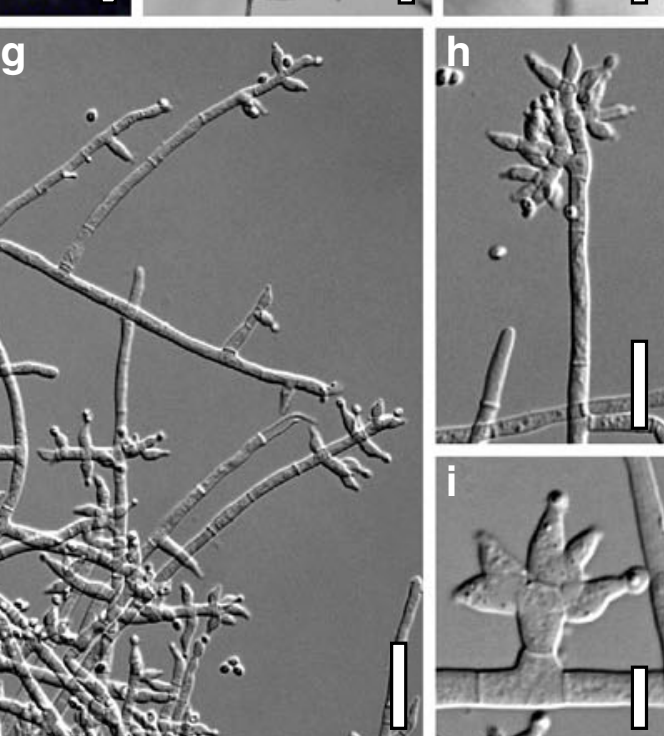
4Fig. 52 Cultures and anamorph of Hypocrea placentula. a, b. Cultures (a. on PDA, 28 days. b. on SNA, 48 days). c. Young conidiation tuft (21 days). d. Right-angled branching in young tuft (24 days). e. Stipitate conidiophore in tuft periphery on growth plate (16 days). f-n. Conidiophores. o, p. Phialides. q-s. Conidia. c-s. On SNA. a-i, $\mathbf{k}, \mathbf{n}, \mathbf{o}, \mathbf{r}$. At $25^{\circ} \mathrm{C}$. $\mathbf{f}-\mathbf{i}, \mathbf{k}, \mathbf{n}, \mathbf{o}, \mathbf{r}$. After 24 days. j, $\mathbf{l}, \mathbf{m}, \mathbf{p}, \mathbf{q}$, s. After 24 days at $25^{\circ} \mathrm{C}$ plus 14 days at $15^{\circ} \mathrm{C}$. a-c, e, j, l, m, p, q, s. CBS 120924. d, f-i, $\mathbf{k}, \mathbf{n}, \mathbf{o}, \mathbf{r}$. C.P.K. 2446. Scale bars $\mathbf{a}, \mathbf{b}=15 \mathrm{~mm}$. $\mathbf{c}=0.2 \mathrm{~mm} . \mathbf{d}=100 \mu \mathrm{m} . \mathbf{e}-\mathbf{g}=20 \mu \mathrm{m} . \mathbf{h}, \mathbf{m}=15 \mu \mathrm{m} . \mathbf{i}, \mathbf{o}, \mathbf{q}, \mathbf{r}=5 \mu \mathrm{m} . \mathbf{j}-\mathbf{l}$, $\mathbf{n}, \mathbf{p}=10 \mu \mathrm{m} . \mathbf{s}=3 \mu \mathrm{m}$

$(2.0-) 2.3-2.8(-3.2) \mu \mathrm{m}, 1 / \mathrm{w}(1.2-) 1.5-1.9(-2.6) \quad(n=120)$, oblong or wedge-shaped; contact areas truncate.

Cultures and anamorph: optimal growth at $25^{\circ} \mathrm{C}$ on all media; no growth at $35^{\circ} \mathrm{C}$.

On CMD after $72 \mathrm{~h} 9-12 \mathrm{~mm}$ at $15^{\circ} \mathrm{C}, 26-28 \mathrm{~mm}$ at $25^{\circ} \mathrm{C}$, $15-24 \mathrm{~mm}$ at $30^{\circ} \mathrm{C}$; mycelium covering the plate after $7-$ 8 days at $25^{\circ} \mathrm{C}$. Colony scarcely visible, hyaline, thin, dense, homogeneous, not zonate, with ill-defined, diffuse margin; of narrow reticulate hyphae with more or less rectangular branching and little variation in width. Aerial hyphae variable, inconspicuous. Autolytic activity absent, coilings variable, scant or common. No chlamydospores, only some hyphal thickenings seen. No diffusing pigment noted; odour indistinct. Conidiation scant, only seen in fresh cultures after entire covering of the plate by mycelium.

On PDA after $72 \mathrm{~h} 5-7 \mathrm{~mm}$ at $15^{\circ} \mathrm{C}, 23-25 \mathrm{~mm}$ at $25^{\circ} \mathrm{C}$, $11-19 \mathrm{~mm}$ at $30^{\circ} \mathrm{C}$; mycelium covering the plate after 10 11 days at $25^{\circ} \mathrm{C}$. Colony dense, homogeneous, not zonate; margin diffuse, surface hyphae in marginal areas aggregated into radial strands. Aerial hyphae abundant, causing a whitish to yellowish downy surface, of two kinds, a) short, erect, spiny hyphae, disposed in dense lawns, particularly in distal areas superposed by an indistinctly zonate reticulum of b) long, several $\mathrm{mm}$ high aerial hyphae forming strands. Autolytic activity inconspicuous or moderate, coilings frequent. No diffusing pigment noted, reverse yellowish, 3-4AB4, 4B5; odour indistinct. No conidiation noted.

On SNA after $72 \mathrm{~h} 10-11 \mathrm{~mm}$ at $15^{\circ} \mathrm{C}, 27-28 \mathrm{~mm}$ at $25^{\circ} \mathrm{C}$, $8-14 \mathrm{~mm}$ at $30^{\circ} \mathrm{C}$; mycelium covering the plate after 1 week at $25^{\circ} \mathrm{C}$. Colony hyaline, thin, dense, homogeneous, not zonate; mycelium reticulate, with rectangular branching; hyphae with more conspicuous difference in width than on CMD; surface hyphae degenerating soon, appearing empty. Aerial hyphae common, several $\mathrm{mm}$ long and high, often branched in right angles. Autolytic activity inconspicuous, more pronounced at $15^{\circ} \mathrm{C}$, coilings frequent. No chlamydospores, only some hyphal thickenings seen. No diffusing pigment, no distinct odour noted. Conidiation noted after (8-) 13 days at $25^{\circ} \mathrm{C}$, developing slowly, examined after 24 52 days; first scant on distal aerial hyphae and in short shrubs close to the distal margin. Shrubs growing to white fluffy tufts appearing in a broad distal zone, spreading back across the entire plate. Tufts compacting to pustules $0.5-3 \mathrm{~mm}$ diam, to $1 \mathrm{~mm}$ thick, with roundish or irregular outline, often semiglobose or oblong, remaining transparent; of a loose reticulum with branches conspicuously at right angles and straight main axes emerging from the reticulum in right angles. Main axes $100-150(-200) \mu \mathrm{m}$ long, first appearing as erect sterile elongations. Branches and elongations beset with numerous small drops, appearing verrucose under low magnification, but dissolving in microscopic mounts. Elongations becoming fertile, i.e. conidiation first terminal, concentrated in the pustule periphery, later also within tufts, dense, eventually making them opaque. Conidiophores (main axes and side branches) 4-6 $\mu \mathrm{m}$ wide basally, attenuated upwards to $2.5-4 \mu \mathrm{m}$, smooth in microscopic preparations, sometimes with clamp-like thickenings, stipitate, with branches generally widely spaced, typically with a short terminal cluster of phialides and/or few short perpendicular branches, and with or without paired or unpaired, short, 1-4 celled side branches along their length. Clusters and side branches $15-40(-60) \mu \mathrm{m}$ long, generally in right angles, typically of a terminal phialide or whorl of phialides and additional phialides or short, sometimes rebranching, branches on 1-3 levels below the terminal whorl, each branch with a whorl of phialides. Conidiophores with a regular treelike shape uncommon. Phialides solitary or divergent, sometimes parallel, in whorls of 2-5(-6), often supported by short cells 4-6×2.5-4 $\mu \mathrm{m}$. Conidia formed in small numbers in minute wet heads to $20 \mu \mathrm{m}$ diam, often densely packed. Phialides (4.5-)5.5-9.0(-12.5)×(2.3-)2.5-3.2(-3.5) $\mu \mathrm{m}, 1 /$ $\mathrm{w}(1.5-) 1.9-3.1(-4.7),(1.4-) 1.8-2.5(-3.0) \mu \mathrm{m}$ wide at the base $(n=78)$, lageniform, less commonly ampulliform, mostly inaequilateral, straight or curved, rarely sinuous, with widening in variable position, mostly in or below the middle. Conidia $(2.5-) 2.8-3.5(-4.2) \times 2.0-2.5(-3.0) \mu \mathrm{m}, 1 / \mathrm{w}(1.0-)$ $1.2-1.5(-1.8)(n=125)$, hyaline, ellipsoidal, less commonly subglobose or oblong, smooth, with several minute guttules, scar indistinct. At $15^{\circ} \mathrm{C}$ no conidiation seen.

Habitat: on recently dead culms of Juncus effusus, and gramineous and herbaceous plants.

Distribution: Europe (Denmark, Germany, United Kingdom).

Holotype: United Kingdom, Warwickshire, Olton Reservoir, base of Juncus stems, 13 Sep. 1884, W.B. Grove (K(M) 154041). Epitype: United Kingdom, Derbyshire, Baslow, Longshaw Country Park, Peak District National Park, 53 $18^{\prime}$ $26^{\prime \prime} \mathrm{N}, 01^{\circ} 36^{\prime} 08^{\prime \prime} \mathrm{W}$, elev. $350 \mathrm{~m}$, on dead culms of Juncus effusus 2-5 mm thick, also on a leaf of Acer sp., soc. imperfect microfungi, 10 Sep. 2004, H. Voglmayr \& W. Jaklitsch, W.J. 2694 (WU 29410, ex-epitype culture CBS 120924=C.P.K. 1970). Holotype of Trichoderma placentula isolated from WU 29410 and deposited as a dry culture with the epitype of $H$. placentula as WU 29410a.

Additional material examined: Denmark, Nordjylland, Tranum Strand, behind the Himmerlandsfondens Kursus- og Feriecenter Tranum Strand, $57^{\circ} 09^{\prime} 04^{\prime \prime} \mathrm{N}, 09^{\circ} 26^{\prime} 12^{\prime \prime}$ E, elev. 
$6 \mathrm{~m}$, on mostly basal parts of Juncus effusus stems, 24 Aug. 2006, H. Voglmayr \& W. Jaklitsch, W.J. 2943 (WU 29411, culture C.P.K. 2446). Germany, Niedersachsen, Landkreis Soltau-Fallingbostel, Soltau, Großes Moor, entering from Wardböhmen, 52 $51^{\prime} 09^{\prime \prime} \mathrm{N}, 09^{\circ} 56^{\prime} 28^{\prime \prime}$ E, elev. $70 \mathrm{~m}$, on standing, dead and partly still green and thick tough culms of Juncus effusus, spreading to leaves, soc. old microfungi; 27 Aug. 2006, H. Voglmayr \& W. Jaklitsch, W.J. 2952 (WU 29412, culture CBS $121134=$ C.P.K. 2452). United Kingdom, Anglesey, Newborough Warren, on decaying stem of ? Epilobium angustifolium, Sep. 1988, P. Roberts (K; only culture IMI 328575 examined). Lancashire, Ribble Valley, Clitheroe, north from and close to Dunsop Bridge, 53 ${ }^{\circ} 56^{\prime} 44^{\prime \prime}$ $\mathrm{N}, 02^{\circ} 32^{\prime} 28^{\prime \prime} \mathrm{W}$, elev. $300 \mathrm{~m}$, on dead culms of Juncus effusus, 6 Sep. 2007, H. Voglmayr \& W. Jaklitsch, W.J. 3139 (WU 29413, culture C.P.K. 3140).

Notes: Hypocrea placentula was described by Grove (1885) in a detailed manner including the anamorph on the natural substrate. Spooner and Williams (1990) redescribed it based on stromata grown on ?Epilobium angustifolium, prepared a culture and added a description of the anamorph in culture including a SEM image of the conidia. Their isolate IMI 328575 is identical in gene sequences and in the anamorph with recently collected material. It differs from $H$. pilulifera, which exceptionally occurs on culms of Juncus, by smaller and more homogeneously pigmented stromata, smaller perithecia, smaller ascospores with more distinctly dimorphic cells, a deeply yellow cortex and peridium, the latter turning red in $\mathrm{KOH}$, presence of hairlike outgrowths on the stroma surface, more distinctly lageniform phialides, ellipsoidal conidia, conidiation on stipitate conidiophores becoming fertile from the tuft periphery, faster growth with its optimum at a higher temperature, and a different hyphal system lacking peg-like secondary hyphae in $H$. placentula.

\section{European species of Hypocrea section Hypo- creanum and other species forming large effused to subpulvinate stromata}

\section{Introduction}

Trichoderma section Hypocreanum was established by Bissett (1991a) for anamorphs of Hypocrea (and Podostroma), with the type species $T$. lacteum Bissett [as T. lactea] formally described as the anamorph of $H$. citrina. Species of this section have primitive, sparsely branched, acremonium- to verticillium-like conidiophores and hyaline conidia highly variable in shape. Respective anamorphs are only rarely encountered in nature, which may be the reason why workers in this group did not establish combinations in Trichoderma. Epithets in Trichoderma for this section are here only established for newly described species, combinations for earlier described species are left to future researchers.

Stromata are usually large, widely effused or subpulvinate. Species of the section were reviewed by Overton et al. (2006a, b), who clarified the nomenclature of $H$. citrina and determined the phylogenetic positions of the species. Unfortunately several species, particularly some described by Doi (1972) from Japan, could not be subjected to sequencing yet. Acremonium- or verticillium-like conidiophores are plesiomorphic; they occur also in other clades than the phylogenetically conceived section Hypocreanum, and even outside generic limits. In terms of teleomorph morphology, several species of other clades form similar stromata, viz. Hypocrea luteffusa of the pachybasium core group and the species of the Brevicompactum clade. These species differ from those described here by green-conidial anamorphs and smaller stromata with minute cortical cells. This chapter describes species of Hypocrea/Trichoderma section Hypocreanum including some species of Hypocrea outside this section, with similar conidiophores and at the same time effused stromata reduced to subicula located 'basal' in the phylogenetic tree of the genus (Fig. 1).

\section{Species descriptions}

The following ten species including two new ones are described below: $H$. alcalifuscescens, $H$. austriaca, $H$. citrina, $H$. decipiens, $H$. delicatula, $H$. parmastoi, $H$. phellinicola, $H$. protopulvinata, $H$. pulvinata, and $H$. sulphurea. Hypocrea austriaca is based on H. fungicola f. raduli.

Hypocrea alcalifuscescens Overton, Stud. Mycol. 56: 62 (2006) Fig. 53

The holomorph of this species was described by Overton et al. (2006b). The following short description of the teleomorph is based on a re-examination of the holotype.

Stromata when dry 3-15×2.4-6.7 mm, 0.1-0.4 mm thick; effused, thin, entirely attached; surface finely downy, with circular, slightly papillate, black ostiolar dots (30-)37-60(-71) $\mu \mathrm{m}(n=30)$ diam; olivaceous-brown to yellow-brown, 3-5F46 to 5F7-8; similar when young and immature, but lacking ostiolar dots. A $\mathrm{KOH}$-treated spot became hard, dark grey with silver shine and papillate surface (ostioles). Perithecia immersed in a single layer, peridium yellow in $\mathrm{KOH}$. Ostioles with partly clavate cells on apices, 3-5 $\mu \mathrm{m}$ wide. Stroma tissues entirely prosenchymatous, a $t$. intricata of hyphae $(2.5-) 3.0-10.5(-18.5) \mu \mathrm{m}(n=45)$ wide, thin-walled, hyaline to dilute olive-yellow, with stronger pigmentation close to the surface; hyphae in part submoniliform with distinctly inflated cells. Asci (89-)93-114(-127)×(4.5-)5.0-5.7(-6.5) $\mu \mathrm{m}$ 

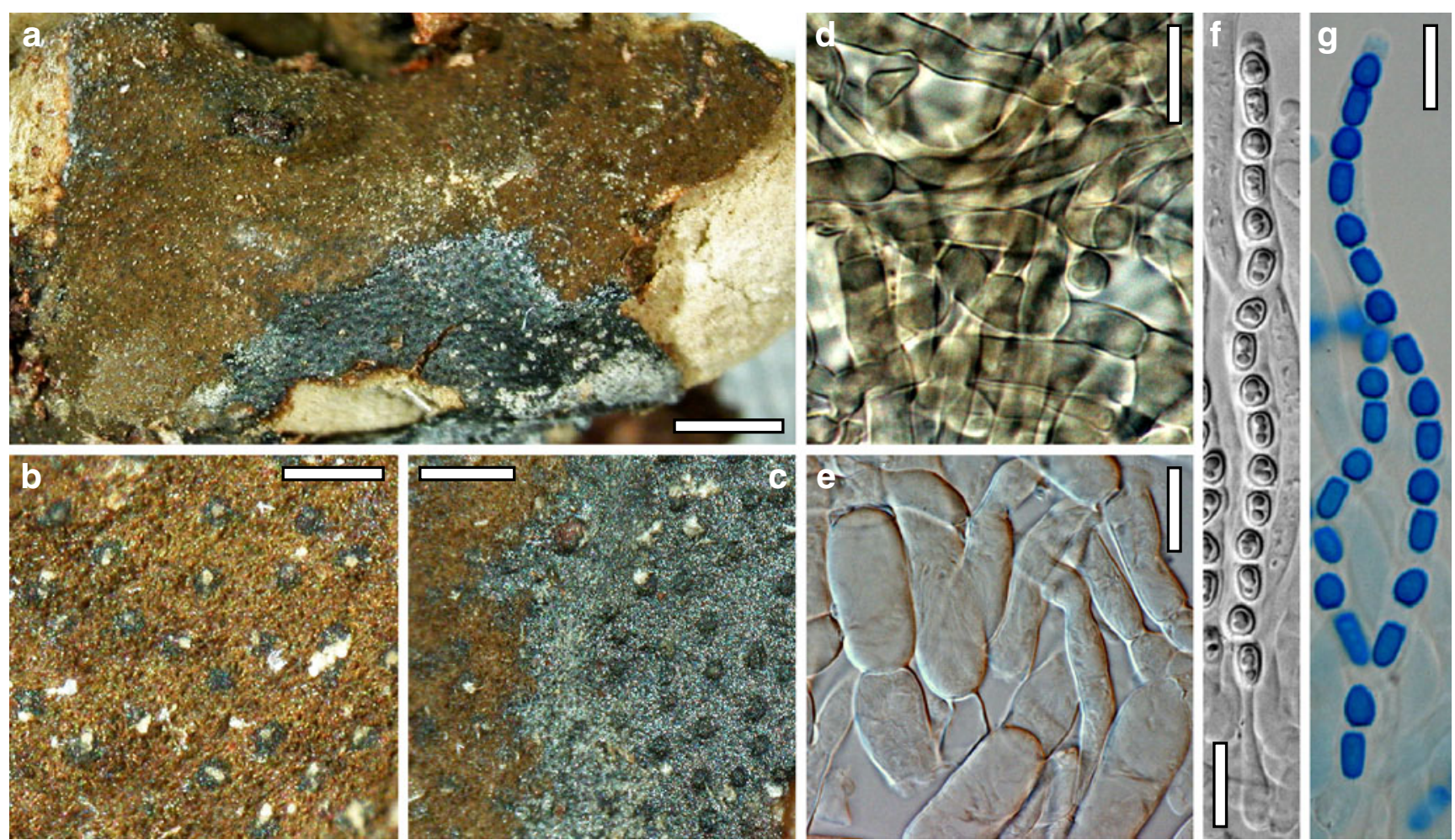

surface, e. submoniliform hyphae). f, g. Asci (g. in cotton blue/lactic

Fig. 53 Teleomorph of Hypocrea alcalifuscescens (holotype BPI 843638). a-c. Dry stroma (b. part of $\mathrm{KOH}$-treated spot; c. stroma surface with ostiolar dots). d, e. Subiculum hyphae (d. close to the

$(n=30)$, stipe $(7-) 10-27(-42) \mu \mathrm{m}(n=30)$ long; no croziers seen. Ascospores hyaline, smooth to finely verruculose, cells dimorphic; distal cell $(3.5-) 3.8-4.5(-5.0) \times(3.3-) 3.5-3.7(-$ 4.0) $\mu \mathrm{m}, 1 / \mathrm{w}(1-) 1.1-1.3(-1.5) \quad(n=30)$, (sub)globose to ellipsoidal, less commonly wedge-shaped; proximal cell $(3.7-) 4.4-5.6(-6.2) \times(2.7-) 2.8-3.0(-3.2) \mu \mathrm{m}, 1 / \mathrm{w}(1.3-) 1.5-$ $1.9(-2.2)(n=30)$, oblong (to ellipsoidal or subglobose).

Habitat: on a Piloderma or Amauroderma sp. on forest debris

Distribution: Europe (Estonia) and USA (Delaware).

Holotype: Estonia, on a Piloderma (?Amauroderma) sp., 13 Sep. 2000, U. Kõljalg, BPI 843638, ex-type culture TFC 2000-36).

Notes: This is one of the few species in Hypocrea that exhibit an entirely prosenchymatous stroma. In addition, it differs from all other species of the genus in its olive colour. Hypocrea alcalifuscescens is probably fungicolous. In the holotype the corticiaceous host (pale yellow loose mycelium without clamps) grew apparently on bark of Picea or Pinus and saw dust. Whether the specimen reported by Overton et al. (2006b) from bark of Liriodendron in Delaware, USA represents the same species is unclear, because no gene sequences from this specimen are available.

Hypocrea austriaca Jaklitsch \& Voglmayr, sp. nov. Fig. 54 acid). Scale bars $\mathbf{a}=1.5 \mathrm{~mm} . \mathbf{b}=0.4 \mathrm{~mm} . \mathbf{c}=150 \mu \mathrm{m} . \mathbf{d}-\mathbf{g}=10 \mu \mathrm{m}$

MycoBank MB 516670

= Hypocrea fungicola f. raduli Höhn. in Rehm, Ann. Mycol. 3: 227 (1905).

Anamorph: Trichoderma austriacum Jaklitsch, sp. nov. Fig. 55

MycoBank MB 516671

Stromata late effusa, lutea, $1-60 \times 1-20 \mathrm{~mm}$. Asci cylindrici, (64-)81-106(-115)×(4.8-)5.4-6.6(-8.0) $\mu \mathrm{m}$. Ascosporae bicellulares, hyalinae, verruculosae vel spinulosae, ad septum disarticulatae, pars distalis (sub)globosa vel ellipsoidea, $(3.7-) 4.2-5.0(-5.7) \times(3.0-) 3.6-4.2(-4.7)$ $\mu \mathrm{m}$, pars proxima ellipsoidea vel oblonga, (4.3-)4.7-5.6($6.5) \times(2.8-) 3.2-3.8(-4.5) \mu \mathrm{m}$. Anamorphosis Trichoderma austriacum. Conidiophora in agaro PDA effuse disposita, simplicia, ramis sparsis brevibus praedita, similia Acremonii vel Verticillii. Phialides divergentes, subulatae vel lageniformes, (9-)15-30(-46)×(2.3-)3.0-3.5(-4.0) $\mu \mathrm{m}$. Conidia oblonga, cylindracea vel ellipsoidea, hyalina, glabra, (3.7-) $4.7-10(-18) \times(2.3-) 3.0-4.0(-5.5) \mu \mathrm{m}$.

Etymology: referring to its occurrence in Austria.

Stromata when fresh $1-60 \times 1-20 \mathrm{~mm}, 0.3-0.8(-1.2) \mathrm{mm}$ thick, thinly and widely effuse, sometimes appearing subpulvinate due to substrate protuberances. Outline variable. Margin mostly broadly rounded, with free edges. Surface smooth, sometimes with white floccules when young. 

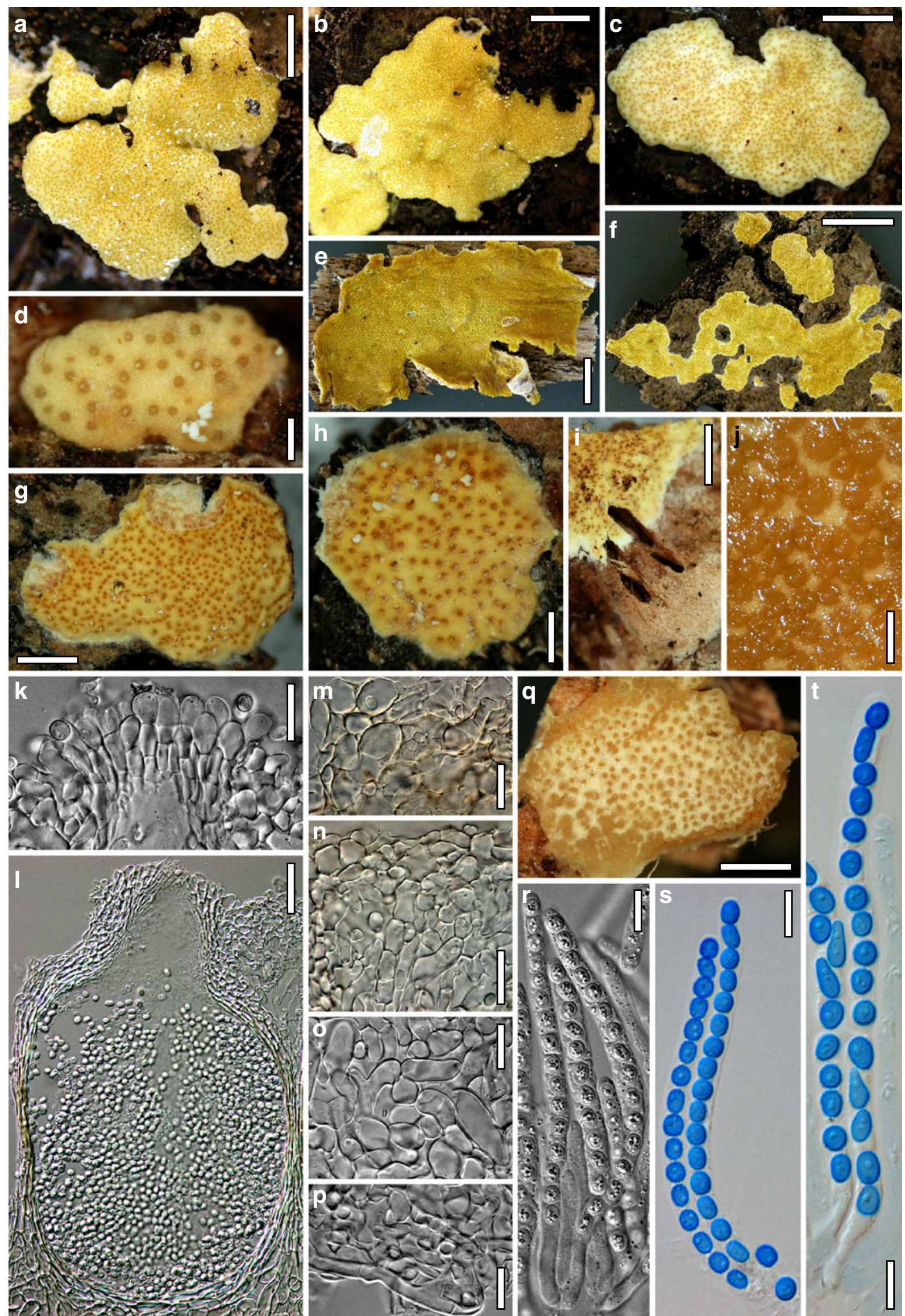
4 Fig. 54 Teleomorph of Hypocrea austriaca. a-d. Fresh stromata. e-i. Dry stromata (i. part of stroma on basidiome of Eichleriella deglubens). j. Stroma surface in $3 \% \mathrm{KOH}$ after rehydration. k. Ostiole in section. l. Perithecium in section. $\mathbf{m}$. Surface of stroma in face view. n. Cortical and subcortical tissue in section. o. Subperithecial tissue in section. p. Stroma base in section. q. Rehydrated stroma. r-t. Asci with ascospores (s, $\mathbf{t}$. in cotton blue/lactic acid). $\mathbf{a}-\mathbf{c}, \mathbf{f}-\mathbf{h}, \mathbf{j}-\mathbf{q}, \mathbf{s}$. WU 29193. d. WU 29194. e, r. WU 29192. i, t. H. fungicola f. raduli (FH). Scale bars $\mathbf{a}, \mathrm{c}=2 \mathrm{~mm} . \mathbf{b}, \mathbf{e}=3 \mathrm{~mm} . \mathbf{d}, \mathbf{j}=0.3 \mathrm{~mm} . \mathbf{f}=7 \mathrm{~mm} . \mathbf{g}, \mathbf{i}$, $\mathbf{q}=1 \mathrm{~mm} . \mathbf{h}=0.5 \mathrm{~mm} . \mathbf{k}, \mathbf{m}, \mathbf{n}, \mathbf{p}=15 \mu \mathrm{m} . \mathbf{l}=30 \mu \mathrm{m} . \mathbf{o}=20 \mu \mathrm{m} . \mathbf{r}-\mathbf{t}=$ $10 \mu \mathrm{m}$

Ostiolar dots plane, pale yellow to yellow-brown on a white to pale yellowish stroma surface. Resulting stroma colour pale or greyish yellow, 3A2-6, 3B4-8. Spore deposits white.

Stromata when dry $1-26(-55) \times(0.5-) 1-11(-28) \mathrm{mm}$, $0.1-0.6(-0.8) \mathrm{mm}$ thick $(n=44)$, solitary, gregarious or aggregated in small numbers; with effluent development, i.e. formed in a large mass, breaking up into smaller stromata, forming blank spaces within; thin, membranaceous, widely effuse, first entirely attached, often becoming detached at the margins; easily detachable from wood. Outline variable, oblong, lobed or circular. Margin usually compact and rounded, less commonly with white, compact, rarely arachnoid white marginal mycelium or radiating hyphae. Surface smooth or tubercular due to unevenness of the substrate. Ostiolar dots (30-)40-90(-160) $\mu \mathrm{m}(n=80)$ diam, numerous and densely disposed, plane or convex, diffuse and pale yellow when young, well-defined, circular and bright yellow, reddish orange or brown when mature. Colour more intense than in fresh stromata, typically bright yellow, 3A4-7, 4A45, or greyish- to orange-yellow, 4B4-7. Rehydrated stromata distinctly lighter in colour than dry ones, white with welldefined, convex, pale yellow-ochre dots 80-105(-240) $\mu \mathrm{m}$ diam; when wet (after prolonged incubation) entire surface homogeneously coloured like the ostiolar dots. After addition of $3 \% \mathrm{KOH}$ no distinct colour change noted, but perithecia swelling and dots larger, 150-250 $\mu \mathrm{m}$, i.e. larger parts of perithecial walls becoming visible.

Stroma anatomy: Ostioles (64-)72-88(-98) $\mu \mathrm{m}$ long, plane or projecting to $30(-40) \mu \mathrm{m},(36-) 48-70(-80) \mu \mathrm{m}$ wide at the apex $(n=30)$, cylindrical, periphysate, with a marginal palisade of clavate or (sub)globose terminal cells, 5-10(-13) $\mu \mathrm{m}$ wide, at the apex. Perithecia (185-)215-270(-305) $\times$ $(100-) 145-230(-260) \mu \mathrm{m}(n=30)$, globose or flask-shaped. Peridium (13-)15-22(-26) $\mu \mathrm{m}$ thick at the base, (7-)10-17(19) $\mu \mathrm{m}$ at the sides $(n=30)$, pale yellowish, at the base often difficult to differentiate from subperithecial tissue. Cortical layer $(20-) 24-40(-54) \mu \mathrm{m}(n=30)$ thick, a hyaline to pale yellowish $t$. angularis of isodiametric or oblong, thin-walled cells $(5-) 7-18(-32) \times(4-) 5-13(-20) \mu \mathrm{m}(n=35)$ in face view, and $(4-) 5-15(-23) \times(3.5-) 4.5-7.5(-10) \mu \mathrm{m}$ in vertical section $(n=35)$; pale yellow in $\mathrm{KOH}$. No hairs, but some solitary, projecting cells seen on surface. Subcortical tissue if present a $t$. intricata of hyaline, thin-walled hyphae (2.5-)4-8 $(-9) \mu \mathrm{m}(n=30)$ wide. Subperithecial tissue narrow, a hyaline t. angularis of thin-walled cells (6-)10-31(-43) $\times(6-) 8-17(-$ 25) $\mu \mathrm{m}(n=35)$, interspersed with some wide hyphae. Base consisting of a narrow layer of variably oriented, thickwalled, (sub)hyaline hyphae $(2.5-) 3.5-7.0(-9.5) \mu \mathrm{m}(n=30)$ wide. Asci $(64-) 85-113(-126) \times(4.8-) 5.5-7.0(-8.0) \mu \mathrm{m}$, stipe $(0-) 3-23(-47) \mu \mathrm{m}$ long $(n=80)$. Ascospores hyaline, verruculose or finely spinulose, cells dimorphic, often with little difference between cells; distal cell (3.7-)4.3-5.5($6.5) \times(3.0-) 3.7-4.5(-5.0) \mu \mathrm{m}, 1 / \mathrm{w}(0.9-) 1.1-1.3(-1.6) \quad(n=$ 168), (sub)globose or ellipsoidal; proximal cell (4.0-)4.5-6.5 $(-9.2) \times(2.8-) 3.2-4.0(-4.5) \mu \mathrm{m}, 1 / \mathrm{w}(1.1-) 1.3-1.8(-2.4)(n=$ $168)$, ellipsoidal, oblong or wedge-shaped.

Cultures and anamorph: optimal growth at $25^{\circ} \mathrm{C}$ on all media; no growth at $35^{\circ} \mathrm{C}$.

On CMD after $72 \mathrm{~h} 13-20 \mathrm{~mm}$ at $15^{\circ} \mathrm{C}, 38-40 \mathrm{~mm}$ at $25^{\circ} \mathrm{C}, 30-33 \mathrm{~mm}$ at $30^{\circ} \mathrm{C}$; mycelium covering plate after 5 days at $25^{\circ} \mathrm{C}$. Colony hyaline, thin, not zonate; mycelium loose, little on the surface, with conspicuously thick primary and thin secondary hyphae, surface hyphae soon appearing empty; mycelium becoming dense in the distal half, with long aerial hyphae and conidiophores on the colony surface. Aerial hyphae scant, becoming more frequent with time and forming white floccules after $c a$ 2 weeks, causing a mottled appearance of the colony surface. No autolytic excretions noted, coilings inconspicuous. No diffusing pigment, no distinct odour noted. Conidiation noted after 3-4 days, scant, short, simple, acremonium- to irregularly verticillium-like, longer and slightly denser towards the distal margin, also submerged in the agar. Phialides scattered and solitary on surface hyphae, or in whorls of 3-4. Conidia densely packed in minute heads, first wet, soon dry. Chlamydospores noted after 57 days, measured after 17 days, (6-)9-22(-32) $\times(6-) 9-17(-$ 22) $\mu \mathrm{m}, 1 / \mathrm{w} 0.9-1.5(-2.3)(n=32)$, uncommon and with uneven distribution, globose, also oblong, ellipsoidal, oval or clavate, terminal and intercalary.

On PDA after $72 \mathrm{~h} \mathrm{4-7} \mathrm{mm}$ at $15^{\circ} \mathrm{C}, 8-13 \mathrm{~mm}$ at $25^{\circ} \mathrm{C}$, 4-5 $\mathrm{mm}$ at $30^{\circ} \mathrm{C}$; mycelium covering plate after 6 days at $25^{\circ} \mathrm{C}$. Growth slow with a distinct lag phase of $\mathrm{ca} 2$ days, followed by considerably faster logarithmic growth. Colony circular, dense, margin wavy to sublobed; hyphae with short, forked terminal branches at the colony margin; surface becoming white and hairy due to aerial hyphae. Aerial hyphae numerous, wide, radially arranged, forming strands and large crossing points and drops. Centre remaining flat, with few aerial hyphae, turning yellow, pale orange, greyish orange to brown-orange, 5AB4, 5BC5-6. No autolytic excretions noted, coilings inconspicuous. Odour indistinct or slightly must-like. Conidiation noted after 3 days, effuse, concentrated in the flat centre, also spreading in a lawn at low levels, short or ascending on 

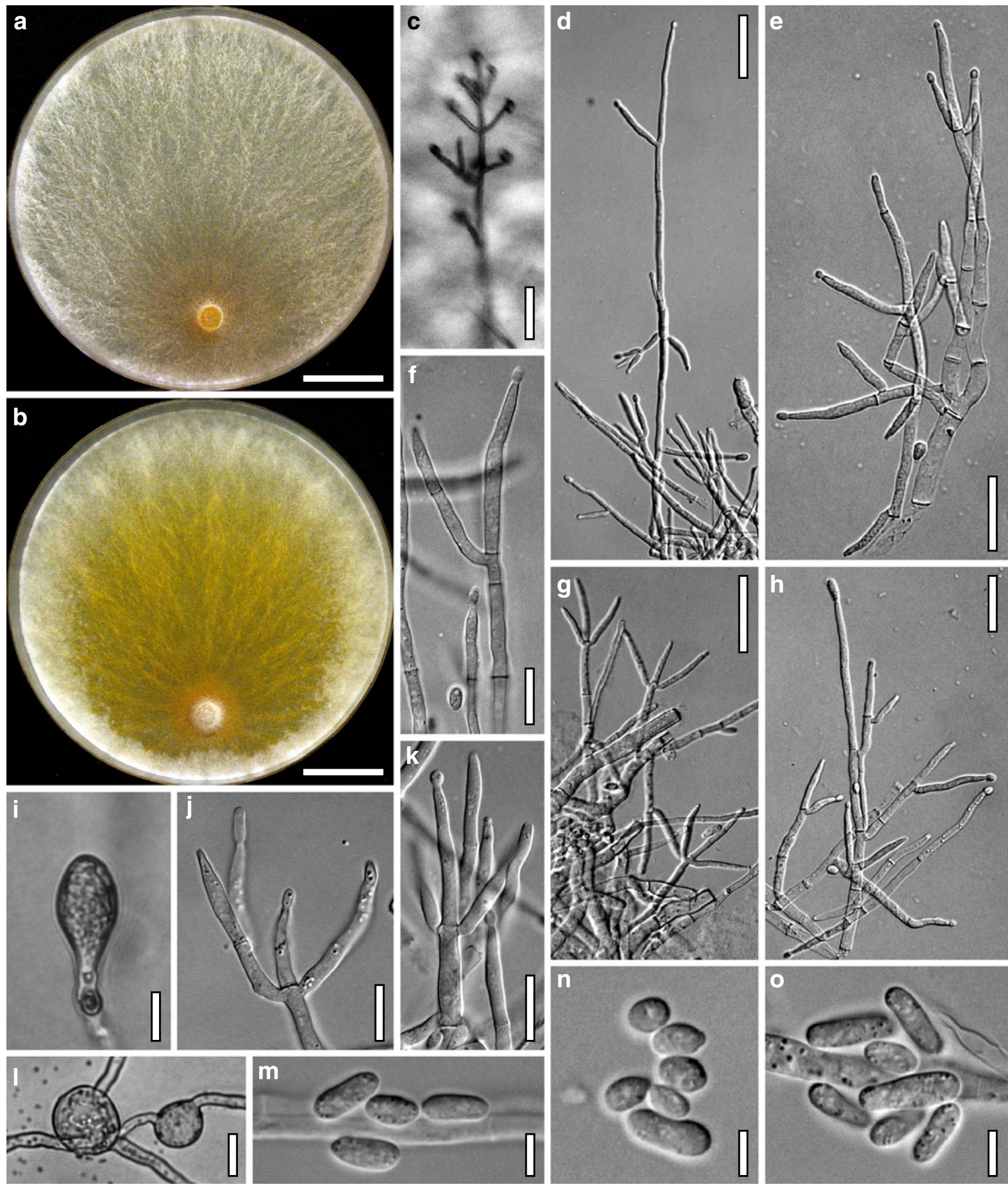

Fig. 55 Cultures and anamorph of Hypocrea austriaca. a, b. Cultures on PDA (a. $25^{\circ} \mathrm{C}, 7$ days. b. $30^{\circ} \mathrm{C}, 10$ days). c. Conidiophore on growth plate. d, e, $\mathbf{g}, \mathbf{h}$. Conidiophores. $\mathbf{f}, \mathbf{j}, \mathbf{k}$. Phialides. i, $\mathbf{l}$. Chlamydospores (CMD, 17 days). m-o. Conidia. a-o. All on/from

PDA except $\mathbf{i}$ and $\mathbf{l} . \mathbf{c}-\mathbf{h}, \mathbf{j}, \mathbf{k}, \mathbf{m}-\mathbf{o}$. At $25^{\circ} \mathrm{C}$ after 4 days. a-d, $\mathbf{g}, \mathbf{i}, \mathbf{k}$, l. CBS 122494. e, f, h, j, m-o. CBS 122770. Scale bars $\mathbf{a}, \mathbf{b}=19 \mathrm{~mm}$. c, $\mathbf{d}, \mathbf{g}=40 \mu \mathrm{m}$. e, $\mathbf{h}=20 \mu \mathrm{m}$. $\mathbf{f}, \mathbf{i}-\mathbf{l}=10 \mu \mathrm{m}$. $\mathbf{m}-\mathbf{0}=5 \mu \mathrm{m}$ 
aerial hyphae, simple, acremonium- to irregularly verticillium-like. Conidiophores loosely disposed, mostly to $200(-300) \mu \mathrm{m}$ long on surface hyphae, ca $100 \mu \mathrm{m}$ long on aerial hyphae; simple, of a thick-walled axis, 6-10 $\mu \mathrm{m}$ wide at and close to the base, attenuated upward to $4-6 \mu \mathrm{m}$, unbranched, with solitary phialides or a single terminal whorl of phialides, or with sparse, short, typically unpaired, 1-celled side branches in various angles, also downward, 2$3(-4) \mu \mathrm{m}$ wide, corresponding to the width of the phialide origins. Phialides often solitary or divergent in whorls of 2 4. Phialides (9-) $15-30(-46) \times(2.3-) 3.0-3.5(-4.0) \mu \mathrm{m}, 1 /$ w (3.1-)4.8-9.4(-12), (1.4-)2.0-3.2(-4.0) $\mu \mathrm{m}$ wide at the base $(n=70)$, subulate or lageniform, mostly equilateral, widest at or slightly above the base, symmetric or slightly curved or sinuous. Conidia mostly formed in dry heads $<30 \mu \mathrm{m}$ diam; conidia (3.7-)4.7-10(-18) $\times(2.3-) 3.0-4.0(-$ 5.5) $\mu \mathrm{m}, 1 / \mathrm{w}(1.2-) 1.4-2.8(-4.4)(n=70)$, hyaline, smooth, variable, mostly oblong, but also ellipsoidal or subglobose (small) or long-cylindrical (large), with or without minute guttules, scar indistinct or truncate; often adhering in globose packets of $c a 5(-10)$. At $30^{\circ} \mathrm{C}$ colony circular, thick, dense. Aerial hyphae forming strands arranged in a stellate manner, becoming yellow-orange. Conidiation inconspicuous, spreading across the plate. Diffusing pigment discolouring the agar bright yellow, 3A4-8, 4AB5-6, from the centre, changing to bright orange, $4 \mathrm{~A} 7-8,5 \mathrm{AB} 6-8$; margin subsequently becoming covered by white cottony mycelium.

On SNA after $72 \mathrm{~h} 6-9 \mathrm{~mm}$ at $15^{\circ} \mathrm{C}, 16-20 \mathrm{~mm}$ at $25^{\circ} \mathrm{C}$, $12-17 \mathrm{~mm}$ at $30^{\circ} \mathrm{C}$; mycelium covering the plate after 9 days at $25^{\circ} \mathrm{C}$. Colony circular, considerably denser than on CMD, indistinctly zonate; margin ill-defined; superficial mycelium locally condensed to $0.5 \mathrm{~mm}$ diam with numerous conidial heads on the top. Aerial hyphae inconspicuous, loose, becoming fertile. Autolytic excretions scant, coilings moderate. Chlamydospores noted after 57 days, uncommon, variable, terminal and intercalary. Conidiation noted after 2 days, similar to but more pronounced than that on CMD, mostly acremonium-like; conidia formed in wet heads $<50 \mu \mathrm{m}$ diam.

Habitat: on and around basidiomes of Eichleriella deglubens, particularly on branches of Populus tremula.

Distribution: Eastern Austria.

Holotype: Austria, Vienna, 23rd district, Maurer Wald, MTB 7863/4, 48 $09^{\prime} 00^{\prime \prime} \mathrm{N} 16^{\circ} 15^{\prime} 11^{\prime \prime}$ E, elev. $330 \mathrm{~m}$, on basidiomes of Eichleriella deglubens on a branch of Populus tremula, also on bark, wood and effete ?Cryptosphaeria lignyota, soc. hyphomycetes, 4 Oct. 2007, H. Voglmayr, W.J. 3175 (WU 29193, ex-type culture CBS 122494=C.P.K. 3165). Holotype of Trichoderma austriacum isolated from WU 29193 and deposited as a dry culture with the holotype of $H$. austriaca as WU 29193a.

Other specimens examined: Austria, Burgenland, Bad Sauerbrunn, Hirmer Wald, MTB 8264/1, elev. ca 250 m, on basidiomes of Eichleriella deglubens on a branch of Populus tremula, soc. effete Cryptosphaeria lignyota in the bark, 10 Aug. 2008, A. Urban, W.J. 3213 (WU 29194, culture CBS 123829=C.P.K. 3538. Niederösterreich, Tulln, Langenschönbichler Donau-Auen, on Radulum kmetii (=Eichleriella deglubens) and bark of Populus sp., soc. effete ?Cryptosphaeria lignyota, Oct. 1904, Höhnel (Rehm: Ascomycetes exs. Fasc. 34, no. 1588; as H. fungicola $\mathrm{f}$. raduli in $\mathrm{M}$ ! and $\mathrm{FH}$ !). Weichtalklamm, south side of Schneeberg, MTB 8260/4, elev. ca $1000 \mathrm{~m}$, on a branch of ?Populus tremula, on wood, soc. effete pyrenomycete, and rhizomorphs, 17 Jun. 2007, A. Urban, W.J. 3101 (WU 29192, culture CBS $122770=$ C.P.K. 3124). Vienna, 23rd district, Maurer Wald, MTB 7863/4, on basidiomes of Eichleriella deglubens on Populus tremula, 8 Oct. 2009, H. Voglmayr, WU 29538.

Notes: Hypocrea austriaca appears to be specifically associated with the heterobasidiomycete Eichleriella deglubens. The latter occurs typically on Populus tremula in eastern Austria; basidiomes are usually sterile at the time of infection and stroma development. In the occurrence on a heterobasidiomycete and in morphology $H$. austriaca is similar to $H$. sulphurea, which differs in a more intense, deep yellow colour when fresh and by slightly larger ascospores from $H$. austriaca. Growth of $H$. austriaca on PDA is substantially slower than that of $H$. sulphurea or H. citrina. Hypocrea fungicola f. raduli was edited as a part of an exsiccatum by Rehm (1905). No description apart from collection data and the presumed host Radulum kmetii Bres. was given. The latter is now considered a synonym of Eichleriella deglubens (Berk. \& Broome) Lloyd. Two parts of Höhnel's specimen (from M and FH) were examined. They agree with recently collected material, except for some large aberrant ascospores. The basidiomycetous host is not apparent in the part in $\mathrm{M}$. Phylogenetically the closest relative of $H$. austriaca is the morphologically similar Australian H. victoriensis. No fungal host of the latter has been detected yet.

Hypocrea citrina (Pers. : Fr.) Fr., Summa Veg. Scand.: 383 (1849). Fig. 56

三Sphaeria citrina Pers., Obs. Mycol. 1: 68. 1796 : Fr., Syst. Mycol. 2: 337 (1823).

= Sphaeria lactea Fr., K. Svenska VetenskAkad. Handl. II, 37: 141. 1816 : Fr., Syst. Mycol. 2: 337 (1823).

$\equiv$ Hypocrea lactea (Fr. : Fr.) Fr., Summa Veg. Scand.: 383 (1849).

Anamorph: Trichoderma lacteum Bissett [sect. Hypocreanum Bissett], Can. J. Bot. 69: 2367 (1991a). Fig. 57

Stromata when fresh $1-40 \times 1-20 \mathrm{~cm}, 1-4 \mathrm{~mm}$ thick, widely effuse, indeterminate, covering large areas of tree stumps, forest soil and debris, usually spreading as one 


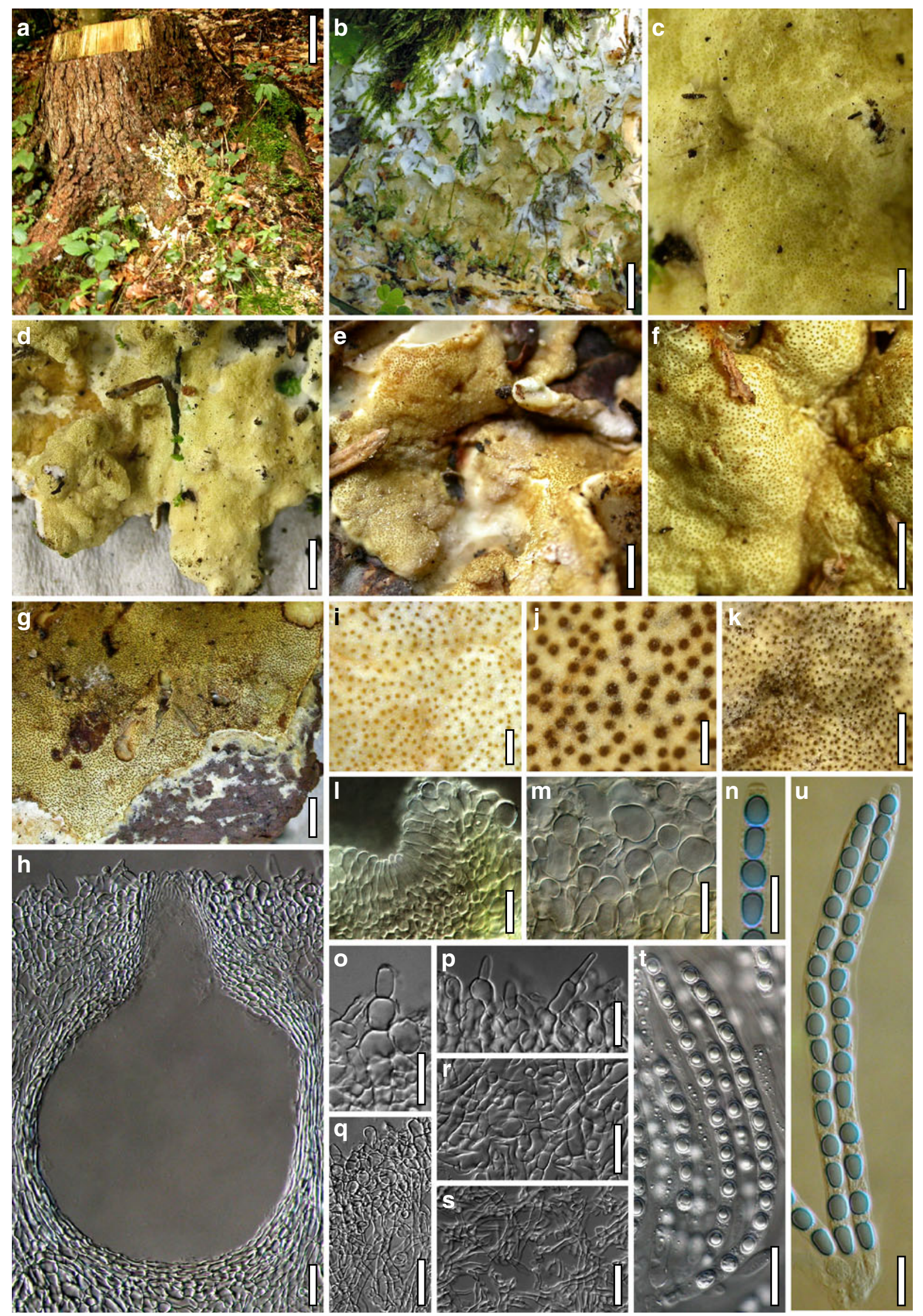


4Fig. 56 Teleomorph of Hypocrea citrina. a-f. Fresh stromata (a, b. habit). g. Part of old dry stroma. h. Perithecium in section. i-k. Stroma surface (i. fresh, j. dry, k. rehydrated). l. Ostiolar cells in section. m. Cortical tissue in face view. n. Ascus apex and ascospores (in cotton blue/lactic acid). o, p. Hairs on stroma surface. q. Cortical and subcortical tissue in section. r. Subperithecial tissue in section. s. Stroma base in section. $t, u$. Asci with ascospores (u. in cotton blue/lactic acid). a, e, f. WU 29210. b. WU 29214. c, d. WU 29211. g. WU 29207. h, i, k, o-s. WU 24803. j, l-n, u. WU 29533. t. WU 29208. Scale bars: $\mathbf{a}=10 \mathrm{~cm} . \mathbf{b}=40 \mathrm{~mm} . \mathbf{c}, \mathbf{k}=1 \mathrm{~mm} . \mathbf{d}=4 \mathrm{~mm}$. $\mathbf{e}-\mathbf{g}=2 \mathrm{~mm} . \mathbf{h}, \mathbf{q}-\mathbf{s}=$ $25 \mu \mathrm{m} . \mathbf{i}=0.5 \mathrm{~mm} . \mathbf{j}=0.2 \mathrm{~mm}$. $\mathbf{l}, \mathbf{m}, \mathbf{o}, \mathbf{p}, \mathbf{t}=15 \mu \mathrm{m} . \mathbf{n}, \mathbf{u}=10 \mu \mathrm{m}$

large mass on the substrate forming irregular patches with discontinuities, eventually sometimes dividing into discrete part stromata; entirely attached. Margin usually sterile, white or concolorous, mycelial. Surface smooth or irregularly wrinkled. Perithecia entirely immersed, ostiolar dots circular, brown. Colour whitish, pale citrine, greyish yellow, or light brown, 3A3-4, 3B4-6, 5D6-7, 4C7-8; dull and dark yellow- or olive-brown when old.

Stromata when dry $0.2-3.4 \mathrm{~mm}(n=33)$ thick, widely effuse, following and incrusting debris; starting as white mycelium, becoming compact, white with indistinct yellowish ostiolar dots, turning yellow with brown dots. Outline extremely variable. Margin often thin, cottony, white or yellowish. Surface smooth, becoming farinose due to spore powder. Ostiolar dots (35-)45-77(-90) $\mu \mathrm{m}(n=33)$ diam, in young stromata diffuse and honey coloured or yellowish-brown, later fine but distinct, plane to convex or semiglobose, medium, olive- or dark brown, numerous, variably arranged. Stromata at first white to pale yellow (corresponding to stroma surface with no or few ostiolar dots), 1-3A2, becoming dull or greyish yellow to olivebrown, or brown-orange, 2-4A2-3(-4), 3-4B3-4(-5), 4CD4-8, 5CD3-4, (5E6-8); white inside. Spore powder white or yellow. Rehydrated stromata not changing colour or turning slightly brownish in $3 \% \mathrm{KOH}$.

Stroma anatomy: Ostioles (55-)65-90(-115) $\mu \mathrm{m}$ long, projecting to $13(-20) \mu \mathrm{m},(30-) 34-51(-55) \mu \mathrm{m}$ wide at the apex $(n=20)$, periphysate, lined at the apex by hyaline, clavate to cylindrical cells to $7 \mu \mathrm{m}$ wide, broadly rounded at ends. Perithecia (166-)200-280(-300) $\times(82-) 130-210$ $(-230) \mu \mathrm{m} \quad(n=20)$, flask-shaped or globose, laterally compressed when crowded; peridium (14-)17-24(-27) $\mu \mathrm{m}$ thick at the base, (7-)9-16(-20) $\mu \mathrm{m}$ at the sides $(n=20)$, hyaline to pale yellowish. Cortical layer (22-)28-58(-87) $\mu \mathrm{m}(n=30)$ thick, a hyaline to pale yellowish $t$. globulosaangularis of thin-walled, globose, angular or oblong cells $(4-) 7-15(-20) \times(3.5-) 6-11(-15) \mu \mathrm{m}(n=60)$ in face view and in vertical section, penetrated by some hyphae of subcortical origin. Hairs on mature stroma (10-)16-30 $(-40) \times(3.5-) 5-9(-11) \mu \mathrm{m} \quad(n=20)$, inconspicuous, $1-3$ celled, smooth or slightly verruculose, of variable shape, often ampulliform or appearing as short, submoniliform chains of cells. Subcortical tissue a hyaline $t$. intricata of thin-walled hyphae $(2-) 4-7(-9) \mu \mathrm{m}(n=30)$ wide, in part appearing as $t$. globulosa due to variable orientation of hyphae. Subperithecial tissue a dense $t$. epidermoidea of thin-walled cells $(4.5-) 6-22(-34) \times(3.5-) 6-13(-16) \mu \mathrm{m}$ $(n=30)$, penetrated by hyphae $(4-) 5-10(-12) \mu \mathrm{m}(n=20)$ wide. Stroma base a loose hyaline $t$. intricata of thin-walled hyphae (3-)4-9(-12) $\mu \mathrm{m}(n=20)$ wide. Asci (84-)93-115 $(-124) \times(5.0-) 5.3-6.3(-7.0) \mu \mathrm{m}$, stipe $(2-) 5-17(-30) \mu \mathrm{m}$ long $(n=30)$; base not or slightly thickened, no croziers seen. Ascospores hyaline, verrucose or spinulose, cells dimorphic, distal cell (3.7-)4.4-5.2(-5.8) $\times(3.5-) 3.8-4.4(-4.8) \mu \mathrm{m}$, 1/w (1.0-)1.1-1.3(-1.5) $(n=90)$, subglobose, oval or oblong, proximal cell $(3.6-) 4.7-6.0(-7.0) \times(2.8-) 3.3-4.0(-4.3) \mu \mathrm{m}$, 1/w (1.0-)1.3-1.7(-2.1) $(n=90)$, oblong or wedge-shaped; often turning yellow or orange after ejection.

Cultures and anamorph: optimal growth at $25^{\circ} \mathrm{C}$ on $\mathrm{CMD}$ and PDA, at $25-30^{\circ} \mathrm{C}$ on SNA, faster on PDA than on CMD and SNA; no growth at $35^{\circ} \mathrm{C}$.

On CMD after $72 \mathrm{~h} 12-14 \mathrm{~mm}$ at $15^{\circ} \mathrm{C}, 42-49 \mathrm{~mm}$ at $25^{\circ} \mathrm{C}$, 33-36 $\mathrm{mm}$ at $30^{\circ} \mathrm{C}$; mycelium covering the plate after 4 5 days at $25^{\circ} \mathrm{C}$. Colony hyaline, hardly visible, thin, smooth, not zonate; hyphae loosely disposed, thick, sinuous, sometimes with submoniliform thickenings. Aerial hyphae sparse and short, longer towards the distal margin. No autolytic activity and coilings noted. No distinct odour, no pigment noted, but agar sometimes becoming slightly reddish brown after prolonged storage. Chlamydospores noted after 810 days, infrequent. Conidiation noted after 4-6 days, effuse, sparse, mostly in the distal half of the plate, macroscopically invisible, colourless. Conidiophores simple, verticillium-like, phialides subulate, conidial heads wet, large. At $15^{\circ} \mathrm{C}$ concentric zones of unequal width noted, conidiation after $2-$ 3 weeks sometimes in compact white pustules, with phialides in part converging gliocladium-like. Chlamydospores abundant, noted after $4-5$ days. At $30^{\circ} \mathrm{C}$ slight diffuse greenishyellowish pigment noted in the agar after 1 weeks. Conidiation noted after $2-3$ days, more abundant than at $25^{\circ} \mathrm{C}$, mainly along the margin; conidiophores acremonium- and verticillium-like, phialides subulate, in whorls of 2-3.

On PDA after $72 \mathrm{~h} 11-12 \mathrm{~mm}$ at $15^{\circ} \mathrm{C}, 54-56 \mathrm{~mm}$ at $25^{\circ} \mathrm{C}$, $43-48 \mathrm{~mm}$ at $30^{\circ} \mathrm{C}$; mycelium covering the plate after 4 days at $25^{\circ} \mathrm{C}$. Mycelium dense, surface hyphae conspicuously thick, becoming submoniliform around the plug. Aerial hyphae sparse in the centre, conspicuous in other parts, thick, radially arranged, forming a thick and dense, cottony mat reaching the lid of the Petri dish, collapsing and condensing into strands within a week. No autolytic activity noted, coilings inconspicuous. No distinct odour noted; diffusing pigment formed, yellow to orange, 3-4A4-7 to 4B5-7. Conidiation noted after 3 days, effuse, white, verticilliumlike, starting at the proximal margin and in the centre, spreading across the entire plate, abundant and ascending on 

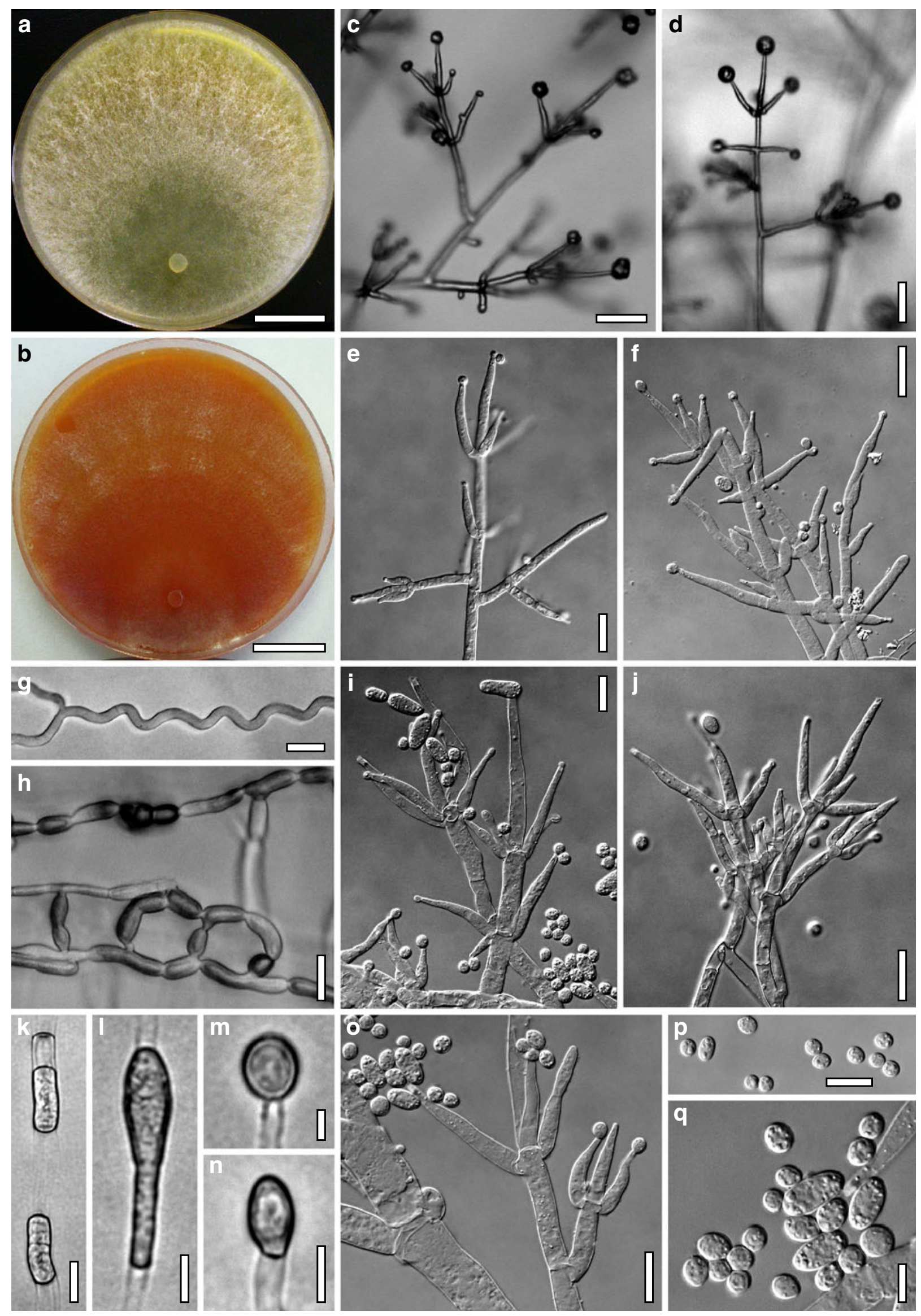
4 Fig. 57 Cultures and anamorph of Hypocrea citrina (CBS 121278). a, b. Cultures on PDA (a. $25^{\circ} \mathrm{C}, 7$ days. b. $30^{\circ} \mathrm{C}, 12$ days). c, d. Conidiophores on growth plate (5-8 days). e, f, i, j. Conidiophores (9 days). g, h. Hyphae in culture after 3 days (g. sinuous, on CMD; $\mathbf{h}$. submoniliform, from the colony centre, on PDA). k-n. Chlamydospores (k, l. intercalary; $\mathbf{m}, \mathbf{n}$. terminal; $11-20$ days, $\left.\mathbf{l} .15^{\circ} \mathrm{C}\right)$. $\mathbf{0}$. Phialides and conidia (9 days). p, q. Conidia (9 days). c-q. On SNA except $\mathbf{g}$ and $\mathbf{h} . \mathbf{c}-\mathbf{q}$. At $25^{\circ} \mathrm{C}$ except $\mathbf{l}$. Scale bars $\mathbf{a}, \mathbf{b}=20 \mathrm{~mm}$. c, $\mathbf{d}$, $\mathbf{g}, \mathbf{h}=30 \mu \mathrm{m}$. e, $\mathbf{f}, \mathbf{j}, \mathbf{k}=15 \mu \mathrm{m}$. i, l, $\mathbf{n}-\mathbf{p}=10 \mu \mathrm{m}$. $\mathbf{m}, \mathbf{q}=5 \mu \mathrm{m}$

aerial hyphae. At $30^{\circ} \mathrm{C}$ alternating broad and narrow concentric zones, flat radial mat of aerial hyphae and abundant conidiation after 2-3 days produced. Pigment conspicuous, more intense than at $25^{\circ} \mathrm{C}$, first light yellow to orange-yellow, 2-3A3-6, 4AB7-8, turning bright orange, golden yellow to orange-brown, 5BC7-8, 6AC6-8, 7C7-8.

On SNA after $72 \mathrm{~h} 10-12 \mathrm{~mm}$ at $15^{\circ} \mathrm{C}, 31-33 \mathrm{~mm}$ at $25^{\circ} \mathrm{C}$, $28-32 \mathrm{~mm}$ at $30^{\circ} \mathrm{C}$; mycelium covering the plate after 6 days at $25^{\circ} \mathrm{C}$. Colony hyaline, hardly visible, thin, smooth, not zonate, hyphae loosely disposed. Aerial hyphae apparent toward the downy or floccose distal margin, becoming fertile. No autolytic activity and coilings, no distinct odour and pigment noted. Chlamydospores noted after 4 days at $15^{\circ} \mathrm{C}$ (after 7 days at $25^{\circ} \mathrm{C}$, less commonly), 6-21(-66) $\times(4-) 6-10$ $(-12) \mu \mathrm{m}, 1 / \mathrm{w}$ 0.9-2.4(-4.0) (n=51), abundant, more frequent than on CMD, terminal and intercalary, variable in shape and size, globose, oval, ellipsoidal, fusoid, clavate or rectangular, sometimes 2-3(-4) celled, smooth. Conidiation noted after $3 \mathrm{~d}$, effuse, spreading from proximal margin across the colony, becoming visible as whitish down, white floccules or fluffy tufts to $1 \mathrm{~mm}$ diam, later also as white spots of wet conidial heads to $120 \mu \mathrm{m}$ diam on densely disposed, short, spinulose conidiophores arising from compacted mycelium. Conidiophores solitary, erect, simple, often on a long stipe, of a main axis to $11 \mu \mathrm{m}$ wide at the base, with $2-3$ fold asymmetric branching at the apex; branches attenuated upwards to (3-)4-6 $\mu \mathrm{m}$. Phialides solitary, or paired or in whorls of $2-5$, usually divergent, verticillium-like; in terminal whorls sometimes distinctly curved, inaequilateral and parallel, gliocladium-like. Phialides (8-)12-34(-47) $\times$ $(2.3-) 3.0-4.5(-5.2) \mu \mathrm{m},(2.2-) 2.4-4.0(-5.2) \mu \mathrm{m}$ wide at the base, $1 / \mathrm{w}(3.0-) 3.7-8.2(-11)(n=30)$, subulate, sometimes widened below the middle and constricted at the base, longest in terminal position in the conidiophores. Conidia $3.3-8.0(-15.5) \times(2.4-) 3.0-4.2(-5.3) \mu \mathrm{m}, 1 / \mathrm{w}(1.0-) 1.1-2.0(-$ 3.0) $(n=60)$, hyaline, subglobose, ellipsoidal, sometimes oblong or cylindrical, smooth, with minute guttules; scar mostly indistinct.

Habitat: spreading from stumps or tree bases on soil and debris such as small twigs, bark, leaves, dead plants; incorporating also living plants; more rarely on bark of logs on the ground. Most typically in mixed coniferous forests.

Distribution: widespread and locally common. In Europe collected in Austria, Czech Republic, Germany, Nether- lands and UK; typically from the end of August to the beginning of October; only rarely found outside this period.

Neotype: Belgium, Hestreux near Eupen, on leaf litter including pine needles, Oct. 1985, W. Gams 4031 (CBS 894.85); not examined, but gene sequences verified.

Specimens examined: Austria, Burgenland, Mattersburg, Forchtenstein, between Kohlstatt and Weißes Kreuz, MTB $8263 / 4,47^{\circ} 42^{\prime} 26^{\prime \prime} \mathrm{N}, 16^{\circ} 18^{\prime} 33^{\prime \prime}$ E, elev. $620 \mathrm{~m}$, on soil, leaf litter and bark of Pinus sylvestris, 16 Sep. 2005, H. Voglmayr, W.J. 2856 (WU 29209). Forchtenstein, WulkaQuellengebiet/Rosalia, MTB 8263/4, 47 ${ }^{\circ} 42^{\prime} 37^{\prime \prime} \mathrm{N}, 16^{\circ} 18^{\prime}$ 09" E, elev. $600 \mathrm{~m}$, on and around stump of Larix decidua, on wood, bark and debris, 22 Sep. 2007, W. Jaklitsch \& O. Sükösd, W.J. 3170 (WU 29213). Kärnten, Klagenfurt Land, St. Margareten im Rosental, MTB 9452/3, 46 $32^{\prime} 29^{\prime \prime}$ N, $14^{\circ} 24^{\prime} 31^{\prime \prime}$ E, elev. $500 \mathrm{~m}$, spreading from a stump of Picea abies on leaves, bark and twigs, 24 Sep. 2006, H. Voglmayr \& W. Jaklitsch, W.J. 2980 (WU 29210, culture CBS $121271=$ C.P.K. 2469). Niederösterreich, Krems, Egelsee, close to Waldhof, MTB 7579/3, 48 $25^{\prime} 55^{\prime \prime} \mathrm{N}, 15^{\circ} 33^{\prime} 25^{\prime \prime} \mathrm{E}$, elev. $420 \mathrm{~m}$, on soil around Fagus and Picea, 28 Aug. 2000, W. Klofac, W.J. 1617 (WU 29535; part BPI 748251). Wien-Umgebung, Gablitz, south of the train station, MTB 7762/4, elev. $300 \mathrm{~m}$, on soil and leaf litter, 30 Sep. 2002, A. Urban, W.J. 1990 (WU 29536). Oberösterreich, Braunau, Wanghausen bei Ach, Oberer Weilhartsforst, forest path from the northern forest margin to Heilbrünnl, MTB 7842/ 4, elev. $400 \mathrm{~m}$, spreading from a stump onto forest soil, 20 Sep. 2006, I. Krisai-Greilhuber, W.J. 3000 (WU 29211, culture C.P.K. 3121). Schärding, Raab, Rothmayrberg, mixed forest NE of Rotes Kreuz, MTB 7648/1, elev. $470 \mathrm{~m}$, on the base of a dead oak tree (Quercus robur), H. Voglmayr, 30 Aug. 2008, W.J. 3214 (WU 29214). Schärding, St. Willibald, Großer Salletwald, MTB 7648/3, $48^{\circ} 20^{\prime} 57^{\prime \prime} \mathrm{N}, 13^{\circ} 42^{\prime} 22^{\prime \prime}$ E, elev. $660 \mathrm{~m}$, on corticated stump bases of Picea abies, $30 \mathrm{~cm}$ thick, spreading on surrounding soil, leaf litter, bark and plants, 8 Sep. 2003, H. Voglmayr, W.J. 2391 (WU 29206, culture CBS 121278=C. P.K. 956); same place, different stump, 14 Sep. 2003, H. Voglmayr, W.J. 2395 (WU 24803, culture C.P.K. 960). Steiermark, Feldbach, St. Anna bei Aigen, Deutsch Haseldorf, MTB 9261/2, elev. 400 m, on soil and bark of Pinus sylvestris, 11 Sep. 2002, G. Koller, W.J. 1947 (WU 29534).

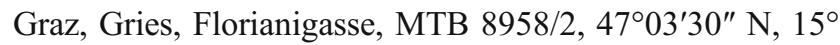
25'24" E, elev. $350 \mathrm{~m}$, on soil and plants at the base of a Prunus avium tree in a garden, identified using ITS extracted from stroma, 6 Aug. 2001, H. Teppner, Mycotheca Graecensis 367 (part: WU 29533). Vienna, 23 $3^{\text {rd }}$ district, Maurer Wald, MTB 7863/4, 48 $09^{\prime} 00^{\prime \prime}$ N 16 $16^{\circ} 15^{\prime}$ $11^{\prime \prime} \mathrm{E}$, elev. $330 \mathrm{~m}$, spreading on the ground from the base of an oak stump, 8 Oct. 2009, H. Voglmayr (WU 29539).

Czech Republic, Bohemian Switzerland, Mezní Louka, Kozí Hrbet/Ponova Louka, MTB 5151/2, 5052'58" N, $14^{\circ}$ 
18'49" E, elev. $250 \mathrm{~m}$, on corticated branch of Picea abies $11 \mathrm{~cm}$ thick lying on the ground, on bark, infected by a hyphomycete, soc. Trichoderma viride, 19 Sep. 2003, J. Holec \& W. Jaklitsch, W.J. 2398 (WU 29207, culture C.P. K. 961). Netherlands, Putten, in Drie-Continentenbos of the arboretum Landgoed Schovenhorst, elev. $0 \mathrm{~m}$, on and around thick old stump of Pseudotsuga menziesii $1 \mathrm{~m}$ thick, on bark, soil and plants, 19 Nov. 2006, H. Voglmayr, W.J. 3046 (WU 29212). United Kingdom, Devon, Bovey Tracey, Great Plantation, SX8275, 50 ${ }^{\circ} 35^{\prime} 00^{\prime \prime} \mathrm{N}, 03^{\circ} 41^{\prime} 00^{\prime \prime}$ W, elev. $60 \mathrm{~m}$, on soil and forest litter, 5 Sep. 2004, P. Roberts, (WU 29208, culture C.P.K. 1909).

Notes: Overton et al. (2006a) clarified the complex nomenclature of this widespread species. They also pointed out that Hypocrea lactea sensu Doi (1972) is probably a different taxon in Japan. Hypocrea citrina differs from other species forming effuse stromata by growth on soil and forest debris. It forms the largest stromata known in Hypocrea. H. sulphurea differs e.g. by distinctly brighter stroma colour, occurrence on Exidia on branches, larger ascospores, lack of hairs on the stroma surface and lack of chlamydospores in culture. Hypocrea pulvinata differs from $H$. citrina by its occurrence on polypores, a tendency to form determinate pulvinate stromata, inhomogeneously distributed pigment and verrucose hairs on the stroma surface, lanceolate ostiolar cells, and slightly smaller, more or less monomorphic ascospores. $H$. auranteffusa, $H$. margaretensis, $H$. luteffusa, and $H$. rodmanii differ e.g. by minute cortical cells and green-conidial anamorphs. The moniliform surface hyphae on PDA around the plug seem to be characteristic for $H$. citrina; in addition all fresh isolates of $H$. citrina formed a yellow to orange pigment on PDA, particularly at $30^{\circ} \mathrm{C}$. This ability may be lost in older strains, as the CBS strain studied by Overton et al. (2006a) did not form a distinct pigment.

Hypocrea decipiens Jaklitsch, K. Põldmaa \& Samuels, Mycologia 100: 981 (2008a). Fig. 58

= 'Hypocrea farinosa Berk. \& Broome' sensu Overton et al. Stud. Mycol. 56: 59 (2006).

[non Hypocrea farinosa Berk. \& Broome, Ann. Mag. Nat. Hist. Ser. 2, 7: 186 (1851).]

Anamorph: Trichoderma sp., acremonium/verticillium-like.

For descriptions and illustrations see Overton et al. (2006b) under Hypocrea farinosa. A short redescription of stromata based on a re-examination of the holotype is given here.

Stromata when dry 5-43 $\times 2-17 \mathrm{~mm}, 0.1-0.4 \mathrm{~mm}$ thick $(n=9)$, thinly effuse, indeterminate, entirely attached. Margin hyphal, white or yellowish. Stroma surface smooth, or more or less farinose, uneven, also rugose, depending on substrate contours; whitish between ostiolar dots or perithecia. Ostiolar dots $(16-) 22-38(-50) \mu \mathrm{m}(n=30)$ diam in face view when dry, prominent, papillate or conical, concolorous with or lighter than the perithecial apex, sometimes surrounded at the apex by a white fringe of often apically enlarged hyphae. Perithecial outlines translucent, visible part (35-)45-155(-205) $\mu \mathrm{m}(n=30)$ diam in face view when dry. Perithecia brown, numerous, crowded, slightly projecting, some free at the margin, globose, not collapsed except for few old perithecia. Colour brownorange or light brown, 5CD4-5(-5B3), 6CD5-6; a previously $\mathrm{KOH}$-treated spot was discoloured orange- to reddish-brown, $8 \mathrm{CD} 5-8$. Younger stroma parts lighter or whitish, with perithecia at larger distances. Spore deposits fine, white. Stroma turning orange-brown in $3 \% \mathrm{KOH}$, with stromatal hyphae and cells remaining unchanged, but peridium turning bright orange; bright yellow after subsequent addition of lactic acid. Cortical tissue of hyaline or brownish, thin-walled hyphae (3.0-)3.5-6.0(-7.5) $\mu \mathrm{m}(n=30)$ wide; surface pseudoparenchymatous around the ostioles in face view. Subperithecial tissue compact, a $t$. angularis of hyaline or brownish, thin-walled, angular to globose cells (5-)6-12 $(-15) \times(3-) 5-9(-10) \mu \mathrm{m}(n=30)$, mixed with some wide hyaline hyphae. Asci (57-)65-73(-76) $\times(3.0-) 3.5-4.5 \mu \mathrm{m}$, stipe (1-)2-6(-8) $\mu \mathrm{m}$ long $(n=31)$, fasciculate on long ascogenous hyphae; no croziers seen. Ascospores hyaline, spinulose, cells dimorphic; distal cell (3.0-)3.3-3.7×3.0-3.2 $(-3.5) \mu \mathrm{m}, 1 / \mathrm{w}(1.0-) 1.1-1.2(-1.3) \quad(n=30)$, (sub)globose, ellipsoidal or wedge-shaped; proximal cell (3.2-)3.5-4.5 $(-5.5) \times(2.2-) 2.3-2.7(-3.0) \quad \mu \mathrm{m}, 1 / \mathrm{w} \quad(1.1-) 1.4-2.0(-2.3)$ $(n=31)$, oblong, wedge-shaped or subglobose.

Habitat: bark/immersed ascomycetes and aphyllophoralean fungi (Stereum, Lentinula cultures, Phellinus gilvus).

Known distribution: France, USA, ?Japan.

Holotype: France, Pyrénées atlantiques, Forêt Domaniale d'Oloron, on Quercus sp., soc. effete stromatic pyrenomycete (?Botryosphaeria sp.), 30 Aug. 1997, F. Candoussau 513 (BPI 747356; culture G.J.S. 97-207=CBS 121307).

Notes: The holotype is the only specimen of $H$. decipiens known from Europe. It remains to be clarified, whether specimens occurring on wood of Lentinula cultures in Japan (Overton et al. 2006b) indeed represent $H$. decipiens, because no Japanese material has been sequenced. For a description of the anamorph see Overton et al. (2006b) under Hypocrea farinosa. The latter is a synonym of Protocrea farinosa, the type species of Protocrea Petch. Jaklitsch et al. (2008b) have clarified the phylogenetic and phenotypic concept of this genus. The main distinguishing characters of Protocrea are the absence of a pseudoparenchymatous subperithecial stroma tissue, and a white Gliocladium anamorph.

Hypocrea delicatula Tul. \& C. Tul., Selecta Fung. Carpol. 3: 33, t. IV, f. 7-13 (1865). Fig. 59 

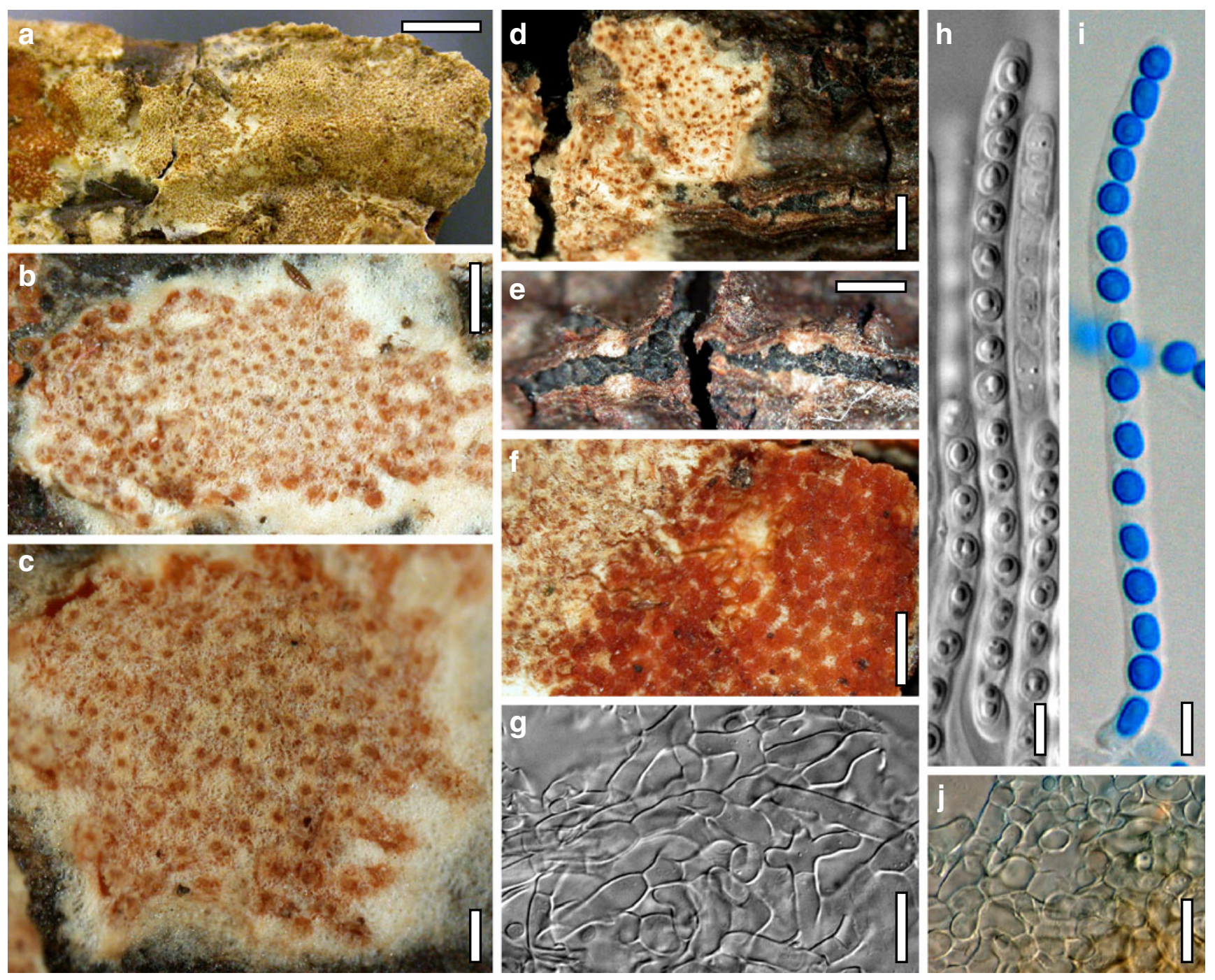

Fig. $58 H$. decipiens (holotype BPI 747356). a-d, f. Dry stromata (f. spot treated with $\mathrm{KOH}$ ). e. Pyrenomycete associated with stromata. g. Cortical tissue. h, i. Asci with ascospores (i. in cotton blue/lactic acid). j. Subperithecial tissue in section. Scale bars $\mathbf{a}=3 \mathrm{~mm}, \mathbf{b}, \mathbf{c}=0.3 \mathrm{~mm}$, $\mathbf{d}-\mathbf{f}=0.5 \mathrm{~mm}, \mathbf{g}, \mathbf{j}=10 \mu \mathrm{m}, \mathbf{h}, \mathbf{i}=5 \mu \mathrm{m}$

from scant hyphae, thin arachnoid mycelium to a thick, dense, continuous and membranaceous hyphal mat, often fraying out at the margins; with delicate, bright ochre, orange to light brown perithecia superficial on to nearly entirely immersed in the subiculum. Perithecia scattered, gregarious or densely aggregated, mostly sphaeroid to globose, also ampulliform to subconical, often showing lateral collapse, only rarely collapsed from above, smooth, glabrous or partly covered by radiating hyphae; visible part (55-)80-118(-140) $\mu \mathrm{m}(n=90)$ diam. Ostioles $(16-) 24-43$ $(-63) \mu \mathrm{m}(n=90)$ diam, distinctly prominent, cylindrical or conical, sometimes pointed, more rarely short papillate, amber, caramel or dark brown, typically darker than the perithecial body. Overall colour pale apricot, dull cream to pale orange, $5 \mathrm{AB}(2-) 3-4,6 \mathrm{~A} 3$, or brown, $6 \mathrm{CD}(5-) 7-8$, 67E5-8. Spore deposits minute, white. After rehydration 


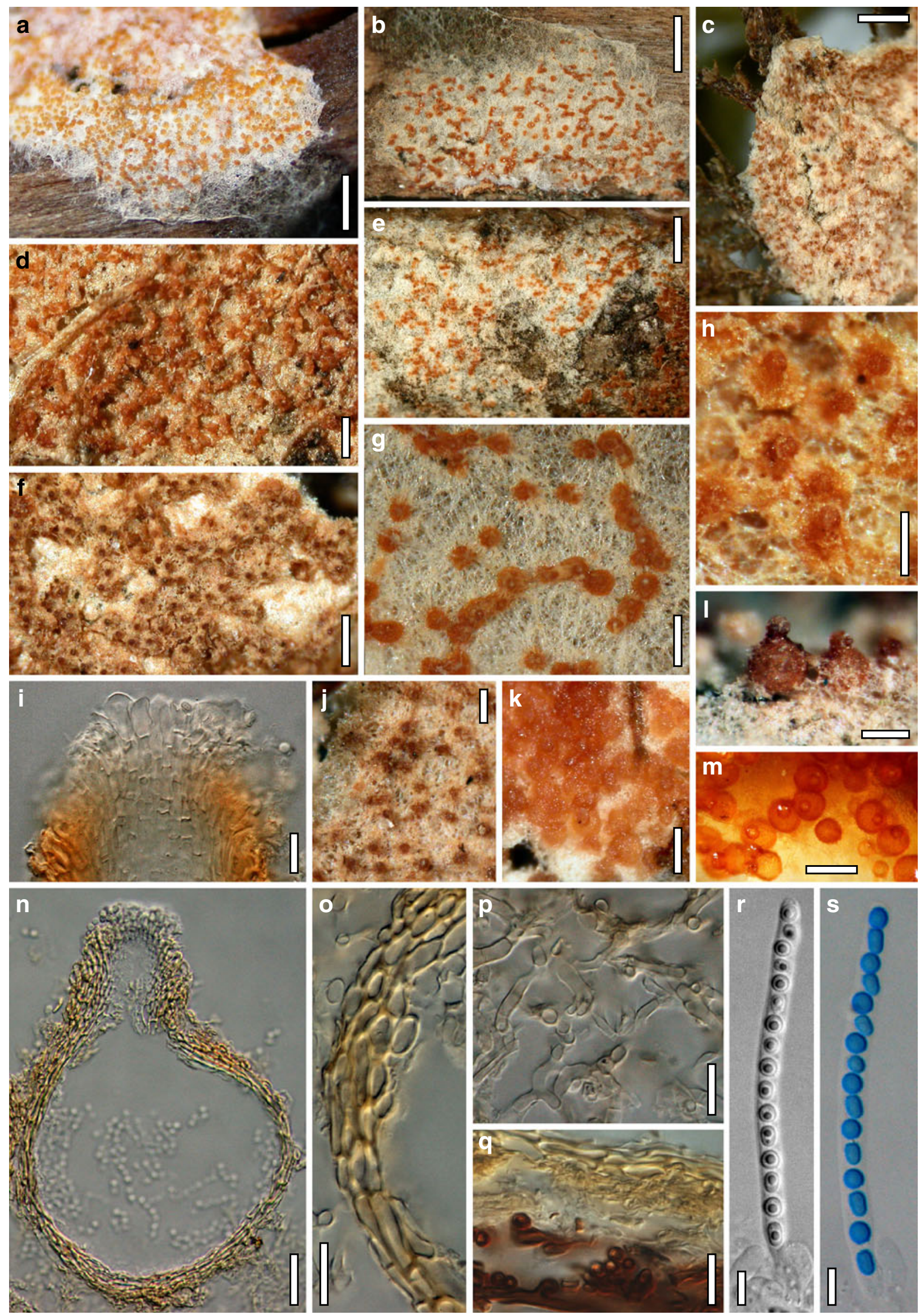


4Fig. 59 Teleomorph of Hypocrea delicatula. a. Part of fresh stroma. b-h, j. Dry stromata (d, f. overmature; f, h. showing papillate ostioles). i. Ostiole in section showing wide apical cells. k. Part of rehydrated stroma. I. Perithecia superficial on subiculum. m. Perithecia in $3 \% \mathrm{KOH}$ after rehydration. n. Perithecium in section. o. Peridium in section. p. Subiculum in section. q. Base of peridium and collapsed subiculum hyphae on host hyphae. r, s. Asci with ascospores (s in cotton blue/lactic acid). a, b, h, n, q-s. WU 29225. $\mathbf{c}-\mathbf{e}, \mathbf{i}, \mathbf{k}-\mathbf{m}, \mathbf{o}, \mathbf{p}$. lectotype PC 93188. f, g, j. PC 93187. Scale bars $\mathbf{a}$, $\mathbf{b}=1 \mathrm{~mm}$. c, $\mathbf{e}=0.6 \mathrm{~mm}$. d, $\mathbf{f}=0.3 \mathrm{~mm} . \mathbf{g}, \mathbf{k}, \mathbf{m}=0.2 \mathrm{~mm} . \mathbf{h}, \mathbf{j}, \mathbf{l}=$ $0.1 \mathrm{~mm} . \mathbf{i}, \mathbf{o}-\mathbf{q}=10 \mu \mathrm{m} . \mathbf{n}=20 \mu \mathrm{m} . \mathbf{r}, \mathbf{s}=5 \mu \mathrm{m}$

perithecia slightly larger, not collapsed, sphaeroid, smooth, orange-brown, 6CD6-8. No distinct colour change after addition of $3 \% \mathrm{KOH}$, perithecia only slightly darker brown, subiculum unchanged.

Stroma anatomy: Ostioles (36-)46-68(-84) $\mu \mathrm{m}$ long, projecting from the perithecial body by $(25-) 33-55(-70)$ $\mu \mathrm{m},(18-) 33-61(-76) \mu \mathrm{m}(n=60)$ wide at the apex, conical or cylindrical, periphysate, hyaline inside, yellow outside; apex sometimes flattened, with hyaline, cylindrical or subclavate cells $3-5(-9) \mu \mathrm{m}$ wide. Perithecia (78-)100$140(-160) \times(78-) 94-140(-200) \mu \mathrm{m}$, total height including ostiole (115-)140-185(-205) $\mu \mathrm{m} \quad(n=61)$, globose or subconical, loosely disposed or aggregated, in lactic acid smaller than in KOH. Peridium (6-)9-16(-21) $\mu \mathrm{m}(n=122)$ thick at the base and sides, pseudoparenchymatous, of narrow, thick-walled, yellow cells $(4-) 5-11(-14) \times(3-) 4-8$ $(-12) \mu \mathrm{m}(n=30)$ in face view, $2-6 \mu \mathrm{m}$ wide in section; ochre or pale orange in $\mathrm{KOH}$. Subiculum variable, a loose or dense $t$. intricata of hyphae $(1.5-) 2-4(-7.5) \mu \mathrm{m}(n=65)$ wide; hyphae thin-walled, hyaline or pale yellow-brown, sometimes ascending to the ostiolar level; sometimes intermingled with submoniliform hyphae (7-)8-12(-16) $\mu \mathrm{m}(n=20)$ wide, collapsed when old. Asci (52-)55-62($70) \times(3.2-) 3.5-4.0(-4.2) \mu \mathrm{m}$, stipe $3-8(-10) \mu \mathrm{m}(n=31)$ long; no croziers seen. Ascospores hyaline, becoming yellowish orange after ejection, finely verruculose; cells dimorphic; distal cell (2.3-)2.5-3.0(-3.7) $\times(2.0-) 2.5-3.0(-$ 3.2) $\mu \mathrm{m}, 1 / \mathrm{w}(0.9-) 1.0-1.1(-1.3)$, (sub)globose; proximal cell $(2.4-) 3.0-4.0(-4.7) \times(1.7-) 2.0-2.5(-2.8) \mu \mathrm{m}, 1 /$ w (1.0-)1.3-1.7(-2.1) ( $n=106)$, oblong or subglobose.

Cultures and anamorph: optimal growth at $25^{\circ} \mathrm{C}$ on all media; limited growth at $30^{\circ} \mathrm{C}$ on all media, terminating after reaching a radius of $5-10 \mathrm{~mm}$, and hyphae autolysing; no growth at $35^{\circ} \mathrm{C}$.

On CMD after $72 \mathrm{~h} 4-6 \mathrm{~mm}$ at $15^{\circ} \mathrm{C}, 11-13 \mathrm{~mm}$ at $25^{\circ} \mathrm{C}$, 6-8 $\mathrm{mm}$ at $30^{\circ} \mathrm{C}$; mycelium covering the plate after $>2$ weeks at $25^{\circ} \mathrm{C}$. Colony hyaline, thin, finely zonate, with irregular or lobed margin. Mycelium loose, hyphae narrow, wavy, little on the agar surface. Area around the plug becoming dense and white due to fluffy aerial mycelium spreading from the plug. Autolytic activity inconspicuous, coilings frequent. No diffusing pigment, no distinct odour noted. No chlamydospores seen. Conidiation noted after 2 days, white, effuse, short and sessile on surface hyphae, or on aerial hyphae of variable length; spreading from the plug across the plate. Conidia formed in wet heads on long narrow phialides, drying soon; scant after few transfers. At $15^{\circ} \mathrm{C}$ a rosy to pale carrot pigment, $5 \mathrm{~A} 4,6 \mathrm{~A} 2-4,7 \mathrm{~A} 2$, spreading from the plug.

On PDA after $72 \mathrm{~h} 2-4 \mathrm{~mm}$ at $15^{\circ} \mathrm{C}, 10-12 \mathrm{~mm}$ at $25^{\circ} \mathrm{C}$, 4-5 $\mathrm{mm}$ at $30^{\circ} \mathrm{C}$; mycelium covering the plate after $c a$ 2 weeks at $25^{\circ} \mathrm{C}$. Colony first thin, becoming covered by a thick white layer of cottony aerial hyphae ascending to the lid of the Petri dish. Aerial hyphae dichotomously branched, appearing rigid or setose terminally, with inconspicuous and widely spaced septa. Autolytic excretions numerous, turning orange to reddish-brown. Plug becoming rosy, carrot to dark reddish-brown, 7-8EF6-8; colony becoming discoloured from the plug in zones, pale orange, reddish-brown, carrot, to dull orange-brown, 5AB5-6, 6BD5-7. No distinct odour noted. Conidiation noted after 3 days, effuse on long aerial hyphae, verticillium-like, particularly dense in the centre. At $15^{\circ} \mathrm{C}$ conidiation reduced, colony turning orange to brown, 5AB4-6 to 7DE7-8, pigment diffusing from pigmented hyphae into the agar.

On SNA after $72 \mathrm{~h} 4-6 \mathrm{~mm}$ at $15^{\circ} \mathrm{C}, 11-13 \mathrm{~mm}$ at $25^{\circ} \mathrm{C}$, $3-5 \mathrm{~mm}$ at $30^{\circ} \mathrm{C}$; mycelium covering the plate after more than 2 weeks at $25^{\circ} \mathrm{C}$. Colonies similar to $\mathrm{CMD}$, but more irregular, marginal hyphae forming pegs. Aerial hyphae abundant, cottony, ascending to the lid of the Petri dish, dichotomously branched, appearing nearly setose with pointed ends. Autolytic excretions scant, coilings frequent. No diffusing pigment, no distinct odour noted. No chlamydospores seen. Conidiation noted after 3-4 days, effuse, white, loose, translucent, verticillium-like. Main axes 7-9 $\mu \mathrm{m}$ wide, with walls to $2.5 \mu \mathrm{m}$ thick and outer layer deliquescent, bearing numerous short, usually unpaired conidiophores, often in right angles. Conidiophores mostly 3-6 $\mu \mathrm{m}$ wide, sometimes widening to $7.5 \mu \mathrm{m}$; terminally 2 $3 \mu \mathrm{m}$ wide. Side branches simple or rebranching, $60-160 \mu \mathrm{m}$ long; tips of side branches with phialides or short, unpaired or paired, 1-celled branches 10-20 $\mu \mathrm{m}$ long, slightly inclined upwards. Phialides solitary or divergent in whorls of 2-6(-8), arising from cells $2-4(-5.5) \mu \mathrm{m}$ wide, forming conidia in minute wet heads mostly $<20 \mu \mathrm{m}$ diam. Phialides (8-)11-16 $(-23) \times(2.0-) 2.3-3.0(-3.5) \mu \mathrm{m}, 1 / \mathrm{w}(3.3-) 4.0-6.6(-10), 1.5-$ 2.5(-3.0) wide at the base $(n=40)$, narrowly lageniform, subulate or fusoid, widest in or below middle. Conidia (2.6-) $3.0-4.0(-5.2) \times(2.0-) 2.2-2.5(-2.8) \mu \mathrm{m}, 1 / \mathrm{w} \quad 1.2-1.7(-2.2)$ $(n=50)$, hyaline, ellipsoidal or oblong, smooth, with several guttules and indistinct scar.

Habitat: on wood and bark of deciduous and coniferous trees, leaves, and moss.

Known distribution: Europe (Austria, France, United Kingdom).

Lectotype, designated by Rossman et al. (1999): France, Clamart, 4 Jan. 1860, M.L.-R. Tulasne, PC 93188 (PC); 

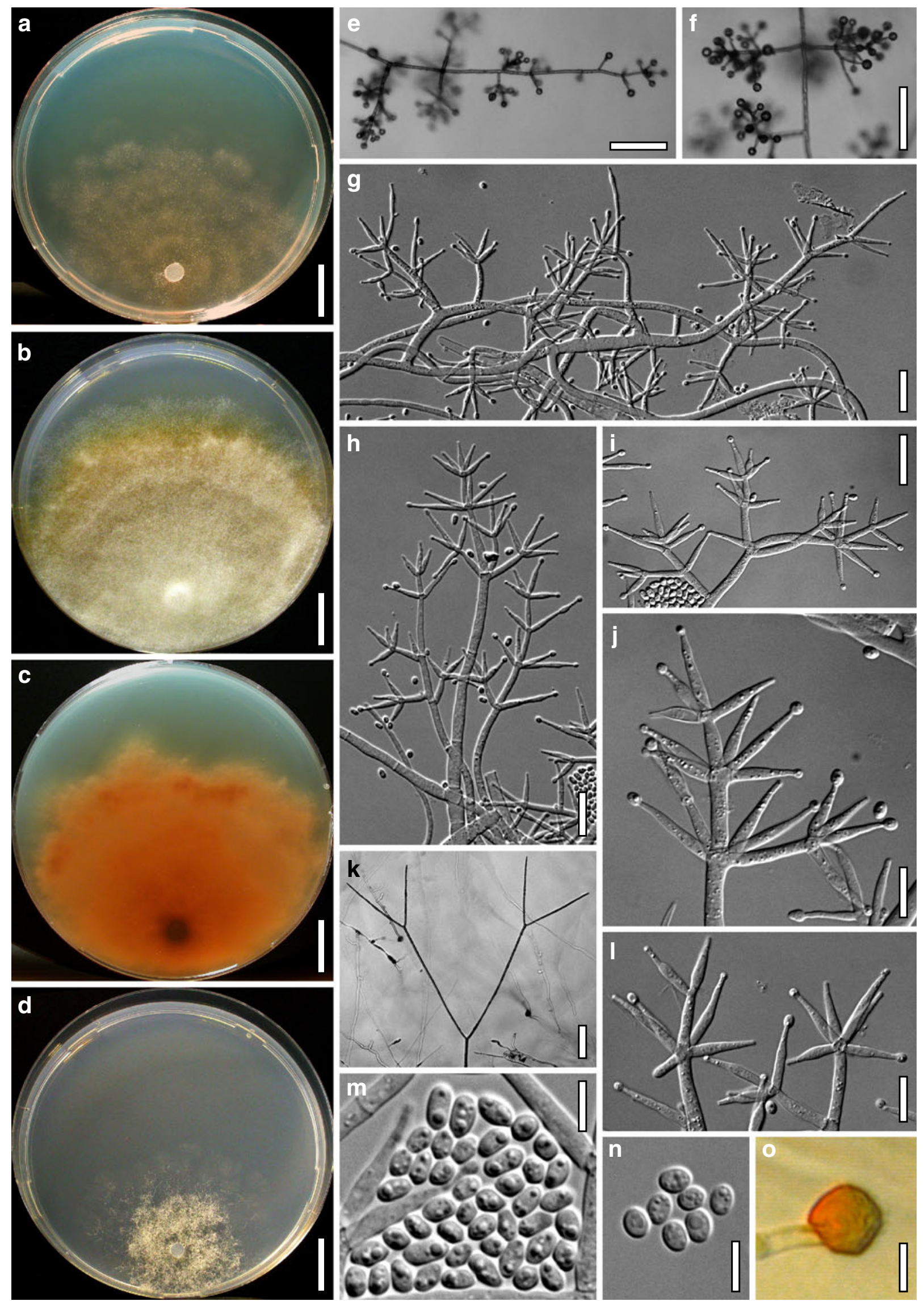
4 Fig. 60 Cultures and anamorph of Hypocrea delicatula (CBS 120631). a-d. Cultures (a. on CMD, 15 days; b. on PDA, 9 days; c. on PDA, 15 days, reverse; $\mathbf{d}$. on SNA, 10 days). e, f. Conidiophores on growth plate (SNA, 10 days). $\mathbf{g}-\mathbf{j}, \mathbf{l}$. Conidiophores and phialides (SNA, 5 days). k. Dichotomously branched, setose aerial hyphae (PDA, 8 days). m, n. Conidia (SNA, 5 days). o. Pigmented autolytic excretion (PDA, $15^{\circ} \mathrm{C}, 10$ days). a-n. At $25^{\circ} \mathrm{C}$. Scale bars $\mathbf{a}-\mathbf{d}=$ $15 \mathrm{~mm}$. e, f, $\mathbf{k}=0.1 \mathrm{~mm} . \mathbf{g}-\mathbf{i}, \mathbf{o}=20 \mu \mathrm{m} . \mathbf{j}, \mathbf{l}=10 \mu \mathrm{m}$. $\mathbf{m}, \mathbf{n}=5 \mu \mathrm{m}$

fungus on thin twig of Quercus, moss and leaves, soc Mycosphaerella punctiformis on leaves. Epitype here designated in order to connect the morphology with molecular phylogeny: Austria, Osttirol, Lienz, Kals am Großglockner, Teischnitztal, MTB 8941/4, 4701'46" N, $12^{\circ} 37^{\prime} 49^{\prime \prime}$ E, elev. $1670 \mathrm{~m}$, on $\log$ of Picea abies $14 \mathrm{~cm}$ thick at roadside, on ?Tomentellastrum sp. and wood, attacked by a hyphomycete, 5 Sep. 2003, W. Jaklitsch W. J. 2377 (WU 29225, culture CBS 120631=C.P.K. 1603). Holotype of Trichoderma delicatulum isolated from WU 29225 and deposited as a dry culture with the epitype of $H$. delicatula as WU 29225a.

Other specimens examined: France, Chaville, 21 Mar. 1860, M.L.-R. Tulasne, PC 93187 (PC); 2 pieces of ? Quercus bark, soc. effete black pyrenomycete. United Kingdom, Devon, Dartmoor, Bellever forest, 30 Sep. 1990, P. Roberts, (K(M)16595). Wiltshire, Lucknam, April 1866, Herb. C.E. Broome (K).

Notes: Superficially, stromata of Hypocrea delicatula look like those of a Hypomyces. Although teleomorph morphology would suggest affiliation with Protocrea, particularly due to the absence of any pseudoparenchymatous stroma tissue, gene sequences place it within Hypocrea. $H$. delicatula differs from $P$. farinosa by different hosts, different perithecial colour, smaller perithecia and ascospores, a yellow, distinctly pseudoparenchymatous peridium, which is less susceptible to collapse upon drying, and a verticillium-like anamorph. Protocrea pallida differs e.g. by a distinct, purple $\mathrm{KOH}-$ reaction and laterally pinched collapse of the perithecia. The anamorphs of Protocrea spp. are morphologically typical Gliocladium, while $H$. delicatula has a verticillium-like anamorph. Arachnocrea stipata differs by biconical ascospores from all species discussed here.

Hypocrea parmastoi Overton, Stud. Mycol. 56: 62 (2006b). Fig. 61

Anamorph: Trichoderma sp. [sect. Hypocreanum]. Fig. 62

Stromata when fresh to $7 \times 3 \mathrm{~cm}$, thinly effuse, of a subiculum to $1 \mathrm{~mm}$ thick, with hyaline to dull brownish perithecia immersed in a single layer; outline variable; margin mycelial, white to distinctly yellow. Surface smooth apart from slightly projecting ostiolar dots, colour red in fertile areas. Spore deposits white.
Stromata when dry 3-70×3-30 mm, 0.15-0.5(-0.8) mm thick $(n=20)$, indeterminate, widely and thinly effused on wood, incorporating leaves and other plant material, of longish to irregular patches, entirely attached. Surface hyphal to hairy, finely rough due to slightly projecting ostioles. Ostiolar dots (30-)45-73(-87) $\mu \mathrm{m}(n=60)$ diam, papillate to conical and pointed or with flattened apices, irregularly disposed or arranged in lines, dark red (including upper part of perithecia); surrounded by radiating mycelium, red around the perithecia, gradually lighter to whitish or yellow with distance from the ostiolar dots. Margin cottony or membranaceous, white to yellow, 4A3-4, 4B4-5. Colour of fertile areas pink with yellow tones, greyish red or reddish brown, 8CD6-8, 9CD5-6, 9DE7-8, 10AB4, to dark red or violaceous-brown, 10CD4-6, 10E4-8, 11DE5-8. Subiculum in section whitish to bright yellow in lower layers. After rehydration, perithecial mounds becoming evident, upper part and subiculum yellow to orange-red, upper layer turning deeply purple in 3\% $\mathrm{KOH}$; ostioles minute, hyaline. Previously KOH-treated spot of the holotype discoloured dark reddish brown to purple, with collapsed perithecia (150-) 170-240 $(-252) \mu \mathrm{m}(n=20)$ diam, surrounded by black lines, and dark red ostioles with hyaline openings.

Stroma anatomy: Ostioles (70-)84-105(-123) $\mu \mathrm{m}$ long, projecting to $40(-60) \mu \mathrm{m},(37-) 40-65(-85) \mu \mathrm{m}$ wide at the apex $(n=30)$, blunt conical, periphysate; marginal cells on apices variable, long-cylindrical and $2-$ $3 \mu \mathrm{m}$ wide, or clavate and 5-8(-10) $\mu \mathrm{m}$ wide, broadly rounded, or fusoid, or cylindrical with inflated bases. Perithecia (170-)200-255(-285)×(118-)145-210(-240) $\mu \mathrm{m}(n=30)$, large, globose to sphaeroid or flask-shaped, crowded or separated by hyphae; peridium (15-)17-23(27) $\mu \mathrm{m}$ thick at the base and sides $(n=60)$, subhyaline to pale yellow, in $3 \% \mathrm{KOH}$ purple around the ostiolar apex. Cortical and subcortical tissue consisting of a loose $t$. intricata of thin-walled hyphae (1.5-)2-5(-6) $\mu \mathrm{m}(n=30)$ wide above and between the perithecia, hyaline, in uppermost layers subhyaline to yellow; turning purple to violet in 3\% $\mathrm{KOH}$. Subperithecial tissue variable, thick or nearly absent with perithecia sitting directly on the wood, a $t$. intricata to epidermoidea of thin-walled hyphae (2-)3-9(-14) $\mu \mathrm{m}(n=60)$ wide, with partly inflated, submoniliform cells $(6-) 8-25(-36) \times(4-) 6-11(-15) \mu \mathrm{m}$ $(n=30)$, hyaline to yellowish, not changing colour in $3 \%$ $\mathrm{KOH}$. Base of densely intertwined, cylindrical, thinwalled, hyaline hyphae $(2-) 3-4(-5)(n=30)$ wide. Asci $(68-) 78-103(-123) \times(3.8-) 4.2-5.0(-5.5) \mu \mathrm{m}$, stipe $(5-)$ $12-35(-50) \mu \mathrm{m}$ long $(n=50)$; on spiral ascogenous hyphae; no croziers seen. Ascospores hyaline, verruculose to spinulose; cells dimorphic; distal cell (3.0-)3.5-4.5($5.5) \times(2.5-) 3.0-3.5(-4.0) \mu \mathrm{m}, 1 / \mathrm{w}(1.0-) 1.1-1.4(-1.8)(n=$ $63)$, subglobose to wedge-shaped; proximal cell (3.5-)4.0$5.0(-6.6) \times(2.3-) 2.5-3.0(-3.5) \mu \mathrm{m}, 1 / \mathrm{w} \quad(1.3-) 1.4-1.8(-$ 

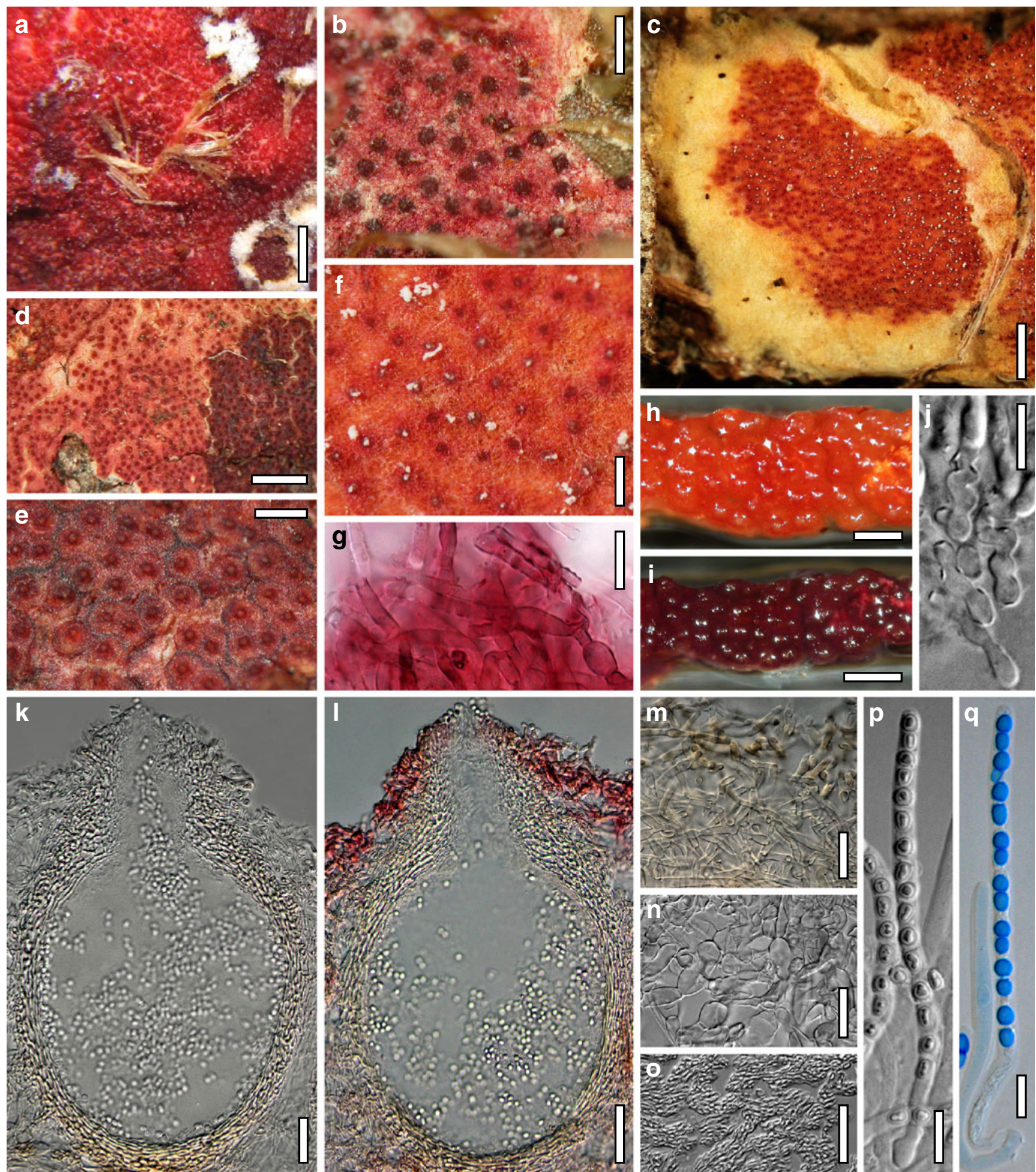

Fig. 61 Teleomorph of Hypocrea parmastoi. a. Part of fresh stroma (attacked by white mould). b-f. Dry stromata (c. with yellow subiculum; d. part with $\mathrm{KOH}$-treated spot on the right side; e. part of $\mathrm{KOH}$-treated spot; f. stroma surface). g. Surface hyphae in $3 \%$ $\mathrm{KOH}$. h. Part of rehydrated stroma. i. Part of stroma in $3 \% \mathrm{KOH}$ after rehydration. j. Ascogenous hyphae. k, l. Perithecia in section (k. in lactic acid; $\mathbf{l}$. in $3 \% \mathrm{KOH})$. $\mathbf{m}$. Cortical and subcortical tissue in section. n. Subperithecial tissue in section. o. Stroma base in section. p, q. Asci with ascospores (q. in cotton blue/lactic acid). a. WU 29526. c, f, g-i, k-o, q. WU 29033. b, d, e, j, p. holotype BPI 843639. Scale bars a, $\mathbf{c}, \mathbf{d}=1.2 \mathrm{~mm}$. b, $\mathbf{f}=0.2 \mathrm{~mm}$. e, $\mathbf{h}=0.3 \mathrm{~mm} . \mathbf{g}, \mathbf{j}$, $\mathbf{p}, \mathbf{q}=10 \mu \mathrm{m} . \mathbf{i}=0.5 \mathrm{~mm}$. $\mathbf{k}, \mathbf{l}=30 \mu \mathrm{m} . \mathbf{m}, \mathbf{n}=20 \mu \mathrm{m} . \mathbf{o}=50 \mu \mathrm{m}$ 

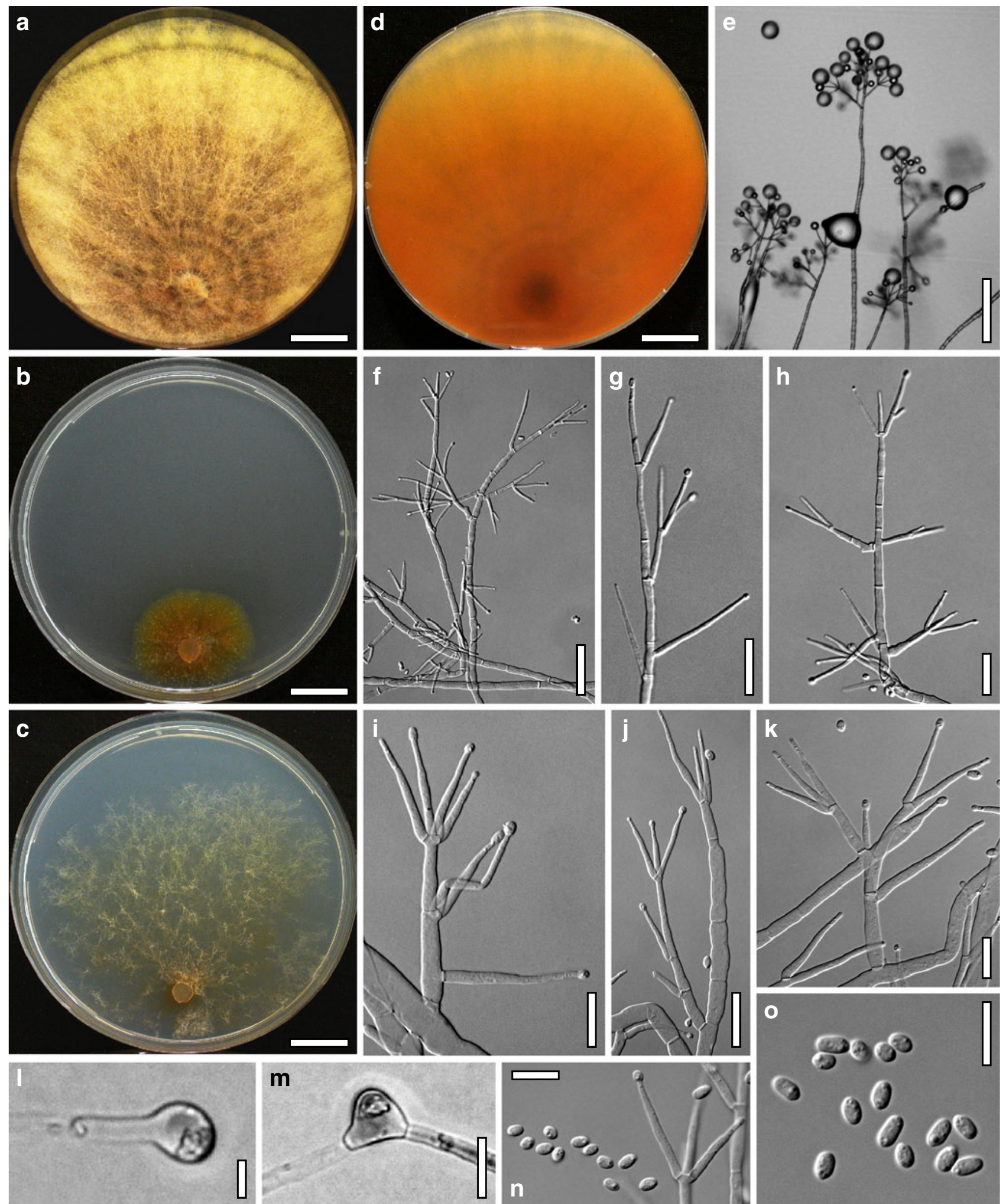

m
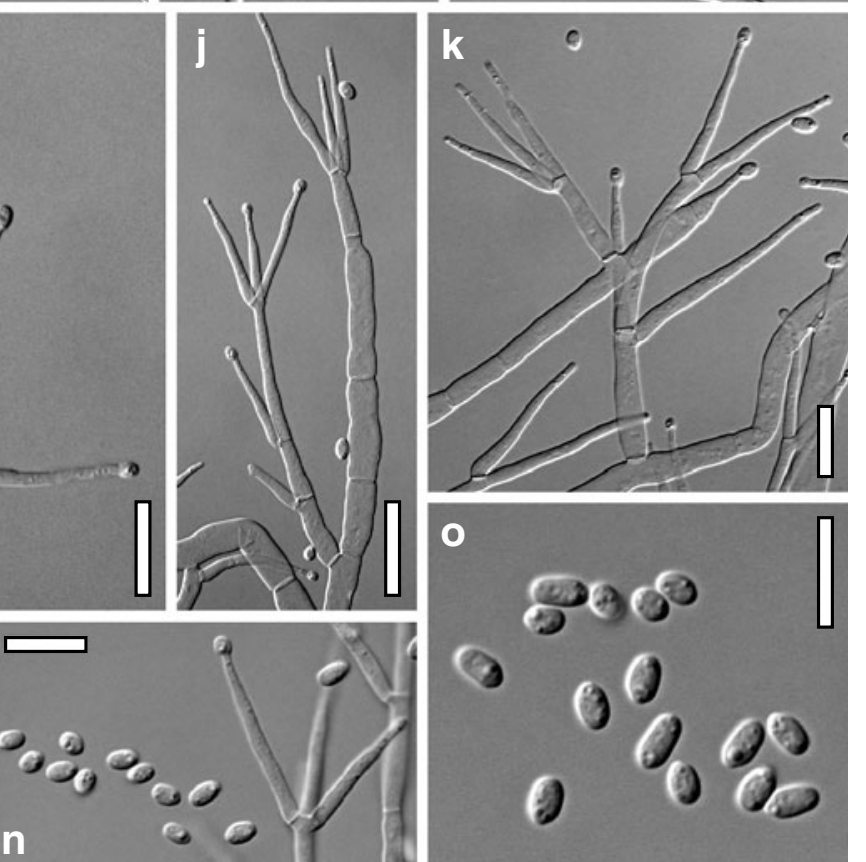

$(3$

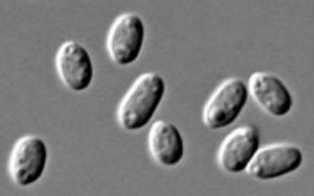

Fig. 62 Cultures and anamorph of Hypocrea parmastoi (CBS 121139). a-d. Cultures after 14 days (a. on PDA; b. on CMD; c. on SNA; d. on PDA, reverse). e. Conidiophores attached to the lid of the Petri dish (PDA, 7 days). f-k. Conidiophores (PDA, 5 days). I, m.
Chlamydospores (CMD, 17 days). n, o. Conidia and phialides (PDA, 5 days). a-o. All at $25^{\circ} \mathrm{C}$. Scale bars $\mathbf{a}-\mathbf{d}=15 \mathrm{~mm} . \mathbf{e}=100 \mu \mathrm{m} . \mathbf{f}=$ $40 \mu \mathrm{m} . \mathbf{g}, \mathbf{h}, \mathbf{j}=20 \mu \mathrm{m}$. i, $\mathbf{k}, \mathbf{m}-\mathbf{o}=10 \mu \mathrm{m} . \mathbf{l}=5 \mu \mathrm{m}$ 
2.3) ( $n=63)$, wedge-shaped, oblong, ellipsoidal, less commonly subglobose.

Cultures and anamorph: optimal growth at $25^{\circ} \mathrm{C}$ on all media, poor growth at $30^{\circ} \mathrm{C}$, no growth at $35^{\circ} \mathrm{C}$.

On CMD after $72 \mathrm{~h} 3-4 \mathrm{~mm}$ at $15^{\circ} \mathrm{C}, 4-6 \mathrm{~mm}$ at $25^{\circ} \mathrm{C}$, $1-2 \mathrm{~mm}$ at $30^{\circ} \mathrm{C}$; growth limited; mycelium not covering the plate within a month. Colony hyaline, thin, dense, subcircular, not zonate, of narrow hyphae branched in steep angles; soon turning yellow-orange, yellow-, golden- to orange-brown, 4AB6-8, 5-6CD7-8. Aerial hyphae variable, scant or frequent, short or long, distinctly less than on PDA and SNA, becoming fertile, collapsing to form inconspicuous whitish floccules. Autolytic activity and coilings absent or scant. Odour slightly unpleasant, reminiscent of Sarcodon imbricatus mixed with apple. Chlamydospores noted after 9-11 days, terminal and intercalary, mainly in surface hyphae, (7-)8-13(-19) $\times(5-) 6-10(-12)$ $\mu \mathrm{m}(n=30), 1 / \mathrm{w} 1.0-1.7(-2.7)(n=30)$, subglobose, clavate or ellipsoidal, smooth, often with a pedicel. Conidiation noted after 1-2 days, effuse, colourless, acremonium- to verticillium-like, spreading from the plug on surface and aerial hyphae. Conidia produced in minute wet heads $<40 \mu \mathrm{m}$ diam on long thin phialides in steep whorls of 4 6. At $30^{\circ} \mathrm{C}$ growth soon stopping, hyphae forming pegs; yellow pigment diffusing into the agar; conidiation scant.

On PDA after $72 \mathrm{~h} 2-4 \mathrm{~mm}$ at $15^{\circ} \mathrm{C}, 3-5 \mathrm{~mm}$ at $25^{\circ} \mathrm{C}$, $<1 \mathrm{~mm}$ at $30^{\circ} \mathrm{C}$; mycelium covering the plate after $c a$ 2 weeks at $25^{\circ} \mathrm{C}$. Colony circular, dense to opaque, indistinctly zonate; of richly branched, narrow, radial hyphae. Aerial hyphae abundant, dichotomously branched, first forming a white flat mat in distal areas, turning yellowish and ascending as a loose or dense fluffy mat, becoming fertile up to the lid of the Petri dish. Autolytic excretions scant; no coilings noted. Colony surface turning reddish-brown, 8CD5-6, hyphal mat whitish to yellow $4 \mathrm{~A} 3-4$ or pale orange. Reverse orange-brown, 5-6CD7-8, to dark brown, $6 \mathrm{~F} 7-8,7 \mathrm{EF} 7-8$, in the centre, yellow, $4 \mathrm{AB} 4-5$, orange, $4 \mathrm{~A} 5-7$, to orange-brown, $6-7 \mathrm{CD} 7-8$, in the residual colony. Odour as on CMD or more fruity. Conidiation noted after 2 days, effuse, spreading from the centre on surface and aerial hyphae, acremonium- to irregularly verticillium-like. Conidiophores arising from aerial hyphae mostly in steep angles, mostly unpaired, short, unbranched or once loosely rebranching with side branches similar to the main axis, mostly 1-2 celled. Conidiophores and aerial hyphae 4-7 $\mu \mathrm{m}$ wide, attenuated upwards and terminally $2-3 \mu \mathrm{m}$ wide. Phialides divergent in whorls of 2-4 on the apices of main and side branches, and solitary or paired along their length. Phialides (10-)16$28(-38) \times(1.8-) 2.0-3.0(-3.5) \mu \mathrm{m}, 1 / \mathrm{w}(3-) 7-11(-13)$, $(1.5-) 1.7-2.5(-3.5) \mu \mathrm{m}$ wide at the base $(n=30)$, subulate, equilateral, only rarely thickened close to the base. Conidia formed in low numbers in minute wet heads to $30 \mu \mathrm{m}$ diam; conidia (3.2-)3.5-5.0(-6.0) $\times(2.0-) 2.3-2.6(-2.8)$ $\mu \mathrm{m}, 1 / \mathrm{w}(1.2-) 1.4-2(-2.5)(n=30)$, hyaline, ellipsoidal to oblong, smooth, with few small guttules, and often with a projecting scar. At $15^{\circ} \mathrm{C}$ colony similar to that at $25^{\circ} \mathrm{C}$, but more regularly zonate, aerial hyphae forming a flatter mat. At $30^{\circ} \mathrm{C}$ hardly growing, yellow pigment forming minute radiating hair-like crystals around the plug.

On SNA after $72 \mathrm{~h} 4-5 \mathrm{~mm}$ at $15^{\circ} \mathrm{C}, 4-12 \mathrm{~mm}$ at $25^{\circ} \mathrm{C}$, $1-2 \mathrm{~mm}$ at $30^{\circ} \mathrm{C}$; mycelium covering the plate after $\mathrm{ca}$ 3 weeks at $25^{\circ} \mathrm{C}$. Growth at first slow, producing a small dense circular colony centre. Residual colony with an irregularly lobed margin produced by fast growing, long aerial hyphae first arising from the plug and central colony area, declining, reaching the agar and propagating the colony on the surface and in the uppermost layer of the agar; hyphae generally dichotomously branched; mycelium looser than on CMD and PDA; soon degenerating, hyphae becoming yellow or empty. Aerial hyphae abundant, long, forming a high, loose, hairy, irregular mat, ascending several $\mathrm{mm}$, partly reaching the lid of the Petri dish, eventually collapsing to large longish strands and floccules. Autolytic activity and coilings moderate to conspicuous; coilings turning yellow-orange upon autolysis. Colony pale yellow to orange $4-5 \mathrm{AB} 3-4$. Odour as on CMD, but less distinct. Chlamydospores noted after 9-11 days, terminal and intercalary, mainly in surface hyphae. Conidiation noted after 1-2 days, effuse, spreading from the centre on surface and aerial hyphae, acremonium- to irregularly verticillium-like. Conidia produced in minute wet heads $<40 \mu \mathrm{m}$ diam. At $30^{\circ} \mathrm{C}$ little growth, yellow pigment forming minute radiating hair-like crystals around the plug.

Habitat: on medium to well-decayed wood and bark of deciduous trees.

Distribution: Europe (Austria, Estonia, Finland, France, Germany); uncommon.

Holotype: Estonia, Võru Commune, Võrumaa County, Kütiorg, in a spruce forest, $57^{\circ} 47^{\prime} \mathrm{N}, 27^{\circ} 9^{\prime} \mathrm{E}$, on partly moss-covered bark of a fallen trunk of Alnus incana, 3 Oct. 1997, I. Parmasto (TAA(M) 169055; ex-type culture TFC 97-143); isotype BPI 843639.

Other specimens examined: Austria, Niederösterreich, Wien-Umgebung, Mauerbach, Friedhofstraße, MTB 7763/ $1,48^{\circ} 15^{\prime} 20^{\prime \prime} \mathrm{N} 16^{\circ} 10^{\prime} 12^{\prime \prime} \mathrm{E}$, elev. $330 \mathrm{~m}$, on decorticated branch of Fagus sylvatica $5 \mathrm{~cm}$ thick, on wood, soc. Corticiaceae, 7 Oct. 2006, W. Jaklitsch \& H. Voglmayr, W. J. 3006 (WU 29033, culture CBS 121139=C.P.K. 2483). Salzburg, Anthering, Acharting-Würzenberg, Adelsberg, Haunsberg-Forststraße, MTB 8044/3, elev. 650 m, on cut wood of Fagus sylvatica, 11 Sep 2010, M. Dämon (WU). Finland, near Tampere, on wood of Alnus sp., 18 Oct. 2010, L. Kosonen (WU 30203). Germany, BadenWürttemberg, Schwäbisch Gmünd, Weiler i. d. B., "Költ", MTB 7225/1, elev. $450 \mathrm{~m}$, on decorticated deciduous wood 
at a Fraxinus/Fagus forest borderline, 13 Oct. 10, leg. \& comm. L. Krieglsteiner. Bavaria, Magnetsried, between Gumpenau and Hirschberg am Haarsee south of the Starnberger See and Ammersee, in a steep mixed beech forest, MTB 8133/341, elev. 640 m, on a branch of Fagus sylvatica $10 \mathrm{~cm}$ thick, on medium- to well-decomposed wood, overmature, 6 Dec. 2008, P. Karasch (WU 29527). München-Dachau, Karlsfeld, Nature Reserve Krenmoos, MTB 7734/422, elev. $480 \mathrm{~m}$, on well-decayed deciduous wood of ?Alnus glutinosa, attacked by a Hypomyces, 1 Nov. 2008, K. Reitmeier, comm. B. Fellmann (WU 29526, culture C.P.K. 3717). Niedersachsen, "Oderwald" s. Wolfenbüttel, MTB 3829/1, elev. $120 \mathrm{~m}$, on decaying wood in an Quercus-Carpinus mixed forest, 21 Sep. 10, leg. \& comm. L. Krieglsteiner.

Notes: This species is characteristic because of its red or purple colour of the indeterminate effuse hyphal stromata. The above description includes characteristics of the holotype. Similar to $H$. alcalifuscescens, the inflated, submoniliform cells, particularly in the subperithecial tissue indicate a tendency of stroma development from a subiculum towards a pseudoparenchymatous tissue.

\section{Hypocrea phellinicola Jaklitsch, sp. nov. Fig. 63 MycoBank MB 516696}

Trichoderma phellinicola Jaklitsch, sp. nov. Fig. 64 MycoBank MB 516697

Stromata late effusa vel pulvinata in basidiomatibus generis Phellinus, lutea, $0.1-30 \times 0.1-5 \mathrm{~cm}$. Asci cylindrici, $(50-) 60-70(-80) \times 3.5-4.5(-5.5) \mu \mathrm{m}$. Ascosporae bicellulares, hyalinae, verruculosae, ad septum disarticulatae, pars distalis (sub)globosa, $(2.4-) 2.7-3.5(-4.7) \times(2.3-) 2.5-3.0(-$ 3.5) $\mu \mathrm{m}$, pars proxima oblonga, ellipsoidea vel subglobosa, $(2.7-) 2.8-4.2(-5.2) \times 2.0-2.7(-3.4) \mu \mathrm{m}$. Anamorphosis Trichoderma phellinicola. Conidiophora in agaro PDA effuse disposita, simplicia, ramis sparsis brevibus, similia Acremonii vel Verticillii. Phialides divergentes, subulatae vel cylindricae, (11-)19-33(-41)×(1.8-)2.0-3.0(-3.2) $\mu \mathrm{m}$. Conidia oblonga vel cylindracea, hyalina, glabra, (5-)6-11 $(-15) \times(2.0-) 2.2-2.7(-3.0) \mu \mathrm{m}$.

Etymology: reflecting its specific occurrence on basidiomes of Phellinus spp.

Stromata when fresh $0.1-11(-30) \times 0.1-5 \mathrm{~cm}, 0.5-2.5 \mathrm{~mm}$ thick, gregarious, densely aggregated or effluent, starting as white mycelium, becoming compacted and pigmented, broadly pulvinate or widely effuse, often with a white cottony to arachnoid margin sometimes forming extended mats. Outline and surface variable, depending on the host, entirely attached, indeterminate, overgrowing leaves lying on the substrate. Ostiolar dots distinct, usually densely disposed, plane or convex, yellowish, olive, amber to brown dots, sometimes diffuse spots, rarely conical and projecting to $c a$
$80 \mu \mathrm{m}$. Surface smooth or coarsely tubercular depending on the host surface. Perithecia entirely immersed, rarely projecting at the stroma margin. Stromata first white, turning yellow, 3A3-5, 4A3-6, yellow-, orange-brown, pale brown, 5CD5-7, 6C6-7, or greyish yellow, 4B4-8, 5B5.

Stromata when dry typically shrunken to thin crusts $0.1-0.4 \mathrm{~mm}$ thick $(n=24)$, even when initially pulvinate, membranaceous to papery, flat pulvinate or widely effuse with discontinuities. Outline highly variable, margin rounded or extended as white mycelium. Surface smooth, sometimes velvety when immature. Ostiolar dots numerous, (35-)40-80(-105) $\mu \mathrm{m}(n=30)$ diam, distinct, more diffuse and irregularly distributed when immature, plane, convex or conical and slightly projecting; yellowishbrown to dark brown, always darker than the stroma surface. Stromata at first whitish, turning yellow, orangeyellow, greyish orange, 4A4-5, 4B6-7, 5B4, yellowbrown, golden, orange-brown, brown, 5-6CD5-8, 5E78. Reaction to $3 \% \mathrm{KOH}$ variable, reddish, orange-brown or darker brown, confined to the perithecial wall and apex. Spore deposits white or yellow.

Stroma anatomy: Ostioles (32-)43-60(-62) $\mu \mathrm{m}$ long, plane or projecting to $25 \mu \mathrm{m}$, rarely to $80 \mu \mathrm{m},(20-) 24-36$ $(-42) \mu \mathrm{m}$ wide at the apex $(n=20)$, conical, with broadly clavate to subglobose, hyaline marginal cells 3-8 $\mu \mathrm{m}$ diam wide at the apex. Perithecia (154-)160-190(-210) $\times(90-)$ $100-160(-190) \mu \mathrm{m}(n=20)$, globose, flask-shaped or ellipsoidal, crowded or widely spaced; peridium (10-)1219(-22) $\mu \mathrm{m}(n=20)$ thick at the base, $(3-) 7-12(-14) \mu \mathrm{m}(n$ $=20)$ at the sides, yellow. Cortical layer (14-)16-22(-26) $\mu \mathrm{m}(n=30)$ thick, clearly differentiated, a dense $t$. globulosa-angularis of mostly isodiametric, thick-walled ( $\mathrm{ca}$ $1 \mu \mathrm{m})$ cells $(2-) 4-10(-16) \times(2-) 3-6(-7) \mu \mathrm{m}(n=60)$ in face view and in vertical section; yellow or pale brownish in lactic acid, orange in $\mathrm{KOH}$. Hairs on mature stroma infrequent, $7-16(-26) \times(2-) 3-5 \mu \mathrm{m} \quad(n=20)$, hyaline to yellowish, 1-3 celled, apically rounded or truncate, smooth, or warted, cylindrical or basally widened to $6 \mu \mathrm{m}$; basal cells often embedded in the cortex. Subcortical tissue a $t$. intricata of thin-walled hyaline hyphae $2-5(-6) \mu \mathrm{m}(n=30)$ wide, mixed with angular cells 3-9(-17) $\mu \mathrm{m}(n=30)$ diam. Subperithecial tissue a t. epidermoidea of hyaline, thinwalled, angular, oblong or lobed cells $(3-) 7-20(-30) \times$ $(2.5-) 5-13(-15)(n=30)$, interspersed with some hyphae to $8 \mu \mathrm{m}$ wide in basal regions. Asci $(50-) 60-70(-80) \times 3.5-$ $4.5(-5.5) \mu \mathrm{m}$, stipe $(2-) 3-10(-14) \mu \mathrm{m}$ long $(n=30)$, fasciculate; ascospores sometimes biseriate in the apical part. Ascospores hyaline, often yellow-orange outside asci, verruculose; cells dimorphic but often asci with monomorphic ascospores present in the same perithecium; distal cell $(2.4-) 2.7-3.5(-4.7) \times(2.3-) 2.5-3.0(-3.5) \quad \mu \mathrm{m} \quad(n=30), 1 /$ W 1.0-1.3(-1.7) $(n=30)$, (sub-)globose; proximal cell $(2.7-) 2.8-4.2(-5.2) \times 2.0-2.7(-3.4) \mu \mathrm{m}(n=30), 1 / \mathrm{w}(1.1-)$ 

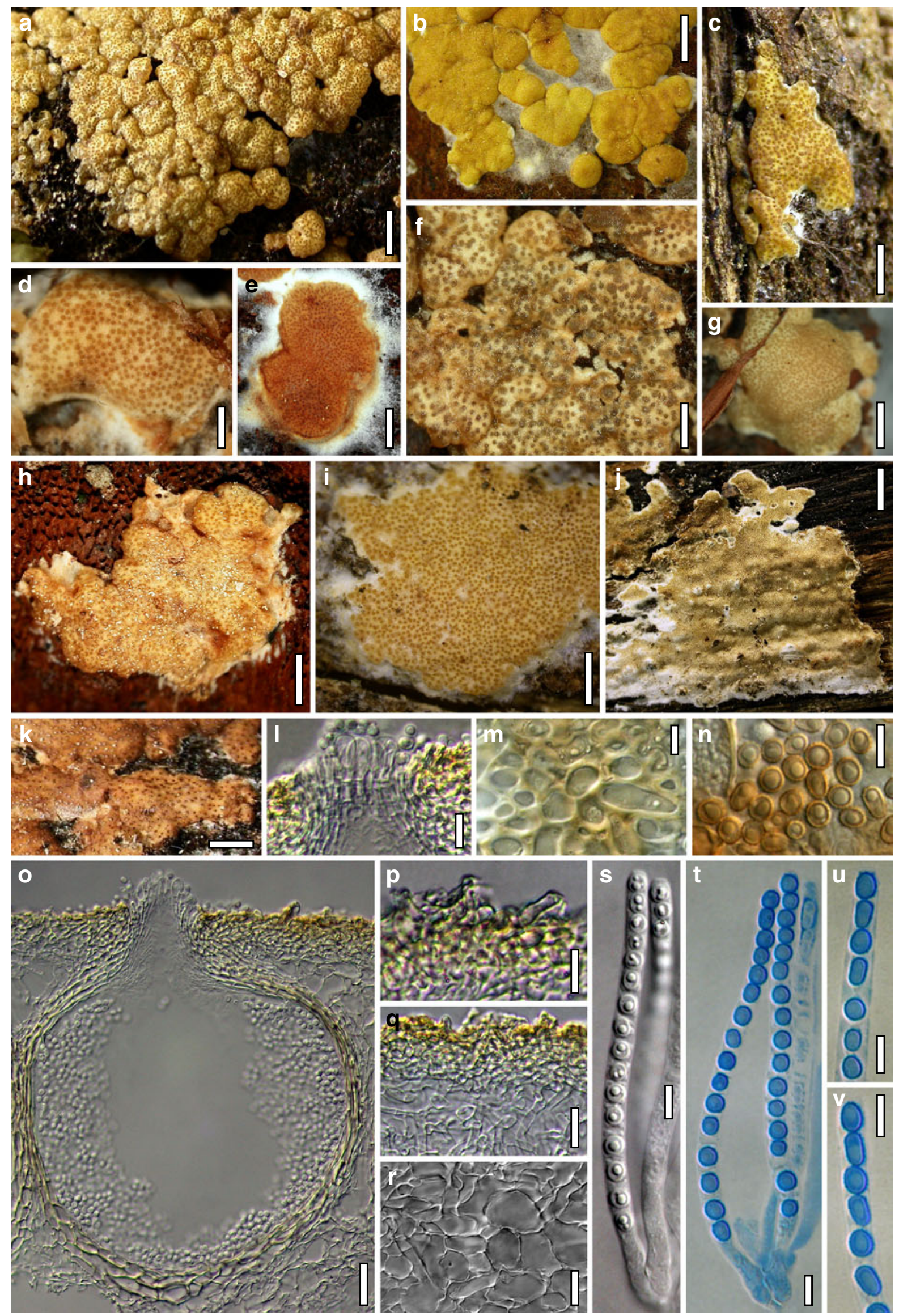
4Fig. 63 Teleomorph of Hypocrea phellinicola. a-d, f-i. Fresh stromata. e, j. Dry stromata. k. Rehydrated stromata. I. Ostiolar apex in section. $\mathbf{m}$. Cortical tissue in face view. $\mathbf{n}$. Ejected yellow-orange ascospores. o. Perithecium in section. p. Cortex with hairs in section. q. Cortical and subcortical tissue in section. r. Subperithecial tissue in section. s, t. Asci with ascospores (t. in cotton blue/lactic acid). $\mathbf{u}, \mathbf{v}$. Apical ascospores with dimorphic cells in cotton blue/lactic acid. a, f, s, t. WU 29404. b, e, g. WU 29407. c, k-m, o-r. WU 29402. d. WU 29403. h. WU 29406. i, j, n, u, v. WU 29401. Scale bars: a, c, e, $\mathbf{g}-\mathbf{i}=$ $1 \mathrm{~mm} . \mathbf{b}=3 \mathrm{~mm}$. $\mathbf{d}, \mathbf{k}=0.7 \mathrm{~mm}$. $\mathbf{f}=0.5 \mathrm{~mm} . \mathbf{j}=5 \mathrm{~mm}$. $\mathbf{l}, \mathbf{p}, \mathbf{r}=10 \mu \mathrm{m}$. $\mathbf{m}, \mathbf{n}, \mathbf{s}-\mathbf{v}=5 \mu \mathrm{m} . \mathbf{o}, \mathbf{q}=20 \mu \mathrm{m}$

$1.2-1.8(-2.4)(n=30)$, oblong, ellipsoidal or subglobose, only slightly attenuated towards the base.

Cultures and anamorph: optimal growth at $25^{\circ} \mathrm{C}$ on all media, slightly faster on CMD than on PDA and SNA; at $30^{\circ} \mathrm{C}$ death autolysis of hyphae after short growth; no growth at $35^{\circ} \mathrm{C}$.

On CMD after $72 \mathrm{~h} 19-21 \mathrm{~mm}$ at $15^{\circ} \mathrm{C}, 32-35 \mathrm{~mm}$ at $25^{\circ} \mathrm{C}, 1-1.5 \mathrm{~mm}$ at $30^{\circ} \mathrm{C}$; covering the Petri dish after 56 days at $25^{\circ} \mathrm{C}$. Colony homogeneous, not zonate. Mycelium first loose, becoming more dense in distal regions, hyphae thin, with little differences in width, third order hyphae short and thin in marginal regions, surface hyphae becoming empty with distinct septa, little mycelium on surface, growth radially fan-shaped with forked to fasciculate ends, centre shiny, margin wavy, becoming downy to slightly mottled after 2 weeks. Aerial hyphae inconspicuous, autolytic activity and coilings absent, hyaline, no odour noted. Little central conidiation from 2 to 6 days, later also on the distal margin, effuse, short, simple, phialides single or in small whorls of 2-3. Chlamydospores noted after 3 days, infrequent, (5-)6-14 $(-18) \times(4-) 5-8(-10) \mu \mathrm{m}(n=30), 1 / \mathrm{w}(0.9-) 1.1-1.9(-2.4)$ $(n=30)$; variable in shape and size, globose, clavate or with a pedicel, hyaline, sometimes $2-3$ celled. At $15^{\circ} \mathrm{C}$ mycelium loose, soon degenerating. Red diffusing pigment developed upon storage at $15^{\circ} \mathrm{C}$ for $>1$ month.

On PDA after $72 \mathrm{~h} 13-14 \mathrm{~mm}$ at $15^{\circ} \mathrm{C}, 24-26 \mathrm{~mm}$ at $25^{\circ} \mathrm{C}$, $0-0.5 \mathrm{~mm}$ at $30^{\circ} \mathrm{C}$, covering the Petri dish after 6 days at $25^{\circ} \mathrm{C}$. Colony circular, centre flat and shiny, margin wavy, coarsely fan-shaped to nearly radially folded or lobed. Mycelium dense, surface hyphae thick, ends fasciculate. Surface white and villose by a loose mat of numerous long and thick, radially arranged aerial hyphae, ascending several $\mathrm{mm}$, forming conspicuous thick strands with large connectives, collapsing and developing yellow, $3 \mathrm{~A} 6$ to $4 \mathrm{AB} 4-5$, guttules to 0.6 diam in a broad distal region; also aerial hyphae turning yellow to orange. Agar plug turning red, surrounding central area yellowish to pale reddish. White tufts developing in the centre. Autolytic activity inconspicuous, coilings infrequent. Odour slightly mushroomy. Conidiation noted after 2 days around the plug, effuse, short, simple, sessile, acremonium-like, long phialides singly or in pairs, spreading across the plate, later verticillium-like, concentrated at the end of the flat centre, and ascending on aerial hyphae, loosely disposed, with phialides often in pairs or cruciform, from 1 week white granules or tufts $0.4-0.8 \mathrm{~mm}$ diam around the plug with numerous wet heads mostly to $20 \mu \mathrm{m}$ diam, some $60-100 \mu \mathrm{m}$ diam. Tufts appearing as white spots to $4 \mathrm{~mm}$ diam, spreading irregularly across the plate. At $15^{\circ} \mathrm{C}$ colony indistinctly zonate; agar and hyphae turning sometimes bright yellow, $3 \mathrm{~A} 5-8$, orange 5AB7-8, 6B7-8, or darker, brown from $c a 10$ days on.

On SNA after $72 \mathrm{~h} 13-16 \mathrm{~mm}$ at $15^{\circ} \mathrm{C}, 24-29 \mathrm{~mm}$ at $25^{\circ} \mathrm{C}$, $0.5-1 \mathrm{~mm}$ at $30^{\circ} \mathrm{C}$, covering the Petri dish after 6-7 days at $25^{\circ} \mathrm{C}$. Colony homogeneous, not zonate, similar to CMD, but hyphae wider and more densely disposed; margin coarsely wavy and distinctly radially fan-shaped. Surface hyphae thick, terminal branches fasciculate, often wavy and curved, mycelium only loose in the centre, hyphae degenerating and becoming empty after $<1$ week; nearly no macroscopic changes after 1 week, except for the margin becoming finely downy to floccose due to dense conidiation. Aerial hyphae inconspicuous, long and thick and more frequent at distal and lateral margins, becoming fertile. Autolytic activity low to moderate, coilings infrequent. No distinct odour, no diffusing pigment observed. Chlamydospores rare. Conidiation better developed and denser than on CMD, starting after 2 days, effuse, acremonium- to verticillium-like, irregularly distributed, absent or scant in the centre, mainly concentrated in distal and lateral regions of the plate; sessile or on long aerial hyphae. Conidiophores simple or rebranching $1(-2)$ times, i.e. 1 main axis of variable length, tapering from 7 to $8 \mu \mathrm{m}$ at the base to 2-3 $\mu \mathrm{m}$ wide terminally, with 1-2 celled, often asymmetric terminal branches, replaced by phialides in apical regions. Phialides solitary or divergent in whorls of $2-4(-5)$, often distinctly inclined upwards, arising from cells $2-4 \mu \mathrm{m}$ thick. Phialides (11-)19-33(-41) $\times(1.8-) 2.0-3.0(-3.2) \mu \mathrm{m}$, $(1.3-) 1.5-2.5(-3.2) \mu \mathrm{m}$ wide at the base, $1 / \mathrm{w}(5.7-) 7.8-13.5$ $(-16.8)(n=30)$, subulate or cylindrical, widest at or slightly above the base, straight or curved. Conidia formed in minute wet heads, rarely $>50 \mu \mathrm{m}$ diam, distributed across the whole plate, denser around the margin. Conidia $(5-) 6-11(-15) \times$ (2.0-)2.2-2.7(-3.0) $\mu \mathrm{m}, 1 / \mathrm{w} \quad(2.0-) 2.5-4.2(-5.0) \quad(n=30)$, oblong, cylindrical, less commonly sub-ellipsoidal, hyaline, smooth, with few minute guttules; scar indistinct.

Habitat: On basidiomes of resupinate species of Phellinus, particularly $P$. ferruginosus on wood strongly decomposed by the basidiomycete.

Distribution: Europe (Austria, Denmark, Germany).

Holotype: Austria, Niederösterreich, Wien-Umgebung, Mauerbach, walking path from the cemetery, MTB 7763/1, $48^{\circ} 15^{\prime} 16^{\prime \prime} \mathrm{N} 16^{\circ} 10^{\prime} 33^{\prime \prime}$ E, elev. $350 \mathrm{~m}$, on Phellinus ferruginosus/Fagus sylvatica, decorticated branch $6 \mathrm{~cm}$ thick, on the polypore and wood, 24 Sep. 2005, W. Jaklitsch \& O. Sükösd, W.J. 2857 (WU 29402, culture CBS $119283=$ C.P.K. 2137). Holotype of Trichoderma phellinicola isolated from WU 29402 and deposited as a 

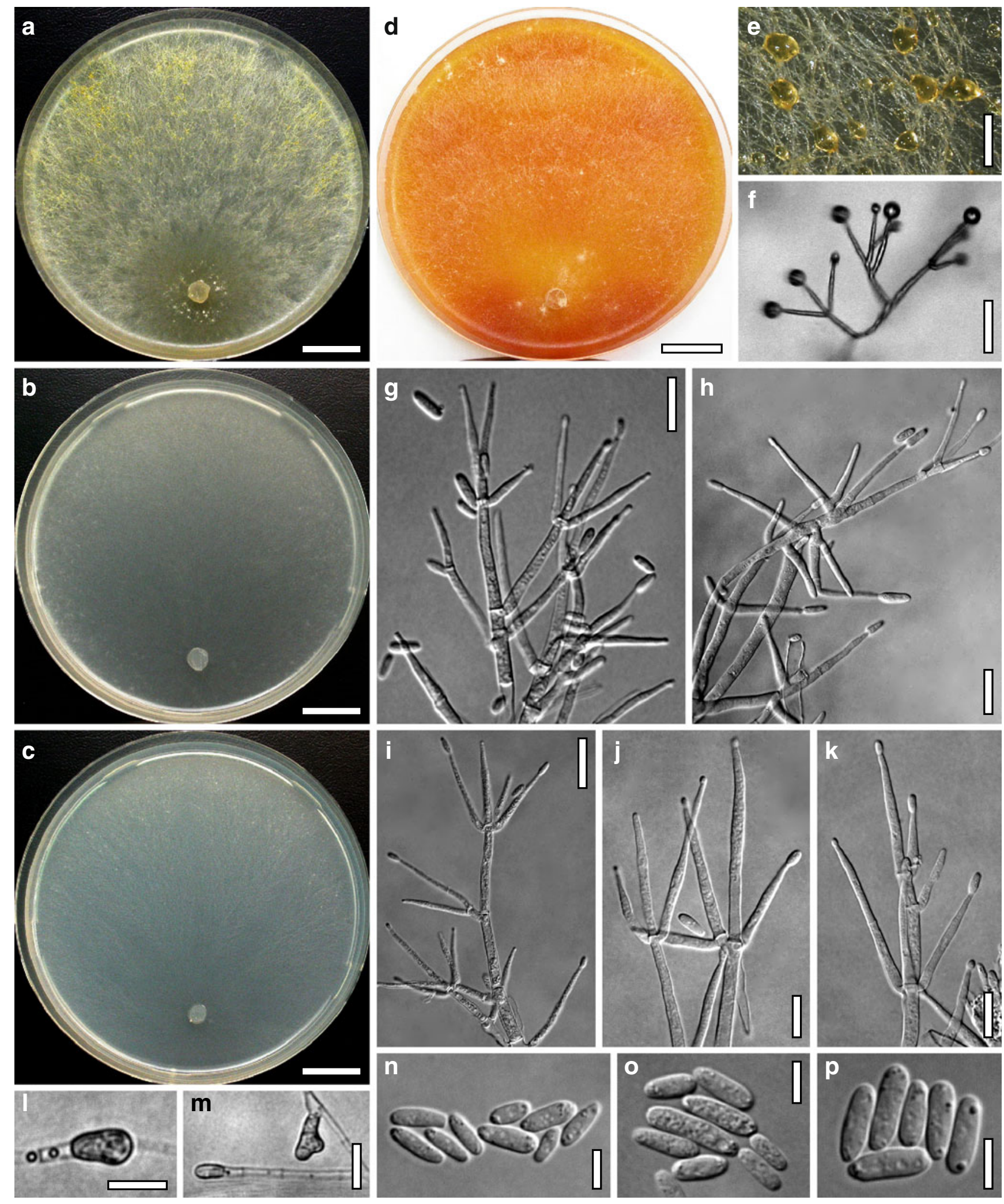

Fig. 64 Cultures and anamorph of Hypocrea phellinicola (CBS 119283). a-d. Cultures (a. on PDA, 7 days; b. on CMD, 14 days; c. on SNA, 14 days; $\mathbf{d}$. on PDA, $15^{\circ} \mathrm{C}, 28$ days). e. Golden drops on aerial hyphae (PDA, 7 days). f. Conidiophore on the growth plate. $\mathbf{g}-\mathbf{k}$.
Conidiophores and phialides. $\mathbf{l}, \mathbf{m}$. Chlamydospores (CMD, 8-18 days). n-p. Conidia. a-p. All at $25^{\circ} \mathrm{C}$ except d. f-k, n-p. On SNA after 4 days. Scale bars $\mathbf{a}-\mathbf{d}=15 \mathrm{~mm}$. $\mathbf{e}=0.4 \mathrm{~mm}$. $\mathbf{f}=30 \mu \mathrm{m}$. $\mathbf{g}-\mathbf{i}, \mathbf{m}=15 \mu \mathrm{m}$. $\mathbf{j}-\mathbf{l}=10 \mu \mathrm{m} . \mathbf{n}-\mathbf{p}=5 \mu \mathrm{m}$ 
dry culture with the holotype of $H$. phellinicola as WU 29402a.

Other specimens examined: Austria, Niederösterreich, Baden, Heiligenkreuz, SW Siegenfeld, NE slope of the Schaberriegel, MTB 7963/3, elev. 380 m, mixed forest, on Phellinus ferruginosus on branches of ?Carpinus betulus 10-15 cm thick in leaf litter, 14 Sep. 2008, W.J. 3216 (WU 29407). Wien-Umgebung, Mauerbach, close to the ceme-

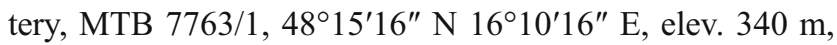
on Phellinus ferruginosus/Carpinus betulus, decorticated branch $9 \mathrm{~cm}$ thick, soc. Ophiostoma sp., Trichoderma cerinum, 10 Sep. 2005, W. Jaklitsch \& O. Sükösd, W.J. 2851 (WU 29401). Oberösterreich, Schärding, St. Willibald, riverine forest near Aichet, MTB 7648/1, elev. $400 \mathrm{~m}, 48^{\circ} 21^{\prime}$ $17^{\prime \prime} \mathrm{N} 13^{\circ} 41^{\prime} 01^{\prime \prime} \mathrm{E}$, on Phellinus sp. on a partly decorticated branch of Fraxinus excelsior 4-5 cm thick, on and around the polypore, 27 Aug. 2005, H. Voglmayr, W.J. 2830 (WU 29400). St. Willibald, between Loitzmayr and Obererleinsbach am Erleinsbach, MTB 7648/3, 48 $20^{\prime} 43^{\prime \prime}$ N 1343'3" E, elev. $420 \mathrm{~m}$, on Phellinus ferruginosus on a branch of Fraxinus excelsior on the ground, 2 Sep. 2006, H. Voglmayr, W.J. 2966 (WU 29406). Vienna, $23^{\text {rd }}$ district, Maurer Wald, MTB 7863/4, 48 $09^{\prime} 00^{\prime \prime}$ N 16 16 15'12" E, elev. $330 \mathrm{~m}$, on Phellinus ferruginosus on a decorticated branch of Quercus cerris, 11 Oct. 2005, H. Voglmayr, W.J. 2862 (WU 29403). Same area, 4808'53" N 16¹4'55" E, elev. $340 \mathrm{~m}$, on Phellinus ferruginosus/Quercus cerris, 11 Oct. 2005, H. Voglmayr, W.J. 2863 (WU 29404). Denmark, Sjælland, Strødam Reservatet, on Phellinus ferruginosus on Quercus sp., 27 Sep. 2009, T. Laessøe TL-13844 (WU 29537; part in C). Germany, Sachsen-Anhalt, Landkreis Aschersleben-Staßfurt, Staßfurt, in the Horst, a moist

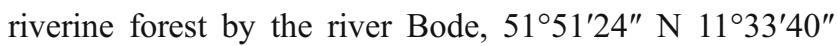
E, elev. $70 \mathrm{~m}$, on Phellinus ferruginosus on Quercus robur $2 \mathrm{~cm}$ thick, 22 Aug. 2006, H. Voglmayr \& W. Jaklitsch, W. J. 2934 (WU 29405).

Notes: Hypocrea phellinicola is characterised by its association with effused basidiomata of Phellinus, possibly being specific for Phellinus ferruginosus. Stromata of $H$. phellinicola exhibit a remarkable variability in shape, size and colour. Effuse stromata are reminiscent of $H$. austriaca, $H$. citrina, $H$. decipiens and $H$. sulphurea with colours usually closer to $H$. citrina or $H$. decipiens. None of these species has been found on Phellinus and all except $H$. decipiens have larger ascospores. Also species of the Brevicompactum clade such as $H$. auranteffusa, $H$. margaretensis or $H$. rodmanii have larger ascospores and also differ in having green-conidial anamorphs. Small pulvinate stromata may be mistaken for $H$. moravica when fresh, particularly if the Phellinus host is inconspicuous. However, stromata characteristically shrink to thin crusts upon drying. H. moravica, which has not been found on effuse species of Phellinus, differs by more pulvinate stromata, larger ascospores, and a pachybasium-like anamorph with subglobose to ellipsoidal green conidia. Yellow discoid stromata surrounded by a white subiculum are reminiscent of $H$. subalpina, which occurs on wood and bark of conifers, mostly at higher altitudes. Ascospores apparently die rapidly after harvest, showing usually 1-2 guttules per cell when the stroma is still fresh and soft. This may be the reason why only one out of nine specimens provided a culture. Specimens of $H$. phellinicola are often contaminated with other Trichoderma spp., e.g. T. harzianum or $T$. cerinum (three specimens). The pigment formed in culture is similar to that of $H$. citrina, although on PDA it only formed at $15^{\circ} \mathrm{C}$ and on CMD only after extended storage at $15^{\circ} \mathrm{C}$.

Hypocrea protopulvinata Yoshim. Doi, Bull. Natl. Sci. Mus. 15: 695. (1972). Fig. 65

Anamorph: Trichoderma sp. [sect. Hypocreanum]. Fig. 66

Stromata when fresh extending over $0.2-20 \mathrm{~cm}$, to $2 \mathrm{~mm}$ thick, mostly dependent on the host, widely effuse, less frequently small and subpulvinate, mostly on and often covering nearly the entire hymenium of the host, less commonly spreading to its upper surface. Surface smooth, ostiolar dots first diffuse and olive to amber, later more distinct and brown. Stromata whitish to pale yellowish when young; turning citrine or shades of yellow, sometimes with an olive tone, 3A2-3, 4A2-6, 3B4-7, often whitish, cream or yellowish due to thick and densely packed spore powder.

Stromata when dry $0.1-0.5(-0.8) \mathrm{mm}(n=25)$ thick, thinly effuse or flat pulvinate, entirely attached; margin indistinct, rounded, rarely thinly mycelial. Surface of white hyphae when young, darkening in age, smooth to usually finely regularly granulose due to projecting perithecia, sometimes folded due to the uneven surface of the host. Perithecia usually densely disposed, more or less equidistant. Ostiolar dots (39-)48-90(-142) $\mu \mathrm{m}(n=90)$ diam, amber to deeply brown, often distinctly projecting, convex, semiglobose to conical. Stromata white to pale yellowish or greyish- to greenish yellow when young, 2-3BC3-4, 3A24, 4A3, 4B3-5, or olive, 4CD4-5, later amber to light greyish orange or dull brown, 5B4, 5CD4-6, eventually dark brown, 6F6-8, with dark brown to nearly black perithecia. Pigment homogeneously distributed except for brown perithecial protuberances. Stroma surface often whitish to yellowish and farinose due to thick condensed spore powder. Perithecia turning red, dark orange-brown or reddish-brown in $3 \% \mathrm{KOH}$.

Stroma anatomy: Ostioles (50-)65-86(-94) $\mu \mathrm{m}$ long, projecting (7-)12-42(-62) $\mu \mathrm{m},(27-) 34-53(-57) \mu \mathrm{m}(n=20)$ wide at the apex, conical, lined by a palisade of cylindrical to clavate or subglobose hyaline cells (2-)3-8 $\mu \mathrm{m}$ wide at the 

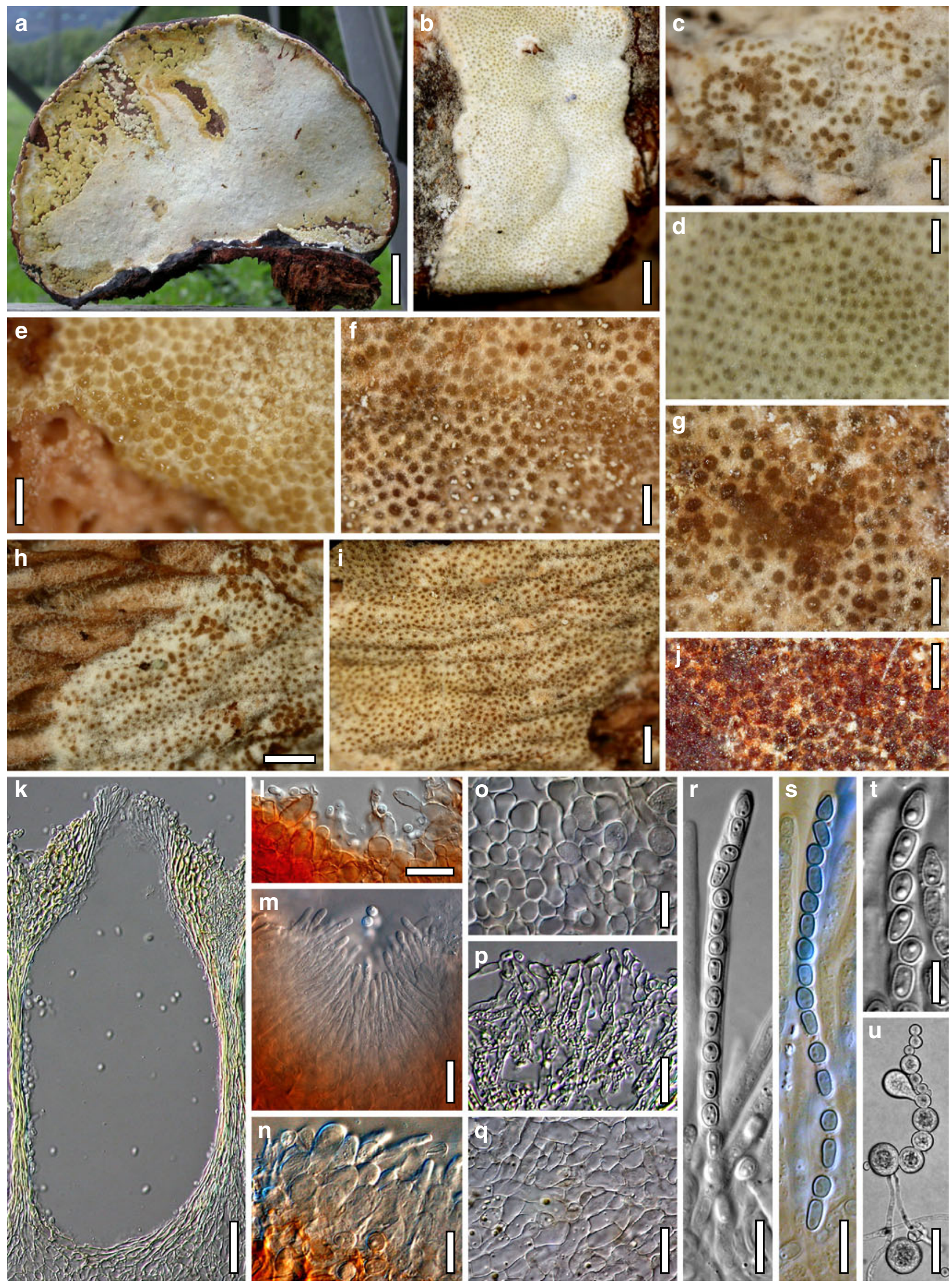
4 Fig. 65 Teleomorph of Hypocrea protopulvinata. a-g. Fresh stromata (a. habit, soc. H. pulvinata on upper left side; b-d. immature; d-g. surface). h, i. Parts of dry stromata. j. Stroma surface in $3 \% \mathrm{KOH}$. $\mathbf{k}$. Perithecium in section. I. Hairs on stroma surface. $\mathbf{m}$. Apical periphyses. n. Marginal cells at the ostiolar apex. o. Cortical tissue in face view. $\mathbf{p}$. Cortical and subcortical tissue in section. q. Subperithecial tissue in section. r, s. Asci with ascospores (s. in cotton blue/lactic acid). t. Ascospores in ascus apex. u. Swollen and germinating ascospores on agar surface. l-n. In 3\% KOH. a, r-t. WU 29425. b, d, e, h, i, l-n, u. WU 29417. c, f, g. WU 29416. j. WU 29419. k, o-q. WU 29414. Scale bars $\mathbf{a}=20 \mathrm{~cm} . \mathbf{b}=1 \mathrm{~mm} . \mathbf{c}, \mathbf{i}=0.5 \mathrm{~mm} . \mathbf{d}, \mathbf{j}=0.15 \mathrm{~mm}$. e- $\mathbf{g}=0.3 \mathrm{~mm}$. $\mathbf{h}=0.8 \mathrm{~mm}$. $\mathbf{k}, \mathbf{u}=30 \mu \mathrm{m}$. $\mathbf{l}, \mathbf{p}, \mathbf{q}=20 \mu \mathrm{m} . \mathbf{m}-\mathbf{0}, \mathbf{r}, \mathbf{s}=10 \mu \mathrm{m} . \mathbf{t}=5 \mu \mathrm{m}$

apex; ends rounded; periphyses 1-3 $\mu \mathrm{m}$ wide. Perithecia $(120-) 190-270(-310) \times(100-) 110-160(-180) \quad \mu \mathrm{m}(n=20)$, flask-shaped, often densely crowded; peridium (12-)13-25 $(-37) \mu \mathrm{m}(n=20)$ thick at the base, $(5-) 8-15(-17) \mu \mathrm{m}(n=$ $20)$ at the sides, bright yellow in lactic acid, deeply orange in $\mathrm{KOH}$. Cortical and subcortical layer when present 20-53(70) $\mu \mathrm{m}(n=30)$ thick, a homogeneous $t$. intricata of thinwalled, hyaline to yellowish hyphae (2-)3-6(-9) $\mu \mathrm{m}(n=30)$ wide in vertical section, surrounding entire perithecia, often scant between upper parts of the perithecia, sometimes with yellow guttules; appearing as globose to oblong cells (3-)4 $12(-22) \times(3-) 4-7(-9) \mu \mathrm{m}(n=30)$ in face view. Hyphal ends ('hairs') on the surface inconspicuous, (9-)13-27(-38) $\times(3-)$ 5-8(-10) $\mu \mathrm{m}(n=30)$, smooth or roughened, cylindrical to clavate, yellowish, not or only slightly projecting as single cells or rows of 2-3 cells with constricted septa, orange in $\mathrm{KOH}$, often collapsed in mature stromata. Subperithecial tissue a dense hyaline to yellowish $t$. angularis-epidermoidea of thin-walled cells $5-21(-34) \times(3-) 5-9(-11) \mu \mathrm{m}(n=$ $30)$, mixed with few broad yellowish hyphae; often strongly reduced between perithecia and host surface, but often deeply penetrating into the pores of the host. Asci (63-)70$90(-116) \times(4.0-) 4.3-5.0(-5.5) \mu \mathrm{m}$, stipe $(0-) 3-12(-18) \mu \mathrm{m}$ $(n=30)$ long; no croziers seen. Ascospores hyaline, often yellow to orange after ejection, smooth to finely spinulose, cells dimorphic; distal cell (3.0-)3.3-4.2(-5.0) $\times(2.7-) 3.0$ $3.5(-4.0) \mu \mathrm{m}, 1 / \mathrm{w}(0.9-) 1.1-1.3(-1.5)(n=90)$, subglobose, ellipsoidal or wedge-shaped; proximal cell (3.3-)4.0-5.5($6.3) \times(2.3-) 2.5-3.0(-3.5) \mu \mathrm{m}, 1 / \mathrm{w}(1.0-) 1.5-2.0(-2.4) \quad(n=$ 90) oblong or wedge-shaped. Ascospores characteristically conspicuously swelling to $c a 25 \mu \mathrm{m}$ diam on the agar surface before germination.

Cultures and anamorph: optimal growth at $30^{\circ} \mathrm{C}$ on $\mathrm{CMD}$ and SNA, at $25^{\circ} \mathrm{C}$ on PDA, at $25^{\circ} \mathrm{C}$ faster on PDA than on CMD and SNA; no growth at $35^{\circ} \mathrm{C}$.

On CMD after $72 \mathrm{~h} 10-12 \mathrm{~mm}$ at $15^{\circ} \mathrm{C}, 17-20 \mathrm{~mm}$ at $25^{\circ} \mathrm{C}, 18-24 \mathrm{~mm}$ at $30^{\circ} \mathrm{C}$; mycelium covering the plate after $12-14$ days at $25^{\circ} \mathrm{C}$. Colony hyaline, thin, not or indistinctly zonate, with wavy margin; mycelium loose, hyphae thin, little branched, irregularly oriented and coarsely wavy, causing radially oriented fan-shaped struc- tures. Surface becoming downy, floccose or farinose along the margin due to conidial heads. Aerial hyphae scant, short. Autolytic activity moderate, excretions small, hyaline to yellowish; coilings rare or absent: No diffusing pigment formed. Odour fruity. Chlamydospores uncommon, only seen at $30^{\circ} \mathrm{C}$, intercalary, rarely terminal, (11-)13-26($35) \times(8-) 9-20(-27) \mu \mathrm{m}, 1 / \mathrm{w}(1-) 1-1.7(-2.1) \mu \mathrm{m}(n=30)$, broadly ellipsoidal, subglobose, pyriform or oblong. Conidiation starting after 2 days on short, simple or scarcely asymmetrically branched, acremonium-like conidiophores, loosely disposed, becoming dense along the margin of the plate; with solitary subulate phialides and wet conidial heads to $150 \mu \mathrm{m}$ diam. Conidia as described on SNA, hyaline, conspicuously swelling after transfer to fresh agar. Some conidiation also submerged in the agar. Fruity, applelike odour noted also at 15 and $30^{\circ} \mathrm{C}$. At $15^{\circ} \mathrm{C}$ fan-shaped colony becoming diffuse yellow, 2-3AB3-4, conidiation dense along the margin. At $30^{\circ} \mathrm{C}$ colony irregular, fanshaped to lobed; conidiation concentrated in powdery or granular distal concentric zones, in white tufts to $1.5 \mathrm{~mm}$ diam or in broad white spots. Tufts loosely asymmetrically branched, right angles frequent.

On PDA after $72 \mathrm{~h} 10-11 \mathrm{~mm}$ at $15^{\circ} \mathrm{C}, 30-33 \mathrm{~mm}$ at $25^{\circ} \mathrm{C}$, 20-22 $\mathrm{mm}$ at $30^{\circ} \mathrm{C}$; mycelium covering the plate after 56 days at $25^{\circ} \mathrm{C}$. Colony flat, indistinctly zonate, imbricate, mottled due to varying mycelial density, white in denser regions; margin wavy to lobed, thinner than the residual colony. Mycelium dense; surface hyphae thick. Surface becoming farinose or granulose due to conidial heads. Aerial hyphae in lawns of varying density, short, thick, erect, often fasciculate, becoming fertile. Sometimes dense white spots appearing, with brownish droplets, turning golden brown. Autolytic excretions abundant, small, $<50 \mu \mathrm{m}$ diam; coilings absent. Agar/reverse turning pale rosy with yellow tones or dull orange around the plug, 5AB4-5. Odour fruity, applelike. No chlamydospores seen. Conidiation noted after 2 days, effuse, in a dense lawn of simple, short, scarcely branched, acremonium-like conidiophores 3-5 $\mu \mathrm{m}$ wide terminally, 6 $8 \mu \mathrm{m}$ basally, with 1-2 terminal phialides, spreading from the centre. Conidia formed in numerous wet heads $20-80(-160)$ $\mu \mathrm{m}$ diam, confluent, becoming irregular. Phialides (6-)25-53 $(-76) \times(2.8-) 3.5-5.5(-7.0) \mu \mathrm{m}, 1 / \mathrm{w}(2-) 6-12(-18),(2.5-)$ $3.5-5.0(-6.5) \mu \mathrm{m}(n=90)$ wide at the base, subulate or cylindrical, straight, curved or sinuous. Conidia (5-)7-14($18) \times(3-) 4-8(-12) \mu \mathrm{m}, 1 / \mathrm{w} \quad(1.1-) 1.3-2.0(-2.7) \quad(n=90)$, hyaline, quite variable, subglobose, oval, pyriform, oblong to cylindrical, smooth, with minute guttules and indistinct or truncate scar. At $15^{\circ} \mathrm{C}$ colony crystal-, fan- or star-shaped due to fasciculate radial surface hyphae, becoming mottled with large thick powdery whitish spots to $1 \mathrm{~cm}$ long. Agar rosy, greyish orange or reddish, 5AB4-5, 6B4-5, 7A4; odour distinct, 'artificially fruity'. Conidiation in numerous wet heads to $250 \mu \mathrm{m}$ diam, particularly dense in white spots. 

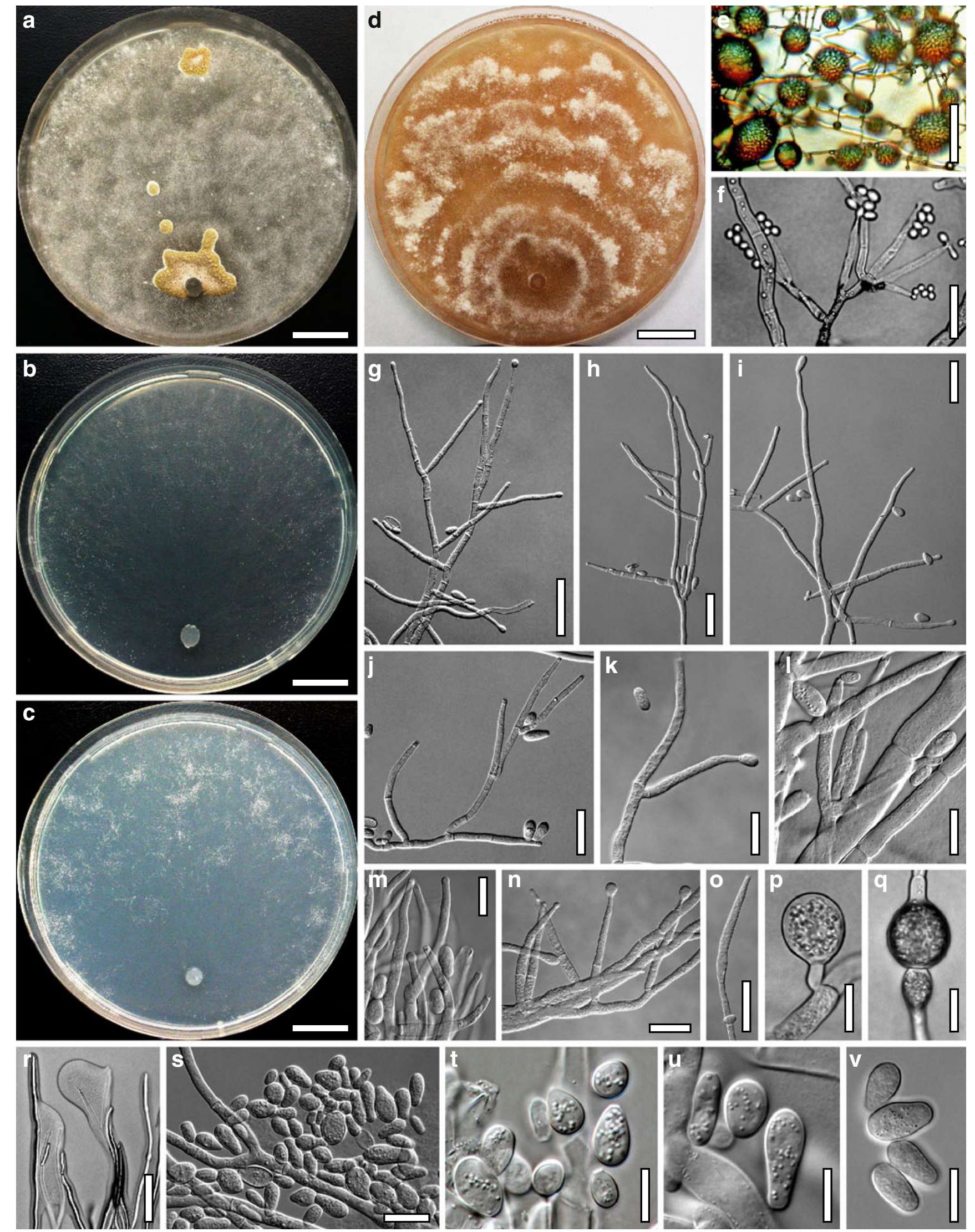
4Fig. 66 Cultures and anamorph of Hypocrea protopulvinata. a-d. Cultures (a. on PDA, 21 days. b. on CMD, 14 days. c. on SNA, 14 days. d. on $\mathrm{PDA}, 30^{\circ} \mathrm{C}, 13$ days). e. Conidial heads on growth plate close to the plug (SNA, 7 days). f. Conidiophore on growth plate (CMD, $30^{\circ} \mathrm{C}, 14$ days). g-o. Conidiophores and phialides $(\mathbf{g}-\mathbf{k}, \mathbf{n}$. SNA, 4-8 days; $\mathbf{l}, \mathbf{m}, \mathbf{o}$. PDA, 3 days). p, q. Chlamydospores (CMD, $30^{\circ} \mathrm{C}, 14$ days). r. Autolytic excretions on hyphal tips (PDA, $15^{\circ} \mathrm{C}$, 5 days). s-v. Conidia (s. SNA, 6 days; t-v. PDA, 3-6 days). a-c, e, go, s-v. At $25^{\circ}$ C. a-f, $\mathbf{k}, \mathbf{l}, \mathbf{n}-\mathbf{r}$, u. C.P.K. 2434. $\mathbf{g}-\mathbf{j}$, s. CBS 121270 . m, v. CBS 739.83. t. CBS 121274. Scale bars $\mathbf{a}-\mathbf{d}=15 \mathrm{~mm}$. $\mathbf{e}=0.2 \mathrm{~mm}$. f, $\mathbf{i}, \mathbf{j}, \mathbf{n}=30 \mu \mathrm{m} . \mathbf{g}, \mathbf{h}=50 \mu \mathrm{m} . \mathbf{k}, \mathbf{m}, \mathbf{o}, \mathbf{s}=20 \mu \mathrm{m} . \mathbf{l}, \mathbf{p}, \mathbf{q}=15 \mu \mathrm{m} . \mathbf{r}=$ $80 \mu \mathrm{m} . \mathbf{t}-\mathbf{v}=10 \mu \mathrm{m}$

At $30^{\circ} \mathrm{C}$ colony of white concentric zones on reddish agar and yellow to orange-red spots due to dead yellow hyphae; irregularly mottled. Conidial heads to $300 \mu \mathrm{m}$ around the plug. Agar turning greyish orange to greyish red, 6B4-6, $7 \mathrm{AB} 3-4$; pigment more distinct than at 15 and $25^{\circ} \mathrm{C}$; odour indistinct.

On SNA after $72 \mathrm{~h} 8-10 \mathrm{~mm}$ at $15^{\circ} \mathrm{C}, 20-22 \mathrm{~mm}$ at $25^{\circ} \mathrm{C}$, $22-24 \mathrm{~mm}$ at $30^{\circ} \mathrm{C}$; mycelium covering the plate after 10 11 days at $25^{\circ} \mathrm{C}$. Colony similar to $\mathrm{CMD}$, but denser. Surface hyphae soon degenerating, appearing empty. Aerial hyphae variable, long in distal and lateral areas of the colony, becoming fertile, sometimes aggregating to loose tufts, forming indistinct concentric zones or white spots. Autolytic activity inconspicuous, coilings rare or absent. No pigment, no distinct odour noted. No chlamydospores seen. Conidiation starting after 2 days mostly around the plug and towards proximal margin, or irregularly distributed; on simple, erect, acremonium-like to irregularly verticillium-like conidiophores, short or on long aerial hyphae at the distal margin. Conidia amassing in numerous wet heads growing to $200 \mu \mathrm{m}$ diam, largest around the plug, becoming concentrated in irregular white spots or in irregular loose tufts of aerial hyphae, sometimes in few concentric zones, finally becoming dry. Conidial yield conspicuously higher than on CMD and PDA. Conidiophores to $2 \mathrm{~mm}$ long, 6-9 $\mu \mathrm{m}$ wide at the base, attenuated terminally to $2.5-6 \mu \mathrm{m}$, asymmetrically branched, typically of a single main axis with several long, unpaired, widely spaced branches. Branches with short side branches or phialides. Phialides solitary, not in whorls, often on 1-celled side branches, or in extension of the conidiophore or branching off in right angles. Phialides (10-)30-60(-95) $\times$ (3-)4-6(-7) $\mu \mathrm{m}, 1 / \mathrm{w}(3-) 6-12(-17)(n=90),(2.7-) 4.0-5.5$ $(-6.3) \mu \mathrm{m}(n=90)$ wide at the base, subulate or cylindrical, straight or slightly sinuous, widest at or slightly above the base. Conidia (5-)8-16(-26)×(3-)4-9(-12) $\mu \mathrm{m}, 1 / \mathrm{w}(1.3-)$ 1.4-2.2(-3.6) $\mu \mathrm{m}(n=93)$, hyaline, smooth, highly variable, oval to pyriform, oblong to cylindrical, or irregular, usually broadly rounded, base often truncate, eguttulate, often densely packed in heads. At $30^{\circ} \mathrm{C}$ conidiation in up to 8 finely granular concentric zones.
Habitat: on basidiomes of Fomitopsis pinicola, often in association with $H$. pulvinata.

Distribution: Europe (Austria, Czech Republic, Spain, Switzerland), Japan, North America, depending on the distribution of its host.

Holotype: Japan, Chiba Prefecture, Fudagou, Kiyosumi Forestry Exp. Station of the Univ. of Tokyo, on Fomitopsis pinicola, 24 Oct. 1967, Y. Doi (TNS.D-365=TNS-F-223431; ex-type culture CBS 739.83; only culture examined).

Specimens examined: Austria, Kärnten, Völkermarkt, Eisenkappel, at roadside, $1-2 \mathrm{~km}$ from the village, heading to Seebergsattel, MTB 9553/3, 46 $26^{\prime} 16^{\prime \prime} \mathrm{N} 14^{\circ} 33^{\prime} 40^{\prime \prime} \mathrm{E}$, elev. $780 \mathrm{~m}$, on the hymenium of Fomitopsis pinicola/Picea abies, soc. Ophiostoma polyporicola, 31 Oct. 2005, H. Voglmayr \& W. Jaklitsch, W.J. 2882 (WU 29414, culture CBS 121274=C.P.K. 2430). Niederösterreich, Lilienfeld, Sankt Aegyd am Neuwalde, Lahnsattel, virgin forest Neuwald, MTB 8259/1, 4746'32" N 15³1'25" E, elev. $980 \mathrm{~m}$, on the hymenium of a basidiome of Fomitopsis pinicola lying on the ground, soc. Melanospora sp., Ophiostoma polyporicola, 27 Sep. 2006, H. Voglmayr, W. J. 2990 (WU 29416, culture C.P.K. 2476). Mödling, Wienerwald, Kaltenleutgeben, between Am Brand and Stangau, MTB 7862/4, 48 $06^{\prime} 41^{\prime \prime}$ N, 16 $6^{\circ} 08^{\prime} 26^{\prime \prime}$ E, elev. $500 \mathrm{~m}$, on a basidiome of Fomitopsis pinicola on a log of Fagus sylvatica, soc. Hypocrea pulvinata, 5 Oct. 2008, W. Jaklitsch \& O. Sükösd, W.J. 3221 (WU 29418). Steiermark, Bruck/Mur, Gußwerk, Rotmoos bei Weichselboden, forest edge, MTB 8356/2, 4740'58" N 1509'26" E, elev. 690 m, on Fomitopsis pinicola on corticated log of Alnus incana lying on the ground, $12 \mathrm{~cm}$ thick, soc. Ophiostoma polyporicola, 27 Sep. 2006, H. Voglmayr, W.J. 2993 (WU 29417, culture CBS $121270=$ C.P.K. 2478). Tirol, Innsbruck-Land, Zirl, Zirler Alnetum (south of the river

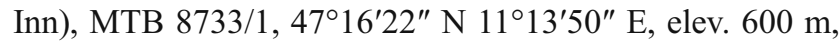
on hymenium and upper side of Fomitopsis pinicola fallen from standing trunk of Alnus incana to the ground, also on bark, soc. H. pulvinata, 2 Sep. 2003, W. Jaklitsch, W.J. 2359 (WU 29425). Czech Republic, Southern Bohemia, Žofín, Žofínský prales, MTB 7354/1, on a basidiome of Fomitopsis pinicola, soc. Ophiostoma polyporicola, 27 Sep. 2008, A. Urban, W.J. 3223 (WU 29419). Spain, Asturias, Puerto de Pajares, Hayedo de Valgrande, $43^{\circ} 00^{\prime}$ 04" N 5 46' 41" W, elev. 1000 m, on Fomitopsis pinicolal Fagus sylvatica; 14 Aug. 2009 (ERD-4884). Switzerland, Bern, Büetigen, on Fomitopsis pinicola, soc. various hyphomycetes, overmature, 13 Oct. 2005, W. Gams (WU 29415, culture C.P.K. 2434).

Notes: This species, originally described from Japan (Doi 1972), occurs also in North America, but was apparently unknown in Europe until recently. It often occurs together with $H$. pulvinata on the same basidiome, both species residing on the hymenium, while $H$. pulvinata 
frequently also grows on the upper side. Both species are often accompanied by Ophiostoma polyporicola, sometimes by Melanospora cf. lagenaria. Morphological differences permit easy distinction from $H$. pulvinata. Examination of the surface of fresh stromata, ideally before ascospore ejection, in the stereo-microscope is usually sufficient: $H$. pulvinata has minute ostioles surrounded by a ring-like, diffusely greenish yellow to orange-brown coloured stroma surface, followed by white mycelium, while $H$. protopulvinata has wide brown perithecial dots surrounded by a homogeneously coloured, white to brownish stroma surface. Further differences are lanceolate ostiolar cells and more or less monomorphic ascospores in H. pulvinata. In culture the apple-like odour and the large phialides are characteristic for $H$. protopulvinata. Earlier authors (Doi 1972; Overton et al. 2006a) reported considerably smaller phialides. However, a re-examination of the ex-type strain CBS 739.83 on PDA revealed phialides (13-) $32-55(-67) \times(4-) 5-6(-7) \mu \mathrm{m}(n=30)$. See also the website www.asturnatura.com for a good illustration of $H$. protopulvinata.

Hypocrea pulvinata Fuckel, Jahrb. Nassau. Ver. Naturk. 23-24: 185 (1870 ['1869’]). Fig. 67

= Hypocrea citrina $*$ fungicola P. Karst., Mycol. Fenn. 2: 204 (1873).

$\equiv$ Hypocrea karsteniana Niessl in Rehm. Ascomyceten, Hedwigia 22: 53 ([Apr.] 1883).

$\equiv$ Hypocrea fungicola (P. Karst.) Sacc., Syll. Fung. 2: 528 ([13 June] 1883a).

$\equiv$ Protocrea fungicola (P. Karst) Lar.N. Vassiljeva, NizshieRasteniya, Griby i Mokhoo-braznye Dal'nego Vostoka Rossii, Griby. Tom 4. Pirenomitsety i Lokuloaskomitsety (Sankt-Petersburg): 162 (1998).

= Hypocrea colliculosa Fr., in Cooke, Grevillea 12: 79 (1884).

= Hypocrea citrina (Fr.) Fr. var. citrina sensu Canham, Mycologia 61: 318 (1969).

Anamorph: Trichoderma sp. [sect. Hypocreanum]. Fig. 68

Stromata when fresh $1-150 \times 0.5-130 \mathrm{~mm}, 0.5-2 \mathrm{~mm}$ thick, solitary, gregarious or densely aggregated, small and pulvinate or large and broadly pulvinate or effuse; outline roundish, elongate or irregular. Surface smooth, slightly velutinous; ostiolar dots minute, plane, (olive-)brown, pale and diffuse when young. Stroma colour white, yellowish, greenish-yellow, brown-orange, 2-3A2-4, 3-4A5-6, $5 \mathrm{CD} 8$, often with olive tones.

Stromata when dry $0.2-0.8(-1.5) \mathrm{mm}(n=30)$ thick, broadly pulvinate, subeffuse or effuse, the latter particularly on the hymenial margin of the host, broadly attached, with rounded, less commonly mycelial margin. Surface velutinous or farinose; perithecia immersed or perithecial contours sometimes slightly projecting. Ostioles visible as minute, plane, brown perforations. Ostiolar areas (27-)40 $77(-94) \mu \mathrm{m}(n=30)$ diam, including brown diffuse margins. Stroma colour first white, after the development of ostioles pale yellowish, greenish- or greyish-yellow; later yellowbrown or dull (orange-)brown with olive tones, 3-4A2-3, 4B3-4, 5CD4-6. Pigment inhomogeneously distributed, usually only present around the ostioles, lighter or white outside the ostiolar areas. Reaction to $3 \% \mathrm{KOH}$ variable, inconspicuous or reddish, orange-red to dark red. Spore deposits white or yellow, often condensing to a thick crust.

Stroma anatomy: Ostioles (62-)72-90(-97) $\mu \mathrm{m}$ long, projecting to $16(-27) \mu \mathrm{m},(22-) 36-56(-62) \mu \mathrm{m}$ wide at the apex $(n=20)$, filled with short narrow cylindrical periphyses and lined by a palisade of narrow hyaline hyphae with characteristic lanceolate or conical apical cells to $16 \times 2.5$ $4.5 \mu \mathrm{m}$ at the apical margin. Perithecia (175-)210-260 $(-270) \times(110-) 140-210(-225) \mu \mathrm{m}(n=21)$, globose or flaskshaped, often densely crowded; peridium (20-)28-46(-55) $\mu \mathrm{m}$ thick at the base, $(10-) 13-26(-35) \mu \mathrm{m}(n=21)$ at the sides, bright yellow in lactic acid, orange-red in $3 \% \mathrm{KOH}$, particularly in upper parts. Cortical including subcortical layer (17-)25-53(-77) $\mu \mathrm{m}(n=30)$ thick, a mixture of hyaline to yellowish thin-walled (sub-)globose, angular to oblong cells $(3-) 4-11(-18) \times(2-) 3.5-8(-12) \mu \mathrm{m}(n=60)$ in face view and vertical section and hyphae (2.5-)3.5-7.0 $(-8.5) \mu \mathrm{m}(n=30)$ wide, vertical between perithecia. Surface with numerous cylindrical to clavate hairs $(8-) 11-27(-35) \times$ (3.0-)3.5-5.5(-7.0) $\mu \mathrm{m}(n=30)$, hyaline or yellowish, mostly vertically arranged, with verrucose to spinulose, broadly rounded terminal cells; verrucae globose, 0.5$2 \mu \mathrm{m}$ diam. Subperithecial tissue a dense, homogeneous t. epidermoidea of thick-walled (1-2.5 $\mu \mathrm{m})$, globose, oblong or curved hyaline cells $(5-) 8-22(-29) \times(4-) 7-14(-17) \mu \mathrm{m}$ $(n=30)$, penetrated by few vertical hyphae $(3-) 5-14 \mu \mathrm{m}$ wide, yellowish towards the base. Asci (59-)72-88(-95) $\times$ 3.3-4.7(-6.0) $\mu \mathrm{m}$; stipe to $13(-26) \mu \mathrm{m}(n=33)$ long; no croziers seen. Ascospores hyaline, sometimes yellow after their ejection, smooth or finely roughened, eguttulate; cells more or less monomorphic; distal cell (2.5-)3.3-4.5(-6.3) $(2.3-) 2.5-3.2(-3.7) \mu \mathrm{m}, 1 / \mathrm{w} \quad(1.0-) 1.1-1.7(-2.4) \quad(\mathrm{n}=33)$;

Fig. 67 a-v. Teleomorph of Hypocrea pulvinata. a-f. Fresh stromata (a. habit on Piptoporus betulinus; e. on PDA; f. surface). g-k. Dry stromata (j. with spore deposits; $\mathbf{k}$. white and yellow spore deposits). I. Ostiole in section showing periphyses and apical marginal cells). $\mathbf{m}$. Marginal cells at ostiolar apex. n. Hairs on stroma surface. o. Stroma in $3 \% \mathrm{KOH}$. p. Perithecium in section. q. Stroma surface in face view. r. Cortical and subcortical tissue in section. s. Subperithecial tissue in section. t-v. Asci with ascospores (v. in cotton blue/lactic acid). w. Hypocrea americana. Asci with ascospores. a, g, m, n, q. WU 29423. b, k. WU 29435. c, f, t, u. WU 29440. d. WU 29434. e, j, l, p, r, s, v. WU 29425. h, i. WU 29430. o. WU 29441. w. WU 29540. Scale bars $\mathbf{a}=10 \mathrm{~mm} . \mathbf{b}, \mathbf{f}=0.15 \mathrm{~mm} . \mathbf{c}, \mathbf{g}, \mathbf{i}-\mathbf{k}, \mathbf{o}=0.5 \mathrm{~mm} . \mathbf{d}, \mathbf{e}, \mathbf{h}=0.9 \mathrm{~mm} . \mathbf{l}-\mathbf{n}$, $\mathbf{q}, \mathbf{t}-\mathbf{v}=10 \mu \mathrm{m} . \mathbf{p}, \mathbf{r}, \mathbf{s}=25 \mu \mathrm{m} . \mathbf{w}=5 \mu \mathrm{m}$ 

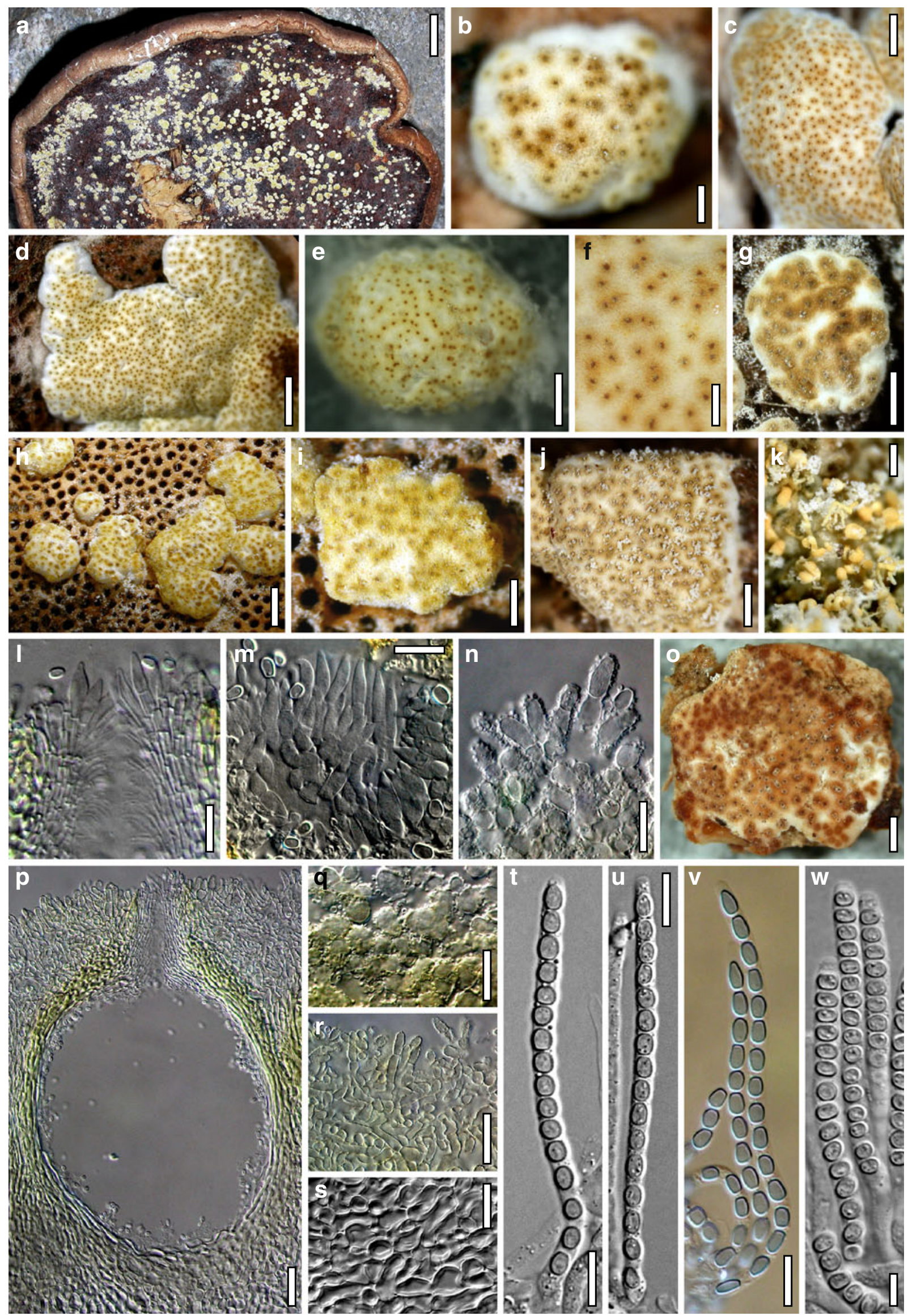

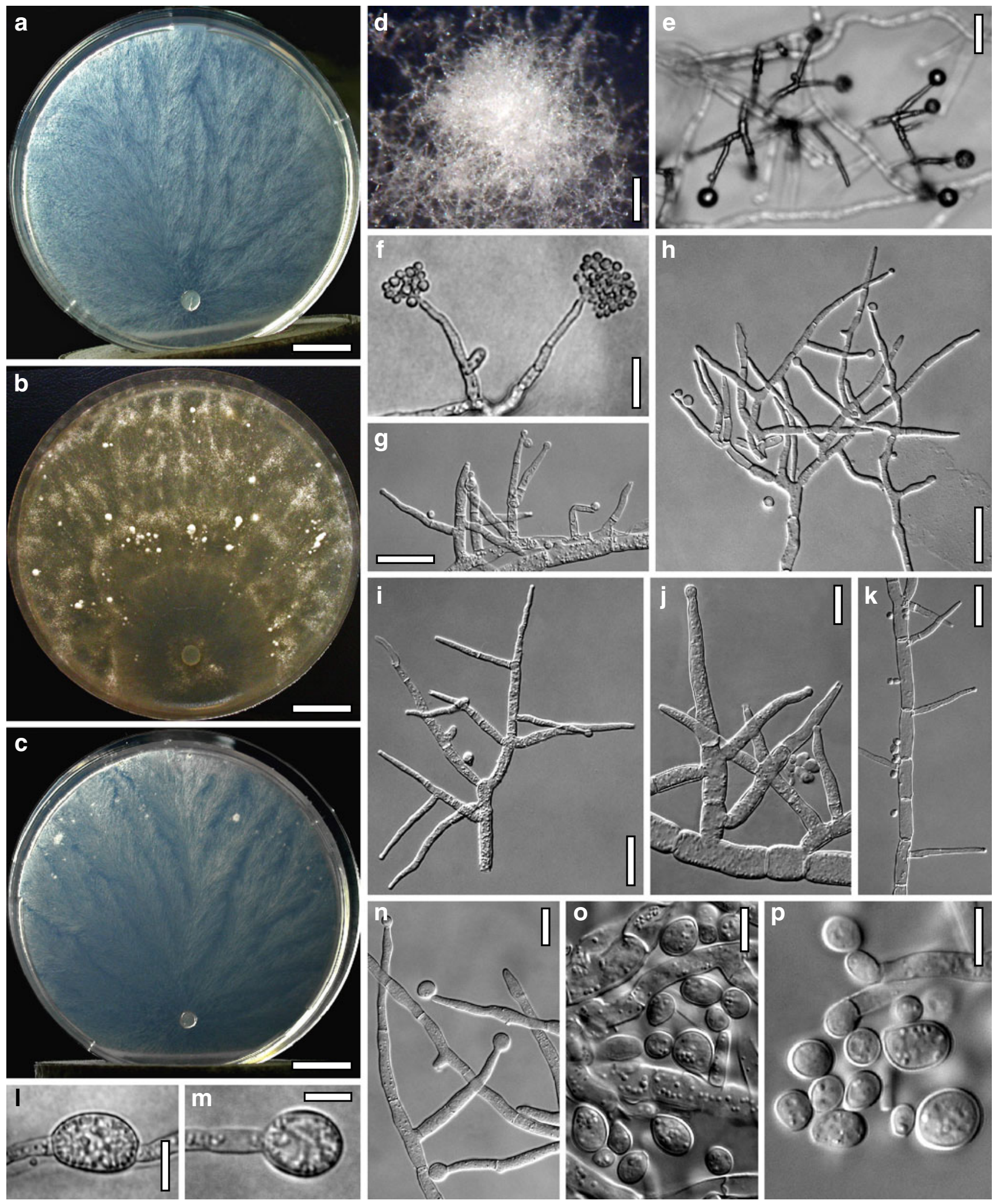

Fig. 68 Cultures and anamorph of Hypocrea pulvinata. a-c. Cultures (a. on CMD, 7 days. b. on PDA, 14 days. c. on SNA, 14 days). d. Conidiation tuft (SNA, 15 days). e. Simple conidiophores on growth plate (CMD, 8 days). f. Simple conidiophores submerged in agar (CMD, 14 days). $\mathbf{g}-\mathbf{k}, \mathbf{n}$. Conidiophores and phialides (PDA, 4-
5 days). $\mathbf{1}, \mathbf{m}$. Chlamydospores (CMD, $30^{\circ} \mathrm{C}, 30$ days). o, p. Conidia (PDA, 5 days). a-k, n-p. At $25^{\circ}$ C. a-d, f-p. CBS 121279. e. C.P.K. 1991. Scale bars $\mathbf{a}-\mathbf{c}=15 \mathrm{~mm}$. $\mathbf{d}=0.3 \mathrm{~mm}$. e, $\mathbf{h}=30 \mu \mathrm{m}$. f, $\mathbf{g}, \mathbf{i}, \mathbf{k}=$ $20 \mu \mathrm{m} . \mathbf{j}, \mathbf{l}, \mathbf{n}=10 \mu \mathrm{m} . \mathbf{m}, \mathbf{o}, \mathbf{p}=7 \mu \mathrm{m}$ 
proximal cell $(3.0-) 3.5-5.0(-5.5) \times(2.0-) 2.5-3.2(-3.7) \mu \mathrm{m}$, $1 / \mathrm{w}(0.9-) 1.1-1.8(-2.4) \quad(n=33)$; both cells ellipsoidal or oblong, nearly rectangular or projectile-shaped, sometimes subglobose, often truncate at the contact area and wider towards rounded ends; sometimes dimorphic in the ascus base, less commonly in other positions.

Cultures and anamorph: optimal growth at $25^{\circ} \mathrm{C}$ on all media; no growth at $35^{\circ} \mathrm{C}$.

On CMD after $72 \mathrm{~h} 10-11 \mathrm{~mm}$ at $15^{\circ} \mathrm{C}, 23-27 \mathrm{~mm}$ at $25^{\circ} \mathrm{C}, 13-15 \mathrm{~mm}$ at $30^{\circ} \mathrm{C}$; mycelium covering the plate after 1 week at $25^{\circ} \mathrm{C}$. Colony hyaline, thin, not zonate; margin wavy or forming lobes. Mycelium loose, organised in radial patches, little on the agar surface; primary hyphae to $c a 15 \mu \mathrm{m}$ wide. Aerial hyphae short, scant. No autolytic activity and coilings noted. No diffusing pigment, no distinct odour noted. Chlamydospores absent or rare, slightly more frequent at $30^{\circ} \mathrm{C},(8-) 10-17(-26) \times(8-) 9-15$ $(-23) \mu \mathrm{m}, 1 / \mathrm{w}(0.9-) 1.0-1.4(-1.6) \quad(n=30)$, (sub)globose, ellipsoidal or pyriform, terminal, less frequently intercalary and then more angular, multiguttulate. Conidiation starting after 3-4 days mainly around the plug and at the proximal margin, variable, scant or abundant, on solitary phialides sessile on surface hyphae or minute erect, acremonium-like to irregularly verticillium-like conidiophores; sometimes concentrated in narrow concentric zones, sometimes also submerged in the agar to the bottom of the plate; macroscopically invisible, sometimes appearing in white fluffy tufts in distal areas. Conidial heads to $50 \mu \mathrm{m}$ diam. At $15^{\circ} \mathrm{C}$ dense white pustules noted after 2 weeks, mostly at the colony sides. At $30^{\circ} \mathrm{C}$ colony forming empty spaces, resembling snow crystals.

On PDA after $72 \mathrm{~h} 12-13 \mathrm{~mm}$ at $15^{\circ} \mathrm{C}, 19-30 \mathrm{~mm}$ at $25^{\circ} \mathrm{C}$, $1-5 \mathrm{~mm}$ at $30^{\circ} \mathrm{C}$; mycelium covering the plate after 1 week at $25^{\circ} \mathrm{C}$. Colony irregularly leaf- or crystal-like, flat, margin wavy; mycelium dense, primary hyphae to $c a 10(-15) \mu \mathrm{m}$ thick, parallel and particularly densely arranged at the margin. Centre thin, becoming finely farinose to granular at the surface; residual part of the colony developing several concentric, downy, whitish, mottled zones or becoming irregularly mottled with more or less radially arranged whitish downy spots. Aerial hyphae thick, short and dense in the centre; long, rather flat and radially arranged toward the margin, becoming fertile. Autolytic activity inconspicuous, coilings absent. No pigment, no distinct odour noted. Conidiation starting after 3-4 days at the proximal margin and around the plug, short, mostly on 1-2(-3) phialides on aerial and surface hyphae, dense, spreading across entire plate, concentrated in concentric zones and white spots, often on stromatic bases, sometimes in irregularly distributed white tufts or pustules to $1.5(-4) \mathrm{mm}$ diam. Conidial heads wet, minute, sometimes to $50 \mu \mathrm{m}$ diam. Conidiophores (main axis) short, simple, acremonium-like, or irregularly verticillium-like, unbranched or branched 3 fold, thick- walled and to $10(-15) \mu \mathrm{m}$ wide at the base, erect or obliquely arising from surface hyphae, gradually attenuated upwards to $3 \mu \mathrm{m}$; bearing phialides in irregular distances, mostly solitary, infrequently paired, often in right angles on the main axis, often on 1-celled, sometimes thickened branches. Phialides $(7-) 17-38(-59) \times(2.7-) 3.3-4.2(-4.5)$ $\mu \mathrm{m}, 1 / \mathrm{w}(2.8-) 4.8-9.5(-14) \quad(n=30),(2.5-) 3.0-3.8(-4.3)$ $\mu \mathrm{m}(n=30)$ wide at the base, subulate, usually straight, widest at or slightly above the base. Conidia (2.5-)3.7-8.5 $(-11) \times(2.5-) 3-6(-7.5) \mu \mathrm{m}, 1 / \mathrm{w}(1.0-) 1.1-1.6(-2.0)(n=30)$, hyaline, oval, subglobose or pyriform, smooth, finely multiguttulate, often with distinct truncate scar. At 15 and $30^{\circ} \mathrm{C}$ often yellow spots apparent due to pigmented hyphae, 3A4, 3B6-7, becoming brown, $5 \mathrm{CD} 5-8$. At $30^{\circ} \mathrm{C}$ colony zonate; autolytic activity sometimes conspicuous in yellow spots.

On SNA after $72 \mathrm{~h} 10-11 \mathrm{~mm}$ at $15^{\circ} \mathrm{C}, 25-27 \mathrm{~mm}$ at $25^{\circ} \mathrm{C}$, $3-7 \mathrm{~mm}$ at $30^{\circ} \mathrm{C}$; mycelium covering the plate after 1 week at $25^{\circ} \mathrm{C}$. Colony hyaline, thin, leaf-like with empty spaces, not zonate; margin wavy or irregular; mycelium loose, little on the agar surface; primary hyphae thick. Aerial hyphae short, infrequent. Autolytic activity and coilings lacking. No pigment, no distinct odour noted. Chlamydospores infrequent, noted after 2 weeks, earlier at $30^{\circ} \mathrm{C}$. Conidiation starting after 3-4 days mainly around the plug and at the proximal margin, on solitary phialides on surface hyphae or 1-2 phialides on short, often 1-celled, acremonium-like conidiophores, usually scant, loosely arranged, spreading across the plate, after $>10$ days denser in white fluffy tufts to $2 \mathrm{~mm}$ diam in distal areas. At $15^{\circ} \mathrm{C}$ helical hyphae inside agar around the plug. At $30^{\circ} \mathrm{C}$ colony irregular, autolytic activity, terminal and intercalary thickenings of hyphae conspicuous; no conidiation seen. After $c a 1$ year at $15^{\circ} \mathrm{C}$ small stromata seen. Fertile pulvinate stromata $2-4 \mathrm{~mm}$ diam agreeing in morphology with stromata found in nature also formed within a month at $15^{\circ} \mathrm{C}$ on MEA covered by cellophane.

Habitat: on basidiomes of Fomitopsis pinicola and Piptoporus betulinus. Reports from Laetiporus sulphureus and Ganoderma spp. have not been confirmed in recent years.

Distribution: common in north temperate regions of the world, Europe, Japan, North America.

Lectotype, designated by Overton et al. (2006a): Germany, Hessen, Eltville am Rhein, Hattenheimer Wald (Geis), on Polyporus sulphureus (= Laetiporus sulphureus), identified as Fomitopsis pinicola !, L. Fuckel, autumn, No. 876 (FH!).

Other specimens examined: Austria, Burgenland, Mattersburg, Bad Sauerbrunn, Hirmer Wald, MTB 8264/1, $47^{\circ}$ 45'28" N 16²1'26" E, elev. 270 m, on Piptoporus betulinus, 13 Jul. 2004, W. Jaklitsch \& H. Voglmayr. Oberpullendorf,

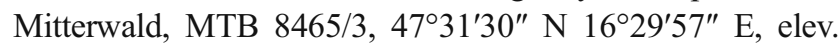
270 m, on Piptoporus betulinus, 13 Jul. 2004, W. Jaklitsch. Kärnten, Klagenfurt Land, St. Margareten im Rosental, 
Schwarzgupfweg-Umwiese, MTB 9452/4, 46³1'52" N $14^{\circ}$ $24^{\prime} 55^{\prime \prime}$ E, elev. $730 \mathrm{~m}$, on hymenium of Fomitopsis pinicola on Picea abies, soc. Ophiostoma polyporicola, 6 Sep. 2003, W. Jaklitsch, W.J. 2384 (WU 29426, culture C.P.K. 952).

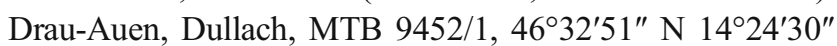
E, elev. 410 m, on Fomitopsis pinicola, 22 Oct. 2003, W. Jaklitsch. Niederösterreich, Baden, Klausen-Leopoldsdorf, Hochstraß, MTB 7862/3, 4807'40" N 15 59'26" E, elev. 470 m,on Fomitopsis pinicolalFagus sylvatica, 23 May 1999, W. Jaklitsch, W.J. 1319. Klosterneuburg, Kritzendorf Kierlinger Gasse, on hymenium of Piptoporus betulinus, effuse form, $15 \mathrm{~cm}$ long, 2 Dec. 2009, C. Bazant (WU 30204). Lilienfeld, Sankt Aegyd am Neuwalde, Lahnsattel,

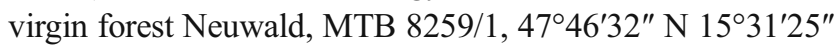
E, elev. 980 m, on Fomitopsis pinicola lying on the ground, 27 Sep. 2006, H. Voglmayr, W.J. 2990 (WU 29434). Mödling, Wienerwald, Kaltenleutgeben, between Am Brand and Stangau, MTB 7862/4, 48 $06^{\prime} 41^{\prime \prime} \mathrm{N}, 16^{\circ} 08^{\prime} 26^{\prime \prime}$ E, elev. $500 \mathrm{~m}$, on a basidiome of Fomitopsis pinicola on a log of Fagus sylvatica, soc. Hypocrea protopulvinata, 5 Oct. 2008, W. Jaklitsch \& O. Sükösd, W.J. 3222 (WU 29441). WienUmgebung, Mauerbach, Friedhofstraße, MTB 7763/1, 48 $15^{\prime} 09^{\prime \prime} \mathrm{N} 16^{\circ} 10^{\prime} 19^{\prime \prime} \mathrm{E}$, elev. $340 \mathrm{~m}$, on upper side of Piptoporus betulinus, 23 Jul. 2005, W. Jaklitsch, W.J. 2821 (WU 29432). Oberösterreich, Schärding, Kopfing, Hötzenedt, MTB 7548/1, elev. 730 m, on Piptoporus betulinus on standing trunk of Betula pubescens, 15 Aug. 2006, H. Voglmayr, W.J. 2930 (WU 29433). Steiermark, Bruck/Mur, Gußwerk, Rotmoos bei Weichselboden, riverine forest, MTB $8356 / 2,47^{\circ} 40^{\prime} 57^{\prime \prime} \mathrm{N} 15^{\circ} 09^{\prime} 26^{\prime \prime} \mathrm{E}$, elev. $690 \mathrm{~m}$, on Fomitopsis pinicola on a trunk of Alnus incana lying on the ground, 27 Sep. 2006, H. Voglmayr, W.J. 2994 (WU 29435). Liezen, Kleinsölk, close to the crossing Tuchmoar/ Breitlahnhütte, MTB 8649/4, 47¹9'46" N 1356'38" E, elev. $1140 \mathrm{~m}$, on hymenium of Piptoporus betulinus on Betula pendula, 5 Aug. 2003, H. Voglmayr \& W. Jaklitsch, W.J. 2289 (WU 29423). Same region, Wasserschaupfad, between

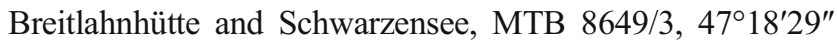
N 13 53'07" E, elev. $1100 \mathrm{~m}$, on hymenium of Fomitopsis pinicola on Picea abies, 6 Aug. 2003, H. Voglmayr \& W. Jaklitsch, W.J. 2294 (WU 29424, culture C.P.K. 2385).

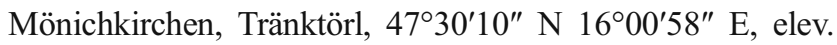
1030 m, on Piptoporus betulinus, 13 Sep. 2008, W. Jaklitsch \& O. Sükösd, W.J. 3207 (WU 29440). Tirol, InnsbruckLand, Zirl, Zirler Alnetum (south of the river Inn), MTB $8733 / 1,47^{\circ} 16^{\prime} 22^{\prime \prime} \mathrm{N} 11^{\circ} 13^{\prime} 50^{\prime \prime} \mathrm{E}$, elev. $600 \mathrm{~m}$, on hymenium and upper side of Fomitopsis pinicola fallen from standing trunk of Alnus incana to the ground, also on bark, soc. H. protopulvinata, 2 Sep. 2003, W. Jaklitsch, W.J. 2359 (WU 29425, deposited as H. protopulvinata, culture CBS 121279=C.P.K. 946). Vorarlberg, Bludenz, Sonntag, forest path at the Lutz bridge, Großes Walsertal, MTB 8725/ $3,47^{\circ} 14^{\prime} 17^{\prime \prime} \mathrm{N} 09^{\circ} 54^{\prime} 27^{\prime \prime}$ E, elev. $780 \mathrm{~m}$, on Fomitopsis pinicola, 1 Sep. 2004, H. Voglmayr \& W. Jaklitsch. Czech Republic, Southern Bohemia, Stráž nad Nežárkou, nature reserve Fabián, district Jindrichuv Hradec, ca $4 \mathrm{~km} \mathrm{E}$ of Liborezy village near Stráž nad Nežárkou town, 4901'55" N $14^{\circ} 59^{\prime} 00^{\prime \prime}$ E, elev. $600 \mathrm{~m}$, on Fomitopsis pinicola on Picea abies, 18 Oct. 2003, G. Koller, W.J. 2487 (WU 29429, culture C.P.K. 1991). Germany, Baden Württemberg, Freiburg, Landkreis Breisgau-Hochschwarzwald, St. Märgen, shortly after Glashütte coming from Hexenloch, MTB 8014/ 2, 47 $59^{\circ} 37^{\prime \prime} \mathrm{N} 08^{\circ} 07^{\prime} 32^{\prime \prime}$ E, elev. $750 \mathrm{~m}$, on hymenium of Fomitopsis pinicola on Picea abies, 2 Sep. 2004, H. Voglmayr \& W. Jaklitsch, W.J. 2666 (WU 29431). Schramberg, Heiligenbronn, Schwarzwald, Spitalwald, on basidiome of Fomitopsis pinicola, 4 Oct. 2006, W. Gams, W.J. 3055 (WU 29436, culture CBS 120643). Bavaria, Starnberg, Tutzing, Hartschimmel, Goaslweide, MTB 8033/3/1, 47 $56^{\prime}$ $35^{\prime \prime} \mathrm{N} 11^{\circ} 11^{\prime} 02^{\prime \prime}$ E, elev. $735 \mathrm{~m}$, on hymenium of Fomitopsis pinicola, 22 Oct. 2003, P. Karasch, W.J. 2488 (WU 29430, culture C.P.K. 1992). Hessen, Eltville am Rhein, Hattenheim, forest at Geis, on Polyporus resinosus, identified as Fomitopsis pinicola, L. Fuckel, autumn, Fungi Rhenani 2467 (M!). Italy, Südtirol, Pustertal, Sexten, Porzenwald, near Moos, MTB 9340/1, 46 40'34" N 12 $23^{\circ} 08^{\prime \prime}$ E, elev. 1470 m, on Fomitopsis pinicola, 1 Sep. 2000, W. Jaklitsch \& H. Voglmayr. Sweden, Uppsala Län, Österbybruk, 3-4 km north from the town, right from the road to Forsmark, MTB $4373 / 4,60^{\circ} 14^{\prime} 10^{\prime \prime} \mathrm{N} 17^{\circ} 55^{\prime} 41^{\prime \prime}$ E, elev. $40 \mathrm{~m}$, on hymenium of Fomitopsis pinicola on Picea abies, soc. Melanospora sp., Ophiostoma polyporicola, scant material, 5 Oct. 2003, W. Jaklitsch, W.J. 2439 (WU 29427, culture C.P.K. 2395). Stockholms Län, Nothamn, forest at the east coast, MTB $4179 / 3,60^{\circ} 01^{\prime} 45^{\prime \prime} \mathrm{N} 18^{\circ} 50^{\prime} 43^{\prime \prime}$ E, elev. $10 \mathrm{~m}$, on hymenium and upper part of Fomitopsis pinicola on Picea abies, 7 Oct. 2003, W. Jaklitsch, W.J. 2446 (WU 29428, culture C.P.K. 2397). Switzerland, Neuchatel, Lac de la Gruère, on basidiome of Fomitopsis pinicola, 10 Oct. 2006, W. Gams, W.J. 3056 (WU 29437, culture CBS 120640=C.P.K. 2862). United Kingdom, Buckinghamshire, Slough, Burnham

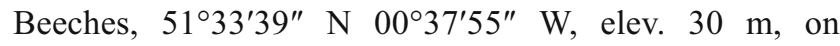
hymenium of Piptoporus betulinus $23 \mathrm{~cm}$ diam, 15 Sep. 2007, W. Jaklitsch \& H. Voglmayr, W.J. 3166 (WU 29439). Herefordshire, Leominster, Queenswood Country Park,

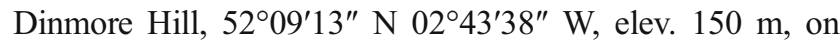
Piptoporus betulinus $2 \mathrm{~m}$ above ground on a standing trunk of Betula pendula, 11 Sep. 2007, W. Jaklitsch \& H. Voglmayr, W.J. 3152 (WU 29438).

Notes: This species is common and easily identified by ecological (growth on polypores) and morphological characteristics (unevenly distributed pigment, monomorphic ascospores, verrucose surface hairs, and lanceolate ostiolar cells). On Fomitopsis pinicola, H. pulvinata is often accompanied by $H$. protopulvinata; for differentiation see also under that species. To verify whether the fungus occurs on 
Laetiporus sulphureus (Polyporus sulphureus) and Ischnoderma resinosum (Polyporus resinosus), the lectotype from FH and the part of Fungi Rhenani 2467 from M were examined. In both specimens the host has a light to medium brown context and a resinous crust that melts in heat. This latter trait occurs only in basidiomata of Fomitopsis pinicola and uncommon species of Ganoderma, viz. G. pfeifferi and G. resinosum. The latter genus differs from Fomitopsis by a dark brown context. No generative hyphae and no conspicuous binding hyphae characteristic for $L$. sulphureus were found.

Hypocrea citrina stromata occur on the ground spreading from trunks; their yellow pigment is not concentrated around the ostioles. Conidiation in H. citrina is generally more regularly verticillium-like. The type specimen of Hypocrea colliculosa $(\mathrm{K})$ was examined and found to represent $H$. pulvinata, based on the shape and size of ascospores, verrucose hairs on the stroma surface and colour and $\mathrm{KOH}$ reaction of stromata. The host of $H$. colliculosa is apparently old Fomitopsis pinicola with a largely disintegrated tooth-like hymenium. The specimen was collected in Vermlandia, Sweden and named but not published by Fries. He sent the specimen to Berkeley. Cooke found it in Berkeley's herbarium and described it.

Hypocrea sulphurea (Schwein.) Sacc., Syll. Fung. 2: 535 (1883a). Fig. 69

三Sphaeria sulphurea Schwein., Trans. Amer. Phil. Soc. 2: 193 (1832).

= Hypocrea sulphurea f. macrospora Yoshim. Doi, Bull. Natl. Sci. Mus. 15: 699 (1972).

Anamorph: Trichoderma sp. Fig. 70

Stromata fresh and dry with little difference, (1-)3-50($120) \times(1-) 3-22(-50) \mathrm{mm}(n=50) ; 0.2-2(-3) \mathrm{mm}$ thick when fresh, mostly less than $1 \mathrm{~mm}$ thick when dry, solitary or in dense aggregations to $c a 30 \mathrm{~cm}$ long, widely effuse, flat, rarely subpulvinate, of indeterminate growth, following its heterobasidiomycetous host, often erumpent from cracks in bark. Outline circular, elongate to irregular, depending on the dimensions of the host, thinner at the periphery, entirely attached, enclosing leaves, twigs; margin sterile, thin, finely fibrous to membranaceous, white to yellowish; when dry often becoming detached with the host. Surface smooth, rugose or tubercular; perithecia entirely immersed. Ostiolar dots (31-) 47-73(-110) $\mu \mathrm{m}(n=80)$ diam, densely disposed, welldefined, mostly plane or slightly convex, yellow-brown, ochre, orange or reddish brown. Stroma development and colour: starting as a white to yellow mycelium, becoming compacted, turning light yellow, 2A4-6, when immature, bright yellow, greyish yellow, citrine to orange-yellow, sometimes with olive tints, $3 \mathrm{AB}(3-) 5-8$, 4AB4-6(-8) when mature; white inside, perithecial layer reddish; colour unchanged in $3 \% \mathrm{KOH}$.
Stroma anatomy: Ostioles (57-)70-94(-104) $\mu \mathrm{m}$ long, plane with the surface or projecting to $20(-27) \mu \mathrm{m} ;(40-) 45-$ $64(-72) \mu \mathrm{m}$ wide at the apex $(n=23)$; apex lined with mostly clavate hyaline cells to $9 \mu \mathrm{m}$ wide. Perithecia (260-)275$315(-325) \times(120-) 145-230(-270) \mu \mathrm{m}(n=30)$; peridium $(7-) 9-13(-15) \mu \mathrm{m}(n=16)$ thick at the base, $(12-) 17-24(-$ 26) $\mu \mathrm{m}(n=16)$ apically; hyaline to pale yellowish. Cortical layer (40-)47-64(-74) $\mu \mathrm{m}(n=30)$ thick, glabrous, a dense $t$. angularis-globulosa of thin-walled, hyaline to pale yellowish cells (4-)6-16(-24)×(4-)5-12(-14) $\mu \mathrm{m}(n=60)$ in face view and vertical section. Subcortical layer a $t$. intricata of hyaline hyphae $(3.5-) 5-6(-7) \mu \mathrm{m}(n=11)$ wide, mixed with hyaline cells $(3.5-) 7-19(-27) \times(3-) 6-13(-17) \mu \mathrm{m}(n=30)$. Subperithecial tissue a coarse and dense $t$. angularisepidermoidea of thin-walled cells (6-)10-28(-35) $\mu \mathrm{m} \times(5-)$ 9-15(-19) $\mu \mathrm{m}(n=30)$, tending to be smaller towards the base; cells sometimes distinctly elongate directly below the perithecia. Base comprising a $t$. intricata of hyphae (3-)4-6 $(-7) \mu \mathrm{m}(n=20)$ wide. Asci $(100-) 115-140(-155) \times(5.5-)$ $6.0-7.5(-8.8) \mu \mathrm{m}$, stipe to $16(-32) \mu \mathrm{m}$ long $(n=50)$. Ascospores hyaline, verruculose, cells dimorphic; distal cell (5-)6-8(-10)×(4.3-)5.0-6.0(-7.0) $\mu \mathrm{m}, 1 / \mathrm{w}(1.0-) 1.1-1.4(-$ 1.7) $(n=90)$, ellipsoidal, oval, oblong or subglobose; proximal cell $(5.7-) 6.5-8.5(-10.5) \times(4.0-) 4.5-5.3(-6.0)$ $\mu \mathrm{m}, 1 / \mathrm{w}(1.1-) 1.3-1.7(-2.2) \quad(n=90)$, oblong, ellipsoidal, oval or wedge-shaped; cells sometimes nearly monomorphic.

Cultures and anamorph: growth rate optimal at $25^{\circ} \mathrm{C}$ on all media, no growth at $35^{\circ} \mathrm{C}$.

On CMD after $72 \mathrm{~h} 7-14 \mathrm{~mm}$ at $15^{\circ} \mathrm{C}, 30-37 \mathrm{~mm}$ at $25^{\circ} \mathrm{C}$, 19-29 $\mathrm{mm}$ at $30^{\circ} \mathrm{C}$; mycelium covering the plate after 56 days at $25^{\circ} \mathrm{C}$. Colony hyaline, thin, loose, with inhomogeneous density, typically broadly lobed with irregular margin; lobes meeting at the distal margin of the plate, margin becoming downy due to long aerial hyphae. Primary hyphae thick, curved, with conspicuous septa; surface hyphae soon becoming empty from the centre. Autolytic excretions absent or rare, coilings infrequent or moderate. Odour indistinct. After 2 weeks sometimes pale yellow 1A3-4, 2-3B4-5 pigment diffusing through the agar from the distal margin. No chlamydospores seen. Conidiation noted after 6-8 days, sparse or lacking, sometimes denser after 2-3 weeks at margins, visible as white granules, of conidial heads to $50 \mu \mathrm{m}$ diam. Structure as described on SNA. At $30^{\circ} \mathrm{C}$ growth often limited, diffusing pigment yellow $2 \mathrm{~A} 4-5$ to $3 \mathrm{~A} 5$, or lacking.

On PDA after $72 \mathrm{~h} 2-6 \mathrm{~mm}$ at $15^{\circ} \mathrm{C}, 18-32 \mathrm{~mm}$ at $25^{\circ} \mathrm{C}$, $23-25 \mathrm{~mm}$ at $30^{\circ} \mathrm{C}$, mycelium covering the plate after 6 8 days at $25^{\circ} \mathrm{C}$. Hyphae thick, curved, becoming densely agglutinated. Colony first thin, hyaline to whitish, compact, not or indistinctly zonate; margin crystal-like, angular to coarsely wavy. Surface becoming white, velvety or downy by a dense flat mat of long aerial hyphae from 2 days; floccose in distal regions due to dense aggregations to $0.5 \mathrm{~mm}$ diam of aerial hyphae bearing numerous conidial 

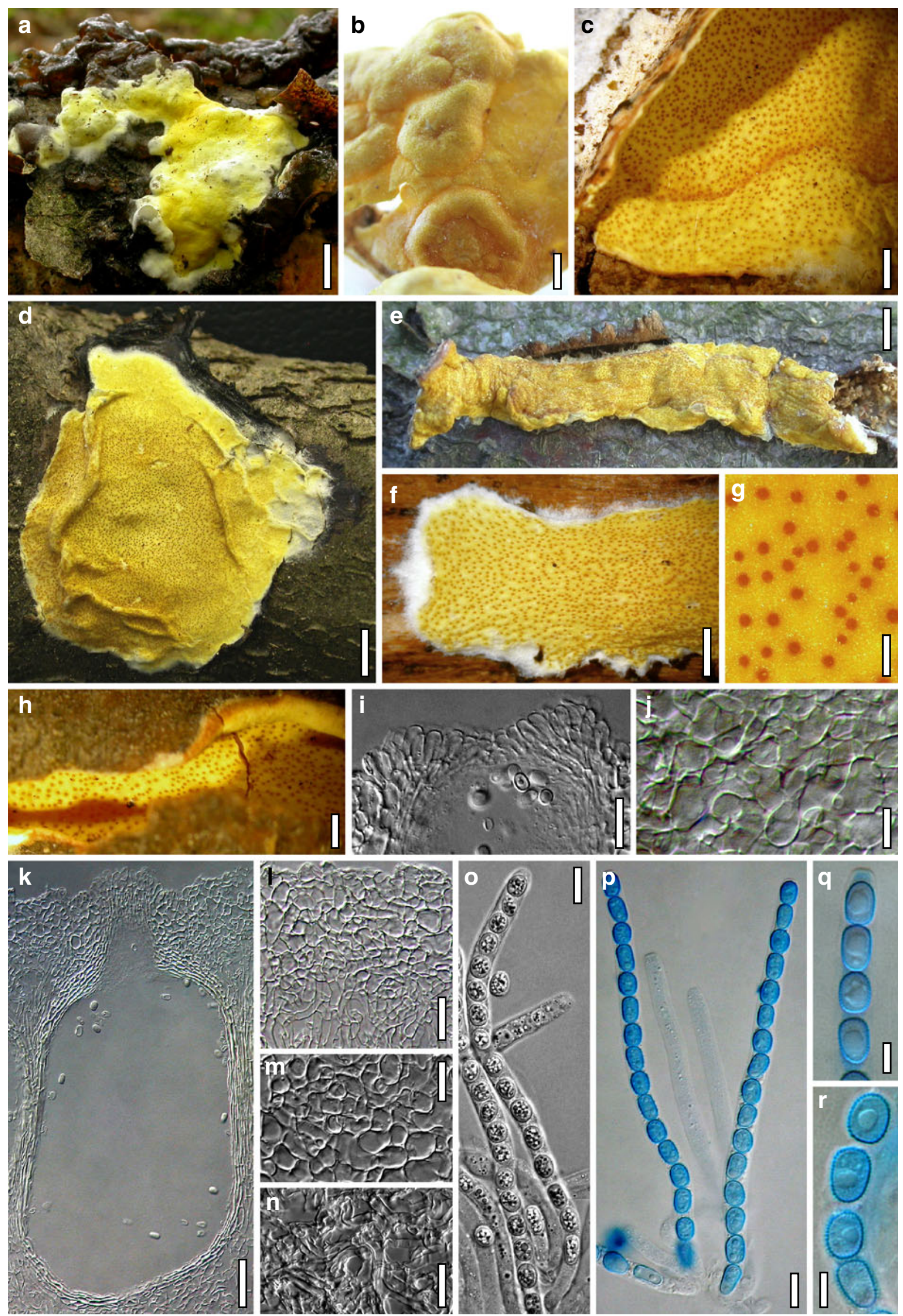
4Fig. 69 Teleomorph of Hypocrea sulphurea. a, b, e. Fresh stromata (a. initial stage on fresh Exidia). c, d, $\mathbf{f}-\mathbf{h}$. Dry stromata (f. showing mycelial margin; g. surface showing ostiolar dots; $\mathbf{h}$. in bark fissure). i. Apical ostiolar cells. j. Surface cells in face view. k. Perithecium in section. I. Cortical and subcortical tissue in section. m. Subperithecial tissue in section. n. Stroma base in section. o, p. Asci with ascospores (p. in cotton blue/lactic acid). q, r. Ascospores in cotton blue/lactic acid. a. Mauerbach, 5 June 2004. b. WU 29497. c, h, i, k-n, r. WU 29491. d, g, j. WU 29492. e. WU 29498. f. WU 29493. o. WU 29504. p. WU 29502. q. WU 29494. Scale bars $\mathbf{a}=7 \mathrm{~mm}$. b, e=1.5 mm. $\mathbf{c}, \mathbf{f}=$ $1 \mathrm{~mm} . \mathbf{d}=3 \mathrm{~mm}$. $\mathbf{g}=0.2 \mathrm{~mm}$. $\mathbf{h}=0.5 \mathrm{~mm}$. $\mathbf{i}, \mathbf{l}-\mathbf{n}=20 \mu \mathrm{m} . \mathbf{j}, \mathbf{o}, \mathbf{p}=$ $10 \mu \mathrm{m} . \mathbf{k}=40 \mu \mathrm{m} . \mathbf{q}, \mathbf{r}=5 \mu \mathrm{m}$

heads and drops; centre dense and finely farinose due to short and loosely arranged aerial hyphae. Autolytic activity low to moderate. Odour indistinct, no diffusing pigment formed, reverse only slightly yellowish, 4A3-4B4, after 2 weeks. Conidiation starting around the plug after 24 days, dense, effuse, on short conidiophores and aerial hyphae, spreading across the whole plate within a week; conidia produced in heads to $50 \mu \mathrm{m}$ diam. At $15^{\circ} \mathrm{C}$ autolytic activity sometimes more distinct, at $30^{\circ} \mathrm{C}$ growth limited.

On SNA after $72 \mathrm{~h} 5-8 \mathrm{~mm}$ at $15^{\circ} \mathrm{C}, 7-18 \mathrm{~mm}$ at $25^{\circ} \mathrm{C}$, $14-16 \mathrm{~mm}$ at $30^{\circ} \mathrm{C}$, mycelium covering the plate after (5-) $10-15$ days at $25^{\circ} \mathrm{C}$. Colony hyaline, thin, leaf-like or fanshaped with wavy outline; density irregular; orientation of hyphae irregular, hyphae narrower than on CMD, curved; surface hyphae soon degenerating from the centre. Long aerial hyphae frequent, particularly at the downy margins, loose and little ascending; minute white pustules forming along the margin. Autolytic activity absent or low, sometimes increasing after 1 weeks, coilings in some cultures extremely abundant, conspicuous, 50-120 $\mu \mathrm{m}$ diam. Conidiation starting after 4-5 days, effuse, spreading from the plug and proximal margin, better developed than on CMD, white, downy, becoming farinose to finely floccose. Phialides formed on surface hyphae, on simple, short, unbranched acremonium-like or sparsely branched, verticillium-like conidiophores to $300 \mu \mathrm{m}$ long and $200 \mu \mathrm{m}$ diam, arising from surface or aerial hyphae, the latter to 0.5 $(-1) \mathrm{mm}$ long at the distal margin. Main axes of conidiophores 3-7 $\mu \mathrm{m}$ wide, with mostly unpaired branches mostly distinctly inclined upwards, simple or once rebranching; terminal branches $1-2$ celled. Phialides formed on cells $3-5(-6) \mu \mathrm{m}$ wide, solitary or divergent in whorls of 2-3, often cruciform at conidiophore apices. Conidia formed in large numbers in wet heads eventually growing up to $120 \mu \mathrm{m}$ diam and appearing as fine white granules, particularly dense in distal regions, soon drying with conidia lying on the agar surface. Phialides (10-)14$28(-40) \times 3.0-4.5(-5) \mu \mathrm{m}, 1 / \mathrm{w}=(3.0-) 4.0-7.4(-8.3),(2.0-)$ $2.5-3.5(-4.7) \mu \mathrm{m}$ wide at the base $(n=30)$, subulate, lageniform or nearly cylindrical, straight or curved to sinuous, widest at or slightly above the base. Conidia
$(4.0-) 5.3-10.5(-12.5) \times(2.5-) 3.0-4.0(-5.0) \mu \mathrm{m}, 1 / \mathrm{w}(1.3-)$ $1.5-3.0(-3.8)(n=60)$, hyaline, variable in shape, oblong, cylindrical, ellipsoidal or oval, oft attenuated towards one end, smooth, with few minute guttules or eguttulate; scar indistinct or truncate. At $15^{\circ} \mathrm{C}$ growth limited.

Habitat: on basidiomes of Exidia spp., most commonly E. glandulosa $(=E$. plana), sometimes occurring on decorticated wood, probably after entire digestion of the host.

Distribution: Europe (eastern Austria, Ukraine). Reported also from Japan and North America (Doi 1972; Overton et al. 2006b).

Isotype: USA, Pennsylvania, Salem \& Bethlehem, on Exidia sp., H. sulphurea (K, herb. Schweinitz; not examined).

Specimens examined: Austria, Burgenland, Eisenstadt Umgebung, Wimpassing, Leithagebirge, Lebzelterberg, mixed forest of Quercus/Carpinus W of the road Hornstein/Leithaprodersdorf, MTB 8064/4, elev. $250 \mathrm{~m}$, on branch of Carpinus betulus, 16 Sep. 2007, H. Voglmayr, W.J. 3168 (WU 29503). Mattersburg, Bad Sauerbrunn, Hirmer Wald, MTB 8264/1, 4745'37" N, 16²1'38" E, elev. $260 \mathrm{~m}$, on Exidia glandulosa/Betula pendula, 19 June 2004, H. Voglmayr, W.J. 2515 (WU 29500, culture C.P.K. 2041). Oberpullendorf, Mitterwald, MTB 8465/3, 47³1'

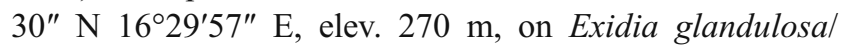
Quercus petraea, immature, 13 July 2004. Neckenmarkt, NSG Lange Leitn, MTB 8365/3, 47 $38^{\prime} 04^{\prime \prime} \mathrm{N}, 16^{\circ} 32^{\prime} 00^{\prime \prime}$ E, elev. $430 \mathrm{~m}$, on corticated branch of Quercus petraea, 2 Oct. 2001, W. Jaklitsch, not harvested. Raiding, Ragerwald, MTB 8465/1, 47³3'56" N, 16³3'23" E, elev. 290 m, on Exidia glandulosa on decorticated branch of Quercus cerris 5-6 cm thick, 13 July 2004, W. Jaklitsch \& H. Voglmayr, W.J. 2527 (WU 29501, culture C.P.K. 2042). Niederösterreich, Wien-Umgebung, Mauerbach, Friedhofstraße, MTB $7763 / 1,48^{\circ} 15^{\prime} 15^{\prime \prime} \mathrm{N}, 16^{\circ} 10^{\prime} 14^{\prime \prime}$ E, elev. $325 \mathrm{~m}$, on branch of Carpinus betulus 4-6 cm thick, Exidia apparently decomposed, on wood and bark, starting mostly on inner bark, 9 July 2003, W. Jaklitsch, W.J. 2277 (WU 29491, culture C.P.K. 1593). Same area, 23 Aug. 2003, W. Jaklitsch, W.J. 2339 (WU 29495). Same area, 48¹5'13" N, $16^{\circ} 10^{\prime} 13^{\prime \prime}$ E, elev. $320 \mathrm{~m}$, on branch of Quercus cerris $7 \mathrm{~cm}$ thick, on bark, mainly below the epidermis, Exidia apparently decomposed, soc. Diatrypella quercina, 23 Aug. 2003, W. Jaklitsch, W.J. 2340 (WU 29496, culture C.P.K. 2390). Same area, $48^{\circ} 15^{\prime} 16^{\prime \prime} \mathrm{N}, 16^{\circ} 10^{\prime} 11^{\prime \prime}$ E, elev. $320 \mathrm{~m}$, on corticated branch of Fagus sylvatica, 17 Oct. 1998, W. Jaklitsch, W.J. 1232. Same area, on Exidia/Carpinus betulus, soc. Cheirospora botryospora, 23 Sep. 2000, W. Jaklitsch, W.J. 1595. Same area, 5 Oct. 2002, W. Jaklitsch,

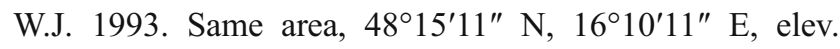
$320 \mathrm{~m}$, on fresh thick Exidia glandulosa on Carpinus betulus, immature, 31 May 2004 and 5 June 2004, same stromata overmature and mouldy on 18 July 2004, W. 

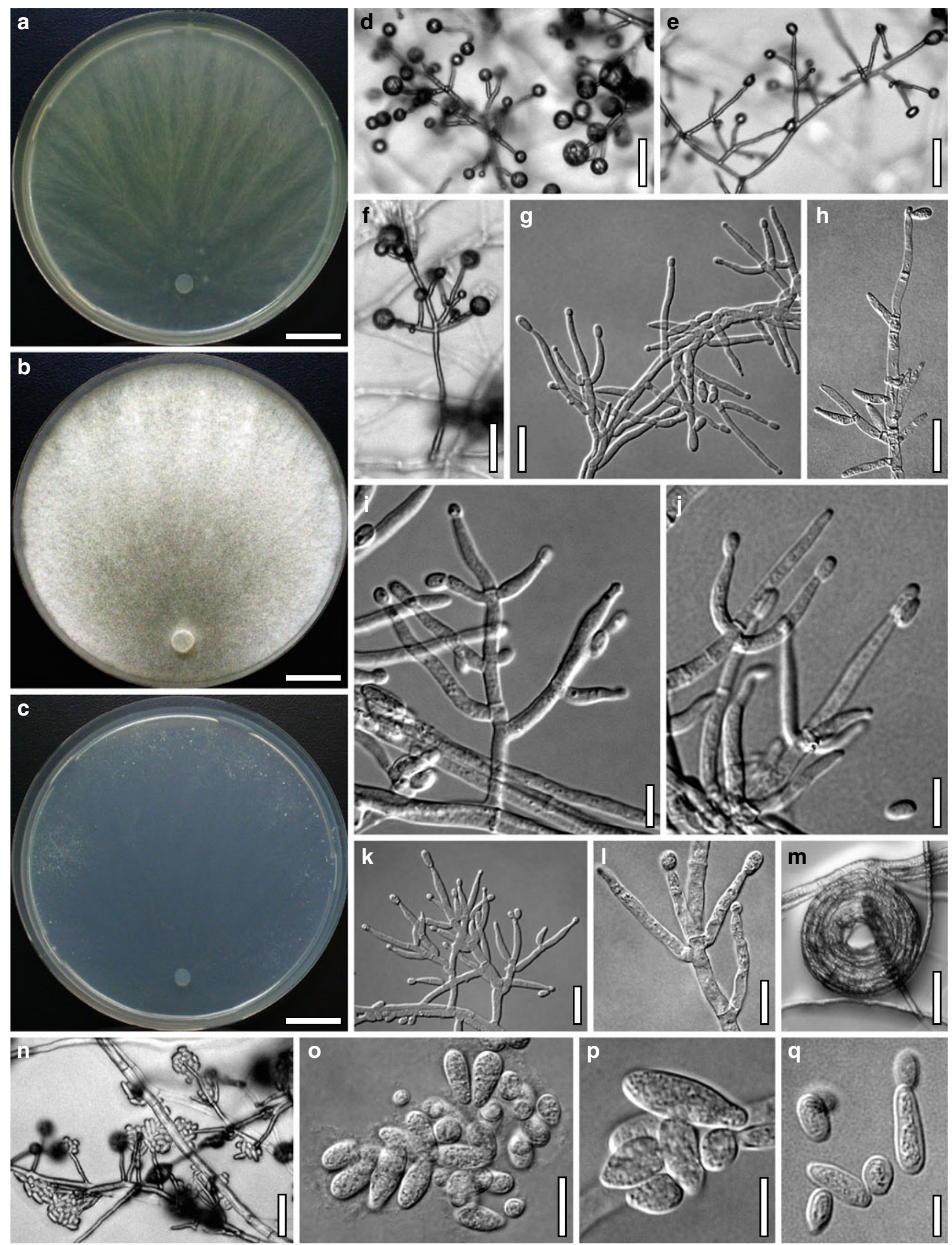
Fig. 70 Cultures and anamorph of Hypocrea sulphurea. a-c. Cultures after 14 days (a. on CMD. b. on PDA. c. on SNA). d-f. Conidiophores on growth plates $\left(5-10\right.$ days; f. $\left.30^{\circ} \mathrm{C}\right)$. g-k. Conidiophores (10-19 days). I. Phialides (19 days). m. Coiling (CMD, 10 days). n. Conidiophore with dry conidia on agar surface (19 days). o-q. Conidia (7-19 days). d-q. On SNA except m. d-q. At $25^{\circ} \mathrm{C}$ except f. a-d, f, h, l, n-p. C.P.K. 1593. e, g, i, k, m. CBS 119929. j, q. C.P.K. 1597. Scale bars $\mathbf{a}-\mathbf{c}=15 \mathrm{~mm}$. $\mathbf{d}-\mathbf{f}, \mathbf{m}=40 \mu \mathrm{m} . \mathbf{g}, \mathbf{h}, \mathbf{k}=20 \mu \mathrm{m}$. $\mathbf{i}, \mathbf{j}, \mathbf{l}, \mathbf{o}=10 \mu \mathrm{m} . \mathbf{n}=30 \mu \mathrm{m} . \mathbf{p}, \mathbf{q}=5 \mu \mathrm{m}$

Jaklitsch \& O. Sükösd, not harvested. Same area, 48 $15^{\prime} 19^{\prime \prime}$ N, 16 $10^{\prime} 13^{\prime \prime}$ E, elev. 330 m, on Exidia on Quercus sp., soc. hyphomycetes, 6 Aug. 2006, W. Jaklitsch \& O. Sükösd, W. J. 2927 (WU 29502). Mödling, Wienerwald, Gießhübl, Wassergspreng, MTB 7963/1, 48 $06^{\prime} 00^{\prime \prime} \mathrm{N} 16^{\circ} 13^{\prime} 05^{\prime \prime} \mathrm{E}$, elev. 460 m, on Fagus sylvatica, immature. 27 June 2004, H. Voglmayr. Wöglerin, MTB 7862/4, elev. $490 \mathrm{~m}$, on Exidia sp. on a lying trunk of Fagus sylvatica $10 \mathrm{~cm}$ thick, soc. Lopadostoma turgidum in bark, 16 Aug. 2008, W. Jaklitsch \& O. Sükösd (WU 29504). Sulz im Wienerwald, SE from the pub Wöglerin, MTB 7862/4, 48 $06^{\prime} 30^{\prime \prime} \mathrm{N}, 16^{\circ}$ 07'39" E, elev. $460 \mathrm{~m}$, on branch of Carpinus betulus, 7 Oct. 2003, H. Voglmayr \& I. Greilhuber, W.J. 2444 (WU 29497, culture C.P.K. 987). Wien Umgebung, Pressbaum, Rekawinkel, forest path south from the train station, MTB 7862/1, 48 ${ }^{\circ} 10^{\prime} 37^{\prime \prime} \mathrm{N}, 16^{\circ} 01^{\prime} 33^{\prime \prime}$ E, elev. 415 m, on Exidia glandulosa on Fagus sylvatica, 21 Sep. 2002, W. Jaklitsch, W.J. 1975. Same area, 48 $10^{\prime} 40^{\prime \prime}$ N, 1601'54" E, elev. $380 \mathrm{~m}$, on corticated log of Carpinus betulus $12 \mathrm{~cm}$ thick, erumpent through cracks in bark, soc. green Trichoderma below bark, 18 Oct. 2003, H. Voglmayr \& W. Jaklitsch, W. J. 2473 (WU 29498, culture C.P.K. 2407). Steiermark, Graz-Umgebung, Mariatrost, Wenisbucherstraße, close to the crossing with Himmelreichweg, MTB 8858/4, 47 $06^{\prime}$ $47^{\prime \prime} \mathrm{N}, 15^{\circ} 29^{\prime} 03^{\prime \prime}$ E, elev. $470 \mathrm{~m}$, on Exidia glandulosa on Corylus avellana 3-4 cm thick, soc. Corticiaceae, 8 Aug. 2003, H. Voglmayr \& W. Jaklitsch, W.J. 2319 (WU 29492, culture C.P.K. 1597). Same area, on/soc. Exidia glandulosa on twigs of Carpinus betulus and Fagus sylvatica $2-3 \mathrm{~cm}$ thick, W.J. 2320 (WU 29493, culture CBS 119929=C.P.K. 1598). Leibnitz, Berghausen, Graßnitzberg, MTB 9259/4, elev. ca 350 m, on Fagus sylvatica, 20 Sep. 1996, W. Jaklitsch, W.J. 958. Weiz, Laßnitzthal, from Arboretum Gundl across the main road, MTB 8959/2, 4704'17" N, $15^{\circ} 38^{\prime} 38^{\prime \prime}$ E, elev. $420 \mathrm{~m}$, on/soc. Exidia glandulosa on Fagus sylvatica, branch $4 \mathrm{~cm}$ thick, 8 Aug. 2003, H. Voglmayr \& W. Jaklitsch, W.J. 2326 (WU 29494, culture C. P.K. 2388). Ukraine, Kharkivska Oblast, Kharkov, Zmiev area, Gomolshansky National nature park, 49 42'09" N $36^{\circ}$ 22'37" E, elev. $100 \mathrm{~m}$, on Exidia glandulosa on Quercus sp., 25 June 2004, A. Akulov, W.J. 2513 (WU 29499, culture C.P.K. 2040).

Notes: Hypocrea sulphurea is a conspicuous species, easily recognized by the large, bright yellow stromata occurring on basidiomes of Exidia spp. The Exidia host usually does not mature when attacked by the Hypocrea. Stromata are often more or less dry when collected, because they develop predominantly in warm and dry Quercus/ Carpinus forests. In Austria stromata of $H$. sulphurea occur in the East, i.e. Lower Austria, Burgenland to southern Styria, where they can be observed from May or June onwards starting as a homogeneous, subiculate, yellow covering on fresh and thick Exidia basidiomes. Specimens from the Ukraine suggest that this species is predominantly distributed in south-eastern regions in Europe. Fresh stromata are thicker and slightly less bright than dry stromata. Largest ascospore measurements, i.e. ascsopore cells $>9 \mu \mathrm{m}$ are from fresh specimens. Ascospore cells in North American and Japanese specimens of $H$. sulphurea are in average 1-2 $\mu \mathrm{m}$ smaller than in European specimens. This variation in ascospore size had led Doi (1972) to erect H. sulphurea f. macrospora. H. megalosulphurea Yoshim. Doi (Doi 1972) differs from $H$. sulphurea by pulvinate stromata, while $H$. subsulphurea Syd. has monomorphic ascospores (Overton et al. 2006b). Similar are also H. austriaca and $H$. victoriensis. Hypocrea austriaca differs from $H$. sulphurea by lighter stromata, slightly smaller ascospores and the occurrence on Eichleriella deglubens, while no fungal host has so far been detected for the Australian H. victoriensis.

\section{The Brevicompactum, Lutea and Psychrophila Clades}

\section{Introduction}

Species of three clades adjacent in the generic phylogenetic tree of the genus Hypocrea/Trichoderma (Fig. 1) are here subsumed, primarily in order to reach comparable quantitative scopes in each descriptive chapter.

The Brevicompactum clade is the result of an integrated approach of molecular biology (DNA sequence data), morphology, phytopathology (search for plant-protective agents useful for biocontrol of the vine diseases Eutypa dieback and Esca) and profiling of secondary metabolites such as peptaibiotics and trichothecenes. First recognised by Degenkolb et al. (2006) the clade was established by Degenkolb et al. (2008a) with the new formally described species Trichoderma arundinaceum, T. turrialbense, T. protrudens and Hypocrea rodmanii, in addition to $T$. brevicompactum that had been described by Kraus et al. (2004). Chemotaxonomic potential, prediction of biocontrol suitability, health concerns of secondary metabolites including trichothecenes and hydrophobins analysed by mass spectrometry of this group of species was discussed by Degenkolb et al. (2008b). Three holomorphic Hypocrea/Trichoderma species including two new ones are described in this clade below. 
The Lutea clade currently comprises only the two species $H$. lutea and H. melanomagna (Chaverri and Samuels 2003). A third species is added below. The clade is exceptional due to the distinctly gliocladium-like anamorphs characterised by more or less mononematous penicillate conidiophores and green conidia that are eventually embedded in a mucous exudate. Like the Semiorbis clade, this clade contains both species with hyaline and green ascospores. The typification of $H$. lutea is clarified here and the anamorph of H. lutea, Gliocladium deliquescens, is combined in Trichoderma.

Hypocrea megalocitrina and H. psychrophila were recognised as the Megalocitrina clade (Chaverri and Samuels 2003). This was adopted by Jaklitsch et al. (2006a) when describing H. crystalligena. The clade including $H$. megalocitrina is now called the Psychrophila clade; it is well supported and now comprises four European species including two new ones. These species are characterised by pulvinate stromata and white-conidial anamorphs with more or less gliocladium-like conidiophores.

\section{Species descriptions}

Clades and the species within the clades are arranged in alphabetical order. The Brevicompactum clade comprises the three species $H$. auranteffusa, $H$. margaretensis, and $H$. rodmanii. The anamorphic T. brevicompactum falls outside the scope of this work. The Lutea clade includes H. lutea and $H$. luteocrystallina. The Psychrophila Clade comprises the four species $H$. calamagrostidis, $H$. crystalligena, $H$. psychrophila, and $H$. rhododendri.

\section{Hypocrea auranteffusa Jaklitsch, sp. nov. Fig. 71}

MycoBank MB 516667

Anamorph: Trichoderma auranteffusum Jaklitsch, sp. nov. Fig. 72

MycoBank MB 516668

Stromata effusa vel subpulvinata, 1-30 mm lata, laete flava vel aurantiaca. Asci cylindrici, (73-)80-95(-106) $\times(4.0-) 4.5-$ 5.5(-6.2) $\mu \mathrm{m}$. Ascosporae bicellulares, ad septum disarticulatae, hyalinae, verruculosae vel spinulosae; pars distalis (sub)globosa, $(3.2-) 3.5-4.4(-5.0) \times(3.0-) 3.3-3.8(-4.3) \mu \mathrm{m}$; pars proxima oblonga, cuneata vel subglobosa, $(3.5-) 4.0-5.5(-7.0) \times(2.5-)$ 2.7-3.3(-4.0) $\mu \mathrm{m}$. Anamorphosis Trichoderma auranteffusum. Conidiophora in agaro SNA effusa et in pustulis disposita. Pustulae elongationes sparsas, steriles vel fertiles praebentes. Phialides lageniformes, (4-)5-9(-12) $\times(2.0-) 2.3-2.8(-3.3)$ $\mu \mathrm{m}$. Conidia pallide luteo-viridia, subglobosa vel ellipsoidea, glabra, (1.8-)2.5-3.2(-4.0)×(1.8-)2.0-2.4(-2.6) $\mu \mathrm{m}$.

Etymology: the epithet stands for the orange, effuse stromata.
Stromata when fresh $1-30 \times 1-12 \mathrm{~mm}, 0.5-1.5 \mathrm{~mm}$ thick, solitary, gregarious or densely aggregated, effuse to subpulvinate, outline circular to irregularly lobed; broadly attached. Stromata bright yellow to bright orange, 3A5-6, 4-5A7-8, 5B5-7, turning dark orange, brown-orange to dull brown, 6A6-8, 6CD7-8, with age, finally dark reddish brown, 8CF7-8. Margin white or yellow, mycelial and sterile when young, later concolorous, becoming free and acute or rounded. Surface smooth or tubercular, with numerous plane, reddish- to dark brown ostiolar dots. Spore deposits white to distinctly yellow.

Stromata when dry $1-30 \times 1-11 \mathrm{~mm}, 0.2-0.4(-0.7) \mathrm{mm}$ $(n=50)$ thick; thinly effuse, crustose, or flat pulvinate. Margin often rounded, sometimes free and revolute, rarely with some perithecia projecting. Surface smooth to somewhat wavy or wrinkled or finely velutinous to floccose due to loose, collapsed hyphae. Ostiolar dots (24-)35-75(-118) $(n=70)$ diam, broad reddish-brown, plane to umbilicate spots and barely distinct when young, distinct, plane to convex, light brown to nearly black dots when mature. Stromata pale yellow, 3-4A3-4 (without ostioles), bright yellow, 4A5-6 (partly with ostioles), orange, 5A4-8, 5B57 when young, later grey-orange to reddish orange 6AB58, 7B6-8, brown-orange, to reddish-brown 6-8CD6-8, (to 7E6-8). Stromata losing the bright colour upon rehydration; turning somewhat darker brown or vinaceous in $3 \% \mathrm{KOH}$, without a conspicuous colour change.

Stroma anatomy: Ostioles (47-)58-77(-80) $\mu \mathrm{m}$ long, plane or slightly umbilicate, $(15-) 17-28(-32) \mu \mathrm{m}(n=21)$ wide at the apex excluding walls, cylindrical, narrow, periphysate, sometimes with narrowly clavate to subglobose cells to $6 \mu \mathrm{m}$ wide at the apex. Perithecia (140-)160-210(240) $\mu \mathrm{m} \times(100-) 120-170(-190) \mu \mathrm{m}(n=21)$ diam, globose or flask-shaped. Peridium (10-)13-21 $(-25) \mu \mathrm{m}(n=21)$ thick at the base, $(6-) 11-16(-20) \mu \mathrm{m}(n=21)$ at sides, pale yellowish. Cortical layer 19-30(-37) $\mu \mathrm{m}(n=30)$ thick, a small-celled dense $t$. angularis of pale yellowish, thinwalled, angular or subglobose cells $(2-) 3-7(-9) \times(2-) 3-5(-$ 7) $\mu \mathrm{m}(n=30)$ in face view and in vertical section. Numerous similar (sub-)globose cells loosely disposed on the stroma surface present. Hairs projecting from mature stroma (5-)8$25(-38) \times(2-) 3-5(-6) \mu \mathrm{m}(n=30)$, hyaline, short, 1 to few-

Fig. 71 Teleomorph of Hypocrea auranteffusa. a-e. Fresh stromata (c. immature). f-h. Dry stromata. i. Rehydrated stroma. j. Stroma surface in face view. k, l. Hairs on stroma surface (l. originating in subcortical tissue). m. Ejected ascospores. n. Perithecium in section. o. Cortical and subcortical tissue in section. p. Subperithecial tissue in section. q. Stroma base in section. r, s. Asci with ascospores (s. in cotton blue/lactic acid). a, i-l, n-r. Holotype (WU 29183). b. WU 29187. c, f. WU 29181. d. WU 29182. e. WU 29185. g. WU 29191. h. specimen from GZU. m. WU 29180. s. WU 29179. Scale bars a, d, $\mathbf{e}=2.5 \mathrm{~mm} . \mathbf{b}, \mathbf{g}=1.5 \mathrm{~mm} . \mathbf{c}=5 \mathrm{~mm} . \mathbf{f}=0.5 \mathrm{~mm} . \mathbf{h}, \mathbf{i}=1 \mathrm{~mm} . \mathbf{j}, \mathbf{p}, \mathbf{r}, \mathbf{s}=$ $10 \mu \mathrm{m} . \mathbf{k}, \mathbf{l}, \mathbf{o}=15 \mu \mathrm{m} . \mathbf{m}=5 \mu \mathrm{m} . \mathbf{n}, \mathbf{q}=30 \mu \mathrm{m}$ 

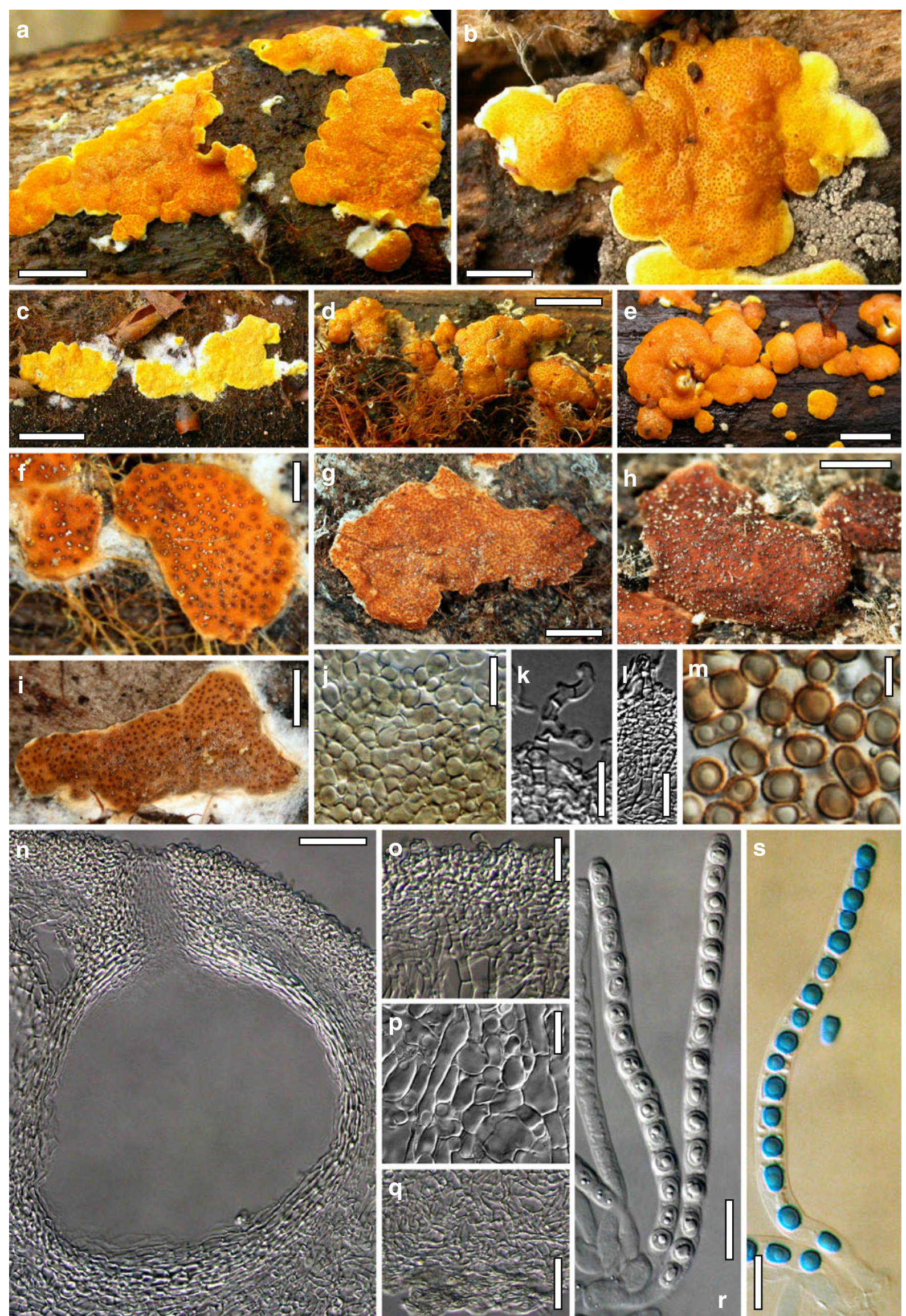

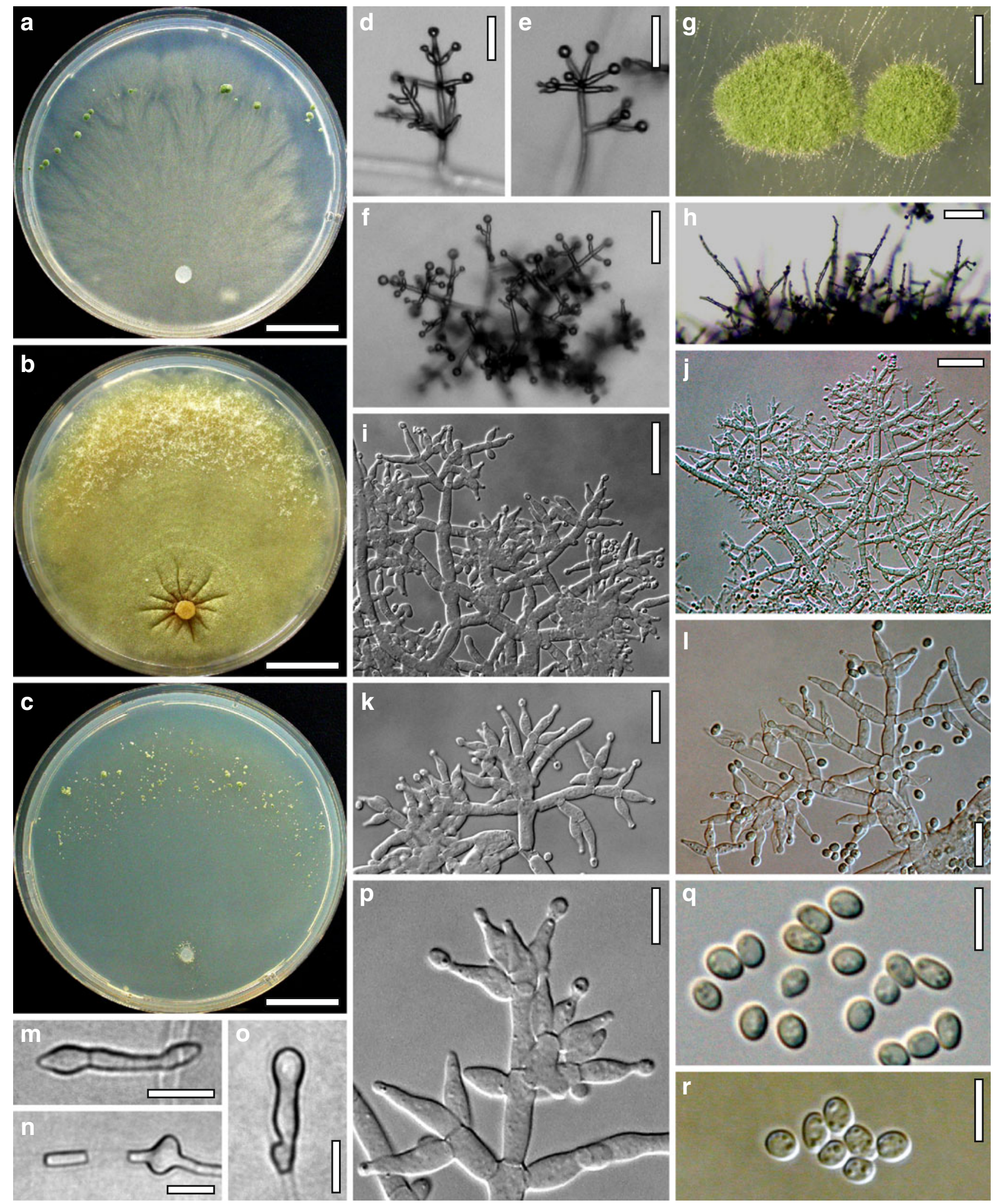

Fig. 72 Cultures and anamorph of Hypocrea auranteffusa. a-c. Cultures (a. on CMD, 49 days. b. on PDA, 42 days. c. on SNA, 49 days). d-f. Conidiophores on growth plate (d, e. simple, f. shrub; SNA; d. 16 days; e, f. 6 days.). g. Conidiation pustules (CMD, 39 days). h. Elongations on pustule margin (SNA, 18 days). i-l.
Conidiophores. m-o. Chlamydospores (SNA, 35 days). p. Phialides. q, r. Conidia. a-r. All at $25^{\circ} \mathrm{C}$. j, l, q. On MEA, after 15 d. i, k, p, r. On SNA, after 7 days. a-g, m-o. CBS 119285. h. CBS 119287. i, $\mathbf{k}, \mathbf{p}, \mathbf{r}$. CBS 119284. j, l, q. C.P.K. 2409. Scale bars $\mathrm{a}-\mathrm{c}=20 \mathrm{~mm}$. d, e, $\mathbf{i}=$ $15 \mu \mathrm{m} . \mathbf{f}, \mathbf{j}=25 \mu \mathrm{m} . \mathbf{g}=1 \mathrm{~mm} . \mathbf{h}=50 \mu \mathrm{m} . \mathbf{k}-\mathbf{0}=10 \mu \mathrm{m} . \mathbf{p}-\mathbf{r}=5 \mu \mathrm{m}$ 
celled, cylindrical, ends rounded, rooting in cortical or subcortical tissues, entire length to $c a 50 \mu \mathrm{m}$; young stromata with long and branched hyaline to light brownish collapsing hyphae. Subcortical tissue a loose to dense $t$. intricata of hyaline thin-walled hyphae (2-)3-4(-5) $\mu \mathrm{m}(n=$ $30)$ wide. Subperithecial tissue a $t$. epidermoidea to $t$. intricata at the base, of variable hyaline, thin-walled cells $(3-) 4-28(-47) \times(3-) 4-8(-10) \mu \mathrm{m}(n=30)$. Hyphae compressed at the basal margin. Asci (73-)80-95(-106) $\times(4.0-)$ 4.5-5.5(-6.2) $\mu \mathrm{m}$, stipe (3-)6-16(-24) $\mu \mathrm{m}$ long $(n=60)$. Ascospores hyaline, verruculose to spinulose, cells dimorphic; distal cell $(3.2-) 3.5-4.4(-5.0) \times(3.0-) 3.3-3.8(-4.3)$ $\mu \mathrm{m}, 1 / \mathrm{w} 1.0-1.2(-1.3)(n=90)$, (sub-)globose or tapered upward; proximal cell $(3.5-) 4.0-5.5(-7.0) \times(2.5-) 2.7-3.3(-$ 4.0) $\mu \mathrm{m}, 1 / \mathrm{w}(1.2-) 1.3-1.9(-2.4)(n=90)$, oblong, wedgeshaped or subglobose. Discharged ascospores often yellow to orange in $\mathrm{KOH}$.

Anamorph on natural substrates effuse and pale bluishgreen, 25DE4-5, 26D3-4, often with white margin.

Cultures and anamorph: growth slow, optimal at $25^{\circ} \mathrm{C}$ on all media, on CMD sometimes slightly faster at $30^{\circ} \mathrm{C}$ than at $25^{\circ} \mathrm{C}$; no growth at $35^{\circ} \mathrm{C}$.

On CMD after $72 \mathrm{~h} 0.2-1 \mathrm{~mm}$ at $15^{\circ} \mathrm{C}, 4-6 \mathrm{~mm}$ at $25^{\circ} \mathrm{C}$, 3-6 $\mathrm{mm}$ at $30^{\circ} \mathrm{C}$; growth often terminating before the Petri dish is covered by mycelium. Colony hyaline, first circular, becoming lobed at margin, thin, with little mycelium on the surface, dense, silky, finely and regularly zonate, zones of more or less equal width; hyphae narrow $(<10 \mu \mathrm{m}$ wide). Aerial hyphae scant. Coilings and autolytic activity absent. Chlamydospores noted from 2 weeks. No pigment, no distinct odour noted. Conidiation after 3-4 days, green after 2-4 weeks, rarely earlier, or remaining hyaline for more than 2 months, depending on the isolate; effuse, first on minute conidiophores around the plug, spreading irregularly or in concentric rings, remaining invisible, growing to small, inconspicuous greenish granules, or rarely (CBS 119285) emerging from compact and opaque, grey-green, 27D4, 28DE4-6, pustules $1-5 \mathrm{~mm}$ diam and $1-1.5 \mathrm{~mm}$ thick, with straight sterile or fertile elongations on the distal margin of the colony after 1-2 months. Pustule formation enhanced by incubation at $15^{\circ} \mathrm{C}$ after growth at $25^{\circ} \mathrm{C}$. Conidia yellow-green in mass.

On PDA after $72 \mathrm{~h}$ reaching at most $0.5 \mathrm{~mm}$ at $15^{\circ} \mathrm{C}, 4$ $5 \mathrm{~mm}$ at $25^{\circ} \mathrm{C}, 0.5-4.5 \mathrm{~mm}$ at $30^{\circ} \mathrm{C}$; mycelium covering the entire plate after $c a 6$ weeks; hyphae conspicuously narrow. Colony circular, dense, thin, smooth, indistinctly zonate, with radial folds formed around the plug; with short aerial hyphae becoming fertile. Margin downy after $c a 1$ month due to long aerial hyphae. Autolytic excretions rare or uncommon, no coilings seen. No distinct odour, no diffusing pigment noted. Reverse becoming pale yellow, 3-4A3-4, from the centre. Conidiation noted after 3 days, effuse, spreading from the plug on short conidiophores, appearing powdery, yellow, turning greenish, 30A3, from ca 2 weeks; white, downy to cottony, close to margin after $>1$ month. At $30^{\circ} \mathrm{C}$ colony turning yellow to brown-yellow, 3A6-7, 4AB4-6, 5C5-7; conidiation remaining white (within 2 weeks).

On SNA after $72 \mathrm{~h} 0.2-1 \mathrm{~mm}$ at $15^{\circ} \mathrm{C}, 2-3 \mathrm{~mm}$ at $25^{\circ} \mathrm{C}$, $0-2.5 \mathrm{~mm}$ at $30^{\circ} \mathrm{C}$; mycelium covering the entire plate after $>6$ weeks, scant on the surface; hyphae thin, soon degenerating, becoming multiguttulate. Colony dense, with irregular outline, finely and often indistinctly zonate, hyaline. Aerial hyphae scant, short, becoming fertile. No autolytic excretions, no coilings noted. No diffusing pigment, no distinct odour noted. Chlamydospores noted after 10 days, $(5-) 6-17(-25) \times(3-) 4-7(-9) \mu \mathrm{m}, 1 / \mathrm{w}=(0.9-)$ $1.2-3.3(-5.7)(n=30)$, extremely variable in shape, terminal and intercalary. Conidiation noted after 4 days, effuse, on short simple conidiophores spreading from the centre, and in small granules or pustules (with granular surface) $0.3-1$ $(-2.5) \mathrm{mm}$ diam in a broad distal concentric zone. Pustules first white, becoming pale yellowish green or grey-green, 29-30B3-4, after 1 or several week; first maturing within pustule, dense and green, while white and with sparse or without straight sterile elongations in the periphery. Elongations $30-150 \mu \mathrm{m}$ long from last side branch, with numerous guttules, appearing verrucose under low magnification, becoming fertile. Structure of conidiophores examined after 6-18 days. Simple conidiophores or shrubs around the agar plug of a short stipe with 1-3 main axes to ca $75 \mu \mathrm{m}$ long, bearing several asymmetric or paired $1-4(-$ 6) celled terminal branches with phialides solitary or in whorls of 2-5. Pustules of a loose reticulum with rightangled branching. Branches mostly unpaired, with numerous free ends bearing terminal whorls of phialides and minute conidial heads $<15 \mu \mathrm{m}$. Conidiophores $2-5 \mu \mathrm{m}$ wide, with side branches increasing in length from the top in a short distance, resulting in broad structures. Branching points often thickened to $6 \mu \mathrm{m}$. Phialides arising from cells 2-3 $\mu \mathrm{m}$ wide. Conidiophores appearing verrucose with age due to fine guttules. Phialides $(4-) 5-9(-12) \times(2.0-) 2.3-2.8$ $(-3.3) \mu \mathrm{m}, 1 / \mathrm{w}=(1.5-) 2.0-3.7(-5.0),(1.3-) 1.7-2.3(-2.6)$ $\mu \mathrm{m}$ wide at the base $(n=70)$, narrowly lageniform to subulate, often inaequilateral, widest in or below the middle. Conidia $(1.8-) 2.5-3.2(-4.0) \times(1.8-) 2.0-2.4(-2.6)$ $\mu \mathrm{m}, 1 / \mathrm{w}=(1.0-) 1.2-1.5(-1.7) \quad(n=100)$, subglobose, ellipsoidal or attenuated at one end, individually nearly colourless, light (yellowish) green in mass, smooth, with few minute guttules; scar indistinct. At 15 and $30^{\circ} \mathrm{C}$ no or limited irregular growth; hyphae distorted or forming pegs.

On MEA growth substantially faster than on the above media, after 2 weeks mycelium covering the plate nearly completely. Colony finely zonate, with greenish pustules $0.3-1.5 \mathrm{~mm}$ diam on the entire plate, concentrated in thick concentric zones; smaller pustules translucent, larger 
opaque. Pustule stipe and primary branches $7-8 \mu \mathrm{m}$ wide. Conidiophores (= main axes) projecting to $0.5 \mathrm{~mm}$ from pustule margins, 3-4(-5) $\mu \mathrm{m}$ wide, 2-3.5 toward ends. Main axes richly rebranching, with side branches mostly $80-150 \mu \mathrm{m}$ long, increasing in length from the top in a short distance, causing broad dense structures. Branches mostly in right angles or slightly inclined upward, paired or not; branching points often thickened to $7(-8) \mu \mathrm{m}$. Phialides solitary or distinctly divergent in whorls of 2-5; conidia formed in minute wet heads $<15 \mu \mathrm{m}$ diam, soon drying. Phialides lageniform, less commonly ampulliform, often inaequilateral, widest in or below the middle. Conidia subhyaline to greenish yellow, light green in mass, ellipsoidal, less commonly subglobose or pyriform, smooth, with few minute guttules; scar indistinct. Measurements of phialides and conidia combined with those on SNA. Asynchronous development of conidiation within pustules.

Habitat: on wood and bark of deciduous trees in association with basidiomycetous rhizomorphs, overgrowing leaves and other fungi, mainly on Fagus.

Distribution: Central Europe (collected in Austria and Germany).

Holotype: Austria, Niederösterreich, Melk, Weins, eastern access, left side at main road to Persenbeug, MTB $7756 / 3,48^{\circ} 12^{\prime} 00^{\prime \prime} \mathrm{N}, 15^{\circ} 02^{\prime} 39^{\prime \prime} \mathrm{E}$, elev. $290 \mathrm{~m}$, on two partly decorticated branches of Fagus sylvatica, 3-6 cm thick, on wood and bark, soc. effete pyrenomycete and rhizomorphs (ozonium) of a Coprinellus, 25 July 2004, H. Voglmayr \& W. Jaklitsch, W.J. 2542 (WU 29183, ex-type culture CBS 119284=C.P.K. 1972). Holotype of Trichoderma auranteffusum isolated from WU 29183 and deposited as a dry culture with the holotype of $H$. auranteffusa as WU 29183a.

Additional specimens examined: Austria, Burgenland, distr. Eisenstadt, W Mörbisch, on ozonium on Robinia pseudacacia, grid square 8265/2, elev. 200 m, 11 Sep 2010, H. Voglmayr \& I. Greilhuber (WU). Burgenland, Leithagebirge, Lebzelterberg, between Hornstein and Leithaprodersdorf, MTB 8064/4, elev. $250 \mathrm{~m}$, on branch of Carpinus betulus, 16 Sep. 2007, H. Voglmayr, W.J. 3167 (WU 29190). Kärnten, Klagenfurt Land, St. Margareten im Rosental, Gupf (Writze), MTB 9452/2, 46 $33^{\prime} 04^{\prime \prime} \mathrm{N}, 14^{\circ}$ $27^{\prime} 11^{\prime \prime}$ E, elev. $730 \mathrm{~m}$, on partly decorticated branches of Salix caprea and Corylus avellana 3-6 cm thick, on wood and cutting area, holomorph, soc. rhizomorphs, 24 Sep. 2006, W. Jaklitsch \& H. Voglmayr, W.J. 2982 (WU 29189, culture C.P.K. 2470). St. Margareten im Rosental, village area, close to Bauhof Jaklitsch, MTB 9452/4, elev. 600 m, on well-decayed branch of Fagus sylvatica $2 \mathrm{~cm}$ thick, soc. brown rhizomorphs and Lasiosphaeria strigosa, 29 Sep. 2007, W. Jaklitsch, W.J. 3174 (WU 29191, culture C.P.K. 3158). Niederösterreich, Hollabrunn, Hardegg, beech forest close to Felling, MTB 7161/1, 48 $51^{\prime} 47^{\prime \prime} \mathrm{N}, 15^{\circ} 49^{\prime} 49^{\prime \prime} \mathrm{E}$, elev. $480 \mathrm{~m}$, on decorticated branch of Fagus sylvatica 4$5 \mathrm{~cm}$ thick, on wood, 21 Jul. 2004, H. Voglmayr \& W. Jaklitsch, W.J. 2534 (WU 29181, culture C.P.K. 1617). Krems, Krumau, virgin forest at the Dobrasperre on south side of the Dobra storage lake, MTB 7458/1, elev. 490 m, $48^{\circ} 35^{\prime} 19^{\prime \prime} \mathrm{N}, 15^{\circ} 23^{\prime} 56^{\prime \prime} \mathrm{E}$, on branch of Fagus sylvatica $2 \mathrm{~cm}$ thick, on wood and bark, 12 Jul. 2003, W. Jaklitsch, W.J. 2281 (WU 29179, culture C.P.K. 1594). Loosdorf, Dunkelsteiner Wald, $0.7 \mathrm{~km}$ south from Umbach, MTB $7758 / 4,48^{\circ} 14^{\prime} 04^{\prime \prime} \mathrm{N}, 15^{\circ} 25^{\prime} 48^{\prime \prime} \mathrm{E}$, elev. $370 \mathrm{~m}$, on decorticated branch of Fagus sylvatica $2-4 \mathrm{~cm}$ thick, on wood, 5 Oct. 2004, W. Jaklitsch (not harvested). Melk, Leiben, at Hofmühle, Weitental, MTB 7757/2, 48 ${ }^{\circ} 14^{\prime} 51^{\prime \prime}$ N, $15^{\circ} 17^{\prime} 23^{\prime \prime}$ E, elev. $270 \mathrm{~m}$, on 3 decorticated branches of Fagus sylvatica $1.5-5 \mathrm{~cm}$ thick, on wood, soc. ozonium of Coprinellus cf. domesticus, Lasiosphaeria hirsuta and other effete pyrenomycetes, and Auricularia auricula-judae, 25 July 2004, H. Voglmayr \& W. Jaklitsch, W.J. 2538 (WU 29182, culture C.P.K. 1971). Melk, Sankt Leonhard am Forst, $\mathrm{ca} 400 \mathrm{~m}$ after Großweichselbach in direction Melk, MTB 7857/2, 48 $10^{\prime} 39^{\prime \prime} \mathrm{N}, 15^{\circ} 17^{\prime} 48^{\prime \prime} \mathrm{E}$, elev. $380 \mathrm{~m}$, on decorticated branch of Fagus sylvatica, on wood, holomorph, 30 Sep. 2004, W. Jaklitsch (not harvested). WienUmgebung, Mauerbach, Friedhofstrasse, MTB 7763/1, elev. $335 \mathrm{~m}, 48^{\circ} 15^{\prime} 22^{\prime \prime} \mathrm{N}, 16^{\circ} 10^{\prime} 14^{\prime \prime} \mathrm{E}$, on branch of Carpinus betulus $6 \mathrm{~cm}$ thick, on wood, soc. Hypoxylon howeianum, 13 Aug. 2005, W. Jaklitsch (not harvested). Pressbaum, Rekawinkel, forest path south of the train station, MTB 7862/1, 48 $10^{\prime} 46^{\prime \prime} \mathrm{N}, 1^{\circ} 02^{\prime} 03^{\prime \prime}$ E, elev. $365 \mathrm{~m}$, on decorticated branch of Fagus sylvatica $3 \mathrm{~cm}$ thick, on wood, overgrowing leaves on branch, soc. white Corticiaceae, holomorph, 18 Oct. 2003, W. Jaklitsch \& H. Voglmayr, W.J. 2477 (WU 29180, culture CBS 119285=C. P.K. 1605). Same area, elev. $430 \mathrm{~m}, 48^{\circ} 10^{\prime} 33^{\prime \prime} \mathrm{N}, 16^{\circ} 02^{\prime}$ $03^{\prime \prime}$ E, on decorticated branch of Fagus sylvatica $7 \mathrm{~cm}$ thick, on wood, holomorph, soc. ozonium, 20 Aug. 2005, W. Jaklitsch, W.J. 2827 (WU 29186, culture C.P.K. 2409). Oberösterreich, Vöcklabruck, Nußdorf am Attersee, close to Limberg, MTB 8147/1, 47 $51^{\prime} 48^{\prime \prime} \mathrm{N}, 13^{\circ} 30^{\prime} 27^{\prime \prime} \mathrm{E}$, elev. $680 \mathrm{~m}$, on 3 partly decorticated branches of Fagus sylvatica $1.5-3 \mathrm{~cm}$ thick, on wood, below bark and leaves, on and soc. Lasiosphaeria strigosa, soc. Tubeufia cerea, ozonium and a ?Tomentella sp., 8 Aug. 2004, W. Jaklitsch \& H. Voglmayr, W.J. 2593 (WU 29184, culture C.P.K. 1973). Steiermark, Riegersburg, MTB 8961/4, on decorticated branch of Fagus sylvatica, 26 Oct. 2004, Dobernig, Draxler \& Maurer (GZU). Weiz, Laßnitzthal, opposite to the Arboretum Gundl across the road, MTB 8959/2, elev. $420 \mathrm{~m}, 4^{\circ} 04^{\prime} 17^{\prime \prime} \mathrm{N}, 15^{\circ} 38^{\prime} 38^{\prime \prime} \mathrm{E}$, on branch of Fagus sylvatica 11 Sep. 2002, H. Voglmayr \& W. Jaklitsch, W.J. 2883. Vienna, $23^{\text {rd }}$ district, Maurer Wald, MTB 7863/1, elev. $350 \mathrm{~m}$, on decorticated branch of Acer pseudoplatanus, on wood and Eutypa maura, 4 Oct. 2002, H. 
Voglmayr, W.J. 1991. Vorarlberg, Feldkirch, Rankweil, behind the LKH Valduna, MTB 8723/2, 47 $15^{\prime} 40^{\prime \prime} \mathrm{N}, 09^{\circ}$ $39^{\prime} 00^{\prime \prime}$ E, elev. $510 \mathrm{~m}$, on decorticated branch of Fagus sylvatica 3-4 cm thick, on wood, below bark and leaves, soc. old Eutypa sp. and ozonium, 31 Aug. 2004, H. Voglmayr \& W. Jaklitsch, W.J. 2645 (WU 29185, culture CBS $119287=$ C.P.K. 1974). Germany, Bavaria, Starnberg, Tutzing, Erling, Hartschimmel-Gelände, 47 $56^{\prime} 34^{\prime \prime} \mathrm{N}, 11^{\circ}$ $10^{\prime} 47^{\prime \prime}$ E, elev. $700 \mathrm{~m}$, on three decorticated branches of Fagus sylvatica $2-6 \mathrm{~cm}$ thick, on wood, holomorph, soc. Phlebiella vaga, ?Tulasnella sp., old Lasiosphaeria sp., 3 Sep. 2005, W. Jaklitsch, W.J. 2834 (WU 29187). Unterfranken, Landkreis Haßberge, Haßfurt, close to Mariaburghausen, left roadside heading from Knetzgau to Haßfurt, MTB 5929/3, 50 $00^{\prime} 31^{\prime \prime} \mathrm{N}, 10^{\circ} 31^{\prime} 17^{\prime \prime} \mathrm{E}$, elev. $270 \mathrm{~m}$, on partly decorticated branch of Fagus sylvatica $6 \mathrm{~cm}$ thick, on wood and bark, soc. ozonium, rhizomorphs, Lopadostoma turgidum in bark, 29 Aug. 2006, H. Voglmayr \& W. Jaklitsch, W.J. 2963 (WU 29188, culture C.P.K. 3119).

Notes: Stromata of $H$. auranteffusa are usually accompanied by rhizomorphs, particularly those of Coprinellus domesticus ('ozonium'). Colour and micro-morphological characteristics of this species are similar to those of $H$. splendens. However, the type material of the latter species (on Prunus laurocerasus) is represented by distinctly pulvinate stromata not found in the numerous specimens of $H$. auranteffusa. Searches for fresh material of H. splendens in England conducted to elucidate the concept and phylogenetic relationships of the latter species have been without success. The species phylogenetically most closely related to $H$. auranteffusa in the Brevicompactum clade are $H$. margaretensis and $H$. rodmanii. H. margaretensis differs from $H$. auranteffusa by bright yellow, not orange stromata when fresh, by $4-5$ times faster growth at $25^{\circ} \mathrm{C}$ on all media, and zonations of distinctly unequal width in colonies on CMD. In addition, no conidiation pustules have been seen in cultures of $H$. margaretensis on CMD. H. rodmanii differs from $H$. auranteffusa in more pulvinate or discoid stromata, pale yellow when fresh, in well-defined green conidiation zones on PDA, and in growth rates even faster than in $H$. margaretensis. The substantially faster growth of $H$. auranteffusa on MEA versus CMD, PDA and SNA suggests that it is one of the species requiring richer media for optimal development. All species of this clade are characterised by minute cortical cells.

Hypocrea margaretensis Jaklitsch, sp. nov. Fig. 73

MycoBank MB 516689

Anamorph: Trichoderma margaretense Jaklitsch, sp. nov. Fig. 74

MycoBank MB 516690

Stromata effusa vel subpulvinata, $1-18 \mathrm{~mm}$ lata, laete flava. Asci cylindrici, $(75-) 88-106(-117) \mu \mathrm{m} \times(4.0-) 4.5-$
5.5(-6.5) $\mu \mathrm{m}$. Ascosporae hyalinae, verruculosae, bicellulares, ad septum disarticulatae; pars distalis (sub)globosa, $(3.5-) 3.8-5.0(-6.0) \times(3.3-) 3.5-4.2(-5.0) \mu \mathrm{m}$, pars proxima oblonga, cuneata vel subglobosa, $(3.5-) 4.3-6.2(-7.6) \times(2.7-)$ 3.0-3.6(-4.7) $\mu \mathrm{m}$. Anamorphosis Trichoderma margaretense. Conidiophora in agaro SNA effusa et in pustulis disposita, similia Verticillii vel Pachybasii. Phialides lageniformes, $(4.5-) 6-11(-18) \times(2.0-) 2.5-3.3(-4.0) \mu \mathrm{m}$. Conidia pallide viridia, subglobosa, ovoidea vel ellipsoidea, glabra, $(2.2-)$ $2.5-3.5(-5.5) \times(1.8-) 2.0-2.5(-3.0) \mu \mathrm{m}$.

Etymology: margaretensis owing to its currently exclusive occurrence around St. Margareten im Rosental, Kärnten, Austria.

Stromata when fresh 1-10(-18) $\mathrm{mm}$ long, 1-6(-9) mm wide, $0.5-1.5(-2) \mathrm{mm}$ thick; solitary, gregarious or aggregated in small numbers; starting as white mycelium, semi-effuse to flat subpulvinate, broadly attached. Outline circular or irregular with lobed margins. Margin first white and sterile, soon becoming free, narrow, whitish or yellowish. Surface smooth, shiny. Ostiolar dots numerous, minute when young, becoming distinct, fine, olive-, orange- or reddish brown. Stromata first white, later light or bright yellow, 3-4A3-8, brown, $6 \mathrm{D} 7-8$, when old. Spore deposits white or yellow.

Stromata when dry $0.15-0.4(-0.7) \mathrm{mm}(n=40)$ thick; thinly effuse, membranaceous, roundish or oblong, broadly attached, sometimes becoming detached with margin irregularly revolute; sometimes subpulvinate, with height exceeding the thickness. Surface smooth or finely tomentose, coarsely wavy to tubercular in older stromata. Margin usually concolorous, rounded and mostly free; in young stromata white, adnate, mycelial to membranaceous. Ostiolar dots (24-)30-62(-87) $\mu \mathrm{m}$ diam $(n=60)$, well-defined, plane or convex to semiglobose, with circular, sometimes oblong outline (laterally compressed), reddish-brown or brown, pale yellowish when young. Stromata at first white, centre becoming yellow, then the whole stroma light yellow, 4A3-5, light or greyish orange, orange-brown, light brown, 5AB4-7, 6B5-7, 6CD4-8, to medium or dark brown, 7CD7-8, 6-7EF5-8, when old. No distinct colour change by $3 \% \mathrm{KOH}$ noted.

Associated anamorph effuse, often in small patches, often with white margin, pale green, greyish green or turquoise, 24B3, 25-26A3, 25CD3-4, 26B3-4, 26DE4-5.

Stroma anatomy: Ostioles 87-124(-160) $\mu \mathrm{m}$ long, projecting to $14(-25) \mu \mathrm{m},(20-) 24-40(-50) \mu \mathrm{m}(n=20)$ wide at the apex, cylindrical, marginal cells sometimes clavate and widened to $5 \mu \mathrm{m}$ at the apex. Perithecia (160-) $210-265(-275) \times(110-) 120-160(-186) \mu \mathrm{m}(n=20)$, flaskshaped or nearly cylindrical, usually crowded and often laterally compressed due to mutual pressure. Peridium (13-)16-22(-25) $\mu \mathrm{m}$ thick at the base, (6-)10-17(-19) $\mu \mathrm{m}$ at the sides $(n=20)$, hyaline; pale yellowish in thick sections. Cortical layer (20-)24-35(-40) $\mu \mathrm{m}(n=30)$ thick, 

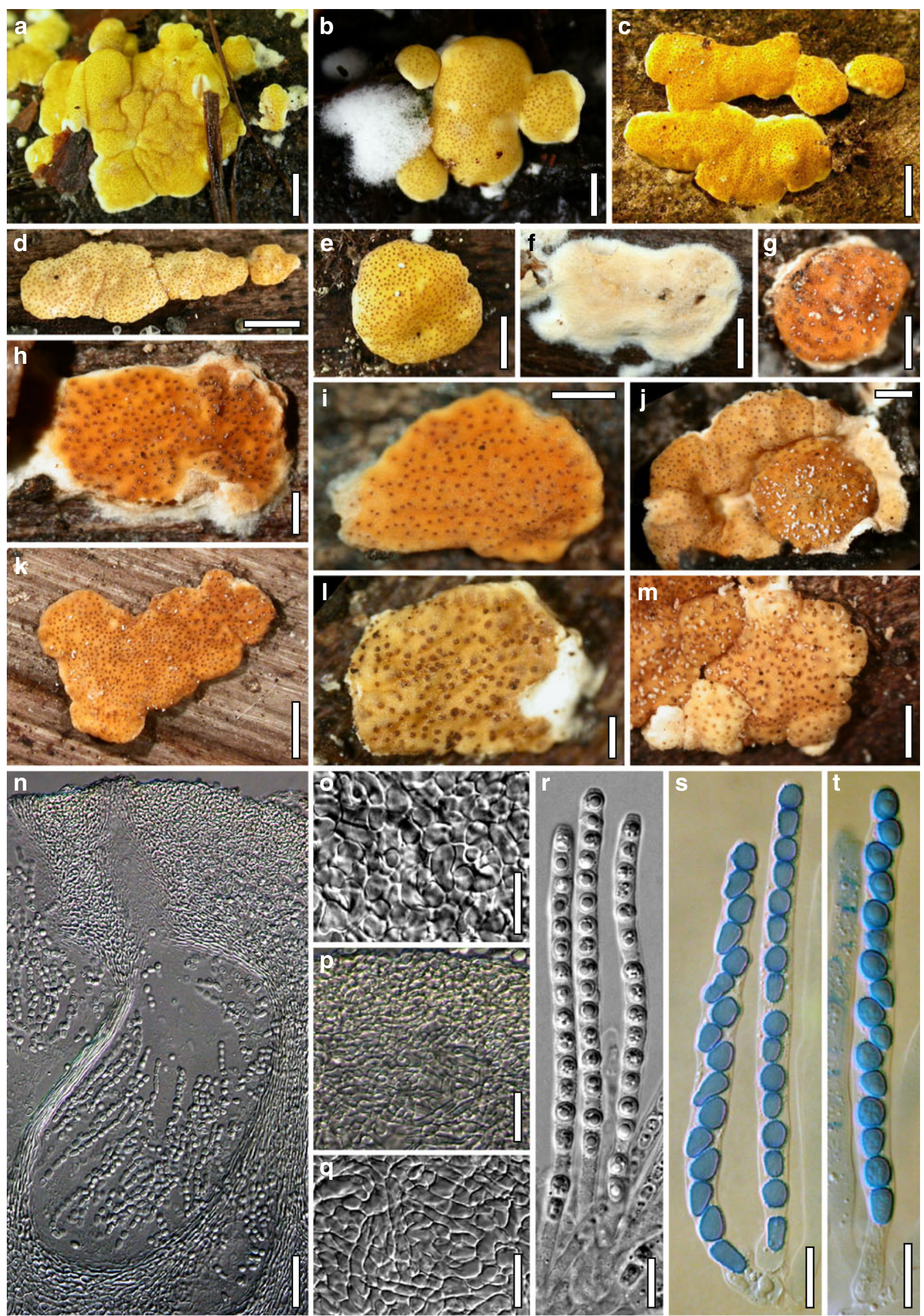
4 Fig. 73 Teleomorph of Hypocrea margaretensis. a-e. Fresh stromata (b. with young anamorph). f-l. Dry stromata (f. immature, early phase). m. Rehydrated stromata. n. Perithecium in section. o. Stroma surface in face view. p. Cortical and subcortical tissue in section. q. Subperithecial tissue in section. $\mathbf{r}-\mathbf{t}$. Asci with ascospores $(\mathbf{s}, \mathbf{t}$. in cotton blue/lactic acid). a. WU 29203. b, d-f, h. WU 29201. c, l, mq. WU 29199. g, j, s, t. WU 29202. i, r. WU 29205. k. WU 29200. Scale bars $\mathbf{a}, \mathbf{c}, \mathbf{d}=1.5 \mathrm{~mm}$. b, e, f, $\mathbf{k}=1 \mathrm{~mm}$. $\mathbf{g}-\mathbf{j}, \mathbf{m}=0.5 \mathrm{~mm} . \mathbf{l}=$ $0.3 \mathrm{~mm} . \mathbf{n}=30 \mu \mathrm{m} . \mathbf{0}, \mathbf{r}-\mathbf{t}=10 \mu \mathrm{m} . \mathbf{p}, \mathbf{q}=20 \mu \mathrm{m}$

a dense $t$. angularis of hyaline or pale yellow, thin-walled cells $(2.5-) 4-8(-10) \times(2-) 3-6(-7) \mu \mathrm{m}(n=60)$ in face view and in vertical section. Surface smooth. Subcortical tissue a loose $t$. intricata of thin-walled hyphae (2.0-)2.5-4.5(-6.0) $\mu \mathrm{m}(n=30)$ wide, mixed with some subhyaline, angular cells. Subperithecial tissue a dense homogeneous $t$. epidermoidea-angularis of variously shaped, thin-walled, hyaline cells $(5-) 7-26(-36) \times(4-) 5-11(-13) \quad(n=30)$; cells smaller towards the base, and interspersed with thickwalled, yellowish hyphae, $(2.0-) 2.5-4.5(-6.0) \mu \mathrm{m}(n=30)$ wide. Asci (75-)88-106(-117) $\times(4.0-) 4.5-5.5(-6.5) \mu \mathrm{m}$, stipe (6-)9-23(-35) $\mu \mathrm{m}$ long $(n=73)$; no croziers seen. Ascospores hyaline, verruculose; cells dimorphic, but often similar; distal cell (3.5-)3.8-5.0(-6.0) $\times(3.3-) 3.5-4.2(-5.0)$ $\mu \mathrm{m}, 1 / \mathrm{w} 1.0-1.3(-1.7) \quad(n=72)$, subglobose or slightly elongated and attenuated upward; proximal cell (3.5-)4.3$6.2(-7.6) \times(2.7-) 3.0-3.6(-4.7) \mu \mathrm{m}, 1 / \mathrm{w}(1.1-) 1.3-1.9(-2.3)$ $(n=72)$, oblong, wedge-shaped, or subglobose.

Cultures and anamorph: optimal growth at $25^{\circ} \mathrm{C}$ on all media; no growth at $35^{\circ} \mathrm{C}$.

On CMD after $72 \mathrm{~h} 7-11 \mathrm{~mm}$ at $15^{\circ} \mathrm{C}, 22-28 \mathrm{~mm}$ at $25^{\circ} \mathrm{C}$, $11-21 \mathrm{~mm}$ at $30^{\circ} \mathrm{C}$; mycelium covering plate after 7-8 days at $25^{\circ} \mathrm{C}$. Colony hyaline, distinctly circular with well-defined margin, with little mycelium on surface, forming up to 7 broad and 6 narrow concentric zones. Mycelium radially arranged, with conspicuous difference in width between primary and secondary hyphae. Surface hyphae degenerating, appearing empty. Aerial hyphae scant, short, more frequent and longer mainly at distal margin of the plate Autolytic activity and coilings absent or rare. No distinct odour noted. Sometimes pale yellowish on distal margin from 2 weeks, with minute yellow crystals at the very distal margin in densely packed mycelium. Chlamydospores (7-)8-12(-16) ×(5.5-)6-11(-14) $\mu \mathrm{m}, 1 / \mathrm{w} 0.9-1.5(-2)(n=32)$, noted after 50 days, uncommon, terminal and intercalary, globose, ovoid or clavate. Conidiation from 1 to 2 weeks, macroscopically invisible, scant, effuse, on loosely disposed, minute, simple conidiophores spreading from the plug and proximal margin; at distal margin also on long aerial hyphae; greenish only in the stereo microscope; degenerating from $\mathrm{ca} 3$ weeks; cultures usually sterile after several transfers.

On PDA after $72 \mathrm{~h} 4-9 \mathrm{~mm}$ at $15^{\circ} \mathrm{C}, 19-26 \mathrm{~mm}$ at $25^{\circ} \mathrm{C}, 8-$ $14 \mathrm{~mm}$ at $30^{\circ} \mathrm{C}$; mycelium covering plate after $8-10$ days at $25^{\circ} \mathrm{C}$. Colonies circular, dense, compact, indistinctly zonate, mycelium radially arranged, surface hyphae becoming moniliform in the centre due to ?chlamydospores. Aerial hyphae inconspicuous, loosely disposed, short and needle-like, superposed by scant thin and long hyphae, decreasing outwards, forming thin radial strands, soon degenerating, collapsing, giving surface finely downy to granular appearance. Autolytic activity and coilings absent or rare. Odour faint, like fermenting fruits (noted from 1 weeks), colony turning pale or greyish yellow, 3AB3-4, 3B5-6, from the centre. Conidiation from 3 to 5 days, macroscopically invisible, effuse, short, spreading from the plug, becoming farinose in the centre, remaining colourless ( 1 month). At $15^{\circ} \mathrm{C}$ conidiation dense in white central area.

On SNA after $72 \mathrm{~h} 4-7 \mathrm{~mm}$ at $15^{\circ} \mathrm{C}, 10-15 \mathrm{~mm}$ at $25^{\circ} \mathrm{C}$, $1-9 \mathrm{~mm}$ at $30^{\circ} \mathrm{C}$; mycelium covering plate after $c a 2$ weeks at $25^{\circ} \mathrm{C}$. Colonies distinctly circular with well-defined margin, compact, hyaline, thin, silky, with fine concentric zonation of unequal width. Hyphae radially arranged, thin, little on surface; surface hyphae degenerating, becoming multiguttulate. Aerial hyphae scant. Autolytic excretions rare; coilings variable, sometimes abundant. No distinct odour, no pigment noted. Chlamydospores uncommon. Conidiation noted after 4-6 days, better developed than on CMD, invisible to the unaided eye, effuse, on loosely disposed minute conidiophores spreading from the plug and proximal margin irregularly across the entire colony; at the distal margin also verticillium-like on aerial hyphae. Conidial heads minute, $<30 \mu \mathrm{m}$ diam, wet, becoming dry, greenish in the stereo-microscope. Conidiophores (after 612 days at $25^{\circ} \mathrm{C}$ ) to $150(-300) \mu \mathrm{m}$ long, erect, simple, asymmetric, of a short stipe or single axis 3-5 $\mu \mathrm{m}$ wide, with a single terminal whorl of phialides and some scattered solitary phialides, or with up to five steep, unpaired main axes emerging at low levels. Main axes unbranched or with unpaired branches. Branches 2-3 $\mu \mathrm{m}$ wide at ends, bearing solitary phialides or short, tree-like, often paired and mainly 1-celled terminal branches, strongly inclined upwards. Phialides arising from cells 2-4 $\mu \mathrm{m}$ wide, solitary or divergent in whorls of 2-4(-6). Phialides (5-)7-12(-18) $\mu \mathrm{m}(n=120) \mu \mathrm{m}$ long, lageniform or subcylindrical, less commonly ampulliform with long neck, mostly inaequilateral. Conidia as in granules. After $c a 1$ month (or growth for 16 days at $25^{\circ} \mathrm{C}$ plus $6-12$ days at $15^{\circ} \mathrm{C}$ ) conidiation becoming visible as minute, white to greenish granules or minipustules $0.2-0.8 \mathrm{~mm}$ diam, formed mainly along margin of the plate; slightly more complex and stout in structure than effuse conidiation. Compared to effuse conidiation, main axes more pachybasium-like, longer, with 1-2 fold branching at higher levels, terminal branches short, often paired and right-angled or inclined upwards, 13 celled. Branches 3-5(-6) $\mu \mathrm{m}$ wide. Phialides arising singly or in whorls on cells $2.5-4 \mu \mathrm{m}$ wide. Phialides (4.5-) $5.5-9.0(-12) \times(2.3-) 2.5-3.2(-3.7) \mu \mathrm{m}, 1 / \mathrm{w}(1.5-) 1.7-3.2(-$ 4.8), (1.4-)1.8-2.5(-2.8) $\mu \mathrm{m}(n=61)$ wide at the base; 

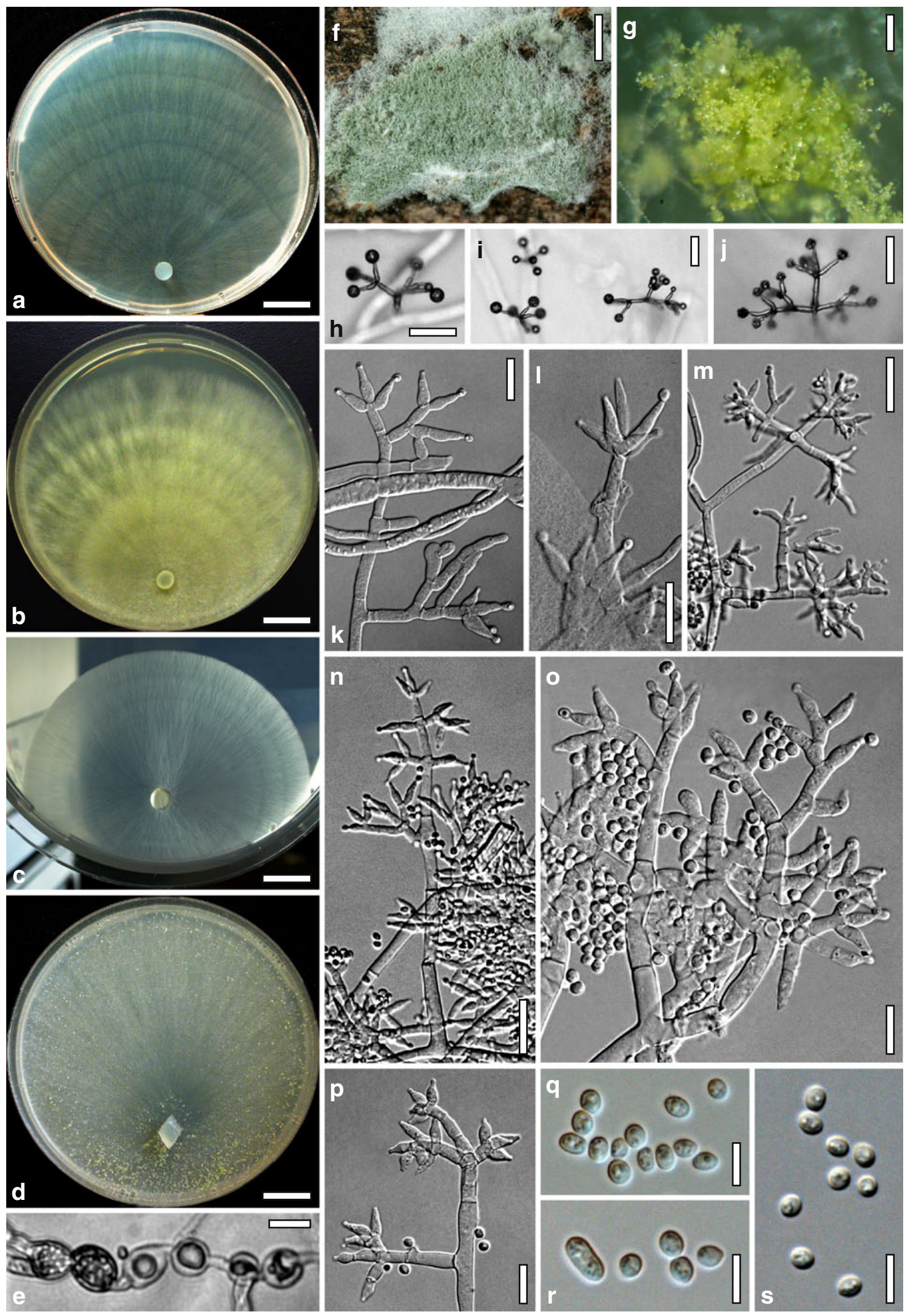
4Fig. 74 Cultures and anamorph of Hypocrea margaretensis. a-d. Cultures (a. on CMD, 13 days, showing unequal zonation. b. on PDA, 7 days. c. on SNA, 7 days, showing well-defined circular colony. d. on MEA, 11 days, showing green granules). e. Chlamydospores (CMD, 52 days). f. Anamorph on the natural substrate. g. Conidiation shrub (MEA, 11 days). $\mathbf{h}-\mathbf{j}$. Conidiophores of effuse conidiation on growth plate (SNA, 9 days; $\mathbf{j}$. dry heads, without lid). k, l. Conidiophores of effuse conidiation (k. MEA, 5 days. I. SNA, 6 days). m-p. Conidiophores of pustulate conidiation (MEA, 11 days). q-s. Conidia (MEA, 5-11 days). a-s. All at $25^{\circ} \mathrm{C}$. a-c, e, h-j. CBS 119320. d, g, m-r. CBS 120540. f. WU 29199. k, l, s. C.P.K. 3129. Scale bars $\mathbf{a}, \mathbf{b}, \mathbf{d}=14 \mathrm{~mm}$. $\mathbf{c}=10 \mathrm{~mm}$. e, $\mathbf{k}, \mathbf{l}, \mathbf{o}, \mathbf{p}=10 \mu \mathrm{m} . \mathbf{f}=$ $0.7 \mathrm{~mm} . \mathbf{g}=100 \mu \mathrm{m} . \mathbf{h}-\mathbf{j}=30 \mu \mathrm{m} . \mathbf{m}, \mathbf{n}=20 \mu \mathrm{m} . \mathbf{q}-\mathbf{s}=5 \mu \mathrm{m}$

narrowly lageniform or subulate, more rarely ampulliform, straight, sometimes curved or sinuous, usually widest below the middle, without conspicuous thickenings. Ampulliform phialides more frequent in microtufts or granules formed late. Phialides from simple conidiophores and granules combined (4.5-)6-11(-18) $\times(2.0-) 2.5-3.3(-$ 4.0) $\mu \mathrm{m}, 1 / \mathrm{w}(1.5-) 2-4(-7.5)(n=181)$. Conidia $(2.2-) 2.5-$ $3.5(-5.5) \times(1.8-) 2.0-2.5(-3.0) \mu \mathrm{m}, 1 / \mathrm{w}(1.0-) 1.1-1.5(-2.1)$ $(n=180)$, subhyaline to pale yellowish green, subglobose, oval, less commonly ellipsoidal, smooth, with few minute guttules; scar indistinct. At $15^{\circ} \mathrm{C}$ growth irregular, effuse conidiation on the entire colony except the centre.

On MEA mycelium covering the plate entirely after $c a$ 10 days. Aerial hyphae abundant, forming strands and causing a white, hairy colony surface. Coilings numerous, also in aerial hyphae. No diffusing pigment, no distinct odour noted. Conidiation effuse, on simple conidiophores often emerging in right angles on long aerial hyphae, solitary, unpaired or fasciculate. Conidiation also in pale yellowish green shrubs or granules along the margin and next to the plug. Shrubs or granules (examined after 11 days) $0.2-0.8(-1) \mathrm{mm}$ diam, confluent to $2-3 \mathrm{~mm}$; of a loose reticulum, with primary branches to $7 \mu \mathrm{m}$ wide, often at right angles, and with broad peripheral conidiophores to $c a$ $120 \mu \mathrm{m}$ long. Conidiophores (simple and in minipustules) 3-6 $\mu \mathrm{m}$ wide, 2-3 $\mu \mathrm{m}$ at the ends; sometimes widening to 7-10(-11) $\mu \mathrm{m}$; variable, short and regular, or asymmetric and main axis with 1-2 fold additional branching. Branches straight, slightly inclined upward. Phialides arising on cells 2-4 $\mu \mathrm{m}$ wide, solitary or in whorls of $2-4(-5)$. Phialides lageniform, mostly equilateral, widest in or below the middle. Conidia formed in minute wet or dry heads; subhyaline to pale yellowish green, minute, smooth, subglobose or ellipsoidal, less commonly oblong, finely multiguttulate or with one guttule and with indistinct or truncate scar. Measurements as on SNA, results combined.

Habitat: on medium- to well- decayed wood and bark of deciduous trees, typically at forest edges.

Distribution: Europe (Austria).

Holotype: Austria, Kärnten, Klagenfurt Land, St. Margareten im Rosental, 'Aussicht', MTB 9452/3, 46³2'50" N $14^{\circ} 25^{\prime} 01^{\prime \prime} \mathrm{E}$, elev. $600 \mathrm{~m}$, at forest edge, on decorticated branches of Fagus sylvatica 1-4 cm thick, in leaf litter on the ground; holomorph, soc. Tubeufia cerea, Lasiosphaeria strigosa, Mollisia sp., 29 Oct. 2005 and 14 Oct. 2006 (from the same branches), W. Jaklitsch \& H. Voglmayr, W.J. 2868 (WU 29201, culture CBS $120540=$ C.P.K. 2423). Holotype of Trichoderma margaretense isolated from WU 29201 and deposited as a dry culture with the holotype of $H$. margaretensis as WU 29201a.

Additional specimens examined: Austria, Kärnten, Klagenfurt Land, St. Margareten im Rosental, 'Aussicht', MTB $9452 / 3$, elev. $600 \mathrm{~m}, 46^{\circ} 32^{\prime} 48^{\prime \prime} \mathrm{N} 14^{\circ} 25^{\prime} 00^{\prime \prime} \mathrm{E}$, on branches of Fagus sylvatica, on wood, soc. Lasiosphaeria strigosa, Corticiaceae, holomorph, 3 July 2007, W. Jaklitsch, W.J. 3107 (WU 29203, culture C.P.K. 3127). St. Margareten im Rosental, Gupf, close to Berghof Schuschnig, MTB 9452/4,

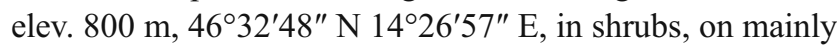
corticated branch of Crataegus monogyna $1-4 \mathrm{~cm}$ thick, in leaf litter on the ground; on wood and bark, soc. Hyphodontia sp., Crepidotus sp., Mollisia sp., ?Tomentella sp., holomorph, 21 Oct. 2003, W. Jaklitsch, W.J. 2481 (WU 29199, culture C.P.K. 994. Same locality, same date, on decorticated branch of Carpinus betulus 1-2 cm thick, on wood, upper side, holomorph, W.J. 2482 (WU 29200, culture CBS $119320=$ C.P.K. 1609). Same locality; on corticated branch of Carpinus betulus, 1-2 cm thick, in bark fissures, holomorph, 29 Oct. 2005, H. Voglmayr \& W. Jaklitsch, W.J. 2877 (WU 29202, culture C.P.K. 2428). St. Margareten im Rosental, Sabosach, MTB 9452/3, elev.

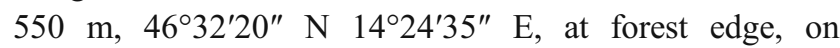
decorticated branch of Fagus sylvatica 1-2 cm thick, immersed in leaf litter, on dark decayed wood, soc. leaves, rhizomorphs, hyphomycetes, etc., holomorph, 9 July 2007, W. Jaklitsch, W.J. 3116 (WU 29204, culture C.P.K. 3128). St. Margareten im Rosental, at the brook 'Tumpfi', close to Ledra, at forest edge, MTB 9452/2, elev. $570 \mathrm{~m}, 46^{\circ} 32^{\prime} 58^{\prime \prime}$ $\mathrm{N} 14^{\circ} 25^{\prime} 52^{\prime \prime} \mathrm{E}$, on branches of Fagus sylvatica and Carpinus betulus 1-6 cm thick, on medium to well decayed wood, a black crust, bark and leaves, soc. effete black pyrenomycete and Tubeufia cerea, holomorph, 9 July 2007, W. Jaklitsch, W.J. 3118 (WU 29205, culture C.P.K. 3129).

Notes: Hypocrea margaretensis has only been found around St. Margareten im Rosental, Kärnten, Austria, and always at forest edges, typically on steep slopes. The bright yellow and subeffuse stromata are reminiscent of sect. Hypocreanum, particularly $H$. sulphurea, but they are less than $2 \mathrm{~cm}$ diam, and the anamorph is green-conidial, as in other species of the Brevicompactum clade. The ascospores are distinctly smaller than in H. sulphurea. Hypocrea margaretensis is most closely related to $H$. auranteffusa and $H$. rodmanii and difficult to distinguish from these species in teleomorphs. The colour of fresh stromata is intermediate between the pale yellow $H$. rodmanii and the 
bright orange $H$. auranteffusa, but there are transitions particularly between the latter and $H$. margaretensis. Compared to $H$. auranteffusa, $H$. margaretensis grows substantially faster and colonies on CMD show zones of unequal width in alternating light/darkness. No statistically significant differences were found between effuse and pustulate conidiation; only phialides are slightly longer on simple conidiophores, as noted in many other species of the genus. Conidiophores of effuse disposition are reminiscent of those of H. lixii and H. strictipilosa. H. rodmanii differs from H. margaretensis in more pulvinate or discoid stromata with pale yellow colour when fresh, as well as in well-defined green conidiation zones on PDA and in faster growth.

Hypocrea rodmanii Samuels \& Chaverri, in Degenkolb et al., Mycol. Progress 7: 213 (2008a). Fig. 75

Anamorph: Trichoderma sp. Fig. 76

Stromata when fresh 1-8 $\mathrm{mm}$ diam, to $c a 1 \mathrm{~mm}$ thick, effuse, discoid or pulvinate, broadly attached, margin often free; outline variable. Surface smooth, ostiolar dots diffuse when young, becoming distinct, densely arranged, brown on yellow stroma surface. Stromata white to pale yellow, $3 \mathrm{~A}(2-) 3$, when immature, turning ochre-yellow, greyish- to dull orange-yellow, 4B5-8, or golden-brown, finally dull reddish brown.

Stromata when dry $(0.4-) 1.3-4.4(-7.6) \times(0.4-) 1.1-2.6$ $(-4) \mathrm{mm}, 0.1-0.4(-0.7) \mathrm{mm}$ thick $(n=70)$, solitary, gregarious or aggregated in small numbers, thinly effuse, following contours of the substrate, or flat pulvinate, thinner than fresh; broadly attached, or discoid and typically narrowly attached. Outline roundish, longish or irregular. Margin of effuse stromata typically adnate, thin and cottony, sometimes fraying out as white radiating mycelium; often thin, sharp and widely free in discoid stromata, rounded with free edge in pulvinate stromata; sometimes undulate; often white when young. Surface smooth, finely granular or slightly rugose, yellow to nearly orange. Ostiolar dots $(27-) 30-70(-118) \mu \mathrm{m}(n=$ 90) diam, irregularly or evenly and densely distributed, plane or convex, roundish or longish, first diffuse, greyish, pale reddish brown or nearly orange when young, later well-defined, ochre, brown to nearly black even on a single stroma. Development and colour: Stromata starting as white mycelial tufts, compacting, turning pale yellow to greyish yellow with first white margin becoming concolorous, 3-4A2-4, 4B3-6; after the appearance of ostiolar dots deeper yellow, yellowbrown to dull orange, greyish orange, 5-6B4, 5CD5-8, 5E6-8, finally dull brown, 6CD4-8, 7E5-6, when old. Spore deposits white or yellow. Mature stromata after rehydration up to $30 \%$ larger than in dry condition, reddish brown, in the stereo-microscope yellow with flat ochre to reddish brown dots. Reaction to $3 \% \mathrm{KOH}$ variable, typically becoming more distinctly orange- to reddish brown when mature.

Stroma anatomy: Ostioles (50-)60-100(-110) $\mu \mathrm{m}$ long, plane or projecting to $10(-17) \mu \mathrm{m},(30-) 40-60(-$ 70) $\mu \mathrm{m}$ wide at the apex inside $(n=30)$, without differentiated marginal cells; periphyses to $3.5 \mu \mathrm{m}$ wide. Perithecia (150-)180-240(-260)×(105-)130-200(-230) $\mu \mathrm{m}(n=30)$, crowded, globose, ellipsoidal or flaskshaped; peridium (11-)14-20(-23) $\mu \mathrm{m}(n=30)$ thick at the base, $(6-) 10-16(-20) \mu \mathrm{m}(n=30)$ thick at the sides, yellow, when mature in $\mathrm{KOH}$ orange-red, particularly at the sides. Cortical layer (9-)11-23(-30) $\mu \mathrm{m}(n=30)$ thick, a thin, dense, yellow $t$. angularis of minute, partly compressed cells $(2-) 3-7(-9) \times(2-) 3-5(-6) \mu \mathrm{m}(n=60)$ in face view and in vertical section, orange in $3 \% \mathrm{KOH}$. Subcortical tissue of thin-walled, hyaline or yellowish hyphae $(2.5-) 3.0-5.0(-7.0) \mu \mathrm{m}(n=30)$ wide, partly appearing as angular cells $(3-) 4-8(-12) \times 3-6 \mu \mathrm{m}(n=30)$ due to variable orientation. Subperithecial tissue a hyaline $t$. angularis-epidermoidea of thin-walled cells $6-25(-44) \times$ $(3.5-) 5-14(-20) \mu \mathrm{m}(n=35)$, becoming smaller and yellowish towards the base and mixed with thick-walled yellow hyphae (2.5-)3.5-7.0(-9.5) $\mu \mathrm{m}(n=30)$; in attachment areas exclusively pseudoparenchymatous of cells $3-15 \mu \mathrm{m}$ diam. Asci (62-)75-90(-101)×(4.3-)4.5-5.5(-6.5) $\mu \mathrm{m}$, stipe (1-) $5-13(-20) \mu \mathrm{m}(n=80)$ long. Ascospores hyaline, yellow when old, verruculose, cells dimorphic; distal cell (3.3-)3.7$4.5(-5.5) \times(2.8-) 3.5-4.0(-4.2) \mu \mathrm{m}, 1 / \mathrm{w}(0.9-) 1.0-1.2(-1.4)$ $(n=90)$, (sub)globose or ellipsoidal; proximal cell (3.8-)4.3$5.8(-7.4) \times(2.5-) 3.0-3.3(-3.5) \mu \mathrm{m}, 1 / \mathrm{w}(1.2-) 1.4-1.9(-2.4)$ $(n=90)$, oblong or wedge-shaped, often longer in the ascus base.

Cultures and anamorph: optimal growth at $25-30^{\circ} \mathrm{C}$ on all media; slow and often limited growth at $35^{\circ} \mathrm{C}$.

On CMD after $72 \mathrm{~h} 10-12 \mathrm{~mm}$ at $15^{\circ} \mathrm{C}, 32-34 \mathrm{~mm}$ at $25^{\circ} \mathrm{C}, 34-37,1-5 \mathrm{~mm}$ at $35^{\circ} \mathrm{C}$; mycelium covering the plate after $6-7$ days at $25^{\circ} \mathrm{C}$. Colony hyaline, thin, circular, dense, with indistinct light/dense and darker/ looser concentric zones; denser zones slightly narrower. Hyphae curved, secondary hyphae narrow, sinuous, in steep angles in growth direction; little mycelium on the agar surface. Aerial hyphae scant, short. Autolytic activity lacking or inconspicuous, no coilings seen. No

Fig. 75 Teleomorph of Hypocrea rodmanii. a-f. Fresh stromata (a, b. immature). g-i, k, l. Dry stromata (g, h. immature). j. Rehydrated stroma. m. Stroma surface in face view. n. Stroma in $3 \% \mathrm{KOH}$ after rehydration. o. Perithecium in section. p. Cortical and subcortical tissue in section. q. Subperithecial tissue in section. r. Stroma base in section. $\mathbf{s}-\mathbf{u}$. Asci with ascospores (u. in cotton blue/lactic acid). a, $\mathbf{c}, \mathbf{g}, \mathbf{j}-\mathbf{l}, \mathbf{n}-\mathbf{s}$. WU 29443. t. WU 29445. b, d-f, h, i, m, u. WU 29444. Scale bars $\mathbf{a}=$ $3 \mathrm{~mm} . \mathbf{b}, \mathbf{d}, \mathbf{e}, \mathbf{j}-\mathbf{l}, \mathbf{n}=0.5 \mathrm{~mm}$. $\mathbf{c}=1.5 \mathrm{~mm} . \mathbf{f}-\mathbf{h}=1 \mathrm{~mm} . \mathbf{i}=0.2 \mathrm{~mm} . \mathbf{m}, \mathbf{p}$, $\mathbf{t}, \mathbf{u}=10 \mu \mathrm{m} . \mathbf{o}=30 \mu \mathrm{m} . \mathbf{q}, \mathbf{r}=15 \mu \mathrm{m} . \mathbf{s}=5 \mu \mathrm{m}$ 

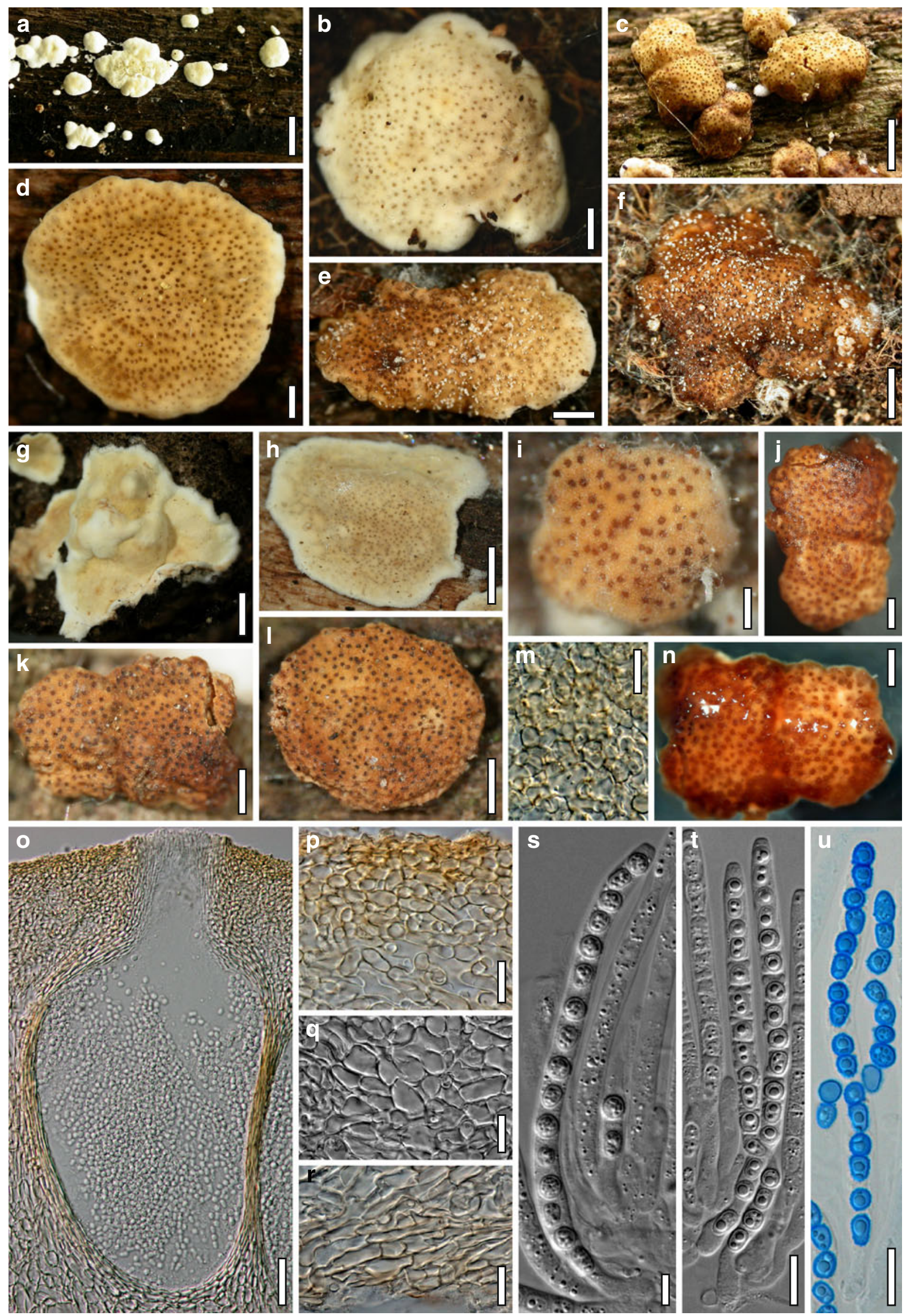

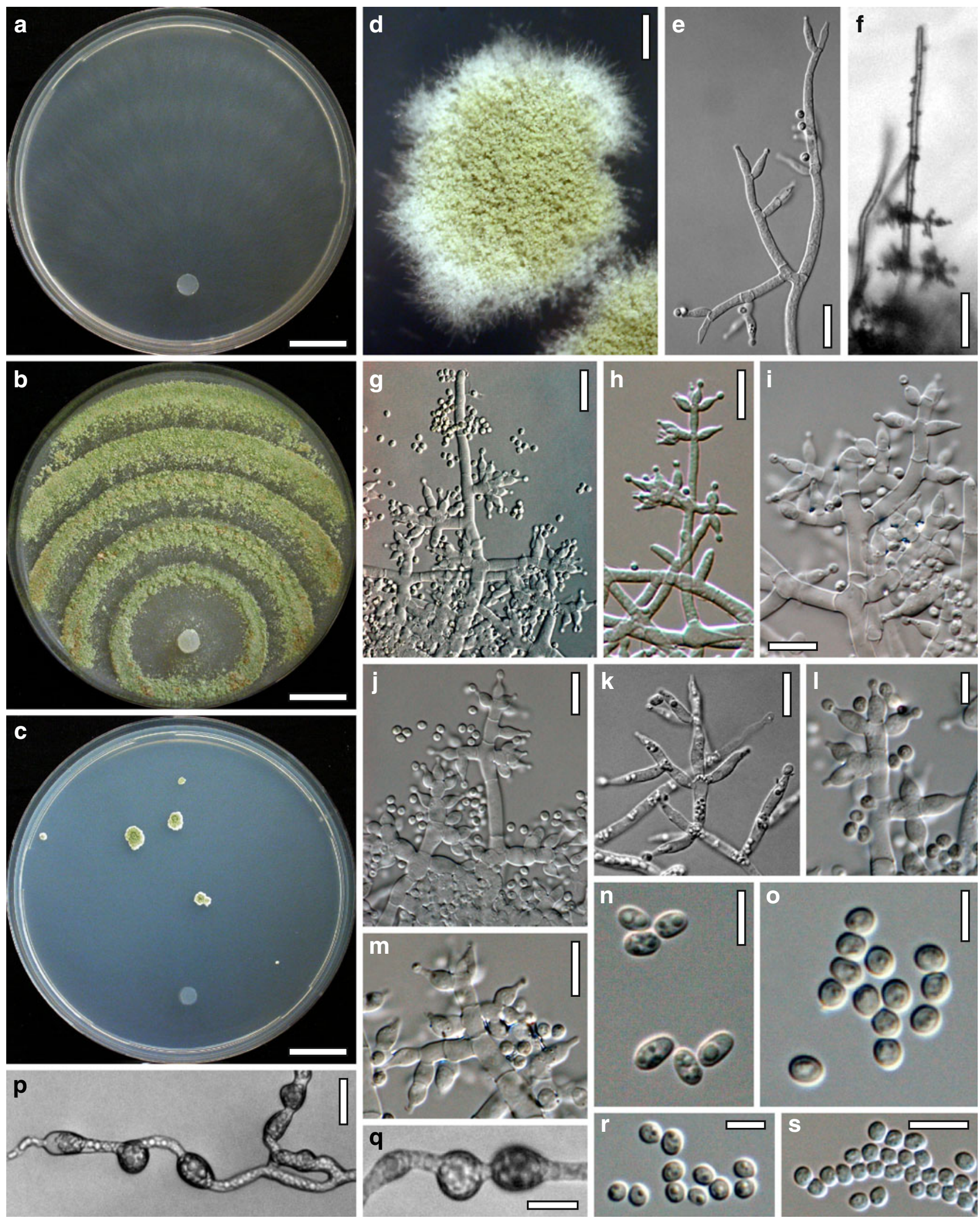
4Fig. 76 Cultures and anamorph of Hypocrea rodmanii. a-c. Cultures at $25^{\circ} \mathrm{C}$ (a. on CMD, 7 days. b. on PDA, 14 days. c. on SNA, 14 days). d. Conidiation pustule (SNA, $15^{\circ} \mathrm{C}, 21$ days). e. Conidiophore of effuse conidiation (SNA, 9 days). f. Conidiophore with sterile elongation on pustule margin on growth plate (SNA, 9 days). $\mathbf{g}-\mathbf{j}$. Conidiophores of pustulate conidiation $(\mathbf{g}, \mathbf{h}, \mathbf{j}$. SNA, 9 days; i. PDA, 7 days). k-m. Phialides (k. from effuse conidiation, CMD, 6 days; $\mathbf{l}$, m. SNA, 13 days). $\mathbf{n}, \mathbf{o}, \mathbf{r}, \mathbf{s}$. Conidia (n, r. from effuse conidiation; $\mathbf{n}$. CMD, 6 days; o. SNA, 13 days; r, s. SNA, 9 days). p, q. Chlamydospores (CMD, 16 days). a-s. All at $25^{\circ} \mathrm{C}$ except d. a-e, i, I, m, o-r. CBS 121553. k, n. C.P.K. 2871. f-h, j, s. C.P.K. 2852. Scale bars $\mathbf{a}-\mathbf{c}=15 \mathrm{~mm} . \mathbf{d}=0.5 \mathrm{~mm}$. e, $\mathbf{g}, \mathbf{h}, \mathbf{p}=15 \mu \mathrm{m} . \mathbf{f}=25 \mu \mathrm{m}$. $\mathbf{i}-\mathbf{k}$, $\mathbf{m}, \mathbf{q}, \mathbf{s}=10 \mu \mathrm{m} . \mathbf{l}, \mathbf{n}, \mathbf{o}, \mathbf{r}=5 \mu \mathrm{m}$

diffusing pigment, no distinct odour noted. Chlamydospores noted after 4-7 days, uncommon, terminal and intercalary, $(6-) 8-13(-16) \times(6-) 7-10(-11) \mu \mathrm{m}, 1 / \mathrm{w} 0.9-$ $1.5(-2)(n=30)$, globose, oblong, ellipsoidal or clavate. Conidiation at $25^{\circ} \mathrm{C}$ starting after 3-4 days, not becoming green within 2 weeks; effuse, on mostly short, simple conidiophores concentrated in the centre and in lighter concentric zones, longer in distal areas; sometimes also in minute loose shrubs formed on locally aggregated hyphae; some conidiation also submerged in the agar. Short simple conidiophores 1-2 celled, with phialides solitary or in a terminal whorl of 2-3; longer ones of a main axis with few unpaired side branches; side branches with short, 1-2 celled, unpaired or paired terminal branches. Shrubs broad, to ca $0.5 \mathrm{~mm}$ diam, consisting of a thick-walled stipe 6-8 $\mu \mathrm{m}$ wide, of one or few similar, straight or curved primary branches (=main axes), sometimes thickened to $8.5 \mu \mathrm{m}$, bearing unpaired side branches mostly 4$6 \mu \mathrm{m}$ wide and to $0.6 \mathrm{~mm}$ long, and terminal branches to $100 \mu \mathrm{m}$ long. All branches slightly inclined upwards, sometimes in right angles. Phialides originating on cells 2-4 $\mu \mathrm{m}$ wide, divergent in whorls of $2-3$ or to 6 in 'pseudowhorls', i.e. a phialide in a whorl replaced by a branch bearing a terminal whorl of phialides; phialides more rarely solitary. Phialides (from CMD and SNA) $(5-) 7-13(-16.5) \times(2.0-) 2.5-3.0(-3.8) \mu \mathrm{m}, 1 / \mathrm{w}(1.7-) 2.5-$ $4.9(-7.3),(1.5-) 1.8-2.5(-2.7) \mu \mathrm{m}$ wide at the base $(n=$ 71 ), lageniform or subulate, slender, not or only slightly thickened in the middle, straight or curved upwards. Conidial heads wet, $<30 \mu \mathrm{m}$ diam, greenish in the stereo-microscope. Conidia (from CMD and SNA) (2.3-) $2.7-3.5(-4.5) \times(2.0-) 2.2-2.7(-3.2) \mu \mathrm{m}, 1 / \mathrm{w}(1.0-) 1.1-1.4$ $(-1.8) \quad(n=110)$, subglobose or oval, less commonly ellipsoidal or oblong, hyaline to pale greenish, green in mass, smooth, with few minute guttules; scar indistinct. After $\mathrm{ca} 1$ week sometimes small green pustules with thick straight sterile elongations appearing in distal areas. At $30^{\circ} \mathrm{C}$ colony similar to $25^{\circ} \mathrm{C}$ with concentric zones slightly more distinctly separated; conidiation scant, effuse. At $35^{\circ} \mathrm{C}$ colony dense, circular, forming a dense white ring around the plug with scant effuse conidiation.
On PDA after $72 \mathrm{~h} 11-12 \mathrm{~mm}$ at $15^{\circ} \mathrm{C}, 29-31 \mathrm{~mm}$ at $25^{\circ} \mathrm{C}$, $28-30 \mathrm{~mm}$ at $30^{\circ} \mathrm{C}, 0-0.5 \mathrm{~mm}$ at $35^{\circ} \mathrm{C}$; mycelium covering the plate after 7 days at $25^{\circ} \mathrm{C}$. Colony circular, conspicuously dense, becoming zonate with broad, slightly downy zones and narrow, well-defined, convex, white farinose zones, the latter turning light to greyish green, 28-29CD4-6, 30CD4, 29B3, 28B3-5, from the centre, containing densely aggregated conidiation tufts or pustules, turning partly brown; some pustules also formed between concentric zones. Aerial hyphae numerous, mostly short, becoming fertile from the centre. Autolytic activity lacking or inconspicuous, no coilings seen. No diffusing pigment, no distinct odour noted. After storage for 1.5 years at $15^{\circ} \mathrm{C}$ white to yellowish sterile stromata to $5 \mathrm{~mm}$ long observed. Conidiation at $25^{\circ} \mathrm{C}$ starting after 2 days, green after 5 days, first simple, irregularly verticillium-like on short aerial hyphae concentrated in the centre and in denser zones, later abundant, pachybasium-like in pustules. Pustules 0.5-1.5 mm diam, densely aggregated to confluent in concentric rings, with short, straight, sterile elongations to ca $0.3 \mathrm{~mm}$ long. Elongations often becoming fertile. Resulting peripheral conidiophores numerous, projecting and giving the pustule surface a granular or plumose aspect, regularly tree-like, of a main axis with short, thick, 1-2(-3) celled side branches mostly 10-20 $\mu \mathrm{m}$ long near conidiophore ends, paired, unpaired or in whorls; typically in right angles. Main axis and side branches 3-6 $\mu \mathrm{m}$ wide, terminally $2.5-3 \mu \mathrm{m}$, with branching points often thickened to $7-10(-12) \mu \mathrm{m}$. Phialides arising on cells $2.5-4 \mu \mathrm{m}$ wide, solitary or in dense (pseudo-)whorls of 2-5(-6), lageniform or ampulliform, straight, mostly equilateral, neck often long, cylindrical. Wet minute conidial heads $<20 \mu \mathrm{m}$ diam soon becoming dry. Conidia subglobose or oval, hyaline to greenish, yellow-green in mass, smooth, with minute guttules; scar indistinct (see under SNA for measurements). At $15^{\circ} \mathrm{C}$ colony not or only indistinctly zonate, margin becoming irregularly dentate; conidiation in numerous large confluent tufts forming a continuum in the centre only tardily turning pale greenish. At $30^{\circ} \mathrm{C}$ concentric conidiation zones broad, in larger numbers than at $25^{\circ} \mathrm{C}$, turning only faintly green; conidial yield strongly reduced relative to $25^{\circ} \mathrm{C}$. At $35^{\circ} \mathrm{C}$ little slow growth; colony brownish.

On SNA after $72 \mathrm{~h} 6-10 \mathrm{~mm}$ at $15^{\circ} \mathrm{C}, 25-27 \mathrm{~mm}$ at $25^{\circ} \mathrm{C}, 23-25 \mathrm{~mm}$ at $30^{\circ} \mathrm{C}, 0-1 \mathrm{~mm}$ at $35^{\circ} \mathrm{C}$; mycelium covering the plate after $7-8$ days at $25^{\circ} \mathrm{C}$. Colony similar to CMD, but zonation considerably more indistinct and zones narrower; surface hyphae soon appearing empty. Large roundish to irregular pustules 0.5-2(-3.5) $\mathrm{mm}$ diam, confluent to $7 \mathrm{~mm}$ diam, with granular surface and often with white hairy margin, appearing irregularly distributed on the colony surface, turning green, 28CD4-6, 28-30E4-6. Aerial hyphae scant. Autolytic activity lacking or inconspicuous, no coilings seen. No diffusing pigment, no distinct odour 
noted. Chlamydospores noted after 4-7 days, rare. After storage for 1.5 years at $15^{\circ} \mathrm{C}$ small sterile stromata observed. At $15^{\circ} \mathrm{C}$ colony centre loose, margin dense; conidiation in the centre pachybasium-like in green, 2830CD4-6, pustules $2-4 \mathrm{~mm}$ diam, with rough, straight, sterile elongations to $0.5 \mathrm{~mm}$ long. At $30^{\circ} \mathrm{C}$ colony similar to $25^{\circ} \mathrm{C}$, indistinctly zonate; conidiation effuse, scant. At $35^{\circ} \mathrm{C}$ growth slow, colony circular, dense, finely zonate; hyphae forming pegs; conidiation effuse, scant. Conidiation at $25^{\circ} \mathrm{C}$ starting after 3-5 days, green after $c a 11$ days. Effuse conidiation scant, simple, minute, in narrower zones; substantially less than on CMD (for measurements see CMD). Conidiation in pustules pachybasium-like. Primary branching within pustule asymmetric, thick, often in right angles, with short intervals between secondary branches. Conidiophores numerous, fertile to the tip or terminating in short straight sterile elongations to $200(-300) \mu \mathrm{m}$ long, the latter appearing rough under lower magnifications, but smooth or with minute droplets on their surface in the microscope, often becoming fertile. Conidiophores often regularly treelike in peripheral position on the pustule, comprising a main axis with side branches progressively longer from the tip downwards. Side branches paired or unpaired, in right angles or slightly inclined upwards, short, ca 10$50 \mu \mathrm{m}$ long, 1-celled in terminal position, 1-4 celled on lower levels, giving rise to 1 -celled secondary side branches, all bearing dense whorls of phialides, i.e. forming dense structures. Main axes and side branches 4-6 $\mu \mathrm{m}$ wide, terminally $2.5-4 \mu \mathrm{m}$, with some globose thickenings to $7-10 \mu \mathrm{m}$. Phialides divergent in whorls of (2-)4-6 on cells $2.5-4.5 \mu \mathrm{m}$ wide, rarely solitary. Phialides (from SNA and PDA) (4.5-)5.0-8.0(-12.5) $\times$ $(2.5-) 2.8-3.5(-3.8) \mu \mathrm{m}, 1 / \mathrm{w}(1.3-) 1.5-2.6(-4.8),(1.3-)$ 2.0-2.8(-3.3) $\mu \mathrm{m}$ wide at the base $(n=97)$, lageniform or ampulliform, often with long, abruptly attenuated neck, straight, symmetric, widest in or below the middle. Conidial heads $<20 \mu \mathrm{m}$ diam, wet in shrubs, dry in pustules. Conidia (from SNA and PDA) (2.2-)2.5-3.0($3.5) \times(1.7-) 2.0-2.5(-2.8) \mu \mathrm{m}, 1 / \mathrm{w} 1.1-1.3(-1.5)(n=106)$, pale green, subglobose or oval, smooth, with few minute guttules; scar indistinct. Combined measurements from effuse and pustulate conidiation (CMD, PDA, SNA): phialides $(4.5-) 5.0-10.5(-16.5) \times(2.0-) 2.5-3.3(-3.8) \mu \mathrm{m}$, $1 / \mathrm{w}(1.3-) 1.5-4(-7.3),(1.3-) 1.8-2.5(-3.3) \mu \mathrm{m}$ wide at the base $(n=168)$. Conidia $(2.2-) 2.5-3.3(-4.5) \times(1.7-) 2.0-2.5$ $(-3.2) \mu \mathrm{m}, 1 / \mathrm{w}(1.0-) 1.1-1.4(-1.8)(n=216)$.

Habitat: on medium- to well-decayed wood, below peeling bark, less commonly on bark.

Distribution: Canada, Central Europe (Austria, Germany), USA (Maryland, Virginia).

Holotype: USA, Virginia, Giles County, Cascades Recreation Site, 4 mi N of Pembroke, along Little Stony
Creek, $37^{\circ} 02^{\prime} \mathrm{N}, 80^{\circ} 35^{\prime} \mathrm{W}$, elev. $838 \mathrm{~m}, 18$ Sep. 1991 , on branchlets, G.J. Samuels, C.T. Rogerson, S.M. Huhndorf, S. Rehner \& M. Williams (BPI 1112859, ex-type culture CBS 120895; not examined).

Specimens examined: Austria, Vienna, 22nd district, Lobau, at the Panozzalacke, MTB 7865/1, 48 ${ }^{\circ} 11^{\prime} 06^{\prime \prime} \mathrm{N}$, $16^{\circ} 29^{\prime} 20^{\prime \prime}$ E, elev. $150 \mathrm{~m}$, on branches of Populus alba, Ulmus campestris and Fraxinus excelsior, on little to welldecayed wood, partly on a brown ?Tomentella and Eutypa sp., soc. brown rhizomorphs and its pale green anamorph, 18 Nov. 2006, W. Jaklitsch W.J. 3039 (WU 29444, culture C.P. K. 2852). Canada, Québec, Ville de Québec, Arrondissement de Beauport, forest SW of the Lac du Délaissé, on twig of Fagus grandifolia $1 \mathrm{~cm}$ thick, on medium decayed wood, soc. effete pyrenomycetes, white to light green Trichoderma, pustulate on bark, effuse on wood, 29 Jul. 2006, H. Voglmayr W.J. 3060 (WU 29445, culture C.P.K. 2871). Germany, Sachsen-Anhalt, Landkreis Bernburg (Saale), Bernburg, Krumbholzallee, alluvial forest at the river Saale, MTB, $51^{\circ} 47^{\prime} 23^{\prime \prime} \mathrm{N}, 11^{\circ} 43^{\prime} 00^{\prime \prime}$ E, elev. $85 \mathrm{~m}$, on branches of Fraxinus excelsior 2-3 cm thick, on medium to welldecayed wood and Eutypa sp., partly also on bark, soc. effete cf. Lasiosphaeris hirsuta, Patellaria atrata, brown rhizomorphs, 22 Aug. 2006, H. Voglmayr \& W. Jaklitsch W. J. 2931 (WU 29443, culture CBS 121553=C.P.K. 2439).

Notes: Hypocrea rodmanii produces stromata that are generally less brightly pigmented and more pulvinate than $H$. auranteffusa and $H$. margaretensis when fresh; when dry they are thinly effuse. Among the species with effuse stromata, $H$. rodmanii forms the smallest ones. The dull yellow stroma colour may cause confusion with $H$. moravica or $H$. bavarica. 'Trichoderma rodmanii' differs from $T$. auranteffusum and T. margaretense by pustulate conidiation arranged in dense concentric rings on PDA. For comparison with Degenkolb et al. (2008a), who described the pustulate anamorph, I give measurements of phialides and conidia separately for effuse and pustulate conidiation. In the effuse conidiation phialides are more slender and distinctly lageniform, and conidia are produced in wet heads and are more variable in shape than in the pustulate conidiation. Sizes of phialides and conidia are similar in all species of the Brevicompactum clade treated here, but the species can be unequivocally identified by gene sequences.

Hypocrea lutea (Tode : Fr.) Petch, J. Bot. (Lond.) 75: 231 (1937). Fig. 77

$\equiv$ Sphaeria gelatinosa $\alpha$ lutea Tode, Fungi Mecklenb. 2: 48 (1791).

$\equiv$ Sphaeria gelatinosa b. lutea Tode : Fr., Syst. Mycol. 2 (2): 336 (1823).

Anamorph: Trichoderma deliquescens (Sopp) Jaklitsch, comb. nov. Fig. 78 
MycoBank MB 516684

$\equiv$ Gliocladium deliquescens Sopp, Monogr. Penicillium, p. 89, tab. 1, Fig. 15 (1912)

= Gliocladium viride Matr., Bull. Soc. Mycol. Fr. 9: 251 (1893)

Stromata when fresh $0.5-2.5 \mathrm{~mm}$, to $c a 1 \mathrm{~mm}$ thick, solitary, gregarious or aggregated in small numbers, or initially an effuse stroma breaking up into 2-4 partstromata; pulvinate or turbinate, broadly attached; outline typically angular or irregular; margin often lobed, attached or free; surface flat, smooth, or with some coarse tubercles. Perithecia entirely immersed, sometimes prominent at the margin. Ostiolar dots first appearing as large diffuse spots, becoming distinct, brown. Stromata first white, turning pale yellow, 1-4A2-5, greyish yellow or argillaceous, 4B5-6.

Stromata when dry $(0.3-) 0.6-1.5(-2.1) \times(0.2-) 0.5-1.2$ $(-1.9) \mathrm{mm},(0.15-) 0.2-0.3(-0.45) \mathrm{mm}$ thick $(n=75)$, flat pulvinate or discoid, sometimes with convex surface, broadly or narrowly attached; outline mostly isodiametric and angular; margin attached or free, often lobed, white or pale yellow, often lighter than the stroma centre when young; sides often vertical, often covered with white mycelium. Surface smooth, coarsely tubercular or rugose, glabrous or finely white-farinose or floccose, finely downy when young. Ostiolar dots (24-)40-80(-134) $\mu \mathrm{m}$ $(n=120)$ diam, plane or convex, diffuse or distinct, brown, often appearing as dark rings with hyaline centres. Stromata pale yellow, 4A2-4, 4B4-5, when immature, later pale to greyish orange, $5 \mathrm{AB} 4-5$, brown yellow or brown orange, 5AB5-6, 5-6CD6-8. Spore deposits white or yellow. Rehydrated stromata more pulvinate; surface smooth, more orange- to reddish brown due to darker dots; after addition of $3 \% \mathrm{KOH}$ turning orange red; ostioles convex, hyaline.

Stroma anatomy: Ostioles (60-)70-103(-125) $\mu \mathrm{m}$ long, projecting to $30(-70) \mu \mathrm{m}$, hyaline part (23-)33-52(-70) $\mu \mathrm{m}$ wide at the apex $(n=30)$, cylindrical, periphysate, more prominent at the stroma periphery; with broad clavate or subglobose cells to $7 \mu \mathrm{m}$ wide at their apical margins. Perithecia (164-)190-250(-275)×(107-)140-205(-230) $\mu \mathrm{m}(n=30)$, globose or flask-shaped; peridium (10-)12-18 $(-22) \mu \mathrm{m}(n=30)$ thick at the base, $(6-) 10-16(-18) \mu \mathrm{m}(n=$ $30)$ thick at the sides, pale yellow, in $3 \% \mathrm{KOH}$ rosy-orange at the sides. Cortical layer (14-)17-29(-37) $\mu \mathrm{m}(n=30)$ thick, of a few layers of a well-defined, coarse $t$. angularis of thin-walled cells (4-)6-16(-24)×(3-)5-10(-16) $\mu \mathrm{m}(n=$ 73 ) in face view and in vertical section; yellow, subhyaline at stroma sides; orange-red in 3\% KOH. Hairs on upper and lateral surface of mature stromata $(7-) 8-23(-37) \times(3.5-) 4-$ $7(-9) \mu \mathrm{m}(n=35)$, of $1-2(-4)$ cells, subhyaline or yellow, cylindrical, often with a globose basal cell, smooth or rough, sometimes moniliform or branched. Subcortical tissue a hyaline $t$. intricata of thin-walled hyphae (2-)3-6 $(-8) \mu \mathrm{m}(n=35)$ wide, appearing also as angular or globose cells $(2.5-) 4-9(-13) \times(2.5-) 3-6(-8) \mu \mathrm{m} \quad(n=30)$ due to varying cutting angles. Subperithecial tissue a hyaline $t$. epidermoidea-angularis of variable thin-walled cells (7-)9$24(-39) \times(5-) 7-14(-22) \mu \mathrm{m}(n=30)$. Stroma base similar to subperithecial tissue except for a narrow layer of subhyaline or yellowish, thin- or thick-walled hyphae (2-)3-6(-9) $\mu \mathrm{m}$ $(n=30)$ wide at attachment areas. Asci $(70-) 80-96(-106) \times$ (4.3-)4.5-5.5(-6.3) $\mu \mathrm{m}$, stipe (3-)8-16(-21) $\mu \mathrm{m}$ long $(n=$ $70)$, with two basal septa; often formed on sinuous ascogenous hyphae. Ascospores hyaline, sometimes yellow or orange when old, verruculose; cells dimorphic; distal cell $(3.2-) 3.8-4.5(-5.0) \times(3.0-) 3.2-3.6(-4.5) \mu \mathrm{m}, 1 / \mathrm{w}(0.8-)$ 1.1-1.3(-1.5) $(n=100)$, subglobose or ellipsoidal; proximal cell $(3.7-) 4.3-5.5(-6.5) \times(2.4-) 2.5-3.2(-5.0) \mu \mathrm{m}, 1 /$ $\mathrm{w}(0.7-) 1.5-2.0(-2.5)(n=100)$, wedge-shaped or oblong, less commonly subglobose.

Anamorph on the natural substrate: gliocladium-like conidiophores to $250 \mu \mathrm{m}$ long, with dry green heads 30 $100(-170) \mu \mathrm{m}$ diam, appearing on or around stromata.

Cultures and anamorph: optimal growth at $30^{\circ} \mathrm{C}$ on all media; good growth at $35^{\circ} \mathrm{C}$.

On CMD after $72 \mathrm{~h} 17-19 \mathrm{~mm}$ at $15^{\circ} \mathrm{C}, 51-58 \mathrm{~mm}$ at $25^{\circ} \mathrm{C}, 64-66 \mathrm{~mm}$ at $30^{\circ} \mathrm{C}, 48-53 \mathrm{~mm}$ at $35^{\circ} \mathrm{C}$; mycelium covering the plate after 4 days at $25^{\circ} \mathrm{C}$. Colony hyaline, thin; hyphae with conspicuous differences in width; mycelium mostly of primary hyphae, loose, forming radial strands; conspicuously wide (to $c a 15 \mu \mathrm{m}$ ) at the marginal surface. Aerial hyphae absent or scant. Autolytic excretions lacking or rare, no coilings seen. No diffusing pigment, no distinct odour noted. Agar of cultures stored for $\mathrm{ca} 3$ months at $15^{\circ} \mathrm{C}$ sometimes rosy. Chlamydospores noted after $1-$ 2 days at $25-35^{\circ} \mathrm{C}$, spreading from the centre across entire plate, numerous, globose, mostly terminal in narrow hyphae. Conidiation noted after $2(-3) \mathrm{d}$ at $25-35^{\circ} \mathrm{C}$, green after 3-4 days; effuse, first appearing mainly around the plug and along the margin as green to black dots $150 \mu \mathrm{m}$ diam, growing to $c a 0.5 \mathrm{~mm}$ diam, eventually arranged in indistinct concentric zones; zones becoming more distinct and regular with increasing temperature. Conidiophores (after 8 days) solitary or in fascicles of up to 10 to $0.6 \mathrm{~mm}$ wide in total; to $0.4 \mathrm{~mm}$ long including conidial head; originating from several hyphal fascicles (roots) and often surrounded by narrow hyphae on lower levels. Conidiophores consisting of a single erect, thick-walled stipe or main axis $7-13(-14) \mu \mathrm{m}$ wide at the base, attenuated to $7 \mu \mathrm{m}$ upwards and mostly to $120 \mu \mathrm{m}$ long to the first branching, smooth, appearing rough under low magnification due to guttules; repeatedly narrow branches growing out below septa, directed downwards, giving the impression of a synnema; bearing an apical penicillus of 3-4 levels of steeply ascending, nearly parallel unicellular branches 

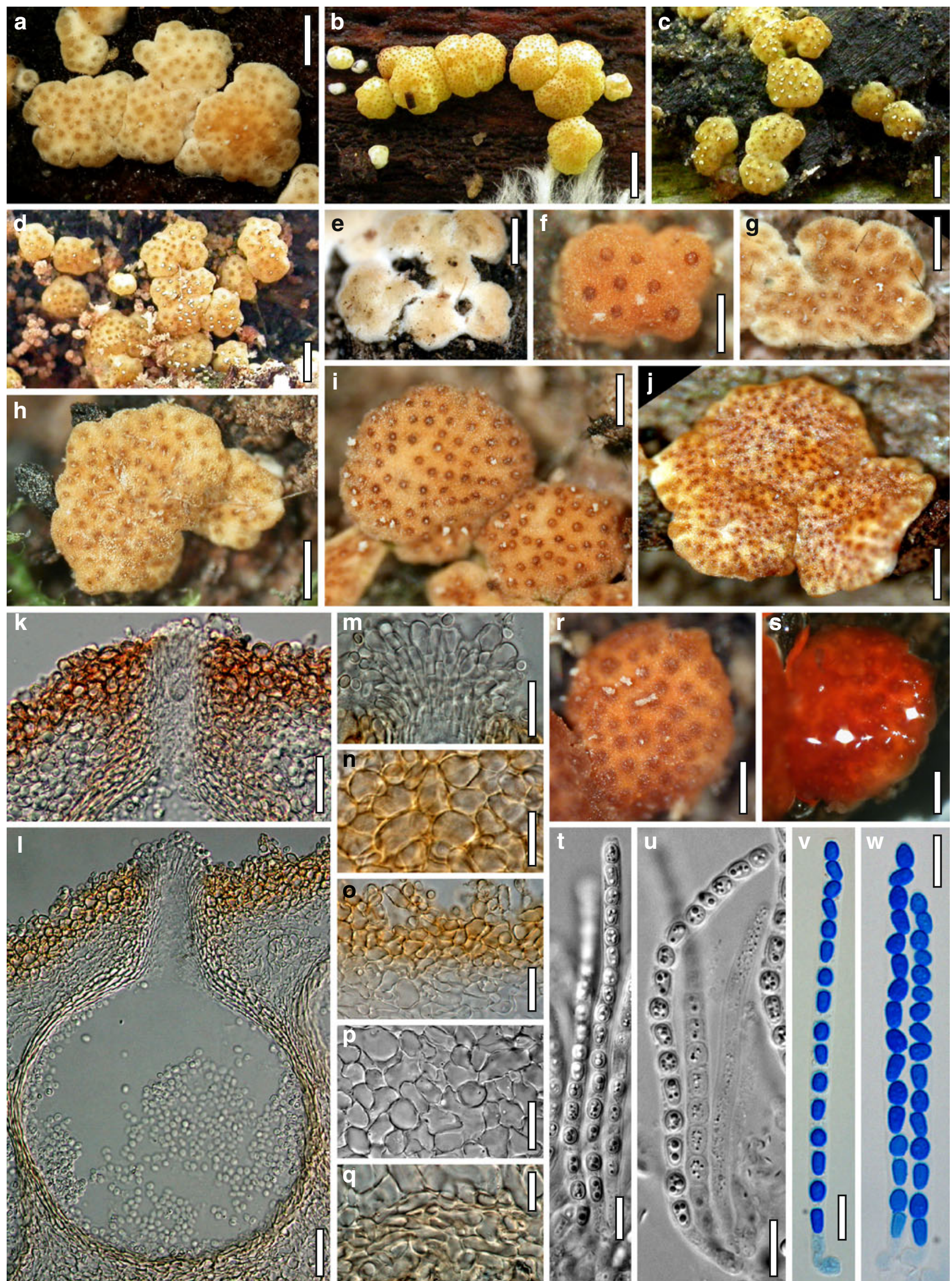

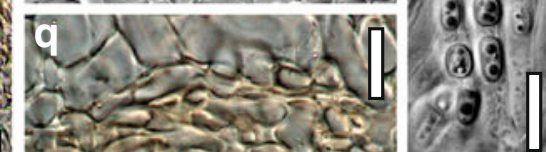
r.

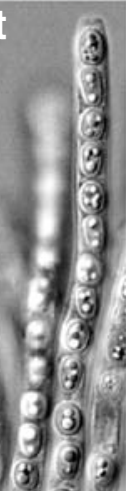
(3) (2) (8) 9 (2) (2)

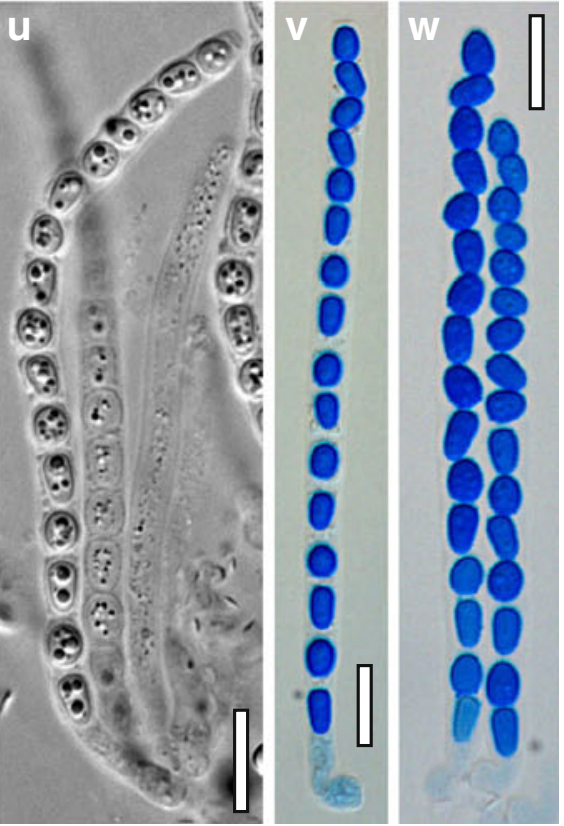


4 Fig. 77 Teleomorph of Hypocrea lutea. a-d. Fresh stromata. e-j. Dry stromata (e. stroma initials; h. showing farinose to floccose stroma surface). $\mathbf{k}$. Cortex and ostiole in $3 \% \mathrm{KOH}$ in section. $\mathbf{l}$. Perithecium in section. $\mathbf{m}$. Cells of ostiolar apex in side view. $\mathbf{n}$. Stroma surface in face view. o. Cortical and subcortical tissue in section with hairs on the surface. p. Subperithecial tissue in section. q. Base in section. $\mathbf{r}$. Rehydrated stroma. s. Stroma in 3\% KOH after rehydration. t-w. Asci with ascospores (v, w. in cotton blue/lactic acid). a, g, w. WU 29235. b, j. WU 29233. c-f, i, k-t, v. neotype WU 29232. h, u. WU 29234. Scale bars $\mathbf{a}, \mathbf{c}, \mathbf{d}=0.6 \mathrm{~mm}$. $\mathbf{b}=1 \mathrm{~mm}$. e, $\mathbf{g}, \mathbf{h}, \mathbf{j}=0.4 \mathrm{~mm} . \mathbf{f}=0.2 \mathrm{~mm}$. $\mathbf{i}$, $\mathbf{r}, \mathbf{s}=0.3 \mathrm{~mm} . \mathbf{k}, \mathbf{l}=30 \mu \mathrm{m} . \mathbf{m}-\mathbf{0}=15 \mu \mathrm{m} . \mathbf{p}=20 \mu \mathrm{m} . \mathbf{q}, \mathbf{t}-\mathbf{w}=10 \mu \mathrm{m}$

originating on a single level, re-branching into whorls of (1-)4-5(-6) similar branches. Penicilli without conidial masses in mounts mostly to $100 \mu \mathrm{m}$ long and $70-120 \mu \mathrm{m}$ wide at the apex. Branches attenuated from $6 \mu \mathrm{m}$ at the base to $2.5-3.5 \mu \mathrm{m}$ upwards. Phialides formed densely appressed and parallel in whorls of 2-6 on terminal branches (=metulae) $2.5-3.5 \mu \mathrm{m}$ wide. Phialides (6-)8-11 $(-12) \times(1.8-) 2.0-2.5(-3.0) \mu \mathrm{m}, 1 / \mathrm{w} \quad(2.3-) 3.4-5.1(-6.1)$, $(1.0-) 1.3-2.0(-3.0) \mu \mathrm{m}$ wide at the base $(n=60)$, lageniform, subulate or subcylindrical, inaequilateral and curved when lateral in the whorl, neck short, becoming green with age. Conidia produced in large masses in heads (30-)80200(-270) $\mu \mathrm{m}$ diam. Heads wet, mucous, shiny, appearing velutinous when dry, small and light green when young, growing and becoming opaque, dark green to black. Conidia (3.0-)3.2-3.8(-4.7) $\times(2.2-) 2.3-2.5(-2.7) \mu \mathrm{m}, 1 /$ w (1.2-)1.3-1.6(-2) ( $n=68)$, (yellow-)green, ellipsoidal or oblong, often attenuated towards the base, smooth, with few minute guttules, scar indistinct. At $35^{\circ} \mathrm{C}$ hyphae narrower than at lower temperatures; conidiation in distinct concentric zones of green to black dots. Conidiophores arising in bundles to $1 \mathrm{~mm}$ diam; conidia formed in heads to $0.4 \mathrm{~mm}$ diam.

On PDA after $72 \mathrm{~h} 15-16 \mathrm{~mm}$ at $15^{\circ} \mathrm{C}, 38-40 \mathrm{~mm}$ at $25^{\circ} \mathrm{C}$, $46-48 \mathrm{~mm}$ at $30^{\circ} \mathrm{C}, 38-41 \mathrm{~mm}$ at $35^{\circ} \mathrm{C}$; mycelium covering the plate after $6-7$ days at $25^{\circ} \mathrm{C}$. Colony first hyaline, dense, becoming concentrically zonate; zones and margin thick, convex, densely hairy to cottony; numerous red crystals to $c a$ $150 \mu \mathrm{m}$ diam appearing in the agar; green, 27D5-6, 27F7-8, later black dots appearing in the centre and in the concentric zones, confluent to spots $2.5 \mathrm{~mm}$ long. Aerial hyphae numerous, several $\mathrm{mm}$ high, forming strands. Autolytic excretions lacking or rare at lower temperatures, abundant at $35^{\circ} \mathrm{C}$, no coilings seen. Reverse exhibiting varying colours, olive, 1E5-6, yellowish, 3B4, and grey- to brown-red, $8 \mathrm{BC} 5-6$; conidiation zones on the reverse finally yellow- to orange-brown, 5CD5-6. No distinct odour noted. Conidiation noted after $1-2$ days at $25-35^{\circ} \mathrm{C}$, green after 2-3 days; appearing as numerous, mostly unbranched, short gliocladium-like 'brushes' around the plug; conidial heads to $c a 0.3 \mathrm{~mm}$ diam, wet or dry, green, confluent. Red crystals formed at all temperatures; gliocladium-like conidiophores spreading across entire plate at $15^{\circ} \mathrm{C}$. At $30^{\circ} \mathrm{C}$ conidiation in several concentric zones; zones flat; crystals dissolving in the agar with time. Conidiation abundant, green, 27EF7-8, conidial heads confluent early. Reverse brown-orange, 7C5-6, below concentric zones. At $35^{\circ} \mathrm{C}$ colony with fine farinose green zones. Conidiation abundant; conidial heads small. Autolytic excretions abundant, yellowish. Centre on the reverse yellowish, 1-3AB4-5.

On SNA after $72 \mathrm{~h} 15-16 \mathrm{~mm}$ at $15^{\circ} \mathrm{C}, 44-47 \mathrm{~mm}$ at $25^{\circ} \mathrm{C}$, $54-57 \mathrm{~mm}$ at $30^{\circ} \mathrm{C}, 32-36 \mathrm{~mm}$ at $35^{\circ} \mathrm{C}$; mycelium covering the plate after $4-5$ days at $25^{\circ} \mathrm{C}$. Colony as on CMD; but hyphae degenerating soon, appearing empty. Autolytic excretions lacking or rare at lower temperatures, abundant at $35^{\circ} \mathrm{C}$, coilings lacking or moderate. No diffusing pigment, no distinct odour noted. Chlamydospores noted after 1-2 days, abundant at all temperatures, distinctly more abundant than on CMD, mostly terminal, also intercalary, (4-)6-10(-12) $\times$ (3.5-)5-9(-12) $\mu \mathrm{m}, 1 / \mathrm{w}(0.9-) 1.0-1.2(-1.5)(n=70)$, (sub-) globose, less commonly ellipsoidal or fusoid, smooth. Conidiation noted after $2-3$ days at $25-35^{\circ} \mathrm{C}$, green after 3-4 days. Gliocladium-like conidiophores arising in bundles to $1 \mathrm{~mm}$ diam of up to 25 , basal branching or aggregations of conidiophores in bundles more pronounced than on CMD and more pronounced with increasing temperature; also concentric conidiation zones more distinct and regular with increasing temperature. Main axes of conidiophores appearing verrucose under low magnification due to small drops. Conidial heads to $0.4 \mathrm{~mm}$ diam, green to black, confluent.

Habitat: teleomorph on soft, crumbly wood of deciduous trees; also reported from leaves (Petch 1938); anamorph in soil, on diverse fungi and other substrates (see Domsch et al. 2007).

Distribution: Europe, North America, possibly cosmopolitan; teleomorph uncommon.

Typification: No original specimen exists, because Tode's specimens were destroyed in World War II. Holotype: illustration Tab. XVI, Fig. 123a-f in Tode (1791). Fries (1823, p. 336) sanctioned the name. No material seen by Fries could be located in UPS. Petch (1937) elevated the infraspecific taxon to species rank. The two specimens cited by him are scant and not particularly well representative of the species. Petch did not designate a type. Therefore the following epitype is here designated in order to define the correct relationship of teleomorph, anamorph and gene sequences: United Kingdom, Buckinghamshire, Slough, Burnham Beeches, $51^{\circ} 33^{\prime} 13^{\prime \prime} \mathrm{N}, 00^{\circ}$ $37^{\prime} 52^{\prime \prime} \mathrm{W}$, elev. $30 \mathrm{~m}$, on a wet cut log of Fagus sylvatica $27 \mathrm{~cm}$ thick, on well-decomposed, crumbly wood, soc. effete Eutypa spinosa, coelomycetes, hyphomycetes, rhizomorphs, waxy Corticiaceae; holomorph, 15 Sep. 2004, W. Jaklitsch W.J. 2715 (WU 29232, ex-epitype culture CBS $121131=$ C.P.K. 1942). The anamorph has apparently never been typified, therefore a neotype is proposed for Gliocladium deliquescens: isolated from WU 29232 and deposited as a dry 

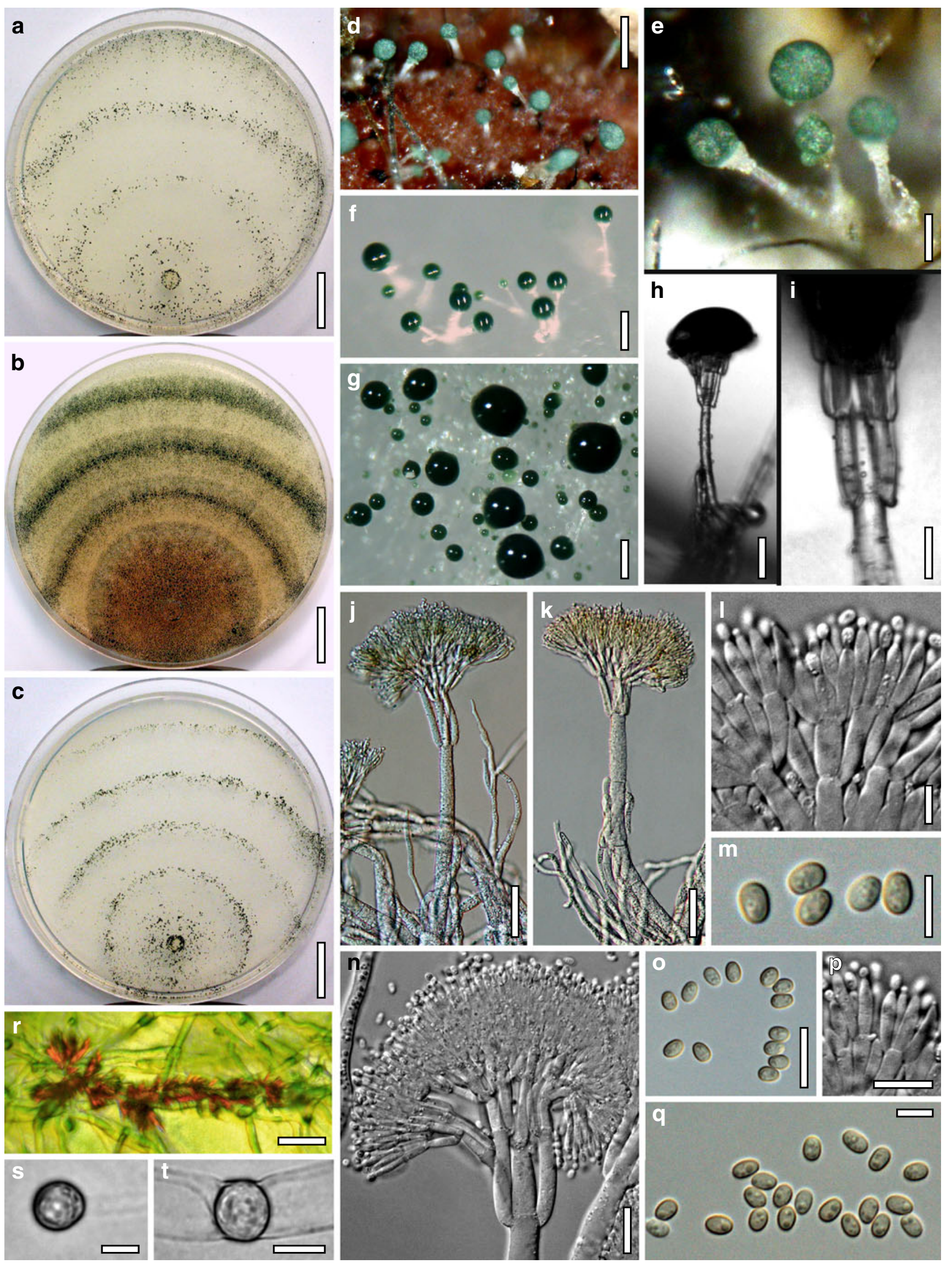
4 Fig. 78 Cultures and anamorph of Hypocrea lutea. a-c. Cultures after 7 days (a. on $\mathrm{CMD}, 35^{\circ} \mathrm{C}$; b. on PDA, $25^{\circ} \mathrm{C}$; c. on SNA, $35^{\circ} \mathrm{C}$ ). d, e. Conidiophores/conidial heads on the natural substrate. f, g. Conidiophores/conidial heads in culture. $\mathbf{h}$. Conidiophore on inoculation plug (SNA, 3 days). i. Part of conidiophore on growth plate showing basal architecture of apical penicillus (SNA, 16 days). j, k. Conidiophores. l, p. Phialides. m, o, q. Conidia. n. Apical penicillus of conidiophore. r. Crystals along a hypha submerged in agar (PDA, $15^{\circ} \mathrm{C}, 5$ days). s, t. Chlamydospores (SNA, 16 days; $\mathbf{s}$. terminal, t. intercalary). f-t. All at $25^{\circ} \mathrm{C}$ except $\mathbf{r}$. f, g, j-q. On CMD after 8 days. a-c, g-i, l-q, r-t. CBS 121131. d, e. WU 29235. f, j, k. CBS 121132. Scale bars $\mathbf{a}-\mathbf{c}=15 \mathrm{~mm}$. d, $\mathbf{f}, \mathbf{g}=150 \mu \mathrm{m}$. e, h, j, $\mathbf{k}, \mathbf{r}=40 \mu \mathrm{m} . \mathbf{i}, \mathbf{n}=$ $15 \mu \mathrm{m}$. $\mathbf{l}, \mathbf{m}, \mathbf{q}, \mathbf{s}=5 \mu \mathrm{m}$. $\mathbf{o}, \mathbf{p}, \mathbf{t}=10 \mu \mathrm{m}$

culture with the epitype of $H$. lutea as Trichoderma deliquescens WU 29232a.

Other specimens examined: Germany, NordrheinWestfalen, Detmold, Landkreis Lippe, Hiddesen, Teutoburger Wald, nahe Donoper Teich, MTB 4018/4, 51 '55'43" N, $08^{\circ} 48^{\prime} 17^{\prime \prime}$ E, elev. $150 \mathrm{~m}$, on partly decorticated branch of Fagus sylvatica $10 \mathrm{~cm}$ thick, on wood, soc. effete pyrenomycete, coelomycete, white Corticiaceae, Phlebiella vaga; largely immature, 19 Sep. 2004, W. Jaklitsch, W.J. 2730 (WU 29233, culture C.P.K. 1943). Sachsen-Anhalt, Landkreis Aschersleben-Staßfurt, Staßfurt, Horst, MTB 4135/1, 51 $51^{\prime} 24^{\prime \prime} \mathrm{N}, 11^{\circ} 33^{\prime} 40^{\prime \prime}$ E, elev. $70 \mathrm{~m}$, on decorticated branch of Fraxinus excelsior $6-8 \mathrm{~cm}$ thick, on black, crumbly wood, soc. moss, effete pyrenomycetes (Chaetosphaerella sp., Eutypa sp., Lasiosphaeria sp.), Mollisia sp. and few conidiophores of the anamorph, 22 Aug. 2006, W. Jaklitsch \& H. Voglmayr, W.J. 2932 (WU 29234, culture CBS 121132=C.P.K. 2440). United Kingdom, Buckinghamshire, Slough, Burnham Beeches, 51 $33^{\prime}$ $30^{\prime \prime} \mathrm{N}, 00^{\circ} 37^{\prime} 43^{\prime \prime} \mathrm{W}$, elev. $40 \mathrm{~m}$, on log of Fagus sylvatica $40 \mathrm{~cm}$ thick, on dark, moist, crumbly wood, soc. longnecked coelomycete, dark hyphomycete on a light mucous corticiaceous fungus and Eutypa spinosa in bark, holomorph, 15 Sep. 2007, W. Jaklitsch \& H. Voglmayr, W.J. 3164 (WU 29235, culture C.P.K. 3152).

Notes: The gliocladium-like anamorph is essential for morphology-based identifications of Hypocrea lutea. The teleomorph is characterised by small yellow stromata with angular outline, usually appearing in small numbers, but this is hardly sufficient for recognition, because several other species may produce similar stromata, e.g. $H$. luteocrystallina, $H$. moravica, $H$. pachypallida or $H$. parapilulifera. These species differ markedly in their anamorphs except $H$. luteocrystallina. The latter species is similar to $H$. lutea in both teleomorph and anamorph, but can be distinguished by yellow crystals on the mature stroma surface turning violet in $\mathrm{KOH}$, a conspicuous white young stage, subglobose conidia, slower growth, a growth optimum at $25^{\circ} \mathrm{C}$ and virtually no growth at $35^{\circ} \mathrm{C}$. The red pigment is produced by both species. According to G.J.
Samuels (pers. comm.), isolates of $H$. lutea are known that do not produce a reddish pigment. $H$. lutea typically occurs on the upper side of logs or branches or on standing branches, i.e. freely exposed to climatic elements. This correlates with its growth at $35^{\circ} \mathrm{C}$.

Species concept and history: Tode (1791) described Sphaeria gelatinos $a$ with the two varieties $\alpha$. lutea and $\beta$. viridis. Petch (1937) summarised the history of the two varieties and the interpretations of Tode's (1791) protologues by various mycologists. The notion whether the stromata were gelatinous or not varied among authors, and S. gelatinosa was regarded as having hyaline ascospores until Saccardo (1883a) described it with green ascospores. Petch (1937) determined that Tode meant two different species, i.e. Sphaeria gelatinosa f. viridis representing the green-spored Hypocrea gelatinosa and a hyaline-spored Sphaeria gelatinosa f. lutea Tode, which he elevated to species rank as Hypocrea lutea. He based this latter species on yellow stromata collected by F. Currey in 1856 and Hawley in 1905 on leaves. An anamorph was never included in the description of $H$. lutea. Also Petch's scant material is not particularly informative due to the lack of conidiophores. Doi (1966) observed a gliocladium-like anamorph in ascospore-derived cultures of Hypocrea lutea, and later (Doi in Samuels et al. 1990) he named it Gliocladium cf. deliquescens. The connections $H$. lutea/G. viride $(=G$. deliquescens) was accepted by Chaverri and Samuels (2003), Domsch et al. (2007) and Samuels (2006) and is also accepted here.

The anamorph name: Matruchot (1893) described Gliocladium viride Matr. from a Stereum $\mathrm{sp}$. with conidia 3-6× 2-3 $\mu \mathrm{m}$. Sopp (1912) described Gliocladium deliquescens from Cerrena unicolor with conidia $1.5-2 \times 1 \mu \mathrm{m}$ on top of phialides during their formation, noting that 'later the conidia become more roundish and larger, but not much'. Morquer et al. (1963) kept the two species separate, stating nearly identical conidial sizes for them, but obviously these authors studied a generically heterogeneous assemblage of species, because $G$. deliquescens and other species were characterised by catenate conidiation. Matsushima (1975, 1989), Domsch et al. (2007) and the MycoBank database (CBS; under $G$. deliquescens) treat $G$. deliquescens as a synonym of $G$. viride, although without explanations. If it is assumed that the wide variation of conidial size given by Matruchot (1893) is due to nonstandardised culture conditions, including aberrant extremes, and that the size given by Sopp (1912) is based on immature conidia, then the synonymy makes sense. The fact that type material is neither available for $G$. viride (J. Mouchacca, pers. comm.) nor for G. deliquescens (W. Gams, pers. comm.) makes a verification impossible. The description by Gilman and Abbott (1927; also cited by Gilman 1957, Thom 1930, Subramanian 1971) of $G$. 
deliquescens is morphologically in accordance with the anamorph of $H$. lutea. Assuming conspecificity of $G$. deliquescens and G. viride, the latter would have priority for the combination of the anamorph taxon in Trichoderma, but is unavailable because of the resulting homonymy with $T$. viride Pers. Therefore $G$. deliquescens becomes the valid name to be combined in Trichoderma as the anamorph of $H$. lutea.

Morphologically $T$. deliquescens is an extreme form or final stage in a development from dendritic Trichoderma conidiophores with divergent phialides to a virtually unbranched conidiophore with more or less parallel phialides, i.e. mononematous, penicillate conidiophore, and in addition with conidia wrapped in a mucous exudate. This latter trait is absent in other species of Trichoderma except for T. luteocrystallinum. Considerably more distinctly branched conidiophores with a gliocladium-like arrangement of phialides and green conidia are found in several other species of Trichoderma, e.g. T. gelatinosum. Similar conidiophores but with hyaline conidia occur in the Psychrophila clade.

Hypocrea luteocrystallina Jaklitsch, Siepe \& L.G. Krieglst., sp. nov. Fig. 79

MycoBank MB 516687

Anamorph: Trichoderma luteocrystallinum Jaklitsch, sp. nov. Fig. 80

MycoBank MB 516688

Stromata in ligno arborum coniferarum, solitaria vel gregaria vel dense aggregata, $0.3-2.2 \times 0.2-1.6 \mathrm{~mm}$, pulvinata, alba vel lutea ad brunnea, ostiolis brunneis, superficie saepe flavis crystallis obtecta. Asci cylindrici, (58-)67-82($91) \times(4.0-) 4.2-5.0(-5.5) \mu \mathrm{m}$. Ascosporae bicellulares, verruculosae, hyalinae, ad septum disarticulatae, pars distalis subglobosa vel ellipsoidea, (3.0-)3.4-3.8(-4.0)×(2.5-)2.93.2(-3.3) $\mu \mathrm{m}$, pars proxima oblonga, cuneata vel ellipsoidea, $(3.3-) 3.7-4.7(-6.0) \times(2.0-) 2.3-2.7(-3.0) \mu \mathrm{m}$. Anamorphosis Trichoderma luteocrystallinum. Conidiophora similia Gliocladii. Phialides lageniformes, $(5-) 7-10(-13) \times(2.0-) 2.2-2.8$ $(-3.4) \mu \mathrm{m}$. Conidia viridia, subglobosa, glabra, (2.5-)2.7$3.3(-3.6) \times(2.2-) 2.5-2.8(-3.1) \mu \mathrm{m}$ in agaro SNA.

Etymology: referring to the yellow crystals formed on mature stromata.

Stromata not seen in fresh condition. Stromata when dry $(0.3-) 0.5-1.4(-2.2) \times(0.2-) 0.4-1.0(-1.6) \mathrm{mm},(0.15-) 0.2-$ $0.4(-0.8) \mathrm{mm}$ thick $(n=45)$, solitary, gregarious or aggregated in large numbers; effluent, large subeffuse complexes disintegrating into individual stromata; (flat) pulvinate, broadly attached; with white basal mycelium when young. Outline circular, angular or irregular. Margin rounded, edge free; sides often vertical and concolorous with the surface. Surface smooth, or tubercular by convex dots or projecting perithecia, slightly downy or powdery due to minute sulphur-yellow crystals, mostly on brown spots; crystals less common on light-coloured young, immature stromata; rarely covered by white scurf. Ostiolar dots (30-)40-90(157) $\mu \mathrm{m}(n=60)$ diam, conspicuous, diffuse when young, becoming distinct, well-defined, plane or convex, circular, ochre or brown, sometimes black when old. Stromata white to pale yellowish, 1-4A2-A3, when young, turning greyish yellow, 3-4B3, pale or grey-orange, 5A3-4, 5B4, yellowbrown, or light brown, 5-6CD4-6, when mature; finally entirely brown when old and crystals disappear. Spore deposits white. Stroma surface after rehydration smooth, nearly white, the convex ochre to brown ostiolar dots with hyaline centres; turning light brown or ochre with darker ostiolar rings after addition of $3 \% \mathrm{KOH}$.

Stroma anatomy: Ostioles (49-)61-87(-98) $\mu \mathrm{m}$ long, plane or projecting to $12 \mu \mathrm{m},(28-) 34-61(-90) \mu \mathrm{m}$ wide at the apex $(n=30)$, conical, periphysate, with thick walls orange in $\mathrm{KOH}$ in the upper part; margin lined by hyaline cylindrical to clavate cells $2-6(-8) \mu \mathrm{m}$ wide at the apex. Perithecia (140-)180-240(-275)×(95-)115-205(-280) $\mu \mathrm{m}$ $(n=30)$, flask-shaped, crowded, 5-6 per mm stroma length; peridium $(11-) 13-20(-23) \mu \mathrm{m}(n=30)$ thick at the base, $(8-) 10-16(-20) \mu \mathrm{m}(n=30)$ thick at the sides, yellowish. Cortical layer (15-)20-30(-36) $\mu \mathrm{m}(n=30)$ thick, a pale yellow $t$. angularis of thin-walled cells (4-)6-12(-18) $\times$ $(2.5-) 4-8(-12) \mu \mathrm{m}(n=100)$ in face view and in vertical section. Surface with undifferentiated hyphae when young, rarely with some projecting cells to $26 \times 4-7 \mu \mathrm{m}$ when mature. Crystals on the stroma surface without a distinct structure, golden-yellow in water, dissolving and turning violet in $3 \% \mathrm{KOH}$; becoming dissolved as oily drops in lactic acid. Subcortical tissue a hyaline $t$. angularis of thinwalled cells $(4-) 5-10(-14) \times(2.5-) 3-6(-7) \mu \mathrm{m}(n=30)$, interspersed with hyphae $(2-) 3-5(-7) \mu \mathrm{m}(n=30)$ wide. Subperithecial tissue a hyaline $t$. angularis-epidermoidea of variable, thin-walled cells $(5-) 10-24(-33) \times(5-) 7-15(-$ 21) $\mu \mathrm{m}(n=60)$. Base not differentiated or limited by a narrow layer of thick-walled compressed hyaline hyphae $(1.5-) 2.5-5(-7) \mu \mathrm{m}(n=60)$ wide facing the substrate. Asci $(58-) 67-82(-91) \times(4.0-) 4.2-5.0(-5.5) \mu \mathrm{m}$, stipe $(0-) 3-12$ $(-20) \mu \mathrm{m}$ long $(n=50)$. Ascospores hyaline, finely verruculose with verrucae to $0.4 \mu \mathrm{m}$ high; cells dimorphic; distal

Fig. 79 Teleomorph of Hypocrea luteocrystallina. $\mathbf{a}-\mathbf{h}$. Dry stromata (a-c. immature. e, f. showing yellow crystals on stroma surface. d, e, g. showing white spore deposits). i. Rehydrated stroma. j. Stroma in $3 \% \mathrm{KOH}$ after rehydration. k. Ostiolar apex in 3\% $\mathrm{KOH}$. I. Stroma surface in face view. $\mathbf{m}$. Yellow crystals from stroma surface in water. n. Crystals from stroma surface in $3 \% \mathrm{KOH}$. o. Perithecium in section. p. Cortical and subcortical tissue in section. q. Subperithecial tissue in section. $\mathbf{r}-\mathbf{u}$. Asci with ascospores (t, $\mathbf{u}$. in cotton blue/lactic acid). a, h, s-u. L.K. 53/2008. b, d, e, g, i-r. WU 29237. c, f.L.K. 26/2007. Scale bars $\mathbf{a}-\mathbf{c}=0.5 \mathrm{~mm}$. d, $\mathbf{h}, \mathbf{j}=0.4 \mathrm{~mm}$. $\mathbf{e}=100 \mu \mathrm{m}$. f, $\mathbf{g}, \mathbf{i}=0.2 \mathrm{~mm}$. $\mathbf{k}, \mathbf{I}=15 \mu \mathrm{m}$. m, $\mathbf{n}, \mathbf{p}, \mathbf{r}-\mathbf{u}=10 \mu \mathrm{m} . \mathbf{o}=35 \mu \mathrm{m} . \mathbf{q}=20 \mu \mathrm{m}$ 

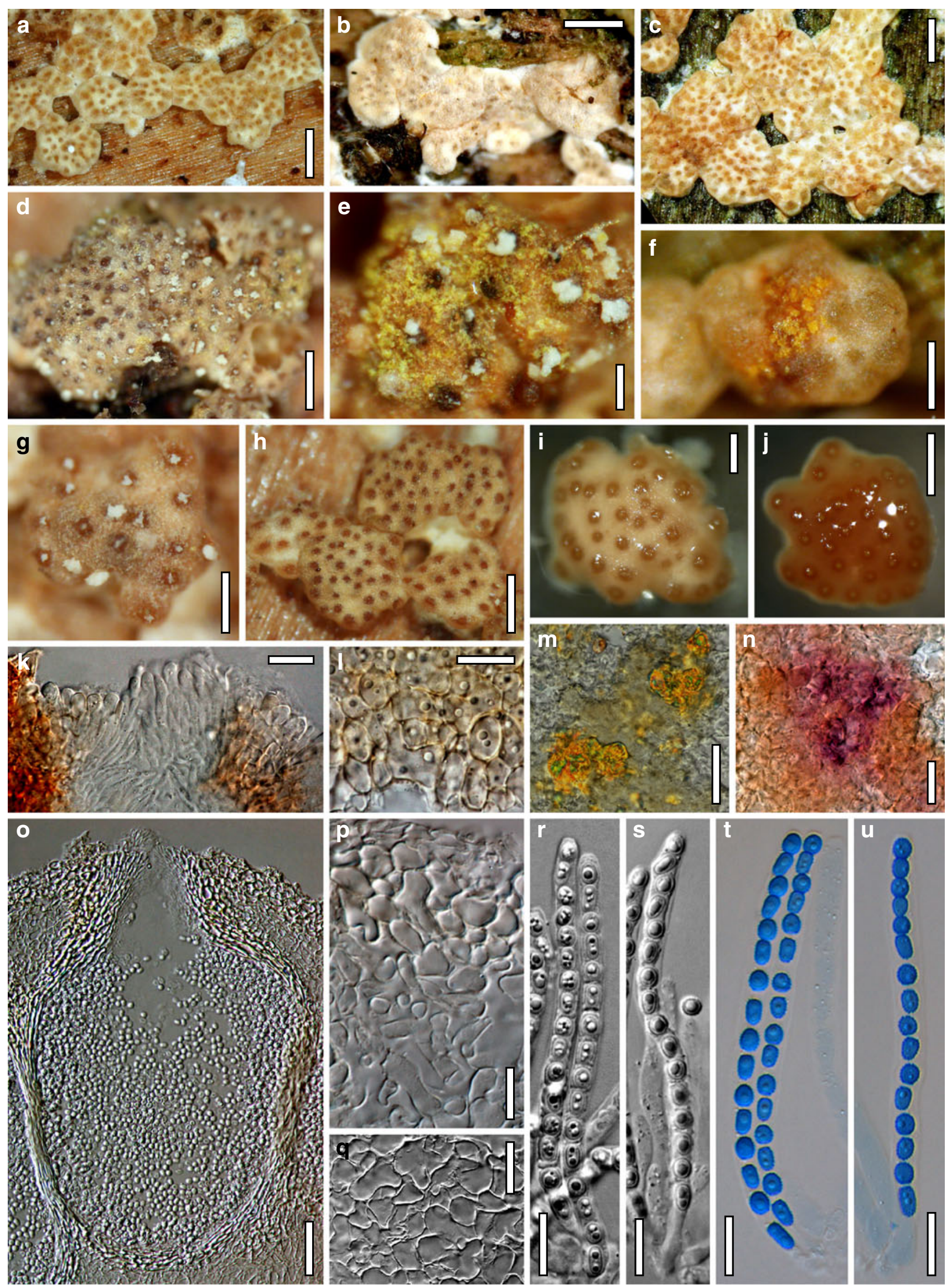

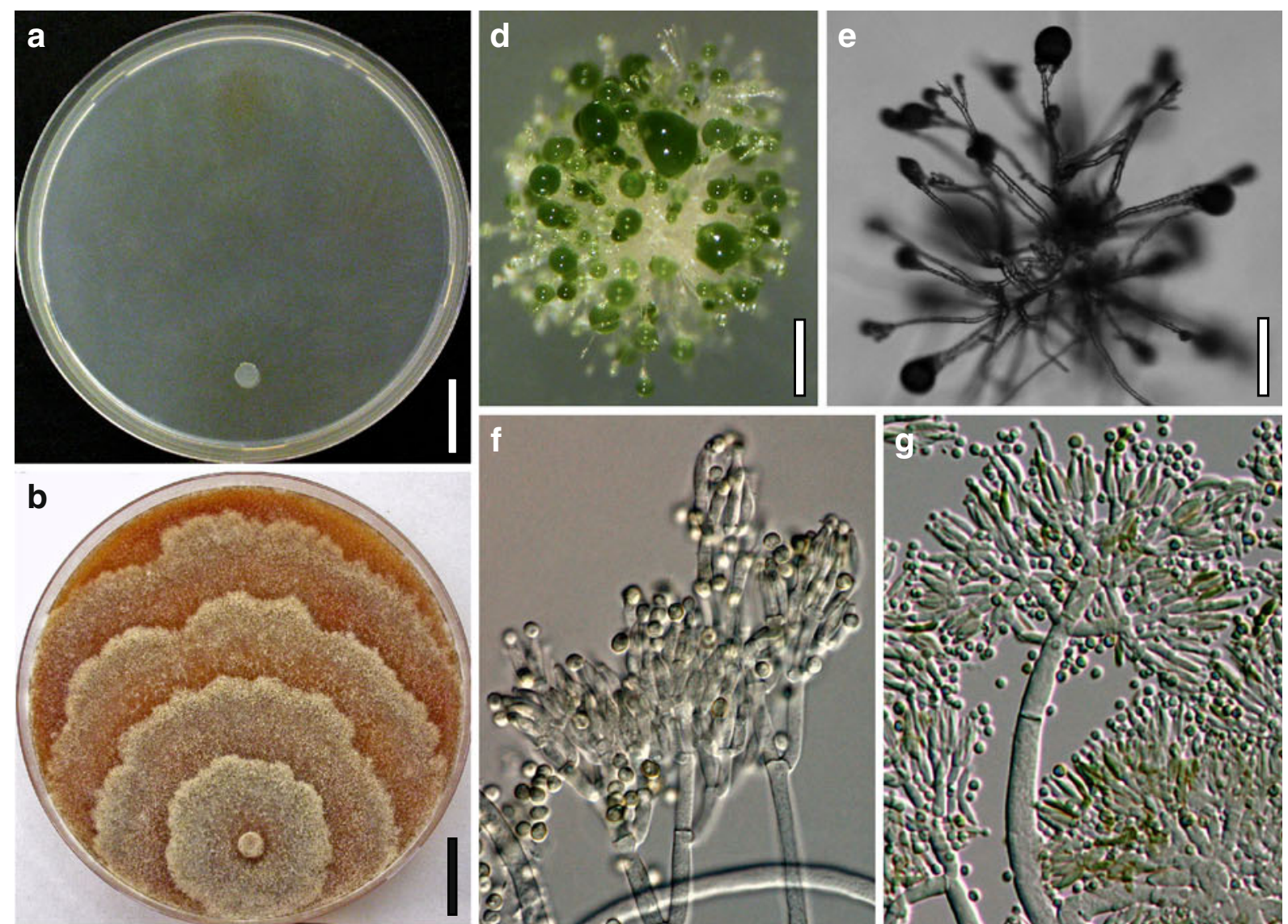

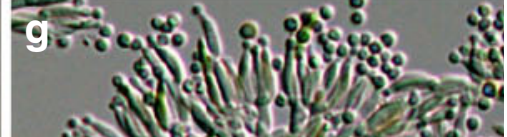
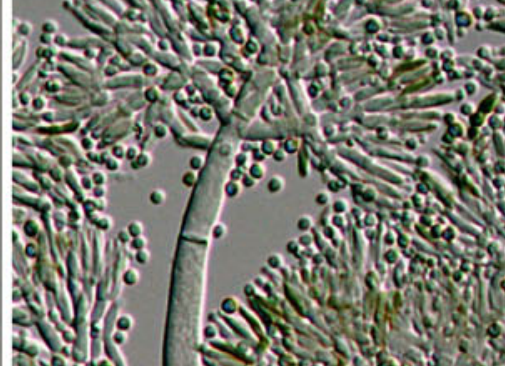
मite 1 -
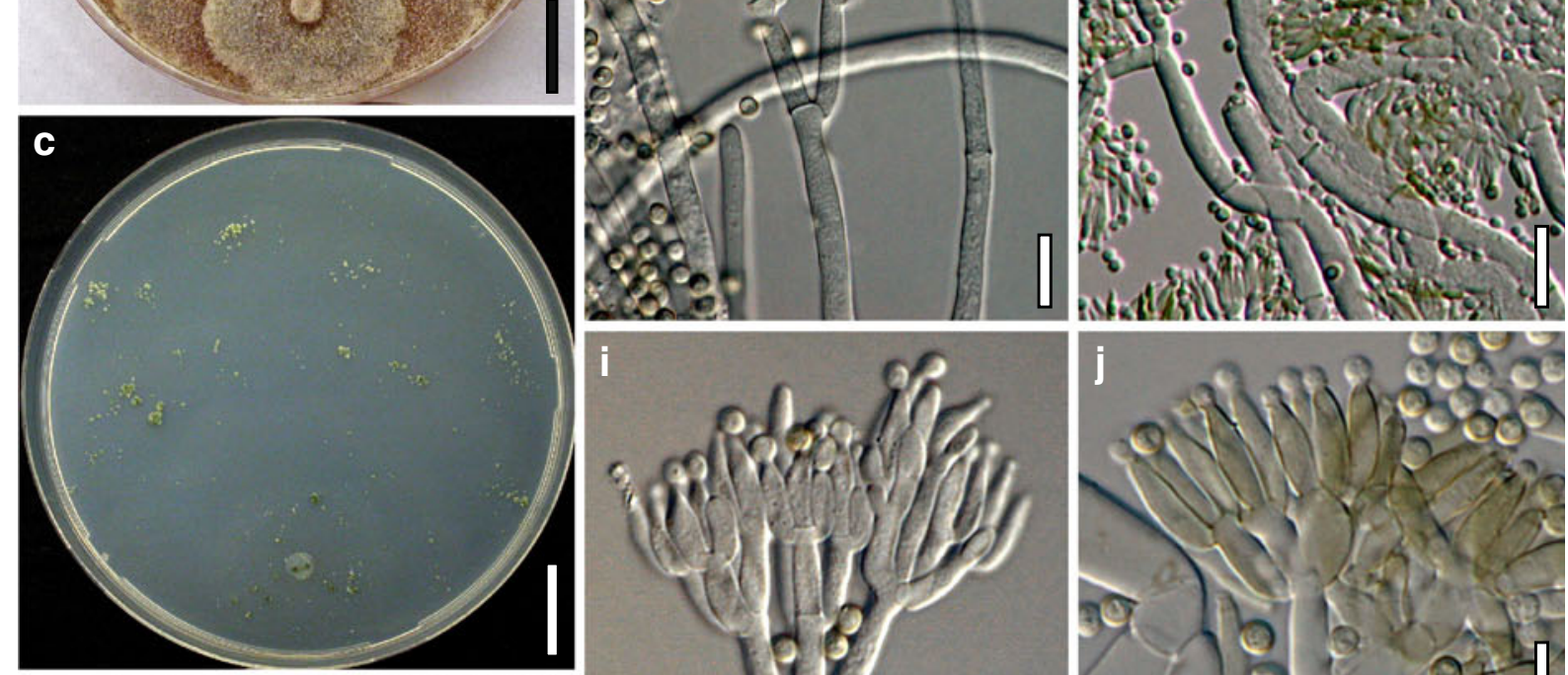

i
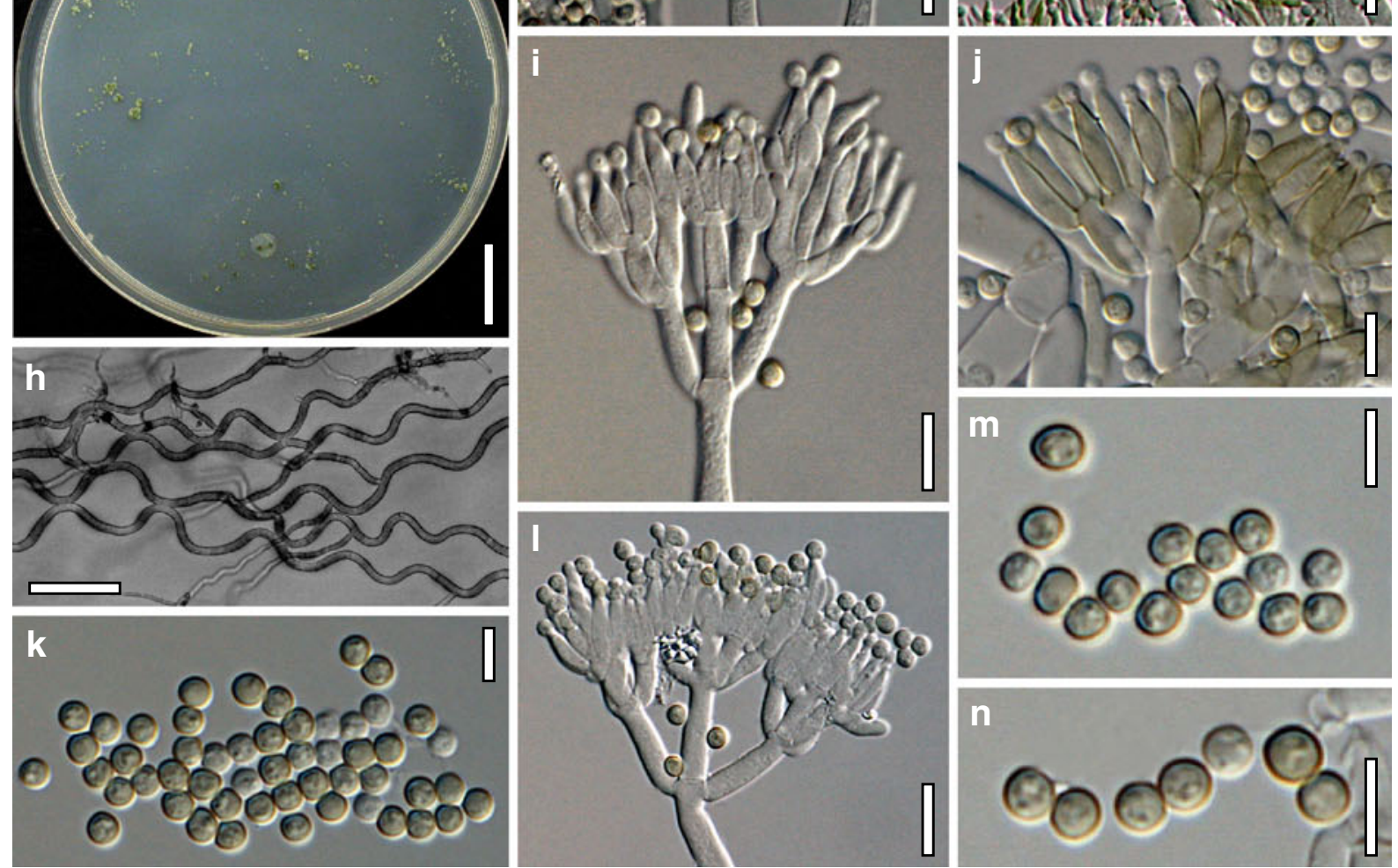
4 Fig. 80 Cultures and anamorph of Hypocrea luteocrystallina (CBS 123828). a-c. Cultures at $30^{\circ} \mathrm{C}$ after 21 days (a. on CMD; b. on PDA; c. on SNA). d. Conidiation pustule on growth plate in face view $\left(30^{\circ}\right.$ C, 12 days). e. Architecture of young pustule $\left(30^{\circ} \mathrm{C}, 21\right.$ days $) . \mathbf{f}, \mathbf{g}$. Conidiophores (f. $30^{\circ} \mathrm{C}, 12$ days, g. $25^{\circ} \mathrm{C}, 19$ days). h. Sinuous hyphae (CMD, $25^{\circ} \mathrm{C}, 12$ days). i, l. Apical parts (penicilli) of conidiophores $\left(30^{\circ} \mathrm{C}, 15\right.$ days $)$. j. Phialides $\left(25^{\circ} \mathrm{C}, 19\right.$ days $) . \mathbf{k}, \mathbf{m}$, n. Conidia $\left(25^{\circ} \mathrm{C}, 19\right.$ days $)$. d-g, i-n. On SNA. Scale bars $\mathbf{a}-\mathbf{c}=$ $15 \mathrm{~mm} . \mathbf{d}=0.2 \mathrm{~mm}$. e, $\mathbf{h}=0.1 \mathrm{~mm} . \mathbf{f}, \mathbf{i}, \mathbf{l}=10 \mu \mathrm{m} . \mathbf{g}=15 \mu \mathrm{m} . \mathbf{j}, \mathbf{k}, \mathbf{m}$, $\mathbf{n}=5 \mu \mathrm{m}$

cell $(3.0-) 3.4-3.8(-4.0) \times(2.5-) 2.9-3.2(-3.3) \mu \mathrm{m}, \mathrm{l} /$ $\mathrm{W}(1.0-) 1.1-1.3(n=60)$, subglobose or ellipsoidal; proximal cell $(3.3-) 3.7-4.7(-6.0) \times(2.0-) 2.3-2.7(-3.0) \mu \mathrm{m}, \mathrm{l} /$ $\mathrm{w}(1.2-) 1.4-2.0(-2.5) \quad(n=60)$, oblong, wedge-shaped or ellipsoidal.

Cultures and anamorph: optimal growth at $25^{\circ} \mathrm{C}$ on all media; no growth at $35^{\circ} \mathrm{C}$ after hyphae reaching a radius of less than $1 \mathrm{~mm}$ on all media.

On CMD after $72 \mathrm{~h} 17-21 \mathrm{~mm}$ at $15^{\circ} \mathrm{C}, 39-42 \mathrm{~mm}$ at $25^{\circ} \mathrm{C}, 21-28 \mathrm{~mm}$ at $30^{\circ} \mathrm{C}$; mycelium covering the plate after 6 days at $25^{\circ} \mathrm{C}$. Colony circular, hyaline, thin, dense, homogeneous, not zonate; mycelium with radial arrangement; hyphae with conspicuous difference in width, primary surface hyphae to $c a 10 \mu \mathrm{m}$ wide, secondary hyphae thin and scant. Aerial hyphae lacking. Autolytic excretions and coilings rare. No diffusing pigment, no distinct odour noted. Chlamydospores rare, minute. Conidiation noted after 2-7 days, gliocladium-like with wet heads to $100 \mu \mathrm{m}$ diam; scant, mostly around the plug and at the distal margin when the mycelium has covered the entire plate. At $30^{\circ} \mathrm{C}$ colony developing yellowish $4 \mathrm{~A} 2-3$ spots; conidiation scant, mostly on unbranched gliocladium-like conidiophores; coilings frequent at the distal margin.

On PDA after $72 \mathrm{~h} 10-12 \mathrm{~mm}$ at $15^{\circ} \mathrm{C}, 30-32 \mathrm{~mm}$ at $25^{\circ}$ C, $21-26 \mathrm{~mm}$ at $30^{\circ} \mathrm{C}$; mycelium covering the plate after 8 9 days at $25^{\circ} \mathrm{C}$. Colony circular, dense; surface hyphae sinuous, primary hyphae thick; central surface becoming mottled, hyphae becoming pigmented, forming dull orange spots. Aerial hyphae infrequent, richly branched in a hairy reticulum of short strands, intermingled with numerous widely branched microtufts, forming several concentric zones with wavy outline, with whitish grey, hairy to floccose surface on orange-brown background; finally collapsing, containing numerous drops. Autolytic activity moderate, excretions minute; coilings inconspicuous. Reverse from the centre dull reddish orange, orange-brown, 68CD6-8, 8EF6-8, to reddish-brown, 7E6-8. No distinct odour noted. Conidiation noted after 2-3 days, on several thick mononematous conidiophores with a gliocladium-like apical penicillus arising from common bases forming micropustules to $0.6 \mathrm{~mm}$ diam, superposed by aerial hyphae. Conidia formed in small numbers in wet or dry heads, remaining colourless; only few heads appearing greenish in the stereo-microscope. Poor conidial yield also noted at other temperatures. Phialides more divergent than on CMD and SNA.

On SNA after $72 \mathrm{~h} 11-14 \mathrm{~mm}$ at $15^{\circ} \mathrm{C}, 25-28 \mathrm{~mm}$ at $25^{\circ} \mathrm{C}$, $16-17 \mathrm{~mm}$ at $30^{\circ} \mathrm{C}$; mycelium covering the plate after 10 11 days at $25^{\circ} \mathrm{C}$. Colony hyaline, thin, circular, dense, not zonate; mycelium radial, scarce on the agar surface; margin wavy. Aerial hyphae scant or lacking. Autolytic excretions and coilings lacking. No diffusing pigment, no distinct odour noted. Chlamydospores noted after $1-3$ weeks, infrequent and inconspicuous, mostly terminal, (5-)6-10(-12) $\times(5-) 6-9(-$ 10) $\mu \mathrm{m}, 1 / \mathrm{w} 1.0-1.7(n=30)$, globose or pyriform. Conidiation at $25^{\circ} \mathrm{C}$ noted after 8-9 days, green to black after 2 weeks; first appearing as solitary, simple, mononematous gliocladium-like brushes; later pustules appearing mainly on the distal margin or irregularly distributed, white, becoming dark green to black. Pustules growing to $1 \mathrm{~mm}$ diam, with conidia formed abundantly in wet heads to $c a 250 \mu \mathrm{m}$ diam, growing and confluent to $600 \mu \mathrm{m}$ diam, green, turning black; small and light green when dry. At $15^{\circ} \mathrm{C}$ similar, development slower, conidiation in small pustules. Conidiation positively correlated with the temperature, most abundant at $30^{\circ} \mathrm{C}$. At $30^{\circ} \mathrm{C}$ conidiation in green, mostly 2-3E4-6, pustules loosely distributed in several ill-defined concentric zones or irregularly distributed. Pustules to $1(-1.5) \mathrm{mm}$ diam, confluent to $2.5 \mathrm{~mm}$ long, with numerous, radially arranged, straight gliocladium-like conidiophores and wet conidial heads 80-250 $\mu \mathrm{m}$ diam; with high conidial yield. Development and maturation asynchronous, i.e. numerous fresh, small, light green heads formed above older, large, dark green heads in the same pustule. Branches in pustules (after 12-22 days) loose, often in right angles, giving rise to additional few or numerous, radially arranged, straight, mononematous gliocladium-like stipes; the latter mostly 100-250 $\mu \mathrm{m}$ long, more rarely to $400 \mu \mathrm{m}, 7-9(-10) \mu \mathrm{m}$ wide at the base, attenuated upwards to $3-6(-8) \mu \mathrm{m}$ to the first branching point; appearing verrucose under low magnification due to guttules, in mounts smooth, to somewhat verrucose when old. Each conidiophore with a single penicillus typically $20-35 \mu \mathrm{m}$ diam and length at the apex, including the phialides; with 1-3 branching levels. First level symmetric or asymmetric, sometimes of only 1 , but mostly several steep branches arising from a single point at each level. Branches nearly parallel, 3-5 $\mu \mathrm{m}$ wide, last branches (metulae) often resembling phialides in shape and size, $6-8 \times 2.5-3.5(-4.5) \mu \mathrm{m}$, often slightly thickened at the apex. Phialides solitary or more or less parallel in variable whorls of $2-3(-6)$. Phialides $(5-) 7-10(-13) \times(2.0-) 2.2-2.8(-$ 3.4) $\mu \mathrm{m}, 1 / \mathrm{w}(2.0-) 2.6-4.0(-5.1),(1.1-) 1.5-2.1(-2.5) \mu \mathrm{m}$ wide at the base $(n=60)$, lageniform or subulate, sometimes nearly ampulliform, often interspersed with metulae in the same whorl, symmetric, inaequilateral when lateral in the whorl, without conspicuous widenings; becoming green. 
Conidia (2.5-)2.7-3.3(-3.6) ×(2.2-)2.5-2.8(-3.1) $\mu \mathrm{m}, \mathrm{l} /$ $\mathrm{w}(1.0-) 1.1-1.2(-1.3) \quad(n=60)$, yellow-green, globose to subglobose for more than $90 \%$, rarely ellipsoidal or oblong, smooth, eguttulate, with indistinct scar, rarely truncate.

On MEA mycelium covering the entire plate after $c a$ 5 days at $25^{\circ} \mathrm{C}$; surface hyphae distinctly sinuous; conidiation mainly along the margin; gliocladium-like conidiophores arising in fascicles from basal hyphal tufts. Conidial yield poor.

Habitat: wood of conifers (Abies alba, Picea abies).

Distribution: Europe (Denmark, Germany); rare.

Holotype: Germany, Baden Württemberg, Schwäbisch Gmünd, Spraitbach, Welzheimer Wald, at Hof Hafental, MTB 7124/1, elev. $450 \mathrm{~m}$, on partly decorticated thick log of Abies alba, on wood and a black crustose fungus, soc. algae and moss, ?Brachysporium sp., 4 Jul. 2008, L. Krieglsteiner \& K. Siepe (WU 29237, ex-type culture CBS 123828= C.P.K. 3537). Holotype of Trichoderma luteocrystallinum isolated from WU 29237 and deposited as a dry culture with the holotype of H. luteocrystallina as WU 29237a.

Other specimens examined: Denmark, S. Jutland, Bevtoft Plantage, on well decayed Picea wood, 6 Aug. 2010, J. Maarbjerg, comm. T. Laessoe (WU 30202; culture Hypo 636). Germany, same place and $\log$ as given for the holotype, 24 Jun. 2007, L. Krieglsteiner LK 026/2007; 4 Jul. 2008, LK 053/2008.

Notes: Stromata of Hypocrea luteocrystallina resemble those of $H$. pachypallida, but the latter species lacks yellow crystals on the stroma surface and produces a hyalineconidial anamorph. Hypocrea lutea is also similar, particularly in the anamorph. See the notes to that species for morphological differences. Hypocrea luteocrystallina seems to prefer richer media for consistent growth, while the conidial yield is poor on MEA and PDA. The conidial colour in T. luteocrystallinum is apparently light-dependent, because conidial heads turn black at $25^{\circ} \mathrm{C}(12 / 12 \mathrm{~h} \mathrm{light/}$ darkness), but remain green at $30^{\circ} \mathrm{C}$ (darkness).

\section{Hypocrea calamagrostidis Jaklitsch, sp. nov. Fig. 81 MycoBank MB 516678 \\ Anamorph: Trichoderma calamagrostidis Jaklitsch, sp. nov. Fig. 82 \\ MycoBank MB 516679}

Stromata in caulibus Calamagrostidis, $1-2.5 \mathrm{~mm}$ diam, plane pulvinata, aurantio- vel rubro-brunnea. Asci cylindrici, (63-)66-74(-80)×(3.6-)3.8-4.2(-4.6) $\mu \mathrm{m}$. Ascosporae hyalinae, languide verruculosae, ad septum disarticulatae, pars distalis (sub)globosa vel cuneata, $(3.0-) 3.3-4.0(-4.5) \times(2.8-) 2.9-3.3(-3.5) \mu \mathrm{m}$, pars proxima oblonga vel cuneata, $(3.5-) 4.0-4.7(-5.2) \times(2.3-) 2.5-2.8(-$ 3.0) $\mu \mathrm{m}$. Anamorphosis Trichoderma calamagrostidis. Conidiophora in agaris CMD, PDA et SNA effuse disposita, similia Verticillii. Phialides $(10-) 12-18(-22) \times$ $(2.0-) 2.2-2.7(-3.4) \mu \mathrm{m}$, subulatae, cylindricae vel lageniformes. Conidia $(2.5-) 2.8-5.0(-7.5) \times(2.0-) 2.3-2.8(-3.5)$ $\mu \mathrm{m}$, hyalina, glabra, ellipsoidea, oblonga vel subglobosa. In agaro SNA ad $15^{\circ} \mathrm{C}$ conidiophora in pustulis albis disposita, phialidibus in fasciculis divergentibus ad parallelis. Phialides lageniformes, 6-10(-13) $\times(2.5-) 2.8-3.5(-$ 4.0) $\mu \mathrm{m}$. Conidia $(2.8-) 3.5-4.5(-5.7) \times(2.0-) 2.2-2.6(-3.0)$ $\mu \mathrm{m}$, hyalina, glabra, oblonga vel ellipsoidea.

Etymology: calamagrostidis due to its occurrence on stalks of Calamagrostis.

Stromata when fresh 1-2.5 mm diam, $0.5-1 \mathrm{~mm}$ thick, solitary, gregarious or aggregated in small numbers, flat pulvinate; developing from white mycelium, with its centre becoming compacted, turning ochre to pale reddish-brown, and its margin remaining white; later distinct reddish-brown dots appearing on a rosy-brown stroma surface. Colour brown-orange 7CD5-6 when immature, reddish brown, mostly $8 \mathrm{CD} 5-6$, when mature.

Stromata when dry $(0.6-) 0.8-1.5(-2) \times(0.5-) 0.7-1.2(-$ 1.6) $\mathrm{mm},(0.2-) 0.3-0.5(-0.6) \mathrm{mm}(n=30)$ thick, discoid or flat pulvinate, broadly attached. Outline circular, with white to yellowish mycelial margin, often also surrounded by white basal mycelium when mature. Sides often vertical and white in basal parts. Margin partly free on the upper side, rounded. Surface smooth, or uneven, rugose or tubercular due to slightly projecting perithecia. Ostiolar dots $(32-) 42-65(-70) \mu \mathrm{m}(n=30)$ diam, distinct, papillate, broad, circular, darker than stroma surface, with light centres. Colour first white, becoming yellowish rosy or brown-orange, 7CD5-6, later deeply reddish brown, 8E68 , with yellow tones between ostiolar dots, appearing slightly mottled in the stereo-microscope. Spore deposits white. Rehydrated stromata slightly larger, thickly pulvinate, soft, paler, with slightly convex, reddish-brown dots or rings with hyaline centres. Attachment area reddish. Colour unchanged in $3 \% \mathrm{KOH}$.

Stroma anatomy: Ostioles (43-)49-65(-77) $\mu \mathrm{m}(n=30)$ long, plane or projecting to $13(-17) \mu \mathrm{m},(17-) 23-34(-37)$ $\mu \mathrm{m}$ wide at the apex $(n=30)$, cylindrical, periphysate, with an apical palisade of hyaline, cylindrical, apically broadly rounded to subacute cells $2-5 \mu \mathrm{m}$ wide. Perithecia (100-) $140-185(-205) \times(95-) 110-170(-195) \mu \mathrm{m}(n=30), 8-9$ per $\mathrm{mm}$ stroma, globose, ellipsoidal, or flask-shaped, laterally compressed when crowded. Peridium (14-)15-20(-25) $\mu \mathrm{m}$

Fig. 81 Teleomorph of Hypocrea calamagrostidis (WU 29198). a-c. Fresh stromata (a, b. immature). d-f. Dry stromata (d. immature). g. Stroma surface in face view. $\mathbf{h}$. Cortical and subcortical tissue in section. i. Stroma in $3 \% \mathrm{KOH}$ after rehydration. j. Perithecium in section. $\mathbf{k}$. Subperithecial tissue in section. $\mathbf{1}$. Basal tissue in section. $\mathbf{m}-\mathbf{0}$. Asci with ascospores (n, o. in cotton blue/lactic acid). Scale bars $\mathbf{a}-\mathbf{c}=$ $1 \mathrm{~mm} . \mathbf{d}, \mathbf{e}=0.5 \mathrm{~mm} . \mathbf{f}, \mathbf{i}=0.2 \mathrm{~mm} . \mathbf{g}, \mathbf{h}, \mathbf{m}, \mathbf{o}=5 \mu \mathrm{m} . \mathbf{j}=20 \mu \mathrm{m} . \mathbf{k}=$ $15 \mu \mathrm{m} . \mathbf{l}, \mathbf{n}=10 \mu \mathrm{m}$ 

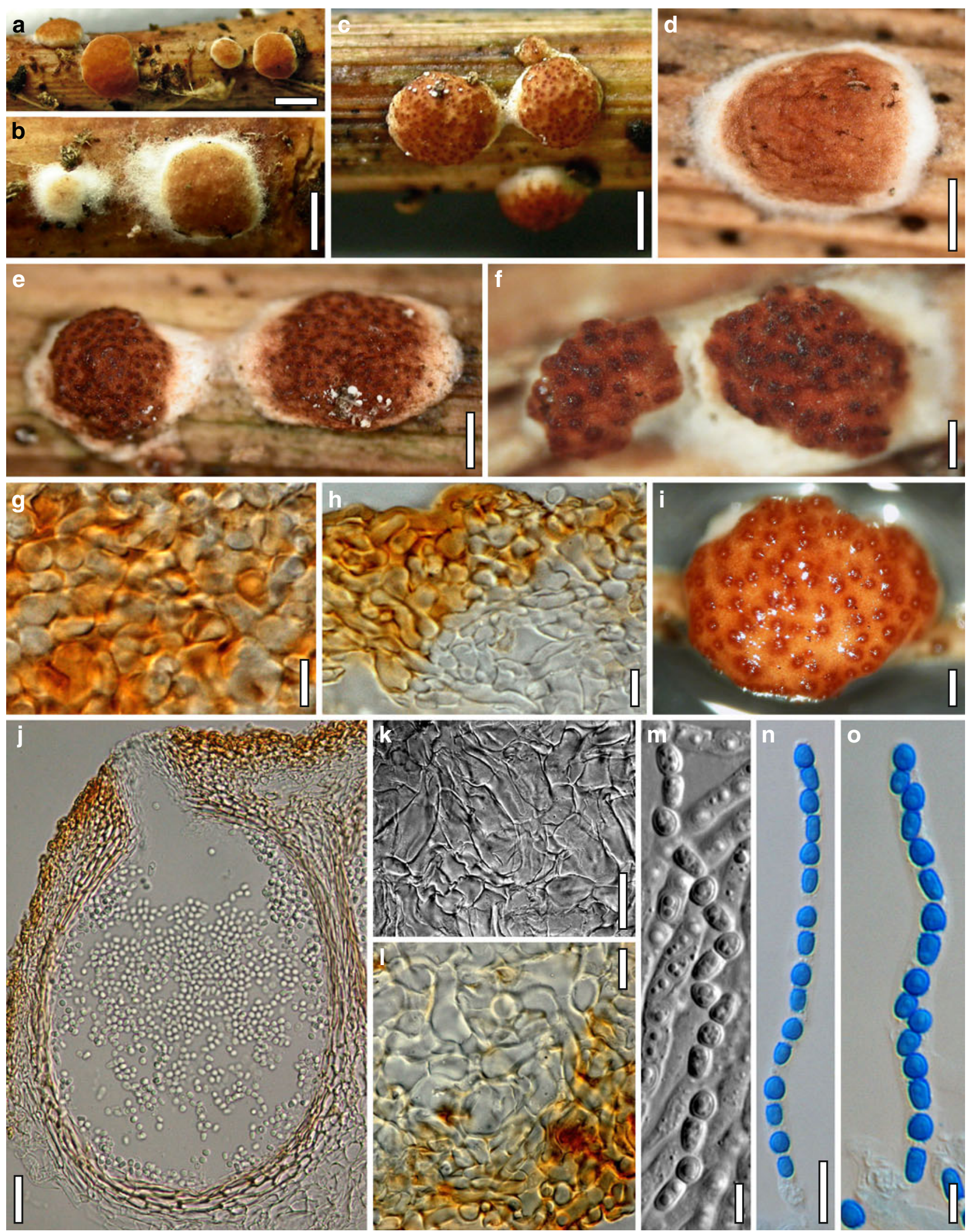

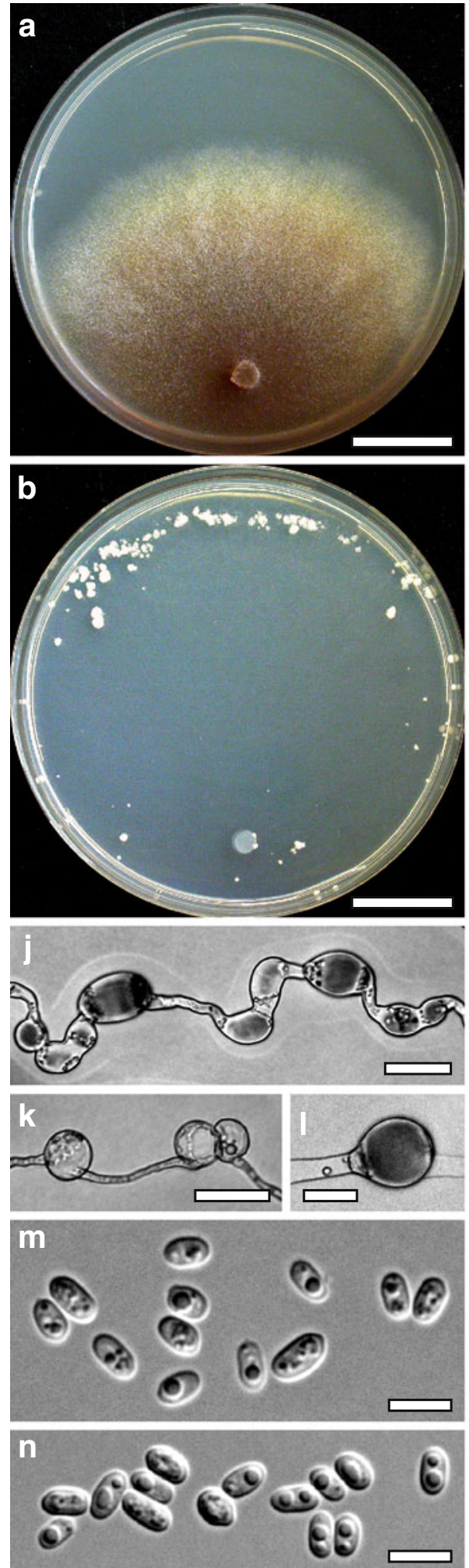
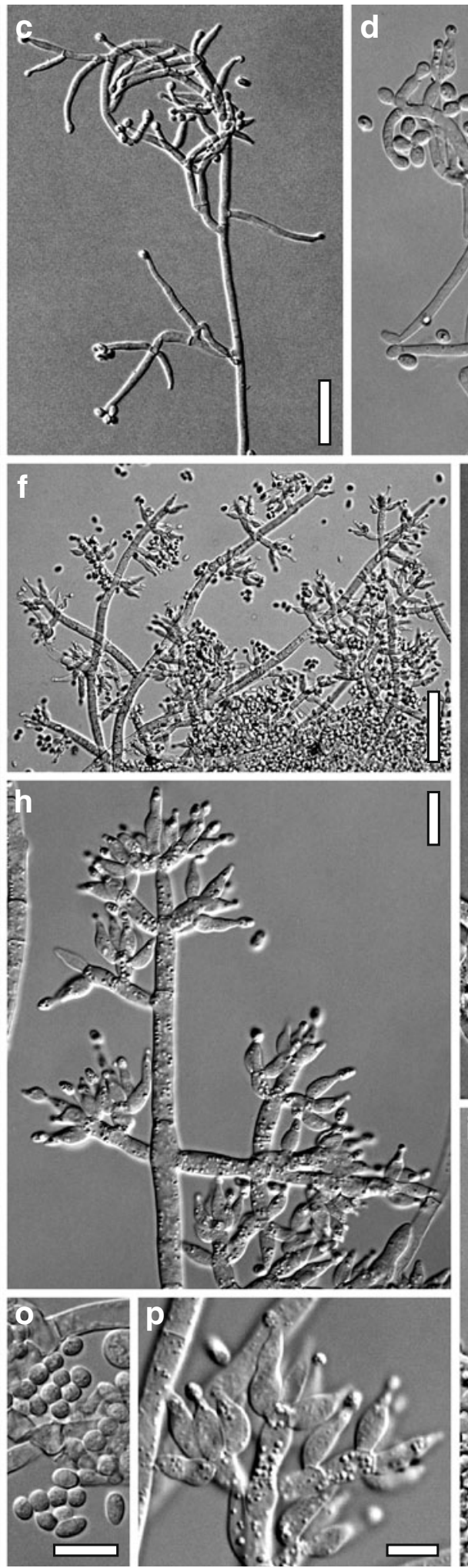

(m, n. from pustules, SNA, $15^{\circ} \mathrm{C}, 26-32$ days; o. effuse conidiation, SNA, $25^{\circ} \mathrm{C}, 16$ days). p. Phialides frpm pustules (SNA, $15^{\circ} \mathrm{C}$, 26 days). Scale bars $\mathbf{a}, \mathbf{b}=20 \mathrm{~mm}$. $\mathbf{c}, \mathbf{j}=20 \mu \mathrm{m}$. d, e, $\mathbf{g - i}, \mathbf{l}, \mathbf{o}=$ $10 \mu \mathrm{m} . \mathbf{f}, \mathrm{k}=30 \mu \mathrm{m} . \mathbf{m}, \mathbf{n}, \mathbf{p}=5 \mu \mathrm{m}$
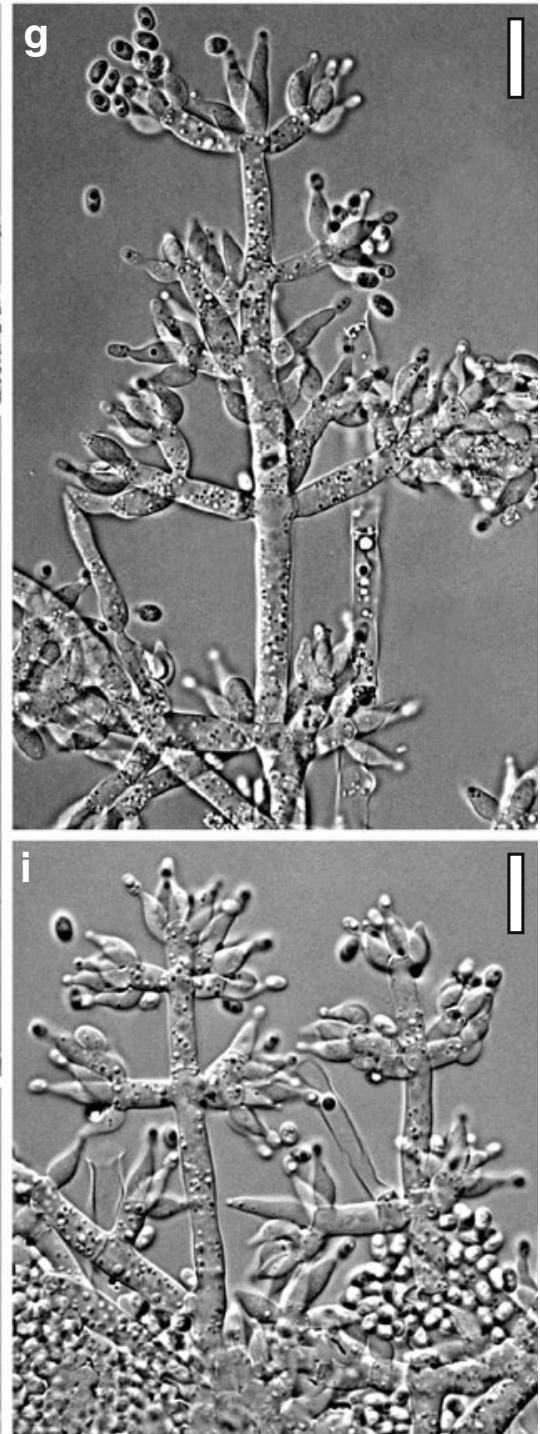

Fig. 82 Cultures and anamorph of Hypocrea calamagrostidis 12 ays) 20 days). $\mathbf{f}-\mathbf{i}$. Conidiophores of pustulate conidiation (SNA, $15^{\circ} \mathrm{C}, 26-$ 32 days). $\mathbf{j}-\mathbf{l}$. Chlamydospores (CMD, $25^{\circ} \mathrm{C}, 22$ days). $\mathbf{m}-\mathbf{0}$. Conidia 
$(n=30)$ thick at the base, $(8.5-) 11-16(-19) \mu \mathrm{m}(n=30)$ at the sides, well-defined, reddish-brownish, nearly hyphal at the sides. Cortical layer (7-)12-21(-27) $\mu \mathrm{m}(n=30)$ thick, a thin, dense, small-celled $t$. angularis of thin-walled, isodiametric, angular cells $(2.5-) 3.5-7(-9) \times(2.0-) 2.5-4.5$ $(-7) \mu \mathrm{m}(n=60)$ in face view and in vertical section; yellow- to dull orange-brown, with inhomogeneously distributed pigment. Subcortical tissue a loose, hyaline $t$. intricata of thin-walled hyphae (1.5-)2-4(-6) $\mu \mathrm{m}(n=30)$ wide. Subperithecial tissue ill-defined, a coarse $t$. epidermoidea to $t$. intricata, of large thin-walled cells (4-)10-28 $(-36) \times(4-) 7-13(-16) \mu \mathrm{m}(n=33)$, and hyphae $(2.0-) 3.5-8$ $(-11.5) \mu \mathrm{m}(n=30)$ wide. Basal tissue similar to the cortex. Asci $(63-) 66-74(-80) \times(3.6-) 3.8-4.2(-4.6) \mu \mathrm{m}$, stipe (3-) $5-11(-16) \mu \mathrm{m}$ long $(n=31)$; no croziers seen. Ascospores hyaline, multiguttulate, dimorphic, smooth to finely verruculose; distal cell (3.0-)3.3-4.0(-4.5)×(2.8-)2.9-3.3(-3.5) $\mu \mathrm{m}, 1 / \mathrm{w}(1-) 1.1-1.3(-1.5)(n=30)$, (sub-)globose to wedgeshaped; proximal cell $(3.5-) 4.0-4.7(-5.2) \times(2.3-) 2.5-2.8(-$ 3.0) $\mu \mathrm{m}, 1 / \mathrm{w}(1.3-) 1.5-1.8(-2)(n=30)$, oblong to plump wedge-shaped.

Cultures and anamorph: optimal growth at $25^{\circ} \mathrm{C}$ on all media; at $30^{\circ} \mathrm{C}$ limited growth, hyphae dying soon; no growth at $35^{\circ} \mathrm{C}$.

On CMD after $72 \mathrm{~h} 5-13 \mathrm{~mm}$ at $15^{\circ} \mathrm{C}, 9-17 \mathrm{~mm}$ at $25^{\circ}$ C, $1-2 \mathrm{~mm}$ at $30^{\circ} \mathrm{C}$; mycelium covering the plate after 920 days at $25^{\circ} \mathrm{C}$. Colony hyaline, thin, circular, dense, homogeneous, not zonate. Hyphae curly or wavy along their length. Centre becoming loose, with hyphae soon degenerating, appearing empty and with conspicuous septa. Aerial hyphae inconspicuous. Autolytic excretions lacking or rare, coilings infrequent, large. No pigment, no distinct odour noted. Conidiation noted after 4-11 days, scant, effuse, on few long aerial hyphae, irregularly distributed, macroscopically invisible. Chlamydospores noted after 910 days, (9-)14-32(-50)×(6-)14-24(-30) $\mu \mathrm{m}, 1 / \mathrm{w}(0.9-)$ $1.0-1.5(-2.0)(n=32)$, globose or ellipsoidal, also fusoid to oblong, often appearing empty inside agar, thick-walled, smooth, abundant in the inner half of the colony; mainly intercalary. At $15^{\circ} \mathrm{C}$ rarely scant conidiation in white pustules to $1 \mathrm{~mm}$ diam.

On PDA after $72 \mathrm{~h} 4-8 \mathrm{~mm}$ at $15^{\circ} \mathrm{C}, 9-16 \mathrm{~mm}$ at $25^{\circ} \mathrm{C}$, $<1 \mathrm{~mm}$ at $30^{\circ} \mathrm{C}$; mycelium covering the plate after 10 20 days at $25^{\circ} \mathrm{C}$. Colony circular, dense, opaque; hyphae curly. Surface downy to hairy, becoming bright yellow, 4B4-8 to 4C6-8, on and around the plug, pigment spreading and finally turning dull brown. Numerous minute yellow crystals and tiny stromatic condensations of surface hyphae formed throughout the pigmented region. Aerial hyphae abundant, forming a loose irregular reticulum of strands several $\mathrm{mm}$ high, collapsing after forming large drop-like branching and crossing points. Autolytic excretions lacking, but conspicuous at $15^{\circ} \mathrm{C}$; coilings rare.
Reverse becoming discoloured from the centre, yellow, 3A4-6, 4B4, brown-orange, yellow-brown, reddish-brown to dark brown, 5-8CD5-6, 6E5-8, 7-8EF5-8. Odour indistinct. Conidiation noted after 3-4 days, white, effuse, starting in short narrow, ill-defined, sinuous trees, ascending on long central aerial hyphae, and spreading across the colony. At $15^{\circ} \mathrm{C}$ autolytic excretions abundant; centre becoming greyish red, 7B4, 7CD5-6, with irregular brown spots, 8E6-8. Conidiation scant, effuse, and in few small pachybasium-like pustules with minute phialides.

On SNA after $72 \mathrm{~h} 5-7 \mathrm{~mm}$ at $15^{\circ} \mathrm{C}, 7-12 \mathrm{~mm}$ at $25^{\circ} \mathrm{C}$, to $1 \mathrm{~mm}$ at $30^{\circ} \mathrm{C}$; mycelium covering the plate after $2-4$ weeks at $25^{\circ} \mathrm{C}$. Colony hyaline, thin, margin ill-defined. Mycelium appearing macroscopically curly; hyphae loose, little branched, soon degenerating and appearing empty from around the plug. Aerial hyphae inconspicuous, more frequent and long along the margin, often becoming fertile. No autolytic excretions noted; coilings infrequent, more frequent at $15^{\circ} \mathrm{C}$. No pigment, no distinct odour noted. Chlamydospores noted after 9-14 days, mostly intercalary in wide surface hyphae around the plug, often angular or severalcelled, less common than at $15^{\circ} \mathrm{C}$ and on CMD. Conidiation irregular, effuse and/or pustulate; pustule formation distinctly enhanced by lower temperatures $\left(15^{\circ} \mathrm{C}\right)$. Effuse conidiation noted after 3-7 days, scant, but more than on CMD; macroscopically invisible. Conidia formed in small numbers in minute wet heads to $10 \mu \mathrm{m}$ diam on short, usually unpaired, sinuous conidiophores to $100(-150) \mu \mathrm{m}$ long and 4-5 $\mu \mathrm{m}$ wide at the base, $2-3 \mu \mathrm{m}$ terminally. Conidiophores arising mostly from long aerial hyphae 4-5(-6) $\mu \mathrm{m}$ wide, loosely disposed, thin, asymmetric, with sparse paired branches; of a main axis bearing long, thin phialides and 1-celled side branches. Branches and phialides often curved to sinuous, in right angles or inclined upwards or downwards; phialides solitary or in ill-defined whorls of 2-3(-5); mainly supported by cells $2-3 \mu \mathrm{m}$ wide. Phialides $(10-) 12-18(-22) \times(2.0-) 2.2-$ $2.7(-3.4) \mu \mathrm{m}, 1 / \mathrm{w}(3.7-) 4.7-8(-9.5)(n=30),(1.0-) 1.6-2.4(-$ 3.1) $\mu \mathrm{m}$ wide at the base $(n=30)$, subulate, cylindrical, or lageniform. Conidia (2.5-)2.8-5.0(-7.5) $\times(2.0-) 2.3-2.8(-$ 3.5) $\mu \mathrm{m}, 1 / \mathrm{w}(1-) 1.2-1.8(-2.7)(n=45)$, hyaline, smooth, ellipsoidal, oblong or subglobose, with few small guttules; scar indistinct or projecting. Pustulate conidiation after 34 weeks at $15^{\circ} \mathrm{C}$ : pustules $0.5-2.5 \mathrm{~mm}$ diam, irregularly distributed in varying numbers across the colony or concentrated close to the distal margin; white, loose, with frequent right angles, and several main axes. Main axes broad, forming conidiophores to $c a 0.6 \mathrm{~mm}$ long or bearing shorter lateral trees. Trees mostly wider downwards; branches right-angled or slightly inclined upwards, usually paired, unpaired in lower regions, 1-celled at the top, 2- to several-celled downwards, with 1-2 further 1-celled branches bearing terminal whorls of phialides. Phialides mostly in whorls of 3-4(-5), divergent, but often strongly 
curved upward and nearly parallel, gliocladium-like. Conidia formed in small numbers. Stipe and primary branches thickwalled and to $8-9 \mu \mathrm{m}$ wide, conidiophores $3-5 \mu \mathrm{m}$ wide for the most part; phialide origins $3-4 \mu \mathrm{m}$ wide. Phialides $6-10$ $(-13) \times(2.5-) 2.8-3.5(-4.0) \mu \mathrm{m}, 1 / \mathrm{w}(1.7-) 2.0-3.1(-4),(1.5-)$ $1.9-2.6(-3) \mu \mathrm{m}(n=40)$ wide at the base, lageniform, or beak-like with a pointed apex, widest in or below the middle, sometimes strongly curved to sinuous. Conidia (2.8-)3.5-4.5 $(-5.7) \times(2.0-) 2.2-2.6(-3.0) \mu \mathrm{m}, 1 / \mathrm{w}(1.3-) 1.5-1.8(-2.1)(n=$ 46), hyaline, smooth, narrowly ellipsoidal or oblong, with numerous minute guttules or 1 to few larger guttules, scar indistinct or narrowly truncate.

Habitat: on stalks of Calamagrostis epigejos.

Distribution: Denmark, known only from the type location.

Holotype and only known specimen: Denmark, Nordjylland, Tranum, meadow at Vestkystvejen, close to crossing with Strandvejen, $57^{\circ} 08^{\prime} 32^{\prime \prime}$ N, $09^{\circ} 26^{\prime} 28^{\prime \prime}$ E, elev. $10 \mathrm{~m}$, on stalks of Calamagrostis epigejos, 25 Aug. 2006, W. Jaklitsch \& H. Voglmayr, W.J. 2944 (WU 29198, culture CBS 121133=C.P.K. 2447). Holotype of Trichoderma calamagrostidis isolated from WU 29198 and deposited as a dry culture with the holotype of $H$. calamagrostidis as WU 29198a.

Notes: Hypocrea calamagrostidis differs from H. junci, found on Juncus in a comparable habitat, in distinct ostiolar dots, lighter and more rosy stroma colour, and a whiteconidial anamorph. The pachybasium- to gliocladium-like conidiation on stout conidiophores in white pustules is in good agreement with other species of the Psychrophila clade like $H$. crystalligena and $H$. psychrophila.

Hypocrea crystalligena Jaklitsch, Mycologia 98: 502 (2006a). Fig. 83

Anamorph: Trichoderma crystalligenum Jaklitsch, Mycologia 98: 502 (2006a). Fig. 84

Stromata when fresh 1-6(-8) diam, 0.5-2 $\mathrm{mm}$ high, gregarious or densely aggregated, typically in large numbers; pulvinate or semiglobose, less commonly discoid, broadly attached. Outline circular or irregular. Margin free, white or concolorous. Surface finely tomentose to velutinous when young, becoming glabrous and smooth, often covered with a white crystalline powder in addition to white ascospore deposits. Ostiolar dots typically indistinct, but often becoming distinct with age, appearing as dark rings with light-coloured centres. Colour light (yellowish-, ochreor reddish-)brown, 4A4, 5-6B5-6, 6-7D5-6, 7-8CD7-8, when young, turning to dull red, 8-9B4, or mostly dark brown to dark reddish brown, 9DE7-8, 8E6-8, 9F5-8.

Stromata when dry $(0.7-) 1.5-3.5(-4.7) \times(0.5-) 1.2-3.0(-$ $4.0) \mathrm{mm},(0.2-) 0.5-1.0(-1.7) \mathrm{mm}$ thick $(n=30)$, flatter than fresh, pulvinate or discoid. Surface velutinous when young; when mature finely verrucose, tubercular or wrinkled, glabrous, but often covered with conspicuous waterinsoluble, white powder. Ostiolar dots (24-)32-53(-63) $\mu \mathrm{m}(n=30)$ wide, typically inconspicuous when young, due to colours similar to the surrounding stroma surface, more distinct and dark with age; ostioles after addition of water appearing as minute hyaline dots on a bright red stroma surface. Colour of young, velutinous stromata greyish orange, brown-orange, light, medium, yellow- or greyish brown, 5B4-6, 5CD3-8, 6CD4-6, 6E4-8, 7CD7-8, 5EF24, 6F4-5; mature stromata reddish-, violaceous- or dark brown, 9D7-8, 6-10EF5-8 or darker. No distinct colour change in $3 \% \mathrm{KOH}$ noted.

Stroma anatomy: Ostioles in section (42-)48-69(-77) $\mu \mathrm{m}$ long, plane or projecting to $16(-22) \mu \mathrm{m},(20-) 22-45(-$ 69) $\mu \mathrm{m}$ at the apex $(n=20)$, cylindrical, with an apical palisade of narrow hyaline hyphae terminating in distinctly clavate to subglobose cells to $6 \mu \mathrm{m}$ wide. Perithecia (169-) $200-230(-245) \times(97-) 110-160(-211) \mu \mathrm{m}(n=30)$, flaskshaped, subglobose in lateral regions. Peridium $8-13(-15)$ $\mu \mathrm{m}$ thick at the base, $(14-) 15-20(-22) \mu \mathrm{m}$ at the apex $(n=$ $15)$, yellowish- to reddish brown. Cortical layer (12-)15-22 $(-25) \mu \mathrm{m}(n=15)$ thick, reddish brown in water, orangebrown in lactic acid, with inhomogeneously disposed pigment; of small angular, thick-walled, glassy, compressed cells of indistinct outline, $(3-) 5-10(-11) \mu \mathrm{m}$ diam in face view, $3-6(-7) \mu \mathrm{m}$ diam $(n=15)$ in vertical section. Hairs rare on mature stromata, $10-20 \mu \mathrm{m}$ long, subhyaline to reddish brown, apically rounded. Subcortical tissue thin, a loose $t$. intricata of thin-walled, hyaline hyphae (3-)4-7(9) $\mu \mathrm{m}(n=15)$ wide. Subperithecial tissue a dense hyaline $t$. angularis-epidermoidea of isodiametric subglobose or angular, thin-walled cells (4-)12-44(-63)×(3.5-)6-15(19) $\mu \mathrm{m}(n=30)$, becoming smaller towards the stroma base and intermingled with hyphal elements. Asci (68-)72-86(98) $\times(3.5-) 4.0-4.8(-5.2) \mu \mathrm{m}$, stipe $(5-) 7-20(-28) \mu \mathrm{m}$ long $(n=30)$; no croziers apparent. Ascospores hyaline, finely verruculose, cells dimorphic, but often similar, distal cell (2.4-)2.6-3.3(-4.3)×(2.4-)2.5-3.0(-3.6) $\mu \mathrm{m}, 1 / \mathrm{w}(0.9-) 1.0$ 1.2(-1.4) $(n=70)$, subglobose, sometimes slightly tapered towards upper end, proximal cell (2.4-)3.0-3.7(-4.5) $\times(2.0-)$ $2.2-2.6(-3.2) \mu \mathrm{m}, 1 / \mathrm{w}(1.0-) 1.2-1.5(-1.9)(n=70)$, wedgeshaped or oblong, broadly rounded at lower end.

Fig. 83 Teleomorph of Hypocrea crystalligena. a, b, d, f. Fresh stromata (a. young, velutinous, b. with visible ostioles, f. (over-) mature). e, h, i. Dry stromata (e. fraction of d; i. showing white powder on surface). c. Surface of rehydrated wet stroma showing hyaline ostioles. g. Ostiole in section showing periphyses and apical cells. j. Perithecium in section. k. Ostiole in face view. I. Stroma surface in face view. $\mathbf{m}$. Subperithecial tissue in section. $\mathbf{n}, \mathbf{o}, \mathbf{p}$. Asci with ascospores (n, o. in cotton blue/lactic acid). a, c, d, e. WU 24050. b. WU 24059. f. WU 24060. g, h, j-o. holotype WU 24041. i: WU 24053. p: WU 24052. Scale bars: a, e, f, h, $\mathbf{i}=1.5 \mathrm{~mm}$. $\mathbf{b}=0.3 \mathrm{~mm}$. $\mathbf{c}=$ $0.2 \mathrm{~mm} . \mathbf{d}=2 \mathrm{~mm} . \mathbf{g}, \mathbf{l}, \mathbf{p}=10 \mu \mathrm{m} . \mathbf{j}, \mathbf{m}=25 \mu \mathrm{m} . \mathbf{k}, \mathbf{n}, \mathbf{o}=5 \mu \mathrm{m}$ 


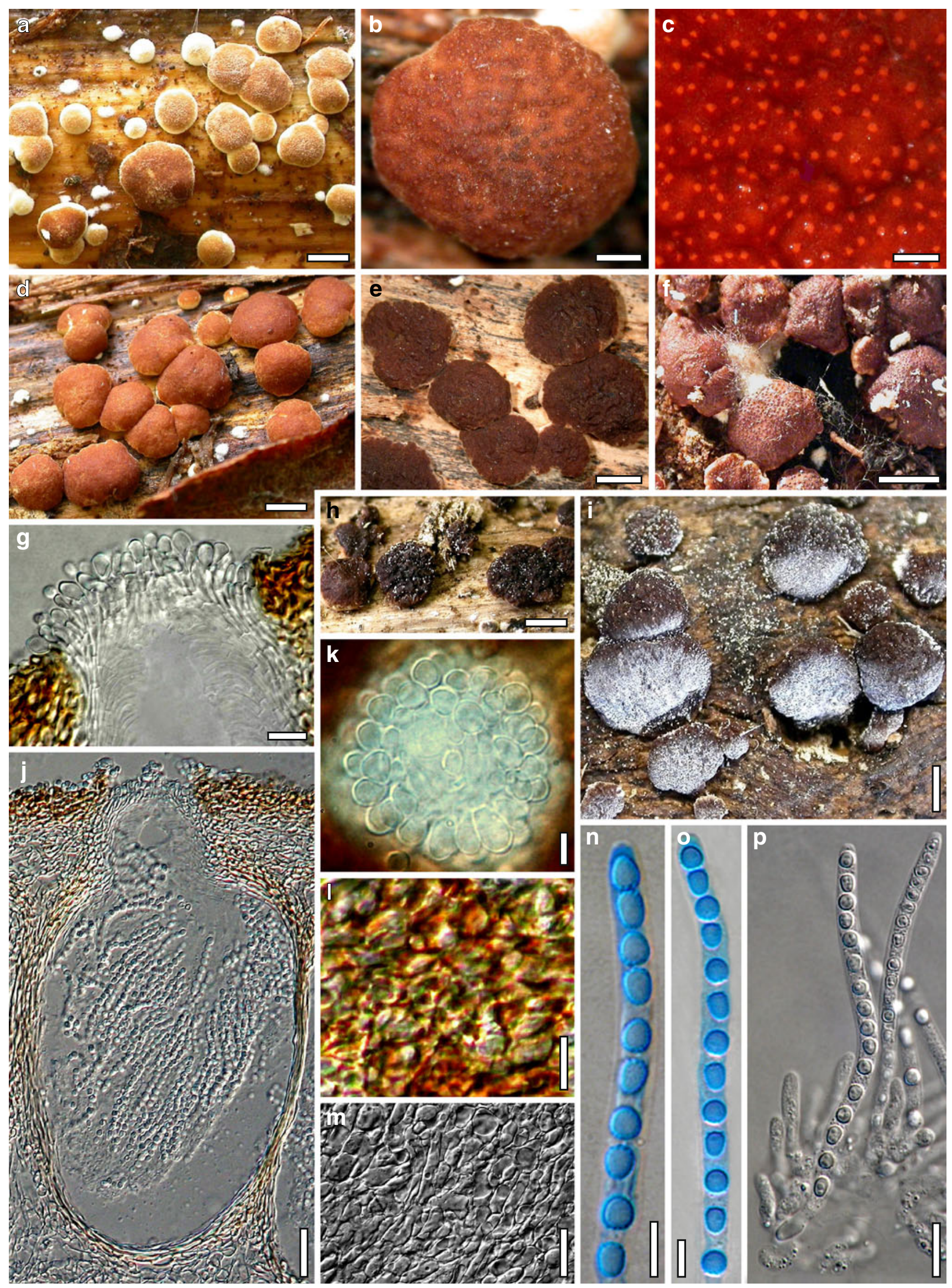



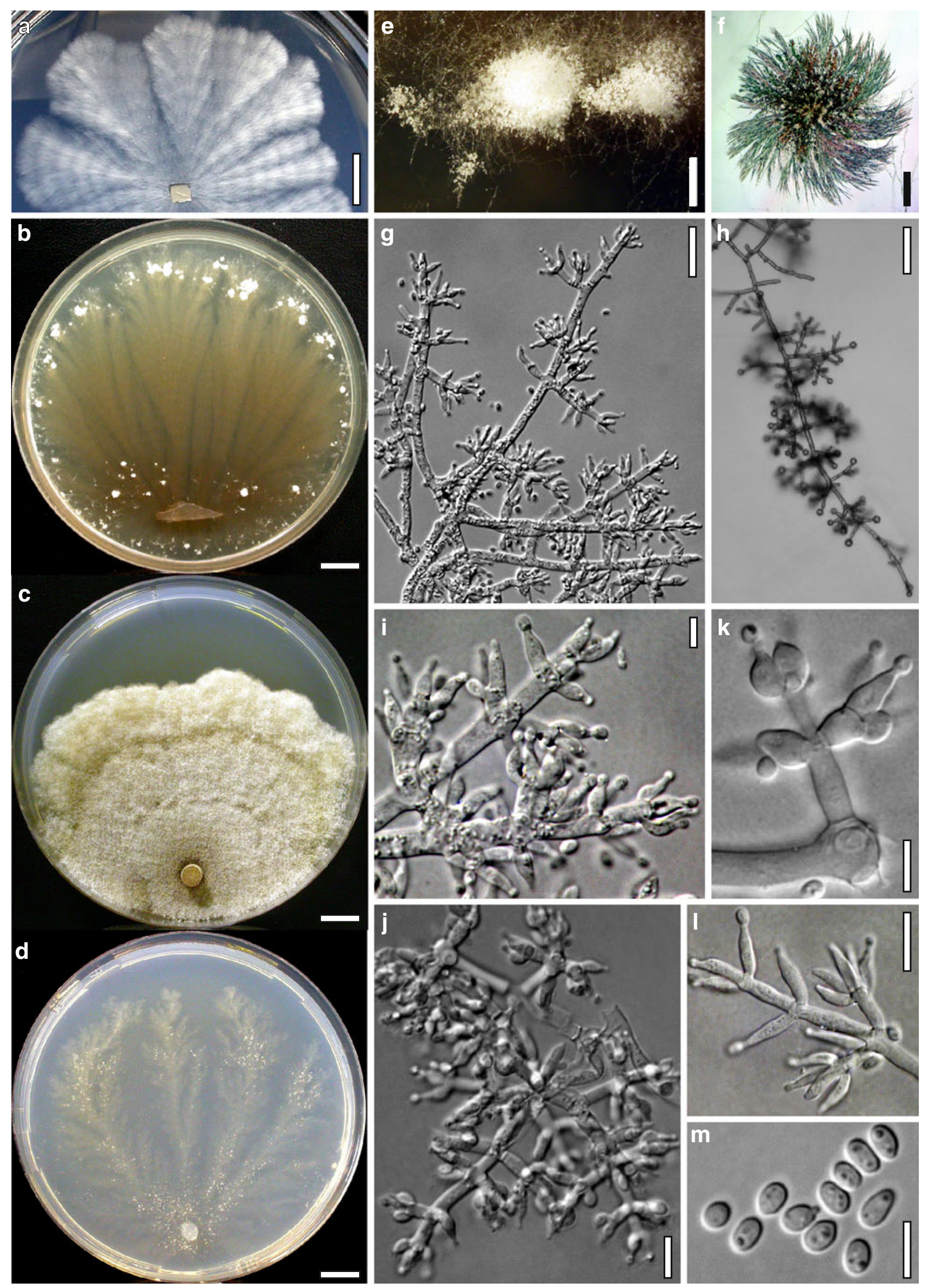
4Fig. 84 Cultures and anamorph of Hypocrea crystalligena. a-d. Cultures (a. on $\mathrm{CMD}, 10$ days; b. on $\mathrm{CMD}, 25$ days $/ 25^{\circ} \mathrm{C}$ plus 23 days $/ 15^{\circ} \mathrm{C}$; c. on PDA, 23 days; d. on SNA, 35 days). e. Conidiation pustules (CMD, 53 days). f. Crystal on agar surface (interference contrast, CMD, 9 days). g-l. Conidiophores and phialides (9 days; $\mathbf{g}$, i. on $\mathrm{CMD} ; \mathbf{h}, \mathbf{l}$. on SNA; j, k. Anamorph on natural substrate). m. Conidia (SNA, 16 days). a-m. All at $25^{\circ} \mathrm{C}$ except b. a, c, e, g-i, l, m. CBS 118980. b. CBS 118979. d, f.C.P.K. 944. j, k. WU 24044. Scale bars $\mathbf{a}-\mathbf{d}=10 \mathrm{~mm}$. $\mathbf{e}=0.4 \mathrm{~mm} . \mathbf{f}=0.2 \mathrm{~mm}$. $\mathbf{g}=15 \mu \mathrm{m} . \mathbf{h}=30 \mu \mathrm{m} . \mathbf{i}, \mathbf{k}, \mathbf{m}=5 \mu \mathrm{m} . \mathbf{j}, \mathbf{l}=10 \mu \mathrm{m}$

Anamorph on the natural substrate (WU 24044): White hairy tufts on wood, partly in close association with stromata, in circular to oblong, confluent patches to $15 \mathrm{~mm}$ long, with long sterile elongations when immature. Main axes 3-5 $\mu \mathrm{m}$ wide, with short branches in right angles, loosely disposed or pachybasium-like, i.e. richly and densely branched, with dense whorls of 2-5(-6) phialides on 1-2 celled branches 3-4(-7) $\mu \mathrm{m}$ wide; branching points often thickened. Phialides (4.2-)4.7-8.2 $(-12.0) \times(2.5-) 2.7-3.2(-3.5) \mu \mathrm{m}, 1 / \mathrm{w}=1.5-2.8(-4.5),(1.4-)$ 2.0-2.7(-3.0) $\mu \mathrm{m}$ wide at the base $(n=30)$, plump, short and thick, ampulliform or lageniform, widest in or below the middle. Conidia (2.2-)2.5-3.2(-3.7) $\times 1.7-2.0(-2.5)$ $\mu \mathrm{m}, 1 / \mathrm{w}=1.2-1.5(-1.7)(n=30)$, hyaline, ellipsoidal or oval, smooth, with one or few guttules.

Cultures and anamorph: optimal growth at $25^{\circ} \mathrm{C}$ on all media, no growth at $35^{\circ} \mathrm{C}$.

On CMD after $72 \mathrm{~h} 5-7 \mathrm{~mm}$ at $15^{\circ} \mathrm{C}, 7-10 \mathrm{~mm}$ at $25^{\circ} \mathrm{C}$, $3-10 \mathrm{~mm}$ at $30^{\circ} \mathrm{C}$; mycelium covering the plate after $3-$ 6 weeks. Colony characteristic, forming silky, fan-shaped lobes, with little mycelium on the agar surface, finely but distinctly zonate; hyphae narrow, soon degenerating in the centre. Aerial hyphae inconspicuous, but sometimes appearing in loose, irregular, sterile or fertile tufts mostly in distal or lateral regions of the colony, on plates entirely covered by mycelium. After $c a 6$ days often characteristic colourless to white crystals appearing on the surface, growing to $0.5-1.5 \mathrm{~mm}$ diam, sometimes appearing as oily drops inside the agar; in some isolates or after several transfers no crystals formed. Autolytic activity and coilings variable, usually inconspicuous. No distinct odour detected. Either no diffusing pigment formed or a diffuse greyish yellow, golden- or yellow-brown, 4B4-7 to 5CD7-8, unevenly distributed pigment noted. Chlamydospores 5 $19(-29) \times(5-) 6-15(-17) \mu \mathrm{m}(n=10)$, rare, terminal and intercalary, globose, pyriform or irregular. Conidiation in freshly isolated strains often detected after few days, but scant or absent after several transfers; effuse, on short, scattered conidiophores, or in white tufts or pustules formed mostly at the distal and lateral margins of the colony; often late, e.g. after 1-2 months. Formation of pustules strongly enhanced and accelerated by incubation at $15^{\circ} \mathrm{C}$ after growth at $25^{\circ} \mathrm{C}$ until the mycelium has covered the entire plate. Tufts or pustules $0.4-2 \mathrm{~mm}$ diam, confluent to $5 \mathrm{~mm}$, circular, oblong or irregular, loose, or compact with a granular surface, with slow and asynchronous development. Pustules formed on stipes 6-9 $\mu \mathrm{m}$ wide, with variable branching; branching points sometimes thickened to $6 \mu \mathrm{m}$. Main axis radial, with stout side branches, with width increasing from top to bottom. Terminal branches often paired and in right angles, $(2-) 3-5(-6) \mu \mathrm{m}$ wide. Phialides formed in dense whorls of 3-5(-6) on cells 3.0-4.5(-5.5) $\mu \mathrm{m}$ wide; straight and divergent, or strongly curved and parallel, gliocladium-like; both types seen on the same conidiophore. Conidia formed in minute heads to $10 \mu \mathrm{m}$ diam. Phialides (3.7-)5.0-7.5(-10.0) $\times(2.0-) 2.2-3.5(-4.5)$ $\mu \mathrm{m}, 1 / \mathrm{w}=(1.5-) 1.7-3.0(-3.5),(1.2-) 1.6-2.2(-2.7) \mu \mathrm{m}$ wide at the base $(n=60)$; lageniform, conical, or ampulliform, widest in or below the middle, with neck often long and pointed; solitary phialides generally longer and narrower. Conidia (2.2-)2.5-3.5(-4.0) $\times(1.5-) 1.7-2.2(-2.5) \mu \mathrm{m}, 1 / \mathrm{w}=$ $(1.2-) 1.3-1.7(-2.2) \quad(n=90)$, hyaline, ellipsoidal or oval, smooth, with few small guttules, sometimes with truncate scar.

On PDA after $72 \mathrm{~h} 1-5 \mathrm{~mm}$ at $15^{\circ} \mathrm{C}, 8-10 \mathrm{~mm}$ at $25^{\circ} \mathrm{C}$, 0-7 $\mathrm{mm}$ at $30^{\circ} \mathrm{C}$; mycelium covering the plate after 4 5 weeks or growth terminating earlier. Mycelium densely compacted, hyphae thin. Aerial hyphae forming thick, whitish, downy to cottony mats. Colony without distinct zonation. Autolytic activity inconspicuous, with small brownish excretions from dying hyphae; no crystals seen. No distinct odour noted. Reverse becoming yellow, 2A4-5, $3 \mathrm{~A} 4-8$ to $4 \mathrm{~A} 6-7$, gradually changing to yellow- or goldenbrown, 5CD6-8, 6CD5-6. Conidiation effuse, whitish, farinose, spreading from the plug after $2-3$ days as numerous densely disposed, minute conidiophores and fascicles of phialides on long aerial hyphae.

On SNA after $72 \mathrm{~h} 2-6 \mathrm{~mm}$ at $15^{\circ} \mathrm{C}, 5-9 \mathrm{~mm}$ at $25^{\circ} \mathrm{C}$, $0-7 \mathrm{~mm}$ at $30^{\circ} \mathrm{C}$; individual lobes reaching the plate margin within 3 weeks or later. Colony similar to CMD but usually more irregular, often with wide gaps between mycelial lobes; zonation indistinct. Aerial hyphae scant or forming loose sterile tufts to $1.5 \mathrm{~mm}$ diam. Autolytic excretions more frequent than on CMD. Crystals lacking or inconspicuous. No distinct odour, no pigment noted. Chlamydospores rare. Conidiation appearing on SNA more reliably than on CMD, first noted after 3 days around the plug, effuse, later in small white floccules, tufts or pustules in varying numbers, sizes and arrangements, mostly $0.1-$ $1 \mathrm{~mm}$ diam; sometimes large pustules to $7 \mathrm{~mm}$ diam developing within $2-3(-8)$ weeks. Pustules with irregularly or radially arranged main axes, with $2-3$ fold further branching, bearing mostly regular trees with right-angled and often paired branching. Trees with phialides or 1-2 celled branches at the apices; branches paired or not, increasing in length downwards. Phialides supported by 
cells $2-3 \mu \mathrm{m}$ wide, solitary or in dense terminal whorls of $3-5(-8)$, divergent or parallel. Phialides (4.7-)5.5-9.0($13.0) \times 2.2-2.7(-3.2) \mu \mathrm{m}, 1 / \mathrm{w}=(1.5-) 2.0-3.5(-5.7),(1.2-)$ $1.5-2.0(-2.5) \mu \mathrm{m}$ wide at the base $(n=30)$, narrow, straight or curved upwards, widest mostly below the middle. Conidia $(2.5-) 2.7-3.5(-4.0) \times 1.8-2.0(-2.2) \mu \mathrm{m}, \quad 1 / \mathrm{w}=$ $(1.2-) 1.5-1.7(-2.0) \mu \mathrm{m}(n=30)$, hyaline, ellipsoidal or oblong, smooth, abscission scar sometimes distinct.

Habitat: stromata usually occurring in large groups on wood and bark of dead and usually well-rotted branches of various deciduous trees such as Alnus glutinosa, A. incana, Carpinus betulus, Cornus sanguinea, Corylus avellana, Fagus sylvatica, Quercus petraea or Tilia cordata, lying on the ground in warm and dry forests and shrubs; also on fungi, e.g. stromata of Hypoxylon or Diatrypella spp.

Known distribution: Europe (Austria, Estonia, Germany, Netherlands, Sweden, Ukraine, UK).

Holotype: Austria, Steiermark, Weiz, Laßnitzthal, from Arboretum Gundl across the main road, MTB 8959/2, $47^{\circ}$ $04^{\prime} 17^{\prime \prime} \mathrm{N}, 15^{\circ} 38^{\prime} 38^{\prime \prime}$ E, elev. $420 \mathrm{~m}$, on branch of Carpinus betulus $4-5 \mathrm{~cm}$ thick, on the ground, 8 Aug. 2003, W. Jaklitsch \& H. Voglmayr, W.J. 2325 (WU 24041, ex-type culture CBS $118980=$ C.P.K. 1600). Holotype of Trichoderma crystalligenum isolated from WU 24041 and deposited as a dry culture with the holotype of $H$. crystalligena as WU 24041a.

Other specimens examined: Austria, Kärnten, Klagenfurt Land, St. Margareten im Rosental, Gupf, close to Berghof Schuschnig, MTB 9452/4, 46 $32^{\circ} 48^{\prime \prime}$ N, 14²6'57" E, elev. $800 \mathrm{~m}$, on a partly decorticated branch of Cornus sanguinea $4 \mathrm{~cm}$ thick, on the ground in leaf litter, soc. Corticiaceae, 29 Oct. 2005, H. Voglmayr \& W. Jaklitsch, W.J. 2876 (WU 24060, culture C.P.K. 2136). Same village, Trieblacher Weg (from Bauhof), at forest margin, MTB 9452/4, 46 $32^{\prime} 32^{\prime \prime} \mathrm{N}, 14^{\circ} 25^{\prime} 50^{\prime \prime}$ E, elev. $590 \mathrm{~m}$, on twigs of Fagus sylvatica and Sambucus nigra 1-5 cm thick, on bark and wood, soc. Diatrype disciformis, Hypoxylon fragiforme, Steccherinum ochraceum and Stereum hirsutum, 10 Jul. 2007, W. Jaklitsch, W.J. 3120 (WU 29220). Niederösterreich, Krems, Krumau, virgin forest at south side of the Dobra-barrage, MTB 7458/1, 48 $35^{\prime} 16^{\prime \prime} \mathrm{N}, 15^{\circ}$ $24^{\prime} 00^{\prime \prime}$ E, elev. 480 m, on a branch of Fagus sylvatica 3$4 \mathrm{~cm}$ thick, and on old Diatrypella cf. verruciformis, on the ground in leaf litter, soc. effete Hypoxylon fragiforme, 28 Sep. 2003, W. Jaklitsch, W.J. 2433 (WU 24045, culture C. P.K. 980); Hollabrunn, Hardegg, Semmelfeld, forest between Niederfladnitz and Merkersdorf, MTB 7161/3, $48^{\circ}$ $48^{\prime} 49^{\prime \prime} \mathrm{N}, 15^{\circ} 52^{\prime} 43^{\prime \prime} \mathrm{E}$, elev. $450 \mathrm{~m}$, partly decorticated branch of Quercus petraea, 5-6 cm thick, on the ground in leaf litter, 21 Jul. 2004, H. Voglmayr \& W. Jaklitsch, W.J. 2532, (WU 24048, culture C.P.K. 1615); Krems, Egelsee, close to Forsthaus Waldhof, MTB 7559/3, N 48 $25^{\prime} 55^{\prime \prime}$ E $15^{\circ} 33^{\prime} 23^{\prime \prime}$, elev. $420 \mathrm{~m}$, branch of Quercus petraea $2 \mathrm{~cm}$ thick, 24 Sep. 2005, H. Voglmayr, W.J. 2859 (WU 24059). Melk, Leiben, Weitental, at Hofmühle, MTB 7757/2, $48^{\circ}$ $14^{\prime} 51^{\prime \prime} \mathrm{N}, 15^{\circ} 17^{\prime} 23^{\prime \prime} \mathrm{E}$, elev. $270 \mathrm{~m}$, partly decorticated branch of Fagus sylvatica $6 \mathrm{~cm}$ thick, soc. Tubeufia cerea (on ?Diatrype decorticata), Lasiosphaeria hirsuta, Hypoxylon cohaerens, Lopadostoma turgidum, Orbilia inflatula, Corticiaceae, 25 Jul. 2004, H. Voglmayr \& W. Jaklitsch, W. J. 2539 (WU 24049, culture C.P.K. 1910). Melk, Sankt Leonhard am Forst, $2 \mathrm{~km}$ before Großweichselbach towards

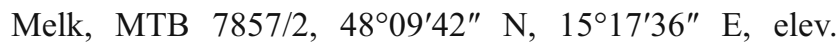
$285 \mathrm{~m}$, on partly decorticated branch of Quercus petraea 3-4 cm thick, soc. effete Diatrypella quercina, Phellinus ferruginosus, 30 Sep. 2004, W. Jaklitsch, W.J. 2748 (WU 24056, culture CBS $118979=$ C.P.K. 1917). Wienerwald, Kaltenleutgeben, near Stangau, MTB 7862/4, 48 $06^{\prime} 20^{\prime \prime}$ N, $16^{\circ} 08^{\prime} 12^{\prime \prime}$ E, elev. $450 \mathrm{~m}$, on thick branch of Quercus cerris, 5 Oct. 2008, W. Jaklitsch \& O. Sükösd, 5 Oct. 2008, W.J. 3220 (WU 29224). Wien-Umgebung, Mauerbach, walking path from the cemetery, MTB 7763/1, 48 $15^{\prime} 19^{\prime \prime}$ $\mathrm{N}, 16^{\circ} 10^{\prime} 13^{\prime \prime} \mathrm{E}$, elev. $330 \mathrm{~m}$, on a log segment of Carpinus betulus on moist ground in leaf litter, soc. Steccherinum ochraceum, 23 Jul. 2005, W. Jaklitsch, W.J. 2820 (WU 24057 , culture C.P.K. 2134). Same area, $48^{\circ} 15^{\prime} 18^{\prime \prime}$ N, $16^{\circ}$ $10^{\prime} 10^{\prime \prime}$ E, elev. $325 \mathrm{~m}$, on decorticated branch of Fagus sylvatica $8 \mathrm{~cm}$ thick, on wood, soc. Bertia moriformis, Hypoxylon fragiforme, 7 Oct. 2006, W. Jaklitsch \& H. Voglmayr, W.J. 3002 (WU 29217). Pressbaum, Rekawin$\mathrm{kel}$, forest path south of the train station, MTB $7862 / 1,48^{\circ}$ $10^{\prime} 47^{\prime \prime} \mathrm{N}, 16^{\circ} 02^{\prime} 03^{\prime \prime} \mathrm{E}$, elev. $360 \mathrm{~m}$, on corticated branch of Alnus glutinosa $5 \mathrm{~cm}$ thick, holomorph, soc. a myxomycete, effete ?Diatrypella, 18 Oct. 2003, H. Voglmayr \& W. Jaklitsch, W.J. 2476 (WU 24047, culture C.P.K. 2133). Oberösterreich, Schärding, St. Willibald, Großer Sallet-

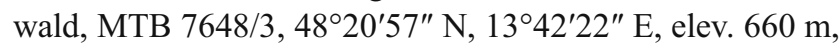
on corticated branch of Fagus sylvatica on the ground, soc. old Corticiaceae, 26 Oct. 2005, H. Voglmayr, W.J. 2866 (WU 24061). Großer Salletwald, MTB 7648/1, elev. 455 m, on branch of Fagus sylvatica, 13 Aug. 2006, H. Voglmayr, W.J. 2928 (WU 29215, culture C.P.K. 3117). Steiermark, Graz-Umgebung, Mariatrost, Wenisbucher Straße, MTB $8858 / 4,47^{\circ} 06^{\prime} 40^{\prime \prime} \mathrm{N}, 15^{\circ} 29^{\prime} 11^{\prime \prime} \mathrm{E}$, elev. $470 \mathrm{~m}$, on a 4 $5 \mathrm{~cm}$ thick branch of a large dead tree of Fagus sylvatica, lying on the ground, 20 Aug. 2004, W. Jaklitsch, W.J. 2611 (WU 24054, culture C.P.K. 1915). Tirol, Innsbruck-Land, Ampass, Ampasser Hügel, MTB 8734/2, 47¹5'31" N, $11^{\circ}$ $27^{\prime} 16^{\prime \prime}$ E, elev. $720 \mathrm{~m}$, on decorticated branch of Alnus incana $2 \mathrm{~cm}$ thick, on ground among moss; holomorph, soc. Nemania serpens, Stereum subtomentosum, 2 Sep. 2003, U. Peintner \& W. Jaklitsch, W.J. 2354 (WU 24043, culture C.P.K. 944). Vorarlberg, Feldkirch, Rankweil, behind the hospital Valduna, MTB 8723/2, 47 ${ }^{\circ} 15^{\prime} 40^{\prime \prime} \mathrm{N}$, $09^{\circ} 39^{\prime} 00^{\prime \prime}$ E, elev. 510 m, on decorticated branch of Fagus sylvatica $4 \mathrm{~cm}$ thick, on the ground in leaf litter, soc. 
Steccherinum ochraceum, 31 Aug. 2004, H. Voglmayr \& W. Jaklitsch, W.J. 2644 (WU 24055, culture C.P.K. 1916).

Estonia, Ida-Virumaa County, Illuka Commune, Puhatu Nature Reserve, Poruni virgin forest, on branch of ?Salix sp., 1 Oct. 2006, K. Pärtel (WU 29218, culture C.P.K. 2485). Germany, Bavaria, Unterfranken, Landkreis Haßberge, Haßfurt, close to Mariaburghausen, left roadside heading from Knetzgau to Haßfurt, MTB 5929/3, 5000' $33^{\prime \prime} \mathrm{N}, 10^{\circ} 31^{\prime} 10^{\prime \prime} \mathrm{E}$, elev. $280 \mathrm{~m}$, on partly decorticated branch of Carpinus betulus $5 \mathrm{~cm}$ thick, holomorph, soc. Phlebiella vaga, 4 Aug. 2004, H. Voglmayr \& W. Jaklitsch, W.J. 2568 (WU 24050, culture C.P.K. 1911); same collection data, on corticated branches of Tilia cordata, W.J. 2570 (WU 24052, culture C.P.K. 1913); same area, $50^{\circ} 00^{\prime} 23^{\prime \prime} \mathrm{N}, 10^{\circ} 31^{\prime} 08^{\prime \prime} \mathrm{E}$, elev. $270 \mathrm{~m}$, on mostly decorticated branch of Fagus sylvatica $4 \mathrm{~cm}$ thick, on wood, 29 Aug. 2006, H. Voglmayr \& W. Jaklitsch, W.J. 2961 (WU 29216, culture C.P.K. 3118). Starnberg, Tutzing, Erling, Goaßlweide near Hartschimmelhof, MTB 8033/3, $47^{\circ} 56^{\prime} 33^{\prime \prime} \mathrm{N}, 11^{\circ} 11^{\prime} 00^{\prime \prime} \mathrm{E}$, elev. $730 \mathrm{~m}$, on partly decorticated branch of Fagus sylvatica $4 \mathrm{~cm}$ thick, on the ground in grass, soc. Bertia moriformis, Neobarya parasitica, Tomentella sp., 7 Aug. 2004, W. Jaklitsch, H. Voglmayr, P. Karasch \& E. Garnweidner, W.J. 2581 (WU 24053, culture C.P.K. 1914). Netherlands, Putten, in the main arboretum of Landgoed Schovenhorst, elev. $0 \mathrm{~m}$, on partly decorticated branch of ?Taxus baccata 7-10 cm thick, on wood and bark, 19 Nov. 2006, H. Voglmayr, W.J. 3047 (WU 29219, culture C.P.K. 2855). Sweden, Uppsala Län, Sunnersta, forest opposite the virgin forest Vardsätra Naturpark across the road, MTB 3871/2, 59 47'23" N, $17^{\circ} 37^{\prime} 53^{\prime \prime}$ E, elev. $15 \mathrm{~m}$, on corticated branch of Corylus avellana 2-3 cm thick, on bare, moist soil, soc. Stereum rugosum, Diatrypella verruciformis, 8 Oct. 2003, W. Jaklitsch, W.J. 2451 (WU 24046, culture C.P.K. 1604). Ukraine, Kharkov district, Zmiev, National nature park Gomolshanskie lesa, flooded forest near Seversky Donets river, on branch of Alnus glutinosa, 26 Jul. 2007, A. Akulov, AS 2439 (WU 29221, culture C.P.K. 3132). United Kingdom, Hertfordshire, Hertford, Waterford, Waterford Heath, Mole Wood, 51 48'44" N, 0005'20" $\mathrm{W}$, elev. $70 \mathrm{~m}$, on Hypoxylon fuscum/Corylus avellana $9 \mathrm{~cm}$ thick, 12 Sep. 2007, W.Jaklitsch, K. Robinson \& H. Voglmayr, W.J. 3155 (WU 29222).

Notes: Hypocrea crystalligena is common in Central Europe, and occurs occasionally also in other European regions. Its white gliocladium-like anamorph is typical of the Psychrophila clade, while the stromata suggest affiliation with sect. Trichoderma, because of the inconspicuous ostiolar dots, at least when young, the downy surface of young stromata, and the inhomogeneously disposed, reddish brown cortical pigment. However, the white, powdery covering on the stroma surface and the globose or clavate cells lining the ostiole apices are not known in sect. Trichoderma. In addition, the ascospores are extraordinarily small, smaller than those of any species of sect. Trichoderma currently known in Europe. Cultures of $H$. crystalligena on CMD and SNA are characteristic due to slow growth and the formation of finely zonate radial lobes. The formation of a diffuse yellowish to brownish pigment varies among the strains. Initially after isolation, nearly all strains formed a water-insoluble substance, appearing as colourless or white crystals on CMD, but after several transfers this ability was lost. This may be attributable to the CMA, because conspicuous crystals were only seen on the first batch of CMA used. On batches used thereafter, crystals were only rarely found (e.g. in C.P.K. 2855), while white crystalline powder was regularly seen on the surface of stromata, at least in larger populations, collected after the original description by Jaklitsch et al. (2006a).

Hypocrea psychrophila E. Müll., Aebi \& J. Webster, Trans. Brit. Mycol. Soc. 58:1 (1972). Fig. 85

Anamorph: Trichoderma psychrophilum Jaklitsch, sp. nov. Fig. 86

MycoBank MB 516699

Anamorphosis Hypocreae psychrophilae: incrementum optimum ad $15-20^{\circ} \mathrm{C}$ in agaris CMD, PDA, SNA, prope absens ad $25^{\circ} \mathrm{C}$; incrementum et sporulatio etiam occurrens ad $6-10^{\circ} \mathrm{C}$ in agaro SNA. Conidiophora in pustulis albis similia Gliocladii in agaro SNA. Phialides lageniformes, $(6-) 7-12(-19) \times(2.3-) 2.8-3.5(-4.5) \mu \mathrm{m}$. Conidia hyalina, ellipsoidea vel oblonga, glabra, $(3.2-) 3.8-5.3(-7.0) \times(2.3-)$ 2.5-3.0(-3.7) $\mu \mathrm{m}$.

Stromata when fresh 2-7 $\mathrm{mm}$ diam, 1-2.5 $\mathrm{mm}$ thick, pulvinate or semi- to subglobose, centrally attached, margin free, often lobed. Surface smooth, bright yellow, ostiolar dots darker yellow or reddish brown, resulting colour $4 \mathrm{~A} 8$.

Stromata when dry $(1.3-) 1.5-3.3(-5.1) \times(0.9-) 1.2-2.4(-$ 3.2) $\mathrm{mm},(0.5-) 0.6-1.4(-2.0) \mathrm{mm}$ thick $(n=20)$, solitary, less commonly gregarious or aggregated in small numbers, erumpent from bark, centrally attached, typically on a white, columnar or pulvinate, compact mycelial base, with upper fertile part free and often incurved at the margin, pulvinate or semiglobose; outline roundish, oblong or irregularly lobed. Surface smooth, slightly tubercular or rugose, glabrous or slightly downy or whitish floccose. Ostiolar dots (30-)47-106(-165) $\mu \mathrm{m}(n=90)$ diam, numerous, densely disposed, well-defined when mature, often confluent, convex to papillate, orange to nearly red. Stroma colour bright orange (bright yellow surface, orange dots), 5-6AB5-8. White inside. Spore deposits white. Dry stromata instantly transparent and discoloured to pale yellowish after addition of $3 \% \mathrm{KOH}$ on a slide. Rehydrated stromata ca $30 \%$ larger than dry, semiglobose, light 

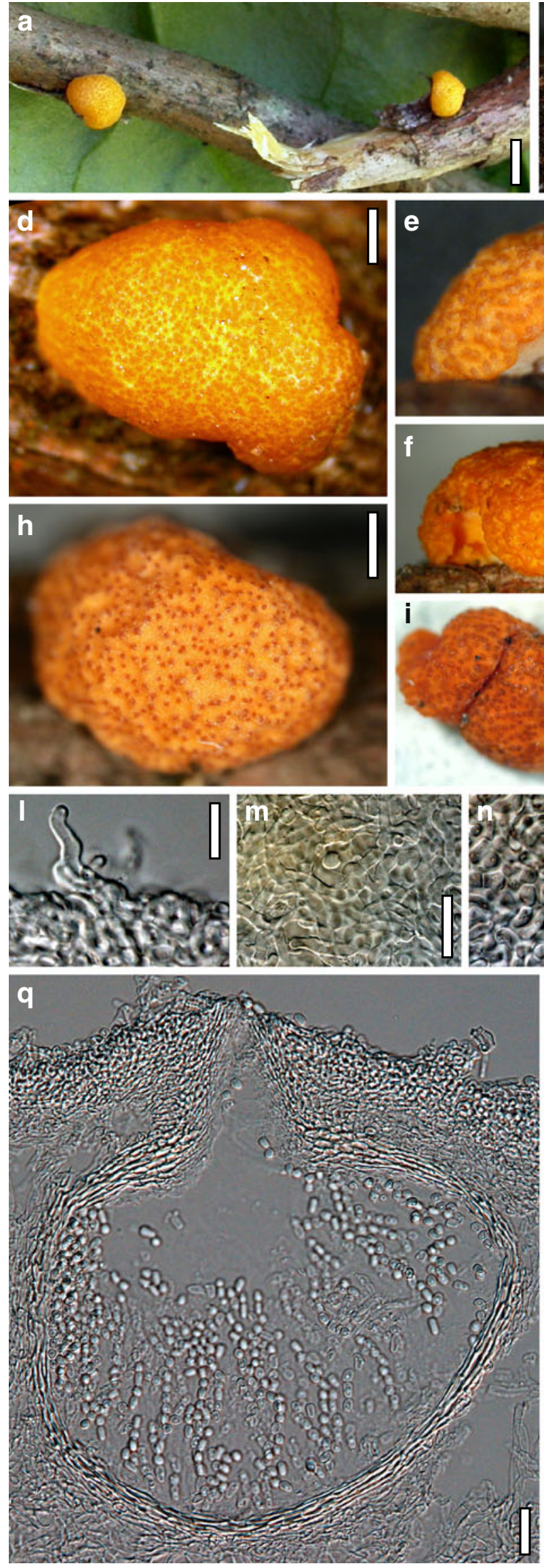
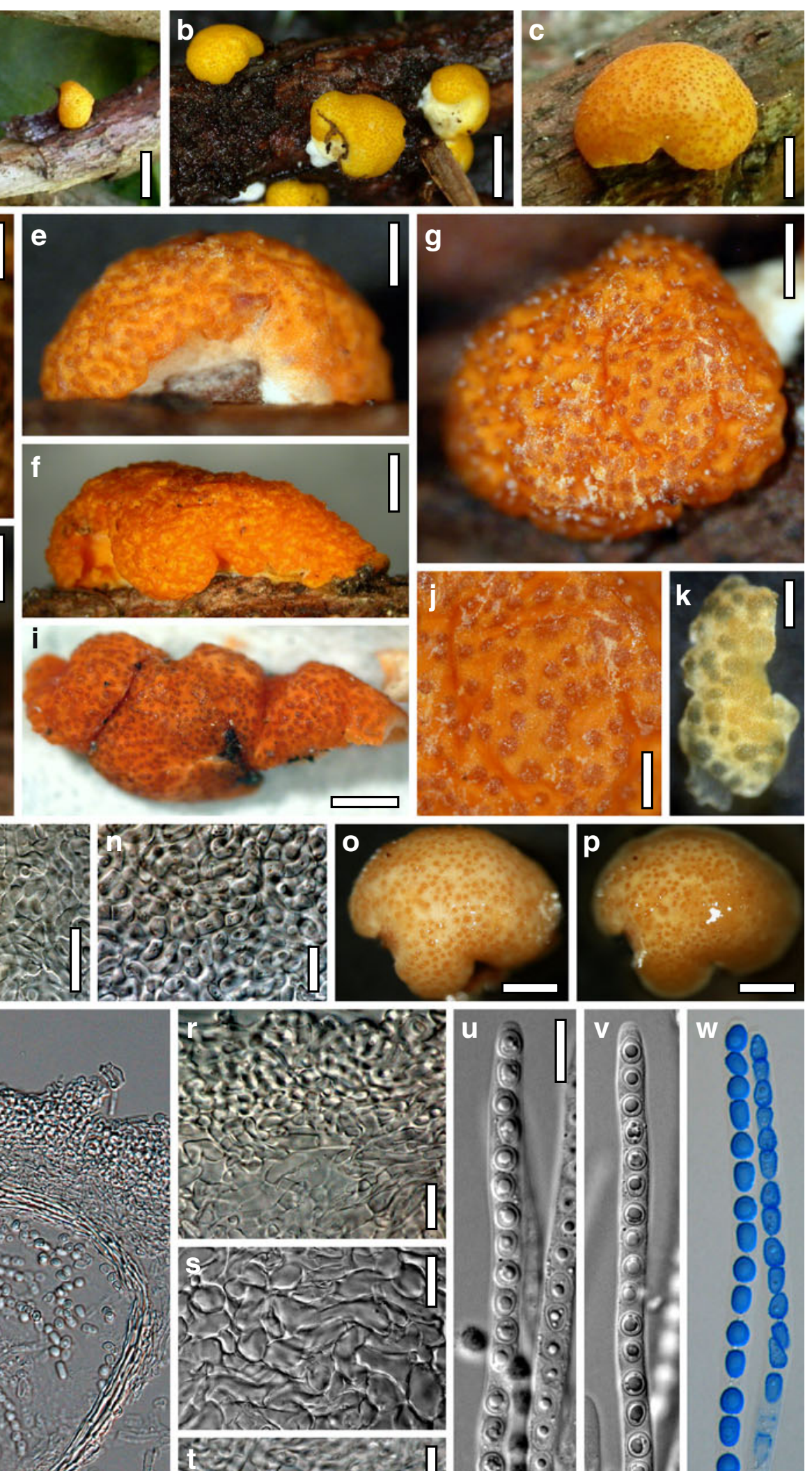

15 So,

$x=0$
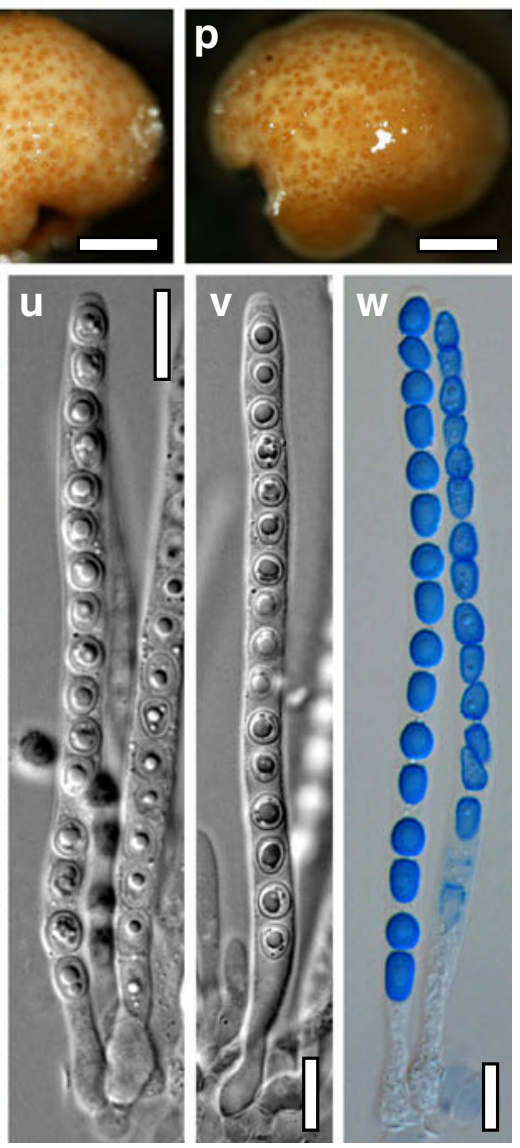
4 Fig. 85 Teleomorph of Hypocrea psychrophila. a-d. Fresh stromata (a, b. habit; d. moist/partly dry). e-j. Dry stromata (e, f. side view; j. stroma surface). k. Dry stroma treated with $3 \% \mathrm{KOH}$. I. Hair on stroma surface in section. $\mathbf{m}$. Hyphae on stroma surface in face view. n. Stroma surface without hyphal covering in face view. o. Rehydrated stroma. p. Stroma in 3\% $\mathrm{KOH}$ after rehydration. q. Perithecium in section. r. Cortical and subcortical tissue in section. s. Subperithecial tissue in section. t. Stroma base in section. $\mathbf{u}-\mathbf{w}$. Asci with ascospores (w. in cotton blue/lactic acid). a, c, h, m. WU 29421. b, e, g, j-l, n-w. WU 29422. d, f. WU 29420. i. holotype K 155404. Scale bars $\mathbf{a}, \mathbf{b}=$ $1.7 \mathrm{~mm}$. c, d, f, i, o, $\mathbf{p}=0.8 \mathrm{~mm}$. e, $\mathbf{g}, \mathbf{h}=0.5 \mathrm{~mm} . \mathbf{j}=0.2 \mathrm{~mm} . \mathbf{k}=$ $0.3 \mathrm{~mm}$. l, n, r, $\mathbf{u}-\mathbf{w}=10 \mu \mathrm{m} . \mathbf{m}, \mathbf{q}, \mathbf{s}, \mathbf{t}=20 \mu \mathrm{m}$

yellowish, discoloured, white with pale orange-ochre ostiolar dots; no change noted after addition of $3 \% \mathrm{KOH}$.

Stroma anatomy: Ostioles (67-)75-98(-116) $\mu \mathrm{m}$ long, plane or projecting to $15(-30) \mu \mathrm{m},(28-) 30-45(-60) \mu \mathrm{m}$ wide at the apex $(n=31)$, typically only periphysate, less commonly with some clavate marginal cells to $6 \mu \mathrm{m}$ wide at the apex; often ostiolum and stroma cortex projecting to 50-90 $\mu \mathrm{m}$. Perithecia (160-)200-250(-290) $\times(90-) 130-$ $200(-215) \mu \mathrm{m}(n=31)$, flask-shaped, ellipsoidal or subglobose, mostly crowded, 7-8 per $\mathrm{mm}$ stroma length. Peridium (11-)13-19(-21) $\mu \mathrm{m}(n=31)$ thick at the base, $(5-) 10-16(-18) \mu \mathrm{m}(n=31)$ at the sides, pale yellowish. Cortical layer (16-)20-30(-35) $\mu \mathrm{m}(n=30)$ thick, a dense, subhyaline to pale yellowish $t$. angularis of isodiametric or oblong, thick-walled cells $(2.5-) 4-8(-11) \times(2.5-) 3-5(-7)$ $\mu \mathrm{m}$ in face view and in vertical section $(n=62)$. Cortex of young stromata covered by a reticulum of thick-walled hyaline hyphae, when mature remaining as hairs (4-)8-24 $(-35) \times(2.5-) 3.0-4.5(-5.5) \mu \mathrm{m}(n=30)$, cylindrical, straight or curved, simple or branched, hyaline, thin-walled. Subcortical tissue a $t$. intricata of thin-walled hyaline hyphae (2.0-)2.5-4.5(-7.0) $\mu \mathrm{m}(n=30)$ wide. Subperithecial tissue a $t$. epidermoidea-intricata of thick-walled hyaline cells $(4-) 7-30(-58) \times(4-) 7-14(-22) \quad \mu \mathrm{m} \quad(n=30)$ and hyphae $(3.5-) 6-13(-19) \mu \mathrm{m}(n=30)$ wide. Nonattached base a loose or dense $t$. intricata of hyaline or yellowish, thick-walled hyphae (2.0-)2.5-4.5(-6.0) $\mu \mathrm{m}(n=$ 30) wide. Asci $(85-) 100-130(-150) \times(5.0-) 5.5-6.2(-7.0)$ $\mu \mathrm{m}$; stipe (5-)13-28(-41) $\mu \mathrm{m}$ long $(n=60)$; croziers present. Ascospores hyaline, verruculose; cells dimorphic; distal cell $(4.0-) 4.5-5.7(-6.7) \times(3.7-) 4.0-4.5(-5.0) \mu \mathrm{m}, 1 / \mathrm{w}(1.0-) 1.1-$ 1.4(-1.7) $(n=110)$, subglobose or wedge-shaped; proximal cell (4.5-)5.2-6.5(-7.8)×(3.0-)3.3-4.0(-4.5) $\mu \mathrm{m}, 1 / \mathrm{w}(1.2-)$ $1.4-1.8(-2.2)(n=110)$, oblong or subglobose; size increasing with maturation.

Cultures and anamorph: optimal growth at $15-20^{\circ} \mathrm{C}$, growth virtually absent at $25^{\circ} \mathrm{C}$, no growth above $25^{\circ} \mathrm{C}$.

On CMD after $72 \mathrm{~h} 3-5 \mathrm{~mm}$ at $15^{\circ} \mathrm{C}, 0.2-1.5 \mathrm{~mm}$ at $25^{\circ} \mathrm{C}$; after 2 weeks $7-11 \mathrm{~mm}$ at $6-10^{\circ} \mathrm{C}$ in the dark and $21-25 \mathrm{~mm}$ at $15^{\circ} \mathrm{C}$; mycelium typically covering the plate after more than a month at $15^{\circ} \mathrm{C}$. Colony at $15^{\circ} \mathrm{C}$ hyaline, thin, indistinctly concentrically zonate, hardly visible; mycelium loose, hyphae hyaline, becoming moniliform and turning reddish brown. Aerial hyphae scant, short, more frequent along the distal margin. Autolytic activity low at $15^{\circ} \mathrm{C}$, conspicuous at $25^{\circ} \mathrm{C}$; coilings inconspicuous. Diffusing pigment turning the agar yellow, pale or greyish orange to yellow-brown, 4-5A3-5, 6B5-6, beginning in the centre. No distinct odour noted. No chlamydospores noted within a month. Conidiation noted after a month or later at $15^{\circ} \mathrm{C}$, gliocladium-like in small white pustules. At $6-10^{\circ} \mathrm{C}$ colony colourless, sterile, margin becoming downy by long aerial hyphae.

On PDA after $72 \mathrm{~h} 3-4 \mathrm{~mm}$ at $15^{\circ} \mathrm{C},<1 \mathrm{~mm}$ at $25^{\circ} \mathrm{C}$; after 2 weeks $3-9 \mathrm{~mm}$ at $6-10^{\circ} \mathrm{C}$ in the dark and $9-24 \mathrm{~mm}$ at $15^{\circ} \mathrm{C}$; mycelium not covering the plate within a month at $15^{\circ} \mathrm{C}$. Colony at $15^{\circ} \mathrm{C}$ first hyaline, thin, dense; becoming downy by long stout aerial hyphae; marginal hyphae sinuous or helical. Autolytic activity moderate at $15^{\circ} \mathrm{C}$, conspicuous at $6-10^{\circ} \mathrm{C}$; no coilings observed. No distinct odour noted. Plug and colony centre turning bright yellow to orange, 3-4A4-7, 6AB6-7, after a week, changing to orange-brown to reddish brown, 6-8CD6-8; 9C7-8; hyphae turning red. Conidiation lacking or noted after $c a$ 1 weeks, scant, around the plug, effuse, spreading, gliocladium-like, soon degenerating.

On SNA after $72 \mathrm{~h} 1-2 \mathrm{~mm}$ at $15^{\circ} \mathrm{C}$; after 2 weeks $2-$ $4 \mathrm{~mm}$ at $6-10^{\circ} \mathrm{C}$ in the dark and $10-16 \mathrm{~mm}$ at $15^{\circ} \mathrm{C}$; mycelium not covering the plate within a month at $15^{\circ} \mathrm{C}$. Colony at $15^{\circ} \mathrm{C}$ hyaline, thin, dense, zonate; margin downy; hyphae with irregular thickenings. Aerial hyphae typically abundant and long in downy distal areas of the colony. Autolytic activity inconspicuous to moderate at $15^{\circ} \mathrm{C}$; coilings inconspicuous or frequent. No diffusing pigment, no distinct odour noted. No chlamydospores seen. Conidiation seen after $(1-) 2-3$ weeks at $15^{\circ} \mathrm{C}$, first scant and effuse in mostly central minute shrubs, becoming visible at the beginning of a broad concentric downy zone as white floccules or tufts $0.5-1.5 \mathrm{~mm}$ diam, confluent to $5 \mathrm{~mm}$, and on long branched aerial hyphae, gliocladium-like. Sometimes tufts evenly or irregularly disposed on the colony surface. Tufts fluffy or compact, typically transparent, of a loosely branched reticulum with long main axes and a minutely granular surface caused by whorls of phialides and conidial heads. Primary branches often paired, terminal branches paired or not. Main axes mostly erect, branched 2-3 fold, with side branches mostly unpaired and inclined upwards in steep angles. Terminal branches emerging in right angles or steeply inclined upwards, at the highest levels often paired, also often in clusters of 2-3. Sometimes conidiation restricted to small clusters or short tree-like conidiophores emerging at right angles terminally on the main axis. Conidiophores (main axes to terminal branches) mostly 4-6 $\mu \mathrm{m}$ wide, terminally $2-3 \mu \mathrm{m}$. Phialides parallel, less commonly divergent, in whorls of 2-6(-8), rarely solitary; whorls solitary when terminal, otherwise often 

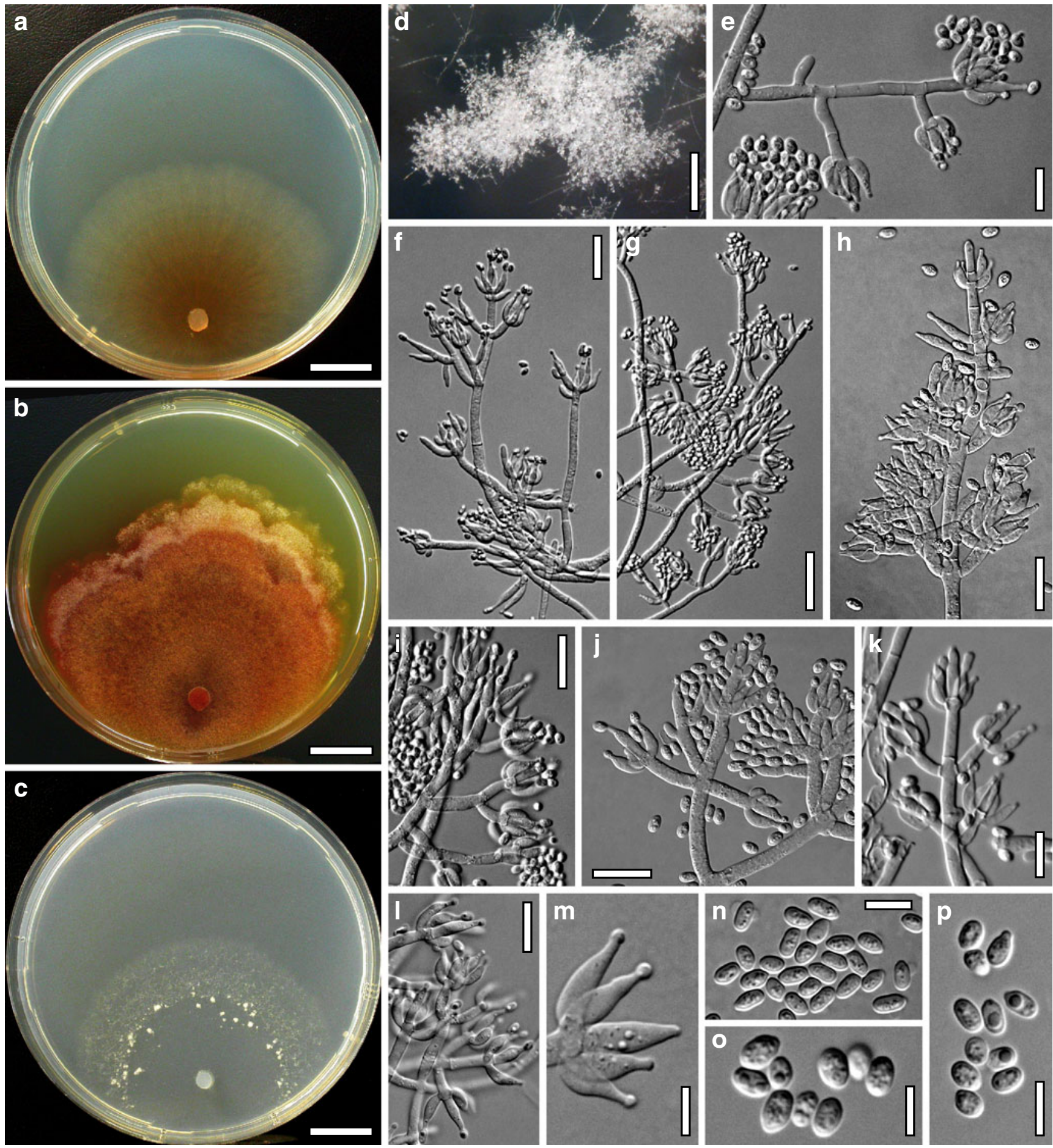

Fig. 86 Cultures and anamorph of Hypocrea psychrophila. a-c. Cultures (a. on CMD, 35 days. b. on PDA, 41 days. c. on SNA, 27 days). d. Conidiation tuft (31 days). e-l. Conidiophores (3139 days). m. Phialides. n-p. Conidia (o, p. 31 days). a-l, o, p. At

paired; supporting cells (metulae) (6-)7-11(-14) $\mu \mathrm{m}$ long, $(2.0-) 3.0-4.0(-4.5) \mu \mathrm{m}$ wide at the apex, 2.2-3.0(-3.5) $\mu \mathrm{m}$ wide at the lower end $(n=20)$, often thickened. Phialides $(6-) 7-12(-19) \times(2.3-) 2.8-3.5(-4.5) \mu \mathrm{m}, 1 / \mathrm{w}(1.8-) 2.3-4.0$ $15^{\circ}$ C. d-l, o, p. On SNA. a-c, h, j, k. C.P.K. 1602 . d, e, g, i, o, p. CBS 119129. f, l. C.P.K. 2435. m, n. holotype K 155404, dry culture. Scale bars $\mathbf{a}-\mathbf{c}=15 \mathrm{~mm} . \mathbf{d}=0.5 \mathrm{~mm}$. e, $\mathbf{k}=10 \mu \mathrm{m} . \mathbf{f}=20 \mu \mathrm{m} . \mathbf{g}=$ $30 \mu \mathrm{m} . \mathbf{h}-\mathbf{j}, \mathbf{l}=15 \mu \mathrm{m} . \mathbf{m}, \mathbf{o}=5 \mu \mathrm{m} . \mathbf{n}, \mathbf{p}=7 \mu \mathrm{m}$

(-5.8), (1.5-)2.0-2.8(-3.5) $\mu \mathrm{m}$ wide at the base $(n=125)$, lageniform, straight in the middle of the whorl, otherwise distinctly curved, inaequilateral, sometimes sigmoid, often attenuated at the base and apex, widest mostly in or below 
the middle; neck variable, often long and thin, abruptly attenuated and nearly cylindrical. Conidia formed in mostly dry minute heads $<20 \mu \mathrm{m}$ diam. Conidia (3.2-)3.8-5.3($7.0) \times(2.3-) 2.5-3.0(-3.7) \mu \mathrm{m}, 1 / \mathrm{w}(1.3-) 1.4-2.0(-2.5)(n=$ 148), hyaline, ellipsoidal to oblong, smooth, eguttulate or finely multiguttulate; scar indistinct or prominent. At $6-10^{\circ}$ $\mathrm{C}$ colony irregular, hyaline, loose; aerial hyphae abundant, arising several $\mathrm{mm}$, arachnoid to nearly cottony.

Fertile stromata characteristically formed in culture on OA (W. Gams, pers. comm.).

Habitat: on dead twigs of Rhododendron ferrugineum and $R$. hirsutum, also reported from stems of Vaccinium myrtillus (Müller et al. 1972).

Distribution: Central Europe (alpine regions of Austria, Germany and Switzerland).

Holotype: Switzerland, Kanton Wallis, Brig, Aletschreservat, alter Belalpweg, on wood of Rhododendron ferrugineum, 12 Sep. 1968, E. Müller \& B. Aebi (K(M) 155404, ex herb. Sheffield Univ. 3031). Holotype of Trichoderma psychrophilum isolated from WU 29420 and deposited as a dry culture with $H$. psychrophila WU 29420 as WU 29420a.

Other specimens examined: Austria, Tirol, Imst, Silz, between Haggen and Kühtai, close to the Zirmbachalm,

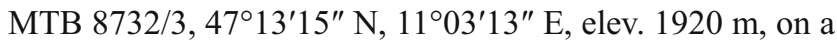
thin corticated twig of Rhododendron ferrugineum $9 \mathrm{~mm}$ thick, on bark, 3 Sep. 2003, W. Jaklitsch, W.J. 2366 (WU 29420 , culture C.P.K. 1602). Same area, $47^{\circ} 13^{\prime} 14^{\prime \prime}$ N, $11^{\circ}$ 03'17" E, elev. $1940 \mathrm{~m}$, on thin corticated twigs of Rhododendron ferrugineum 2-6 cm thick, on bark, 28 Aug. 2004, W. Jaklitsch \& H. Voglmayr, W.J. 2624 (WU 29421, culture CBS $119129=$ C.P.K. 1990). Germany, Bavaria, Landkreis Garmisch-Partenkirchen, Garmisch, Wettersteingebirge, Garmisch-Partnachklamm, Reintal, Kreuzeck MTB 8532/14, elev. $1700 \mathrm{~m}$, on corticated twigs of Rhododendron hirsutum, 30 July 2006, P. Karasch, W.J. 2926 (WU 29422, culture C.P.K. 2435). Switzerland, Kanton Wallis, Brig, Aletschreservat, alter Belalpweg, on wood of Rhododendron ferrugineum, Riederfurka, 9 Sep. 1970, E. Müller (culture CBS 343.71; only culture examined).

Notes: This species is unequivocally characterised by bright yellow to orange stromata on Rhododendron spp. in the Alps. In specimens, stromata of $H$. psychrophila are usually present in small numbers, also in the holotype $\mathrm{K}(\mathrm{M})$ 155404. The identity of $H$. psychrophila is clear due to the holotype and the culture CBS 343.71, therefore an epitypification does not appear to be necessary, although CBS 343.71 is not derived from the holotype but from the second specimen mentioned by Müller et al. (1972). The holotype includes pale yellowish stromata (having lost their colour upon incubation in a damp chamber) on a corticated twig; a convolute of three typical, densely aggregated, bright orange stromata wrapped in filter paper, a dry culture agreeing with the fresh anamorph, and a slide with a stroma section. Conidiophores and whorls of phialides of $T$, psychrophilum are similar to those of the closely related T. crystalligenum, i.e. phialides may be parallel or divergent on the same conidiophore. Sometimes the conidiation is concentrated on the tuft periphery, in such cases tufts are similar to those of $T$. placentula.

Hypocrea rhododendri Jaklitsch \& Voglmayr, sp. nov. Fig. 87

MycoBank MB 516700

Stromata in ramulis Rhododendri ferruginei, pulvinata, pallide lutea. Asci cylindrici, (97-)100-116(-135) $\times(4.5-) 5.0$ $6.0(-6.5) \mu \mathrm{m}$. Ascosporae bicellulares, hyalinae, verruculosae, ad septum disarticulatae, pars distalis subglobosa, ellipsoidea vel cuneata, $(3.8-) 4.0-5.0(-5.5) \times(3.3-) 3.5-4.0(-4.3) \mu \mathrm{m}$, pars proxima cuneata, oblonga vel subglobosa, (4.0-)4.5-5.5($6.0) \times(2.7-) 3.0-3.5(-4.0) \mu \mathrm{m}$. Colonia in vitro sterilis.

Etymology: rhododendri due to its occurrence on Rhododendron.

Stromata when fresh $2-3 \mathrm{~mm}$ diam, to $1 \mathrm{~mm}$ thick, solitary or gregarious, pulvinate. Surface smooth; ostiolar dots yellowish. Stromata whitish to pale yellowish.

Stromata when dry $(0.7-) 1.3-2.6(-3.0) \times(0.7-) 1.0-$ $1.7 \mathrm{~mm}(n=9),(0.2-) 0.3-0.6 \mathrm{~mm}(n=11)$ thick, erumpent through or superficial on bark, pulvinate or discoid; outline roundish or oblong; broadly or centrally attached; margin free, plump, rounded or rolled in at the base, sometimes undulate, pale incarnate. Surface smooth to slightly tubercular by slightly projecting perithecia. Ostiolar dots (30-)52-97(134) $\mu \mathrm{m}(n=30)$ diam, circular, convex or plane, often diffuse. Stroma colour yellowish to pale orange, 5A4, resulting from white surface and cream to yellow-ochre dots or spots; white inside. Spore deposits white. Stromata after rehydration more thickly pulvinate than dry, white with ochre-yellow perithecia; pale yellow, ochre-yellowish, dots (80-)100-160 $\mu \mathrm{m}$ diam; not changing colour in 3\% KOH.

Stroma anatomy: Ostioles (69-)86-111(-126) $\mu \mathrm{m}$ long, plane or projecting 14-37(-45) $\mu \mathrm{m},(32-) 36-54(-75) \mu \mathrm{m}$ wide at the apex $(n=31)$, with clavate marginal cells to $6 \mu \mathrm{m}$ wide at the apex, projecting in fascicles. Perithecia $(170-) 200-245(-270) \times(115-) 130-200(-235) \mu \mathrm{m}(n=31)$, globose, ellipsoidal or flask-shaped, variably disposed; peridium (13-)15-21(-25) $\mu \mathrm{m}(n=31)$ thick at the base, (6-)12-19(-22) $\mu \mathrm{m}(n=31)$ thick at the sides; hyaline to pale yellowish. Cortical layer (15-)20-37(-56) $\mu \mathrm{m}(n=30)$ thick, a dense $t$. angularis of thin- or thick-walled cells (3-) $4-8(-10) \times(2-) 3-5(-8) \mu \mathrm{m}(n=60)$ in face view and in vertical section; subhyaline to pale yellowish. Cortex partly covered by a thin amorphous layer of more or less compressed, undifferentiated hyphae; no differentiated hairs present. Subcortical tissue of thin-walled hyaline cells (3-) $5-8(-10) \times(2.5-) 3.5-5.5(-7.0) \mu \mathrm{m}(n=31)$, mixed with 

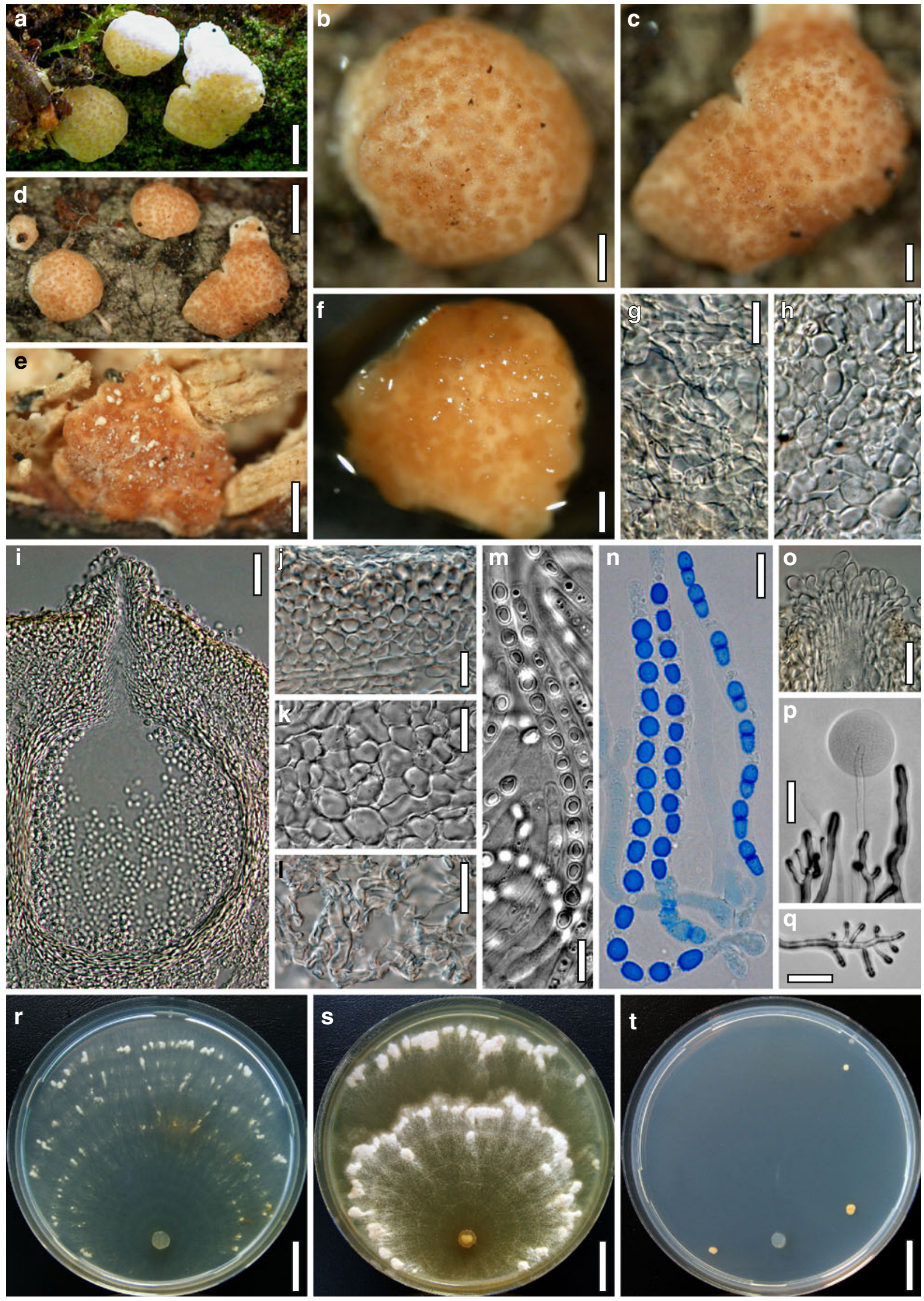
4Fig. 87 Hypocrea rhododendri. a-o. Teleomorph (WU 29442). a. Fresh stromata. b-e. Dry stromata (e. showing spore deposits). f. Stroma in $3 \% \mathrm{KOH}$ after rehydration. g. Hyphae on stroma surface in face view. h. Stroma surface without hyphal covering in face view. i. Perithecium in section. j. Cortical and subcortical tissue in section. $\mathbf{k}$. Subperithecial tissue in section. 1. Stroma base in section. m, n. Asci with ascospores (n. in cotton blue/lactic acid). o. Marginal cells at the ostiolar apex. p-t. Hypocrea rhododendri (CBS 119288) in culture. p. Autolytic excretion (PDA, 4 days). q. Peg-like terminal branches on marginal hypha (PDA, 7 days). r-t. Cultures (r. on CMD, 35 days. s. on PDA, 35 days. t. on SNA, 28 days). p-t. At $15^{\circ} \mathrm{C}$. Scale bars a, d $=1 \mathrm{~mm}$. b, $\mathbf{c}=0.3 \mathrm{~mm}$. e, $\mathbf{f}=0.4 \mathrm{~mm} . \mathbf{g}, \mathbf{h}, \mathbf{j}, \mathbf{m}, \mathbf{n}=10 \mu \mathrm{m} . \mathbf{i}=30 \mu \mathrm{m}$. $\mathbf{k}, \mathbf{l}, \mathbf{o}=15 \mu \mathrm{m} . \mathbf{p}=50 \mu \mathrm{m} . \mathbf{q}=100 \mu \mathrm{m} . \mathbf{r}-\mathbf{t}=15 \mathrm{~mm}$

hyaline hyphae (3.0-)3.5-5.5(-7.5) $\mu \mathrm{m}(n=30)$ wide. Subperithecial tissue a $t$. angularis-epidermoidea of thinwalled hyaline cells $(6-) 8-21(-28) \times(3-) 7-13(-15) \mu \mathrm{m}(n=$ $30)$. Stroma base of often strongly compressed, thickwalled, hyaline to pale yellowish hyphae (1.8-)2.5-5.2(7.5) $\mu \mathrm{m}(n=30)$ wide, extending upwards along the sides and forming the amorphous layer on the upper surface. Asci (97-)100-116(-135)×(4.5-)5.0-6.0(-6.5) $\mu \mathrm{m}$, stipe (11-) $12-24(-31) \mu \mathrm{m}$ long $(n=30)$, croziers present. Ascospores hyaline, verruculose; cells dimorphic; distal cell (3.8-)4.0-5.0 $(-5.5) \times(3.3-) 3.5-4.0(-4.3) \mu \mathrm{m}, 1 / \mathrm{w}(1.0-) 1.1-1.3(-1.4)(n=$ $30)$, subglobose, ellipsoidal or wedge-shaped; proximal cell $(4.0-) 4.5-5.5(-6.0) \times(2.7-) 3.0-3.5(-4.0) \mu \mathrm{m}, 1 / \mathrm{w}(1.1-) 1.4$ 1.7(-1.8) $(n=30)$, wedge-shaped, oblong or subglobose.

Cultures and anamorph: optimal growth at $15^{\circ} \mathrm{C}$ on all media; no growth at and above $30^{\circ} \mathrm{C}$. No conidiation noted on all media.

On CMD after $72 \mathrm{~h} 9-11 \mathrm{~mm}$ at $15^{\circ} \mathrm{C}, 5-7 \mathrm{~mm}$ at $25^{\circ} \mathrm{C}$; mycelium covering the plate after 3 weeks at $15^{\circ} \mathrm{C}$. At $15^{\circ} \mathrm{C}$ colony hyaline, thin, loose, circular with wavy margin, zonate; hyphae finely wavy along their length, wide, narrow secondary hyphae scant. Dense mycelial clumps formed immersed in the agar, becoming visible as whitish spots, $1-6 \times 0.5-2.5 \mathrm{~mm}$, in concentric zones, radially elongate, eventually turning brown. Sometimes few small brown sterile stromata appearing in irregular disposition on the colony surface. Aerial hyphae inconspicuous, more frequent at the margin. Autolytic excretions absent at $15^{\circ} \mathrm{C}$, abundant at $25^{\circ} \mathrm{C}$ in the entire colony, minute, turning yellowish brown; coilings rare. No chlamydospores, only widened cells in surface hyphae seen. Reverse faintly yellowish, 2A3; odour indistinct. At $25^{\circ} \mathrm{C}$ colony irregularly lobed. Hyphae often with short pegs or becoming moniliform, many dying soon. Mycelial density inhomogeneous. Autolytic excretions turning the colony yellowish to dull yellowish brown, 4B4-5.

On PDA after $72 \mathrm{~h} 8-10 \mathrm{~mm}$ at $15^{\circ} \mathrm{C}, 4-5 \mathrm{~mm}$ at $25^{\circ} \mathrm{C}$; mycelium covering the plate after $18-20$ days at $15^{\circ} \mathrm{C}$. At $15^{\circ} \mathrm{C}$ colony well-defined with wavy margin, dense, zonate, mainly of thick primary hyphae finely wavy along their length; marginal surface hyphae conspicuously wide, terminally branched into short pegs. Distal surface becoming hairy due to thick, long and high aerial hyphae radially oriented at the margin, forming short strands, collapsing as fine floccules. Mycelial clumps formed in the agar and above as white, eventually brownish, superficial tufts to $1.5 \mathrm{~mm}$ thick in a broad central zone with irregular margin and in a distal zone. Autolytic activity conspicuous, excretions brownish, absent in fresh growth zones. Coilings frequent, autolysing yellow to reddish. Reverse turning yellowish to brown-orange, 4B4-6, 5C5, darker and with reddish tones below the mycelial spots. At $25^{\circ} \mathrm{C}$ colony conspicuously dense, mycelium with extremely dense broom-like branching, thick; yellow-brown pigment diffusing into the agar; reverse brown 5D5-6, 6E7-8. Odour indistinct. Autolytic excretions frequent, coilings absent.

On SNA after $72 \mathrm{~h} 8-10 \mathrm{~mm}$ at $15^{\circ} \mathrm{C}, 4-6 \mathrm{~mm}$ at $25^{\circ} \mathrm{C}$; mycelium covering the plate after $3-4$ weeks at $15^{\circ} \mathrm{C}$. At $15^{\circ} \mathrm{C}$ colony similar to that on $\mathrm{CMD}$, with little mycelium on the surface; hyphae often helical within the agar; hyphae degenerating, appearing empty; eventually small sterile, yellowish to brownish, roundish, pulvinate stromata to $5 \times$ $3 \mathrm{~mm}$ forming. Aerial hyphae, autolytic activity and coilings inconspicuous. No pigment, no distinct odour noted. Autolytic excretions nearly absent at $15^{\circ} \mathrm{C}$, frequent at $25^{\circ} \mathrm{C}$; coilings rare. Chlamydospores noted after 2 3 weeks at $25^{\circ} \mathrm{C}$, after $3-4$ weeks also at $15^{\circ} \mathrm{C},(6-) 7-12(-$ $15) \times(5-) 6-9(-11) \mu \mathrm{m}, 1 / \mathrm{w}(0.7-) 1.0-1.7(-2.1) \quad(n=21)$, only in distal surface hyphae, terminal and intercalary, subglobose, pyriform or ellipsoidal. Stromata pseudoparenchymatous, of globose to oblong cells (16-)24-48(-60)× (13-)19-32(-41) $\mu \mathrm{m}(n=30)$. At $25^{\circ} \mathrm{C}$ colony as on CMD, but only pale yellowish, 4A3; hyphae often moniliform; minute sterile, pale brownish stromata to $1.5 \mathrm{~mm}$ diam formed.

Habitat: on corticated twigs of Rhododendron ferrugineum. Distribution: Austria, known only from the type locality.

Holotype and only known specimen: Austria, Tirol, Sölden, Venter Tal, Vent, MTB 9131/2, 46 52'24" N, $10^{\circ}$ $55^{\prime} 52^{\prime \prime}$ E, elev. $1840 \mathrm{~m}$, on corticated twigs of Rhododendron ferrugineum $0.5-1.3 \mathrm{~cm}$ thick, emergent through bark, soc. Bertia moriformis, Hymenochaete sp., rhizomorphs; 28 Aug. 2004, H. Voglmayr \& W. Jaklitsch, W.J. 2627 (WU 29442, ex-type culture CBS 119288=C.P.K. 2015).

Notes: Hypocrea rhododendri is known from only a single specimen. It shares the same host and habitat with $H$. psychrophila, differing from the latter mostly by pale stromata lacking hairs on their surface, growth at $25^{\circ} \mathrm{C}$, absence of an anamorph on artificial media and the formation of chlamydospores. 
European species of Hypocrea: Miscellaneous species

\section{Introduction}

The residual European species of Hypocrea not clustered in larger clades are presented in this chapter. It includes also the three species $H$. argillacea, $H$. splendens and $H$. strobilina that have not been recollected recently; accordingly, their phylogenetic position is not known. These species are redescribed below based on their holotypes.

At this point I want to note that at least six additional teleomorphic or holomorphic species of Hypocreal Trichoderma and several anamorphic species have been detected in Europe. They are not described here either due to material insufficient for a thorough description or due to sequencing issues. A description of the undescribed anamorphic species is beyond the scope of this work.

Apart from the three species mentioned above, the following eight are described below: Hypocrea albolutescens, morphologically unique, residing in a basal position of uncertain affinity in the generic tree (Fig. 1); H. moravica as a member of the Semiorbis clade with a marked morphological similarity to species of the pachybasium core group. Hypocrea sambuci, $H$. subalpina and $H$. tremelloides form a weakly supported, therefore unnamed subclade of the section Longibrachiatum, which so far is represented in Europe by only the single holomorphic species $H$. schweinitzii. Included are also $H$. silvae-virgineae, which has a pachybasium-like anamorph and clusters with Trichoderma helicum; and H. voglmayrii, which forms an isolated lineage associated with sect. Trichoderma. For $H$. moravica, $H$. subalpina and $H$. tremelloides the anamorphs are newly described. The anamorphs of the latter two species and of $H$. sambuci are white-conidial, with unusual structures new to Trichoderma. See the notes after each species description for more information on species similarities and delimitation.

\section{Species descriptions}

Hypocrea albolutescens Jaklitsch, sp. nov. Fig. 88 MycoBank MB 516663

Anamorph: Trichoderma albolutescens Jaklitsch, sp. nov. Fig. 89

MycoBank MB 516664

Stromata in ligno putridissimo, pulvinata vel effusa, alba maculis flavis, $0.5-10 \times 0.5-5 \mathrm{~mm}$. Asci cylindrici, (40-) 47-67(-77) $\times(2.7-) 3.3-5.0(-6.0) \mu \mathrm{m}$. Ascosporae bicellulares, hyalinae, verruculosae, ad septum disarticulatae, cellulis forma similibus, (sub-)globosis, (2.0-)2.5-3.5(4.5) $\mu \mathrm{m}$ diam. Anamorphosis Trichoderma albolutescens. Conidiophora in agaro PDA disposita in pustulis elongationes breves, steriles, raro fertiles proferentia. Phialides in pustulis divergentes vel parallelae, ampulliformes vel lageniformes, $(4.0-) 4.5-8.0(-11.0) \times 2.5-3.2(-3.7) \mu \mathrm{m}$. Conidia oblonga vel cylindracea, hyalina, glabra, (3.3-)3.8$5.5(-7.0) \times 2.0-2.5(-3.0) \mu \mathrm{m}$.

Etymology: referring to the white stromata developing yellow spots.

Stromata when fresh $0.5-10 \times 0.5-5 \mathrm{~mm}, 0.5-1.5(-2)$ $\mathrm{mm}$ thick, solitary or gregarious in small numbers, (flat) pulvinate to subeffuse. Outline variable, circular, oblong or slightly lobed, broadly attached. Margin well defined, attached or free, white, sterile, vertical or attenuated towards the base. Surface farinose or papyraceous. Stromata white, often with bright yellow spots. Ostioles distinct, slightly projecting, light olive, yellowish brown, ochre, amber, rarely orange, 60-95 $\mu \mathrm{m}$ diam. Resulting colour white to yellow, 4A1-2, 4A6-8, sometimes becoming entirely yellow with age. Spore deposits white or yellow.

Stromata when dry $(0.5-) 0.8-4.1(-8.4) \times(0.4-) 0.7-2.1(-$ $3.2) \mathrm{mm}, 0.1-0.6(-1) \mathrm{mm}$ thick $(n=51)$; (flat) pulvinate or subeffuse, membranaceous and with white radiating marginal mycelium, broadly attached. Surface often uneven due to the surface of the host, farinose or downy, smooth where pigmented. Outline variable, often considerably longer than wide. Margin rounded, adnate or free. Ostioles (30-)40-70(-95) $\mu \mathrm{m}(n=51)$ diam, distinct, slightly projecting, convex or conical, sometimes laterally compressed, light yellow, yellow-brown, ochre, cinnamon, rarely orange-red. Perithecia sometimes becoming free, distinctly lighter than the ostioles. Stromata white, with yellow to orange spots, resulting colour including ostioles light yellow, greyish yellow to orange-yellow, 4A3-4, 4B3-6(8). Stromata after rehydration slightly thicker and lighter, less yellow than fresh, ostioles more amber, resulting colour yellow to brown-orange, 4B4 to 5C5-6. No change seen in $3 \% \mathrm{KOH}$.

Stroma anatomy: Ostioles (46-)60-83(-93) $\mu \mathrm{m}$ long, projecting (13-)20-52(-80) $\mu \mathrm{m}(n=30)$, broadly conical; with often flattened apex, (38-)52-87(-106) $\mu \mathrm{m}$ wide outside, $(15-) 20-40(-50) \mu \mathrm{m}(n=30)$ inside, margin lined by a palisade of broadly clavate or fusoid hyaline cells $3-7$

Fig. 88 Teleomorph of Hypocrea albolutescens. a-g. Fresh stromata (a. immature). h-i. Dry stromata. j. Rehydrated stroma. k. Ostiolar apex in section. $\mathbf{l}, \mathbf{m}$. Stroma surface in face view (m. textura angularis in pigmented area). n. Part of fresh stroma with free perithecia. o. Perithecium in section. p. Cortical and subcortical tissue in section, from pigmented area. q. Subperithecial tissue facing host in section. $\mathbf{r}-\mathbf{t}$. Asci with ascospores. a, g. WU 29171. b, d, e, h, l, m. WU 29174. c. WU 29176. f, j, k, n, o-q. WU 29172. i, r, s. WU 29170. t. WU 29173. Scale bars $\mathbf{a}, \mathbf{b}, \mathbf{e}=0.3 \mathrm{~mm}$. c, $\mathbf{d}, \mathbf{j}=0.7 \mathrm{~mm}$. f, h, $\mathbf{i}=0.4 \mathrm{~mm} . \mathbf{g}, \mathbf{n}=$ $150 \mu \mathrm{m} . \mathbf{k}=15 \mu \mathrm{m}$. l, $\mathbf{m}, \mathbf{p}-\mathbf{s}=10 \mu \mathrm{m} . \mathbf{o}=20 \mu \mathrm{m} . \mathbf{t}=5 \mu \mathrm{m}$ 

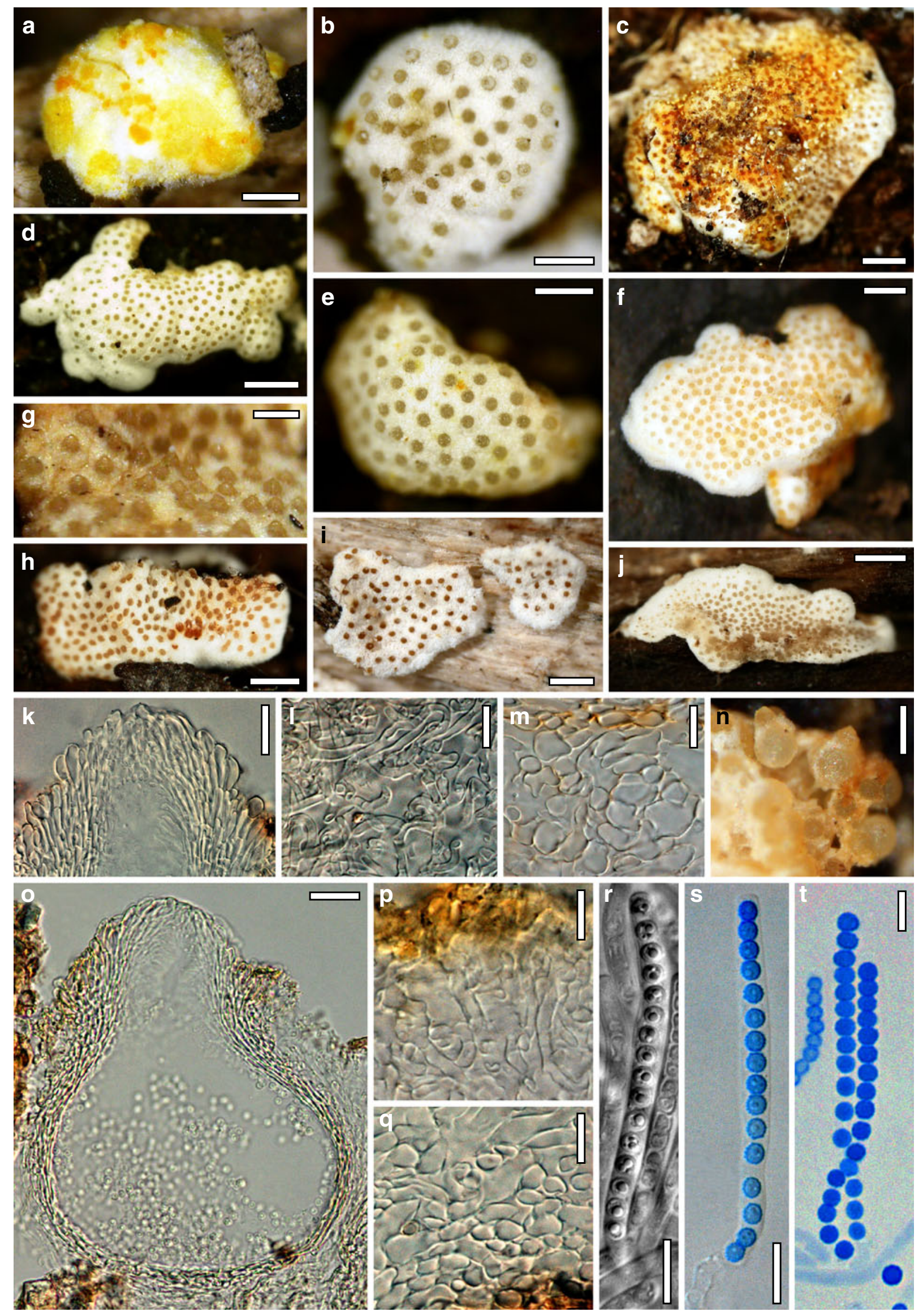

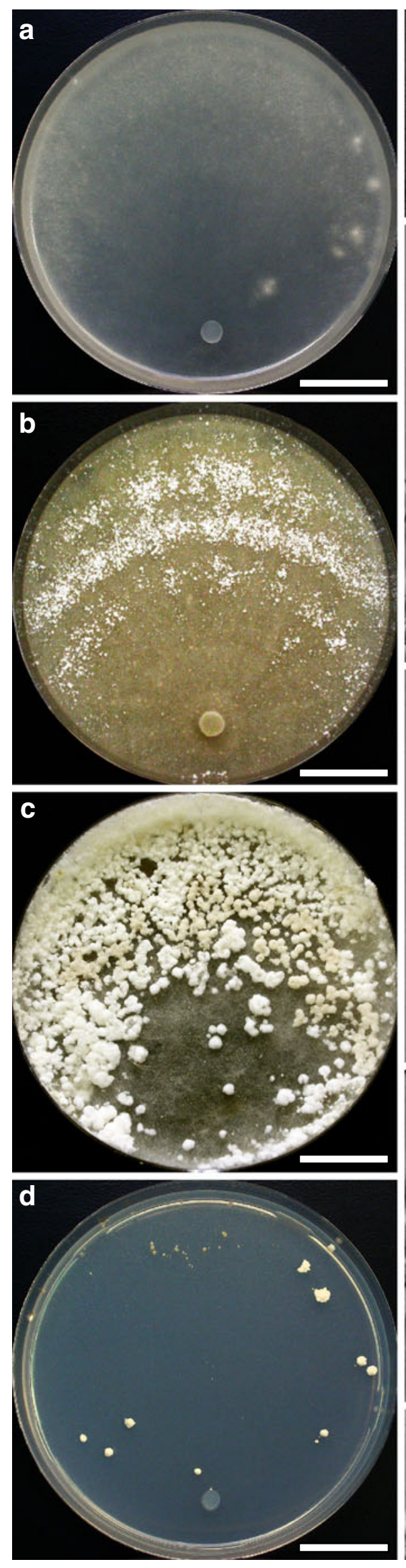
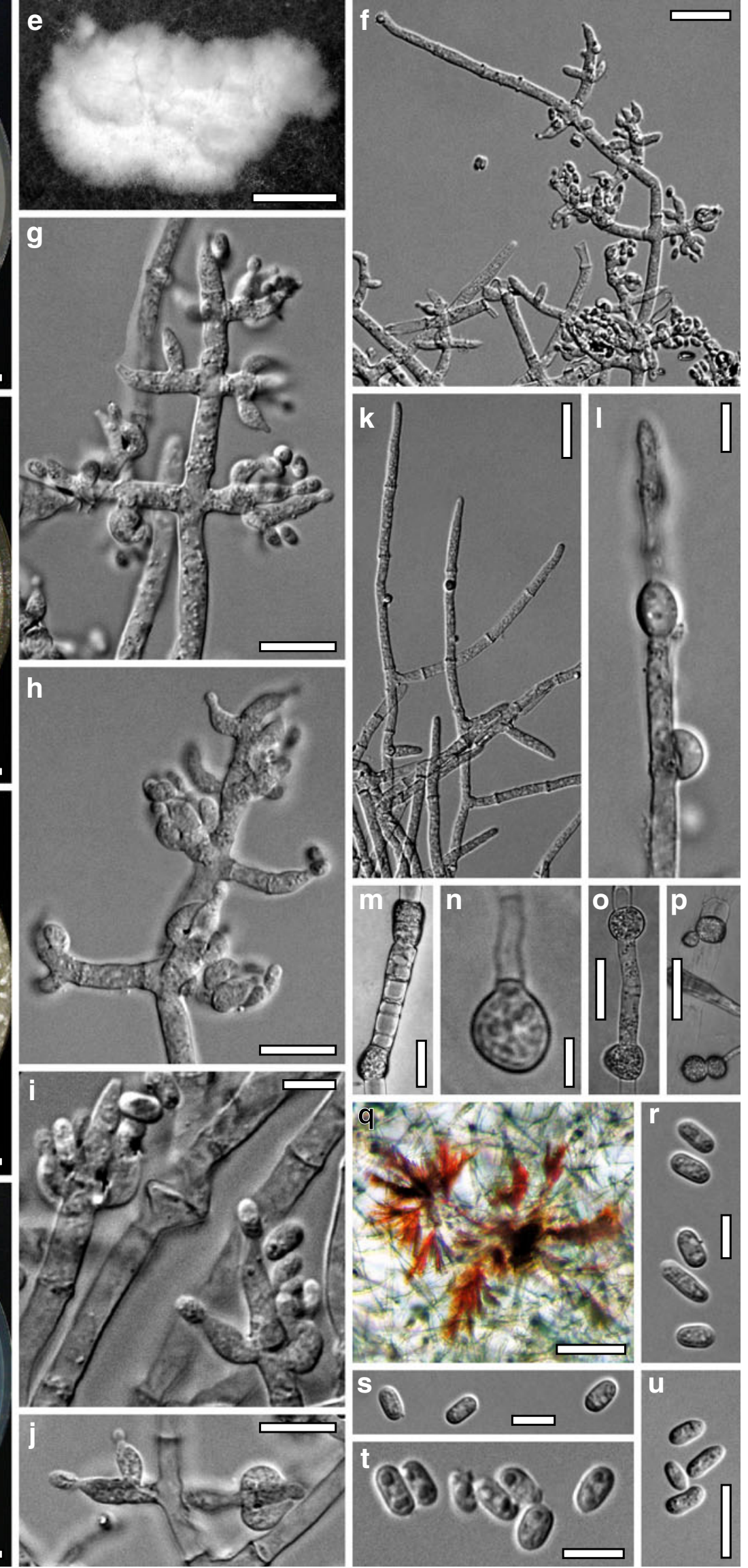
4 Fig. 89 Cultures and anamorph of Hypocrea albolutescens (CBS 119286). a-d. Cultures at $25^{\circ} \mathrm{C}$ (a. on CMD, 35 days. b. on MerckPDA, 21 days. c. on Difco-PDA, 28 days. d. on SNA, 35 days). e. Conidiation pustule. f-h. Conidiophores. i, j. Phialides. k, $\mathbf{l}$. Elongations (l. Terminal part with mucous exudates). m-p. Chlamydospores (SNA, $25^{\circ} \mathrm{C}, 30$ days). q. Crystal formed in MerckPDA $\left(25^{\circ} \mathrm{C}, 8\right.$ days). r-u. Conidia. e-l, r-t. On Difco-PDA after 20 days at $25^{\circ}$ C. u. From specimen WU 29170. Scale bars $\mathbf{a}-\mathbf{d}=$ $21 \mathrm{~mm} . \mathbf{e}=3 \mathrm{~mm} . \mathbf{f}, \mathbf{k}, \mathbf{o}, \mathbf{p}=20 \mu \mathrm{m} . \mathbf{g}, \mathbf{h}, \mathbf{j}, \mathbf{m}, \mathbf{u}=10 \mu \mathrm{m} . \mathbf{i}, \mathbf{l}, \mathbf{n}, \mathbf{r}-\mathbf{t}$ $=5 \mu \mathrm{m} . \mathbf{q}=100 \mu \mathrm{m}$

(-8) $\mu \mathrm{m}$ wide; periphyses $1-2(-3) \mu \mathrm{m}$ wide. Perithecia $(85-) 110-150(-170) \times(100-) 110-150(-185) \mu \mathrm{m} \quad(n=30)$, flask-shaped or globose, usually not crowded; peridium yellowish, $(8-) 10-14(-18) \mu \mathrm{m}(n=60)$ thick at the base and sides. Cortical layer (3-)4-13(-19) $\mu \mathrm{m} \quad(n=30)$ thick, consisting of a hyaline $t$. intricata of narrow, thin-walled hyphae (1.2-)2.0-3.2(-4.3) $\mu \mathrm{m}(n=40)$ wide, often spiral at the surface, and of an incomplete cellular cortex present in pigmented areas, of cells $(5-) 7-13(-15) \times(3-) 4-9(-12) \mu \mathrm{m}$ $(n=30)$ in face view; often covered by yellow(-brown) amorphous material; no subcortical tissue differentiated. Subperithecial tissue a hyaline $t$. intricata of thin-walled hyphae $(2.5-) 3-6(-7) \mu \mathrm{m}(n=40)$ wide, merging into a $t$. angularis-epidermoidea of hyaline, thin-walled, isodiametric to oblong cells $(3-) 4-8(-11) \times(2.5-) 3-6(-9) \mu \mathrm{m}(n=30)$ in discontinuous areas close to the host. Asci (40-)47-67($77) \times(2.7-) 3.3-5.0(-6.0) \mu \mathrm{m}$, stipe $(1-) 3-11(-20) \mu \mathrm{m}$ long $(n=127)$; apex truncate, with a flat ring below the apical thickening; no croziers seen. Ascospores hyaline, smooth inside the asci, finely verruculose after ejection, verrucose in cotton blue/lactic acid; cells monomorphic, (sub-) globose; distal cell (2.0-)2.5-3.5(-4.0) $\mu \mathrm{m}$ diam, 1/w $0.9-$ $1.1(-1.2)$; proximal cell $(2.0-) 2.5-3.5(-4.5) \mu \mathrm{m}$ diam, $1 /$ w $(0.8-) 0.9-1.1(-1.3)(n=181)$.

Stroma margins often bearing conidiophores (1-)2$3.5 \mu \mathrm{m}$ wide, with sinuous ends and sparse, narrow, subulate phialides and minute globose conidial heads 10 $15 \mu \mathrm{m}$ diam. Conidia (3.5-)4.0-5.7(-7.5) $\times(2.0-) 2.5-3.0(-$ 3.4) $\mu \mathrm{m}, 1 / \mathrm{w} \quad(1.2-) 1.5-2.1(-2.6) \quad(n=78)$, oblongcylindrical or ellipsoidal, hyaline, smooth.

Cultures and anamorph: optimal growth at $25^{\circ} \mathrm{C}$ on all media, negligible growth at $30^{\circ} \mathrm{C}$, no growth at $35^{\circ} \mathrm{C}$.

On CMD after $72 \mathrm{~h} 17-22 \mathrm{~mm}$ at $15^{\circ} \mathrm{C}, 36-46 \mathrm{~mm}$ at $25^{\circ} \mathrm{C}$, $0.5-1 \mathrm{~mm}$ at $30^{\circ} \mathrm{C}$; mycelium covering the plate after 5 days at $25^{\circ} \mathrm{C}$. Colony hyaline to pale yellowish or greyish orange, 5A2, 5B3, after 3 weeks, thin, indistinctly zonate, mycelium dense, with radial streaks; primary surface hyphae conspicuously thick and coarsely wavy; mycelial aggregations and long aerial hyphae appearing along the margin, sometimes forming white cottony spots. No conidiation seen within 7 weeks. No autolytic excretions noted. Coilings moderate. No distinct odour noted. Chlamydospores frequent, terminal and intercalary, noted after $3-6$ days at $25^{\circ} \mathrm{C}$.
On PDA after $72 \mathrm{~h} 15-17 \mathrm{~mm}$ at $15^{\circ} \mathrm{C}, 31-36 \mathrm{~mm}$ at $25^{\circ} \mathrm{C}$, $0.3-0.6 \mathrm{~mm}$ at $30^{\circ} \mathrm{C}$; mycelium covering the plate after 1 weeks at $25^{\circ} \mathrm{C}$. Colony circular, thin, zonate, hairy. Margin shiny, thin and smooth. Mycelium densely agglutinated, appearing glassy, primary surface hyphae conspicuously wide. Aerial hyphae of two kinds, a lawn of numerous short, erect, narrow, spiny hyphae becoming verrucose, and numerous long ones forming a reticulum or thick white tomentum above, ascending several $\mathrm{mm}$ high; to the lid of the Petri dish on Difco PDA; with numerous colourless to orange droplets, collapsing, and colony surface becoming mottled. Fan-shaped crystals $0.1-0.7 \mathrm{~mm}$ diam formed within the agar (also numerous at $15^{\circ} \mathrm{C}$ ) after $4-5$ days from the centre, colourless, appearing red in DIC, macroscopically noted as granules, spreading across the entire colony. Numerous light brown, sterile hairy stromata $0.2-2 \mathrm{~mm}$ diam appearing in the centre. Autolytic excretions and coilings inconspicuous. Odour slightly mushroomy, colour white, pale yellow to greyish yellow or beige, 3A4, 3B4-6, 4B4-6, 4C5-8, plus a greenish tone. Conidiation noted after 2 weeks, first scant and effuse in the outer half of the colony, on short, erect conidiophores; later in numerous white, partly confluent tufts or pustules 0.3 $1.5 \mathrm{~mm}$ diam, formed in a thick white tomentum, mostly in the outer half of the colony, forming several concentric zones in addition to the growth zones. Conidiation within pustules dense, but the pustule margin remaining sterile. Structure of pustulate conidiation examined on Difco-PDA after 2022 days: pustules on this medium more numerous than on Merck-PDA, large, 1-11 mm long, 1-2 mm high, with circular or oblong outline; white, turning brownish with age. Margin of pustules beset with numerous short, straight or sinuous elongations 15-300 $\mu \mathrm{m}$ long, smooth, often with semiglobose mucous exudates 5-6 $\mathrm{m}$ long, along the entire length. Elongations tapering to $2.5-4 \mu \mathrm{m}$ towards the narrowly or broadly rounded ends, rarely with a solitary terminal phialide. Pustules inside consisting of a dense, opaque, complex reticulum. Conidiophores 3-6 $\mathrm{m}$, at branching points to $7 \mu \mathrm{m}$ wide, with complex, mostly symmetric, i.e. paired, and often distinctly rectangular branching. Side branches 18 $50 \mu \mathrm{m}$ long, with verticils of short, 1-2 celled side branches at right angles, slightly increasing in length downward. Phialides supported by cells (1.7-)3.0-5.0(-5.5) $\mu \mathrm{m}$ wide, solitary or paired along the conidiophores, and terminally in whorls of (2-)4-6, divergent, sometimes appressed parallel in dense terminal whorls. Phialides $(4.0-) 4.5-8.0(-11.0) \times 2.5-3.2(-$ 3.7) $\mu \mathrm{m}, 1 / \mathrm{w}(1.4-) 1.6-2.8(-4),(1.7-) 2.0-3.0(-3.7) \mu \mathrm{m}$ wide at the base $(n=31)$, ampulliform, less commonly lageniform, short, mostly inequilateral or curved upwards. Conidia formed in minute dry heads $10-15 \mu \mathrm{m}$ diam. Conidia $(3.3-) 3.8-5.5(-7.0) \times 2.0-2.5(-3.0) \mu \mathrm{m}, 1 / \mathrm{w}(1.4-) 1.6-2.4(-$ 3.0) $(n=30)$, hyaline, oblong or cylindrical, less commonly ellipsoidal, smooth, with numerous minute guttules, two guttules when old; abscission scar indistinct. 
On SNA after $72 \mathrm{~h} 13-16 \mathrm{~mm}$ at $15^{\circ} \mathrm{C}, 33-40 \mathrm{~mm}$ at $25^{\circ}$ C, $0-0.1 \mathrm{~mm}$ at $30^{\circ} \mathrm{C}$; mycelium covering the plate after $5-$ 7 days at $25^{\circ} \mathrm{C}$. Colony similar to that on CMD, with less conspicuous zonation. Surface hyphae soon degenerating, appearing empty. Margin hairy due to long aerial hyphae, the latter aggregating to white flakes or tufts in distal areas. Autolytic excretions inconspicuous; coilings moderate. No diffusing pigment, no distinct odour noted. Chlamydospores (5-)7-13(-19) $\times(6-) 7-12(-15) \mu \mathrm{m}, 1 / \mathrm{w} \quad 0.9-1.3(-$ 1.6) $(n=32)$, noted after 4 days at $25^{\circ} \mathrm{C}$, becoming extremely abundant (also at $15^{\circ} \mathrm{C}$ ) on the entire plate, globose, oval or ellipsoidal to angular in thick hyphae, terminal and intercalary. Conidiation unreliable, noted after 2-4 weeks. Effuse conidiation seen as scant minute heads on aerial hyphae, appearing warted under low magnification, in distal areas of the colony. Conidiation dense in few irregularly disposed, compact, white pustules 1-4 mm diam; with short straight to slightly sinuous elongations bearing minute droplets. Conidia formed in minute dry heads of 10-15 $\mathrm{mm}$. Sometimes few light brownish stromata $0.4-1.3 \mathrm{~mm}$ diam appearing close to the distal margin, surrounded by moniliform hyphae.

Habitat: on well-rotted, soft wood of deciduous trees and shrubs, often emerging from underneath loosely attached bark or from cracks in the wood.

Distribution: Europe (Austria, Germany).

Holotype: Germany, Baden-Württemberg, Freiburg, Landkreis Breisgau-Hochschwarzwald, shortly before Breisach heading north, in the riverine forest at the river Rhine, MTB 7911/4, 48 00'10" N, 07³6'55" E, elev. $190 \mathrm{~m}$, on 2 partly decorticated branches of Fraxinus excelsior $3-4 \mathrm{~cm}$ thick, on wood, soc. Gliocladium sp. and Chaetosphaeria pulviscula, 3 Sep. 2004, H. Voglmayr \& W. Jaklitsch W.J. 2671 (WU 29173, culture CBS 119286=C.P.K. 2017). Holotype of Trichoderma albolutescens isolated from WU 29173 and deposited as a dry culture with the holotype of H. albolutescens as WU 29173a.

Other specimens examined: Austria, Kärnten, Klagenfurt Land, St. Margareten im Rosental, Tumpfi, MTB 9452/4, $46^{\circ} 32^{\prime} 35^{\prime \prime} \mathrm{N}, 14^{\circ} 25^{\prime} 32^{\prime \prime} \mathrm{E}$, elev. $565 \mathrm{~m}$, on decorticated branch of Alnus glutinosa $1.5 \mathrm{~cm}$ thick, on wood, 25 Sep. 2006, H. Voglmayr \& W. Jaklitsch, W.J. 2986 (WU 29174). Niederösterreich, Scheibbs, Lunz am See, forest path from Schloß Seehof in direction Mittersee, MTB 8156/3, 47 $50^{\prime}$ $40^{\prime \prime} \mathrm{N}, 15^{\circ} 04^{\prime} 25^{\prime \prime} \mathrm{E}$, elev. $630 \mathrm{~m}$, on decorticated branches of Corylus avellana and Fraxinus excelsior, on wood, soc. Nemania chestersii, 16 Oct. 2003, H. Voglmayr \& W. Jaklitsch, W.J. 2459+2460, WU 29171. Tirol, InnsbruckLand, Ampass, Ampasser Hügel, MTB 8734/2, 47 $15^{\prime} 31^{\prime \prime}$ $\mathrm{N}, 11^{\circ} 27^{\prime} 13^{\prime \prime} \mathrm{E}$, elev. $700 \mathrm{~m}$, on decorticated branches of Corylus avellana, Quercus robur and Alnus incana, on wood, soc. rhizomorphs, 2 Sep. 2003, W. Jaklitsch \& U. Peintner, W.J. 2352+2356 (WU 29170). Vienna, 10th district, recreation park Wienerberg, MTB 7864/1, 48 $09^{\prime}$ $56^{\prime \prime} \mathrm{N}, 16^{\circ} 20^{\prime} 56^{\prime \prime} \mathrm{E}$, elev. $220 \mathrm{~m}$, on thin decorticated branches of well-rotted ?Populus tremula, 1-3 cm thick, on wood, erumpent from holes, between thick fibres, soc. Eutypa sp., Lycogala epidendron, 13 Jun. 2004, W. Jaklitsch, W.J. 2509 (WU 29172). 22nd district, Lobau, at Panozzalacke, MTB 7865/1, 48 $11^{\prime} 06^{\prime \prime} \mathrm{N}, 16^{\circ} 29^{\prime} 20^{\prime \prime} \mathrm{E}$, elev. $150 \mathrm{~m}$, on branches of Prunus padus, 18 Nov. 2006, W. Jaklitsch, W.J. 3035 (WU 29175; white form with smaller ascospores). W.J. 3036 (WU 29176; form with yellow spots).

Notes: Hypocrea albolutescens is one of the exceptions among hyaline-spored species that occur on well-rotted wood. Its stromata resemble those of $H$. chionea Ellis and Everhart (1892). However, no yellow discolorations have been reported for the latter, and the smaller ascospores disarticulate into dimorphic cells (Samuels et al. 2006b). In addition, $H$. chionea typically occurs on recently dead hosts like lianas often well above the ground (G.J. Samuels, pers. comm.). Reports of $H$. chionea from Europe (Bresadola 1903; no specimen seen) are probably $H$. albolutescens. Despite overlapping ranges, two forms differing in ascus and ascospore sizes can be recognized: one (WU 29173, WU $29175)$ with asci $(40-) 45-52(-60) \times(2.7-) 3.0-3.5(-3.8) \mu \mathrm{m}$ $(n=62)$, distal ascospore cell $=(2.0-) 2.2-2.5(-2.7) \times(2.1-)$ $2.2-2.5(-3.0) \mu \mathrm{m}$, and proximal ascospore cell $=(2.0-) 2.2-$ $2.5(-2.7) \times(2.0-) 2.3-2.5(-2.7) \mu \mathrm{m}(n=60)$; the second form (all other specimens) with asci $=(57-) 60-70(-77) \times(4.4-)$ $4.7-5.4(-6.0) \mu \mathrm{m}(n=65)$, distal ascospore cell $=(2.8-) 3.0$ $3.5(-4.0) \times 3.0-3.5(-4.0) \mu \mathrm{m}$, and proximal ascospore cell $=$ $3.0-3.7(-4.5) \times 3.0-3.6(-4.0) \mu \mathrm{m}$. Other traits of the teleomorphs are indistinguishable. Only one (WU 29173) of six specimens yielded a culture on CMD supplemented with vitamins, trace elements and peptone. Although scant, this specimen is designated as the holotype. WU 29172 is more appropriate for the examination of the teleomorph, but has larger asci and ascospores than the holotype. The Trichoderma often present on stroma margins forms the same conidia as the ex-type culture CBS 119286, and is probably the anamorph of $H$. albolutescens. The phialides, however, are subulate and to $c a 25 \mu \mathrm{m}$ long. They resemble terminal cells of pustule elongations on PDA.

Hypocrea argillacea W. Phillips \& Plowr., Grevillea 13: 79 (1885). Fig. 90

Anamorph unknown.

Fig. 90 Teleomorph of Hypocrea argillacea (holotype K 61846). a-d. Dry stromata. e. Rehydrated stromata. f. Ostiolar apex in section. g. Perithecium in section. h. Stroma surface in face view. i. Cortical and subcortical tissue in section. j. Subperithecial tissue in section. k. Stroma in $3 \% \mathrm{KOH}$ after rehydration. $\mathbf{l}, \mathbf{m}$. Ascospores (l. in ascus apex, in cotton blue/lactic acid; $\mathbf{m}$. in ascus base, in $3 \% \mathrm{KOH}$ ). $\mathbf{n}, \mathbf{o}$. Asci with ascospores in cotton blue/lactic acid. Scale bars: $\mathbf{a}, \mathbf{c}-\mathbf{e}, \mathbf{k}=0.3 \mathrm{~mm}$. $\mathbf{b}=$ $0.2 \mathrm{~mm} . \mathbf{f}, \mathbf{i}=15 \mu \mathrm{m} . \mathbf{g}=30 \mu \mathrm{m} . \mathbf{h}, \mathbf{j}, \mathbf{n}, \mathbf{o}=10 \mu \mathrm{m} . \mathbf{l}, \mathbf{m}=5 \mu \mathrm{m}$ 

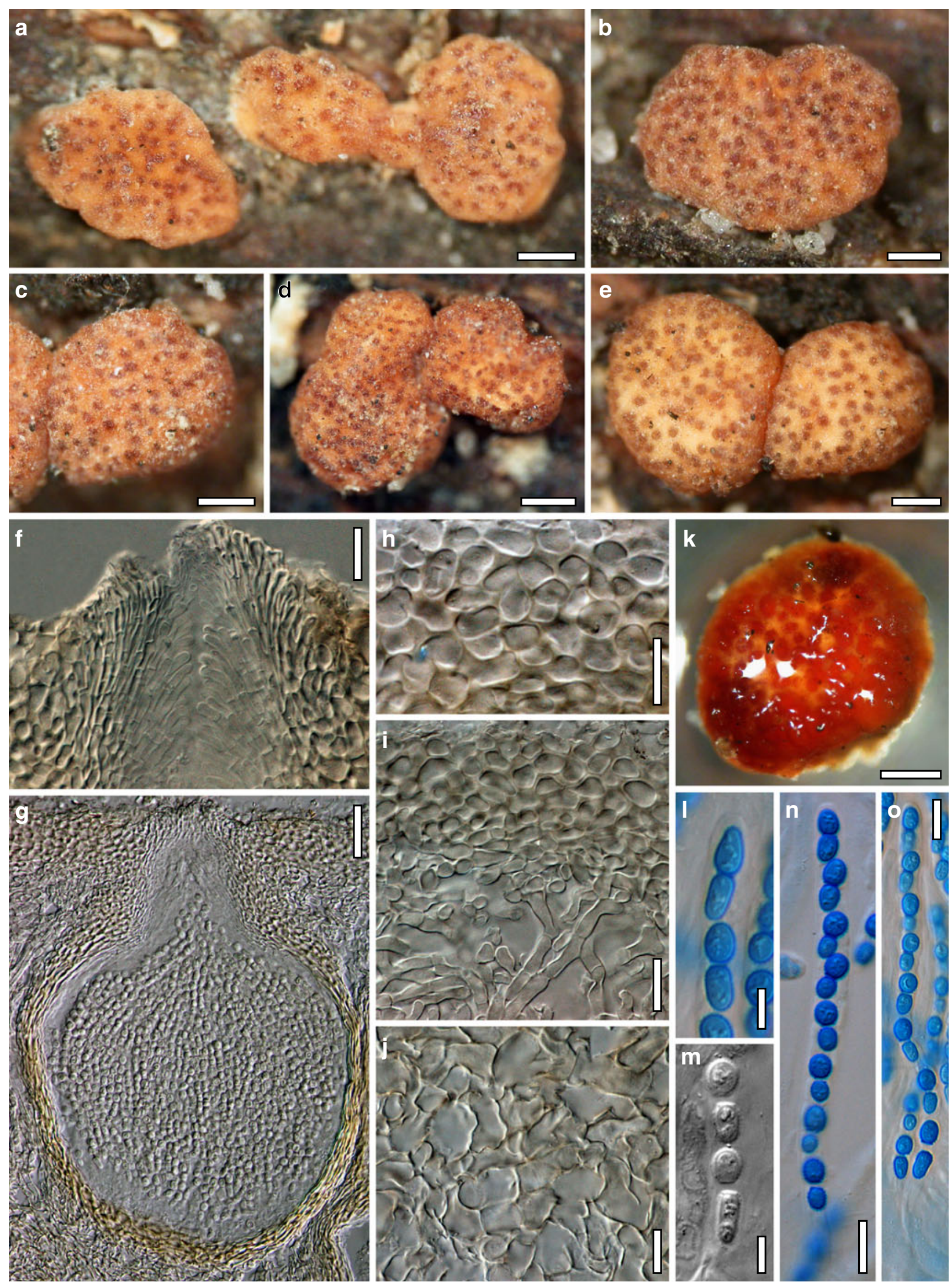

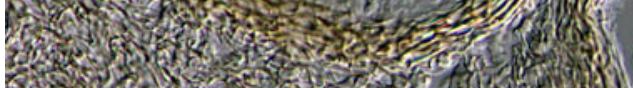


Stromata when dry $(0.4-) 0.8-1.6(-1.7) \times(0.4-) 0.6-1.1(-$ 1.4) $\mathrm{mm},(0.25-) 0.3-0.5(-0.6) \mathrm{mm}$ thick $(n=20)$; gregarious in small numbers; pulvinate, broadly or narrowly attached, with free, broadly rounded margins and sometimes white or brownish mycelium around the base; sometimes with a short stout stipe. Surface smooth, slightly uneven, with some whitish floccules and numerous welldefined, circular, convex, reddish brown ostiolar dots (23-) $37-80(-118) \mu \mathrm{m}(n=30)$ wide. Stroma colour light orange to grey-orange, 5-6AB4. Stroma size unchanged after rehydration, colour more yellow; dots brown; after addition of $3 \% \mathrm{KOH}$ stromata macroscopically black; in the stereomicroscope stroma surface yellow between distinctly orange-red ostiolar dots/perithecia.

Stroma anatomy: Ostioles (55-)70-107(-121) $\mu \mathrm{m}$ long, plane with surface or projecting to $20(-32) \mu \mathrm{m}(n=30)$, (38-)45-65(-77) $\mu \mathrm{m}(n=30)$ wide at the apex, cylindrical or conical, with periphyses $2-4.5 \mu \mathrm{m}$ wide; apical cells inconspicuous, some marginal cells clavate and 4-6 $\mu \mathrm{m}$ wide. Perithecia (160-)190-240(-260)×(100-)120-180(200) $\mu \mathrm{m}(n=30)$, flask-shaped. Peridium (7-)12-19(-22) $\mu \mathrm{m}(n=60)$ thick at the base and sides, yellow in lower parts, turning orange in $\mathrm{KOH}$. Cortical layer (25-)28-41(50) $\mu \mathrm{m}(n=30)$ thick, around entire stroma, but hyphal, thicker and stronger pigmented in lateral and basal regions; pale yellow, distinctly paler than the peridium. Cortical tissue a dense and compact $t$. angularis-globulosa of thickwalled, isodiametric to oblong cells $(3.5-) 5-10(-14) \times(3-)$ $4-7(-9)(n=64)$ in face view and in vertical section. Subcortical tissue a loose $t$. intricata of thin-walled hyaline hyphae $(2-) 3-5(-6) \mu \mathrm{m}(n=30)$ wide, partly also present in areas directly below the perithecia. Subperithecial tissue a loose $t$. epidermoidea of thin-walled, hyaline to yellowish cells $(6-) 9-19(-24) \times(4-) 6-12(-15) \mu \mathrm{m}(n=30)$. Asci 100$120 \times 5-6 \mu \mathrm{m}$, including a stipe $28-38 \mu \mathrm{m}(n=6)$ long (only few intact). Ascospores hyaline, verruculose or spinulose, cells dimorphic, distal cell (4.0-)4.4-5.3(-6.0)×(3.5-)3.84.5(-5.0) $\mu \mathrm{m}, 1 / \mathrm{w}(0.9-) 1.1-1.3(-1.5) \quad(n=40)$, subglobose or ellipsoidal, proximal cell (4.0-)4.8-7.0(-9.0)×(2.8-)3.0$3.7(-4.3) \mu \mathrm{m}, 1 / \mathrm{w}(1.2-) 1.4-2.1(-2.8) \quad(n=40)$, oblong or ellipsoidal, often elongate in the ascus base.

Habitat: on wood of Fraxinus.

Distribution: Europe (England).

Holotype: England, West Norfolk, Dersingham, ex herb. C.B. Plowright, on (blackened) wood of Fraxinus excelsior, Nov. 1881, K(M) 61846.

Notes: Hypocrea argillacea is known with certainty only from the holotype. Two attempts to recollect it during this study failed; therefore its anamorph and phylogenetic placement are unknown. The above description is based on the holotype.

Superficially, $H$. bavarica is similar to $H$. argillacea, but differs by paler stroma colours and distinctly smaller ascospores. H. moravica differs in more distinct ostiolar dots present in lower numbers. H. argillacea could perhaps even be interpreted as a form of $H$. splendens with smaller and less brightly coloured stromata and slightly larger ascospores. Re-descriptions of $H$. tremelloides as ' $H$. argillacea' by Medardi (1999) and Klok (2006) without reference to the holotype may have been based on Ellis and Ellis (1985). The latter work is not recommended to be used for the identification of Hypocrea species. It is also uncertain, which species Petch (1938, p. 291) had seen when he redescribed $H$. argillacea.

Hypocrea moravica Petr., Ann. Mycol. 38: 260 (1940). Fig. 91

Anamorph: Trichoderma moravicum Jaklitsch, sp. nov. Fig. 92

MycoBank MB 516691

Anamorphosis Hypocreae moravicae; conidiophora typo pachybasii, fertilia per totam longitudinem, in pustulis viridibus granulosis in agaris CMD et SNA disposita. Phialides divergentes, variabiles, lageniformes vel ampulliformes, $(4-) 5-10(-20) \times(2.8-) 3.0-4.0(-4.8) \mu \mathrm{m}$. Conidia pallide viridia, ellipsoidea vel subglobosa, partim oblonga, glabra, $(2.5-) 3.0-5.0(-6.8) \times(2.0-) 2.5-3.0(-3.7) \mu \mathrm{m}$.

Stromata when fresh $0.5-4(-18) \mathrm{mm}$ diam, $0.5-1.5 \mathrm{~mm}$ thick, pulvinate, broadly attached, edges free, sometimes with white mycelium around the base. Outline circular, angular or irregular. Surface smooth or finely tubercular. Ostiolar dots numerous, distinct and conspicuous, brown, determining the overall colour; more indistinct, watery and olive when immature. Stromata first white, turning pale yellow, brown dots appearing on yellow stroma surface, resulting in pale yellow, greyish orange, brown-orange, yellow-brown, brown, finally reddish-brown, 2A3, 3-4A3-4, 4A5, 5B5, 6-7CE6-8; colour change to brown enhanced by drying.

Stromata when dry $(0.3-) 0.5-2.5(-4) \times(0.2-) 0.5-2(-3)$ $\mathrm{mm}, 0.2-0.4(-0.6) \mathrm{mm}$ thick $(n=75)$, solitary, gregarious, often densely aggregated in large numbers; pulvinate or discoid, broadly attached, often with white mycelium at the base; when young/immature sometimes effuse, to $18 \mathrm{~mm}$ long, effluent, i.e. breaking up into several part-stromata. Outline circular, angular, oblong or irregular with wavy or indented margin. Sides often vertical, edges free, rounded

Fig. 91 Teleomorph of Hypocrea moravica. a-f. Fresh stromata (a. immature). g-o. Dry stromata (g, j. immature. h. effluent, with granular covering). p. Stroma in 3\% KOH after rehydration. q. Stroma surface in face view. r. Perithecium in section. s. Cortical and subcortical tissue in section. t. Subperithecial tissue in section. u. Stroma base in section. vz. Asci with ascospores (y, z. in cotton blue/lactic acid). a, c, e, f, $\mathbf{n}-\mathbf{u}$, z. WU 29283. b, h, i. WU 29286. d, k. WU 29282. g. WU 29287. j. WU 29284. l, x. WU 29288. m, v. holotype K 154039. w, y. WU 29281. Scale bars: a, $\mathbf{g}, \mathbf{p}=0.6 \mathrm{~mm}$. b-f, $\mathbf{h}, \mathbf{i}=1 \mathrm{~mm} . \mathbf{j}, \mathbf{k}, \mathbf{m}=0.2 \mathrm{~mm} . \mathbf{l}$, $\mathbf{n}, \mathbf{o}=0.4 \mathrm{~mm} . \mathbf{q}, \mathbf{v}-\mathbf{z}=10 \mu \mathrm{m} . \mathbf{r}=30 \mu \mathrm{m} . \mathbf{s}, \mathbf{t}=20 \mu \mathrm{m} . \mathbf{u}=15 \mu \mathrm{m}$ 

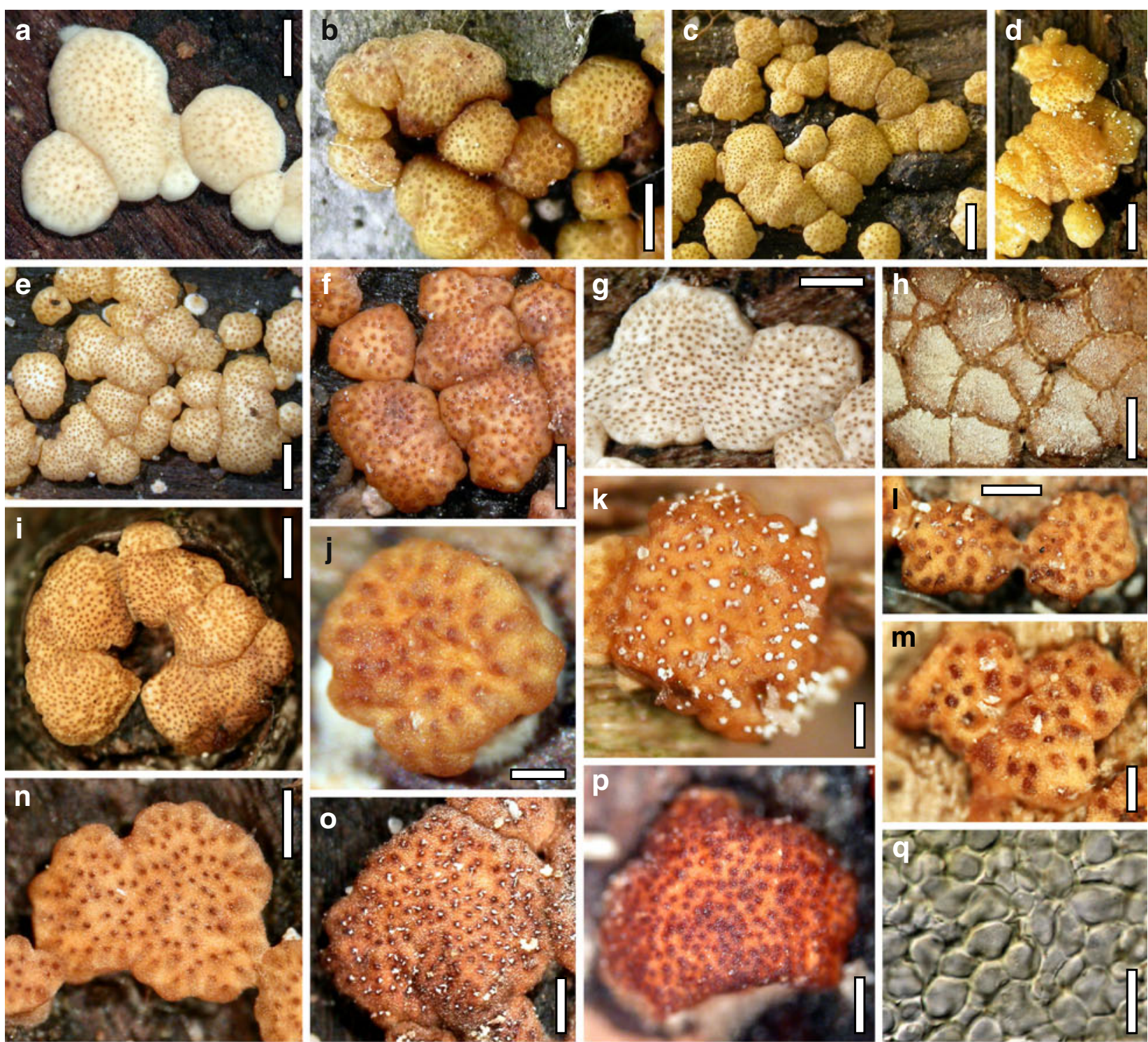

m sovent
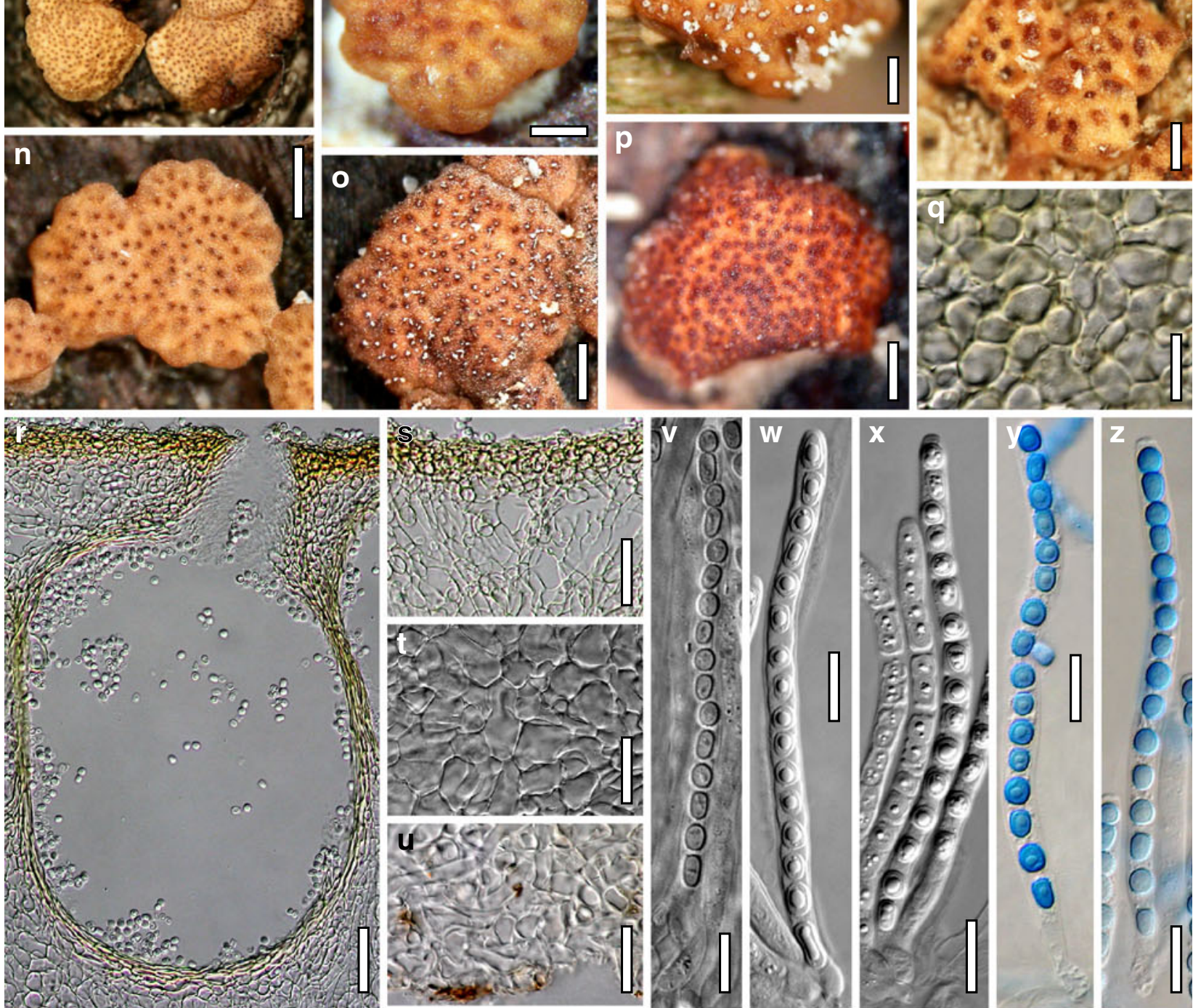

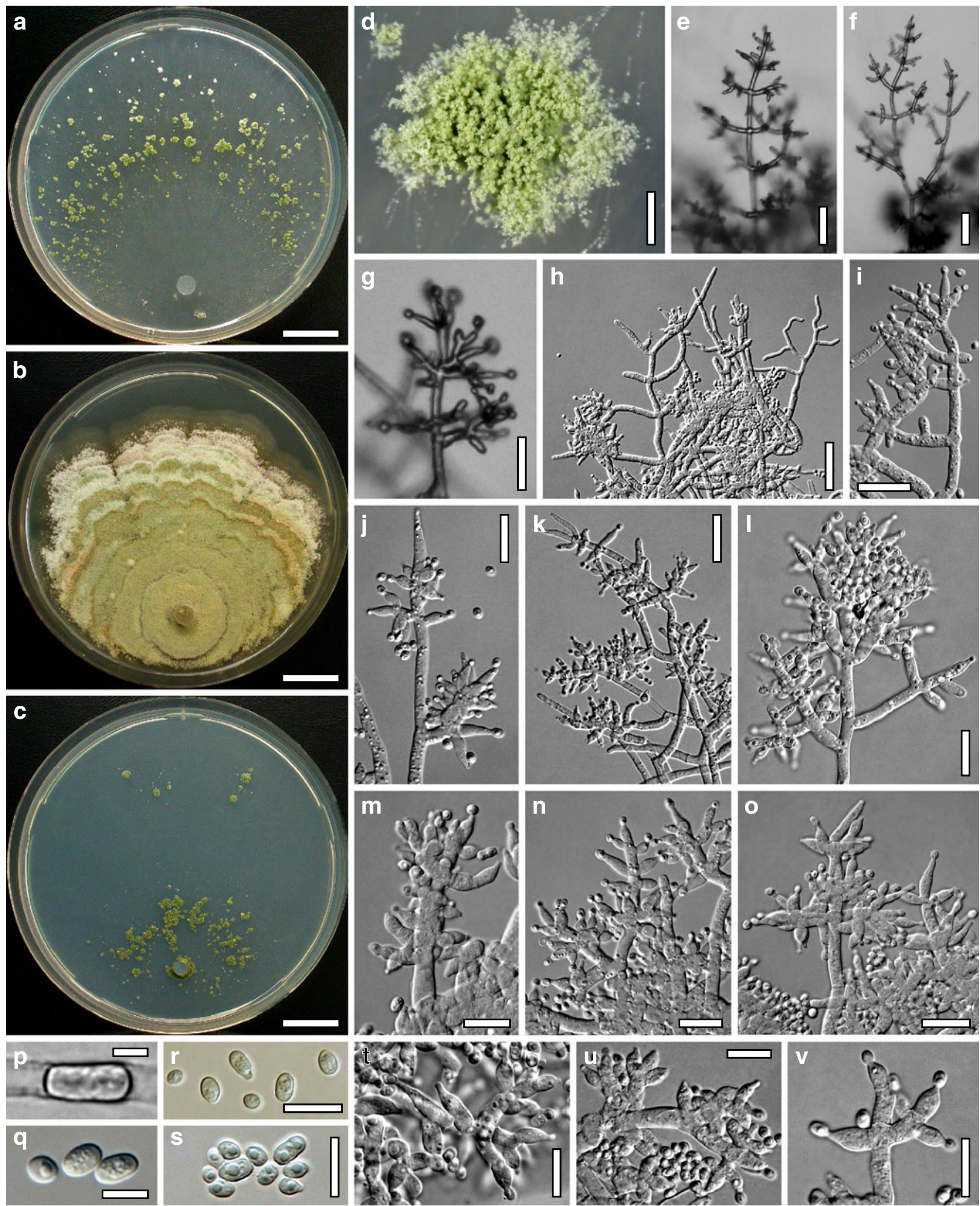
4 Fig. 92 Cultures and anamorph of Hypocrea moravica. a-c. Cultures (a. on CMD, 14 days; b. on PDA, 21 days; c. on SNA, 28 days). d. Conidiation pustule on CMD after 14 days. e-g. Conidiophores on growth plates (9-10 days; e, f. CMD, g. SNA). h-o. Conidiophores (CMD, 8-12 days; h. young, showing curvatures). p. Intercalary chlamydospore (SNA, 35 days). q-s. Conidia (CMD, 8-12 days). t-v. Phialides (CMD, 12 days). a-v. All at $25^{\circ}$ C. a-d, f, g, p. C.P.K. 954. $\mathbf{e}, \mathbf{l}, \mathbf{m}, \mathbf{o}, \mathbf{r}-\mathbf{v}$. CBS 120539. h-k, n, q. C.P.K. 2492. Scale bars $\mathbf{a}-\mathbf{c}=$ $15 \mathrm{~mm}$. $\mathbf{d}=0.4 \mathrm{~mm}$. e, f, $\mathbf{h}=30 \mu \mathrm{m}$. $\mathbf{g}, \mathbf{k}=25 \mu \mathrm{m}$. i, j, $\mathbf{l}, \mathbf{n}, \mathbf{o}=15 \mu \mathrm{m}$. $\mathbf{m}, \mathbf{r}-\mathbf{v}=10 \mu \mathrm{m} . \mathbf{p}, \mathbf{q}=5 \mu \mathrm{m}$

or sharp. Surface first smooth, becoming tubercular by projecting perithecia or convex ostiolar dots, smooth between tubercles, sometimes with fine whitish granular covering in addition to spore deposits. Ostiolar dots (24-) 37-75 $(-102) \mu \mathrm{m}(n=110)$ diam, conspicuous, well-defined, densely disposed, brown, circular, plane or convex, with barely visible pale to hyaline centres. Stromata white when immature and without ostioles, centre compacting and becoming pale cream or yellowish; then diffuse pale olive spots appearing; later colour determined by brown ostiolar dots in various shades on a yellow background, appearing pale yellow, 4A2-5, pale to greyish orange, $5 \mathrm{AB} 3-6,6 \mathrm{~B} 4$, later dull orange-brown, yellow-brown, golden-, light- or medium brown, 5CD6-7, 6CD4-8, finally reddish brown to dark brown $7(-8)$ CD4-6, 7-8EF5-8. Spore deposits white to yellow. Rehydrated stromata pulvinate with considerably increased size, smooth, bright yellow with orange-brown ostiolar dots; in 3\% $\mathrm{KOH}$ turning reddishorange; ostiolar dots dark reddish-brown.

Stroma anatomy: Ostioles (50-)58-80(-94) $\mu \mathrm{m}(n=30)$ long, plane or projecting to $12 \mu \mathrm{m},(15-) 22-36(-45) \mu \mathrm{m}$ wide at the apex internally $(n=30)$, without differentiated apical cells. Perithecia $(130-) 190-250(-260) \times(82-) 115-$ $195(-240) \mu \mathrm{m}(n=30)$, flask-shaped or globose, numerous, often densely disposed and laterally compressed; peridium $(11-) 13-21(-27) \mu \mathrm{m}$ wide at the base, $(5-) 7-13(-15) \mu \mathrm{m}$ $(n=30)$ at the sides; orange in $\mathrm{KOH}$. Cortical layer $(12-)$ 16-25(-30) $\mu \mathrm{m}(n=30)$, a dense yellow $t$. angularisglobulosa of thin-walled isodiametric cells (3-)5-11($16) \times(3-) 4-7(-11) \mu \mathrm{m}(n=90)$ in face view and in vertical section, orange in $\mathrm{KOH}$, at least around the ostiole; without hairs on the surface, but often undifferentiated hyphae on stroma sides present. Subcortical tissue a $t$. intricata of hyaline thin-walled hyphae $(2-) 3-6(-8) \mu \mathrm{m}(n=65)$ wide, sometimes mixed with coarse angular hyaline cells. Subperithecial tissue a $t$. epidermoidea of coarse, thin-walled, angular, oblong or lobed hyaline cells $(6-) 9-30(-48) \times(4-)$ $7-16(-25) \mu \mathrm{m} \quad(n=60)$, interspersed with some wide, mostly vertically oriented hyphae; cells slightly smaller towards the base; basal tissue dense, particularly at the area of attachment to the substrate, of angular to globose cells with walls to $1 \mu \mathrm{m}$ thick, intermingled with thick-walled hyphae 3-6(-8) $\mu \mathrm{m}(n=60)$ wide. Asci $(66-) 75-95(-109) \times$ $(4.8-) 5.0-6.0(-6.5) \mu \mathrm{m}$, stipe $(1-) 5-15(-24) \mu \mathrm{m}$ long $(n=$
100). Ascospores hyaline, sometimes becoming yellow or orange after ejection, verruculose or spinulose; cells dimorphic; distal cell (3.0-)3.5-4.5(-5.3) $\times(2.6-) 3.2-4.0(-4.6) \mu \mathrm{m}$, $1 / \mathrm{w}(0.9-) 1.0-1.3(-1.8)(n=155)$, (sub-)globose, less commonly wedge-shaped; proximal cell $(2.8-) 4.0-5.5(-7.8) \times$ $(2.2-) 2.7-3.3(-3.8) \mu \mathrm{m}, 1 / \mathrm{w}(1.0-) 1.2-2.0(-3.3) \quad(n=155)$, oblong or subglobose.

Cultures and anamorph: optimal growth at $25^{\circ} \mathrm{C}$ on all media; limited growth at $30^{\circ} \mathrm{C}$, no growth at $35^{\circ} \mathrm{C}$.

On CMD after $72 \mathrm{~h} 5-8 \mathrm{~mm}$ at $15^{\circ} \mathrm{C}, 12-13 \mathrm{~mm}$ at $25^{\circ} \mathrm{C}$, 1-7 $\mathrm{mm}$ at $30^{\circ} \mathrm{C}$; mycelium covering the plate after 12 17 days at $25^{\circ} \mathrm{C}$. Colony hyaline, thin, circular, dense, shiny, with little mycelium on the surface, indistinctly zonate; hyphae thin with little difference in width; surface hyphae minutely tuberculate or submoniliform. Aerial hyphae scant, short, erect, loosely disposed, simple, becoming fertile. Autolytic activity absent or inconspicuous. No coilings noted. No diffusing pigment seen; odour indistinct or slightly mushroomy. Chlamydospores rare. Conidiation noted after 4-6 days on scant short solitary conidiophores with minute wet conidial heads $10-40(-50) \mu \mathrm{m}$ diam, and mostly dry in shrubs becoming visible as white floccules, growing to circular or oblong pustules $1-2.5 \mathrm{~mm}$ diam, confluent to 5$7 \mathrm{~mm}$ length, spreading across the plate; after 6-11 days turning light green, 27DE4-6, 28CE5-7(-8), often with white margin; pustule surface appearing granular due to condensed whorls of phialides. Conidiation sometimes also within the agar in aged cultures. Conidiophores (after 10-12 days) usually on short stipes with mostly asymmetrical branching, with two to several primary branches often dichotomously branched at several levels. Stipe and primary branches 6$10 \mu \mathrm{m}$ wide, thick-walled (to $1.5 \mu \mathrm{m}$ ), with coarsely wavy outer wall; further branches thin-walled and $2.5-5 \mu \mathrm{m}$ wide; origin of phialides often thickened, sometimes globose, to $7 \mu \mathrm{m}$ wide. Branches often curved or sinuous. Peripheral conidiophores short (30-100 $\mu \mathrm{m})$, variable, either with long sterile stretches and short irregular terminal heads, or regularly symmetrical with densely arranged, paired, 1-2 celled branches at right angles or slightly inclined upwards; often branches of similar length on all levels. Production of conidia starting within the pustule. Phialides solitary along terminal branches in short intervals and in whorls of 3-5(-6). Phialides $(4-) 5-10(-20) \times(2.8-) 3.0-4.0(-4.8) \mu \mathrm{m}, 1 / \mathrm{w} 1.3-3.0(-6.3)$, $(1.5-) 2.3-3.2(-4.0) \mu \mathrm{m}$ wide at the base $(n=70)$, variable, ampulliform or lageniform, with short necks, widest mostly below the middle; straight or curved upwards and inequilateral, sometimes sigmoid, typically narrowly lageniform on younger and more simple conidiophores; terminal phialides in extension of main axes often appearing longer, but separated from the origin of the whorl by an additional cell. Conidia (2.5-)3.0-5.0(-6.8) ×(2.0-)2.5-3.0(-3.7) $\mu \mathrm{m}, 1 /$ $\mathrm{w}(1.1-) 1.2-1.6(-2.0) \quad(n=80)$, pale greenish, variable, ellipsoidal or subglobose, sometimes oblong, smooth, with 
1-2 guttules; scar indistinct or narrowly projecting; aggregating in chains in age. At $15^{\circ} \mathrm{C}$ conidiation abundant in large green, $27-28 \mathrm{CD} 4-7$ to $27 \mathrm{E} 4-8$, pustules aggregating to $10 \mathrm{~mm}$ length. At $30^{\circ} \mathrm{C}$ either hyphae dying after a few days or colony dense, downy, with growth slowing down after 1 weeks; autolytic activity conspicuous, excretions yellow; conidiation effuse, colourless.

On PDA after $72 \mathrm{~h} 5-8 \mathrm{~mm}$ at $15^{\circ} \mathrm{C}, 8-9 \mathrm{~mm}$ at $25^{\circ} \mathrm{C}$, $1-3 \mathrm{~mm}$ at $30^{\circ} \mathrm{C}$. Growth limited, typically stopping before covering the plate. Hyphae narrow, all of similar width, surface hyphae finely wavy. Colony compact, dense, flat, zonate. Central zone circular, broad, opaque, farinose to finely granulose, first white to yellowish, 3A3-4, becoming light greenish after 7-10 days due to conidiation, with rosy margin, followed by several farinose zones with wavy outline, light green, 28A3-4, 28B4, 28C4-5, 27AB2-3, with rosy to reddish-brown tones, 5B3, 6AB3, 6B4, 6A2-3, 7B4. Reverse becoming yellow with rosy tones from the centre, spreading across the whole plate, finally turning dark brown, (6-)7-8F5-8; pigment diffusing into the agar; also present within hyphae. Aerial hyphae scant, loosely disposed, becoming fertile. Autolytic activity appearing as numerous minute yellowish-brown excretions mainly along hyphae; no coilings noted. Odour indistinct to mushroomy, reminiscent of the mushroom Sarcodon imbricatus. Conidiation noted from 2 to 3 days, effuse, starting around the plug on short erect conidiophores in a dense lawn spreading across the colony, growing to densely branched granules to $1 \mathrm{~mm}$ diam in the centre; mostly dry, first white, becoming green. Phialides short, spiny, inclined upwards, curved to sinuous. At $15^{\circ} \mathrm{C}$ growth limited; surface hyphae widely curved to coiled, forming broom-like structures with pegs or moniliform hyphae; colony becoming yellowish-brown; with little effuse conidiation. At $30^{\circ} \mathrm{C}$ growth limited; hyphae curly, dying soon, sometimes good growth after a slow initial phase; colony zonate; with numerous minute autolytic excretions, little effuse conidiation; centre yellow to reddish-brown, 5AB5 to 9-10F7-8.

On SNA after $72 \mathrm{~h} 5-7 \mathrm{~mm}$ at $15^{\circ} \mathrm{C}, 9-11 \mathrm{~mm}$ at $25^{\circ} \mathrm{C}$, $1-4 \mathrm{~mm}$ at $30^{\circ} \mathrm{C}$; mycelium covering the plate after $1 \mathrm{~m}$ at $25^{\circ} \mathrm{C}$. Colony similar to $\mathrm{CMD}$, denser, silky, not zonate, margin more irregular, wavy to lobed. Surface hyphae minutely tuberculate, with little difference in width, degenerating and appearing empty in aged cultures. Aerial hyphae inconspicuous, but more abundant than on CMD, erect, thin, loosely disposed, long and several $\mathrm{mm}$ high towards the margin, becoming fertile. No autolytic activity and coilings noted. No pigment, no distinct odour noted. Conidiation noted from 4 to 5 days, on white shrubs or granules appearing on the plug margin, growing and condensing into an annular continuum with a granular surface, becoming macroscopically pale green 28DE5-7 after 6-8 days. Additional large granular pustules to $7 \mathrm{~mm}$ long formed in the centre, later also in a more distal concentric zone or irregularly disposed, pale green, 28 29CD4-6, 27-28E4-6; some conidiation also on erect aerial hyphae without structural difference to pustulate conidiation. Conidiation starting within pustules, dense but transparent; marginal branches first appearing as straight to sinuous elongations, becoming fertile, forming mostly broad pachybasium-like conidiophores. Tufts $0.3-4.5 \mathrm{~mm}$ diam, confluent to oblong pustules $7 \times 3 \mathrm{~mm}$. Phialides short, conidia dry or in minute wet heads $<20 \mu \mathrm{m}$ diam, aggregating in chains. Chlamydospores noted after (2-) 3 weeks, infrequent, $6-14(-23) \times(3-) 4-6(-8) \mu \mathrm{m}, 1 / \mathrm{w} 1.0$ $2.7(-4.8) \quad(n=33)$, variable, oval, clavate, rectangular, ellipsoidal, etc., mostly intercalary, size strongly depending on hyphal width. At $15^{\circ} \mathrm{C}$ central granulose tufts coalescing to $10 \mathrm{~mm}$, becoming green 27D4-6, 28AB4, 28D4-6; dry conidiation abundant in tufts with mostly fertile, straight to sinuous elongations; terminal and intercalary chlamydospores noted. At $30^{\circ} \mathrm{C}$ growth often limited; colony dense, silky; conidiation effuse, remaining colourless.

Habitat: usually in large numbers on moist (medium- to) well-decayed wood and bark.

Distribution: Europe (Austria, Czech Republic, Germany)

Holotype: Czech Republic, Mährisch Weißenkirchen, Podhorn, on stump of Fagus sylvatica (determined by wood microscopy), on light, well-decayed wood, soc. hyphomycete, effete pyrenomycete, Oct. 1920, F. Petrak, K(M) 154039. Epitype designated here to establish the correct relationship of teleomorph, anamorph and gene sequences: Austria, Niederösterreich, Wien-Umgebung, Mauerbach, Friedhofstraße, MTB 7763/1, 48 ${ }^{\circ} 15^{\prime} 08^{\prime \prime}$ N, $16^{\circ} 10^{\prime} 34^{\prime \prime}$ E, elev. $380 \mathrm{~m}$, on moist decorticated branch of Carpinus betulus 9-10 cm thick, 10 Sep. 2005, W. Jaklitsch W.J. 2850 (WU 29283, ex-epitype culture CBS 120539=C. P.K. 2418). Holotype of Trichoderma moravicum isolated from WU 29283 and deposited as a dry culture with the epitype of $H$. moravica as WU 29283a.

Other specimens examined: Austria, Kärnten, Klagenfurt Land, St. Margareten im Rosental, Stariwald, MTB 9452/4, 46 $32^{\prime} 51^{\prime \prime} \mathrm{N}, 14^{\circ} 25^{\prime} 29^{\prime \prime} \mathrm{E}$, elev. $580 \mathrm{~m}$, on decorticated branch of Fagus sylvatica $5 \mathrm{~cm}$ thick; soc. Nemanis serpens, effete pyrenomycete, Corticiaceae, Mollisia sp.; holomorph, 16 Sep. 2005, W. Jaklitsch, W.J. 2855 (WU 29284, culture C.P.K. 2419). Trieblach, DrauAuen, below Kucher, MTB 9452/2, 46 $33^{\prime} 12^{\prime \prime}$ N, $14^{\circ} 25^{\prime} 01^{\prime \prime}$ E, elev. $400 \mathrm{~m}$, on partly decorticated branch of Corylus avellana, on wood, bark and stromata of Hypoxylon fuscum, soc. Corticiaceae, 14 Oct. 2006, W. Jaklitsch, W.J. 3021 (WU 29286, culture C.P.K. 2489). Niederösterreich, Hollabrunn, Hardegg, National Park Thayatal, at the traverse of the Umlaufberg (Hardegg side), MTB 7161/3, $48^{\circ} 50^{\prime} 40^{\prime \prime} \mathrm{N}, 15^{\circ} 53^{\prime} 33^{\prime \prime} \mathrm{E}$, elev. $300 \mathrm{~m}$, on fallen decorticated $\log$ of ?Alnus glutinosa $20 \mathrm{~cm}$ thick, on 
strongly decayed crumbly wood, soc. effete pyrenomycetes, 1 Sep. 2005, H. Voglmayr, W.J. 2832 (WU 29282, culture C.P.K. 2411). Mödling, Wienerwald, Kaltenleutgeben, along brook Dürre Liesing between Am Brand and Stangau, MTB 7862/4, $48^{\circ} 06^{\prime} 45^{\prime \prime} \mathrm{N}, 16^{\circ} 08^{\prime} 43^{\prime \prime} \mathrm{E}$, elev. $450 \mathrm{~m}$, on decorticated branches of Alnus glutinosa 5-20 cm thick, on wood, soc. Arcyria sp., Chlorociboria aeruginascens, Orbilia delicatula, Steccherinum ochraceum, effete pyrenomycete, Corticiaceae, 22 Oct. 2006, W. Jaklitsch \& H. Voglmayr, W.J. 3025 (WU 29287, culture C. P.K. 2492). Oberösterreich, Schärding, St. Willibald, riverine forest near Aichet, MTB 7648/1, 48 $21^{\prime} 17^{\prime \prime} \mathrm{N}, 1^{\circ} 41^{\prime} 01^{\prime \prime} \mathrm{E}$, elev. $400 \mathrm{~m}$, on partly decorticated, well-decayed branch of Alnus glutinosa, on wood and bark, soc. Chaetosphaeria ovoidea, Tubeufia cerea/effete pyrenomycete, Diatrypella cf. verrucaeformis in the bark, 26 Oct. 2005, H. Voglmayr, W.J. 2867 (WU 29285, culture C.P.K. 2431); same locality, on branch of Alnus glutinosa, soc. Orbilia delicatula, effete pyrenomycete, hyphomycetes, 27 Oct. 2006, H. Voglmayr, W.J. 3031, WU 29288. Steiermark, Weiz, Laßnitzthal, opposite to the Arboretum Gundl across the road, MTB 8959/2, 47 $04^{\prime}$ $17^{\prime \prime} \mathrm{N}, 15^{\circ} 38^{\prime} 34^{\prime \prime}$ E, elev. $410 \mathrm{~m}$, on moist lower side of decorticated, well-decayed branch of Fagus sylvatica $6 \mathrm{~cm}$ thick, on bare ground beside a small brook, soc. various hyphomycetes, 7 Sep. 2003, W. Jaklitsch, W.J. 2388 (WU 29281, culture C.P.K. 954). Germany, Baden Württemberg, Schwarzwald, SW Fixenhof at Welschenstainach, MTB $7714 / 1$, elev. 480 m, on decorticated branch of Fraxinus excelsior, 19 Oct. 2008, L. Krieglsteiner (WU 29289). Niedersachsen, close to Wolfenbüttel, "Lechlumer Holz", MTB 3829/1, on decorticated branch of Fagus sylvatica, 13 Sep. 2008, L. Krieglsteiner (culture C.P.K. 3566).

Notes: Hypocrea moravica is apparently the most common species in Central Europe of those forming yellow pulvinate stromata lacking an initially rosy or reddish stage. The teleomorph can be mistaken for a number of other species, e.g. Hypocrea lutea, and was regarded a synonym of it by Doi (1972). H. lutea differs by smaller and paler stromata and a distinctly gliocladium-like anamorph. $H$. argillacea is more similar to H. bavarica in terms of stroma colour and ostiolar dots, but in absence of information on the natural variation of $H$. argillacea, $H$. moravica may be a synonym of that species, despite the slightly larger ascospores in $H$. argillacea. Recollection and sequencing of $H$. argillacea is necessary to ascertain this. H. bavarica, once even found together with $H$. moravica on the same branches, differs e.g. by smaller ascospores, usually more diffuse ostiolar dots, an effuse white-conidial anamorph and a characteristic unpleasant odour on PDA. Effuse forms of $H$. moravica are uncommon; they can be mistaken for $H$. phellinicola, which occurs on Phellinus ferruginosus and differs e.g. also by drying to thin crusts and a white-conidial anamorph. Stromata of species of the Brevicompactum clade may sometimes be similar to those of $H$. moravica. They differ e.g. by smaller cortical stroma cells and smaller and mostly paler conidia. On average, the stromata are brighter than those of $H$. lutea or species of the pachybasium core group. All these species are phylogenetically unrelated to $H$. moravica, which belongs to the Semiorbis clade. Conidiophores in pustules of $T$. moravicum are similar to those of the pachybasium core group, but more variable, often curved to sinuous.

Hypocrea sambuci Jaklitsch \& Voglmayr, sp. nov. Fig. 93 MycoBank MB 516701

Stromata in ligno putrido Sambuci nigrae, pulvinata, ceracea ad gelatinosa apparenter, mellea in statu humido, plane pulvinata ad discoidea, mellea vel brunnea in statu sicco. Asci cylindrici, (54-)68-82(-92) $\times(3.7-) 4.0-5.0(-$ 5.7) $\mu \mathrm{m}$. Ascosporae bicellulares, hyalinae, verruculosae, ad septum disarticulatae, pars distalis (sub)globosa vel ellipsoidea, $(2.8-) 3.0-3.8(-4.5) \times(2.5-) 2.8-3.2(-3.5) \mu \mathrm{m}$, pars proxima oblonga vel cuneata, $(3.0-) 3.5-4.7(-6.0) \times$ $(2.0-) 2.3-2.7(-3.2) \mu \mathrm{m}$.

Etymology: the epithet refers to the occurrence on Sambucus.

Stromata when fresh $1-2(-3) \mathrm{mm}$ diam, to $1 \mathrm{~mm}$ thick, solitary, scattered or aggregated in small numbers, pulvinate or lenticular, broadly attached, edge free. Surface smooth or finely verruculose, appearing waxy or gelatinous. Ostioles concolorous, hardly visible when moist, with age distinct brown dots appearing. Stromata first white, later pale yellow, 4A2-4, honey-yellow, honey-brown, yellowish brown, 5CD6-8, 6CD5-7, goldenyellow to dark brown, 7E6-8, when old. Spore deposits white to yellowish.

Stromata when dry $(0.4-) 0.7-1.6(-2.5) \times(0.3-) 0.6-1.3(-$ 2) $\mathrm{mm},(0.12-) 0.2-0.5(-0.7) \mathrm{mm}$ thick $(n=100)$, solitary, gregarious in lawns on wood, often in large numbers, aggregated only in small groups; flat pulvinate, lenticular or discoid, less commonly turbinate with short and thick, white or yellowish, glabrous or downy, sterile cylindrical base; sometimes first subeffuse, breaking up into up to ten laterally fused or densely aggregated parts, broadly attached. Outline circular, angular or oblong. Margin rounded or sharp, free, sometimes involute. Surface convex or flat, smooth, tubercular or rugose, often shiny or iridescent, sometimes glassy, but generally appearing distinctly less glassy or waxy than fresh, sometimes covered with whitish floccules when young. Ostiolar dots $(20-) 30-54(-80) \mu \mathrm{m}(n=170)$ diam, often indistinct and concolorous with the stroma surface when young, later well-defined, circular or oblong in outline, plane or convex, shiny, brown, reddish brown to nearly black when old; sometimes without dots, but light, translucent perithe- 

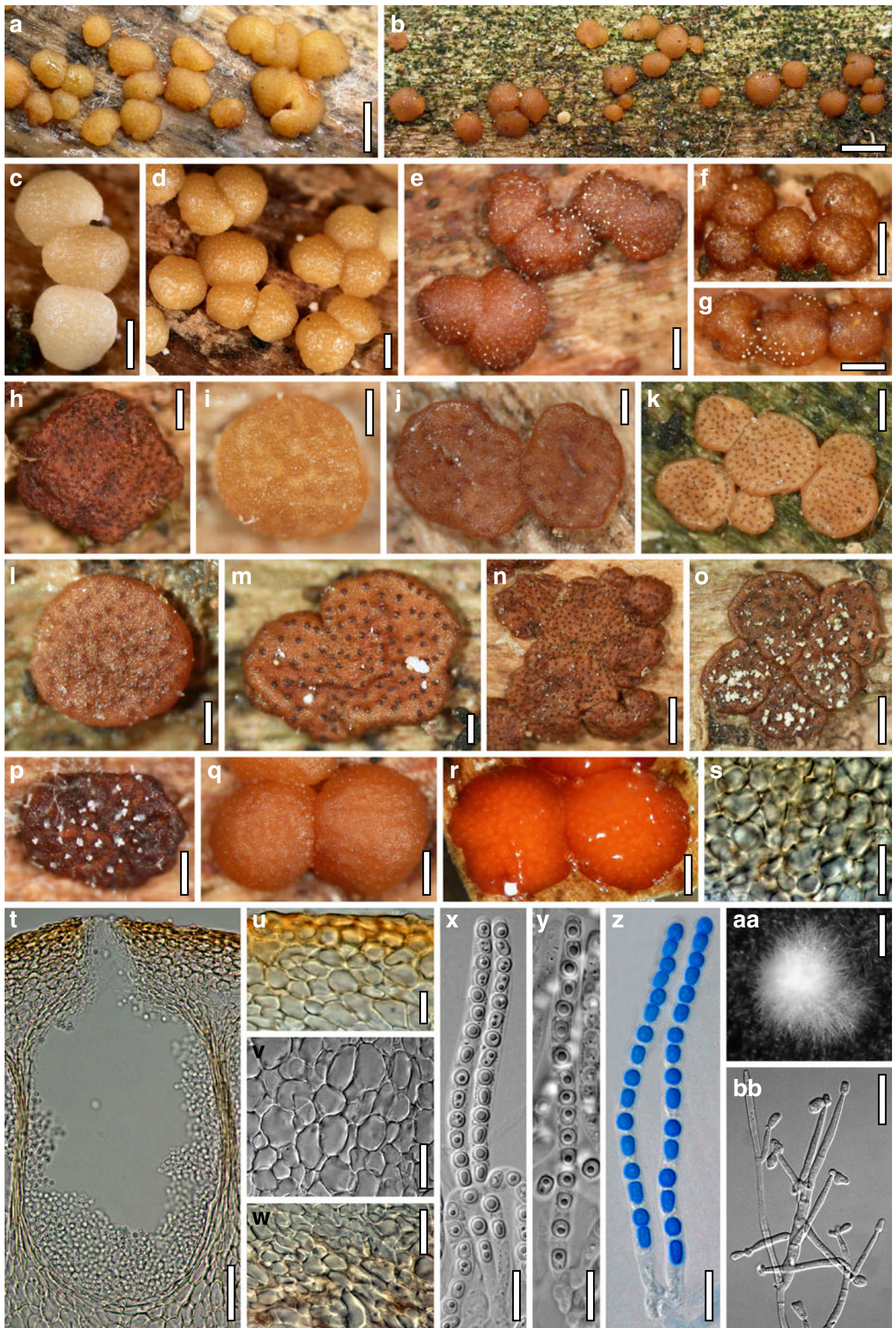
4Fig. 93 Hypocrea sambuci. a-h. Fresh stromata (a-c. immature; $\mathbf{h}$. overmature). i-p. Dry stromata (i-k. immature; p. overmature). q. Rehydrated stromata. r. Stromata in $3 \% \mathrm{KOH}$ after rehydration. s. Stroma surface in face view. t. Perithecium in section. u. Cortical and subcortical tissue in section. $\mathbf{v}$. Subperithecial tissue in section. $\mathbf{w}$. Stroma base in section. $\mathbf{x}-\mathbf{z}$. Asci with ascospores (z. in cotton blue/ lactic acid). aa. Conidiation tuft. bb. Conidiophore with phialides and conidia. a, h. WU 29465. b, k, l, q-w. WU 29463. c, d, i. WU 29467. e-g, n. WU 29466. j. WU 29468. m, o, y, z. WU 29462. p, x. WU 29464. aa, bb. C.P.K. 3718 , MEA, $20^{\circ}$ C, 29 days. Scale bars $\mathbf{a}=$ $1 \mathrm{~mm} . \mathbf{b}=1.5 \mathrm{~mm}$. $\mathbf{c}-\mathbf{g}, \mathbf{n}=0.6 \mathrm{~mm} . \mathbf{h}, \mathbf{k}, \mathbf{o}, \mathbf{q}, \mathbf{r}, \mathbf{a a}=0.4 \mathrm{~mm} . \mathbf{i}, \mathbf{j}, \mathbf{l}$, $\mathbf{m}, \mathbf{p}=0.2 \mathrm{~mm}$. s, $\mathbf{u}, \mathbf{x}-\mathbf{z}=10 \mu \mathrm{m} . \mathbf{t}, \mathbf{w}=30 \mu \mathrm{m} . \mathbf{v}, \mathbf{b} \mathbf{b}=20 \mu \mathrm{m}$

cia projecting, papillate. Stromata first white, turning pale yellow, 4A3, 4B4, light honey-yellow, ochre or greyish orange, brown-orange, light brown, 5B5, 5-6CD5-8, older material mostly dark reddish brown, 7-8EF5-8. Spore deposits white to yellowish; also light honey-yellow stromata sometimes mature, i.e. with spore deposits. Rehydrated stromata thickly pulvinate, up to three times thicker than dry stromata, ochre, without ostiolar dots, but minute concolorous or lighter ostiolar openings visible under strong magnification. Reaction to $3 \% \mathrm{KOH}$ variable, absent in young stromata, surface slightly or distinctly more orange in mature stromata; perithecia translucent, light.

Stroma anatomy: Ostioles (44-)50-66(-78) $\mu \mathrm{m}$ long, plane or projecting to $15 \mu \mathrm{m},(14-) 17-27(-35) \mu \mathrm{m}$ wide at the opening inside $(n=30)$, without specialized apical cells. Perithecia (150-)170-205(-215) $\times(80-) 100-155(-180) \mu \mathrm{m}$ $(n=30)$, flask-shaped, ellipsoidal or subglobose, $c a$ nine per mm stroma length; peridium (10-)13-20(-21) $\mu \mathrm{m}(n=$ $30)$ thick at the base, $(4-) 8-13(-15) \mu \mathrm{m}(n=30)$ at the sides, pale yellow. Cortical layer (7-)10-15(-20) $\mu \mathrm{m}(n=$ $30)$ thick, a thin, light yellow $t$. angularis of 2-3 layers of thick-walled cells $(4.5-) 5.5-11(-19) \times(3-) 4-8(-10) \mu \mathrm{m}(n$ $=65$ ) in face view and in vertical section; orange in $\mathrm{KOH}$; cells tending to be larger and lighter in the lateral cortex; surface smooth, glabrous. Subcortical tissue a hyaline to yellowish $t$. angularis of thin-walled cells $(5-) 6-13(-18) \times$ (3-)4-8(-11) $\mu \mathrm{m}(n=30)$. Subperithecial tissue a (sub-) hyaline $t$. angularis of cells (6-)9-22(-31) $\times(4-) 7-14(-18)$ $\mu \mathrm{m}(n=35)$, often smaller, compressed or yellow towards stroma base. Asci (54-)68-82(-92) $\times(3.7-) 4.0-5.0(-5.7)$ $\mu \mathrm{m}$, stipe $(2-) 6-15(-22) \mu \mathrm{m}$ long $(n=111)$; croziers present. Ascospores hyaline, verruculose, cells dimorphic; distal cell $(2.8-) 3.0-3.8(-4.5) \times(2.5-) 2.8-3.2(-3.5) \mu \mathrm{m}, 1 /$ W 1.0-1.3(-1.6) $(n=180)$, (sub)globose or ellipsoidal; proximal cell $(3.0-) 3.5-4.7(-6.0) \times(2.0-) 2.3-2.7(-3.2)$ $\mu \mathrm{m}, 1 / \mathrm{w}(1.1-) 1.3-1.8(-2.7)(n=180)$, oblong or wedgeshaped, less commonly subglobose.

Cultures and anamorph: Growth slow on CMD, MEA, PDA and SNA.

On MEA colony not reaching more than $12 \mathrm{~mm}$ at $20^{\circ} \mathrm{C}$ after a month. Colony hyaline or turning brown, producing white spiny tufts to $c a 1.6 \mathrm{~mm}$ diam. Tufts comprising a thick long stipe with few thick, asymmetric primary branches, both 5-6.5(-7.5) $\mu \mathrm{m}$ wide, the latter unbranched or bearing some side branches. Side branches/conidiophores tapering to $(2-) 2.5-3(-5) \mu \mathrm{m}$ wide terminally, to $6.5 \mu \mathrm{m}$ wide downwards, simple or branched once, typically projecting as stiff, straight, fertile elongations $0.1-0.5 \mathrm{~mm}$ from the tuft. All branches at acute angles, only rarely 1-2 celled rectangular branches. Phialides produced on 1-6 celled branches, solitary or in whorls of 2-3 (to four in pseudo-whorls). Conidia formed in small numbers. Phialides (3-)10-28(-37) $\times(1.8-) 2.5-3.5(-4.5)$ $\mu \mathrm{m}, 1 / \mathrm{w}(1.7-) 3.7-8.2(-10.9),(1.2-) 2.0-3.3(-4.0) \mu \mathrm{m}$ wide at the base $(n=30)$, subulate, widest below the middle. Conidia (4.8-)6.0-8.7(-10)×(2.8-)3.7-5.8(-7.3) $\mu \mathrm{m}, \mathrm{l} /$ w (0.9-)1.2-2.0(-2.4) $(n=30)$, variable, ellipsoidal, oblong, rhomboid etc., hyaline, smooth, finely multiguttulate, scar indistinct. Sterile, yellowish- to dull reddish brown, pulvinate stromata $1-3 \times 0.9-2.3 \mathrm{~mm}$ produced on MEA after 50 days at $20^{\circ} \mathrm{C}$.

Habitat: on decorticated branches of Sambucus nigra.

Distribution: Europe (Austria, Germany, Italy)

Holotype: Austria, Steiermark, Graz-Umgebung, Mariatrost, Wenisbucher Straße, left side shortly before the main crossing in the forest, MTB 8858/4, 47 $06^{\prime} 40^{\prime \prime} \mathrm{N}, 15^{\circ} 29^{\prime}$ 11" E, elev. $470 \mathrm{~m}$, on decorticated branches of Sambucus nigra 1-2 $\mathrm{cm}$ thick on the ground, on moist wood, partly attacked by a white hyphomycete, soc. green Trichoderma sp., moss, algae, greyish brown Corticiaceae, black debris, 20 Aug. 2004, W. Jaklitsch, W.J. 2612 (WU 29463).

Other specimens examined: Austria, Kärnten, Klagenfurt Land, St. Margareten im Rosental, boggy area behind Bauhof Jaklitsch heading to Trieblach, MTB 9452/4, 46 ${ }^{\circ} 32^{\prime}$ $29^{\prime \prime} \mathrm{N}, 14^{\circ} 25^{\prime} 40^{\prime \prime}$ E, elev. $580 \mathrm{~m}$, on decorticated branches of Sambucus nigra 1-1.5 cm thick, on wet wood, soc. hyphomycete, 19 Aug. 2004, W. Jaklitsch, W.J. 2610 (WU 29462).

Same village, at the brook Tumpfi (upper part), MTB

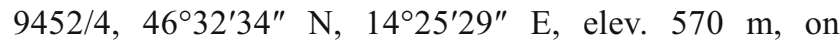
decorticated, well-decayed branches of Sambucus nigra $0.5-2 \mathrm{~cm}$ thick, partly on and soc. Hyphodontia sambuci, soc. white and black mould, effete Lophiostoma sp., etc., 13 Oct. 2006, W. Jaklitsch, W.J. 3018 (WU 29468). Same village, at the brook Tumpfi (lower part), MTB 9452/2, $46^{\circ}$ $32^{\prime} 59^{\prime \prime} \mathrm{N}, 14^{\circ} 25^{\prime} 50^{\prime \prime} \mathrm{E}$, elev. $560 \mathrm{~m}$, on decorticated branches of Sambucus nigra and Clematis vitalba, soc. Hyphodontia sambuci, 9 July 2007, W. Jaklitsch, W.J. 3119 (WU 29469). Niederösterreich, Baden, Berndorf, Großer Geyergraben at Steinhof, MTB 8062/3, 47 56'08" N, $16^{\circ}$ 04'33" E, elev. $360 \mathrm{~m}$, on decorticated branches of Sambucus nigra, soc. algae, mud, 8 Oct. 2005, H. Voglmayr, W.J. 2860 (WU 29466). Hernstein, Grillenbergtal at the Veitsauer brook, shortly after Grillenberg, MTB $8062 / 3,47^{\circ} 55^{\prime} 23^{\prime \prime} \mathrm{N} 16^{\circ} 04^{\prime} 35^{\prime \prime} \mathrm{E}$, elev. $350 \mathrm{~m}$, on 
decorticated branches of Sambucus nigra, soc. moss, old pyrenomycete, 16 Sep. 2006, H. Voglmayr, W.J. 2973 (WU 29467). Hollabrunn, Hardegg, NP Thayatal, at the Bossengraben, alluvial-like forest stretch, MTB 7161/3, 48 50'42" N, $15^{\circ} 53^{\prime} 00^{\prime \prime}$ E, elev. $300 \mathrm{~m}$, on decorticated branches of Sambucus nigra, on wood, soc. moss, effete Diaporthe sp., Hypomyces anamorph, Corticiaceae, green pachybasiumlike Trichoderma, 1 Sep. 2005, H. Voglmayr, W.J. 2831 (WU 29464). Germany, Baden Württemberg, Karlsruhe, Heidelberg, northern shore of the river Neckar, at the Haarlass, MTB 6518/34, on decorticated branch of Sambucus nigra, soc. Trichoderma cf. cerinum, 28 July 2009, M. Bemmann (WU 29103, culture C.P.K. 3718). Bavaria, Starnberg, Tutzing, Erling, Hartschimmel area, MTB $8033 / 1,47^{\circ} 56^{\prime} 35^{\prime \prime} \mathrm{N}, 11^{\circ} 10^{\prime} 51^{\prime \prime} \mathrm{E}$, elev. $700 \mathrm{~m}$, on decorticated branches of Sambucus nigra 10-12 cm thick, on wet wood, soc. moss, Trichoderma harzianum, brown rhizomorphs, effete pyrenomycete, 3 Sep. 2005, W. Jaklitsch, W.J. 2837 (WU 29465). Italy, Apulia, Foggia, Gargano, Foresta Umbra, roadside of SP52bis close to Monte Nicola, $41^{\circ} 48^{\prime} 45^{\prime \prime} \mathrm{N}, 16^{\circ} 00^{\prime} 17^{\prime \prime} \mathrm{E}$, elev. $670 \mathrm{~m}$, on decorticated branches of Sambucus nigra 1-2 cm thick in leaf debris, 21 Nov. 2009, H. Voglmayr \& W. Jaklitsch (WU 30191, culture S 94=CBS 126958).

Notes: Hypocrea sambuci is well characterised by its occurrence on decorticated branches of Sambucus nigra, by minute fresh stromata that appear waxy or gelatinous, similar to those of $H$. tremelloides, and flat pulvinate to discoid dry stromata that often look like a miniature of H. subalpina. $H$. tremelloides differs e.g. by incarnate stromata that are typically densely aggregated in large groups, and by faster growth at higher temperatures. Stromata of $H$. sambuci are usually accompanied by different green-conidial species of Trichoderma, such as T. harzianum or T. cerinum.

Several attempts to prepare a culture under standard conditions failed, because the germ tubes died shortly after germination. Only one specimen (WU 29103) yielded an unstable culture (C.P.K. 3718) upon ascospore isolation on $\mathrm{CMD}$ at $20^{\circ} \mathrm{C}$. The short description above is based on this culture. Conidiophores are similar to those of $T$. tremelloides, albeit somehow simpler and more regular in structure than the latter. It has not yet been possible to obtain the sequence of tefl introns of $\mathrm{H}$. sambuci, due to priming issues. Other sequences were obtained using DNA extracted from stromata (WU 29467) and from the culture C.P.K. 3718. ITS, $r p b 2$ and tef1 exon sequences show that H. sambuci is phylogenetically distinct from, but closely related to, $H$. tremelloides.

Hypocrea schweinitzii (Fr. : Fr.) Sacc., Syll. Fung. 2: 522 (1883a). Fig. 94

$\equiv$ Sphaeria schweinitzii Fr. : Fr., Elench. Fungorum 2: 60 (1828).
$=$ Sphaeria rigens Fr., Elench. Fung. 2: 61 (1828).

$\equiv$ Hypocrea rigens (Fr. : Fr.) Sacc., Michelia 1: 301 (1878).

= Sphaeria lenta Schwein., Schriften Naturf. Ges. Leipzig 1: 4 (1822).

= Sphaeria contorta Schwein., Trans. Amer. Phil. Soc. II, 4 (2): 194 (1832).

$\equiv$ Hypocrea contorta (Schwein.) Berk. \& M.A. Curtis, Grevillea 4: 14 (1875).

= Hypocrea atrata P. Karst., Mycol. Fenn. 2: 207 (1873).

= Hypocrea repanda Fuckel, Symb. Mycol. Nachtr. 1: 312, 3: 23 (1871).

$=$ Hypocrea rufa $*$ umbrina Sacc., Atti Soc. Venet.-Trent. Sci. Nat., Padova 4: 124 (1875).

Anamorph: Trichoderma citrinoviride Bissett, Can. J. Bot. 62: 926 (1984). Fig. 95

Stromata when fresh $1-10 \mathrm{~mm}$ diam, $0.5-2.5 \mathrm{~mm}$ thick, solitary, gregarious or densely aggregated to clusters up to $17 \mathrm{~mm}$ diam, usually in small numbers; first pulvinate or lenticular, becoming discoid, undulate, lobed, convoluted. Outline circular, oblong or irregular. Margin sharp or rounded, often free for a large part, sometimes lighter or white when young. Surface smooth, often with a silvery covering layer with fine fissures, or finely verruculose by numerous black, pointed, slightly projecting ostioles. Stroma colour pale olive or greenish with or without white margin when young, later greyish green to dark grey or dark green, 1DE3-5, 25E4, 25F2-3, 26E2-3, 26-27F1-3(6), 28F5-6 to $29 \mathrm{~F} 4$.

Stromata when dry $(0.8-) 1.8-5.3(-9.1) \times(0.5-) 1.3-4(-$ 7.1) $\mathrm{mm}(n=98),(0.3-) 0.5-1.1(-1.8) \mathrm{mm}(n=91)$ thick, on wood or bark or emerging through bark fissures, solitary and roundish or variably lobed or in densely aggregated, lobed, laterally fused clusters or irregular masses with several attachment areas; variable in shape, pulvinate, lenticular, turbinate, discoid, often lobed, undulate to irregularly folded or distorted by mutual pressure; broadly or more commonly narrowly attached, with often a large portion of the stroma free. Margin mostly free, sharp or rounded, sometimes involute, concolorous with the surface, whitish downy when young. Lower free side concolorous, often brown to black downy. Surface smooth or finely tubercular due to the ostioles or with delicately fissured,

Fig. 94 Teleomorph of Hypocrea schweinitzii. a-c. Fresh stromata (a. immature). d, e, $\mathbf{g}-\mathbf{j}$. Dry stromata (d, e. immature; e. with anamorph; i. stroma initial). f, k. Rehydrated stromata (f. in section; $\mathbf{k}$. in face view). 1. Stroma surface in face view. $\mathbf{m}$. Perithecium in section. $\mathbf{n}$. Cortical and subcortical tissue in section. o. Subperithecial tissue in section. p. Non-attached stroma base in section. q-t. Asci with ascospores (s, t. in cotton blue/lactic acid). a. WU 29473. b, c, r. WU 29471. d, e. WU 29472. g. WU 29476. h, i. WU 29475. k-q, s. WU 29470. f, j. PRM (leg. Pouzar). t. WU 29474. Scale bars: a, e-g= $1 \mathrm{~mm}$. b, i, $\mathbf{k}=0.7 \mathrm{~mm}$. c, $\mathbf{d}=1.5 \mathrm{~mm}$. $\mathbf{h}=0.4 \mathrm{~mm} . \mathbf{j}=2.5 \mathrm{~mm}$. $\mathbf{I}=$ $10 \mu \mathrm{m} . \mathbf{m}=20 \mu \mathrm{m} . \mathbf{n}-\mathbf{p}=15 \mu \mathrm{m} . \mathbf{q}-\mathbf{t}=5 \mu \mathrm{m}$ 

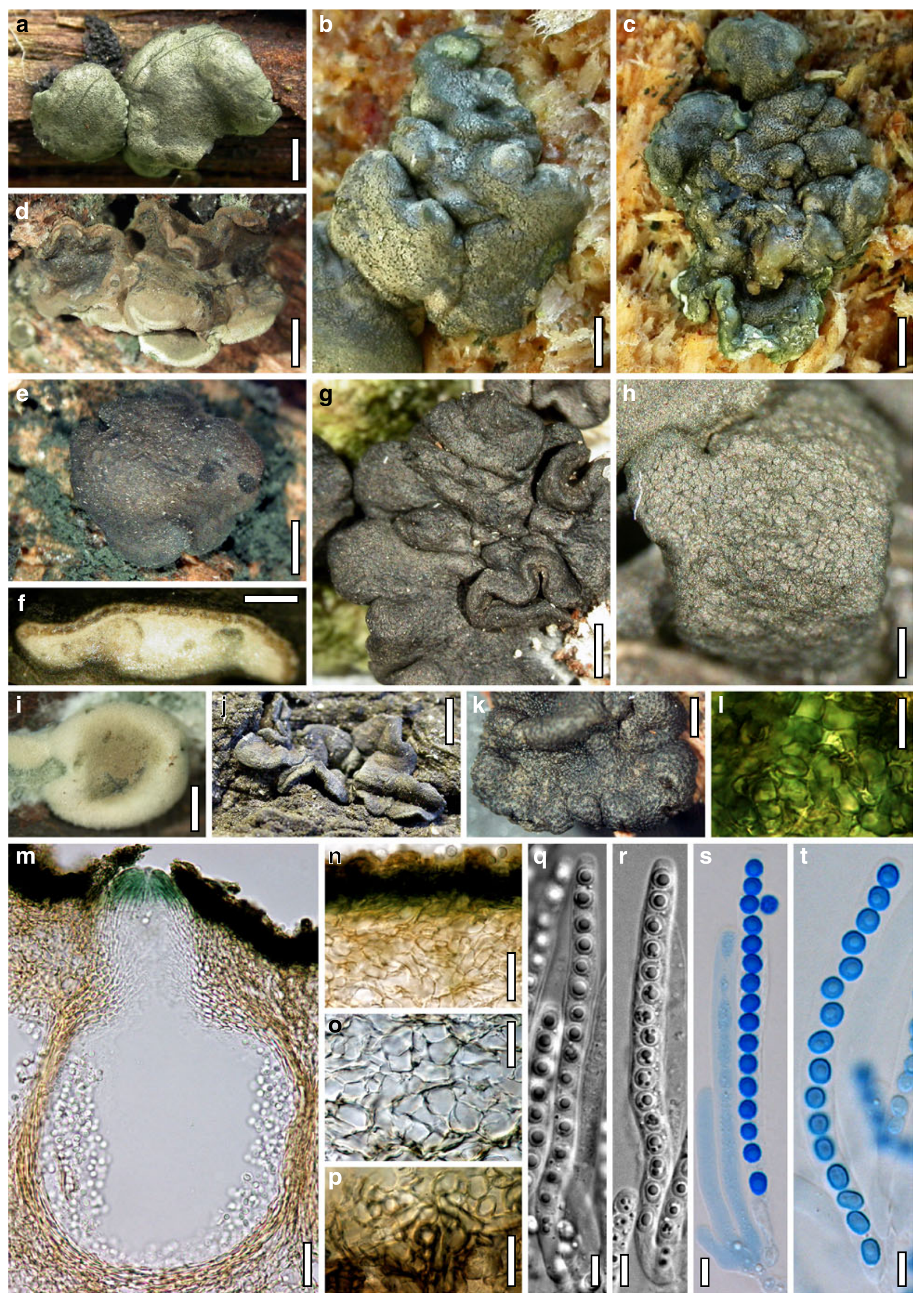

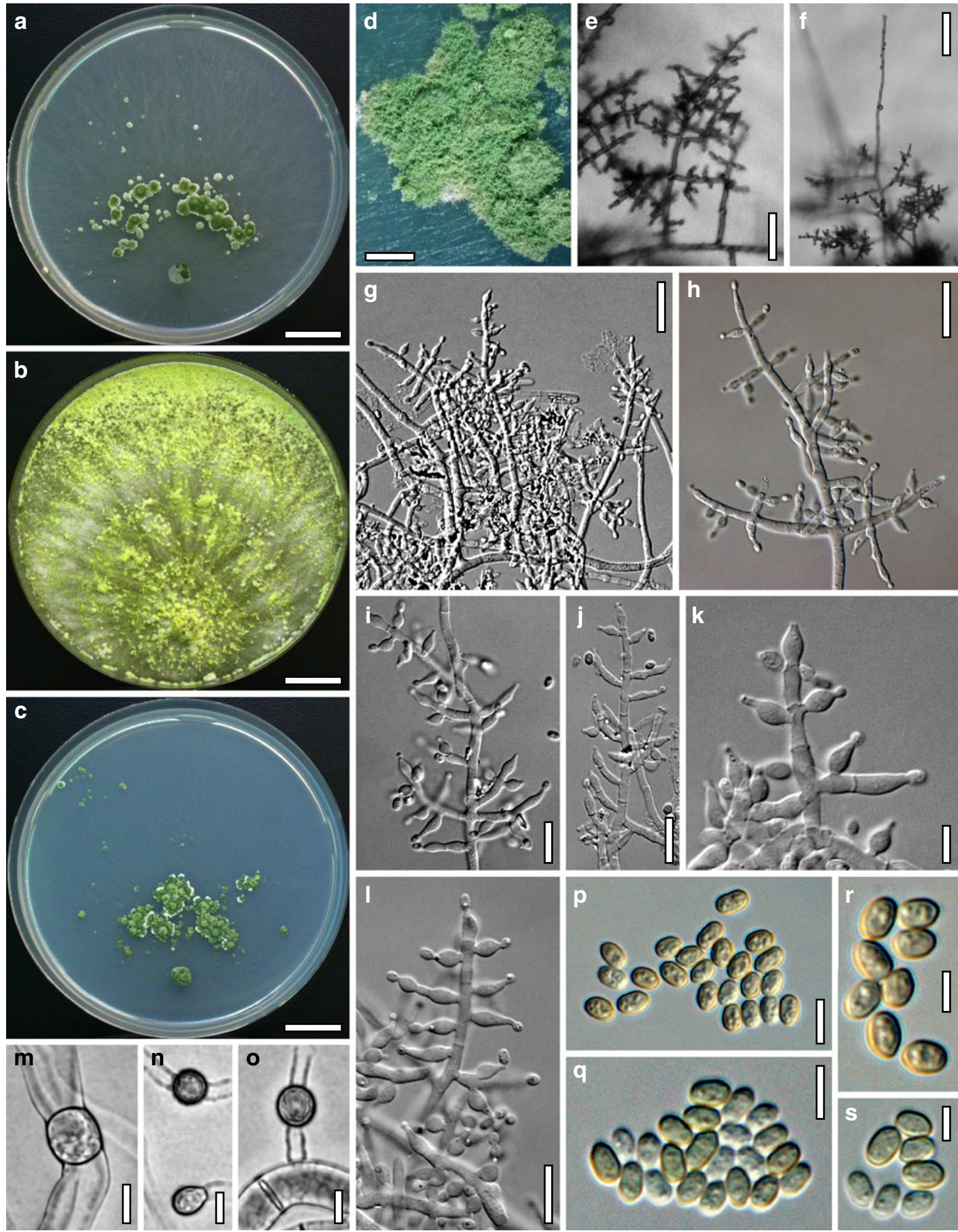
4Fig. 95 Cultures and anamorph of Hypocrea schweinitzii $(=T$. citrinoviride). a-c. Cultures after 7 days (a. on CMD. b. on PDA. c. on SNA). d. Conidiation tufts (SNA, 6 days). e, f. Conidiophores on tuft margins on growth plates (e. tree-like side branch on main axis; $\mathbf{f}$. young main axis with sterile elongation; SNA, 4 days). $\mathbf{g}-\mathbf{j}$. Conidiophores (g, i, j. SNA, 4 days; h. CMD, 6 days). k, l. Phialides (SNA, 4 days). $\mathbf{m}-\mathbf{o}$. Chlamydospores (SNA, 16 days). p-s. Conidia (p, r. CMD, 6 days; q, s. SNA, 4 days). a-s. All at $25^{\circ}$ C. a-c, e-g, io, q, s. CBS 121275. d, h, p, r. C.P.K. 2460. Scale bars $\mathrm{a}-\mathrm{c}=15 \mathrm{~mm}$. $\mathbf{d}=1 \mathrm{~mm} . \mathbf{e}=30 \mu \mathrm{m} . \mathbf{f}=50 \mu \mathrm{m} . \mathbf{g}=20 \mu \mathrm{m} . \mathbf{h}, \mathbf{j}=15 \mu \mathrm{m} . \mathbf{i}, \mathbf{l}=10 \mu \mathrm{m} . \mathbf{k}$, $\mathbf{m}-\mathbf{q}=5 \mu \mathrm{m} . \mathbf{r}, \mathbf{s}=3 \mu \mathrm{m}$

shiny, silvery-grey, greyish green, olive or brownish grey covering layer. Ostioles invisible or appearing as minute, concolorous to black, umbilicate, plane or convex dots (16-)22-42(-63) $\mu \mathrm{m}(n=115)$ diam with circular or oblong outline; sometimes surrounded by stellate fissures. Stroma colour initially whitish, greenish yellowish or brownish, later pale greyish green, pale olive with brown tones or grey with pale olive margin when immature, turning dark greengrey, brown-grey, dull olive, dark grey, 1-6F1-3, 2-3DE46, 27F2-3, 26-28F4-6, 28-30(D)EF(1-)3-6, to black, appearing carbonaceous when lacking the covering layer. Colour inside whitish, partly diffusely brownish or greenish, perithecia appearing dilute olive. Spore deposits white. Rehydrated mature stromata $10-15 \%$ larger than in dry condition, dark grey, surface more distinctly granular than dry; ostiolar dots more distinct, emerging through the covering layer; without distinct difference after addition of $3 \% \mathrm{KOH}$.

Stroma anatomy: Ostioles (50-)56-73(-81) $\mu \mathrm{m}$ long, plane or projecting to $12(-20) \mu \mathrm{m},(17-) 23-40(-48) \mu \mathrm{m}$ wide at the apex $(n=30)$, without specialised cells; periphyses 1-2.5 $\mu \mathrm{m}$ wide, apical fascicle of periphyses dark green in lactic acid, olive in $\mathrm{KOH}$. Perithecia (130-) $145-177(-190) \times(88-) 105-140(-170) \mu \mathrm{m}(n=30)$, small, crowded, flask-shaped, ellipsoidal or subglobose; peridium $(10-) 12-16(-17) \mu \mathrm{m}(n=30)$ thick at the base, $(7-) 10-14(-$ 16) $\mu \mathrm{m}(\mathrm{n}=30)$ at the sides, dull yellowish to light brown, in $\mathrm{KOH}$ dull orange-brown. Cortical layer (7-)11-21(-27) $\mu \mathrm{m}(n=30)$ thick, an ill-defined t. epidermoidea-angularis of thick-walled, vertically compressed cells (3.0-)4.5-7.5($9.0) \times(1.8-) 3.0-5.0(-7.0) \mu \mathrm{m}(n=60)$ in face view and in vertical section; in lactic acid dark green to black, particularly around the ostioles, dense on the upper surface, partially covered by a thin, brown amorphous layer, looser, lighter, more olive to brown and more hyphal at stroma sides and base; dark brown in $\mathrm{KOH}$. Subcortical tissue an ill-defined mixture of subhyaline to pale brown, thinwalled, angular cells $(3-) 4-11(-17) \times(2-) 3-8(-14) \mu \mathrm{m}(n$ $=30)$ and hyphal elements $(2.0-) 2.5-4.0(-4.5) \mu \mathrm{m}(n=30)$ wide. Subperithecial tissue a $t$. epidermoidea of thinwalled, subhyaline to pale brownish or greenish cells (3-) $6-16(-28) \times(3-) 5-11(-16) \mu \mathrm{m} \quad(n=30)$. Stroma base formed by thick-walled brown hyphae (3-)4-6(-8) $\mu \mathrm{m}(n$
$=30)$ wide. Asci $(55-) 65-76(-86) \times(4.4-) 5.0-5.7(-6.5)$ $\mu \mathrm{m}$, stipe $(0-) 3-12(-18) \mu \mathrm{m}$ long $(n=90)$, croziers present. Ascospores hyaline, verruculose, cells monomorphic, globose, subglobose or ellipsoidal, sometimes dimorphic in the ascus base; distal cell (2.7-)3.0-3.8(-4.5) $\times(2.5-) 3.0-3.5(-$ 3.7) $\mu \mathrm{m}, 1 / \mathrm{w}(0.9-) 1.0-1.2(-1.4)(n=160)$; proximal cell $(3.0-) 3.3-4.0(-4.8) \times(2.2-) 3.0-3.5(-4.0) \mu \mathrm{m}, 1 / \mathrm{w} \quad(0.9-)$ $1.0-1.3(-1.8)(n=160)$, sometimes oblong or cuneate.

Anamorph associated with stromata mostly effuse, powdery, first white, turning dull greyish green to dark green, often with white margin.

Cultures and anamorph: optimal growth at $35^{\circ} \mathrm{C}$ on all media. Values above $70 \mathrm{~mm}$ have been extrapolated by linear regression.

On CMD after $72 \mathrm{~h} 22-26 \mathrm{~mm}$ at $15^{\circ} \mathrm{C}, 70-72 \mathrm{~mm}$ at $25^{\circ} \mathrm{C}, 86-88 \mathrm{~mm}$ at $30^{\circ} \mathrm{C}, 93-96 \mathrm{~mm}$ at $35^{\circ} \mathrm{C}$; mycelium covering the plate after $3-4$ days at $25^{\circ} \mathrm{C}$. Colony hyaline, thin, loose, with conspicuous differences in width among thick primary surface hyphae and long and thin, distally reticulate secondary hyphae. Aerial hyphae inconspicuous. Autolytic activity and coilings absent or inconspicuous. Reverse hyaline or diffusely greenish- or greyish-yellow 1B3; colour from above 2A3. Odour indistinct. Chlamydospores appearing after 2 days at $25^{\circ} \mathrm{C}$, terminal and intercalary, globose, ellipsoidal, or fusoid. Conidiation noted after $2-5$ days at $25^{\circ} \mathrm{C}$, green after 3-6 days, earlier at higher temperatures, developing on CMD more slowly than on SNA, first scant, effuse, on aerial hyphae, soon in loose white tufts irregularly disposed or in a concentric zone, turning dull-, greyish- to dark green, 27DE4, 27 28E5-7, 26E4-5, 27F5-8, and thickly pustulate, with margins often long remaining white, some yellow pigment diffusing into the agar around the pustules; cells of surface hyphae around the pustules typically with moniliform thickenings. Tufts $1-9 \mathrm{~mm}$ diam and to $2 \mathrm{~mm}$ thick, confluent to masses of up to $11 \mathrm{~mm}$ long. Structure as described under SNA. At $15^{\circ} \mathrm{C}$ colony circular, conspicuously loose. Conidiation reduced relative to higher temperatures, on aerial hyphae and in broad, thick, loose, cottony fluffy tufts to $6 \times 5 \mathrm{~mm}$, aggregates to $17 \times 11 \mathrm{~mm}$, turning slowly green, $26 \mathrm{E} 4-6$. At $30^{\circ} \mathrm{C}$ colony dense; conidiation developing on CMD faster than on SNA, abundant in numerous, green, 28DE5-6, tufts up to $7 \mathrm{~mm}$ diam and $2 \mathrm{~mm}$ thick, arranged in concentric rings or irregularly distributed. At $35^{\circ} \mathrm{C}$ mycelium loose, conidiation in green, 28E5-7, tufts as at $30^{\circ} \mathrm{C}$.

On PDA after $72 \mathrm{~h} 15-18 \mathrm{~mm}$ at $15^{\circ} \mathrm{C}, 54-58 \mathrm{~mm}$ at $25^{\circ} \mathrm{C}$, $56-59 \mathrm{~mm}$ at $30^{\circ} \mathrm{C}, 62-64 \mathrm{~mm}$ at $35^{\circ} \mathrm{C}$; mycelium covering the plate after 4 days at $25^{\circ} \mathrm{C}$. Colony dense, with wavy to lobed margin; mycelium conspicuously differentiated in width of primary and secondary hyphae. Surface becoming indistinctly zonate, chalky, farinose to fluffy in the centre, outside distinctly radially stellate due to strand-like aggrega- 
tion of surface hyphae. Aerial hyphae numerous, long and ascending several $\mathrm{mm}$, sometimes nearly to the lid of the Petri dish in distal areas, forming strands and a white tomentum with coarse mesh, eventually collapsing and causing a coarsely granular surface. Tufts/pustules appearing in the tomentum, particularly in the centre, turning yellow, 1A5-6, $2 \mathrm{AB} 4$, to pale greenish, spreading, later confluent and eventually covering the plate nearly entirely, with large orange-brown drops on the surface. Autolytic excretions and coilings common, abundant at $35^{\circ} \mathrm{C}$. Yellow diffusing pigment abundantly produced, $1 \mathrm{~A} 4-6$, from above, reverse 2A5-8 to 3A7-8. Odour indistinct or mouldy. Conidiation noted after 1 days at $25^{\circ} \mathrm{C}$, yellow or greenish after 6 days, earlier at higher temperatures, regularly tree-like, basally in a dense, downy central area, less commonly ascending on aerial hyphae, eventually in tufts. At $15^{\circ} \mathrm{C}$ colony stellate and indistinctly concentrically zonate, turning yellow to pale green; conidiation effuse and in loose tufts, less intense than at higher temperatures. At 30 and $35^{\circ} \mathrm{C}$ colony more distinctly zonate with broad alternating whitish yellow and green zones. Conidiation more abundant and more intensely green, $c a$ 28CD4-5, than at lower temperatures; in a dense and fluffy, effuse continuous layer rather than in discrete tufts. Reverse brightly yellow, mixed with green, $1-3 \mathrm{~A} 5-8,1 \mathrm{BC} 5-8,2 \mathrm{~A} 6-$ 8, 3AB7-8.

On SNA after $72 \mathrm{~h} 18-21 \mathrm{~mm}$ at $15^{\circ} \mathrm{C}, 58-60 \mathrm{~mm}$ at $25^{\circ} \mathrm{C}$, $68-71 \mathrm{~mm}$ at $30^{\circ} \mathrm{C}, 77-83 \mathrm{~mm}$ at $35^{\circ} \mathrm{C}$; mycelium covering the plate after 4 days at $25^{\circ} \mathrm{C}$. Colony similar to that on CMD, with wavy margin, mycelium denser and faster on the agar surface, after a week degenerating, many hyphae appearing empty. Aerial hyphae inconspicuous, more frequent and long along the colony margin. Autolytic activity and coilings absent or inconspicuous, more frequent at higher temperatures. No diffusing pigment, no distinct odour produced. Chlamydospores seen after $3-6$ days at $25^{\circ} \mathrm{C}$, frequent, terminal and intercalary, $(5-) 6-10(-13) \times(3.5-) 5-8(-12)$ $\mu \mathrm{m}, 1 / \mathrm{w}(0.9-) 1.0-1.4(-1.9)(n=40)$, globose, ellipsoidal or fusoid. Conidiation noted after $3-4$ days at $25^{\circ} \mathrm{C}$, earlier at higher temperatures, in many amorphous, loose white cottony tufts mostly median from the plug outwards, confluent to masses up to $17 \mathrm{~mm}$ long; white, turning green, 27CD3-4, 27E5-6, 28CE5-8, from inside after 4-5 days; conidiation becoming dense within the tufts, loose at their white margins first with long, straight or slightly sinuous, sterile ends in the periphery, projecting $50-150(-300) \mu \mathrm{m}$ from the tuft margins when young, sterile and beset with minute droplets along their length, mostly becoming fertile and incorporated into the tufts. Tufts consisting of a loose reticulum with mostly unpaired branches often in right angles, giving rise to several main axes. Main axes up to $0.6 \mathrm{~mm}$ long, regularly tree-like, with few or many paired or unpaired side branches often in right angles, mostly (30-) $40-110(-150) \mu \mathrm{m}$ long, progressively longer from the top down, regularly tree-like at lower levels. Branches (1.5-) $2.0-4.0(-5) \mathrm{mm}$ wide, flexuous; apparent paired branches or phialides often not strictly opposite but slightly shifted on the axis. Branching points often thickened to $4.5-7(-9) \mu \mathrm{m}$, particularly in older tufts. Phialides generally solitary along main axes and side branches, also often on cells that resemble phialides, sometimes paired, in terminal position of the main axes sometimes in whorls of $2-3$, often cruciform, or up to four in pseudo-whorls, i.e. including unicellular branches, each of which produces a phialide. Phialides (3.7-)4.7-7.8(-10.5) $\times(2.3-) 2.5-3.0(-3.4) \mu \mathrm{m}, 1 /$ $\mathrm{w}(1.3-) 1.6-3.0(-4.4),(0.9-) 1.2-2.0(-2.2) \mu \mathrm{m}$ wide at the base $(n=70)$, lageniform or ampulliform, symmetric, straight or slightly curved, often distinctly widened in the middle, base often constricted, neck short, less commonly long. Conidia produced in minute heads $<20 \mu \mathrm{m}$ diam, $(2.7-) 3.0$ $3.7(-5.2) \times(1.8-) 2.0-2.5(-2.7) \mu \mathrm{m}, 1 / \mathrm{w}(1.1-) 1.3-1.7(-2.1)$ $(n=90)$, at first hyaline, turning yellow-green, oblong or ellipsoidal, rarely cylindrical with constricted sides, smooth, eguttulate or with minute guttules, scar indistinct, size uniform. At $15^{\circ} \mathrm{C}$ colony irregular in shape, loose; conidiation in green 26-27DE4-5, confluent tufts similar to those at $25^{\circ} \mathrm{C}$; chlamydospores numerous in narrow hyphae. At 30 and $35^{\circ} \mathrm{C}$ colony on SNA denser than on CMD; conidiation abundant in green 27DE3-5, 28E4-5 tufts; tufts smaller and looser than on CMD and at lower temperatures, arranged in the centre or in several ill-defined concentric rings; chlamydospores abundant, terminal and intercalary.

Habitat: on wood and bark of deciduous and coniferous trees, particularly on cut areas, often in exposed habitats on piled wood.

Distribution: teleomorph north-temperate to subtropical (Europe, North America), anamorph widespread, including Antarctica, Philippines and South America, according to Samuels et al. (1998).

Holotype of the teleomorph: presumed USA, Pennsylvania (K, herb. Currey, as Sphaeria lobata Schwein.); holotype of the anamorph: Canada, Ottawa, on decaying wood in a house, J. Bissett, 20 Aug. 1979 (DAOM 172792); not examined; based on Samuels et al. (1998).

Material examined: Austria, Niederösterreich, Melk, Sankt Leonhard am Forst, $c a 2 \mathrm{~km}$ before Großweichselbach right roadside heading to Melk, MTB $7857 / 2,48^{\circ} 09^{\prime} 42^{\prime \prime} \mathrm{N}, 15^{\circ} 17^{\prime} 36^{\prime \prime} \mathrm{E}$, elev. $285 \mathrm{~m}$, on corticated branch of Quercus petraea $1 \mathrm{~cm}$ thick, on wood and bark, in bark fissures, soc. Chaetosphaeria pulviscula, holomorph, 30 Sep. 2004, W. Jaklitsch, W.J. 2749 (WU 29473, culture C.P.K. 2005). Oberösterreich, Bezirk Grieskirchen, Steegen, between Loitzmayr and Obererleinsbach

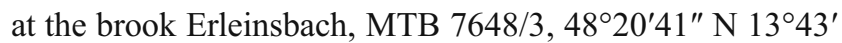
$16^{\prime \prime}$ E, elev. $420 \mathrm{~m}$, on cut areas of exposed trunks of Picea abies $25-40 \mathrm{~cm}$ thick piled up in a meadow, holomorph, 2 Sep. 2006, H. Voglmayr, W.J. 2968 (WU 29476, culture C. 
P.K. 2460). Vorarlberg, Bludenz, Großes Walsertal, Sonntag, forest path at the Lutz bridge, MTB $8725 / 3,47^{\circ} 14^{\prime} 19^{\prime \prime}$ N, 09 $54^{\prime} 32^{\prime \prime}$ E, elev. $790 \mathrm{~m}$, on corticated cut $\log$ of Alnus incana $23 \mathrm{~cm}$ thick, on cut wood area, soc. Armillaria rhizomorphs, holomorph, 1 Sep. 2004, H. Voglmayr \& W. Jaklitsch, W.J. 2651 (WU 29471, culture C.P.K. 2003). Czech Republic, Southern Moravia, Valtice, at Rendezvous (temple of Diana) near Valtice, on a branch of Quercus petraea on the ground, on wood and bark, 15 Sep. 1981, Z. Pouzar (PRM). Germany, Bavaria, Unterfranken, Landkreis Haßberge, Haßfurt, close to Mariaburghausen, left roadside heading from Knetzgau to Haßfurt,

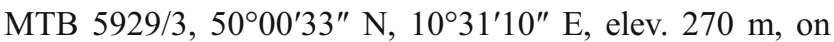
corticated branch of Tilia cordata $4 \mathrm{~cm}$ thick, on bark, soc. effete pyrenomycete and white Lasiosphaeria sp., 4 Aug. 2004, H. Voglmayr \& W. Jaklitsch, W.J. 2563 (WU 29470, culture CBS $121275=$ C.P.K. 2002). Niedersachsen, Landkreis Osterode am Harz, Bad Grund, between Laubhütte and Windhausen, 51 $47^{\prime} 16^{\prime \prime} \mathrm{N}, 10^{\circ} 13^{\prime} 47^{\prime \prime}$ E, elev. $300 \mathrm{~m}$, on cut segment of Corylus avellana $13 \mathrm{~cm}$ thick (remnant of wood pile at roadside), on black wood and inner bark, soc. Armillaria rhizomorphs below bark, immature Hypocrea minutispora, holomorph, teleomorph mostly immature, 28 Aug. 2006, H. Voglmayr \& W. Jaklitsch, W.J. 2956 (WU 29475, culture C.P.K. 2454). Landkreis Soltau-Fallingbostel, Bispingen, Behringen, east of Hengstberg and the road leading to the nature reserve Lüneburger Heide, $53^{\circ} 07^{\prime} 17^{\prime \prime}$ $\mathrm{N}, 09^{\circ} 57^{\prime 2} 27^{\prime \prime}$ E, elev. $95 \mathrm{~m}$, on cut branches of Betula pendula, Pinus sylvestris and Quercus robur 6-10 cm thick, mostly on cut wood areas, soc. Hypocrea viridescens, $H$. minutispora on Betula, holomorph, 26 Aug. 2006, H. Voglmayr \& W. Jaklitsch, W.J. 2949 (WU 29474, culture C. P.K. 2450). United Kingdom, Devon, Exeter, Killerton Park, 50 $47^{\prime} 34^{\prime \prime} \mathrm{N}, 03^{\circ} 27^{\prime} 20^{\prime \prime} \mathrm{W}$, elev. $30 \mathrm{~m}$, on corticated branches of Quercus robur 5-6 cm thick, on bark and wood, on bark and partly black wood, holomorph, teleomorph mostly immature, 8 Sep. 2004, H. Voglmayr, W. Jaklitsch \& J. Webster, W.J. 2688 (WU 29472, culture C.P.K. 2004).

Notes: Hypocrea schweinitzii is distinctive due to its greenish grey undulate stromata containing more or less monomorphic hyaline ascospores. On other continents this species can be confounded with several other similar species like e.g. $H$. andinensis, $H$. novaezelandiae, $H$. orientalis or H. pseudokoningii (see Samuels et al. 1998). Young lenticular stromata may also be mistaken for the greenspored $H$. lixii. The anamorph of $H$. schweinitzii, Trichoderma citrinoviride, is typical of the section Longibrachiatum. In Europe it is the species with the fastest growth rate at the highest optimum temperature. Measurements of phialides and conidia given under SNA are combined with those obtained on CMD. Colonies on PDA before the onset conidiation are reminiscent of $H$. pulvinata.
Hypocrea silvae-virgineae Jaklitsch, sp.nov. Fig. 96 MycoBank MB 516702

Anamorph: Trichoderma silvae-virgineae Jaklitsch, sp. nov. Fig. 97

MycoBank MB 516703

Stromata in ligno putridissimo, pulvinata vel substipitata, tubercularia, testacea vel aurantio-brunnea. Asci cylindrici, $(110-) 116-127(-135) \times(5.8-) 6.3-7.5(-8.0) \quad \mu \mathrm{m}$. Ascosporae bicellulares, hyalinae, verrucosae vel spinulosae, ad septum disarticulatae, pars distalis subglobosa, ellipsoidea vel cuneata, $(4.3-) 5.0-6.8(-9.0) \times(3.3-) 3.8-4.5(-5.3) \mu \mathrm{m}$, pars proxima oblonga vel cuneata, $(4.0-) 5.3-7.8(-10.0) \times$ (2.8-)3.5-4.0(-4.5) $\mu \mathrm{m}$. Anamorphosis Trichoderma silvae-virgineae. Conidiophora typo Pachybasii, fertilia per totam longitudinem, vel elongationes strictas vel sinuosas, steriles vel fertiles proferentia, in pustulis viridibus granulosis in agaris CMD et SNA. Phialides in pustulis divergentes, ampulliformes, (4-)5-7(-9)×(3.2-)3.7-4.2(-4.6) $\mu \mathrm{m}$, in elongationibus lageniformes vel subulatae, (8-)11-22(-39)× $(2.2-) 2.5-3.3(-4.3) \mu \mathrm{m}$. Conidia viridia, oblonga vel ellipsoidea, glabra, (3.5-)3.8-5.0(-7.3)×(2.4-)2.7-3.0(-3.5) $\mu \mathrm{m}$.

Etymology: silvae-virgineae means occurring in virgin forests.

Stromata when fresh 0.5-2 mm diam, 0.5-1.5 mm thick, pulvinate, broadly attached, edges free; surface tubercular due to brown perithecial protuberances. Stromata at first white to yellowish, after the appearance of perithecia turning yellow-orange, 4A6-7, to medium brown, reddish brown when old.

Stromata when dry $(0.3-) 0.7-1.6(-2.1) \times(0.3-) 0.6-1.3(-$ $2) \mathrm{mm},(0.2-) 0.3-0.6(-0.8) \mathrm{mm}$ thick $(n=70)$, gregarious or aggregated, typically in large numbers, pulvinate or more commonly turbinate and substipitate with the fertile layer laterally projecting over a stout, yellow to pale orangebrown stipe with smooth sides vertical or constricted downwards; broadly attached; outline circular, angular or oblong. Margin typically elevated, free, sharp or rounded by projecting perithecia. Surface convex or with sunken centre, smooth and partly covered by minute whitish to greenish anamorph floccules when young, typically becoming distinctly tubercular due to slightly darker projecting perithecia, or rugose and shiny; sometimes, particularly when older, appearing waxy to gelatinous; sometimes entirely consisting of projecting perithecia lacking ostiolar dots. Ostiolar/perithecial dots (39-)55-127(-181) $\mu \mathrm{m}(n=$ 90) diam, large and diffuse, or well-defined, brown, convex to distinctly papillate, yellowish-, orange-brown to brown; ostioles minute, often acute to nearly conical. Stroma colour first white, then white with yellowish brown perithecia, resulting colour light argillaceous, pale yellow, $4 \mathrm{AB} 2-3$, to yellow-orange, greyish orange or apricot, 56AB4-6, when young, turning orange-brown, rust, medium 

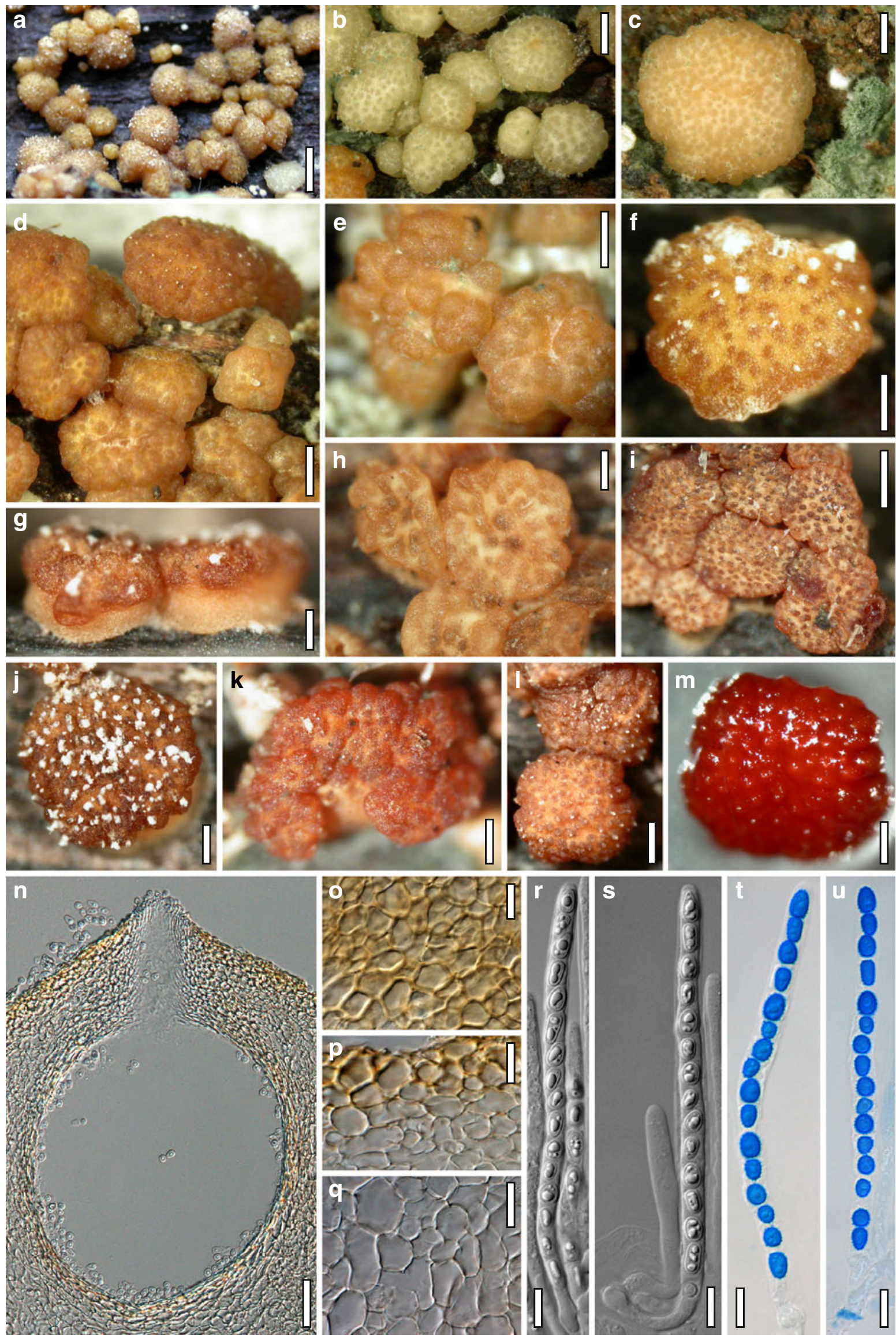
4Fig. 96 Teleomorph of Hypocrea silvae-virgineae. a-f. Fresh stromata (a. habit; b, c, e. immature). g-k. Dry stromata (g. showing sterile stipes; h. immature). I. Rehydrated mature stromata. m. Stroma in 3\% KOH after rehydration. n. Perithecium in section. o. Stroma surface in face view. p. Cortical and subcortical tissue in section. q. Subperithecial tissue in section. r-u. Asci with ascospores ( $t$, u. in cotton blue/lactic acid). a, f, g, j, l-q, s-u. WU 29227. b-e, k, r. WU 29228. h, i. WU 29226. Scale bars: $\mathbf{a}=$ $1.2 \mathrm{~mm}$. b-d, i, $1=0.5 \mathrm{~mm}$. e, f, j, k, m=0.3 mm. $\mathbf{g}, \mathbf{h}=0.2 \mathrm{~mm} . \mathrm{n}=$ $30 \mu \mathrm{m} . \mathbf{0}, \mathbf{p}, \mathbf{r}-\mathbf{u}=10 \mu \mathrm{m} . \mathbf{q}=15 \mu \mathrm{m}$

brown, tan, reddish brown to dark brown, 6CD4, 6E6-8, 78CE5-8, upon maturation; orange colour component more distinct than in the fresh state. Spore deposits white to pale yellowish. Rehydrated mature stromata larger than dry, orange-brown, with smooth yellow surface and projecting brown dots, base yellow; in $3 \% \mathrm{KOH}$ stromata turning bright red to black; ostioles hyaline.

Stroma anatomy: Ostioles (79-)81-103(-124) $\mu \mathrm{m}$ long, plane or projecting to $20(-23) \mu \mathrm{m},(28-) 32-45(-56) \mu \mathrm{m}$ wide at the apex inside $(n=30)$, apical cells cylindrical or terminally slightly widened to $4 \mu \mathrm{m}$. Perithecia (165-)185$235(-270) \times(115-) 130-185(-210) \mu \mathrm{m} \quad(n=30)$, flaskshaped or globose; peridium $(11-) 13-20(-26) \mu \mathrm{m}(n=30)$ thick at the base, (4-)8-16(-17) $\mu \mathrm{m}(n=30)$ laterally; yellow, orange in $\mathrm{KOH}$. Cortical layer (11-)14-20(-23) $\mu \mathrm{m}(n=30)$ thick, a $t$. angularis of cells $(5-) 7-15(-19) \times$ (3-)5-10(-14) $\mu \mathrm{m}(n=60)$ with walls $0.5-1.3 \mu \mathrm{m}$ thick in face view and in vertical section; yellow, orange in $\mathrm{KOH}$. Subcortical tissue a hyaline $t$. angularis of thin-walled cells (4-)6-11(-16) $\times(3-) 4-7(-8) \mu \mathrm{m}(n=33)$, mixed with scant hyphae. Subperithecial tissue a $t$. angularis-epidermoidea of thin-walled cells (5-)11-22(-27) $\times(4-) 9-16(-19) \mu \mathrm{m}$ $(n=30)$, tending to be smaller towards the stroma base. Asci $(110-) 116-127(-135) \times(5.8-) 6.3-7.5(-8.0) \mu \mathrm{m}$, stipe $(10-) 15-28(-40) \mu \mathrm{m}$ long $(n=43)$; croziers present. Ascospores hyaline, verrucose or spinulose with spines to nearly $1 \mu \mathrm{m}$ long, cells distinctly dimorphic; distal cell (4.3-)5.0$6.8(-9.0) \times(3.3-) 3.8-4.5(-5.3) \mu \mathrm{m}, 1 / \mathrm{w}(1.1-) 1.2-1.7(-2.3)$ $(n=90)$, subglobose, ellipsoidal or wedge-shaped; proximal cell (4.0-)5.3-7.8(-10.0) ×(2.8-)3.5-4.0(-4.5) $\mu \mathrm{m}$, 1/w (1.2-)1.5-2.1(-3.2) $(n=90)$, oblong or wedge-shaped.

Anamorph associated with stromata effuse, hairy, light to dull greyish green, mostly 25DE4-5.

Cultures and anamorph: optimal growth at $25^{\circ} \mathrm{C}$ on all media; hyphae autolysing and dying after a few days at $30^{\circ} \mathrm{C}$; no growth at $35^{\circ} \mathrm{C}$.

On CMD after $72 \mathrm{~h} 22-23 \mathrm{~mm}$ at $15^{\circ} \mathrm{C}, 42-43 \mathrm{~mm}$ at $25^{\circ} \mathrm{C}, 1-3 \mathrm{~mm}$ at $30^{\circ} \mathrm{C}$; mycelium covering the plate after 5 days at $25^{\circ} \mathrm{C}$. Colony hyaline, thin, loose, indistinctly zonate, mycelium radially arranged, scant on the agar surface, with conspicuous difference in width between wide primary and narrow secondary hyphae; with long and high, loosely arranged aerial hyphae in a broad marginal zone; surface slightly downy, numerous helical hyphae in the centre within the agar. Autolytic excretions absent or inconspicuous, abundant and yellowish at $30^{\circ} \mathrm{C}$, coilings inconspicuous. No diffusing pigment, no distinct odour noted. Chlamydospores noted after 7-9 days, rare. Conidiation starting after 4 days, first effuse, sessile and on aerial hyphae, scant, ill-defined, verticillium- to mostly gliocladium-like, conidia produced in wet to dry heads up to $25 \mu \mathrm{m}$ diam. After collapse of the effuse conidiation, pustules $0.5-2.4 \mathrm{~mm}$ diam appearing mostly in distal areas, green after $c a 2$ weeks; often with white margins and sterile or fertile, straight to subhelical elongations. Formation of pustules not reproducible, absent after a few transfers. At $15^{\circ} \mathrm{C}$ no conidiation and no chlamydospores seen within 2 weeks.

On PDA after $72 \mathrm{~h} 18-19 \mathrm{~mm}$ at $15^{\circ} \mathrm{C}, 34-35 \mathrm{~mm}$ at $25^{\circ} \mathrm{C}$, $1-2 \mathrm{~mm}$ at $30^{\circ} \mathrm{C}$; mycelium covering the plate after 6 days at $25^{\circ} \mathrm{C}$. Colony dense, zonate, centre flat, farinose to finely granular due to numerous short erect aerial hyphae, residual part covered by a thick white mat of long aerial hyphae arranged in radial strands and irregular aggregations with large drops. Autolytic activity and coilings inconspicuous. No diffusing pigment formed, centre yellowish, 3A3. Odour indistinct. Conidiation starting after 9-11 days, effuse, gliocladium-like, on aerial hyphae, whitish, not turning green within 3 weeks. At $15^{\circ} \mathrm{C}$ conidiation starting after $4-5$ days, effuse, gliocladium-like, developing conspicuously slowly, condensing to tufts up to $1.5 \mathrm{~mm}$ diam on the entire plate, more or less arranged in concentric zones, aggregating to continuous masses, pale greenish after 10 days.

On SNA after $72 \mathrm{~h} 22-25 \mathrm{~mm}$ at $15^{\circ} \mathrm{C}, 34-35 \mathrm{~mm}$ at $25^{\circ} \mathrm{C}$, $1-2 \mathrm{~mm}$ at $30^{\circ} \mathrm{C}$; mycelium covering the plate after 6 days at $25^{\circ} \mathrm{C}$. Colony similar to $\mathrm{CMD}$, but margin whitish, downy due to numerous long aerial hyphae ascending for several $\mathrm{mm}$; not zonate, first dense, but hyphae soon degenerating, becoming empty, replaced by conspicuously abundant chlamydospores after 3-4 days, terminal and intercalary, globose, oval or fusoid in narrow hyphae (4-)5-7(-10) $\times(3.5-) 4-6(-$ 6.5) $\mu \mathrm{m}, 1 / \mathrm{w} 0.9-1.3(-1.8)(n=30)$ or rectangular when intercalary in thicker hyphae, (4-)6-18(-27) $\times(3-) 4-7(-9)$ $\mu \mathrm{m}, 1 / \mathrm{w}(0.6-) 0.7-3.7(-7.6) \quad(n=31)$. Autolytic activity inconspicuous, coilings inconspicuous or common. No diffusing pigment, no distinct odour noticeable. Conidiation starting after 3-5 days, green after a week; first effuse, scant, on few simple, verticillium- to gliocladium-like conidiophores with wet conidial heads to $30 \mu \mathrm{m}$ diam mostly in the centre; after a week dry and dense, pachybasium-like, within green, 28-29CD4-6, 29E6-8, shrubs or tufts 0.3-3 mm diam mostly in a broad distal zone, compacting to transparent pustules with a granular surface, in addition hairy by numerous short elongations. Pustules consisting of a thick stipe with many primary branches in short distances and further paired or unpaired, branching forming a 

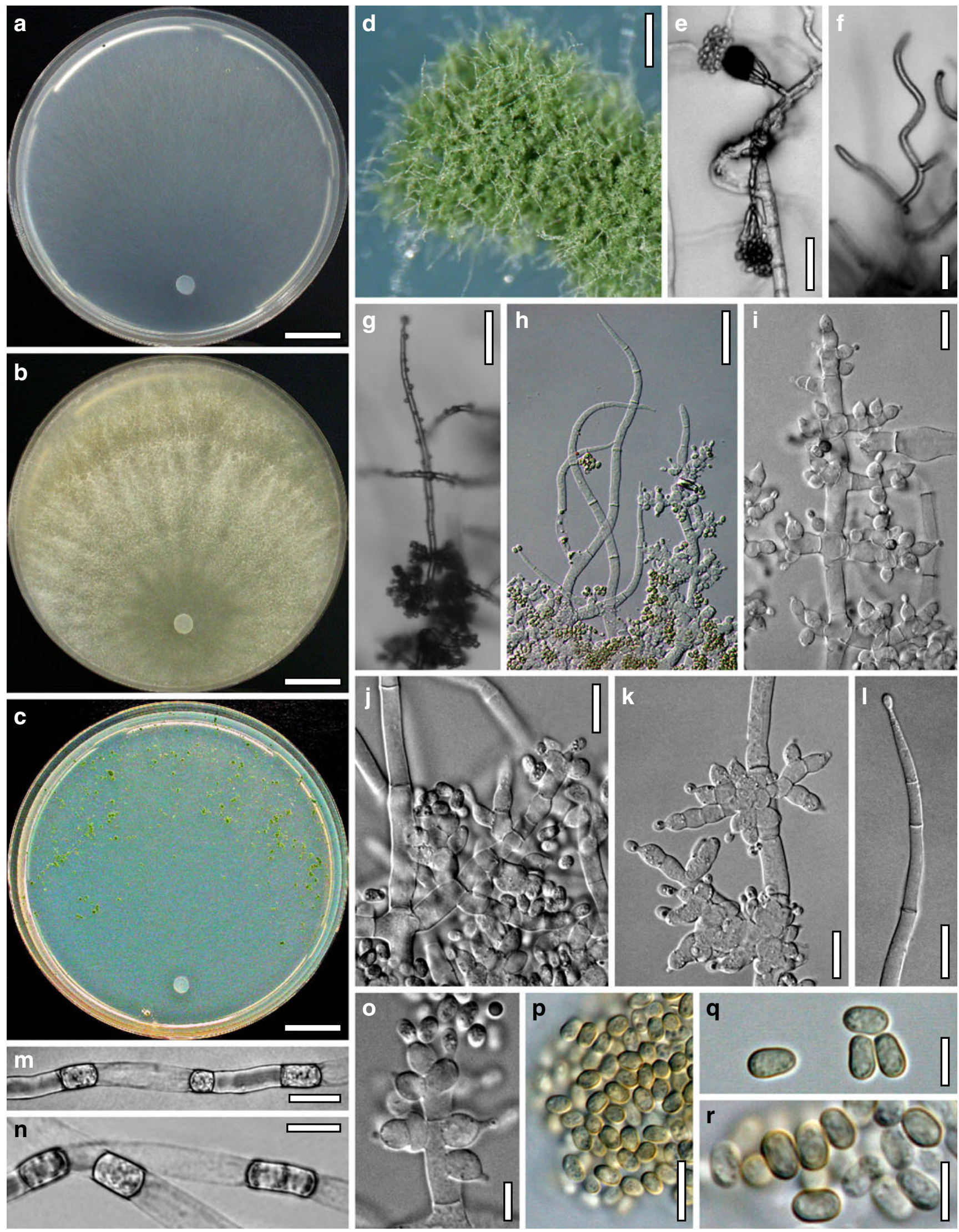
4Fig. 97 Cultures and anamorph of Hypocrea silvae-virgineae. a-c. Cultures (a. on CMD, 20 days. b. on PDA, 20 days. c. on SNA, 14 days). d. Conidiation tuft (SNA, 14 days). e. Gliocladium-like conidiophores of effuse conidiation on growth plate (CMD, 9 days). $\mathbf{f}$. Sterile helical elongation on pustule margin on growth plate (CMD, 20 days). g. Main axis on pustule margin showing fertile elongation and fertile side branches on growth plate (SNA, 8 days). h-k. Conidiophores (h. with sterile elongations; $\mathbf{j}, \mathbf{k}$. side branches on elongation bases; SNA, 9-13 days). I. Phialide on elongation (SNA, 13 days). m, $\mathbf{n}$. Intercalary chlamydospores (SNA, 11 days). o. Ampulliform phialides (SNA, 13 days). p-r. Conidia (SNA, 913 days). a-r. All at $25^{\circ} \mathrm{C} . \mathbf{a}-\mathbf{e}, \mathbf{g}, \mathbf{j}, \mathbf{k}, \mathbf{m}, \mathbf{n}, \mathbf{q}$. CBS 120922 . f.C.P.K. 2401. h, i, l, o, p, r. C.P.K. 974. Scale bars $\mathrm{a}-\mathrm{c}=15 \mathrm{~mm} . \mathrm{d}=0.3 \mathrm{~mm}$. e, $\mathbf{g}, \mathrm{h}=30 \mu \mathrm{m}$. f, $\mathbf{l}, \mathrm{n}=15 \mu \mathrm{m}$. i-k, m, $\mathrm{p}=10 \mu \mathrm{m}$. o, $\mathbf{q}, \mathrm{r}=5 \mu \mathrm{m}$

reticulum with many right angles, giving rise to more or less radially arranged main axes/conidiophores. Conidiophores 4-6(-7) $\mu \mathrm{m}$ wide with branching points often thickened to 7-11 $\mu \mathrm{m}$, fertile to the tip and narrowly tree-like with short, mostly paired terminal branches in right angles, progressively longer downwards; more commonly terminating in one or several elongations. Elongations mostly straight or slightly sinuous to subhelical, 100-200(-250) $\mu \mathrm{m}$ long, 4-7(-9) wide basally, attenuated to $2.5-3 \mu \mathrm{m}$ terminally, with numerous minute droplets along their length, smooth in the microscope, first sterile, becoming fertile at the tip, with a single, rarely two terminal phialides, and on their bases with paired or unpaired fertile side branches mostly 1-5 celled and 10-30 $\mu \mathrm{m}$ long close to the pustule surface, in right angles to the main axis or slightly inclined upwards, unbranched or re-branching with 1-3 celled side branches. Phialides produced in whorls or pseudo-whorls of 4-6 on broadly rounded to submoniliform cells, $(3.0-) 3.5-4.5(-5.5)$ $\mu \mathrm{m}$ wide. Phialides (4-)5-7(-9)×(3.2-)3.7-4.2(-4.6) $\mu \mathrm{m}, \mathrm{l} /$ w (1.0-)1.2-1.8(-2.4), (1.8-)2.7-3.5(-4.0) $\mu \mathrm{m}$ wide at the base $(n=60)$, minute, ampulliform, widest in and below the middle, sometimes with long neck. Phialides on elongations $(8-) 11-22(-39) \times(2.2-) 2.5-3.3(-4.3) \mu \mathrm{m}, 1 / \mathrm{w}(1.9-) 3.6-8.2$ $(-14.9),(2.0-) 2.2-3.0(-3.2) \mu \mathrm{m}$ wide at the base $(n=35)$, lageniform to subulate, rarely ampulliform, straight or slightly curved, forming minute wet conidial terminal heads. Conidia (3.5-)3.8-5.0(-7.3) ×(2.4-)2.7-3.0(-3.5) $\mu \mathrm{m}, 1 /$ $\mathrm{w}(1.2-) 1.3-1.7(-2.8)(n=70)$, yellowish green, oblong to ellipsoidal, smooth, typically with straight, often parallel sides, sometimes slightly attenuated towards one end, ends broadly rounded, with few minute guttules; scar indistinct. At $15^{\circ} \mathrm{C}$ similar, chlamydospores numerous, conidiation in green, 28CD5-6, 27CE4-5, pustules to $3 \mathrm{~mm}$ diam, aggregations to $14 \mathrm{~mm}$ long, with elongations.

Habitat: on well-decayed wood and bark of Fagus sylvatica.

Distribution: Europe (Austria, Czech Republic); in virgin forests, rare.

Holotype: Austria, Niederösterreich, Lilienfeld, Sankt Aegyd am Neuwalde, Lahnsattel, virgin forest Neuwald,

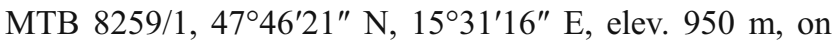

decorticated branch of Fagus sylvatica $14 \mathrm{~cm}$ thick, on well-decayed black wood and on/soc. a white corticiaceous fungus, soc. Steccherinum ochraceum, holomorph, 16 Oct. 2003, H. Voglmayr \& W. Jaklitsch, W.J. 2463 (WU 29227, culture CBS $120922=$ C.P.K. 990). Holotype of Trichoderma silvae-virgineae isolated from WU 29227 and deposited as a dry culture with the holotype of $H$. silvaevirgineae as WU 29227a.

Other specimens examined: Austria, Niederösterreich, Lilienfeld, Sankt Aegyd am Neuwalde, Lahnsattel, virgin

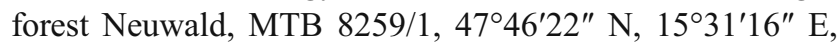
elev. $960 \mathrm{~m}$, on branch of Fagus sylvatica $11 \mathrm{~cm}$ thick, on well-decayed, dark wood and bark, soc. moss, rhizomorphs, holomorph, teleomorph mostly immature, 16 Oct. 2003, H. Voglmayr \& W. Jaklitsch, W.J. 2465 (WU 29228, culture C. P.K. 2401). Czech Republic, Southern Bohemia, Šumava Mts. National Park, Záhvozdí, Černý les, MTB 7149/4, $48^{\circ}$ $50^{\prime} 38^{\prime \prime} \mathrm{N}, 13^{\circ} 58^{\prime} 41^{\prime \prime}$ E, elev. $870 \mathrm{~m}$, on branch of Fagus sylvatica $4 \mathrm{~cm}$ thick, on well-decayed, soft wood black on its surface, soc. effete pyrenomycete, hyphomycete; mostly decayed before maturation, holomorph, 24 Sep. 2003, H. Deckerová, W.J. 2422 (WU 29226, culture C.P.K. 974).

Notes: Hypocrea silvae-virgineae has been collected only in virgin or natural forests in the dry and hot year 2003; the latter fact may be responsible that many asci of the examined material were immature or contained less than eight ascospores. Ascospore size may possibly be slightly smaller in more regularly developed material. Stromata of $H$. silvaevirgineae are reminiscent of several other species. When fresh they may look like immature stromata of the greenspored species $H$. strictipilosa (young, nearly colourless and smooth) or of $H$. gelatinosa (waxy and with perithecial elevations). Yellow stromata are reminiscent of $H$. moravica, but the latter differs e.g. by non-projecting perithecia. Older, overmature, rugose stromata that appear waxy or gelatinous may be mistaken for $H$. tremelloides, which has a somewhat different colour, smaller ascospores and a white-conidial anamorph. The effuse conidiation of Trichoderma silvaevirgineae is scant, but peculiar in its short gliocladium-like conidiophores. Oblong conidia are also typical for $T$. longipile, which differs in more consistently oblong conidia often constricted laterally, and good growth at $30^{\circ} \mathrm{C}$.

Hypocrea splendens W. Phillips \& Plowr, Grevillea 13: 79 (1885). Fig. 98

Anamorph: not known

Stromata when dry $(2.3-) 2.5-5(-6) \times(2.0-) 2.2-3.7(-4)$ $\mathrm{mm}(n=6), 0.5-1.7(-2.2) \mathrm{mm}(n=10)$ thick, solitary, rarely aggregated, distinctly pulvinate, broadly attached, edges free; outline circular to oblong; margin sterile, smooth, yellow. Surface smooth, yellow-orange between numerous minute, plane or convex, shiny, orange-reddish to reddish- 

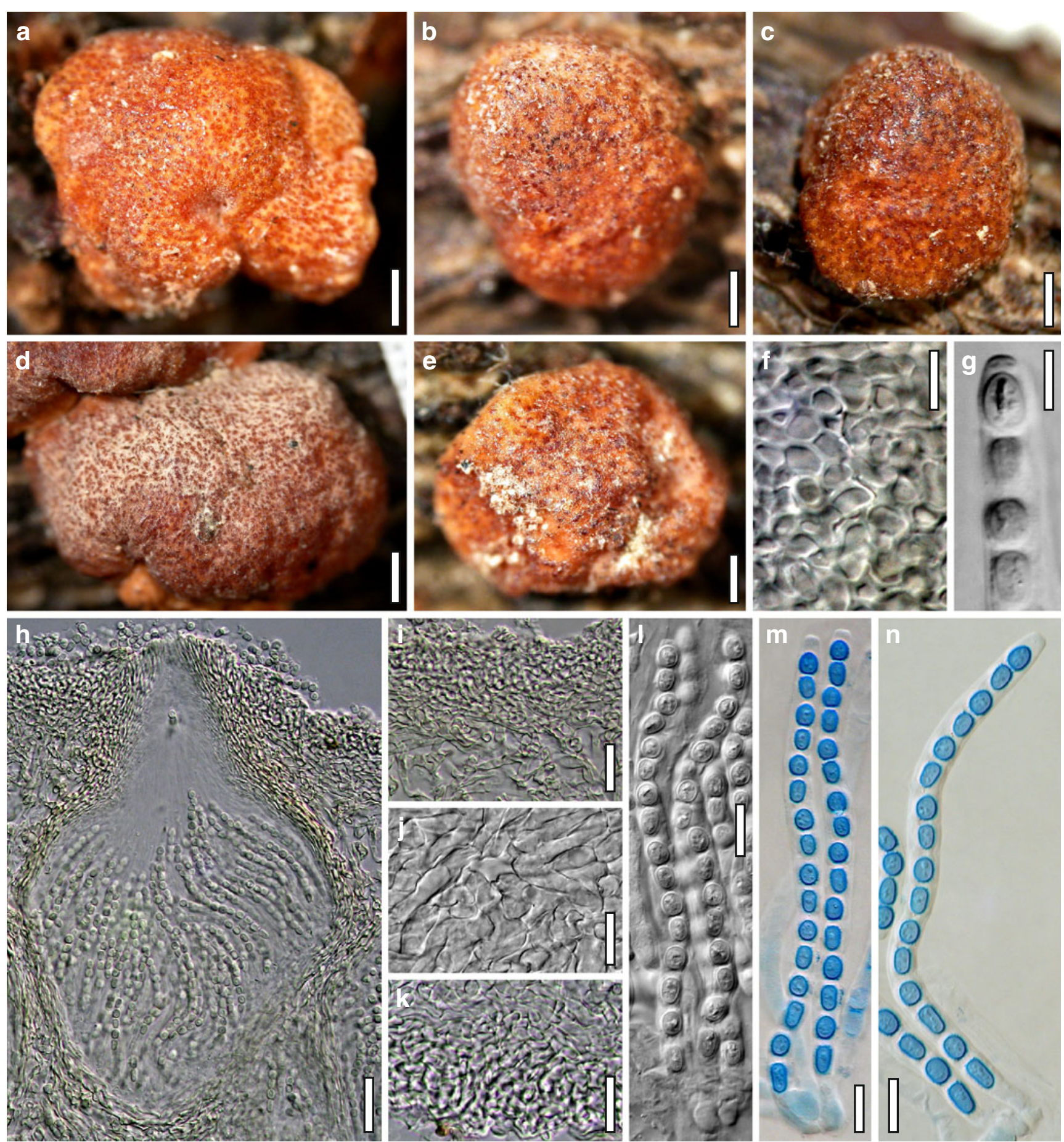

Fig. 98 Teleomorph of Hypocrea splendens (holotype K 137610). ae. Dry stromata. f. Stroma surface in face view. g. Ascus top showing apical ring. h. Perithecium in section. i. Cortical and subcortical tissue in section. j. Subperithecial tissue in section. k. Stroma base in section. $\mathbf{l}-\mathbf{n}$. Asci with ascospores (m, n. in cotton blue/lactic acid). Scale bars: $\mathbf{a}=0.4 \mathrm{~mm} . \mathbf{b}, \mathbf{e}=0.5 \mathrm{~mm} . \mathbf{c}, \mathbf{d}=0.8 \mathrm{~mm} . \mathbf{f}, \mathbf{l}-\mathbf{n}=10 \mu \mathrm{m} . \mathbf{g}=$ $5 \mu \mathrm{m} . \mathbf{h}, \mathbf{k}=25 \mu \mathrm{m} . \mathbf{i}, \mathbf{j}=20 \mu \mathrm{m}$

Stroma anatomy: Ostioles (62-)70-98(-124) $\mu \mathrm{m}$ long, plane or projecting to $35(-57) \mu \mathrm{m},(37-) 40-60(-70) \mu \mathrm{m}$ wide at the apex $(n=20)$; apical palisade of cylindrical to subclavate, hyaline cells 3-6 $\mu \mathrm{m}$ wide. Perithecia (110-) $145-225(-260) \times(95-) 115-180(-206) \mu \mathrm{m}(n=20)$, globose 
or flask-shaped; peridium (6-)10-18(-26 $\mu \mathrm{m}(n=42)$ thick at the base and sides, pale yellow. Cortical layer (20-)24$40(-52) \mu \mathrm{m}(n=30)$ thick, a dense, subhyaline to pale yellowish $t$. angularis of thick-walled cells (3.5-)4.5-9.5($14) \times(2.5-) 3.5-6.0(-8.5) \mu \mathrm{m}(n=60)$ in face view and in vertical section; nearly labyrinthine, containing some hyphae projecting to $c a 30 \mu \mathrm{m}$ from the surface. Subcortical tissue a loose $t$. intricata of thin-walled hyaline hyphae $(2.0-) 2.5-5.0(-6.0) \mu \mathrm{m}(n=30)$ wide. Subperithecial tissue a $t$. intricata-epidermoidea of mostly oblong to cylindrical cells $(7-) 11-44(-52) \times(5-) 7-12(-15) \mu \mathrm{m}(n=30)$ and hyphae of similar width. Basal tissue nearly labyrinthine, a dense, hyaline $t$. epidermoidea of compressed thin-walled hyphae and indistinct, variable cells $(4-) 6-18(-27) \times(3-) 4-$ $9(-11) \mu \mathrm{m}(n=30)$. Asci $(85-) 90-104(-110) \times 5.0-6.0(-6.6)$ $\mu \mathrm{m}$, stipe $(6-) 8-17(-23) \mu \mathrm{m}$ long $(n=30)$; apex containing a flat ring, no croziers present. Ascospores hyaline, verruculose, cells dimorphic; distal cell (3.8-)4.0-4.8($5.2) \times(3.3-) 3.5-4.0(-4.5) \mu \mathrm{m}, 1 / \mathrm{w}(1.0-) 1.1-1.3(-1.4) \quad(n=$ $30)$, subglobose or ellipsoidal; proximal cell (4.3-)4.5-5.8($6.6) \times(2.8-) 3.0-3.5(-4.0) \mu \mathrm{m}, 1 / \mathrm{w}(1.3-) 1.4-1.9(-2.2) \quad(n=$ 30 ), oblong or wedge-shaped.

Habitat: on wood and bark of Prunus laurocerasus.

Distribution: England, known only from the type specimen.

Holotype: United Kingdom, England, Leicestershire, on laurel sticks, soc. effete pyrenomycete in bark fissures, Oct. 1881T. Howse (K 137610).

Notes: Stromata of Hypocrea splendens in the holotype specimen, said to grow on laurel sticks, are obviously not on Laurus, but on corticated branches of Prunus laurocerasus, which, usually planted in dry habitats, is an unusual host for a Hypocrea. The stromata are pulvinate and compact, unlike those of $H$. auranteffusa, while microscopic traits are indistinguishable in the two species. The anamorph and phylogenetic position of $H$. splendens are to date unknown. For another description see Petch (1938).

Hypocrea strobilina W. Phillips \& Plowr., Grevillea 13: 79 (1885). Fig. 99

Anamorph not known

Stromata when dry $0.4-2 \times 0.3-0.8 \mathrm{~mm}, 0.1-0.3 \mathrm{~mm}$ thick $(n=11)$; on and between cone scales, discoid, flat pulvinate, or irregularly membranaceous, non-descript, hardly visible by the unaided eye. Surface white to yellowish, with diffuse flat or slightly projecting, rarely nearly conical, dull orangebrownish perithecial dots; non-reacting to $3 \% \mathrm{KOH}$. Asci mostly remaining as fragments. Ascospores hyaline, verrucose, cells dimorphic; distal cell (4.3-)4.7-5.3(-5.7) $\times(3.5-)$ $4.0-4.5(-4.8) \mu \mathrm{m}, 1 / \mathrm{w}(1.0-) 1.1-1.3(-1.5) \quad(n=30)$, (sub) globose; proximal cell $(4.8-) 5.0-6.8(-8.0) \times(2.8-) 3.5-4.0(-$ 4.5) $\mu \mathrm{m}, 1 / \mathrm{w}(1.2-) 1.3-1.9(-2.3)(n=30)$, oblong.
Among another hyphomycete with brown pyriform, pointed conidia, a scant greenish Trichoderma is present on the holotype. Conidia $(3.3-) 3.7-4.3(-4.7) \times(2.8-) 3.0$ $3.5(-3.8) \mu \mathrm{m}, 1 / \mathrm{w} 1.1-1.3(-1.6) \quad(n=33)$, ellipsoidal or subglobose, brown in $\mathrm{KOH}$, thick-walled, eguttulate, smooth, scar indistinct.

Habitat: on cones of Pseudotsuga menziesii.

Distribution: Europe (United Kingdom), known only from the holotype with certainty.

Holotype: United Kingdom, England, Herefordshire, Hereford, Belmont, on cones of Pseudotsuga menziesii, Nov. 1878, J. Renny (ex herb. C.B. Plowright) (K 154040; only half of the cone received/examined).

Notes: The stromata of $H$. strobilina in the holotype are on a cone of Pseudotsuga menziesii (Douglas fir), not Picea abies ('spruce fir') as given in the protologue or Abies alba $(=$ A. pectinata $)$ as interpreted by Saccardo (1886). Pseudotsuga menziesii was introduced to Europe by D. Douglas in the early 19th century from Western North America. The Hypocrea may have travelled with the host and therefore not be a 'typical European species'. Recent attempts to rediscover H. strobilina in European stands of Douglas fir have been without success. The material received for inspection permitted only an incomplete description; it was not suitable for sectioning. According to the protologue, stromata were 1-4 mm diam. Ascospores were noted by the authors to be unusually large. In fact, ascospore size of $H$. strobilina is in the upper range of hyaline-spored species of Hypocrea, in closest agreement with those of $H$. argillacea and $H$. psychrophila. For another description see Petch (1938).

Hypocrea subalpina Petr., Ann. Mycol. 38: 262 (1940). Fig. 100

$\equiv$ Hypocrea rufa var. discoidea Rehm, Hedwigia 41: 206; Ascom. exs. no. 1446 (1902).

Anamorph: Trichoderma subalpinum Jaklitsch, sp. nov. Fig. 101

MycoBank MB 516704

Conidiophora simplicia, laxe irregulariter ramosa, terminaliter in phialides solitarias exeuntia. Phialides in agaro MEA cylindraceae, saepe ramosae, apicibus dactyloideis, $(5-) 18-41(-46) \times(2.5-) 3.2-4.5(-5.2) \mu \mathrm{m}$. Conidia cylindracea vel allantoidea, hyalina, glabra, $(3.5-) 5-10(-15) \times$ (2.2-)2.3-3.7(-5.0) $\mu \mathrm{m}$.

Stromata when fresh $0.5-4(-10) \mathrm{mm}$ diam, to $1 \mathrm{~mm}$ thick, usually in large numbers on a white subiculum, solitary, gregarious or densely aggregated, sometimes occurring as subeffuse clusters to $25 \times 11 \mathrm{~mm}$ breaking up into smaller partstromata with flattened contact areas; discoid to flat-pulvinate, broadly attached, margin free, rounded. Outline circular, angular, oblong or irregularly lobed. Surface smooth, with 

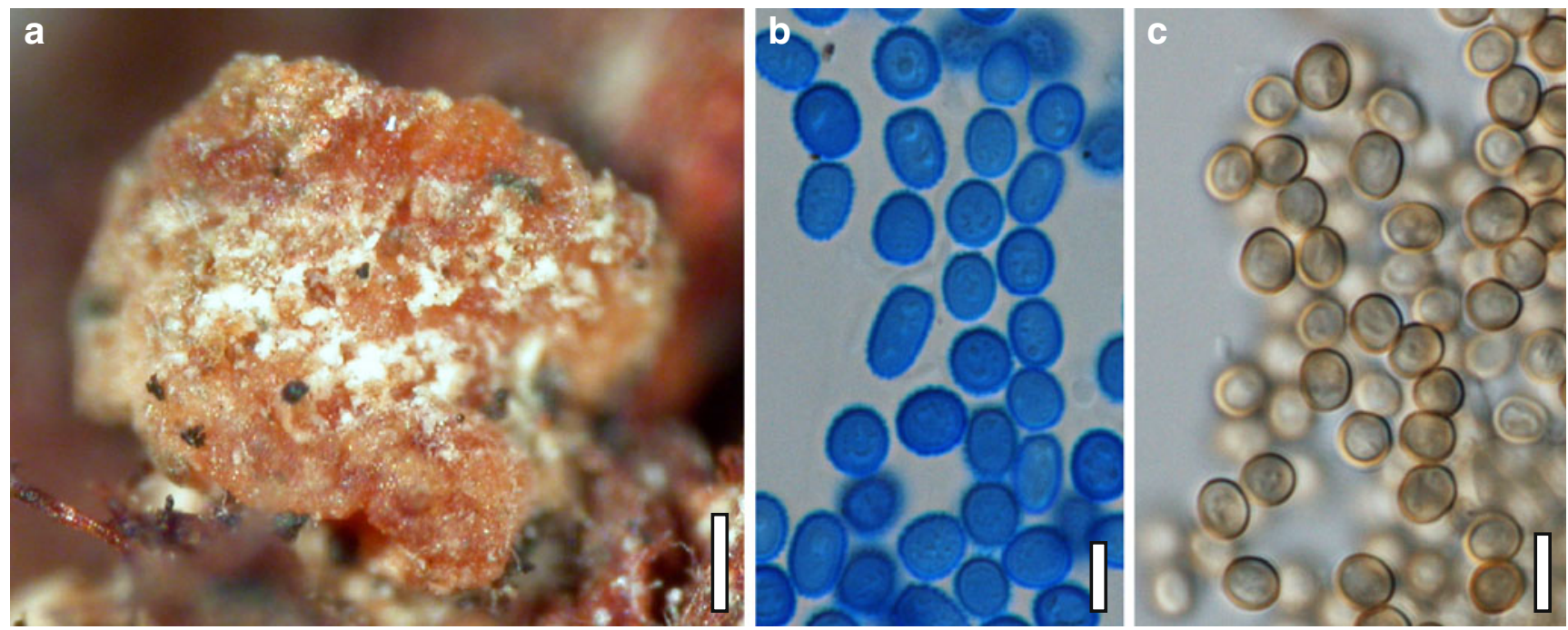

Fig. 99 Teleomorph of Hypocrea strobilina (holotype K 154040). a. Dry stroma. b. Ascospores in cotton blue/lactic acid. c. Conidia associated with stromata. Scale bars $\mathrm{a}=0.15 \mathrm{~mm}$. b, c=5 $\mu \mathrm{m}$

numerous minute, first diffuse, pale greyish to brownish, later well-defined reddish-brown ostiolar dots; perithecia entirely immersed. Stromata pale to bright yellow, 2A2-5, 3A2-7, when immature, yellow, brown-orange or golden-brown when mature, 4A3-4(-5), 5CD5-6.

Stromata when dry $0.5-4(-10) \times 0.5-2.5(-6) \mathrm{mm},(0.1-)$ $0.2-0.3(-0.6) \mathrm{mm}(n=90)$ thick, effuse/effluent, discoid or flat pulvinate, broadly attached. Outline circular, oblong or irregular. Margin free, sharp and projecting upwards, or rounded; sides mostly vertical, smooth or with slightly projecting perithecia on top. Surface smooth, finely tubercular due to convex dots, sometimes rugose; perithecia entirely immersed. Ostiolar dots (23-)30-60(-110) $\mu \mathrm{m}(n=$ 110) diam, numerous, distinct, circular, convex, brown with lighter shiny centres and minute hyaline perforations, distinctly darker than the yellow surface; in young stromata larger, more diffuse and more orange or reddish. Stroma colour mainly determined by the brown ostiolar dots, yellow, 4A3-4(-6), when immature, yellow-brown, yellow-ochre, rust, brown-orange to brown, 5-6CE6-8, less commonly light to greyish-orange, 6AB5-6, when mature, to dark brown, 7E7-8, when old. Spore deposits white to yellowish. Reaction of rehydrated stromata to $3 \%$ $\mathrm{KOH}$ variable, turning slightly darker brown or yelloworange to nearly orange-red, reversible after drying; margin not projecting after rehydration. Subiculum white, pale grey, cream or yellowish, smooth, compact or farinose.

Stroma anatomy: Ostioles (37-)45-60(-72) $\mu \mathrm{m}$ long, plane or projecting to $15(-22) \mu \mathrm{m}$, narrow, inner diam at apex (10-) $12-19(-22) \mu \mathrm{m}$, outer diam at apex $(20-) 25-37(-45) \mu \mathrm{m}(n=$ 30 ); without differentiated apical cells. Perithecia (124-)150 $200(-220) \times(94-) 100-164(-200) \mu \mathrm{m}(n=30)$, globose to flask-shaped; peridium (10-)12-16(-18) $\mu \mathrm{m}(n=30)$ thick at the base, $(5-) 8-13(-17) \mu \mathrm{m}(n=30)$ at the sides, yellow, orange in $\mathrm{KOH}$. Cortical layer (10-)14-22(-25) $\mu \mathrm{m}(n=30)$ thick, a $t$. angularis of thin- to thick-walled cells (3-)4-10($18) \times(2.5-) 3.5-6.5(-8) \mu \mathrm{m}(n=60)$ in face view and in vertical section, encasing the entire stroma except for the attachment area; pale yellow, turning orange-brown in $\mathrm{KOH}$; no hairs but some projecting cylindrical hyaline cells to $15 \times$ $2.5 \mu \mathrm{m}$ sometimes present. Subcortical tissue a loose $t$. intricata of hyaline hyphae (2.0-)2.7-5.2(-7.2) $\mu \mathrm{m}(n=60)$ wide. Subperithecial tissue a dense $t$. angularis to $t$. epidermoidea of thick-walled hyaline cells (5-)11-34(-48) $\times$ $(3-) 7-13(-16) \mu \mathrm{m}(n=30)$, penetrated by some wide thickwalled hyphae; cells smaller in the lower and lateral regions of the stroma, at the base emanating hyaline to yellowish hyphae (2-)3-6(-7.5) $\mu \mathrm{m}(n=60)$ wide, penetrating into bark. Subiculum comprising scant or abundant, branched, septate, mostly thin-walled, hyaline hyphae $2-6 \mu \mathrm{m}$ wide, with widenings to $8 \mu \mathrm{m}$ and walls to $1 \mu \mathrm{m}$ thick, like the hyphae at the stroma base; containing masses of minute amorphous to subcrystalline granules, hyaline to brownish in $3 \% \mathrm{KOH}$. Asci (55-)60-73(-80)×(3.5-)4.0-4.5(-5.2) $\mu \mathrm{m}$, stipe $(2-) 5-15(-22) \mu \mathrm{m}$ long $(n=50)$. Ascospores hyaline, finely spinulose, cells monomorphic; distal cell (2.3-)2.7-3.2

Fig. 100 Teleomorph of Hypocrea subalpina. a-d. Fresh stromata (a, b. immature). e-l. Dry stromata. m. Rehydrated mature stroma. n. Stroma in 3\% KOH after rehydration. o. Stroma surface in face view. p. Perithecium in section. q. Cortical and subcortical tissue in section. $\mathbf{r}$. Subperithecial tissue in section. s. Subiculum hyphae. t, u. Asci with ascospores (u. in cotton blue/lactic acid). v. Ascospores. a. WU 29480. b. WU 29486. c, g, i, m-s. epitype WU 29481. d, l, t, v. WU 29482. e, j, u. syntype W 05672. f. WU 29483. h. syntype GZU. k. Zauchensee (GZU). Scale bars: a, $\mathbf{c}=1.5 \mathrm{~mm} . \mathbf{b}, 1-\mathrm{n}=0.5 \mathrm{~mm}$. d, e $=2 \mathrm{~mm}$. f, g, $\mathbf{k}=$ $1 \mathrm{~mm} . \mathbf{h}=3 \mathrm{~mm} . \mathbf{i}=0.3 \mathrm{~mm} . \mathbf{j}=0.2 \mathrm{~mm} . \mathbf{o}, \mathbf{t}-\mathbf{v}=5 \mu \mathrm{m} . \mathbf{p}=20 \mu \mathrm{m} . \mathbf{q}, \mathbf{r}=$ $15 \mu \mathrm{m} . \mathbf{s}=10 \mu \mathrm{m}$ 

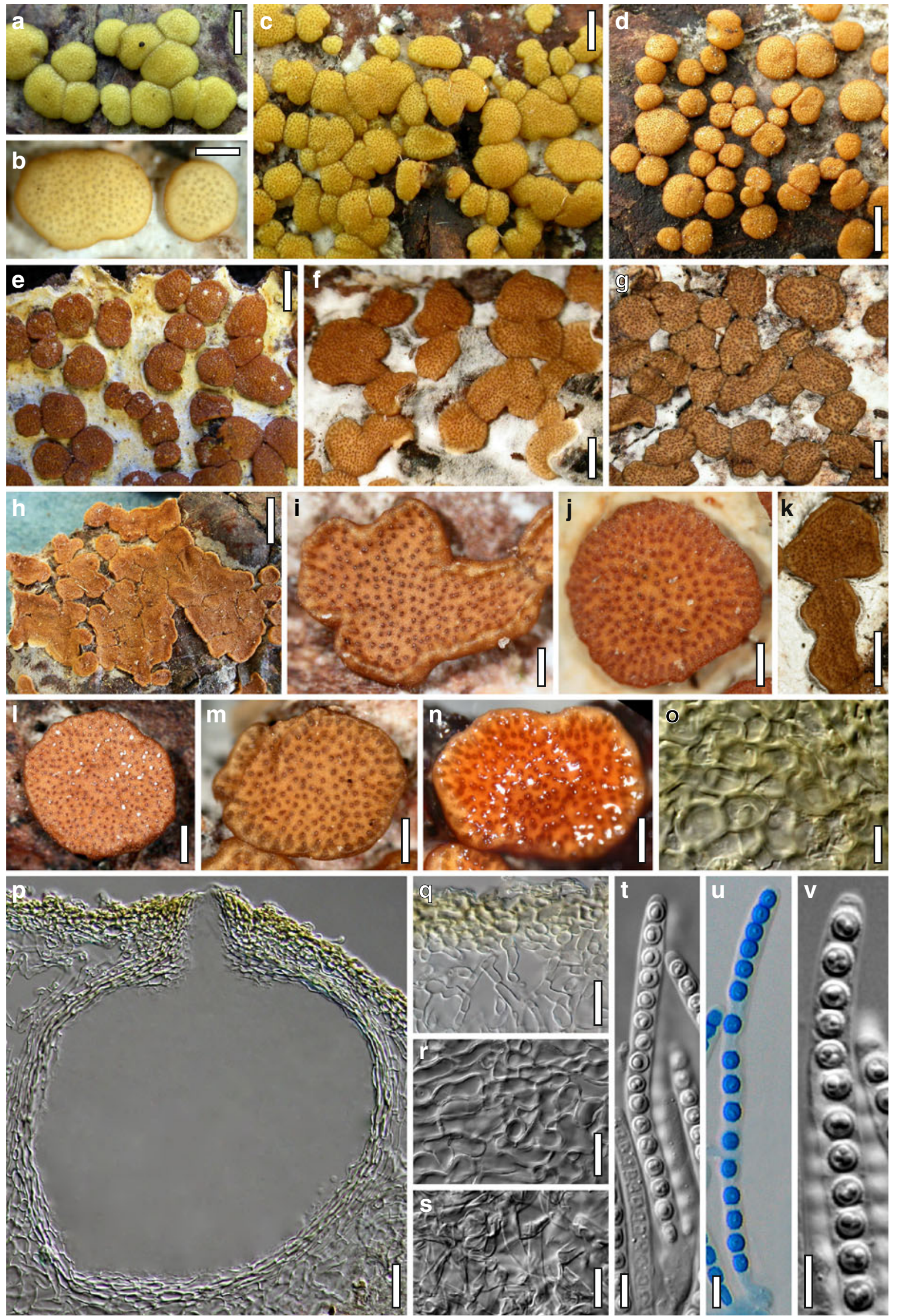


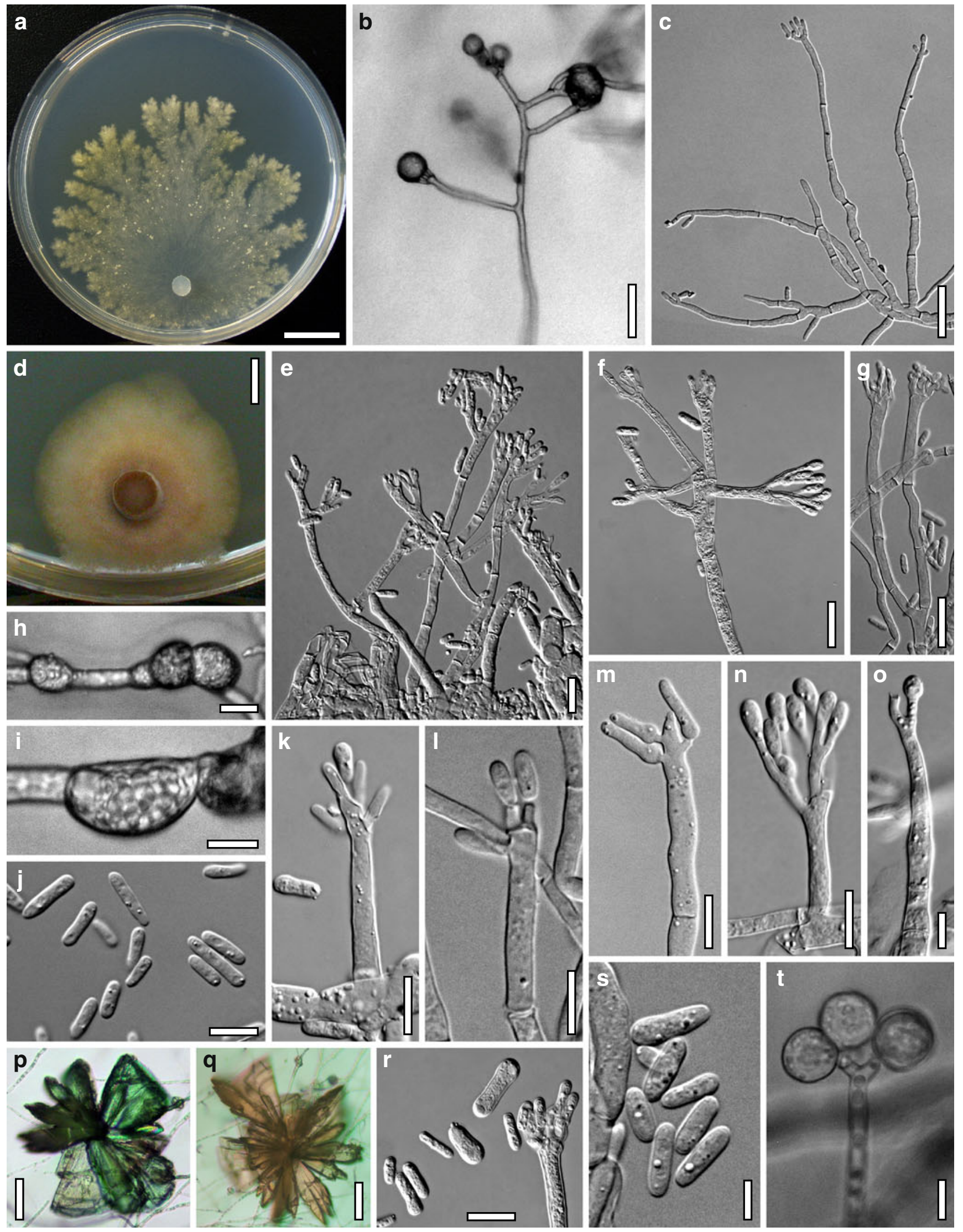


4 Fig. 101 Cultures and anamorph of Hypocrea subalpina (CBS 119128). a, d. Cultures (a. on CMD, 35 days; d. on PDA, 28 days). b. Conidiophore on growth plate (Difco-PDA, 4 days). c, e- $\mathbf{g}$. Conidiophores (c, g. MEA, 10-15 days; e, f. Difco-PDA, 4 days). h, i. Chlamydospores (CMD, 46 days). j, r, s. Conidia (j, s. MEA, 10-14 days; r. Difco-PDA, 4 days). k-o. Phialides (k, n. DifcoPDA, 4 days; I, m. MEA, 14-15 days; o. PDA, 10 days). p, q. Crystals (interference contrast; CMD, 91 days). t. Swollen conidia (CMD, 52 days). a-t. All at $25^{\circ}$ C. Scale bars $\mathbf{a}=15 \mathrm{~mm}$. b, $\mathbf{c}=$ $30 \mu \mathrm{m} . \mathbf{d}=5 \mathrm{~mm}$. $\mathbf{e}-\mathbf{g}=15 \mu \mathrm{m}$. h-n, $\mathbf{r}=10 \mu \mathrm{m}$. $\mathbf{o}, \mathbf{s}, \mathbf{t}=5 \mu \mathrm{m} . \mathbf{p}=$ $70 \mu \mathrm{m} . \mathbf{q}=100 \mu \mathrm{m}$

$(-3.5) \times(2.2-) 2.5-3.0(-3.2) \mu \mathrm{m}, 1 / \mathrm{w}(0.9-) 1.0-1.2(-1.5)(n=$ $90)$, globose to subglobose; proximal cell (2.3-)2.5-3.5($5.0) \times(2.0-) 2.5-3.0(-3.2) \mu \mathrm{m}, 1 / \mathrm{w} \quad 0.9-1.3(-2.5) \quad(n=90)$, (sub)globose; ascospore cells in the ascus base tending to be dimorphic with oblong proximal cells to $5 \mu \mathrm{m}$ long; ascospores sometimes yellow-orange after ejection.

Cultures and anamorph: slow and limited growth between $15^{\circ} \mathrm{C}$ and $25^{\circ} \mathrm{C}$ on all media, slower on PDA than on CMD and SNA; no growth at and above $30^{\circ} \mathrm{C}$.

On CMD $4-7 \mathrm{~mm}$ at $15^{\circ} \mathrm{C}, 8-9 \mathrm{~mm}$ at $25^{\circ} \mathrm{C}$ after $72 \mathrm{~h}$; growth usually terminating before the plate is entirely covered. Colony hyaline, thin, not or indistinctly zonate, smooth; margin discontinuous, wavy to lobed; hyphae wavy along their length, becoming finely submoniliform and irregularly oriented at the colony margin. Aerial hyphae scant, short, little branched, becoming fertile. White crystals up to $c a 2 \times 1.5 \mathrm{~mm}$ appearing after $1-2$ months on the surface and submerged in the agar, causing white spots; the latter also caused by short aerial hyphae emerging in dense fascicles in aged cultures. Autolytic activity low, producing some amorphous brown excretions in aged colonies; coilings absent. Colony remaining hyaline, sometimes turning pale yellowish, 2A3, along the margin; odour indistinct. Widened cells in surface hyphae common; chlamydospores only rarely formed, tardily separated by septa, $(10-) 11-23(-32) \times(9-) 10-14(-16) \mu \mathrm{m}, 1 / \mathrm{w}(1.0-)$ $1.1-1.8(-2.1)(n=21)$, mostly intercalary, variable, globose, ellipsoidal or oblong, smooth, multiguttulate. Conidiation starting after 2-3 days, effuse, scant, starting around the plug, spreading loosely across the colony. Conidiophores appearing gliocladium-like under low magnifications, short, erect, simple, dichotomously branched or with few short unpaired branches along their length, each with a single terminal phialide. Conidia formed in one wet head per phialide, mostly $<30(-60) \mu \mathrm{m}$ diam, eventually drying. Solitary phialides with cylindrical hyaline conidia also formed within the agar. Sizes similar to those determined on PDA and MEA. Aged conidia often swollen, globose, (5-)7-13(-17) $\mu \mathrm{m}(n=33)$ diam.

On PDA $3-4.5 \mathrm{~mm}$ at $15^{\circ} \mathrm{C}, 4-4.5 \mathrm{~mm}$ at $25^{\circ} \mathrm{C}$ after $72 \mathrm{~h}$; growth often terminating after 1 week. Colony small, compact, dense, thick, surface becoming downy, whitish, cream or yellowish, hyphae agglutinating to an opaque continuum in the centre. Aerial hyphae short (but to $c a$ $2 \mathrm{~mm}$ long on Difco-PDA), becoming fertile. No autolytic activity, no coilings seen. Reverse turning yellowish 3A34, to (yellow-)brown, ca 5B4-6, 5CD5-6, 5E7-8. Odour indistinct to slightly mushroomy. Conidiation starting after 2-3 days, gliocladium-like at low magnifications, effuse, on numerous short erect conidiophores around the plug, spreading across the colony; unbranched or of a main axis bearing few widely spaced unpaired branches, the latter sometimes branched once again. Branches 3-6.5 $\mu \mathrm{m}$ wide, with widenings to $10 \mu \mathrm{m}$, each with a solitary terminal phialide. Phialides consisting of a long cylindrical main body (14-)22-32(-38) $\mu \mathrm{m} \times(3.5-) 4-6(-7) \mu \mathrm{m}, 1 / \mathrm{w}(3-) 4-7$ $(-8),(1.7-) 3.2-4.8(-5.6) \mu \mathrm{m}$ wide at the base $(n=32)$, terminally often dichotomously or irregularly branched, each branch with (1-)2-3(-6) parallel or divergent terminal 'fingers', rarely unbranched and subulate, sometimes branched at lower levels to produce 2-3 groups of fingers; fingers $(1-) 2-8(-12) \times 1.2-1.7(-2) \mu \mathrm{m}, 1 / \mathrm{w}(0.7-) 1.3-5.4(-$ 8.6) $(n=30)$, cylindrical, straight or curved, rarely separated by a septum from the main body; producing conidia in colourless wet heads to $40(-50) \mu \mathrm{m}$ diam. Conidia $(3.5-) 5-$ $10(-15) \times 2.2-3.7(-5.0) \mu \mathrm{m}, 1 / \mathrm{w}(1.4-) 2.0-3.3(-4.3) \quad(n=$ $33)$, hyaline, cylindrical, straight, curved to allantoid, less commonly ellipsoidal, oval or kidney-shaped in age, smooth, with few minute guttules or eguttulate, scar indistinct. At $15^{\circ} \mathrm{C}$ colony compact, dense, thick, finely downy, indistinctly zonate, whitish, reverse becoming yellowish 3-4A3-4 to brownish 5B4-5; conidiation denser than at $25^{\circ} \mathrm{C}$.

On MEA colony hyaline to white, dense, homogeneous, long aerial hyphae frequent; conidiophores frequent, erect, simple and with 1 terminal phialide, or basally branched or as a series of branches loosely emerging from aerial hyphae, 6-7.5 $\mu \mathrm{m}$ wide at the base, within a short distance attenuated to $2 \mu \mathrm{m}$. Phialides solitary, terminal on branches, (2.3-)2.5-3.7(-4.7) $\mu \mathrm{m}(n=28)$ wide at the base, variable, sometimes subulate, sometimes branched into 2 whorls of 3-4 fingers; fingers commonly separated by a septum; including the fingers $(5-) 18-41(-46) \times(2.5-) 3.2-4.5(-5.2)$ $\mu \mathrm{m}, 1 / \mathrm{w}(1.3-) 4.4-11(-15)$, often widest at branching points. Conidia $6-11(-15) \times(2.3-) 2.7-4.2(-6.0) \mu \mathrm{m}, \mathrm{l} /$ $\mathrm{W}(1.6-) 2-3(-4)(n=32)$, hyaline, cylindrical, sometimes ellipsoidal or irregular, e.g. constricted in the middle, smooth, scar indistinct or truncate.

On SNA $3.5-5.5 \mathrm{~mm}$ at $15^{\circ} \mathrm{C}, 4.5-7 \mathrm{~mm}$ at $25^{\circ} \mathrm{C}$ after $72 \mathrm{~h}$; growth terminating after 2 weeks before covering the entire plate. Colony hyaline, thin, resembling ice crystals, with little mycelium on the surface, irregular density, irregularly oriented marginal hyphae; mycelium degenerating early, with only loose marginal strands growing. Aerial hyphae scant, mostly short and little branched. Autolytic activity variable, excretions minute; no coilings seen. No 
pigment, no distinct odour noted. Conidiation after 23 days, scant. Structure as described above.

Habitat: usually in large numbers on a white subiculum on bark, less commonly wood, of conifers at upper montane to subalpine altitudes.

Distribution: Europe (Austria, Estonia, Germany, Ukraine). One collection reported by G.J. Samuels (pers. comm.) from the Blue Mts. Natl. Park near Sydney, Australia, agrees well with $H$. subalpina in terms of stromata, phialides and conidia.

Typification: A part of Rehm's original specimen of Hypocrea rufa var. discoidea is here selected as lectotype of Hypocrea subalpina: Austria, Salzburg, Radstadt, on wood and bark of Picea abies; 1901, F. v. Höhnel, Rehm Ascomyceten 1446 (K 165796). Petrak (1940) listed four paratype specimens. The following specimen is here designated as epitype, in order to consolidate the relationship of teleomorph, anamorph and gene sequences: Austria, Vorarlberg, Feldkirch, Satteins, south from Matennawald, MTB 8724/3, 47 $15^{\prime} 03^{\prime \prime} \mathrm{N}, 09^{\circ} 40^{\prime} 33^{\prime \prime}$ E, elev. $930 \mathrm{~m}$, on corticated branch of Abies alba $4 \mathrm{~cm}$ thick, stromata on bark, few on wood, largely immature, 1 Sep. 2004, A. Hausknecht, W.J. 2663 (WU 29481, exepitype culture CBS $119128=$ C.P.K. 2038). Holotype of the anamorph Trichoderma subalpinum isolated from WU 29481 and deposited as a dry culture with the epitype of H. subalpina as WU 29481a.

Other specimens examined: Austria, Niederösterreich, Lunz, on Abies pectinata (= A. alba), July 1939, F. Petrak, Reliquiae Petrakianae 37 (paratype, GZU). Scheibbs, Lunz am See, Rothwald, Kleiner Urwald, MTB 8256/2, elev. $c a$ $1000 \mathrm{~m}$, on branch of Abies alba, on bark, 28 June 2007, A. Urban, W.J. 3105 (WU 29484, culture C.P.K. 3126). Salzburg, Radstadt, on wood and bark of Picea abies; 1901, F. v. Höhnel (as Hypocrea rufa var. discoidea; isotype W 7138). Steiermark, Aussee, on Abies alba, Sep. 1903, R. Rechinger (paratype, W!). Bruck/Mur, Halltal, Walstern, fluvial alder forest at the white Walster east of the

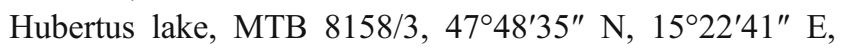
elev. $830 \mathrm{~m}$, on branch of Abies alba $3 \mathrm{~cm}$ thick on the ground, on bark, immature, 23 Sep. 2008, H. Voglmayr, W. J. 3219 (WU 29486). Liezen, Kleinsölk, Schwarzensee, hiking trail to Putzentalalm, MTB 8749/1, elev. $1170 \mathrm{~m}$, $47^{\circ} 17^{\prime} 12^{\prime \prime} \mathrm{N}, 13^{\circ} 52^{\prime} 13^{\prime \prime} \mathrm{E}$, on corticated branch of Larix europaea $6 \mathrm{~cm}$ thick, 7 Oct. 2004, W. Jaklitsch, W.J. 2772 (WU 29482, culture C.P.K. 2039). St. Lorenzen im Paltental, ca $2.5 \mathrm{~km}$ WNW from Trieben, MTB 8552/2, elev. $750 \mathrm{~m}, 47^{\circ} 29^{\prime} \mathrm{N}, 14^{\circ} 27^{\prime} \mathrm{E}$, on bark of Pinus sylvestris, 4 Oct. 2002, A. Draxler \& W. Maurer, Scheuer 4834 (GZU). Zauchensee bei Bad Mitterndorf, MTB 8449/ 2, on bark of Picea abies, 24 Aug. 2004, A. Draxler \& W. Maurer (GZU). Vorarlberg, Bludenz, Sonntag, forest path at the Lutz bridge, Großes Walsertal, MTB 8725/3, elev.
$780 \mathrm{~m}, 47^{\circ} 14^{\prime} 17^{\prime \prime} \mathrm{N}, 09^{\circ} 54^{\prime} 27^{\prime \prime} \mathrm{E}$, on fallen, half decorticated tree of Picea abies 5-7 cm thick, stromata on wood and bark, soc. $c f$. Athelopsis glaucina and an effete setose pyrenomycete, immature, 1 Sep. 2004, H. Voglmayr \& W. Jaklitsch, W.J. 2650 (WU 29480). Estonia, Saaremaa island, Tagamoisa, wooded meadow, on cut branch of Picea abies, on bark, 10 Aug. 2006, K. Pöldmaa KP06-8 (WU 29483). Germany, Baden-Württemberg, Schwarzwald, SW Hornberg, W Oberniedergieß, MTB 7815/1, elev. 580 m, on branch of Picea abies, on bark and wood, immature, 23 Oct. 2008, L. Krieglsteiner. Bavaria, Mittenwald, Klais, heading to Kranzbach, MTB 8533/124, elev. 965 m, on branch of Picea abies 1-2 cm thick, on bark, 24 Aug. 2008, P. Karasch (WU 29485). Ukraine, Carpatirossia, in silvis mixtis virgineis (Abies alba, Picea excelsa, Fagus sylvatica) in valle rivi Berlebas prope vicum Trebušany, alt. 800-1000 m, on bark of Abies alba, Aug. 1937, A. Pilát (syntype W 05672).

Notes: Hypocrea subalpina is well characterised by discoid stromata with numerous minute ostiolar dots occurring on bark of conifers, usually on a white amorphous crust or subiculum, showing a striking colour change from yellow when fresh to rust, orange-brown to brown when dry. A similar colour change is known from stromata of the unrelated $H$. bavarica. The subiculum, although superficially looking similar to the basidiomycete Exidiopsis calcea, apparently belongs to the Hypocrea. No clamps, basidia or basidiospores have been found in the subicular hyphae.

Petrak (1940, p. 262) based his species on H. rufa var. discoidea recognising its uniqueness and giving a detailed description of the teleomorph. Phylogenetically $H$. subalpina is located in a subclade of the section Longibrachiatum, albeit not well supported. The formerly unknown anamorph differs substantially from all known members of that section. It is unique in Trichoderma, differing from all other species by having synchronously branching/bifurcating polyphialides that are similar to those of the genus Polypaecilum G. Sm. The latter genus, however, differs in producing brownish, smooth to verruculose, globose conidia in chains; for descriptions see Smith (1961) and de Hoog et al. (2000). Notable are also the formation of large white crystals on CMD and the conspicuous swelling of conidia on CMD; a similar swelling has been detected in T. bavaricum.

Hypocrea tremelloides (Schumach. : Fr.) Fr., Summa veg. Scand., Sect. Post., p. 383 (1849). Fig. 102

$\equiv$ Sphaeria tremelloides Schumach., Enum. Plant., (Kobenhavn) 2: 173 (1803) : Fr., Syst. Mycol. 2: 335 (1823).

Anamorph: Trichoderma tremelloides Jaklitsch, sp. nov. Fig. 103 


\section{MycoBank MB 516707}

Incrementum tardum. Conidiophora effusa, in agaro CMD plerumque submersa, in agaris PDA et MEA plerumque superficialia, irregulariter subverticillata, ramis superioribus ascendentibus, inferioribus descendentibus. Phialides divergentes vel parallelae, subulatae vel lageniformes, (4-)10-21(-28)×(1.8-)2.5-3.5(-5.0) $\mu \mathrm{m}$. Conidia oblonga, ellipsoidea, subglobosa vel suballantoidea, hyalina, glabra, (3.0-)4.2-8.3(-13.0) $\times(2.0-) 2.8-4.0(-4.7) \mu \mathrm{m}$.

Stromata when fresh $0.5-3 \mathrm{~mm}$ diam, to $1-1.5 \mathrm{~mm}$ thick, gregarious or most commonly densely aggregated, sometimes turned-up laterally by mutual pressure, lenticular, flat pulvinate to distinctly turbinate with attenuated base often clothed with white mycelium; fertile upper part appearing waxy or gelatinous. Outline circular or oblong. Margin free, rounded or sharp, sometimes crenate. Surface shiny, smooth to finely granular due to slightly projecting, pale translucent perithecia. Distinct ostiolar dots absent; ostioles inconspicuous, minute, often slightly projecting, including variable fractions of upper perithecial parts. Stroma colour homogeneous, initially whitish to yellowish, turning pale or greyish orange, mostly incarnate or ochre, 6AB4-6, 5B4, when young, turning orange-, yellow-brown, light brown to reddish brown, 5CD5-8, 7-8CD(5)6-8, 8E6-8.

Stromata when dry $(0.3-) 0.7-1.6(-2.4) \times(0.2-) 0.5-1.4(-$ $2.3) \mathrm{mm}(n=120), 0.2-0.5(-0.8) \mathrm{mm}(n=95)$ thick, gregarious to densely aggregated in large numbers in groups up to $2 \mathrm{~cm}$ long, less commonly singly erumpent through bark; turbinate, with a short stipe attenuated downwards or cylindrical, with white basal mycelium when young; fertile upper part laterally projecting; or flat pulvinate, lenticular to discoid, then mostly broadly attached; appearing waxy, gelatinous or glassy, shiny. Outline circular, angular or oblong. Margin free, rounded or sharp, sometimes lobed, sometimes turned upwards; concolorous with the stroma surface. Surface plane to slightly convex or depressed, smooth when young, becoming finely but distinctly granular due to slightly or distinctly projecting translucent perithecia. No ostiolar dots apparent but under high magnification slightly prominent, light or concolorous ostioles or perithecial elevations $(12-) 25-75(-126) \mu \mathrm{m}(n=115)$ diam noticeable, papillate to conical, light, shiny, with circular perforation, sometimes surface with distinct, long projecting folds or crests, particularly when overmature. Surface between perithecia smooth, yellowish, pale orange to dull orangebrown. Stromata when young pale orange-brown, light brown to ochre, 7CD5-8, 8CD7-8, reddish orange, 7B7-8, 6AB7-8, with stereo-light, or reddish brown, 9CD7-8, 9DE5-6, to dark brown or violaceous brown, 9F5-8, 10EF4-8, less commonly dark reddish-brown, 8-9EF6-8, to nearly black. Colour unchanged in $3 \% \mathrm{KOH}$, sometimes some orange pigment dissolved. Spore deposits white to cream.
Stroma anatomy: Ostioles (60-)70-90(-93) $\mu \mathrm{m}$ long, with respect to the stroma surface umbilicate, plane or projecting to $6(-10) \mu \mathrm{m},(14-) 17-30(-40) \mu \mathrm{m}(n=20)$ wide at the apex, long cylindrical; convergent cylindrical periphyses $1-2.5 \mu \mathrm{m}$ wide, not widened apically. Perithecia $(125-) 140-190(-215) \times(75-) 90-135(-150) \mu \mathrm{m} \quad(n=20)$, globose or flask-shaped, often laterally compressed by mutual pressure; peridium (9-)12-20(-25) $\mu \mathrm{m} \quad(n=40)$ thick at the base and sides; pale yellowish to pale reddish brown. Surface lacking hairs. Entire stroma pseudoparenchymatous. Cortical layer (16-)20-40(-54) $\mu \mathrm{m} \quad(n=30)$ thick, extending around the entire stroma except for the attachment area, comprising a pale yellow- to orangebrown $t$. angularis of 2-5 layers of distinct angular to oblong cells $(6-) 8-15(-22) \times(4-) 6-12(-18) \mu \mathrm{m}(\mathrm{n}=105)$ in face view and in vertical section, with walls $1 \pm 0.5 \mu \mathrm{m}$ thick, gradually merging into the subcortical tissue, a $t$. angularis of paler to hyaline thin-walled cells (6-)12-21($28) \times(5-) 8-13(-15) \mu \mathrm{m}(n=40)$. Subperithecial tissue a $t$. angularis of hyaline to yellowish, thin-walled roundish to oblong cells $(8-) 15-30(-45) \times(6-) 9-20(-33) \mu \mathrm{m}(n=40)$, tending to be smaller towards the base, at the attachment area followed by a palisade of narrow hyaline oblong cells $(12-) 19-38(-54) \times(4-) 5-11(-17) \mu \mathrm{m}(n=40)$. Asci $(55-)$ $60-75(-96) \times(3.5-) 4.0-4.5(-5.5) \mu \mathrm{m}$, stipe $(2-) 5-17(-28)$ $\mu \mathrm{m}$ long $(n=120)$. Ascospores hyaline, verruculose, variable within asci; cells dimorphic but with little difference; distal cell $(2.3-) 3.0-4.0(-5.0) \times(2.3-) 2.7-3.3(-4.7) \mu \mathrm{m}, 1 /$ w (0.9-)1.0-1.2(-1.5) ( $n=192)$, (sub-)globose, ellipsoidal or oblong; proximal cell $(2.3-) 3.0-4.5(-5.7) \times(2.0-) 2.3-3.0$ $(-3.7) \mu \mathrm{m}$, oblong or subglobose, $1 / \mathrm{w}(1.1-) 1.2-1.8(-2.7)$ $(n=192)$, usually narrower than the distal cell; cells often distinctly flattened at the contact area, verrucae $<0.5 \mu \mathrm{m}$ long; the ascospore lowest in the ascus maturing first.

Cultures and anamorph: optimal growth at $25^{\circ} \mathrm{C}$ on $\mathrm{CMD}$ and PDA, no growth at and above $30^{\circ} \mathrm{C}$.

On CMD after $72 \mathrm{~h} / 1$ week $0-2.5 / 6-13 \mathrm{~mm}$ at $15^{\circ} \mathrm{C}$, $0.7-5.5 / 8-21 \mathrm{~mm}$ at $25^{\circ} \mathrm{C}$; mycelium or often only few single hyphae reaching the distal margin of the plate after 20-30 days at $25^{\circ} \mathrm{C}$. Colony hyaline, thin, scarcely visible, margin diffuse. Mycelium loose, hyphae narrow. Aerial hyphae nearly lacking. Autolytic activity moderate, excretions minute, mainly formed within the colony; no coilings present. No diffusing pigment, no distinct odour noted. Chlamydospores mainly intercalary in terminal, fasciculate fertile branches, (7-)9-21(-27)×(8-)9-17(-25) $\mu \mathrm{m}, 1 /$ $\mathrm{w}(0.9-) 1.0-1.3(-1.6) \quad(n=30)$, globose or ellipsoidal, smooth, only tardily separated by septa. Conidiation noted after 3-6 days at $25^{\circ} \mathrm{C}$, spreading from the plug as more or less pyramidal structures on hyphal ends submerged in the agar, descending to the ground level of the agar, typically with only few short branches or phialides emerging above the agar surface. Conidiophores comprising a main axis 

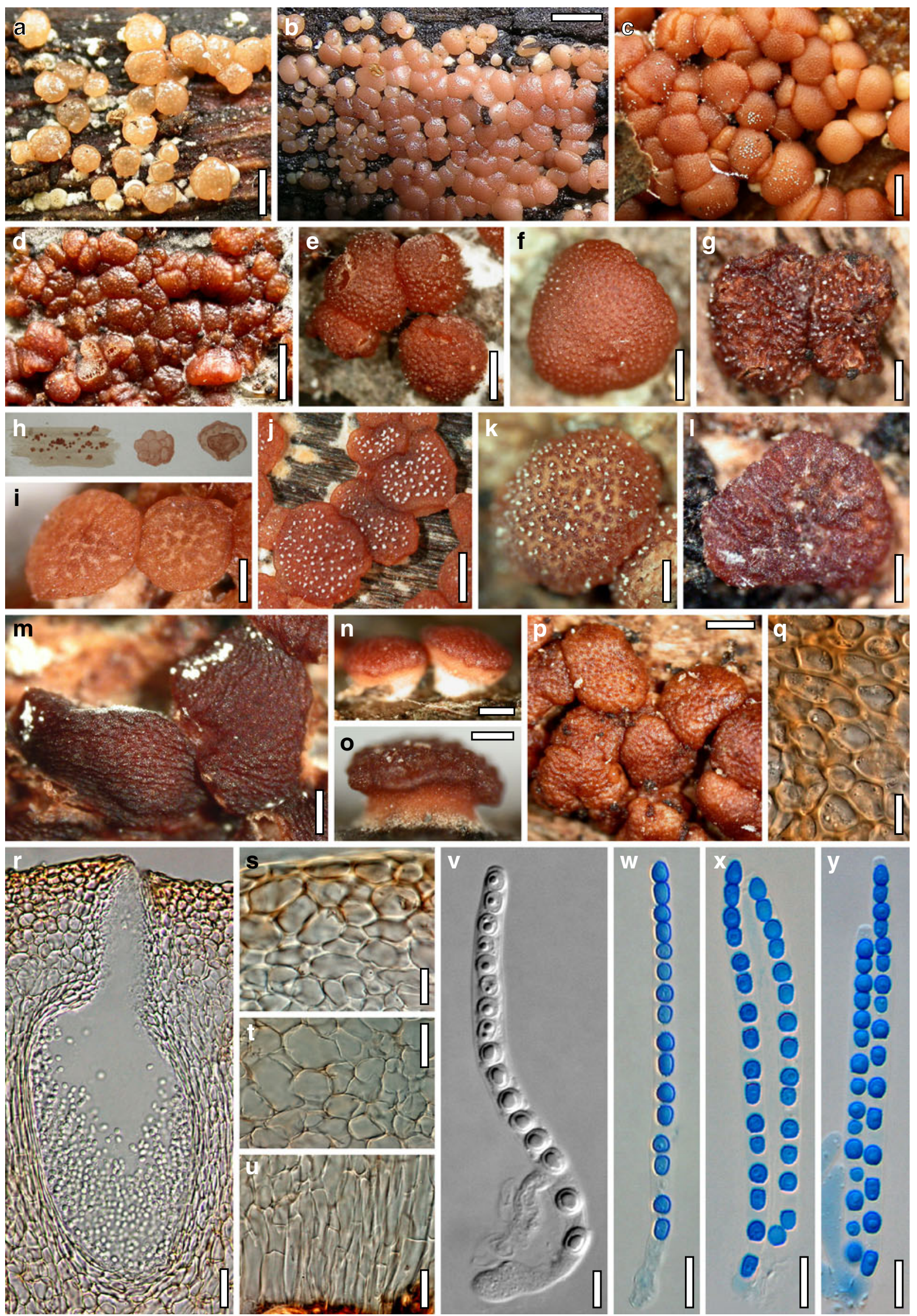
4 Fig. 102 Teleomorph of Hypocrea tremelloides. a-f, $\mathbf{n}$. Fresh stromata (a. immature; n. side view). g-m, o. Dry stromata (o. side view). p. Rehydrated stromata. q. Stroma surface in face view. r. Perithecium in section. s. Cortical and subcortical tissue in section. t. Subperithecial tissue in section. $\mathbf{u}$. Basal palisade in section. $\mathbf{v}-\mathbf{y}$. Asci with ascospores (w-y. in cotton blue/lactic acid). a, d, p-u. WU 29507. b. WU 30193 (image by W. Gams). c. WU 30192. e, f, n, o. WU 29508. g. WU 29506. h. holotype. i, v, w. WU 29515. j. WU 29510. k. WU 29513. I. K 133302. m, x, y. WU 29509. Scale bars: a, e, $\mathbf{f}=0.8 \mathrm{~mm}$. $\mathbf{b}=3 \mathrm{~mm}$. $\mathbf{c}$, $\mathbf{d}=1.3 \mathrm{~mm} . \mathbf{g}, \mathbf{i}=0.3 \mathrm{~mm} . \mathbf{j}, \mathbf{p}=0.6 \mathrm{~mm} . \mathbf{k}-\mathbf{n}=0.4 \mathrm{~mm} . \mathbf{o}=0.2 \mathrm{~mm} . \mathbf{q}, \mathbf{s}$, $\mathbf{w}-\mathbf{y}=10 \mu \mathrm{m} . \mathbf{r}, \mathbf{t}, \mathbf{u}=20 \mu \mathrm{m}$. $\mathbf{v}=5 \mu \mathrm{m}$

with several mostly 1-2 celled, irregularly oriented side branches $<100 \mu \mathrm{m}$ long, solitary or in fascicles or often arising around globose hyphal widenings to $15 \mu \mathrm{m}$ diam, often directed back on the main axis, terminal branches and phialides arising at acute angles with respect to the axis. Phialides usually formed at different levels rather than in well-defined whorls, producing conidia in low numbers. At $15^{\circ} \mathrm{C}$ slightly more conidiation above the agar surface in minute white granules with minute conidial heads $<20 \mu \mathrm{m}$ diam.

On PDA after $72 \mathrm{~h} / 1$ week $0-0.6 / 2-3.5 \mathrm{~mm}$ at $15^{\circ} \mathrm{C}$, $0.2-1.2 / 4-9.5 \mathrm{~mm}$ at $25^{\circ} \mathrm{C}$. Growth limited, colony often not covering the entire plate. Colony circular, dense; hyphae thin. Surface becoming white, farinose, downy to floccose from the centre due to a dense mat of long, wide, little ascending aerial hyphae, forming thick strands, becoming fertile. Autolytic activity inconspicuous, coilings moderate or frequent, to $c a 100 \mu \mathrm{m}$ diam. Reverse turning yellowish, darkening to dull yellowish brown or orangebrown, 4B4-6, 5AB7-8 to 6CE7-8, eventually dark brown, 7E7-8, often in irregular spots with discoloured hyphae. Odour none or slightly fruity. Conidiation noted after 48 days at $25^{\circ} \mathrm{C}$, effuse, white, starting around the plug, as long spiny phialides formed directly on surface hyphae or on short conidiophores oriented in various directions, spreading across the colony on the agar surface, later also on strands of aerial hyphae; loosely distributed. Conidiophores (examined after 2 weeks) erect, short, to $200 \mu \mathrm{m}$ long, irregular, $2-4.5 \mu \mathrm{m}$ wide, locally widened to $7 \mu \mathrm{m}$, consisting of a rigid main axis with few short branches, or more commonly only phialides formed on cells $2-5 \mu \mathrm{m}$ wide, solitary or divergent or parallel in groups of $2(-3)$, the second phialide emerging from the base of the first one, often 3 above each other in an inequilateral erect chain; such chains formed apically or at several levels along the axis. Sometimes several short 1-3 celled conidiophores emerging from globose cells to $16 \mu \mathrm{m}$ diam; conidiophores on thick strands of aerial hyphae sometimes widened basally to $11(-16) \mu \mathrm{m}$ wide. Aged conidiophores and those in white granules $0.1-0.3 \mathrm{~mm}$ diam, ill-defined, with numerous sinuous to helical terminal branches and phialides. Phialides subulate, cylindrical, inequilaterally lageniform or sinuous, sometimes becoming apically branched, widest at or slightly above the base, asymmetrical, not paired; producing conidia in minute heads $<30 \mu \mathrm{m}$ diam. Conidia mostly oblong to cylindrical, but also subglobose or suballantoid, hyaline, smooth, straight or curved, with 1 or few guttules; scar distinct, broad. See under MEA for measurements. At $15^{\circ} \mathrm{C}$ conidiation dense on the agar surface around the plug, effuse, short, spiny to broom-like, irregularly verticillium-like; phialides often parallel. Reverse dull yellow, 4A3-5, 4B4, darkening to orange-, reddish- or dark brown, 5-6BC7-8, 7-8CD7-8, 7E7-8, with pigment diffusing across the colony.

On MEA colony hyaline, dense, circular. Aerial hyphae long and thick, forming a white mat around the plug, becoming fertile. Conidiation sometimes also in small white pustules on the colony margin, sometimes also submerged in the agar. Conidiophores to $c a 1 \mathrm{~mm}$ long, more or less erect, usually with long sterile stretches and fan-like branching on upper levels, or branching irregular, asymmetrical, at acute angles, terminal branches $1-3$ celled; basally to $6 \mu \mathrm{m}$ wide, terminally attenuated to $2.5-3 \mu \mathrm{m}$. Phialides solitary or in dense complex fascicles of 2-10 on cells $2-4.5 \mu \mathrm{m}$ wide, strongly inclined upwards or downwards to nearly parallel, often one phialide originating below the base of another and often lacking a basal septum. Phialides (4-)10-21(-28) $\times(1.8-) 2.5-3.5(-5.0) \mu \mathrm{m}, 1 /$ $\mathrm{w}(2.0-) 3.5-6.5(-8.0),(1.5-) 2.2-3.3(-4.2) \mu \mathrm{m}$ wide at the base $(n=62)$, subulate and equilateral or lageniform, inequilateral, curved upwards and with slightly widened middle, sometimes short-cylindrical, divided by a septum close to the apex, sometimes sinuous; producing conidia in minute wet heads to $25 \mu \mathrm{m}$ diam. Conidia (3.0-)4.2-8.3(-13.0) $\times$ $(2.0-) 2.8-4.0(-4.7) \mu \mathrm{m}, 1 / \mathrm{w}(1.2-) 1.4-2.4(-3.9) \quad(n=63)$, hyaline, smooth, variable in shape, mostly ellipsoidal, also subglobose or oblong to suballantoid, with few minute guttules; scar often distinct, truncate. Measurements include those obtained on PDA. After 5 months small sterile, reddish brown stromata observed (C.P.K. 3138).

On SNA not growing after pre-cultivation on CMD, good but limited growth and conidiation after precultivation on MEA, suggesting a requirement for growth factors. Conidiation similar to CMD, below and above the agar surface, sometimes also in white tufts or pustules to $1.5 \mathrm{~mm}$ diam after $2-3$ weeks, with conidial heads to $70 \mu \mathrm{m}$.

Habitat: usually in large numbers on medium- to wellrotted crumbly wood, less commonly on bark.

Distribution: Europe (Austria, Denmark, Germany, Italy, UK), uncommon.

Typification: no type specimen is preserved in C, but an illustration of the type. Holotype ('iconotype'): colour illustration of the type specimen in the unpublished manuscript Flora Hafniensis, Fungi delineati, vol. 1, p. 10, housed in the Botanical Library, Natural History Museum 

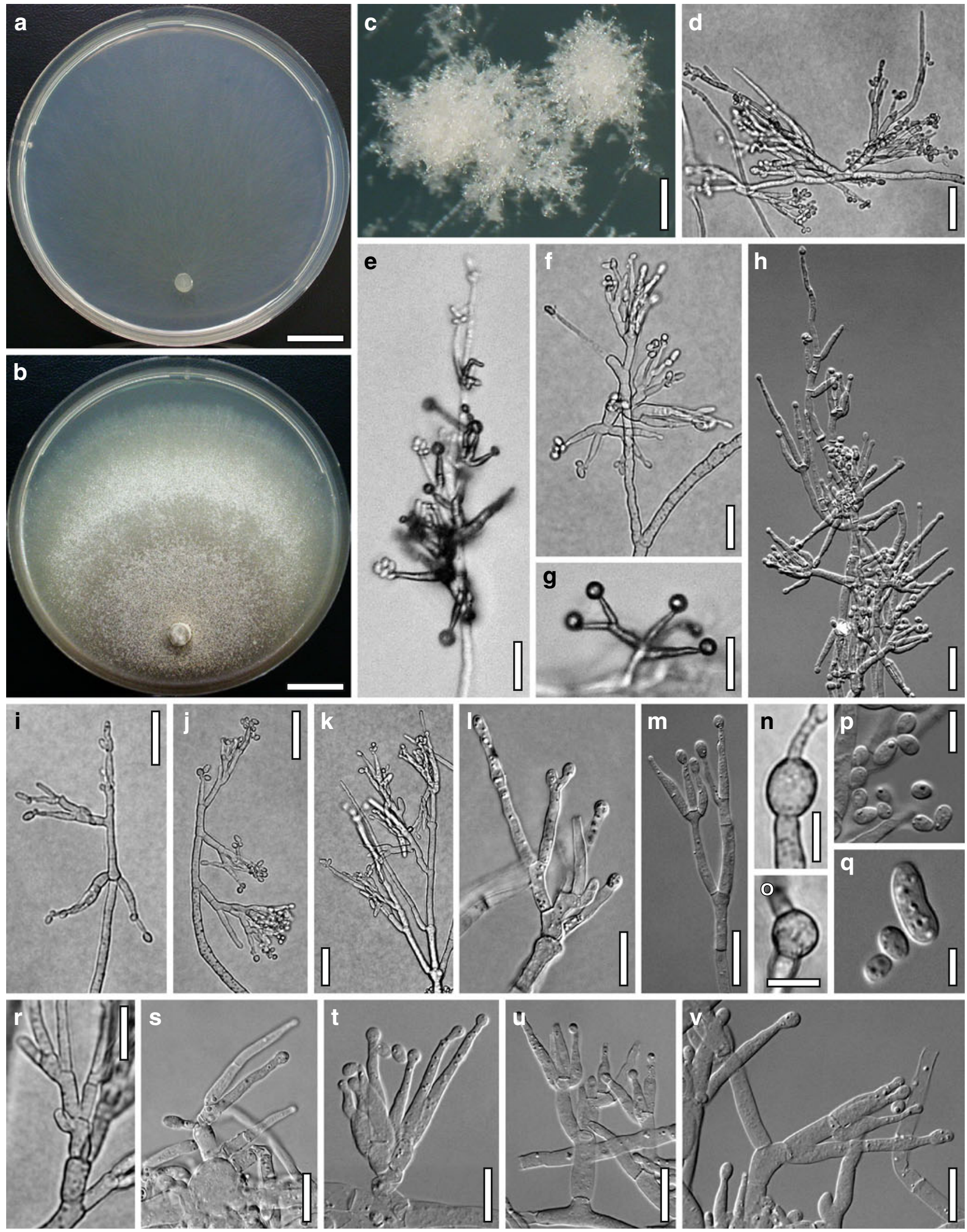
4Fig. 103 Cultures and anamorph of Hypocrea tremelloides. a, b. Cultures at $25^{\circ} \mathrm{C}$ (a. on $\mathrm{CMD}, 35$ days; b. on PDA, 42 days). c. Conidiation tufts (SNA, 20 days). d-g, i-k. Conidiophores on/in growth plates (CMD, 7-15 days; e, g. showing parts above the agar surface). h, l, m. Conidiophores (h, m. MEA, 10 days; l. PDA, 15 days). n, o. Chlamydospores (CMD, 15 days). p, q. Conidia (MEA, 10 days). r. Conidiophore branching (CMD, 15 days). s-v. Phialides (s. PDA, 14 days; t-v. MEA, 10 days). a-v. All at $25^{\circ} \mathrm{C}$. a, b, d-g, i-l, n, o, r, s. CBS 120634. c. C.P.K. 2495. h, m, p, q, t-v. CBS 121140. Scale bars $\mathbf{a}, \mathbf{b}=15 \mathrm{~mm}$. c. $0.2 \mathrm{~mm} . \mathbf{d}, \mathbf{h}-\mathbf{k}=20 \mu \mathrm{m}$. e$\mathbf{g}, \mathbf{m}, \mathbf{s}=15 \mu \mathrm{m} . \mathbf{l}, \mathbf{n}-\mathbf{p}, \mathbf{r}, \mathbf{t}-\mathbf{v}=10 \mu \mathrm{m} . \mathbf{q}=5 \mu \mathrm{m}$

of Denmark, Copenhagen; also reproduced in Flora Danica Tab. 1858, Fig. 2 (cited by Fries 1849). A part of the illustration suggests a globose stroma being hollow inside, but apparently it shows an aggregate of several stromata turned up by mutual pressure forming a cavity. Epitype designated here in order to ascertain the correct relationship between teleomorph, anamorph and gene sequences: Austria, Niederösterreich, Melk, Schönbühel-Aggsbach, Aggsteingraben at walking path to castle ruins Aggstein, MTB 7658/4, 48 $18^{\prime} 40^{\prime \prime} \mathrm{N}, 15^{\circ} 25^{\prime} 32^{\prime \prime} \mathrm{E}$, elev. $380 \mathrm{~m}$, on partly decorticated branch of Carpinus betulus, $3-4 \mathrm{~cm}$ thick, on medium- to well-decomposed wood, soc. and also on Steccherinum ochraceum, 14 Oct. 2006, H. Voglmayr \& I. Krisai-Greilhuber, W.J. 3023 (WU 29508, ex-epitype culture CBS $121140=$ C.P.K. 2490). Holotype of Trichoderma tremelloides isolated from WU 29508 and deposited with the epitype of $H$. tremelloides as WU 29508a.

Other specimens examined: Austria, Niederösterreich, Mödling, Wienerwald, Gruberau, between the village and Buchelbach, MTB 7862/4, 48 $06^{\prime} 17^{\prime \prime} \mathrm{N}, 16^{\circ} 06^{\prime} 01^{\prime \prime} \mathrm{E}$, elev. $380 \mathrm{~m}$, on mostly corticated branch of Quercus petraea 5$6 \mathrm{~cm}$ thick, on well-decayed wood, in bark fissures, also on bark or overgrowing leaves, soc. Corticiaceae, 22 Oct. 2006, H. Voglmayr \& W. Jaklitsch, W.J. 3028 (WU 29509, culture C.P.K. 2495). Steiermark, Grazer Bergland, riverine forest, east from Kickenheim, southeast from St. Radegund, elev. 500 m, on bark, J. Poelt, 27 Sep. 1984, GZU 116.84. Germany, Bavaria, south from Scheidegg, MTB 8425/1, on branch of Abies alba 1-3 cm thick, on bark, mostly overmature, 15 Aug. 2004, P. Karasch (WU 29505). Nordrhein-Westfalen, Arnsberg, Geseke, Eringerfeld, Rosengartenweg, Erlenbruch at A44, MTB 4416/2, 51 35'30" $\mathrm{N}, 08^{\circ} 28^{\prime} 10^{\prime \prime} \mathrm{E}$, elev. ca $100 \mathrm{~m}$, on branch of Alnus sp., soc. Corticiaceae, 6 Oct. 2000, K. Siepe (WU 29515). Münster, Kreis Recklinghausen, Herten, Schloßpark, MTB $4408 / 2,51^{\circ} 36^{\prime} 00^{\prime \prime} \mathrm{N}, 07^{\circ} 08^{\prime} 00^{\prime \prime} \mathrm{E}$, elev. $60 \mathrm{~m}$, on branch of Acer pseudoplatanus on the ground, on wood, soc. effete Eutypa maura, 25 Sep. 2004, F. Kasparek, comm. K. Siepe (WU 29506, culture CBS 120634=C.P.K. 2019). SachsenAnhalt, Landkreis Aschersleben-Staßfurt, Staßfurt, Horst, MTB 4135/1, 51 $51^{\prime} 24^{\prime \prime} \mathrm{N}, 1^{\circ} 33^{\prime} 40^{\prime \prime} \mathrm{E}$, elev. $70 \mathrm{~m}$, on partly decorticated branch of Quercus robur $4-8 \mathrm{~cm}$ thick, on wood, partly on grey Corticiaceae, 22 Aug. 2006, H. Voglmayr \& W. Jaklitsch, W.J. 2933 (WU 29507, culture C. P.K. 2441). Italy, Apulia, Foggia, Gargano, SW from Mandrione, Foresta Umbra/Foresta Domaniale, 41 $52^{\prime} 36^{\prime \prime}$ N, 16 ${ }^{\circ} 03^{\prime} 34^{\prime \prime}$ E, elev. ca $200 \mathrm{~m}$, on Radulomyces molaris/ Quercus cerris branch 8-9 cm thick, also on leaves, soc. Crepidotus mollis var. calolepis, 21 Nov. 2009, W. Jaklitsch \& H. Voglmayr, S 89 (WU 30192). Lazio, Viterbo, Farnese, Selva del Lamone, hiking trail Roppozzo, 42 $34^{\prime} 25^{\prime \prime} \mathrm{N}, 11^{\circ}$ 42'08" E, elev. $320 \mathrm{~m}$, on decorticated branch of Quercus cerris, well-decayed, blackened wood, soc. Steccherinum ochraceum, W. Gams, W. Jaklitsch \& H. Voglmayr, 28 Nov. 2009, S 154 (WU 30193). United Kingdom, Essex, Loughton, Epping Forest, Strawberry Hill Ponds, MTB 43$34 / 1,51^{\circ} 38^{\prime} 57^{\prime \prime} \mathrm{N}, 00^{\circ} 02^{\prime} 41^{\prime \prime} \mathrm{W}$, elev. $30 \mathrm{~m}$, on a branch of Quercus robur $5 \mathrm{~cm}$ thick lying in grass, on well-decayed wood and bark, soc. resupinate polypore, 12 Sep. 2007, W. Jaklitsch \& H. Voglmayr, W.J. 3159 (WU 29514). Herefordshire, Hereford, Mordiford, Sufton Court, on welldecayed wood of Ulmus sp., ex herb. C. B. Plowright, Oct. 1878 (K 133302). Same data, coll. C. Spencer-Percival (K 133065). Leominster, Dinmore, on wood, probably Fagus sylvatica, Oct. 1878, C. B. Plowright (K 132937). Dinmore Hill, 52 $09^{\prime} 23^{\prime \prime} \mathrm{N}, 02^{\circ} 43^{\prime} 09^{\prime \prime} \mathrm{W}$, elev. $120 \mathrm{~m}$, on a branch of Quercus robur $4 \mathrm{~cm}$ thick, on well-decayed wood, soc. Diatrypella quercina in bark, 11 Sep. 2007, W. Jaklitsch \& H. Voglmayr, W.J. 3153 (WU 29513, culture C.P.K. 3148). North Yorkshire, Kirkbymoorside, Dawson's Wood, 54 $15^{\prime}$ N, $00^{\circ} 52^{\prime} \mathrm{W}$, elev. $70 \mathrm{~m}$, on branch of Populus sp. on welldecayed wood, 5 Sep. 2007, H. Voglmayr \& W. Jaklitsch, W.J. 3135 (WU 29510, C.P.K. 3138). Shropshire, Ludlow, Downton on the Rock, 52 $22^{\prime} 14^{\prime \prime} \mathrm{N}, 02^{\circ} 48^{\prime} 58^{\prime \prime} \mathrm{W}$, elev. $140 \mathrm{~m}$, on branch of Acer pseudoplatanus 7-8 cm thick, on well-decayed wood blackened by Xylaria longipes, soc. Corticiaceae, 10 Sep. 2007, W. Jaklitsch \& H. Voglmayr, W.J. 3151 (WU 29512, culture C.P.K. 3147). Warwickshire, Alcester, Oversley Wood, 52 $12^{\prime} 27^{\prime \prime} \mathrm{N}, 01^{\circ} 50^{\prime} 24^{\prime \prime} \mathrm{W}$, elev. $70 \mathrm{~m}$, on corticated branch of Quercus robur 4-6 cm thick, on bark and Diatrypella quercina, 10 Sep. 2007, W. Jaklitsch \& H. Voglmayr, W.J. 3150 (WU 29511).

Notes: Hypocrea tremelloides is morphologically distinct because of its waxy to gelatinous, 'tremelloid' appearance of the stromata, light translucent perithecia and incarnate to pale orange-brown stroma colour. Stromata of the somewhat similar Hypocrea sambuci lack reddish colour tones, except when old, and occur specifically on Sambucus. Immature stromata may sometimes resemble those of immature H. gelatinosa, and Petch (7 Sep. 1936; annotation label) interpreted the specimen $\mathrm{K} 132937$ as immature $H$. gelatinosa, but the latter has larger projecting perithecial protuberances and green ascospores when mature, yielding a green conidial gliocladium-like anamorph. Recent collections are in good agreement with the protologue and the 
slightly extended version in Saccardo (1883a), who noted a similarity with Naematelia, i.e. Tremella basidiomes. An image of this species can be also found in Medardi (1999, p. 331; misidentified as $H$. argillacea). The hyaline-conidial $T$. tremelloides, characterised by densely sympodially elongating conidiophores, with phialides formed in this way often lacking a basal septum, is distinct from all others species of Trichoderma currently known, with the exception of the anamorph of the phylogenetically close $H$. sambuci. Apically branched phialides sometimes seen on PDA are also reminiscent of T. subalpinum, which clusters with $H$. tremelloides and H. sambuci in the phylogenetic analysis (see Fig. 1).

Hypocrea voglmayrii Jaklitsch, Mycologia, 97: 1368 (2005 [2006]). Fig. 104

Anamorph: Trichoderma voglmayrii Jaklitsch, Mycologia, 97: 1368 (2005[2006]). Fig. 105

Stromata solitary or in small caespitose groups, on wood or more commonly erumpent through fissures in the bark with the sterile and light-coloured margin surrounded by the epidermis of the host. Stromata when dry (1.0-)1.3-3.0 $(-5.1) \times(0.7-) 1.0-2.2(-3.2) \mathrm{mm}, 0.3-0.7(-1.0) \mathrm{mm}$ thick $(n$ $=30$ ); pulvinate or discoid when fresh, when dry discoid or more or less turbinate, with a short sterile constricted stipe; base often surrounded by radiating white mycelium. Outline circular, angular or oblong. Margin free, rounded or sharp, sometimes undulate. Surface mostly plane or concave, smooth, glabrous, with perithecia entirely immersed. Ostiolar dots (24-)32-54(-70) $\mu \mathrm{m}(n=60)$ diam, densely arranged, conspicuous, well-defined, slightly raised, dark brown to black. Stromata brick red, 7CD6-7, rosy, greyish- or brownish red 9C5-6 when fresh, greyishor brownish red, 9C5-6, to Cuba red, 9E7-8, or violaceousbrown, 10E7-8, when dry, with the margin concolorous or, like the stipe, whitish, yellowish or pale orange. Only slight differences between fresh and dry stromata apparent, except for a smoother surface and lighter, more reddish brown ostioles in fresh stromata, and some wrinkles and fine fissures sometimes in stellate arrangement around the ostiolar dots in dry stromata. Rehydrated stromata turning dark reddish brown to nearly black in $3 \% \mathrm{KOH}$,

Stroma anatomy: Ostioles (50-)60-89(-100) $\mu \mathrm{m}$ long, projecting to $30(-55) \mu \mathrm{m}(n=60),(26-) 32-49(-55)(n=30)$ wide at the apex, apically appearing as a palisade of elongate, narrow, strongly compressed, orange to reddish cells, resembling those of the lateral peridium. Perithecia ellipsoidal, broadly cylindrical or flask-shaped, (185-)215$260(-285) \times(80-) 100-170(-230) \mu \mathrm{m}(n=31)$, laterally compressed and approximately by $40 \%$ higher than wide on average. Peridium (12-)13-18(-20) $\mu \mathrm{m}(n=20)$ thick at the base, $(5-) 6-12(-16) \mu \mathrm{m}(n=20)$ at the sides; orange- or reddish brown. Cortical tissue (6-)8-16(-22) $\mu \mathrm{m}(n=20)$ thick, consisting of thick-walled, compressed angular cells $3-10 \mu \mathrm{m}(n=30)$ diam of indistinct outline, superposed by a thin compact, amorphous orange or reddish layer. Subcortical tissue a $t$. angularis of subglobose or angular cells $(3-) 5-11(-13) \times(2.5-) 4.5-8.5(-10.0) \mu \mathrm{m}(n=30)$, hyaline, but orange to reddish just below the surface layer; entire tissue above the perithecia (30-)41-67(-77) $\mu \mathrm{m}(n=$ 20) thick. Subperithecial tissue of hyphae with strongly constricted septa and hyaline, refractive, elongate to subglobose cells $(7-) 12-38(-57) \times(6-) 8-18(-24) \mu \mathrm{m}(n=$ 30) with walls $c a 1-2 \mu \mathrm{m}$ thick. Stroma base a hyaline, loose $t$. intricata of hyphae (2.0-)2.5-5.2(-7.5) $\mu \mathrm{m}(n=30)$ wide. Asci (60-)68-84(-94) $\times(3.3-) 4.0-4.5(-5.5) \mu \mathrm{m}(n=$ $60)$, stipe (4-)7-13(-17) $\mu \mathrm{m}(n=30)$ long. Ascospores hyaline, finely spinulose, cells dimorphic; distal cell 3.0 $3.8(-4.5) \times(2.5-) 2.7-3.2(-3.5) \mu \mathrm{m}, 1 / \mathrm{w}(1.0-) 1.1-1.3(-1.7)$ $(n=60)$, subglobose, broadly ellipsoidal or wedge-shaped; proximal cell $(3.3-) 3.8-4.7(-5.5) \times(2.0-) 2.2-2.7(-3.2) \mu \mathrm{m}$, $1 / \mathrm{w}(1.3-) 1.5-2.0(-2.7)(n=60)$, oblong to nearly ellipsoidal, often slightly attenuated toward the base.

Cultures and anamorph: optimal growth at $30^{\circ} \mathrm{C}$ on all media, also growing at $35^{\circ} \mathrm{C}$.

On CMD after $72 \mathrm{~h} 11-12 \mathrm{~mm}$ at $15^{\circ} \mathrm{C}, 35-36 \mathrm{~mm}$ at $25^{\circ} \mathrm{C}, 47-49 \mathrm{~mm}$ at $30^{\circ} \mathrm{C}, 17-19 \mathrm{~mm}$ at $35^{\circ} \mathrm{C}$; mycelium covering the plate after $5-6$ days at $25^{\circ} \mathrm{C}$. Colony hyaline, thin, circular, not zonate, scarcely visible, with little mycelium on the agar surface; hyphae loosely arranged, with conspicuous difference in thickness between primary and secondary hyphae. Distal margin appearing slightly hairy to floccose due to long branched aerial hyphae. Autolytic activity low, coilings conspicuous. A coconut-like odour developing and a yellow pigment diffusing through the agar after 4 days. After 2 weeks the yellow pigment sometimes occurring as long needle-shaped crystals on the agar surface, particularly at higher temperatures. Chlamydospores noted after 6-8 days, scant; see SNA for measurements. Conidiation starting after 2-3 days, effuse; solitary phialides in rows arising from surface hyphae or fascicles of 3-5(-6) phialides from short, erect, scarcely branched conidiophores; within $4-9$ days visible as inconspicuous and ill-defined powdery, white to pale yellow granules mainly in the distal third of the plate. Granules $0.1-0.5(-1.0) \mathrm{mm}$ diam, made up of single or few

Fig. 104 Teleomorph of Hypocrea voglmayrii. a, b. Fresh stromata. ck. Dry stromata (g. part showing black ostiolar dots; k. stipitate stroma in side view). l. Ostiole surrounded by stellate fissures in the cortical crust. m. Stroma surface in face view. n. Rehydrated stroma in $3 \%$ $\mathrm{KOH}$. o. Perithecium in section. p. Cortical and subcortical tissue in section. q. Subperithecial tissue in section. r. Stroma base in section. s, t. Asci with ascospores (t. in cotton blue/lactic acid). a, b, t. WU 25715. c, g, o-s. WU 25713. d, i, l. WU 25712. e, f, j, k, m, n. WU 25711. h. WU 25714. Scale bars $\mathbf{a}=1.5 \mathrm{~mm}$. $\mathbf{b}=1 \mathrm{~mm}$. c, j. $0.7 \mathrm{~mm}$. d-f, $\mathbf{h}=$ $0.4 \mathrm{~mm}$. g, $\mathbf{k}=0.2 \mathrm{~mm}$. i, $\mathbf{n}=0.3 \mathrm{~mm}$. $\mathbf{l}, \mathbf{o}=40 \mu \mathrm{m} . \mathbf{m}=5 \mu \mathrm{m} . \mathbf{p}=15 \mu \mathrm{m}$. $\mathbf{q}, \mathbf{r}=20 \mu \mathrm{m} . \mathbf{s}, \mathbf{t}=10 \mu \mathrm{m}$ 

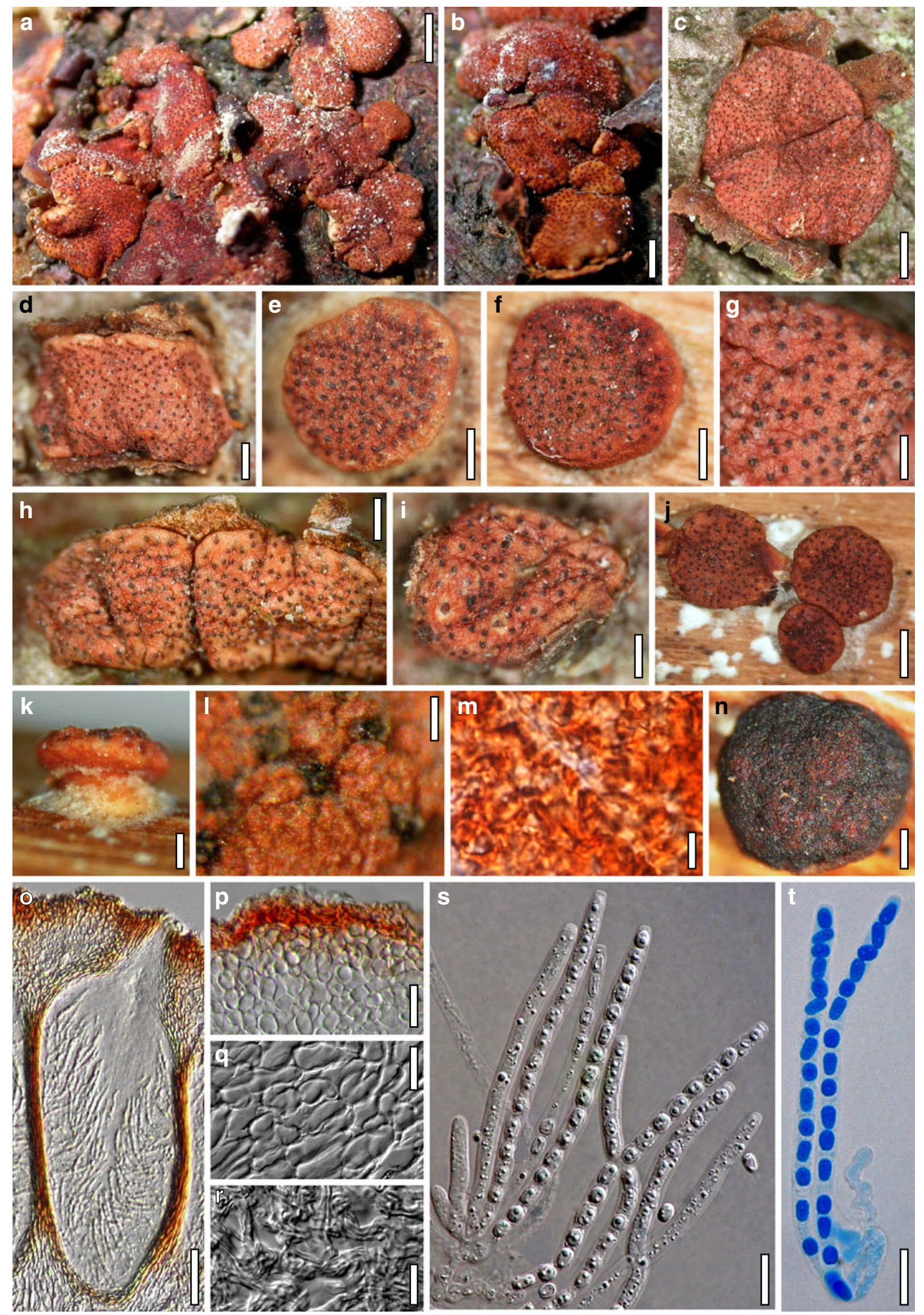

$\therefore$ से के के

3 ह 6 है

a.

s 5

- 4 है

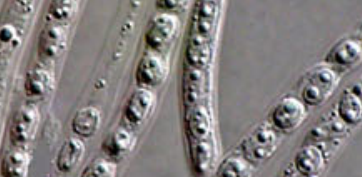

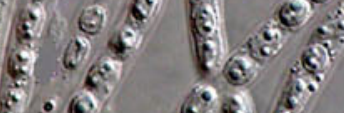

5. 28 का

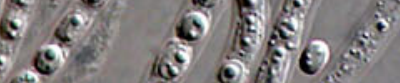
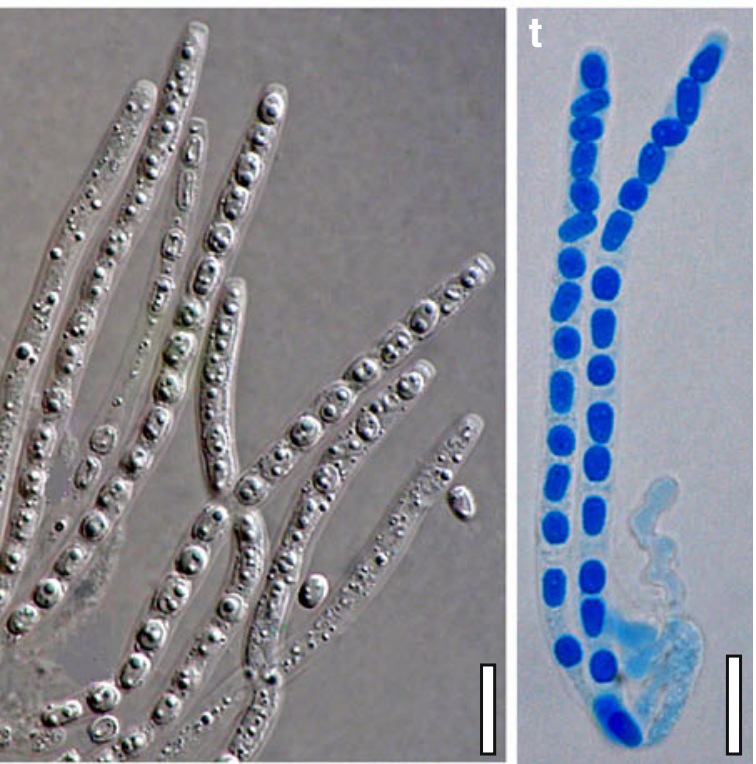


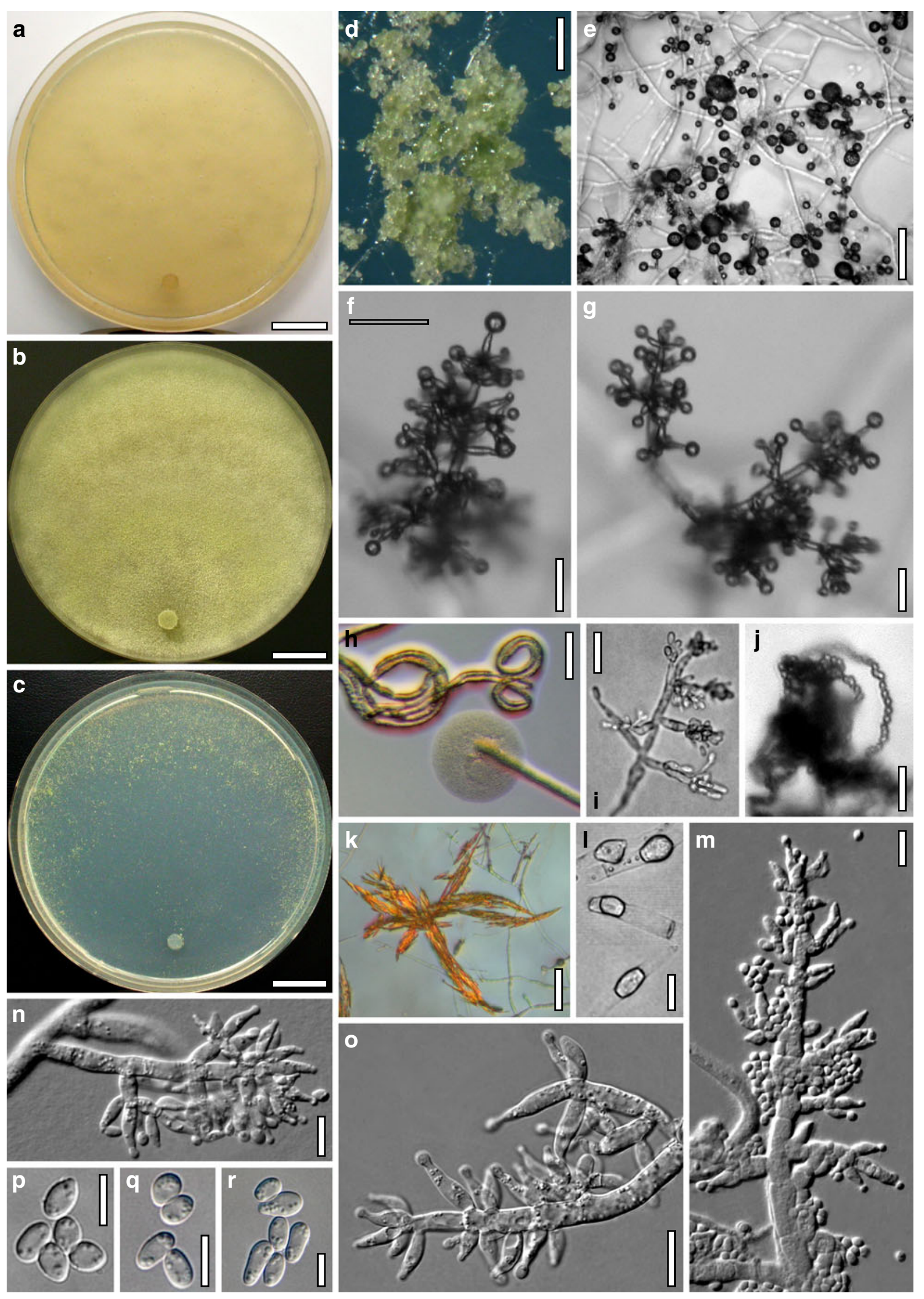


4Fig. 105 Cultures and anamorph of Hypocrea voglmayrii. a-c. Cultures after 14 days (a. on CMD; b. on PDA; c. on SNA). d. Conidiation granules (SNA, $25^{\circ} \mathrm{C}, 14$ days). e. Conidial heads (7 days). f, g. Conidiophores on growth plate (4 days). h. Coilings and autolytic excretion (PDA, $25^{\circ} \mathrm{C}, 5$ days). i. Conidiophore submerged in agar $\left(\mathrm{CMD}, 30^{\circ} \mathrm{C}, 3\right.$ days). j. Conidial chains ( 8 days). k. Crystal formed on agar surface $\left(\mathrm{CMD}, 35^{\circ} \mathrm{C}, 6\right.$ days). $\mathbf{l}$. Chlamydospores (CMD/SNA, $25 / 35^{\circ} \mathrm{C}, 6 / 7$ days). m-o. Conidiophores and phialides (5-7 days). p-r. Conidia (6 days). d-o. All on $\mathrm{CMD}$ at $25^{\circ} \mathrm{C}$ except d, h, i, k, l. a, c, e- $\mathbf{g}, \mathbf{j}, \mathbf{m}-\mathbf{0}$. CBS 117710 . b, d, $\mathbf{h}, \mathbf{i}, \mathbf{k}, \mathbf{l}$, p-r. CBS 117711. Scale bars $\mathbf{a}-\mathbf{c}=15 \mathrm{~mm}$. d, $\mathbf{e}=100 \mu \mathrm{m}$. f, $\mathbf{g}, \mathbf{i}, \mathbf{j}=20 \mu \mathrm{m} . \mathbf{h}, \mathbf{k}=50 \mu \mathrm{m} . \mathbf{l}-\mathbf{o}=10 \mu \mathrm{m} . \mathbf{p}-\mathbf{r}=5 \mu \mathrm{m}$

coalescing conidiophores, bearing conidia in heads of up to $60 \mu \mathrm{m}$ diam and later sometimes in chains. At the same time conidiation also occurring submerged in the agar. Conidiophores to $200 \mu \mathrm{m}$ long, simple or with up to 5(-7) primary branches, mostly regularly tree-like, i.e. consisting of a main axis with short, mostly paired side branches to $35 \mu \mathrm{m}$ long, at right angles in lower positions, inclined upwards in higher positions, increasing in length with distance from the tip, replaced at the tip by phialides. Side branches sometimes rebranching to form complex, dense, non-transparent structures. Phialides solitary or in whorls of 3-5(-7). Sparse conidial development also on long aerial hyphae. Phialides $(5.5-) 7-12(-17) \times(2.7-) 3.2-4.0(-4.7)$ $\mu \mathrm{m}, 1 / \mathrm{w}=(1.4-) 1.9-3.4(-5.0),(1.5-) 2.0-3.0(-4.0) \mu \mathrm{m}$ wide at the base $(n=60)$, terminal phialides often longer than the flanking ones in the fascicle, lageniform to narrowly subcylindrical, sometimes sinuous, less commonly ampulliform or sometimes ventricose, inequilateral and with a long neck, widest point at various positions. Conidia (3.0-)3.5$6.5(-10.5) \times(2.2-) 2.5-3.3(-4.2), 1 / \mathrm{w}=(1.1-) 1.2-2.2(-3.4)$ $(n=75)$, hyaline, yellowish in mass, oval to oblong, often attenuated toward one end, smooth, with guttules often in a group at each end. At $15^{\circ} \mathrm{C}$ development slower; at $30^{\circ} \mathrm{C}$ faster, with more abundant yellowish conidiation submerged in the agar, morphologically indistinguishable from granules on the surface of the agar. Coconut-like odour also formed at all other temperatures. Most abundant chlamydospores and yellow crystals formed at 30 and $35^{\circ} \mathrm{C}$. At $35^{\circ} \mathrm{C}$ growth continuing for $>1$ week, with only few hyphae on the agar surface and scanty effuse, simple conidiation without any granulation after $4-5$ days.

On PDA 9-11 $\mathrm{mm}$ at $15^{\circ} \mathrm{C}, 28-29 \mathrm{~mm}$ at $25^{\circ} \mathrm{C}, 27-$ $31 \mathrm{~mm}$ at $30^{\circ} \mathrm{C}, 3-6 \mathrm{~mm}$ at $35^{\circ} \mathrm{C}$; mycelium covering the plate after 7-8 days at $25^{\circ} \mathrm{C}$; growth slower than on CMD, with hyphae more thickly and densely arranged than on CMD. Colony thick, dense, not or indistinctly zonate, with a thin, finely granular centre of extremely densely interwoven to condensed hyphae and an ill-defined, diffuse margin with surface hyphae forming strands. Surface whitish, turning yellow or greenish, downy to floccose by a reticulum of aerial hyphae forming thick strands and numerous narrow branches without any noticeable orienta- tion. Autolytic activity and coilings conspicuous at 25 and $30^{\circ} \mathrm{C}$. Conidiation finely granular, colourless to white, on numerous single phialides or short verticillium-like, seated on surface and aerial hyphae, effuse, spreading across the entire colony. Reverse and to some extent also surface turning light yellow from the centre, 3A3, 3B5-6, 4B4-5. Odour indistinct to slightly mushroomy. At $35^{\circ} \mathrm{C}$ growth slow, forming small sterile, white, hairy colonies.

On SNA $11-12 \mathrm{~mm}$ at $15^{\circ} \mathrm{C}, 33-35 \mathrm{~mm}$ at $25^{\circ} \mathrm{C}, 42-$ $44 \mathrm{~mm}$ at $30^{\circ} \mathrm{C}, 9-15 \mathrm{~mm}$ at $35^{\circ} \mathrm{C}$; mycelium covering the plate after $5-6$ days at $25^{\circ} \mathrm{C}$. Colony thin, hyaline, growth predominantly submerged in the agar, hyphae loosely arranged and sometimes forming several separated strands rather than a continuous colony. Aerial hyphae scant, more common and longer at the whitish and downy distal margin. Autolytic activity and coilings conspicuous at 25 and $30^{\circ} \mathrm{C}$. Surface hyphae soon degenerating. Conidiation slightly more abundant and denser than on CMD, starting within 3 days with sessile phialides or supported by short conidiophores, mainly at the proximal margin, later also on long aerial hyphae in the distal part of the colony. After 57 days conidiation becoming visible as fine granules to $0.6 \mathrm{~mm}$ diam with conidial heads up to $60 \mu \mathrm{m}$ diam, spreading from the distal margin back nearly across the entire plate, or concentrated in 2-3 concentric zones, turning greyish- to yellowish green, 28-30CD5-6. Granules more regularly shaped on SNA than on CMD, appearing waxy or glassy in the stereo-microscope. No diffusing pigment, no distinct odour detected. At $30^{\circ} \mathrm{C}$ conidiation denser, granules more regularly in 3 concentric zones, with conidial heads up to $100 \mu \mathrm{m}$ diam. At $35^{\circ} \mathrm{C}$ colonies irregular, dense, hairy to floccose, conidiation more abundant than on CMD. Chlamydospores on SNA at $35^{\circ} \mathrm{C}$ more abundant than on CMD, spreading from the plug, (4.5-)6-14(-20)×(4.0-)4.5-7.0(-8.2) $\mu \mathrm{m}$, $1 / \mathrm{w}=1.0-2.7(-4.4)(n=34)$, globose, oval or subclavate and often truncated at one end when terminal, ellipsoidal, irregularly elongate or sinuous and large when intercalary, smooth.

Habitat: on dead, mostly corticated branches and small trunks of Alnus alnobetula ( $=A$. viridis) and A. incana standing or lying on the ground.

Known distribution: Austria, at elev. 1000-1400 m in the upper montane vegetation zone of the central Alps.

Holotype: Austria, Salzburg, Böckstein, hiking trail close to the parking lot in front of the Gasteiner Heilstollen,

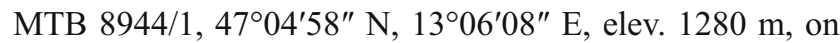
dead partly standing trunk of Alnus alnobetula, 5 Sep. 2003, W. Jaklitsch W.J. 2378 (WU 25711; ex-type culture CBS $117711=$ C.P.K. 948). Holotype of Trichoderma voglmayrii isolated from WU 25711 and deposited as a dry culture with the holotype of $H$. voglmayrii as WU 25711a. 
Other specimens examined: Austria, Kärnten, Stappitz, from Gasthof Alpenrose up along the brook parallel to the

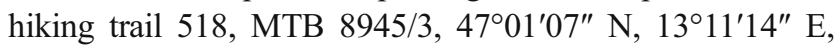
elev. $1360 \mathrm{~m}$, on dead branch of Alnus alnobetula on the ground, 5 Sep. 2003, W. Jaklitsch, W.J. 2382 (WU 25715, culture C.P.K. 951). Salzburg, Felbertal, Mittersill, on branch of Alnus sp., 15 Aug. 2005, G.F. Medardi (K!, as H. rufa). Steiermark, Schladminger Tauern, Kleinsölk, steep forest at the western side of the lake Schwarzensee, MTB 8749/1, $47^{\circ}$ $17^{\prime} 35^{\prime \prime} \mathrm{N}, 13^{\circ} 52^{\prime} 15^{\prime \prime} \mathrm{E}$, elev. $1165 \mathrm{~m}$, on dead branch of Alnus incana on the ground, 6 Aug. 2003, W. Jaklitsch \& H. Voglmayr, W.J. 2302 (WU 25712, culture CBS 117710=C. P.K. 1592); same region, hiking trail between Schwarzensee

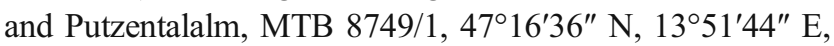
elev. $1320 \mathrm{~m}$, on dead standing trunk of Alnus alnobetula, 6 Aug. 2003, H. Voglmayr \& W. Jaklitsch, W.J. 2304 (WU 25713); same region, $47^{\circ} 17^{\prime} 00^{\prime \prime} \mathrm{N}, 13^{\circ} 52^{\prime} 02^{\prime \prime} \mathrm{E}$, elev. $1190 \mathrm{~m}$, on dead standing trunk of Alnus alnobetula, 6 Aug. 2003, H. Voglmayr \& W. Jaklitsch, W.J. 2305 (WU 25714, culture C.P.K. 941).

Notes: Hypocrea voglmayrii is well-characterised by a set of ecological and morphological traits: the occurrence on Alnus spp., particularly A. alnobetula, at high altitudes in the Alps; the conspicuous dark brown to black ostiolar dots in dry stromata; the effuse conidiation and formation of a coconut odour on CMD. The ability of this species to grow at $35^{\circ} \mathrm{C}$ may be related to its habit to ascend trunks, thereby becoming exposed to microclimatic effects, such as direct sunshine. Phylogenetically $H$. voglmayrii forms a lone lineage in a well-supported clade including the section Trichoderma. The formation of 6-pentyl- $\alpha$-pyrone is otherwise only in that section perceptible as coconut odour (Samuels 2006). However, the conidiation, pale green only on SNA, or growth at $35^{\circ} \mathrm{C}$ are not typical of the section Trichoderma, as well as the glabrous stromata with conspicuous, well-defined dark ostiolar dots. See Jaklitsch et al. (2005) for more details.

\section{List of dubious or excluded names relevant to Europe}

This list provides comments to names or species of Hypocrea/Trichoderma that are relevant for Europe, regarded to be dubious or excluded from the genus, and some species from other regions of the world reported to occur in Europe by other authors. Abbreviations: DU.. dubious, NE.. non-European, EX.. excluded, SYN.. synonym. Recognised binomials in other genera are given in bold. For synonyms of accepted Hypocrea species see under the respective accepted taxon and the Index.

DU Hypocrea armata (Fr.) Fr., Summa Veg. Scand., p. 383 (1849).
三Sphaeria armata Fr., Syst. Mycol. 2: 336 (1823).

Status: dubious. The protologue suggests a species of Hypomyces, such as H. armeniacus Tul. \& C. Tul. No information on ascospores was given.

Type specimen: unavailable in UPS.

Habitat and distribution: on soil in Europe (Germany, Switzerland).

EX Hypocrea atra Fr., Summa Veg. Scand., p. 564 (1849).

Status: a synonym of Hypomyces luteovirens (Fr. : Fr.) Tul. \& C. Tul.

Authentic specimens: UPS 113616 and 113617.

Reference: Rogerson and Samuels (1994, p. 854).

NE Hypocrea brevipes (Mont.) Sacc., Michelia 1: 304 (1878).

$\equiv$ Cordyceps brevipes Mont., Syll. Gen. Spec. Crypt., p. 201 (1856).

Synonyms: Podostroma brevipes (Mont.) Seaver, Podocrea brevipes (Mont.) Sacc. \& D. Sacc.

Status: accepted species, known from tropical America, New Guinea and Japan, but the occurrence in Europe remains to be proven. Doi (1975) interpreted a specimen from England (Herefordshire, Downton Gorge, on Quercus, 17 Sep. 1951, J. Webster IMI 47042), as H. brevipes. Samuels and Lodge (1996) accepted Doi's interpretation. This specimen was examined and identified as H. alutacea with laterally fused stromata, which is not uncommon in this species.

Additional references: Chamberlain et al. (2004), Doi (1979).

DU Hypocrea citrina De Not. in Saccardo, Syll. Fung. 2: 528 (1883a).

Status: dubious; given as a synonym of $H$. fungicola $(=H$. pulvinata) in the cryptic citation by Saccardo 'Sphaeria et Hypocrea citrina Pers. et De Not., ex parte'. Apparently this name has never been validly published. No type specimen is available in PAD.

EX Hypocrea citrina $\beta$ ochracea Sacc., Syll. Fung. 2: 528 (1883a).

$\equiv$ Sphaeria ochracea Pers., Syn. meth. Fung. (Göttingen): 18 (1801).

Status: a synonym of Hypomyces armeniacus Tul., syn. Hypomyces ochraceus (Pers.) Tul. \& C. Tul. According to Rogerson and Samuels (1994, p. 846) there is no type material of Sphaeria ochracea Pers. in L. According to G. Arnold (K. Põldmaa, pers. comm.) there is a drawing next to the original description of Sphaeria ochracea, which could serve as the holotype or lectotype of Hypomyces ochraceus, having precedence over $H$. armeniacus . 
DU Hypocrea cordyceps Velenovsky, Česke Houby, dil. IV-V, Pl. 3 (1922)

Status: dubious. The protologue suggests a typical 'Podostroma', the stroma length of $12-20 \mathrm{~cm}$ suggests $H$. nybergiana, but ascospore cells are given as only $2 \mu \mathrm{m}$ diam. In the absence of type material its identity remains obscure.

Type specimen: not available in PR and PRM.

Habitat and distribution: on the ground between mosses in the Czech Republic (Bohemia).

DU Hypocrea cupularis (Fr.) Sacc., Syll. Fung. 2: 535 (1883a).

三Sphaeria cupularis Fr., Linnaea 5: 530 (1830).

$\equiv$ Chromocrea cupularis (Fr.) Petch, Trans. Brit. Mycol. Soc. 21: 293 (1938).

Status: dubious; according to Chaverri and Samuels (2003), a synonym of $H$. gelatinosa. Hypocrea cupularis was used by Winter 1885 [1887]; as a dubious species), Migula (1913), and Petch (1938) for the fungus identifiable as $H$. dacrymycella based on their redescriptions. See Jaklitsch (2009). Hypocrea cupularis Pat. (1903, nom. illegit. Art. 53 ) is a different species from Guadeloupe.

EX Hypocrea deformans Fuckel, Fungi rhen. exsicc. no. 992. [non E. Bommer \& M. Rousseau, Bull. Soc. Roy. Acad. Belgique, Cl. Sci. 8: 642 (1900)].

Status: a synonym of Hypomyces lateritius (Fr.: Fr.) Tul.

Reference: Fuckel (1870, p. 182).

EX Hypocrea eichleriana Bres. in Saccardo, Syll. Fung. 16: 586 (1902).

Status: redescribed by Jaklitsch (2007) in the new genus Immersisphaeria as I. eichleriana (Bres.) Jaklitsch.

Habitat and distribution: immersed in corticiaceous fungi; in Poland, Europe.

EX Hypocrea farinosa Berk. \& Broome, Ann. Mag. Nat. Hist. Ser. 2, 7: 186 (1851).

Status: basionym of Protocrea farinosa (Berk. \& Broome) Petch. Hypocrea farinosa sensu Overton et al. (2006b) was described as H. decipiens by Jaklitsch et al. (2008b).

Habitat and distribution: on basidiomes of Skeletocutis spp.; Europe, possibly also on other continents.

Reference: Jaklitsch et al. (2008b).

EX Hypocrea fulva (DC.) De Not., Erb Critt. Ital. no. 1473, in sched. (1865).

Status: a synonym of Polystigma fulvum DC., in Lamarck \& de Candolle, Flore Française 6: 164 (1815).

Reference: Cannon (1996).

EX Hypocrea hypomycella Sacc., Michelia 1: 302 (1878)
Status: not a Hypocrea. The type specimen (PAD) consists of a corticiaceous fungus, according to the protologue Peniophora polygonia cracked into numerous parts, many containing more or less discoid, collapsed perithecia of a Neorehmia or Trichosphaerella sp., i.e. with 16 hyaline ascospores in biseriate arrangement in short-clavate asci, but lacking setae. Von Höhnel and Litschauer (1906), p. 293) noted that the fungus possibly represented a new genus.

Distribution: Italy

EX Hypocrea inclusa Berk. \& Broome, Ann. Mag. Nat. Hist., Ser. 3, 7: 461 (Brit. Fungi no. 970, t. 17, Fig. 23) (1861).

Status: a synonym of Battarrina inclusa (Berk. \& Broome) Clem. \& Shear, Gen. Fungi, Edn 2 (Minneapolis) (1931) Habitat and distribution: in Tuber puberulum in Europe. References: Rossman et al. (1999), Saccardo (1883a).

EX Hypocrea lateritia (Fr.) Fr., Summa Veg. Scand., p. 383 (1849).

Status: a synonym of Hypomyces lateritius (Fr. : Fr.) Tul. Reference: Rogerson and Samuels (1994, p. 851).

DU Hypocrea lenta (Tode : Fr.) Berk., in Berkeley \& Broome, Bot. J. Linn. Soc. 14: 112 (1873).

$\equiv$ Sphaeria lenta Tode, Fungi Mecklenb. Sel. 2: 30 (1791): Fries, Syst. Mycol. 2: 349 (1823).

Status: dubious. The identity of Tode's Sphaeria lenta is not known and his herbarium is lost. No type specimen is available. Berkeley only combined the species epithet in Hypocrea, referring to Fries (1823). He most probably meant a different species of Hypocrea occurring in Sri Lanka, possibly the green-spored H. palmicola Berk. \& Broome described in the same paper (type in K; G.J. Samuels, pers. comm.). Petch $(1935,1937)$ discussed the name Hypocrea lenta: 'what Tode described on p. 30 and shown by the figures could be a Hypocrea; it is a generalised description of a fungus with a black stroma on decorticated wood'. Petch says that what Tode wrote later, on p. 63, had been overlooked. There Tode said that the context is very tough but not fibrous, and with time it acquired the hardness of a sclerotium, black when mature. Spores were extruded in a powder as in the other 'Hypoxyli'. According to Petch, based on the description, if it was a Hypocrea then it was one with olivaceous or green spores. In 1937 Petch reproduced Currey's (1863) view that Sphaeria lenta Schwein. (an obligate synonym of H. schweinitzii) was distinct from Sphaeria lenta Tode. Petch (1937) favoured the view that the original Sphaeria lenta Tode on beech was Ustulina (now Kretzschmaria) deusta.

EX Hypocrea lichenoides (Tode) Ellis \& Everh., North Amer. Pyrenom., p. 87 (1892). 
$\equiv$ Acrospermum lichenoides Tode, Fung. mecklenb. sel. (Lüneburg): 9 (1790).

Status: a synonym of Hypocreopsis lichenoides (Tode) Seaver, Mycologia 2: 82 (1910).

Reference: Rossman et al. (1999).

EX Hypocrea luteovirens (Fr. : Fr.) Fr., Summa Veg. Scand., p. 383 (1849).

$\equiv$ Sphaeria luteovirens Fr., Kongl. Vetensk. Akad. Handl. 38: 251 (1817) : Fries, Syst. Mycol. 2: 339 (1823).

Status: a synonym of Hypomyces luteovirens (Fr. : Fr.) Tul. \& C. Tul.

Reference: Rogerson and Samuels (1994, p. 854).

?SYN Hypocrea moliniae Pass., Erb. Critt. Ital. no. 1077 (1881).

Status: probably a synonym of $H$. spinulosa. See Jaklitsch (2009).

EX Hypocrea pallida Ellis \& Everh.. J. Mycol. 2(6): 65 (1886).

Status: basionym of Protocrea pallida (Ellis \& Everh.) Jaklitsch, K. Põldmaa \& Samuels.

Habitat and distribution: on basidiomes of Oligoporus and Tyromyces spp. in Europe, Japan and North America. Reference: Jaklitsch et al. (2008b).

EX Hypocrea papyracea Ellis \& Holw., J. Mycol. 2(6): 66 (1886).

Status: synonym of Arachnocrea stipata (Fuckel) Z. Moravec (1956).

See also under H. stipata.

EX Hypocrea parmelioides (Mont.) Mont., Syll. Gen. Spec. Crypt., p. 210 (1856).

$\equiv$ Sphaeria parmelioides Mont., Ann. Sci. Nat. Bot., Sér. 2, 6: 333, t. 18, Fig. 4 (1836).

Status: a synonym of Hypocreopsis lichenoides (Tode)

Seaver, Mycologia 2: 82 (1910).

References: Rossman et al. (1999), Seaver (1910, p. 82).

NE Hypocrea patella Cooke \& Peck in Peck, Ann. Rep. New York State Mus. Nat. Hist. 29: 57 (1878).

Status: not yet detected in Europe. Dodd et al. (2002), in redescribing the species from North America, also cited two specimens from Styria, Austria, based on teleomorph morphology. One of these specimens (J. Poelt, 27 Sep. 1984, in GZU 116.84) was re-examined and identified as $H$. tremelloides; the other specimen from a nearby area could not be located in GZU.

Habitat and distribution: wood and bark; eastern North America, ?Japan.
NE Hypocrea pseudostraminea Yoshim. Doi, Bull. Natl. Sci. Mus. (Tokyo) 15: 676 (1972).

This species was originally described from Japan. It was treated by Overton et al. (2006a) in sect. Hypocreanum, but no Japanese material was sequenced. Accordingly, it is unclear whether American specimens identified under this name are indeed this species. Overton et al. (2006a) also identified a European specimen (France, Osserain, on Phyllostachys sp., 22 Oct. 1989, F. Candoussau No. 480516 (BPI 1107143) as H. pseudostraminea based on teleomorph morphology. A re-examination of that specimen revealed stromata of $0.5-7 \times 0.5-5 \times 0.1-0.2 \mathrm{~mm}$ with minute ascospores, distal cells $(2.2-) 2.3-2.7(-3.0) \times 2.0-2.5 \mu \mathrm{m}$, proximal cells $(2.5-) 2.8-3.5(-4.0) \times(1.5-) 1.7-2.0 \mu \mathrm{m} \quad(n=$ 30 ), and a Trichoderma with green conidia $2.5-3.5 \times 1.5$ $2.2 \mu \mathrm{m}, 1 / \mathrm{w} 1.3-1.8(n=30)$, directly at the stroma margins. These findings suggest an affiliation of this specimen to the Brevicompactum clade rather than to sect. Hypocreanum.

DU Hypocrea pulvinata $\beta$ serialis Hazsl., Math. es term. Közlem. 25(2): 20 (1892).

Status: obscure in the absence of type material and cultures.

Type specimen: not available in BP.

Habitat and distribution: on Thelephora ochracea Fr. on a conifer (?) in Eperjes, Hungary. If Hazslinsky had meant Steccherinum ochraceum instead of Conferticium ochraceum (Fr.) Hallenb., the currently accepted name of Thelephora ochracea, then he possibly described Hypocrea thelephoricola. The protologue favours this option.

Reference: description in Saccardo (1899).

DU Hypocrea rufa var. lateritia Sacc., Fungi veneti novi vel. crit., Ser. 4: 24 (1875).

Stromata pulvinate, reddish, asci filiform, $95-100 \times 5 \mu \mathrm{m}$, ascospore cells 4-4.5 $\mu \mathrm{m}$ diam, 1-guttulate, hyaline.

Status: dubious, possibly a synonym of $H$. minutispora; not interpretable with certainty without a type specimen.

Type specimen: not available in PAD.

Habitat and distribution: on branches of Fagus sylvatica in Italy.

References: additional descriptions in Saccardo (1878, p. 301), Saccardo (1883a, p. 520).

DU Hypocrea rufa var. minor Z. Moravec, Česká Mykol. 10: 89 (1956).

Status: obscure in the absence of type material.

Type specimen: not available in PRM.

Habitat and distribution: on Stereum sp. in the Czech Republic.

DU Hypocrea rufa var. sublateritia Sacc., Fungi veneti novi vel. crit., Ser. 4: 24 (1875). 
Said to be similar to $H$. rufa var. lateritia, but stromata smaller. Asci 70-80 $\times 3-4.5 \mu \mathrm{m}$, ascospore cells globose, $3-$ $4 \mu \mathrm{m}$ diam, 1-guttulate, hyaline.

Status: dubious, not interpretable without a type specimen.

Type specimen: not available in PAD.

Habitat and distribution: branches of Buxus sempervirens and Celtis in Italy and South America.

References: additional descriptions in Saccardo (1878, p. 301 and 1883a, p. 520).

EX Hypocrea stipata (Lib.) Fuckel, Jb. Nassau. Ver. Naturk. 25-26: 23 (1871).

ESphaeria stipata Lib., Plantae cryptog. Ardenn. no. 343 (1837).

Status: synonym of Arachnocrea stipata (Fuckel) Z. Moravec (1956).

Habitat and distribution: on wood and bark, leaves and fungi in Europe, Japan and North America.

References: Dennis (1981), Moravec (1956), Rossman et al. (1999), Põldmaa (1999; anamorph).

EX Hypocrea tuberculariformis Rehm ex Sacc., Michelia 1: 302 (1878).

Status: a synonym of Nectria tuberculariformis (Rehm ex Sacc.) G. Winter 1884 [1887].

Habitat and distribution: on cow dung/herbs in Tyrol, Austria; alpine.

References: Samuels et al. (1984, p. 1898), Winter 1884 [1887].

DU Hypocrea viridis (Tode : Fr.) Peck, Ann. Rep. New York St. Mus. 31: 49 (1879).

三Sphaeria gelatinosa $\beta$ viridis Tode, Fungi Mecklenb. 2: 49 (1791).

Status: according to Chaverri and Samuels (2003) this name is obsolete, because the type specimen is lost and the protologue is not informative. When following Petch (1937), $H$. viridis becomes a synonym of $H$. gelatinosa. See Notes under Hypocrea lutea. Barr et al. (1986) noted that Peck meant a species distinct from $H$. gelatinosa. Whatever Peck meant, $H$. viridis cannot be used for his material because of the ambiguous status of the basionym.

EX Hypocrea vitalbae Berk. \& Broome, Ann. Mag. Nat. Hist., Ser. 3, 3: 362, pl. 9, f. 8 (1859).

Status: a synonym of Broomella vitalbae (Berk. \& Broome) Sacc.

References: Saccardo (1883b, p. 558), Shoemaker and Müller (1963, p. 1237).

Acknowledgements I want to express my sincere thanks to all the people mentioned in Jaklitsch (2009), who contributed to this work, particularly Hermann Voglmayr, Christian P. Kubicek, Gary J. Samuels and Walter Gams. In addition I want to thank Till R. Lohmeyer, Martin Bemmann, Bernd Fellmann and Christian Gubitz for specimens of Hypocrea teleomorphs. Thanks to Gary Samuels also for literature and investigations into the history of Hypocrea lenta. Special thanks to Walter Gams, Eric McKenzie and Christian Kubicek for reviewing the manuscript. Thanks to Ovidiu Constantinescu for checking for original material of Hypocrea lutea in UPS, and to K. Seifert for the contribution of the generic name Polypaecilum (via G.J. Samuels). The financial support by the Austrian Science Fund (FWF projects P16465-B03, P19143-B17 and P22081-B17) is gratefully acknowledged.

Open Access This article is distributed under the terms of the Creative Commons Attribution Noncommercial License which permits any noncommercial use, distribution, and reproduction in any medium, provided the original author(s) and source are credited.

\section{References}

Atkinson GF (1905) Life history of Hypocrea alutacea. Bot Gaz 40:401-417

Barr ME, Rogerson CT, Smith SJ, Haines JH (1986) An annotated catalog of the pyrenomycetes described by Charles H. Peck. N. Y. State Mus. Bull. 459:1-74. http://www.mykoweb.com/systematics/ Peck.html

Bissett J (1991a) A revision of the genus Trichoderma. II. Infrageneric classification. Can J Bot 69:2357-2372

Bissett J (1991b) A revision of the genus Trichoderma. III. Section Pachybasium. Can J Bot 69:2373-2417

Booth C (1971) The genus Fusarium. Commonwealth Mycological Institute. CAB, Eastern, London, p 237

Bresadola J (1903) Fungi polonici a cl. Viro B. Eichler lecti. Ann Mycol 1:65-131

Cannon PF (1996) IMI Descriptions of Fungi and Bacteria Set 129. CAB International. Mycopathologia 135:37-71

Chamberlain HL, Rossman AY, Stewart EL, Ulvinen T, Samuels GJ (2004) The stipitate species of Hypocrea (Hypocreales, Hypocreaceae) including Podostroma. Karstenia 44:1-24

Chaverri P, Samuels GJ (2003) Hypocrea/Trichoderma (Ascomycota, Hypocreales, Hypocreaceae): species with green ascospores. Stud Mycol 48:1-116

Chaverri P, Castlebury LA, Overton BE, Samuels GJ (2003) Hypocrea/Trichoderma: species with conidiophore elongations and green conidia. Mycologia 95:1100-1140

Currey F (1863) Transactions of the Linnean Society. Botany 25:244, not traced

Dämon W (1996) Bemerkenswerte Pilzfunde aus dem SchwingrasenMoorwald am Krottensee (Gmunden, Oberösterreich). Österr Z Pilzk 5:95-129

De Hoog GS, Guarro J, Gené J, Figueras MJ (2000) Atlas of clinical fungi, 2nd edn. CBS, Utrecht, p 884

Degenkolb T, Gräfenhan T, Nirenberg HI, Gams W, Bückner H (2006) Trichoderma brevicompactum complex: rich source of novel and recurrent plant-protective polypeptide antibiotics (peptaibiotics). J Agric Food Chem 54:7047-7061

Degenkolb T, Dieckmann R, Nielsen KF, Gräfenhan T, Theis C, Zafari D, Chaverri P, Ismaiel A, Brückner H, von Döhren H, Thrane U, Petrini O, Samuels GJ (2008a) The Trichoderma brevicompactum clade: a separate lineage with new species, new peptaibiotics, and mycotoxins. Mycol Prog 7:177-219

Degenkolb T, von Döhren H, Nielsen KF, Samuels GJ, Brückner H (2008b) Recent advances and future prospects in peptaibiotics, hydrophobin, and mycotoxin research, and their importance for 
chemotaxonomy of Trichoderma and Hypocrea. Chem Biodiv 5:671-680

Dennis RWG (1981) British Ascomycetes. Addenda and Corrigenda. J Cramer Vaduz 40

Dodd SL, Lieckfeldt E, Chaverri P, Overton BE, Samuels GJ (2002) Taxonomy and phylogenetic relationships of two species of Hypocrea with Trichoderma anamorphs. Mycol Prog 1:409-428

Dodd SL, Lieckfeldt E, Samuels GJ (2003) Hypocrea atroviridis sp. nov., the teleomorph of Trichoderma atroviride. Mycologia 95:27-40

Doi Y (1966) A revision of Hypocreales with cultural observation I. Some Japanese species of Hypocrea and Podostroma. Bull Natl Sci Mus Tokyo 9:345-357

Doi Y (1972) Revision of the Hypocreales with cultural observations IV. The genus Hypocrea and its allies in Japan. (2) Enumeration of the species. Bull Natl Sci Mus Tokyo 15:649-751

Doi (1975) Revision of Hypocreales with cultural observations VIII. Hypocrea peltata (Jungh.) Berk. and its allies. Bull Natl Sci Mus Tokyo B 1:121-134

Doi Y (1979) Revision of Hypocreales with cultural observations XII Additional note on Hypocrea peltata (Jungh.) Berk. and its allied species. Bull Natl Sci Mus Tokyo B 5:37-49

Domsch KH, Gams W, Anderson T-H (2007) Compendium of soil fungi, 2nd edn. IHW Verlag, Eching, p 672

Ellis MB, Ellis JP (1985) Microfungi on land plants. An Identification Handbook. Croom Helm. London \& Sydney. 818 pp

Ellis JB, Everhart BM (1892) The North American Pyrenomycetes. Newfield, NJ. 793 pp

Fries EM (1823) Sphaeria, Trib. VI. Lignosae. In Systema mycologicum, sistens fungorum ordines, genera et species hucusque cognitas, quas ad normam methodi naturalis determinavit, disposuit atque descripsit 2. Mauritius, Greifswald

Fries EM (1849) Summa Vegetabilium Scandinaviae. Sectio Posterior. Holmiae \& Lipsiae, pp 259-572

Fuckel L (1870) Symbolae Mycologicae. Beiträge zur Kenntnis der Rheinischen Pilze. Jahrb Nassau Ver Naturkd 23-24:1-459

Gilman JC (1957) A manual of soil fungi, 2nd edn. Iowa State College, USA, Iowa, Ames, p 450

Gilman JC, Abbott EV (1927) A summary of the soil fungi. Iowa State Coll J Sci 1:225-343

Grove WB (1885) New or noteworthy fungi: - Part II. J Bot 23:129-134

Hageskal G, Vrålstad T, Knutsen AK, Skaar I (2008) Exploring the species diversity of Trichoderma in Norwegian drinking water systems by DNA barcoding. Mol Ecol Resour 8(6):1178-1188

Hanada RE, de Souza TJ, Pomella AWV, Hebbar KP, Pereira JO, Ismaiel A, Samuels GJ (2008) Trichoderma martiale sp. nov., a new endophyte from sapwood of Theobroma cacao with a potential for biological control. Mycol Res 112:1335-1343

Jaklitsch WM (2007) Immersisphaeria gen. nov. from Poland. Mycotaxon 101:17-23

Jaklitsch WM (2009) European species of Hypocrea. Part I. The green-spored species. Stud Mycol 63:1-91

Jaklitsch WM, Komon M, Kubicek CP, Druzhinina IS (2005) Hypocrea voglmayrii sp. nov. from the Austrian Alps represents a new phylogenetic clade in Hypocrea/Trichoderma. Mycologia 97:1365-1378

Jaklitsch WM, Komon M, Kubicek CP, Druzhinina IS (2006a) Hypocrea crystalligena sp. nov., a common European species with a whitespored Trichoderma anamorph. Mycologia 98:499-513

Jaklitsch WM, Samuels GJ, Dodd SL, Lu B-S, Druzhinina IS (2006b) Hypocrea rufa/Trichoderma viride: a reassessment, and description of five closely related species with and without warted conidia. Stud Mycol 56:135-177

Jaklitsch WM, Põldmaa K, Samuels GJ (2008a) Reconsideration of Protocrea (Hypocreales, Hypocreaceae). Mycologia 100:962984
Jaklitsch WM, Gruber S, Voglmayr H (2008b) Hypocrea seppoi, a new stipitate species from Finland. Karstenia 48:1-11

Kindermann J, El-Ayouti Y, Samuels GJ, Kubicek CP (1998) Phylogeny of the genus Trichoderma based on sequence analysis of the internal transcribed spacer region 1 of the rDNA cluster. Fungal Genet Biol 24:298-309

Klok P (2006) A rare little cushion: Hypocrea argillacea Phill. \& Plowr. Coolia 49:70-71

Kraus GF, Druzhinina I, Gams W, Bisset J, Zafari D, Szakacs G, Koptchinski A, Prillinger H, Zare R, Kubicek CP (2004) Trichoderma brevicompactum sp. nov. Mycologia 96:1059-1073

Kullnig-Gradinger CM, Szakacs G, Kubicek CP (2002) Phylogeny and evolution of the genus Trichoderma: a multigene approach. Mycol Res 106:757-767

Kvas M, Marasas WFO, Wingfield BD, Wingfield MJ, Steenkamp ET (2009) Diversity and evolution of Fusarium species in the Gibberella fujikuroi complex. Fungal Divers 34:1-21

Lieckfeldt E, Samuels GJ, Börner T, Gams W (1998) Trichoderma koningii: neotypification and Hypocrea teleomorph. Can J Bot $76: 1507-1522$

Lu B, Druzhinina IS, Fallah P, Chaverri P, Gradinger C, Kubicek CP, Samuels GJ (2004) Hypocrea/Trichoderma species with pachybasium-like conidiophores: teleomorphs for T. minutisporum and T. polysporum and their newly discovered relatives. Mycologia 96:310-342

Matruchot L (1893) Sur un Gliocladium nouveau. Bull Trimest Soc Mycol Fr 9:249-252

Matsushima T (1975) Icones Microfungorum a Matsushima Lectorum. Kobe, Japan. 209 pp., 415 plates

Matsushima T (1989) Matsushima mycological memoirs (no. 651) 6:21

Medardi G (1999) Studio sul genere Hypocrea Fries. Riv Micol AMB 42:327-338

Migula W (1913) Kryptogamen-Flora von Deutschland, DeutschÖsterreich und der Schweiz. Band III. Pilze. 3. Teil. 1. und 2. Abteilung. Berlin. Gera. 1404 pp

Moravec Z (1956) Arachnocrea, un genre nouveau de la famille des Nectriaceae. Bull Trimest Soc Mycol Fr 72:160-166

Morquer R, Viala G, Rouch J, Fayret J, Bergé G (1963) Contribution à l'étude morphogénique du genre Gliocladium. Bull Trimest Soc Mycol Fr 79:137-241

Müller E, Aebi B, Webster J (1972) Culture studies on Hypocrea and Trichoderma V. Hypocrea psychrophila sp. nov. Trans Br Mycol Soc $58: 1-4$

O’Donnell K, Nirenberg HI, Aoki T, Cigelnik E (2000) A multigene phylogeny of the Gibberella fujikuroi species complex: detection of additional phylogenetically distinct species. Mycoscience 41:61-78

Overton BE, Stewart EL, Geiser DM, Wenner NG, Jaklitsch W (2006a) Systematics of Hypocrea citrina and allies. Stud Mycol 56:1-38

Overton BE, Stewart EL, Geiser DM (2006b) Taxonomy and phylogenetic relationships of nine species of Hypocrea with anamorphs assignable to Trichoderma section Hypocreanum. Stud Mycol 56:39-65

Packer L (2008) Phylogeny and classification of the Xeromelissinae (Hymenoptera: Apoidea, Colletidae) with special emphasis on the genus Chilicola. Syst Entomol 33:72-96

Petch T (1935) Notes on British Hypocreaceae. J Bot Lond 73:184-224

Petch T (1937) Notes on British Hypocreaceae III. J Bot Lond 75:217-231

Petch T (1938) British Hypocreales. Trans Br Mycol Soc 21:243-305

Petrak F (1940) Mykologische Notizen XIII. Ann Mycol 38:181-267

Põldmaa K (1999) The genus Hypomyces (Hypocreales, Ascomycota) and allied fungicolous fungi in Estonia 1. Species growing on aphyllophoralean basidiomycetes. Folia Cryptogam Est Fasc 34:15-31

Põldmaa K, Larsson E, Kõljalg U (1999) Phylogenetic relationships in Hypomyces and allied genera, with emphasis on species growing on wood-decaying homobasidiomycetes. Can J Bot 77:1756-1768 
Rehm H (1905) Ascomycetes exs. Fasc. 34. Ann Mycol 3:224-231

Rifai MA (1969) A revision of the genus Trichoderma. Mycol Pap 116:1-56

Rifai MA, Webster J (1966) Culture studies on Hypocrea and Trichoderma II. Trans Br Mycol Soc 49:289-296

Rogerson CT, Samuels GJ (1993) Polyporicolous species of Hypomyces. Mycologia 85:231-272

Rogerson CT, Samuels GJ (1994) Agaricicolous species of Hypomyces. Mycologia 86:839-866

Rossman AY, Samuels GJ, Rogerson CT, Lowen R (1999) Genera of Bionectriaceae, Hypocreaceae and Nectriaceae (Hypocreales, Ascomycetes). Stud Mycol 42:1-248

Saccardo PA (1878) Enumeratio pyrenomycetum Hypocreacearum hucusque cognitorum systemate carpologico dispositorum. Michelia 1:301

Saccardo PA (1883a) Hypocreaceae, Hyalodidymae, Hypocrea. Syll Fung 2:520-536

Saccardo PA (1883b) Hypocreaceae, Phragmosporae, Broomella. Syll Fung 2:558

Saccardo PA (1885) Fungi Algerienses, Tahitenses et Gallici. Rev Mycol Toulouse 7:158-161

Saccardo PA (1886) Hypocrea. Syll Fung Add 1-4:1-484

Saccardo PA (1899) Pyrenomycetae, Hypocreaceae, Hyalodidymae, Hypocrea. Syll Fung 14:641-645

Samuels GJ (2006) Trichoderma: systematics, the sexual state, and ecology. Phytopathology 96:195-206

Samuels GJ, Ismaiel A (2009) Trichoderma evansii and T. lieckfeldtiae: two new T. hamatum-like species. Mycologia 101:142-156

Samuels GJ, Lodge DJ (1996) Three species of Hypocrea with stipitate stromata and Trichoderma anamorphs. Mycologia 88:302-315

Samuels GJ, Doi Y, Rogerson CT (1990) Contributions toward a mycobiota of Indonesia: Hypocreales. Mem NY Bot Gard 59:6-108

Samuels GJ, Rogerson CT, Rossman AY, Smith JD (1984) Nectria tuberculariformis, Nectriella muelleri, Nectriella sp., and Hyponectria sceptri: low temperature tolerant, alpine-boreal fungal antagonists. Can J Bot 62:1896-1903

Samuels GJ, Petrini O, Kuhls K, Lieckfeldt E, Kubicek CP (1998) The Hypocrea schweinitzii complex and Trichoderma sect. Longibrachiatum. Stud Mycol 41:1-54

Samuels GJ, Dodd S, Lu B-S, Petrini O, Schroers H-J, Druzhinina IS (2006a) The Trichoderma koningii aggregate species. Stud Mycol 56:67-133
Samuels GJ, Rossman AY, Chaverri P, Overton BE, Põldmaa K (2006b) Hypocreales of the Southeastern United States: an identification guide. CBS Biodivers Ser 4:1-145

Samuels GJ, Ismaiel A, Bon M-C, de Respinis S, Petrini O (2010) Trichoderma asperellum sensu lato consists of two cryptic species. Mycologia 102:944-966

Seaver FJ (1910) The Hypocreales of North America - III. Mycologia 2:48-92

Shoemaker RA, Müller E (1963) Generic correlations and concepts: Broomella and Pestalotia. Can J Bot 41:1235-1243

Smith G (1961) Polypaecilum gen. nov. Trans Br Mycol Soc 44:437-440

Sopp OJ (1912) Monographie der Pilzgruppe Penicillium mit besonderer Berücksichtigung der in Norwegen gefundenen Arten. Skrift Vidensk-Selsk Christiana 11:1-208

Spooner BM, Williams MAJ (1990) Hypocrea placentula and its Trichoderma anamorph. Mycologist 4:66-69

Subramanian CV (1971) Hyphomycetes - an Account of Indian Species, except Cercosporae. Indian Council for Agricultural Research, New Delhi

Thom C (1930) The Penicillia. Baillière, Tindall \& Cox. London, p 644

Tode F (1791) Fungi Mecklenburgenses selecti, Fasciculus 2. I.F.G. Lemke, Lüneburg

von Höhnel F, Litschauer V (1906) Revision der Corticien in Dr J. Schröter's 'Pilze Schlesiens' nach seinen Herbarexemplaren. Ann Mycol 4:288-294

Webster J, Rifai MA (1968) Culture studies on Hypocrea and Trichoderma IV. Hypocrea pilulifera sp. nov. Trans Br Mycol Soc 51:511-514

Winter G (1887) Die Pilze. II. Abtheilung: Ascomyceten: Gymnoasceen und Pyrenomyceten. Rabenhorst Kryptogamenflora von Deutschland, Österreich und der Schweiz 1(2):1-928. E. Kummer. Leipzig

\section{Further reading}

Errata in Jaklitsch (2009), Studies in Mycology 63: 1) Legends to Fig. 8 of Hypocrea aureoviridis on page 32: 'WU 29033' is to be replaced by 'epitype K(M) 162235 '. WU 29033 is a specimen of $H$. parmastoi. 2) Notes to $H$. sinuosa on p. 78: 'Generally immature stromata are more diagnostic than dry ones' is to be replaced by 'Generally immature stromata are more diagnostic than mature ones, particularly when dry'. 


\section{Index of fungal names}

(page numbers in bold indicate start of detailed treatment)

Acrospermum lichenoides 244

Arachnocrea 3, 4

stipata 4, 139, 244, 245

Battarrina inclusa 243

Brevicompactum clade 1, 4, 9, 68, 95, 124, 147, 161, 162, $167,171,176,213,244$

Broomella vitalbae 245

Chlorospora clade 9

Chromocrea cupularis 243

Cordyceps

alutacea 69

brevipes 242

Eidamia viridescens 63,65

Fusarium 2

Gliocladium 134, 139

deliquescens 1, 162, 177, 179, 181, 182

viride $177,181,182$

Hypocrea

albofulva 35

albolutescens 202, 206

alcalifuscescens 124, 125, 143

alutacea $\mathbf{6 9}, 73,77,242$

andinensis 221

argillacea 2, 68, 92, 112, 202, 206, 208, 213, 227, 238

armata 242

atlantica $68, \mathbf{8 3}, 87$

atra 242

atrata 216

atroviridis 10, 13, 17

auranteffusa 95, 134, 147, 162, 166, 167, 171, 172, 176, 227

aureoviridis 71,247

austriaca $1,124, \mathbf{1 2 5}, 129,147,161$

bavarica 75, 87, 91, 92, 111, 120, 176, 208, 213, 232

brevipes 73,242

calamagrostidis 186, 190

chionea 206

citrina $68,95,124,129,134,147,152,157,242$

citrina * fungicola 152

citrina $\beta$ ochracea 242

colliculosa 152,157

contorta 216

cordyceps 243

crystalligena 162, 190, 194, 195

cupularis 243

dacrymycella 243

decipiens 134, 147, 243

deformans 243

delicatula 134, 139

eichleriana 243 farinosa 134,243

fulva 243

fungicola 152,242

fungicola $\mathrm{f}$. raduli $1,125,129$

gelatinosa $68,225,237,243,245$

hypomycella 1,243

inclusa 243

junci 13, 17, 190

karsteniana 152

koningii 17, 21, 45

lactea 129,134

lateritia 243

lenta 243

leucopus $\mathbf{7 3}, 77,83$

lichenoides 243

lixii $68,100,101,172,221$

lutea $1,162, \mathbf{1 7 6}, 181,182,186,213,245$

luteffusa $68,92,95,124,134$

luteocrystallina 181, 182, 186

luteovirens 244

margaretensis 95, 134, 147, 167, 171, 172, 176

megalocitrina 162

megalosulphurea 161

melanomagna 162

minutispora $1,31,45,50,67,68,87,95,102,107,221$, 244

moliniae 244

moravica 1, 68, 91, 92, 111, 147, 176, 181, 202, 208, 212, 213,225

neorufa $9, \mathbf{2 1}, 25,31,40,59,63$

neorufoides 9, 25, 29, 31, 40, 54, 59, 63, 102

novaezelandiae 221

nybergiana 77, 81, 83, 243

ochroleuca 31, 35, 54

orientalis 221

pachybasioides 50, 68, 102, 107, 111, 115

pachypallida 95, 107, 111, 112, 181, 186

pallida 4,244

palmicola 243

papyracea 244

parapilulifera $68,107,111,112,115,181$

parmastoi 139, 247

parmelioides 244

patella 244

petersenii $25, \mathbf{3 7}, 40,41,59,63$

phellinicola 143, 147, 213

pilulifera $1,68, \mathbf{1 1 5}, 119,120,124$

placentula $119, \mathbf{1 2 0}, 123,124$

protopulvinata $81, \mathbf{1 4 7}, 152,156$

pseudokoningii 221

pseudostraminea 244

psychrophila 162, 190, 195, 199, 201, 227

pulvinata 134, 151, 152, 156, 157, 221, 242 
pulvinata $ß$ serialis 244

repanda 216

rhododendri 199, 201

rigens 216

rodmanii 95, 134, 147, 161, 167, 171, 172, 176

rogersonii $21,40, \mathbf{4 1}, 45$

rufa $9, \mathbf{4 5}, 49,50,54,68,102$

rufa * umbrina 216

rufa $\mathrm{f}$. sterilis 13,17

rufa var. discoidea 227,232

rufa var. lateritia 244

rufa var. minor 244

rufa var. sublateritia 244

sambuci 1, 202, 213, 216, 237, 238

schweinitzii 1, 67, 202, 216, 221, 243

seppoi $77, \mathbf{8 1}, 83,92$

silvae-virgineae 68, 202, 221, 225

sinuosa 101,247

spinulosa 244

splendens 2, 167, 202, 208, 225, 227

stilbohypoxyli 21, 50, 54

stipata 244,245

strictipilosa 101, 172, 225

strobilina 2, 68, 202, 227

subalpina 1, 92, 147, 202, 216, 227, 232

subeffusa $25,40,54, \mathbf{5 5}, 57,58,63$

subsulphurea 161

sulphurea 129, 134, 147, 157, 161, 171

sulphurea f. macrospora 157, 161

thelephoricola 244

tremelloides 1, 92, 202, 208, 216, 225, 232, 237, 238, 244

tuberculariformis 245

valdunensis $13, \mathbf{5 9}, 61$

victoriensis 129,161

viridescens 9, 13, 17, 50, 61, 63, 65, 68, 221

viridis 245

vitalbae 245

voglmayrii 202, 238, 241, 242

Hypocreopsis lichenoides 244

Hypomyces 139, 242

armeniacus 242

lateritius 243

luteovirens 242, 244

ochraceus 242

Immersisphaeria eichleriana 243

Lutea clade 1, 4, 9, 161, 162

Megalocitrina clade 162

Nectria tuberculariformis 245

Pachybasioides clade 68

Pachybasium hamatum 68

pachybasium core group $1,4,8,31,68,81,92,107,111$, 124, 202, 213

Podocrea 68, 77 alutacea 69

brevipes 242

Podostroma 1, 8, 68, 77, 243

alutaceum 69

brevipes 242

leucopus 73

Polypaecilum 232

Polystigma fulvum 243

Protocrea

delicatula 135

farinosa 4, 134, 139, 243

fungicola 152

pallida 4, 139, 244

Psychrophila clade 1, 4, 9, 161, 162, 182, 190, 195

section Hypocreanum 1, 3, 4, 8, 68, 81, 111, 124, 171, 244

section Longibrachiatum 1, 3, 202, 221, 232

section Pachybasium 9, 68, 107

section Trichoderma 1, 4, 8, 9, 10, 17, 25, 31, 35, 45, 54, $63,81,195,202,242$

Semiorbis clade 68, 162, 202, 213

Sphaeria

alutacea 69

armata 242

citrina 129

clavata 69

contorta 216

cupularis 243

gelatinosa 181

gelatinosa b. lutea 176

gelatinosa $\alpha$ lutea 176,181

gelatinosa $\beta$ viridis 181,245

lactea 129

lenta 216,243

luteovirens 244

ochracea 242

parmelioides 244

rigens 216

rufa 45

schweinitzii 216

stipata 245

sulphurea 157

tremelloides 232

Sporophagomyces

chrysostomus 4

lanceolatus 4

Sporotrichum polysporum 102

T. koningii aggregate species group 9

T. viride aggregate 9

Trichoderma

albolutescens 202

alutaceum 69, 71

arundinaceum 161

asperelloides 10 
asperellum 10

atlanticum 83, 87

atroviride 9, 10, 17

auranteffusum 162, 166, 176

aureoviride 9

austriacum 125, 129

bavaricum 87, 91, 232

brevicompactum 161, 162

calamagrostidis 186, 190

cerinum 106, 147, 216

citrinoviride 216, 221

crystalligenum 190, 194, 199

delicatulum 135, 139

deliquescens 176, 181

gamsii 10, 68

gelatinosum 182

glaucum 45

hamatum 9, 68

harzianum 9, 68, 107, 147, 216

helicum 68, 202

junci 13, 17

koningii 9, 17, 21, 45

koningiopsis 10

lacteum 124, 129

leucopus $\mathbf{7 3}, 77$

lignorum 45

longipile 225

luteffusum 92, 95

luteocrystallinum 182, 186 margaretense 167, 171, 176

martiale 9,50

minutisporum 68, 87, 97, 102

moravicum 208, 212, 213

neorufoides 25, 29, 31

pachypallidum 107, 111

petersenii 37, 40, 59

phellinicola 143, 145

piluliferum 68, 117

placentula 120, 123, 199

polysporum 68, 102, 107

protrudens 161

psychrophilum 195, 199

pubescens 9

rogersonii 21, 41, 45

seppoi $\mathbf{8 1 ,} 83$

silvae-virgineae 221, 225

stilbohypoxyli 21, 31, 50, 54

strigosum 9

subalpinum 227, 232, 238

subeffusum 55, 57, 59

tremelloides 232, 237, 238

turrialbense 161

valdunense 59, 61

viride $9,10,45,49,50,54,68,134,181,182$

viridescens $10,17,50, \mathbf{6 3}, 65,68$

voglmayrii 238, 241

Viride clade 9, 13

Viridescens clade 9 